\title{
Deuteronomium 28 und die adê zur Thronfolgeregelung Asarhaddons: Segen und Fluch im Alten Orient und in Israel
}

\author{
Steymans, Hans Ulrich
}

\begin{abstract}
Die Ähnlichkeiten zwischen einigen Flüchen der adê-Vereidung anlässlich der Thronfolgeregelung Asarhaddons (VTE) und in Deuteronomium 28 bezeugen nicht den Einfluss einer im ganzen Alten Orient verbreiteten Tradition, sondern resultieren aus literarischer Abhängigkeit des Bibeltextes von den VTE. Die vorliegende Studie kommt zu diesem Ergebnis, nachdem die Flüche der VTE mit den publizierten mesopotamischen Fluchpassagen, angefangen beim Kodex Hammurapi, verglichen wurden und anhand mehrsprachiger Inschriften die Übersetzungstreue des Alten Orients überprüft wurde. Die Differenzen zwischen den VTE und Dtn 28 bewegen sich in dem Rahmen, den man im Alten Orient bei Übersetzungen tolerierte. Die Gemeinsamkeiten umfassen eine fast identische Reihenfolge der Inhalte von VTE $\S \S 39,40,42$ und Dtn 28,27-30 (Hautkrankheit, Finsternis und Schändung der Ehefrau), gleichartige Motive in § 63f und Dtn 28,23f (bronzener Himmel und eiserne Erde, Regen verwandelt in Kohle oder Asche; Lev 26,19 dürfte von Dtn 28,23f abhängen) und eine Themenabfolge in VTE § 56, die der von Dtn 28,20-44 weitgehend entspricht. Der palindromisch gestaltete $\S 56$ ruft die grossen Götter des Himmels und der Erde an und stellt Motive des Sonnengottes in die Mitte. Der Sonnengott trug in Mesopotamien Züge, die in Jerusalem JHWH zugeschrieben wurden. Der hebräische Verfasser übernahm VTE § 56 und fügte an thematisch geeigneter Stelle weitere mit dem Sonnengott oder dem Himmel verbundene Abschnitte aus den VTE ein. Innerhalb von $\S \S 39-42$ steht der Fluch des Sonnengotts in $\S 40$. Auch die $\S \S 63 f$, wo es um Himmel und Erde geht, zeigen deutliche Lexembezüge zu Sonnengottflüchen (§§ 40, 68, 101). Der mesopotamische Hintergrund von Dtn 28,20-44 ermöglicht es, die Funktion des Kapitels 28 in der "Fabel" des Deuteronomiums neu zu beleuchten. Die Abhängigkeit von den VTE lässt Schlussfolgerungen für die Redaktionsgeschichte zu: Dtn 28,20-44 (ohne V. 20b,25b,26f) dürfte zum ältesten Kern des Kapitels gehören. Bei der Einfügung des Urdeuteronomiums in die deuteronomistische Landeroberungserzählung kamen der Segen (28,7-13) und wohl auch 28,21b.69 hinzu. Spätestens in dieser Redaktionsphase wurden 28,1.2a.3-6.15.16-19 geschaffen. Deuteronomistischer Redaktion der Exilszeit sind 28,2b.14.20b.25b.36f.45-57.62-68 zuzuordnen. Den letzten Zusatz bildet wohl die poetische Passage in 28,58-61.
\end{abstract}

Posted at the Zurich Open Repository and Archive, University of Zurich

ZORA URL: https://doi.org/10.5167/uzh-142987

Monograph

Published Version

Originally published at:

Steymans, Hans Ulrich (1995). Deuteronomium 28 und die adê zur Thronfolgeregelung Asarhaddons: Segen und Fluch im Alten Orient und in Israel. Freiburg, Switzerland / Göttingen, Germany: Universitätsverlag / Vandenhoeck Ruprecht. 
Hans Ulrich Steymans Deuteronomium 28 und die adê zur Thronfolgeregelung Asarhaddons 


\section{ORBIS BIBLICUS ET ORIENTALIS}

Im Auftrag des Biblischen Instituts

der Universität Freiburg Schweiz,

des Ägyptologischen Seminars der Universität Basel,

des Instituts für Vorderasiatische Archäologie

und Altorientalische Sprachen der Universität Bern

und der Schweizerischen Gesellschaft

für Orientalische Altertumswissenschaft

herausgegeben von

Othmar Keel und Christoph Uehlinger

\section{Zum Autor}

Hans Ulrich Steymans studierte Theologie in Bonn und Wien sowie Altorientalistik in Wien. Seit 1982 ist er Mitglied des Dominikanerordens. Von 1992 bis 1995 arbeitete er als Assistent am Institut für alttestamentliche Bibelwissenschaft der Katholisch-Theologischen Fakultät der Universität Wien. Zur Zeit lehrt er an der Ecole Biblique et Archéologique Française in Jerusalem. 


\section{Orbis Biblicus et Orientalis $\quad 145$}

Hans Ulrich Steymans

\section{Deuteronomium 28 \\ und die adê zur \\ Thronfolgeregelung \\ Asarhaddons}

Segen und Fluch

im Alten Orient und in Israel

Universitätsverlag Freiburg Schweiz

Vandenhoedk \& Ruprecht Göttingen 


\section{Die Deutsche Bibliothek - CIP-Einheitsaufnahme}

\section{Steymans, Hans Ulrich:}

Deuteronomium 28 und adê zur Thronfolgeregelung Asarhaddons: Segen und Fluch im Alten Orient und in Israel/ Hans Ulrich Steymans. - Freiburg, Schweiz: Univ.-Verl.; Göttingen Vandenhoeck und Ruprecht, 1995

(Orbis biblicus et orientalis; 145)

Zugl.: Berlin, Humboldt-Univ., Diss.

ISBN 3-7278-1038-6 (Univ.-Verl.)

ISBN 3-525-53780-8 (Vandenhoeck \& Ruprecht)

NE: GT

Die Druckvorlagen wurden von der Verfasserin als reprofertige Dokumente zur Verfügung gestellt

(C) 1995 by Universitätsverlag Freiburg Schweiz Vandenhoeck \& Ruprecht Göttingen

Paulusdruckerei Freiburg Schweiz

ISBN 3-7278-1038-6 (Universitätsverlag)

ISBN 3-525-53780-8 (Vandenhoeck \& Ruprecht)

Digitalisat erstellt durch Florian Lippke, Departement für Biblische Studien, Universität Freiburg Schweiz 
für

\section{Hedwig und Paul Steymans}

und dem Andenken an

Elisabeth Schimmel

*1939 †1990 



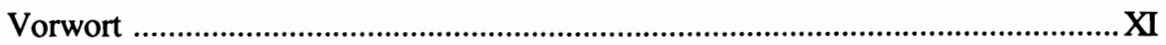

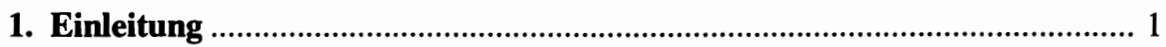

1.1. Untersuchungsprinzipien .................................................................... 7

1.1.1. Die Natur der Verbindung .......................................................... 7

1.1.2. Der Typ der Verbindung ............................................................. 9

1.2. Die Beziehungen Israels und Judas zu Mesopotamien ............................ 14

2. Verwendung und Gestalt der Flüche im Alten Orient ............................... 18

2.1. Vertragsformular und Gesetzespromulgation ........................................... 18

2.2. Die altorientalischen Fluchgattungen ................................................... 28

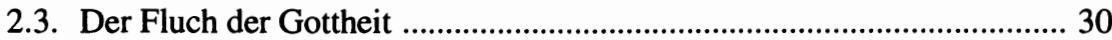

3. Fluchtraditionen in den Thronfolge-adê Asarhaddons ............................... 34

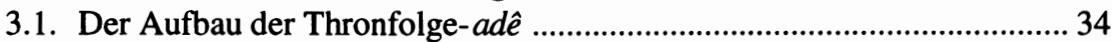

3.1.1. Zum Verständnis der šumma-Sätze ............................................ 34

3.1.2. Gliederung der Thronfolge-adê und Fluchinhalte ........................ 38

3.2. Die Ähnlichkeiten mit Dtn 28 in der Forschungsgeschichte .................... 41

3.3. Methodische Überlegungen .................................................................. 49

3.4. Die zum Vergleich herangezogenen Texte …….................................... 52

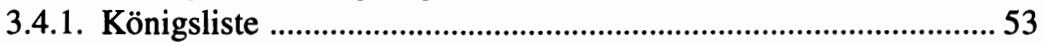

3.4.2. Mesopotamische Texte mit Flüchen ............................................. 55

3.5. VTE § 38A-43 Himmel und Himmelskörper .......................................... 72

3.5.1. VTE § 38A, der Anufluch.................................................... 72

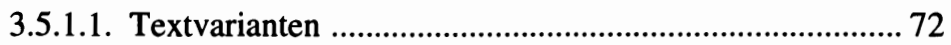

3.5.1.2. Sprachlich-syntaktische Analyse .................................... 72

3.5.1.3. Semantische Analyse .................................................. 74

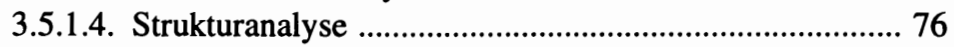

3.5.1.5. Formengeschichte des Anufluchs .................................. 76

3.5.2. VTE § 39, der Sinfluch verglichen mit VTE § 52, dem

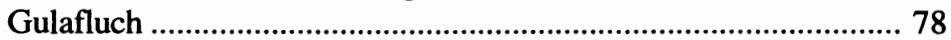

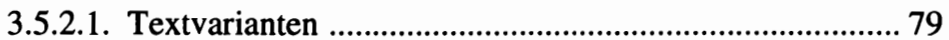

3.5.2.2. Sprachlich-syntaktische Analyse ..................................... 79

3.5.2.3. Semantische Fragen und Formenkritik ........................... 80

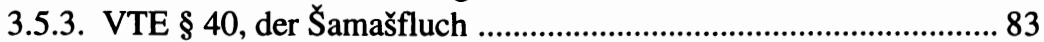

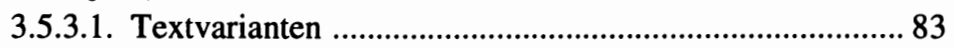

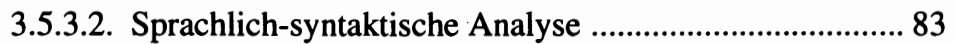

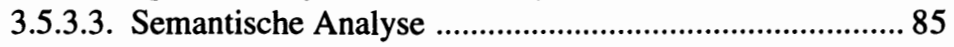

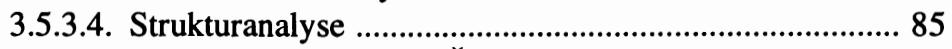

3.5.3.5. Formengeschichte des Šamašfluchs .................................. 86 
3.5.4. VTE § 41, der Ninurtafluch ..................................................... 92

3.5.4.1. Textvarianten ............................................................. 92

3.5.4.2. Sprachlich-syntaktische Analyse ................................... 92

3.5.4.3. Semantische Analyse .................................................... 94

3.5.4.4. Strukturanalyse ............................................................... 97

3.5.4.5. Formengeschichte des Ninurtafluchs .............................. 97

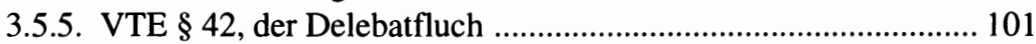

3.5.5.1. Sprachlich-syntaktische Analyse .................................. 101

3.5.5.2. Semantische Analyse .................................................... 103

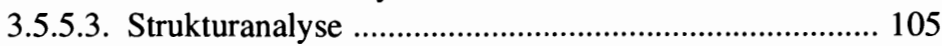

3.5.6. VTE § 43, der Jupiterfluch ....................................................... 105

3.6. VTE § 56, der Fluch bei den großen Göttern ........................................ 109

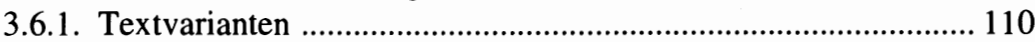

3.6.2. Sprachlich-syntaktische Analyse .............................................. 110

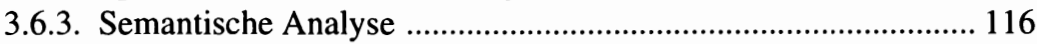

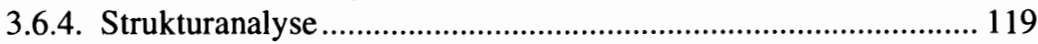

3.6.5. Formengeschichte des Fluchs bei den Göttern ........................... 120

3.7. VTE § 63-65, die Parallele zu Dtn 28,23(-25?) ...................................... 129

3.7.1. Textvarianten ....................................................................... 129

3.7.2. Sprachlich-syntaktische Analyse ............................................. 130

3.7.3. Semantische Analyse .............................................................. 134

3.7.4. Formenkritik ………............................................................... 135

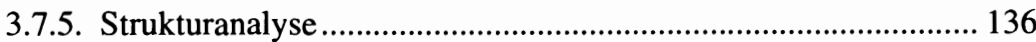

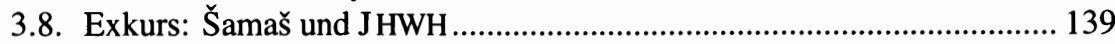

3.9. Ergebnisse: Der altorientalische Hintergrund von Dtn 28 ..................... 143

3.9.1. Die VTE-Parallelen zu Dtn 28 ............................................... 143

3.9.2. Der Aufbau von VTE $\S 56$..................................................... 149

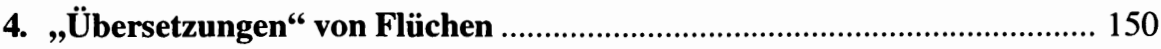

4.1. Zweisprachige Verträge des Hattireiches ............................................... 152

4.1.1. Der Vertrag zwischen Hattu šili III. und Ramses II...................... 152

4.1.2. Die syro-hethitischen Verträge ................................................. 154

4.2. Die Bilinguen von Tell Fekheriye und Karatepe .................................. 156

4.3. Die Bilingue von Kelišin ................................................................. 163

4.4. Die Verträge mit Mati'ilu von Arpad und westsemitische

Inschriften ........................................................................................ 164

4.4.1. Die Sefire-Inschriften und der Assurnirari-Vertrag ..................... 164

4.4.2. Vergleichbare Flüche anderer westsemitischer Inschriften ......... 177

4.5. Exkurs: Der futility curse im Alten Orient ............................................. 181

4.6. Übersetzungen aus persischer Zeit .................................................... 185

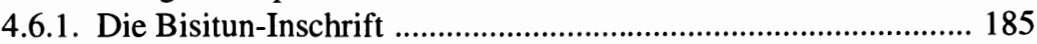

4.6.2. Eine Bilingue aus Sardes ........................................................ 190

4.7. Die aramäische Sprache in der assyrischen Verwaltung ........................... 191

4.8. Ergebnisse: Übersetzungstreue in Fluchtexten des Alten Orients ......... 194 
5. Kontext und „Fabel“" von Dtn 28

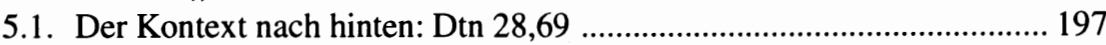

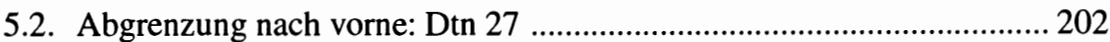

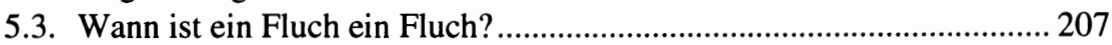

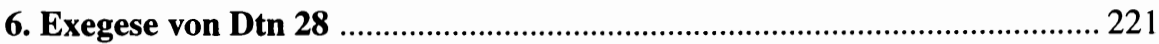

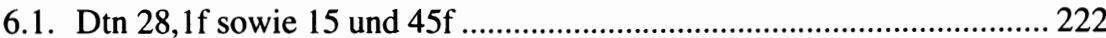

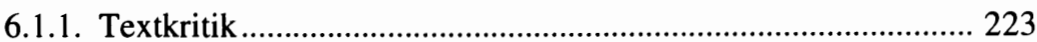

6.1.2. Forschungsgeschichte und Literarkritik ...................................... 225

6.1.3. Zur Herkunft der Einleitungsformeln .......................................... 227

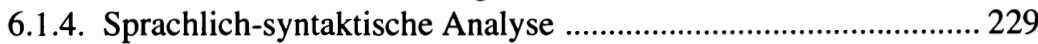

6.1.5. Semantische Analyse ............................................................. 232

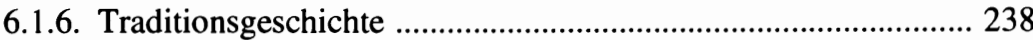

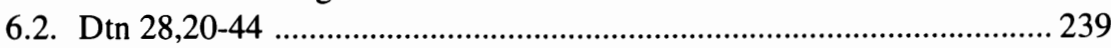

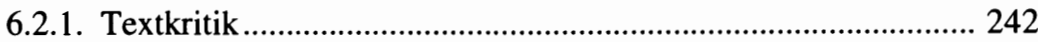

6.2.2. Forschungsgeschichte und Literarkritik .................................... 248

6.2.2.1. Beobachtungen zur Textstruktur ................................... 248

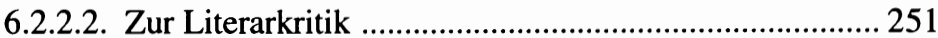

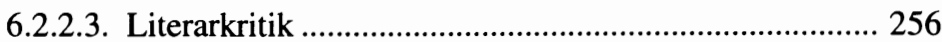

6.2.2.4. Die Bezüge zu Jeremia ................................................ 263

6.2.3. Sprachlich-syntaktische Analyse .............................................. 264

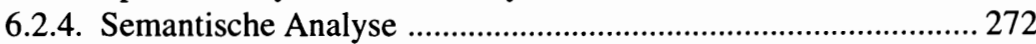

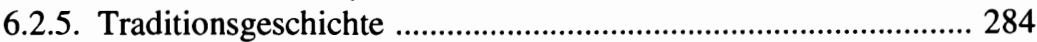

6.2.5.1. VTE § 63f / Lev 26,19 .............................................. 284

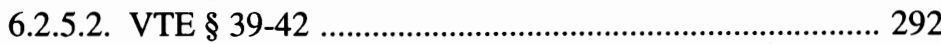

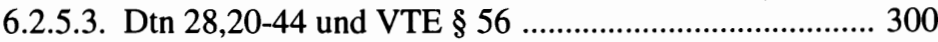

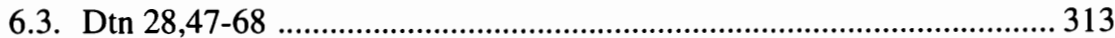

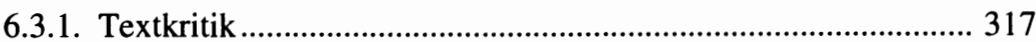

6.3.2. Sprachlich-syntaktische Analyse .............................................. 323

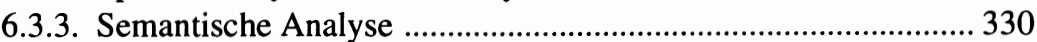

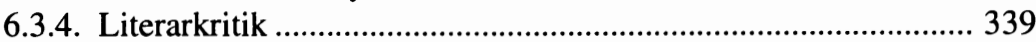

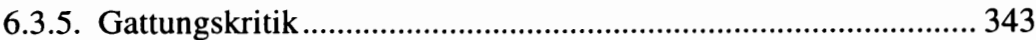

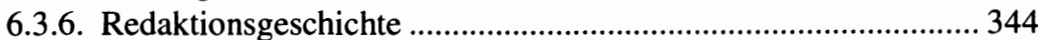

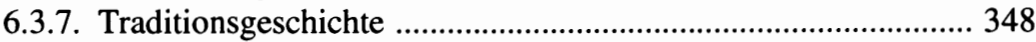

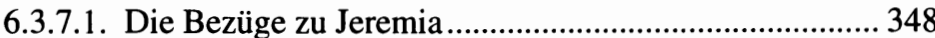

6.3.7.2. Altorientalische Parallelen ............................................... 350

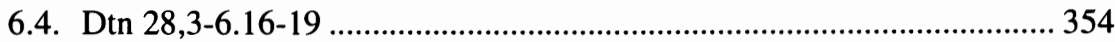

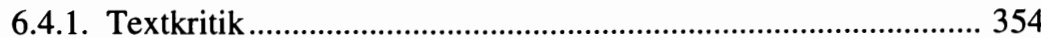

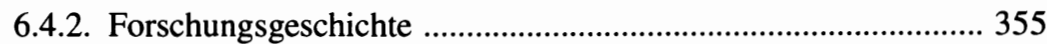

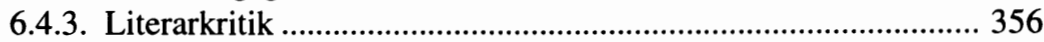

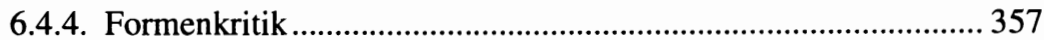

6.4.5. Redaktionsgeschichtliche Schlußfolgerungen ............................ 359

6.4.6. Traditionsgeschichte .................................................................. 360 


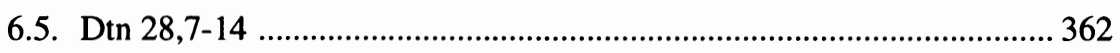

6.5.1. Textkritik ................................................................................ 363

6.5.2. Sprachlich-syntaktische Analyse ............................................. 364

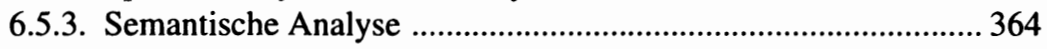

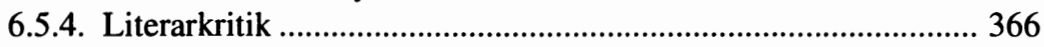

6.5.5. Redaktionsgeschichtliche Schlußfolgerungen ............................. 367

6.6. Exkurs: Segen im Alten Orient ............................................................. 369

7. Versuch einer Redaktionsgeschichte von Dtn 28 .................................... 377

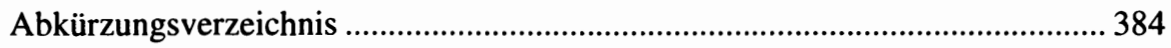

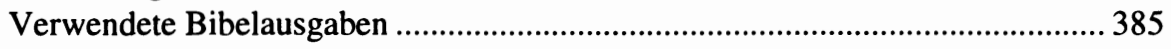

Literaturverzeichnis .................................................................................. 386

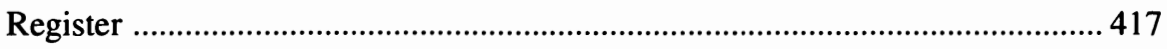




\section{VORWORT}

Die vorliegende Studie wurde im Wintersemester 1994/95 von der Katholisch-Theologischen Fakultät der Universität Wien als Dissertation angenommen. Sie geht auf eine Anregung der Professoren Georg Braulik OSB und Norbert Lohfink SJ zurück. Für den Druck wurde sie geringfügig überarbeitet und gekürzt.

Von Prof. Braulik, der die Arbeit betreute, erfuhr ich Förderung und Unterstützung vielfältiger Art. Prof. Hermann Hunger vom Institut für Orientalistik begleitete meine assyriologischen Studien und übernahm das Zweitgutachten. Beiden Professoren gilt mein aufrichtiger Dank.

Außerdem danke ich Prof. Othmar Keel und Dr. Christoph Uehlinger für die Aufnahme der Untersuchung in die Reihe „Orbis Biblicus et Orientalis“, Dr. Michael Jursa vom Institut für Orientalistik für viele hilfreiche Ratschläge zum Umgang mit den Keilschriftquellen sowie allen, die mir beim Korrigieren und bei Problemen mit der Textverarbeitung geholfen haben.

Gewidmet ist das Buch meinen Eltern und meiner verstorbenen Tante, die schon im Grundschüler das Interesse am Alten Orient weckte. 



\section{EINLEITUNG}

Im Jahre 1955 fanden britische Archäologen im Nabutempel von Nimrud, dem assyrischen Kalhu, dem biblischen Kalah, über 350 Fragmente von zerschmetterten Keilschrifttafeln. Bereits die am Ausgrabungsort von Barbara Parker durchgeführten Versuche, die Scherben zusammenzusetzen und die Tafeln zu lesen, zeigten, daß man politische Dokumente höchsten Ranges entdeckt hatte. Die Fragmente, zu denen ein weiteres aus Assur kam, gehörten zu mindestens acht verschiedenen Manuskripten, in denen sich medische Fürsten dazu verpflichteten, Assurbanipal als Nachfolger Asarhaddons auf dem Throne Assurs und Šamaš-šum-ukin als seinen Nachfolger auf dem Throne Babylons anzuerkennen. ${ }^{1}$

Die assyrische Bezeichnung dieser Dokumente lautet adê. Die Bedeutung des Wortes und infolgedessen der juristische Charakter der Texte sind nicht genau bestimmbar. Die Grundbedeutung von adê scheint „Eid“ zu sein. ${ }^{2}$ Man diskutiert darüber, ob es sich um Vertragseide und daher um eher außenpolitisch bedeutsame Vasallenverträge handelt oder um Treueide, also um innenpolitisch zu verstehende Vereidigungen von Fürsten, die bereits in den assyrischen Staat integriert waren. ${ }^{3}$ Wiseman verstand die Texte in seiner Erstveröffentlichung als Vasallenverträge. ${ }^{4}$ Daher stammt sein Titel „The Vassal-Treaties of Esarhaddon" und die inzwischen eingebürgerte Abkürzung VTE. Sie wird auch in dieser Arbeit verwendet, ohne damit den juristischen Charakter der Texte festlegen zu wollen.

Wiseman wies bereits in der Erstveröffentlichung 1958 auf die Ähnlichkeit der Flüche in VTE $\S 63,64$ und Dtn 28,23.24 hin. ${ }^{5}$ Borger vermutete 1961, die dort verwendeten Bilder seien aus einem assyrischen Vertrag ins Deuteronomium übernommen worden. ${ }^{6}$ Moran nahm diese Ansicht 1963 auf, und im selben Jahr zog Lohfink aus der Rhetorik der VTE Rückschlüsse auf die sprachliche Gestalt der Bundesurkunde Joschijas. ${ }^{7}$ Für McCarthy dagegen spiegeln sich in Dtn 28 die alten Flüche Mesopota-

1 Vgl. Wiseman, „Vassal-Treaties,“ 1; PARPOla / WATANABE, Treaties, XIXX.; Borger, „Vasallenverträge," 160.

$2 \mathrm{Vgl}$. AHw, 14 adû I.

${ }^{3}$ Den innenpolitischen Charakter der Vereidigung betonen: WATANABE, Thronfolgeregelung, 3f; LIVERANI, „Terminologia,“ 133-137; TADMOR, „Treaty,“ 148.

${ }^{4}$ Vgl. „Vassal-Treaties,“ 3, 27f. Ihm folgen: BORGER, „Vasallenverträge,“ 160, PARPOLA in PARPOLA / WATANABE, Treaties, XXX, und KREBERnIK, „Deuteronomiumskommentar,“ 30.

5 Vgl. „Vassal-Treaties,“ 26 Anm. 201.

6 Vgl. „Nimrud,“ 191f.

7 Vgl. MORAN, „Background;“ 83f; LOHFINK, „Bundesurkunde,“ 481f/147f. 
miens, die im Alten Orient quasi als Kanon überliefert wurden. Die Parallelen resultieren nicht aus der Abhängigkeit von einer schriftlichen assyrischen Vorlage, sondem bezeugen nur, daß Dtn 28 mit der altorientalischen Fluchtradition verbunden ist. Gegen die Beziehung zu einem assyrischen Vertrag spricht, daß die sprachlichen Wendungen in Dtn 28 von denen der VTE abweichen. ${ }^{1}$ Hillers führte 1964 die Ähnlichkeiten ebenfalls allein auf die Tradition zurück, wobei er die Unterschiede zwischen VTE $\S 63 \mathrm{f}$ und Dtn 28,23f hervorhob. ${ }^{2}$

Damit ergibt sich die Fragestellung der vorliegenden Arbeit: Läßt sich aus den Ähnlichkeiten zwischen den VTE und Dtn 28 die literarische Abhängigkeit des Bibeltextes von einer assyrischen Vorlage erschließen oder gab es im Alten Orient einen traditionellen Kanon von Fluchmotiven, der die Entstehung gleichartiger Texte in Assyrien und Juda erklärt?

Frankena sammelte 1965 VTE-Parallelen für Dtn 28,20-57, wobei er besonders die Gemeinsamkeiten des Šamaš- und Delebatfluchs (VTE $\S 40$, 42) mit Dtn 28,28-34 hervorhob. Er plädierte für die Abhängigkeit von einer assyrischen Vorlage. ${ }^{3}$ Weinfeld konzentrierte 1965 den Vergleich auf die Verse 26-35. Er beschrieb die in Mesopotamien verbreitete Kombination des Sin- und Šamašfluchs (VTE $\S 39,40$ ) und erklärte damit die Abfolge der Motive in Dtn 28,27-29. Gleiche Themen in gleicher Reihenfolge führten ihn zu der Annahme, ein judäischer Schreiber habe eine assyrische Fluchserie in seinen Text übernommen. ${ }^{4}$

In den folgenden Jahren meldeten sich Stimmen zu Wort, die Gemeinsamkeiten allein auf traditionelles Gut zurückführten. Schächter kam 1966 zu diesem Schluß aufgrund seiner Neuübersetzung der VTE, die er mit weiterem altorientalischen Material und dem Deuteronomium verglich. ${ }^{5}$ Ähnlich urteilten die hauptsächlich literarkritisch, form- und traditionsgeschichtlich angelegten Untersuchungen von Sumner (1968) und Seitz (1971). ${ }^{6}$ Nicholson verwendete 1986 die von Plöger (1966) und Seitz erarbeitete diachrone Schichtung von Dtn 28 als Argument gegen die These,

\footnotetext{
$1 \mathrm{Vgl}$. Treaty 1963, 123.

2 Vgl. Treaty-Curses, $41 \mathrm{f}$.

3 Vgl. „Vassal-Treaties,“"145-150.

4 Vgl. „Traces," 417-427; School, 116-122.

5 Vgl. Fluch, 170-172.
}

6 Vgl. Sumner, Study, 58; SEITz, Studien, 256; PlOGER, Untersuchungen, 134f, 136 Anm. 27, 146 Anm. 64, 156f, 158 Anm. 97, (1966) nahm die Beiträge von BORGER, MORAN und HILLERS in seine literarkritische und formgeschichtliche Argumentation auf, ohne einen Einbau altorientalischen Materials zu thematisieren. PERLITT, Bundestheologie, 46 Anm. 2, (1969) wies zwar auf die Berührungspunkte zwischen den VTE und Dtn 28 hin, enthielt sich jedoch eines Urteils über deren Zustandekommen. 
das Kapitel sei nach dem Modell der Fluchliste altorientalischer Verträge gestaltet. ${ }^{1}$ Doch Jeremias hatte schon 1970 gezeigt, daß eine diachrone Analyse des Kapitels Phasen in dessen Redaktionsgeschichte aufzeigen kann, in denen die Übernahme assyrischen Materials durchaus plausibel scheint. ${ }^{2}$ So fand die Auffassung, Flüche aus Dtn 28 seien von einer assyrischen Vorlage abhängig, weiterhin Zustimmung. ${ }^{3}$ Lohfink fand darin 1976 einen Ansatzpunkt, das deuteronomische Gottesbild vor dem Hintergrund der neuassyrischen Eide und Verträge zu kontrastieren. Auf die als überlegen empfundene Kultur Assyriens reagierte man in Juda, indem alte Traditionen durch das Konzept des Vertrages zwischen Gott und seinem Volk aktualisiert wurden. ${ }^{4}$ Noch ein Textbezug schien gefunden, als Wächter 1967 und Dion 1978 ausführten, daß der Ninurtafluch (VTE § 41), der zwischen den zu 28,26-35 parallelen $\S \S 39-40,42$ steht, zu Dtn 28,25f paßt. Dion vermutete, der Fluch habe bei der Übertragung der $\$ \S 39-42$ in den hebräischen Text den Platz gewechselt. ${ }^{5}$ Doch blieben Zweifel. 1993 betonte Houtman wieder die Unterschiede zwischen den hebräischen und den assyrischen Formulierungen. Ähnliche Erfahrungen der altorientalischen Lebenswelt hätten zu den Übereinstimmungen geführt. ${ }^{6}$

Gleiche Motivabfolge und außergewöhnliche Bilder weisen also für eine Reihe von Forschern auf assyrischen Einfluß hin, unterschiedliche Formulierungen und Wendungen ohne Gegenstück im Vergleichstext sprechen jedoch in den Augen anderer wieder dagegen. Um bei dieser Forschungslage weiterzukommen, erscheint es sinnvoll, das, was die mesopotamische Fluchtradition überlieferte, von dem zu unterscheiden, was auf die literarische Arbeit einzelner Verfasser zurückgeht. Wenn allein traditionelle Elemente zur Gestaltung von Dtn 28 herangezogen wurden, dürften die Gemeinsamkeiten nur in jenen Momenten liegen, die auch die Schreiber der VTE aus ihrer mesopotamischen Tradition übernommen haben, nicht aber in literarischen Charakteristika, die das Spezifikum der VTE-Flüche ausmachen. Um also das Traditionelle vom Individuellen zu trennen, gilt das Interesse, nachdem die altorientalischen Texte und ihre Fluchformen gattungsgeschichtlich eingeordnet worden sind, den VTE. Stammen ihre Dtn 28 besonders ähnlichen Passagen aus der altorientali-

${ }^{1}$ Vgl. God, $76 f$.

2 Vgl. Kultprophetie, 169.

${ }^{3}$ Vgl. Braulik, Testament, 69; Preuss, Deuteronomium, 72f; Ries, Prolog, 77; Plaut, Deuteronomy, 297f; BRAULIK, Deuteronomium II, 206.

${ }^{4}$ Vgl. „Gott,“ 114f/39-41.

5 Vgl. WächteR, Tod, 134 Anm. 44; Dion, ,Aspects,“ $48 f$.

${ }^{6} \mathrm{Vgl}$. Himmel, 148. 
schen Fluchtradition oder können spezifische Gestaltungselemente ihrer assyrischen Verfasser nachgewiesen werden? Um vorgegebenes Gut von Neuformulierungen zu unterscheiden, wird der assyrische Text mit Methoden der Form- und Formenkritik ${ }^{1}$ untersucht, wie sie in der Bibelwissenschaft üblich sind. Zur formenkritischen Einordnung der VTE-Stücke in die altorientalische Fluchkonvention werden alle bekannten Flüche auf veröffentlichten mesopotamischen Keilschriftdokumenten staatlicher Kanzleien aus den 1000 Jahren zwischen dem Kodex Hammurapi und den VTE herangezogen.

Die Arbeit am altorientalischen Material wird durch die Neubearbeitung der VTE erleichtert, die Watanabe 1987 vorgelegt hat. Zum Vergleich mit dem übrigen assyrischen Vertragskorpus dient Band 2 der ,State Archives of Assyria", die Parpola zusammen mit Watanabe herausbrachte. ${ }^{2}$ Auch einige Arbeiten zu altorientalischen Flüchen liegen vor. Gevirtz hatte 1959 deren Motive untersucht. Viele der 1968 von Hunger edierten Kolophone enthalten Flüche. Watanabe arbeitete 1984 die Formengeschichte des Sinfluchs und 1987 die Flüche der Gula und der Göttergattin in einer Weise auf, die für die hier vorgelegten formengeschichtlichen Untersuchungen des VTE-Materials beispielgebend war. ${ }^{3}$ Durch seine 1990 erschienene Sammlung mesopotamischer Fluchformeln ermöglicht Pomponio einen Einblick in die Jahrtausende währende Fluchtradition des Zweistromlandes. 1991 beendete Unterlechner ihre Diplomarbeit, in der sie die Götteranrufungen und Themen der Kudurruflüche zusammenstellte. Die 1993 erschienenen Aufsätze von Sommerfeld und Assmann thematisieren die Funktion der Flüche. Während Sommerfeld auf ihre abschreckende Wirkung zielt ${ }^{4}$, stellt Assmann ausgehend von Dtn 28 die Bedeutung ihrer schriftlichen Fixierung im Zusammenhang literarischer Kommunikation vor Augen. ${ }^{5}$ Mit dem Versuch, die Funktion des Fluches im literarischen Kontext zu bestimmen, spricht Assmann ein Problemfeld an, das auch für die Exegese von Dtn 28 beachtet werden muß.

Nach der Einordnung der VTE-Flüche in die mesopotamische Tradition wird im nächsten Abschnitt dieser Arbeit überprüft, welches Gewicht den

\footnotetext{
${ }^{1}$ Zum Unterschied zwischen Formkritik und Formenkritik oder -geschichte in der Aufteilung diachroner und synchroner Methoden vgl. FOHRER, Exegese, 65, 84-87.

${ }^{2}$ Staatliche Texte mit Flüchen werden auch in der Reihe „Royal Inscriptions of Mesopotamia" neu ediert. Doch fehlen noch die Bände der Kassitenzeit und der assyrischen Königsinschriften nach 859 v. Chr.

3 Vgl. „Überlieferung,“ 101-109; Thronfolgeregelung, 35-42.

4 Vgl. ,Flüche,“ 461-463.

5 Vgl. ,Fluchinschriften,“ 213-241.
} 
Unterschieden der konkreten sprachlichen Gestalt von Dtn 28 und seinen assyrischen Entsprechungen beizumessen ist. Mehrsprachige altorientalische Inschriften mit Flüchen und Segnungen dienen dazu, zu klären, wie vorlagentreu man im Alten Orient übersetzt hat. So soll ein Rückschluß darauf ermöglicht werden, ob das Verhältnis des Bibeltextes zu den VTE auf der Übersetzung einer fremdsprachigen Vorlage beruhen kann.

Vor der Exegese von Dtn 28 wird nach der Funktion des Kapitels im Deuteronomium gefragt. Dabei sind zwei Aspekte bedeutend: die Struktur des kanonischen Buches und die „Fabel“1, zu der Lohfink in letzter Zeit eine Reihe von Aufsätzen veröffentlicht hat. ${ }^{2}$ Für die Beschreibung der Struktur wurden in der Forschung Modelle von außen an das Deuteronomium herangetragen. ${ }^{3}$ Man sah in ihm unter Betonung der diachronen Textanalyse hauptsächlich einen Gesetzeskodex ${ }^{4}$ oder fand darin unter Einbeziehung formgeschichtlicher Beobachtungen die Zeremonien eines Bundeserneuerungsfestes ${ }^{5}$. Andere strukturierten das Deuteronomium nach hethitischen Vasallenverträgen oder nach dem neuassyrischen adê. ${ }^{6}$ Auf die Endgestalt des Buches zielte vRad 1964 ab, als er es Abschiedsrede und Testament des Mose nannte. ${ }^{7}$ Keine dieser Charakterisierungen trifft die Struktur des Deuteronomiums genau. Im Textstück Dtn 5-28 fand Braulik aber Elemente von Gesetzeskodex und Vertrag. Bedeutsam ist dabei, daß einzelne Textpassagen ihre Funktion verändern, je nachdem, ob man sie einem Gesetzeskodex oder einem Vertrag zuordnet. ${ }^{8}$ Die Funktion von Segen und Fluch in Dtn 28 läßt sich also nicht nur aus dem Kapitel selbst erheben. Als Voraussetzung für sein Verständnis und für seine Exegese ist nach der Stellung im Gesamten des Deuteronomiums zu fragen. Außerdem wird bestimmt, wie das Wort „Fluch“ verwendet wird, da dieser Begriff sowohl im Deutschen als auch im Hebräischen mehrdeutig ist.

Die anschließende Analyse des Bibeltextes berücksichtigt die Ergebnisse der Untersuchung des altorientalischen Materials, um Aufbau und

\footnotetext{
${ }^{1}$ Zum literaturwissenschaftlichen Begriff der „Fabel“ und seinem Verhältnis zum Ausdruck „Erzählstruktur“" sowie zu den englischen Begriffen ,plot“ und „story“ vgl. LoHFINK, „Fabel," 65 Anm. 1.

2 Vgl. „Dtn 31-32“; „Moab“; ,Fabel“"

3 Vgl. BraUlik, Deuteronomium, 6.

${ }^{4}$ Zur älteren Forschung vgl. Preuss, Deuteronomium, 33-45; Houtman, Pentateuch, 279. 299.

5 Vgl. Preuss, Deuteronomium, 45-63; Houtman, Pentateuch, 299-309.

6 Vgl. Preuss, Deuteronomium, 63-74; Houtman, Pentateuch, 309-314.

7 Vgl. Buch, 15f.

${ }^{8}$ Vgl. BraUlik, Deuteronomium, 6-8.
} 
Entstehungsprozeß von Dtn 28 zu verstehen. Sie mündet in den Versuch einer Redaktionsgeschichte.

Das umfangreiche Untersuchungsfeld legt Beschränkungen auf. Weitgehend unberücksichtigt bleiben Fragen nach dem redaktionsgeschichtlichen Verhältnis des Kapitels 28 zum übrigen Deuteronomium. Für die Entstehungsgeschichte des Deuteronomiums und die Abgrenzung der verschiedenen Textschichten gibt es in der Forschung unterschiedliche Entwürfe. ${ }^{1}$ Eine ähnliche Meinungsvielfalt herrscht über die deuteronomistischen Bearbeitungsschichten im DtrG und in Jeremia, wo abgesehen von Lev 26 die deutlichsten Parallelen zu Dtn $28 \mathrm{zu}$ finden sind. ${ }^{2}$ Beim Vergleich mit den Bibeltexten die synchrone Ebene zu verlassen, erweist sich als schwierig, da jeweils eine Fülle von Vorentscheidungen innerhalb der Hypothesenvielfalt zu fällen sind. Diese Entscheidungen können aber ausgehend von Dtn 28 kaum getroffen werden, schon gar nicht in Nebenbemerkungen zusätzlich zu der hier hauptsächlich interessierenden Frage nach dem Verhältnis von Dtn 28 zu altorientalischen Texten.

Auch die inhaltliche und theologische Einbettung des Kapitels 28 ins Deuteronomium wird nur kurz angerissen. Dies gilt besonders für die Segensankündigungen, die in verschiedenen Motivierungen das Deuteronomium durchziehen ${ }^{3}$, und den Zusammenhang von Lohn- und Strafe, den manche Gesetzesforderungen und andere Droh- oder Fluchpassagen des Buches ansprechen. ${ }^{4}$ Ein Segen fehlt in den assyrischen Vergleichstexten, und auch die anderen altorientalischen Segnungen zeigen wenig Ähnlichkeit mit Dtn 28,3-14. Daher wird der Segen von Dtn 28,3-14 nur vor dem Hintergrund des Fluchabschnittes besprochen, um seine Position in der Redaktionsgeschichte von Dtn $28 \mathrm{zu}$ bestimmen. Außerdem führen die Segenshinweise im Deuteronomium wieder in die Forschungsdiskussion um die Schichten des Buches, was den Vergleich außerhalb der synchronen Ebene erschwert.

Malul hat in systematischer Weise die Methoden des Vergleichs biblischer Texte mit altorientalischem Material dargestellt. Er definiert methodologische Kriterien für derartige Untersuchungen. ${ }^{5}$ Der folgende $\mathrm{Ab}$ -

1 Vgl. z.B. SEITZ, Studien, 303-311; MAYES, Deuteronomy, 46-48; Preuss, Deuteronomium, 49-61; OTTO, „Bundesbuch,“261-268.

2 Vgl. O'Brien, History, 6-12; HeRrMANn, Jeremia, 66-101.

${ }^{3} \mathrm{Vgl}$. PREUSS, Deuteronomium, $127 \mathrm{f}$.

${ }^{4}$ Vgl. zu Lohn und Strafe: PLOGER, Untersuchungen, 196-213; GAMMIE, „Retribution,“ 512; PREUSS, Deuteronomium, $200 \mathrm{f}$.

5 Vgl. Method, 153-156. Zwar hat Malul vor allem den Vergleich von Rechtstexten im Blick, doch bezieht er selbst auch andere Themen ein (z. B. Patriarchen, 266f, 57, 64, 75f; David, 107; Leben nach dem Tode, 18 Anm. 12, 127 Anm. 19 oder Götterversammlung, 
schnitt legt die verwendeten Untersuchungsprinzipien anhand dieser Kriterien dar.

\subsection{Untersuchungsprinzipien}

Bei der Anwendung der vergleichenden Methode (comparative method) auf Dtn 28 handelt es sich um einen geschichtlichen Vergleich (historical comparison), denn man nimmt an, daß biblische und außerbiblische Gegebenheiten (evidence) in einem historischen Zusammenhang miteinander stehen. Dieser Zusammenhang ist die Kultur, Geschichte und Tradition des alten vorderen Orients. ${ }^{1}$ Damit ergibt sich die Frage nach Natur und Typ einer solchen geschichtlichen Beziehung.

\section{1. 1. Die Natur der Verbindung}

Besteht die Verbindung in literarischen Gemeinsamkeiten, die auf schriftliche Vorlagen für den Bibeltext schließen lassen oder besteht sie in sachlichen Gemeinsamkeiten, also Formen der Kultur, die im ganzen AO verbreitet waren? Die Unterscheidung zwischen schriftlicher Quelle und Lebenswirklichkeiten wird dadurch erschwert, daß auch die Realien, also Institutionen, Gepflogenheiten und Handlungsmuster des AO nur noch in ihren schriftlichen Fixierungen oder kaum leichter zu interpretierenden archäologischen Funden zugänglich sind. ${ }^{2}$ Zunächst verglich man Dtn 28 mit Realien aus dem AO, nämlich mit Verträgen und Gesetzen, wobei es nicht um deren Texte, sondem um Phänomene ihrer Struktur ging. Es interessierte, wie man im AO Bündnisse einging oder Gesetzeskorpora gestaltete. ${ }^{3}$ Weil aber nur bei wenigen Gesetzen und Verträgen des AO Segens- und Fluchabschnitte zu finden sind, reduziert sich das Material für den Vergleich von Schriftzeugnissen auf einen Bruchteil der erhaltenen Texte dieser Gattungen. Segen und Fluch im Epilog von Gesetzen gibt es nur noch im sumerischen Kodex Lipit-Ištar und im altbabylonischen Kodex Hammurapi (KH). ${ }^{4}$ Bei den Verträgen steht mehr Vergleichsmaterial zur Ver-

96). Daher scheint die Anwendung seiner Kriterien auf den Vergleich von Fluchsequenzen angemessen.

1 Vgl. MaLUL, Method, 13. Die Alternative dazu wäre typological comparison, wo Kulturen miteinander verglichen werden, die historisch und geographisch keinen Kontakt hatten.

2 Vgl. MALUL, Method, 87f; UEHLINGER, „Kultreform,“ $59 \mathrm{f}$.

3 Vgl. JiRKU, Kommentar, 124f; Noth, ,Fluch,“ 161-163/132-135; Nicholson, God, 58, 63; RIES, Prolog, 75-78.

${ }^{4}$ „Darüber hinaus ist prinzipiell zu unterscheiden zwischen Kodizes, die mit Prolog und Epilog versehen wurden, so die Kodizes des Urnammu, Lipit-ištar und Hammurapi, sowie 
fügung. Allerdings veränderte sich die Gestalt der Verträge und folglich auch der Segens- und Fluchabschnitte von den ältesten Zeugen aus dem 3. Jt. v. Chr. bis ins 1. Jt. v. Chr., in das die Entstehung des Deuteronomiums datiert wird. ${ }^{1}$ Die Verträge des 3. Jts. aus Sumer, Akkade und Ebla enthalten nur kurze Verwünschungsformeln gegen den, der den Eid bricht. Die Verträge aus Hatti, Allalah und Ugarit aus dem 2. Jt. schlossen meist mit parallelen Fluch- und Segensformeln. Im 1. Jt. trat der Segen zurück und die Flüche wurden breit ausgestaltet. ${ }^{2}$ Dtn 28 ähnelt besonders den Vertragsflüchen des 1 . Jts., vor allem Fluchsequenzen der VTE. Dies zeigen verschiedene Untersuchungen, die altorientalische Parallelen zu Dtn $28 \mathrm{zu}-$ sammenstellen, in denen die Flüche nach gemeinsamen Motiven oder Themen geordnet sind. ${ }^{3}$

Eine Vermischung von Realien und schriftlichen Quellen schlägt sich im Begriff „Vertragsflüche“ nieder, wenn man darunter eine Gattung und nicht nur die Angabe der Herkunft des Vergleichsmaterials versteht. Zwischen den Realien des Vertrages und seinen im AO vorgeschriebenen Strukturen und den schriftlichen Formen seiner Flüche ist zu unterscheiden. ${ }^{4}$ Es gab im AO keine spezifische Gattung des Vertragsfluches. Traditionell festgelegte Fluchmotive und -formulierungen wurden von den Schreibern in die Fluchsektionen verschiedener Textgattungen eingebaut. Die Gestalt des Fluches (und analog des Segens) wird von der Gattung des Textes, in die er eingefügt wurde, nicht beeinflußt. Ein Beispiel dafür bieten Flüche aus dem Epilog des KH, die unverändert in den Vertrag zwischen Marduk-zakir-šumi I. und Šamši-Adad V. aufgenommen wurden. ${ }^{5}$ Auch die Textsorte der Rechtsdokumente legt die Verwendung der Fluchmotive nicht fest. Prologe und Epiloge der altorientalischen Gesetzeskodizes bilden nämlich mit den Rechtskorpora, die sie einschließen, keine

solchen, die keine derartige Rahmung haben, so der Kodex Ešnunna, der Mittelassyrische Kodex und der Hethitische Kodex. Mit der Rahmung durch Prolog und Epilog ändert sich die Gattung der Korpora. Aus rechtsgelehrter Literatur wird eine königliche Rechtsdeklaration mit programmatischer Absicht.“ OTTO, „Bedeutung,“ 149. Zum verloren gegangenen Epilog des Kodex Urnammu vgl. ebd. 155; RIES, Prolog, 11.

1 Vgl. McCARTHY, Treaty 1978, 15, 25, 29-36.

2 Vgl. McCARTHY, Treaty 1978, 141-153.

3 Vgl. McCARTHY, Treaty 1978, 173f; SUMNER, Study, 48-57; SCHÄCHTER, Fluch, 163-170; Preuss, Deuteronomium, 72f; JeREMIAS, Kultprophetie, 168 Anm. 4.

4 Vgl. Perlitt, Bundestheologie, 46 Anm. 2.

${ }^{5}$ KH Kol. XLIX Z. 45 - Kol L Z. 80 = Marduk-zakir-šumi I. / Šamši-Adad V., Z. 22-35. Vgl. BORGER, „Marduk-zākir-šumi,“ 168f; BRINKMAN, „Covenants,“ 111; McCARTHY, Treaty 1978, 173 Anm. zu „Code of Hammurabi“; PARPOLA / WATANABE, Treaties, 4 Anm. 1; SCHÄCHTER, Fluch, 127 Anm. 5. 
genuine Einheit, sondern gehören eher zur Gattung der Königsinschriften. In den Segens- und Fluchpassagen, die die Königsinschriften schützen sollen, stehen Formeln, die denen der Rechtsdokumente gleichen. ${ }^{1}$

\section{1. 2. Der Typ der Verbindung}

Malul unterscheidet vier Möglichkeiten, wie die Gemeinsamkeiten von biblischem und außerbiblischem Zeugnis entstanden sein können. ${ }^{2}$

(1.) Der biblische Verfasser entnahm seine Formulierungen direkt aus einer altorientalischen Quelle. Zumindest einige Flüche in Dtn 28 wären dann aus den VTE übertragen worden. ${ }^{3}$

(2.) Es bestand eine mittelbare Verbindung, d.h. B entnahm seine Formulierungen nicht aus Quelle A, sondern aus C, die von A stammt. ${ }^{4}$ Diese mittelbare Quelle könnte ein Vasallenvertrag zwischen Assyrien und Juda gewesen sein oder eine aramäische Übersetzung der VTE, die die assyrische Hofkanzlei für die westlichen Vasallen herstellte. ${ }^{5}$

(3.) Biblisches und außerbiblisches Zeugnis gehen auf eine gemeinsame Quelle zurück. ${ }^{6}$

(4.) Die gemeinsame Tradition schlug sich in ähnlichen Texten nieder. Diese Auffassung wird bezüglich der Gemeinsamkeiten der VTE mit Dtn 28 häufig vertreten. ${ }^{7}$

Erklärt man die Ähnlichkeiten zwischen dem Bibeltext und den VTE nur aus der gemeinsamen Fluchtradition, so verlangt man von dieser Tradition sehr viel. Denn die Gemeinsamkeiten bestehen nicht bloß in einigen

1 Vgl. McCARTHY, Treaty 1978, 124f Anm. 6; OTTO, „Bedeutung,“ 149, 155.

2 Vgl. MaLUL, Method, 89-91.

3 Vgl. Borger, „Nimrud,“ 191f; Frankena, „Vassal-Treaties,“ 145f; Preuss, Deuteronomium, 72.

4 Vgl. Malul, Method, $90 \mathrm{f}$.

${ }^{5}$ Ein assyrischer Vasallenvertrag mit Juda könnte aus der Regierungszeit Hiskijas stammen und damit älter sein als die VTE. Man hätte Formulierungen aus seiner Fluchsequenz in Assur und Juda weiterverwendet. Es ist aber nicht sicher, daß ein adê zwischen Juda und Assur existierte. Vgl. TADMOR, Treaty, 149-151.

${ }^{6}$ Für Dtn 28,23f und VTE $\S 63 \mathrm{f}$ nehmen WATANABE, Thronfolgeregelung, 33f, und HIILERS den Einfluß westsemitischer Formulierungen an. Vgl. HILlERS, Treaty-Curses, 42 Anm. 21: „It is unlikely that this is a very old traditional curse, since it mentions iron, and the poetic form of the biblical curse may point to an early origin in Israel or Canaan, whence it could have been adopted by Akkadian writers.“ KoTTSIEPER, „Aufnahme,“ 285 Anm. 10, meinte, ,die Motive können auf den verschiedensten Wegen in die eine oder andere Richtung gewandert sein, so daß ihre fremde Herkunft demjenigen, der sie benutzte, durchaus unbekannt sein konnte."

7 Vgl. Hillers, Treaty-Curses, 41; Sumner, Study, 58-60; Schächter, Fluch, 172; Houtman, Himmel, 148; Wiseman, „Peace,“ 311. 
vergleichbaren Motiven, sondern vor allem in einer Passage, wo die Flüche in derselben Reihenfolge angeordnet sind. ${ }^{1}$ Es zeigt sich hier ein Problem, das Malul als die Alternative von coincidence oder uniqueness beschreibt. Die Parallelen zwischen Dtn 28 und den VTE sind so detailliert, daß sie eine Einzigartigkeit innerhalb des altorientalischen Vergleichsmaterials darstellen. ${ }^{2}$ Soll die gleiche Reihenfolge der Motive in zwei verschiedenen Texten von der Tradition vorgegeben worden sein, hätte sie nicht nur einzelne Motive überliefert, sondern auch ein Anordnungsschema, nach welchem in Assyrien und Juda Flüche positioniert wurden. Es ist aber an den mesopotamischen Fluchsequenzen erst nachzuprüfen, ob tatsächlich die Themen als solche in einer festgeschriebenen Reihenfolge überliefert wurden oder ob die Abfolge derartiger Reihen nicht einfach durch die Stellung der Götter im Pantheon bestimmt war. ${ }^{3}$ Wer Dtn 28 nur durch die Tradition mit seinen altorientalischen Parallelen verbunden sieht, impliziert, daß die Tradition die Motive in festen Kombinationen übermittelte. Wurde die Reihenfolge der Fluchmotive nämlich durch die Abfolge der Götter festgelegt, setzt eine gleichartige Struktur im Bibeltext voraus, daß sein Verfasser sich am polytheistischen Referenzsystem der mesopotamischen Götterhierarchie orientierte, also von außerisraelitischen Vorlagen abhängig ist.

Es kann auch nicht unhinterfragt vorausgesetzt werden, daß es im ganzen AO eine allgemeine Fluchtradition gab. Die Unterscheidung in eine westsemitische und eine akkadische Fluchtradition, wie sie Gevirtz vorschlug ${ }^{4}$, wurde zwar abgelehnt ${ }^{5}$, doch inzwischen verbreitet sich die Ansicht, man könne in den Vertragstraditionen selbst eine Differenzierung zwischen dem Westen und Mesopotamien erkennen. ${ }^{6}$ Wenn Verträge im

1 Vgl. Frankena. „Vassal-Treaties,“ 148-149; WeINFELD, „Traces,“ 417-427; School, 116120; Dion, ,Aspects," 48f.

2 ,Apart from the VTE and Deut. 28 no such series of maledictions has as yet been discovered. Since this is the case and since the order of the curses is explicable only against a Mesopotamian background, we may conclude that a Judean scribe transported an entire and consecutive series of maledictions from Assyrian treaty documents to the book of Deuteronomy (Deut. 28:[26] 27-35)."WEINFELD, School, 122.

${ }^{3}$ Vgl. Preuss, Deuteronomium, 72; McCarthy, Treaty 1978, 175, 177 Anm. 37.

4 „In general, a clear difference may be remarked between 'East' and 'West' (including Hebrew) Semitic curses. Whereas East Semitic (Akkadian) maledictions were formulated in a religio-literary tradition which sought for divine approval and execution, importunning a lot of gods through imprecation, West Semitic curses were composed in a tradition which relied, primarily, not upon deity, but upon the power of the word. Hebrew shared the general West Semitic preference for constructions in which the agent of the curse remained undesignated, and for verbs in passive forms.“ GEVIRTZ, „Curse,“750.

$5 \mathrm{Vgl}$. ABOU-ASSAF / BordREUIL / Millard, Statue, 79.

6 Vgl. McCARTHY, Treaty 1978, 122, der daraufhin die gemeinsamen Elemente betont. Verschiedene Traditionsstränge, in denen teilweise sogar dieselben akkadischen Begriffe 
Westen und in Mesopotamien nach unterschiedlichen Traditionen formuliert und geschlossen wurden, kann man nur noch unter Vorbehalt postulieren, die darin aufscheinende Fluchtradition sei im Westen und im Osten dieselbe.

Will man der altorientalischen Fluchtradition nachspüren, um herauszufinden, wie streng fixiert sie Motive und Reihenfolge überlieferte, reicht es nicht, sich nur auf Rechtsdokumente zu beschränken. ${ }^{1}$ Es müssen vielmehr alle altorientalischen Textsorten in den Blick kommen, die mit Segen und/oder Fluch versehen wurden. Neben den Segens- und Fluchabschnitten auf Rechtsdokumenten, d.h. Gesetzeskodizes mit Epilogen, Verträgen, Vereidigungen und Kudurrus (Grenzsteine, bzw. besser Besitzrechtskundmachungen auf Stelen), werden daher auch entsprechende Passagen in Bau-, Weihe- und sonstigen Königsinschriften berücksichtigt.

Stellen die motivischen und strukturellen Gemeinsamkeiten von Dtn 28 und den VTE einen Sonderfall (uniqueness) dar oder gibt es in anderen biblischen und außerbiblischen Segens- und Fluchtexten ähnliche Baupläne (coincidence)? Es geht also nicht um die altorientalische Fluchtradition an sich, sondern um ihre Beziehungen zu Dtn 28. Daher kann eine Eingrenzung der herangezogenen altorientalischen Vergleichstexte vorgenommen werden. Für Dtn 28 diskutierte man in der Forschung bisher nur die literarische Abhängigkeit zu einem assyrischen Vertrag im Stile der VTE. Beziehungen zu anderen altorientalischen Texten waren höchstens als Einfluß der Tradition angesehen worden. ${ }^{2}$ Um zu erkennen, ob die Ähnlichkeiten zwischen den VTE und Dtn 28 auf literarischer Vermittlung beruhen oder ob sie aus der Tradition hervorgehen, genügt es, die Traditionsgeschichte der Flüche in den VTE zu erforschen. Fall es bisher nicht erkannte Bezüge zu anderen altorientalischen Fluchtexten gibt, werden sie bei der Sammlung der in die VTE eingeflossenen Traditionen auftauchen. Zusammen mit der Untersuchung der innerbiblischen Traditions- und Redaktionsgeschichte von Dtn 28 sollte sich erschließen lassen, ob in der Bibel unabhängig von einer mesopotamischen Vorlage derartige Motivkombinationen auftreten konnten. Diese Arbeit bietet keine allgemeine Traditionsgeschichte der VTE-Flüche, sondern es werden vor allem VTE $\S \S 39-42$ und $\S 63 \mathrm{f}$ behandelt, in denen eine Parallelität zu Dtn 28 herrscht. Weil §§ 39$42 \mathrm{zu}$ einer Reihe von Anrufungen astraler Gottheiten gehören, die in $\S$

unterschiedliche Bedeutung besäßen, vermuten TADMOR, „Alleanza,“ 20, 23; BRINKMAN, „Covenants,“ 91-93, 99; WEINFELD, „Heritage,“ 160f, 179.

${ }^{1}$ Für den Vergleich methodisch nur ein Nebeneinanderstellen gleicher Textgattungen zuzulassen, wie SCHÄCHTER, Fluch, 127, forderte, verengt den Blick.

2 Vgl. PREUSS, Deuteronomium, 70-73, 154-157. 
38A mit Anu, dem personifizierten Himmel, beginnt, und in $\S 43 \mathrm{mit} \mathrm{Ju}$ piter endet, sind $\S \S 38 \mathrm{~A}+43$ in die Analyse einbezogen, um den Kontext der Reihe zu wahren.

Es geht also um die Bauprinzipien altorientalischer Fluchsequenzen. Ist das Bauprinzip im AO die Götterhierarchie oder gibt es andere Strukturen? Diese Frage kann nur unter Berücksichtigung des Kriteriums beantwortet werden, das Malul „context" ${ }^{1}$ nennt. Sowohl der biblische Kontext als auch der Kontext der außerbiblischen Flüche ist entscheidend. Dieses Kriterium entspricht einer Forderung, die Otto für den Vergleich von Rechtssätzen aufgestellt hat. Es reicht nicht, einander ähnelnde Motive nebeneinanderzustellen, vielmehr muß jeweils der literarische Kontext berücksichtigt werden. ${ }^{2}$ Deshalb enthält die vorliegende Arbeit eine Liste sämtlicher Flüche auf mesopotamischen Dokumenten königlicher Kanzleien, die 1000 Jahre vor die Entstehung der VTE (672 v. Chr.) zurückgeht und die angerufenen Götter mit den ihnen zugeordneten Fluchwünschen zusammenstellt. Chronologisch geordnet soll diese Liste den Traditionsstrom altorientalischer Flüche und die Bauprinzipien der Fluchsequenzen aufzeigen. Außerdem werden durch die beigefügten bibliographischen Angaben die Schlußfolgerungen bezüglich der Verwurzelung von Dtn 28 in der altorientalischen Fluchtradition für den Leser nachprüfbar.

Darüber hinaus empfiehlt sich die Untersuchung des Fluches bei den großen Göttern des Himmels und der Erde (VTE § 56). In diesem Text werden nämlich Motive unterschiedlicher Flüche kombiniert. VTE § 56 ähnelt somit prinzipiell Dtn 28. Die Flüche sind von der Bindung an bestimmte Gottheiten gelöst und auf das Götterkollektiv als gemeinsames Subjekt bezogen. Das in VTE $\S 56$ verwendete Anordnungsschema sollte auch in anderen mesopotamischen Fluchsequenzen zu finden sein, wenn es sich um Traditionsgut handelt, d.h. wenn Fluchmotive unabhängig von der Götterhierarchie in festgelegten Schemata tradiert wurden. Nur dann konnten diese Schemata, vermittelt durch die Tradition, auch einen rein auf JHWH orientierten Bibeltext strukturieren. Trotz aller Vorbehalte, die die Begrenztheit der gefundenen und veröffentlichten Textzeugen für jede Traditionsgeschichte im AO auferlegt ${ }^{3}$ dürfte in VTE $§ 56$ der Umgang der

\footnotetext{
$1^{1}$ Method, $157 \mathrm{f}$.

2 Vgl. Otto. .,Bedeutung,“ 145.

${ }^{3}$ Vgl. Parpola / Watanabe, Treaties, XIII; ParPola, „Treaties,“ 162: „If anything is surprising, it is the relatively small size of the Neo-Assyrian treaty corpus: the eleven different treaties identified to date only constitute a fraction of the references to various treaties found in contemporary texts ..., and these in turn can be but a fraction of all treaties once drawn up and filed in the Assyrian archives."
} 
altorientalischen Schreiber mit ihrer Fluchtradition besonders klar zum Ausdruck kommen.

Der Vergleich mit Dtn 28 kann grundsätzlich drei Ergebnisse erbringen:

(1.) VTE $\S 56$ und Dtn 28 ähneln einander überhaupt nicht. Das bedeutet, die Fluchtradition legt die Reihenfolge der Motive nicht fest, wenn diese von den Gottheiten und deren Stellung im Pantheon gelöst sind. Die gleichartige Abfolge der Motive in VTE § 39-42 und Dtn 28,26-30 muß dann entweder aus der Abhängigkeit von einer mesopotamischen Vorlage resultieren oder auf den Einfluß biblischer oder in außerbiblischen westsemitischen Zeugnissen zu suchender Anordnungsschemata zurückgehen.

(2.) VTE § 56 und Dtn 28 ähneln einander, und gleichzeitig lassen sich noch andere altorientalische Fluchsequenzen finden, die nach dem gleichen Bauplan strukturiert sind. Dann ergibt sich, daß die Tradition fest verbundene Motivkombinationen überliefert hat, die in beiden Texten unabhängig voneinander Verwendung finden konnten.

(3.)VTE § 56 und Dtn 28 ähneln einander, aber weder im bisher bekannten altorientalischen Material noch in der Bibel gibt es weitere Texte mit einem derartigen Bauplan. Dann wäre VTE $\S 56$ innerhalb der altorientalischen Traditionsgeschichte als literarisches Produkt der assyrischen Staatskanzlei zu betrachten, wo man unter Verwendung traditioneller Elemente einen reich ausgestalteten allgemein gehaltenen Fluch geschaffen hätte. Die Ähnlichkeit mit Dtn 28 kann dann nicht auf der Fluchtradition beruhen, sondern legt die direkte literarische Abhängigkeit der biblischen Fluchkomposition von der assyrischen Vorlage nahe. Dabei ist zu fordern, daß der Bauplan von VTE $\$ 56$ auch die übrigen Parallelen zwischen Dtn 28 und den VTE-Flüchen einbezieht und erklärt, warum die Stellung dieser Parallelen innerhalb ihrer jeweiligen Gesamttexte (VTE / Dtn 28) voneinander abweicht.

Sollten die Untersuchungen an den VTE die direkte Übernahme assyrischer Formulierungen in den hebräischen Text nahelegen, bedarf dies weiterer kritischer Sichtung. Trotz der Ähnlichkeiten weist die konkrete Textgestalt gerade in den besonders parallelisierten Passagen Dtn 28,2630 / VTE $\S \S 39-42$ (Z. 419-430) und Dtn 28,23f / VTE § 63f (Z. 528-533) deutliche Unterschiede auf. ${ }^{1}$ Wenn eine Abhängigkeit von den VTE vorliegt, sind die parallelen Passagen aus einem fremdsprachigen - assyrischen oder aramäischen - Text übernommen, d.h. übersetzt worden. Daher taucht die Frage auf, wie man im AO übersetzt hat. Als Anschauungsmaterial dienen die Segens- und Fluchpassagen altorientalischer Bilinguen und zweisprachig erhaltener Verträge. Wie vorlagengetreu übertrug man Segens-

1 Vgl. McCARTHY, Treaty 1978, 175. 
und Fluchformeln in andere Sprachen? Können die Unterschiede der Parallelen zwischen Dtn 28 und den VTE im Laufe eines solchen Übersetzungsoder Übertragungsvorganges entstanden sein? Dieser Abschnitt der Arbeit bezieht auch Fluch- und Segenstexte anderer Epochen und Regionen des AO mit ein und ermöglicht so einen über Mesopotamien hinausgehenden Vergleich mit altorientalischen Fluch- und Segenstraditionen.

Grundlage des historischen Vergleichs ist die Annahme eines gemeinsamen geschichtlichen Stroms, der biblische und außerbiblische Zeugnisse miteinander verbindet. Für einen solchen Fluß von Ideen oder sogar schriftlichen Quellen fordert Malul die Bestätigung (corroboration) seiner geschichtlichen Möglichkeit. ${ }^{1}$ Deshalb soll die folgende kurze Beschreibung der Beziehungen Israels und Judas zu Mesopotamien den historischen Rahmen abstecken, in dem der Bibeltext unter Einfluß der altorientalischen Tradition oder einer fremdsprachigen Vorlage entstanden sein könnte.

\section{2 Die Beziehungen Israels und Judas zu Mesopotamien}

Aššurnașirpal II. (883-859 v. Chr.) stieß als erster Herrscher des neuassyrischen Reiches nach Nord- und Mittelsyrien vor und machte die dortigen Staaten tributpflichtig. Historisch greifbar werden Beziehungen Israels zu Assur in der Schlacht von Qarqar (854). Dem assyrischen König Salmanassar III. (858-824) steht eine Koalition von Königen gegenüber, unter denen er auf seinem Monolithen auch Ahab von Israel verzeichnete. ${ }^{2}$ Das nächste erhaltene assyrische Zeugnis von einem Herrscher Israels ist die Abbildung Jehus auf dem schwarzen Obelisken Salmanassars III. (841), der den israelitischen König in devoter Haltung vor Salmanassar zeigt und

1 Vgl. Method, 99-112.

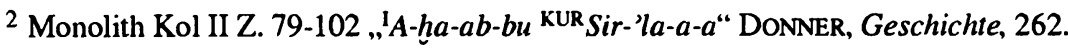


von Tributleistungen berichtet. ${ }^{1}$ Spätestens zu diesem Zeitpunkt scheint Israel in die erste Stufe der assyrischen Vasallität eingetreten zu sein. Es ist nicht sicher, daß zur Festschreibung dieser ersten Phase, die ein semiautonomes Königreich übrigließ, immer ein Vasallenvertrag (adê) gehörte. Auch ohne formellen Vasalleneid geriet Israel in ein ardūtu-Verhältnis zu Assur, das von dem Untergebenen Tributleistungen und gegebenenfalls Hilfstruppen forderte. ${ }^{2}$ An Juda scheinen die Assyrer zunächst nicht interessiert gewesen zu sein, denn es lag abseits vom Landweg nach Ägypten, den man sich dadurch sicherte, daß die Philisterstädte am Meer in ein Abhängigkeitsverhältnis gebracht wurden. ${ }^{3}$

Judas Abhängigkeit von Assyrien begann wohl mit dem Hilferuf des Ahas an Tiglat-Pileser III. (744-727) (2 Kön 16,7-9; Jes 7,1-9; 2 Chr 28,57 ), die beiden assyrischen Vasallen Israel und Damaskus, die gegen Jerusalem anrückten, zur Vernunft zu bringen. ${ }^{4} \mathrm{Da}$ es sich bei der Aktion des Ahas um eine freiwillige Unterwerfung und Tributleistung gegenüber Assur handelte, ist es möglich, daß auch mit Juda kein Vasallenvertrag abgeschlossen wurde, als es nun in das ardūtu-Verhältnis zu Assyrien eintrat. Sicherlich jedoch erwartete der assyrische Hof von nun an Tributlieferungen und Loyalität. Sanherib wird später in seinem Bericht über die Revolte des Hiskija dem König von Juda nicht vorwerfen, einen adê gebrochen zu haben. ${ }^{5}$ Ob sich Sanherib jedoch nur mit den Tributleistungen Hiskijas begnügte und keinen Treueid von ihm verlangte, ist aufgrund des Schweigens biblischer und assyrischer Quellen nicht zu entscheiden. Jedenfalls war Juda zur Zeit des Hiskija eine politische Größe, mit der man rechnete. Nur so ist die Gesandtschaft des babylonischen Revolutionärs Merodachbaladan II. (721-711) nach Jerusalem zu erklären, der für kurze Zeit Babylonien der assyrischen Herrschaft entriß und offensichtlich in Hiskija einen Verbündeten auf der anderen Seite der syrischen Wüste suchte (2 Kön 20,12f). Doch weder Babylon noch Juda gelang es, der assyrischen Machtexpansion zu entgehen.

Seit dem Fall Samarias (722) und der Umwandlung des Restes, der von Israel noch übriggeblieben war, in eine assyrische Provinz verlief die

${ }^{1}$ Die Assyrer hatten von der Ausrottung der Omriden scheinbar keine Kenntnis genommen, denn sie ,nannten Jehu ,Sohn Omris‘, wie wenn nichts geschehen wäre. Es blieb einfach bei der Bezeichnung, unter der zuerst ein israelitischer König in den Gesichtskreis Assurs getreten war." DONNER, Geschichte, 280.

2 Vgl. TADMOR, ,Treaty,“ 149.

${ }^{3}$ Sanherib (707-681) wird ausdrücklich erwähnen, daß Padi, der König von Ekron, durch einen adê an ihn gebunden war. Vgl. LUCKENBILL, Sennacherib, 31; TADMOR, „Treaty”, 146.

$4 \mathrm{Vgl}$. LOWERY, Kings, $125 \mathrm{f}$.

5 Vgl. TADMOR, ,Treaty,“ $150 f$. 
Reichsgrenze Assyriens nur wenige Kilometer von Jerusalem entfernt. ${ }^{1}$ Manasse (699-643) war ein treuer Tributzahler an Assyrien und der Prophet Nahum erwähnt assyrische Gesandte, die wohl in Jerusalem ein- und ausgingen (Nah 2,14). Seit Sanheribs Palästinafeldzug (701) war Juda eng an Assyrien gebunden. Im Norden lagen die drei assyrischen Provinzen Dü'ru (Dor), Samerīna (Samaria) und Magiddū (Megiddo). Im Osten lagen die assyrische Provinz Gal'az[a] (Gilead) und die assyrischen Vasallen Ammon und Moab. Im Westen waren die Philisterstädte in assyrischer Hand und im Südwesten gab es in Tell Jemmeh sogar eine assyrische Garnison. Außerdem zog Asarhaddon (680-669) in den Jahren 673 und 671 auf seinen Ägyptenfeldzügen durch Palästina. ${ }^{2}$ Es ist daher undenkbar, daß man in Jerusalem unberührt blieb von dem Großereignis, das 672 das politische Geschehen in Assur bestimmte.

Asarhaddon versammelte Vertreter ganz Assyriens und wohl auch Repräsentanten der abhängigen Fremdvölker, um sie auf die Nachfolgeregelung für seine Söhne Assurbanipal und Šamaš-šum-ukin zu vereidigen. Diese Zeremonie muß mehrere Tage gedauert haben, da Assurbanipal sie auf den 12. Ajjar datiert, die erhaltenen adê-Texte jedoch das Datum des 16. und 18. Ajjar tragen. Für die Vereidigungen wurde ein adê geschaffen, der sowohl für die assyrische Reichsnobilität als auch für die Repräsentanten der Randgebiete des assyrischen Herrschaftsbereiches anwendbar war. Dieser Text liegt in seinen für die medischen Fürsten bestimmten Versionen in den VTE vor. ${ }^{3}$ Parpola meint, daß die VTE zwar zur Vereidigung ganz Assyriens konzipiert waren, bei den erhaltenen Exemplaren handle es sich aber um eine sekundäre Anwendung auf Vasallen im Sinne von Vasallenverträgen. Diese Sicht erhöht die Wahrscheinlichkeit, daß man auch die Vasallen im Westen mit einem solchen adê vereidigte. ${ }^{4}$ Unbezweifelbar gehörte Juda zur Regierungszeit des Manasse (699-643) zum Hegemonialbereich Assurs. Jerusalem mußte von der Thronfolgeregelung und der

1 Vgl. NeLSON, ,Realpolitik,“ 178.

2 Vgl. NELSON, ,Realpolitik,“ 180.

3 Vgl. WatanaBE, Thronfolgeregelung, 3f. Von Versionen kann man sprechen, weil die Fragmente erkennen lassen, daß die adê nicht nur in der Namensnennung und dem Datum, sondern auch in Textdetails voneinander abweichen.

4 ,In sum. it can be stated that at least four ... of the eight 'city-rulers' figuring in these treaties had become Assyrian vassals within a period of three years before the treaties were concluded. This being so, it seems quite possible that these texts really were meant to function as 'vassal-treaties', instruments relegating the oath-taking rulers to a status of permanent vassalage. This interpretation is not in conflict with the texts' obvious character as loyalty oaths; the two concepts are not mutually exclusive." PARPOLA / WATANABE, Treaties, XXXI. 
Aufteilung des Landes in einen assyrischen und einen babylonischen Herrschaftsteil in Kenntnis gesetzt werden. Vielleicht bewahrt der Bericht der Chronik von einem Mesopotamienaufenthalt Manasses noch die Erinnerung daran. daß auch der König von Juda zu denen gehörte, die Asarhaddon zur Thronfolgevereidigung versammelte $(2 \mathrm{Chr} 33,11) .{ }^{1}$ Doch selbst wenn Manasse nicht an der Zeremonic teilgenommen hätte, wurde der VTE-Text sicherlich auf diplomatischem Wege unter den Nachbarn Assyriens verbreitet. Damit ist historisch die Möglichkeit gegeben, daß Flüche aus den VTE in das Kapitel 28 des Deuteronomiums gelangen konnten.

Die assyrische Kultur übte große Faszination auf das Juda des Manasse aus. $^{2}$ Mit dem Niedergang des assyrischen Reiches, der in der Zerstörung Ninives 612 gipfelte, nahm das Interesse an Assyrien ab. Das neubabylonische Reich trat die Nachfolge Assyriens an und verleibte Juda seinem Herrschaftsgebiet ein. Mit Zidkija schloß Nebukadnezar einen Vertrag (adê; Ez 17,13f.). Nach 586 wurde Juda babylonische Provinz und fiel schließlich wie Babylon selbst unter persische Herrschaft. Die Epoche, in der die in Jerusalem vorliegende Fassung der VTE die Gestaltung hebräischer Texte beeinflußt haben könnte, beschränkt sich somit auf die Zeitspanne zwischen der Vereidigung (672) und dem Vertrag zwischen Nebukadnezar und Zidkija (597). Ab dann hätte man sich wohl eher an dem neuen adê orientiert, zumal darin offenbar JHWH selbst als Vertragsgarant angerufen worden war. Ab diesem Zeitpunkt ist ein direkter Einfluß der VTE auf Dtn 28 unwahrscheinlich. Texte aus persischer Zeit zeigen jedoch, daß alte Formulierungen und Traditionen weiterhin in Fluchsequenzen Verwendung fanden. Solche durch die Tradition vermittelten Elemente konnten bei der Gestaltung des Bibeltextes auch in exilischer und nachexilischer Zeit wirksam sein.

Dieser geschichtliche Abriß eröffnet die historischen Voraussetzungen dafür, daß die VTE schriftliche Quelle für Dtn 28 waren. Doch besteht darüber hinaus die Möglichkeit, daß die Ähnlichkeit der Texte durch Realien hervorgebracht wurde, die in Assyrien und Juda gleichartigen schriftlichen Niederschlag fanden. Das folgende Kapitel widmet sich Realien, in denen die altorientalische Kultur Flüche verwendete, und versucht eine Einteilung der Fluchformen in verschiedene Gattungen.

1 Vgl. Nelson, „Realpolitik,“ 180; Lowery, Kings, 185-189; SPIECKERMANN, Juda, 333 338.

2 Vgl. SPIECKERMANN, Juda, 216-219, 221; Nelson, ,Realpolitik,“ 181. 


\section{VERWENDUNG UND GESTALT DER FLÜCHE IM ALTEN ORIENT}

Der kulturellen Verwurzelung des Fluchens im Leben altorientalischer Menschen kann in dieser Arbeit nicht allgemein nachgegangen werden. ${ }^{1}$ Greifbar werden die Flüche in heutiger Zeit nur noch dort, wo sie schriftlichen Ausdruck gefunden haben. Die Kultur des AO kannte Lebensbereiche, in denen die schriftliche Fixierung von Flüchen üblich war. Für den Vergleich mit dem Deuteronomium bieten sich vor allem Texte aus dem Rechtsleben an. ${ }^{2}$ Hier zeigen sich nicht nur gemeinsame Motive in den Fluchsequenzen, sondern die gesamte Struktur der Textsorten kann in Beziehung zum Aufbau des Deuteronomiums gesetzt werden. In der Forschung wurde dies vor allem bei zwei Realien herausgearbeitet, die Israel und dem AO gemeinsam waren: Verträge und Gesetzeskodizes.

\subsection{Vertragsformular und Gesetzespromulgation}

Korošec fand in den Vasallenverträgen der Hethiter ein Vertragsformular, dessen Aufbau auch in den paritätischen Verträgen kaum abgewandelt wurde. ${ }^{3}$ Mendenhall und Baltzer entdeckten dieselbe Struktur im Bund Gottes mit Israel am Sinai. Wegen dieser Parallelität zwischen bronzezeitlichem Vertrags- und biblischem Bundesformular schlossen sie auf das hohe Alter der Bundestradition in Israel. ${ }^{4}$ McCarthy und Weinfeld setzten den Vergleich altorientalischer Verträge mit alttestamentlichen Bundestexten fort und erkannten, daß auch das Deuteronomium nach dem Bundesformular aufgebaut ist. ${ }^{5}$

Die Frühdatierung des alttestamentlichen Bundesgedankens und die Strukturierung des Deuteronomiums nach dem Bundesformular wurde in der weiteren Forschung wieder in Frage gestellt. Perlitt verlegte die Entste-

\footnotetext{
${ }^{1}$ Hinweise dazu bei SOMMERFELD, „Flüche," 452f, 461f; AssmaNn, „Fluchinschriften,“ 244-255.

2 Vgl. Nicholson, God, 77f; Preuss, Deuteronomium, 73; LehmanN, „Oaths,“ 75-77. WEINFELD, School, 66-68, 72-74, 81, fand im Deuteronomium auch Züge von Landschenkungsurkunden. Zur Ähnlichkeit der Fluchmotive dieser Textgattungen mit Dtn 28 und Lev 26 vgl. WÄCHTER, Tod, 132-137.

3 Vgl. Staatsverträge, 12-14.

4 Vgl. Mendenhall, Recht, 33-44; „Suzerainty,“ 87; BALTZER, Bundesformular, 37-40; KITCHEN, ,Fall,“ 119.

5 Vgl. McCARTHY, Treaty 1978, 157-187; WEINFELD, School, 66-68; LOHFINK, Hauptgebot, 108-111; LOWERY, Kings, $199 \mathrm{f}$.
} 
hung der Vorstellung vom Bund zwischen Gott und Israel ins 7. Jh. v. Chr. ${ }^{1}$ Nicholson kritisierte den Vergleich zwischen altorientalischen Verträgen und dem biblischen Bund. Das Deuteronomium sei überhaupt nicht nach dem Bundesformular gestaltet. ${ }^{2}$

Kitchen wendete dagegen ein, der westsemitische Begriff berît taucht bereits 1400 v. Chr. im syrischen Qatna und als Lehnwort im 13. und 12. Jh. in Ägypten auf, z.B. in einem Dekret Sethos des I. ${ }^{3}$ Im 13. Jh. nennt ein hurritischer Hymnus aus Ugarit den semitischen Gott El unter anderem ,'El.brt, 'El.dn". ${ }^{4}$ In einem Text aus Medinet Habu aus der Zeit Ramses III. (ca. 1170 v. Chr.) wird brt sogar im politischen Sinn für Vasallenvertrag, vielleicht auch für Vereinbarung oder Bund verwendet. ${ }^{5}$ Die ägyptische Diplomatie schloß eine vertragliche Verpflichtung des Pharao aus. Das Verhältnis zu ausländischen Fürsten wurde, vom Vertrag zwischen Huattušili III. und Ramses II. abgesehen, möglichst nach dem Modell der Beamteninstruktionen oder einseitig auferlegter Treueide gestaltet. Diese ägyptische Haltung führte bei den Stadtfürsten Palästinas zu Mißverständnissen. Daran erkennt man eine unterschiedliche inhaltliche Füllung der Beziehungen, die durch Verträge mit einem überlegenen Souverän bestanden. Die Stadtfürsten Palästinas scheinen vom Pharao eine Schutzfunktion erwartet zu haben, die der Haltung des hethitischen Herrschers entsprach. ${ }^{6}$

$1 \mathrm{Vgl}$. Bundestheologie, 280-284. Zur Forschungsgeschichte des Bundesformulars vgl. PrEUSS, Deuteronomium, 63-74, 217-219; zum Spätansatz des Bundesgedankens im Gefolge von WellhaUSEN und der Diskussion darüber vgl. KITCHEN, „Fall,“ 118-120, 134; McCARTHY, Treaty 1978, 13-24; NICHOLSON, God, 3-117; ZENGER, „Bundestheologie,“ 1922.

2 "The weakness is that one begins with the view that Deuteronomy is modelled upon the treaty-form (or, as Mayes believes, came to reflect it at a secondary stage of editing) and then has to explain why it is nonetheless quite different form it in two key sections, the prologue and the central legal section." NicHOLSON, God, 78. Vgl. auch die Diskussion von NICHOLSONs Auffassungen bei ZENGER, „Bundestheologie,“ 24-26 und LOHFINK, „Nicholson,“" 2966 .

${ }^{3}$, ,... One may cite the TAR beriti awīlī (pl.) aša $[\ldots]$ and TAR beriti $[\ldots] n u$... . (...) The ideogram TAR/KUD can stand for one or other of several Akkadian synonyms (or parasynonyms) for krt, 'cut': parāsu, nakāsu, batāqu, etc.“ KrTCHEN, „Egypt,“" 459; vgl. „Fall,“” 122.

${ }^{4}$ KrTCHEN, „Fall,“ 122: „'El.dn was immediately recognised as 'El of Judgement', and ... 'El.brt was recognised in turn as 'El of the Covenant' ... ." Vgl. „Egypt,“ 458.

5 Vgl. Craigie, Deuteronomy, 81.

6 Vgl. TADMOR, „Treaty,“ 140; McCARTHY, Treaty 1978, 125; ZACCAGNINI, „Forms,“ 51 54, 51 Anm. 45: „... I shall simply remark that the Old Testament echoes traditions of the Syro-Anatolian world of the late II millennium - possibly with fresh influences deriving from practices of late Sargonid Assyria, at the time of Esarhaddon - but $n$ o $t$ the Pharaonic administative system of the Palestinian area during the New Kingdom." 
Der Begriff berît begegnet also im AO bereits von etwa 1400 bis 1170 v. Chr. in religiösem und sozialem Kontext. Die Vorstellung von einem Bund zwischen Gott und Mensch kann bereits im 3. Jt. v. Chr. im Bund zwischen dem König Uru'inimgina (Urukagina) von Lagaš und seinem Gott Ningirsu gefunden werden. ${ }^{1}$ Im 1 . Jt. v. Chr. scheint ein Prophetenwort der Ištar von Arbela an den assyrischen König Asarhaddon von einem Vertrag oder der Vereidigung assyrischer Vasallen durch die Göttin zu sprechen:

Kol. III „ ${ }^{3}$ Ein Trinkgefäß von 1 Seah (Kapazität) ${ }^{4}$ fülltest du mit Wasser aus dem Weihwasserkrug ${ }^{5}$ (und) gabst (es) ihnen. ${ }^{6}$ Doch ihr spracht in eurem Herzen: ${ }^{7}$,Ischtar hält Wache‘. ${ }^{8}$ (Doch dann) geht ihr in eure Städte, ${ }^{9}$ eure Bezirke, eßt Brot ${ }^{10}$ (und) verge $B t$ diese Eide. ${ }^{12}$ Trinkt ihr ${ }^{11}$ jedoch von diesem Wasser, ${ }^{12}$ werdet ihr euch erinnern ${ }^{13}$ (und) diese Eide beachten, ${ }^{14}$ die ich bezüglich Asarhaddons ergehen lieB.“2

Sabäische Bauinschriften aus dem 8. und 7. Jh. v. Chr. enthalten eine Bundesschließungsformel. In ihr drückt sich der Gedanke des Bundes zwischen einer Gottheit, Herrscher und Volk aus. ${ }^{3}$ Für den westsemitischen Bereich belegt die aus dem 7. Jh. v. Chr. stammende Inschrift von Arslan Tasch die Praxis, mit Gottheiten und anderen übermenschlich-dämonischen Mächten einen Bund zu schließen.

„Vs. ${ }^{1}$ Beschwörung: O Göttin Fliegerin! ${ }^{2}$ Gott Sasam, Sohn der Paidras ${ }^{3}$ sa! ${ }^{4} \mathrm{O}$ Würgerin des ${ }^{5}$ Lammes: In das Haus, in das ich komme, ${ }^{6}$ sollt ihr nicht kommen! Rs. (...) ${ }^{9}$ Einen ewigen Bund schlo $B$ mit uns ${ }^{10}$ Assur, schlossen ${ }^{11}$ mit uns alle Söhne der Götter ${ }^{12}$ und das ganze Geschlecht aller Heiligen: ${ }^{13} \mathrm{Im}$ ewigen Bann des Himmels und der Erde! ${ }^{14}\left[\right.$... ] Im Bann Ba'als, ${ }^{15}$ des Herrn der

\footnotetext{
1 Vgl. Thureau-Dangin, Königsinscliriften, 12 Z. 26-33. KTtchEN, „Fall,“ 122f; „Egypt.“ 462; McCARTHY, Treaty 1978, 31; ZENGER, „Bundestheologie,“ 35.

2 HeCKER, „Zukunftsdeutung," 61 (ABRT I, 24 = K. 2401). Im zitierten Abschnitt scheint die Göttin Menschen einen adê, eine Vereidigung, aufzuerlegen, da das akkadische Verb nașāru in III 13 der terminus technicus für das Einhalten von Verträgen und Dekreten ist (gegen HECKER, ebd. Anm. III 10a, der adû als "Offenbarung" verstehen will). Vgl. ZENGER, „Bundestheologie,“ 35 Anm. 76; LOHFINK, „Gott,“ 115 Anm. 52. Im von LoHFINK erwähnten Abschnitt Kol. II Z. 10-32 bezeichnet adû keinen „Vertrag, Bund“, sondern einen einseitigen „Eid, Schwur" des Gottes Assur. Der Gott bindet sich durch einen Schwur an sein Versprechen. Vgl. PARPOLA, „Treaties,“ 181.

3 Vgl. WissmanN, Inschriftenkomplex, 32-35; Geschichte, 180f. Eine Bundesschließungsformel lautet z.B.: „Yada“il Dharih ... hat ummauert den Tempel des Almaqah, als er zum dritten Mal ein Heiligtum ausführte und jede Gemeinde eines Gottes und Patrons eines Bundes und Vertrags einrichtete.“ MULLER, „Bauinschrift,“ 659f.
} 
Erde! Im Bann ${ }^{16}$ Haurons, dessen Wort wahr ist, ${ }^{17}$ seiner sieben Nebenfrauen 18 und der acht Frauen des heiligen Herrn!"1

Die Erinnerung an einen Bund mit Assur, den Gottessöhnen und dem Obersten bzw. der Gesamtheit positiver überweltlicher Mächte dient in der Beschwörung dazu, negative Gottheiten oder Dämonen von dem Haus fernzuhalten, in dem eine Geburt stattfindet. In Jes 28,15 werden den Israeliten ähnliche Bündnisse mit beschwörendem Charakter vorgeworfen:

Ihr habt gesagt: Wir haben mit dem Tod ein Bündnis geschlossen, wir haben mit der Unterwelt einen Vertrag gemacht. Wenn die Flut heranbraust, erreicht sie uns nicht; denn wir haben unsere Zuflucht zur Lüge genommen und uns hinter der Täuschung versteckt. ${ }^{2}$

Die religiöse Dimension des Bundesgedankens betont Munn-Rankin. Im AO seien zwischenstaatliche Beziehungen als Schöpfung der Götter betrachtet worden, in denen man die eigentlichen Eigentümer und Leiter der Staaten sah. ${ }^{3}$ Die Verträge von Sefire (I B)bringen das explizit zum Ausdruck:

„<Die Verträge des Bar-Ga'yah, Königs von Ktk, mit Mati`-Il, Sohn des> 1 ['Attar-sumk, dem König von Ar]pad. (...) ${ }^{4}$... Und die Verträge der Bürger von $K t k$ mit den ${ }^{5}$ [Verträgen der Bürger von A]rpad und mit seinem Volk. Und die Verträge der Götter von $K t k$ mit den Verträgen der ${ }^{6} \mathrm{Gö}[t t e r$ von Arpad. Und] göttliche Verträge sind es, welche die Götter gesetzt haben." ${ }^{4}$

Vor diesem Hintergrund wäre JHWH als eigentlicher Herrscher Israels, von dessen Erwählung die Könige von Juda und Israel ihre Regentschaft herleiteten, in deren Verträgen mit anderen Staaten direkt einbezogen gewesen.

Kitchen folgerte aus den von ihm bereits für die Zeit der MerenptahStele aufgezeigten Bundesvorstellungen im AO, in denen dasselbe Wort

${ }^{1}$ BUTTERweck, „Beschwörung,“ 436. Vgl. LOHFINK, „Diskussion,“ 29 Anm. 32; ZENGER, „Bundestheologie,“ 35f; KAI Nr. 27.

2 Man könnte Jes 28,15a auch übersetzen: ... Wir haben mit (dem Unterweltgott) Mot einen Bund geschlossen. Vgl. Jes 28,18. Vgl. den Forschungsüberblick über Arslan Tasch bei CRAWFORD, Blessing, 133-141.

${ }^{3} \mathrm{Vgl}$. „Diplomacy,“ 72: „Although in the extant treaties of the second and first millennia kings alone are named as the contracting parties, they were acting as repesentatives of the gods of their respective states and the earthly treaty was but a counterpart of a divine agreement. This is clearly implied by the following passages in the treaty of Hattusilis and Ramses II. "The king of the land of Egypt, in order to bring about the relationship that the Sun-god and the Storm-god have effected for the land of Egypt with the Hatti land, ... ."“ Für Israel bezeugt dieses Denken Ez 17,13.19f. Zum religiösen Hintergrund der VTE vgl. KREBERNIK, „Deuteronomiumskommentar,“ 30.

${ }^{4}$ ROSSLER, „Verträge,“" 182. 
wie in der Bibel verwendet wird, daß Israel wohl kaum bis ins 8. oder 7. Jh. v. Chr. hermetisch von dieser Bedeutung von berît abgeriegelt war. Der Bundesgedanke in Israel ist demnach alt. Dennoch kritisierte er die Rückführung biblischer Bundestexte auf das Bundesformular bei Mendenhall, McCarthy und Weinfeld. Den Bund in den Büchern Ex-Lev, Dtn und Jos verstand er als Zusammenfluß von Vertrag und Gesetz. Gesetz, Vertrag und Bund bilden ein konzeptionelles Triptychon. Die altorientalischen $\mathrm{Ge}$ setzeskodizes zeigen häufig einen den Verträgen ganz ähnlichen Aufbau. Der Vorrang des kurzen Segens vor dem Fluch in Dtn 28 entspricht eher dem Aufbau der Gesetze. Die Ähnlichkeit der Struktur des Deuteronomiums mit dem Aufbau alter Gesetze, z.B. Kodex Hammurapi, Urnammu, Lipit-Ištar und Ešnunna, war jedoch auch McCarthy und Weinfeld aufgefallen. ${ }^{1}$ Die Ähnlichkeiten zwischen Dtn 28 und neuassyrischen Verträgen resultieren nach Kitchen nicht aus direkter Abhängigkeit, sondem aus einer gemeinsamen bis in die altbabylonische Zeit zurückreichenden Tradition. ${ }^{2}$

Die Funktion von Segen und Fluch ist in Verträgen und Gesetzen jedoch keineswegs dieselbe. Segen und Fluch am Ende von altorientalischen Gesetzen sollen vor allem den Erhalt der Inschrift und den Ruhm des Gesetzgebers sichern. Nur der KH enthält auch die Forderung, die Gesetze zu beobachten. ${ }^{3}$

Dagegen haben Segen und Fluch in den Verträgen die Aufgabe, zur Einhaltung der Vertragsklauseln zu motivieren. Segen und vor allem Fluch stehen hier in engem Zusammenhang mit dem Eid, durch den die Vereinbarung geschlossen wird. Dies schlägt sich sogar in der Terminologie nieder. Zur Zeit der Hethiter wurde der Vertrag mit dem Hendiadyoin riksu u māmìtu bezeichnet, was den Bund, also die auferlegte Verpflichtung einerseits, und den Eid, also die Übernahme dieser Verpflichtung andererseits,

\footnotetext{
1 Vgl. KITCHEN, ,Fall,“ 123f; WeINFELD, School, 146-157; mit klarer Zuweisung des Deuteronomiums zum Bundesformular McCARTHY, Treaty 1978, 181.

2 Vgl. „Fall,“ 129, 133, zu Gesetzen, hethitischen Verträgen und dem Siani-Bund, 127: „LAW SINAI COVENANT TREATIES ...

1. Title/Preamble

1. Title/preamble

2. Prologue(religious)

3. Laws

2. Historical prologe

3. Laws, regulations

4. Epilogue 4a/b.Deposit; Reading Witnesses

5a Blessings (few) 6a Blessings (few)

$5 b$. Curses (many) 6b. Curses (many) 7. Epilogue

1. Title/preamble.

2. Historical prologe

3. Stipulations 4a/b.Deposit; Reading 5. Witnesses $6 \mathrm{~b}$ Curses 6a. Blessings

From this table, we can see directly the "confluence' mentioned above."

3 Vgl. KH Kol. XLIX Z. 5.22; McCARTHY, Treaty 1978, 181f; RIES, Prolog, 27.
} 
ausdrückt. ${ }^{1}$ Die Assyrer veränderten diesen Doppelausdruck zu adê māmīte, das Hebräische kennt ihn in Dtn 29,11.13 als ברית ואלה, und selbst

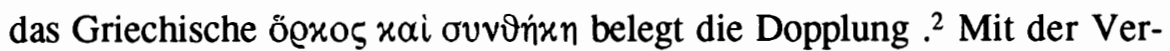
wendung des doppelten Ausdrucks steht das Deuteronomium in der altorientalischen Vertragstradition. ${ }^{3}$

Segen und Fluch kommen beim Schwören des Vertrages als Sanktion iuris divini wesentliche Bedeutung zu. Der beschworene Eid macht die Götter zu Garanten der Vertragserfüllung. Dieser Eid bestand in den Verträgen Hattis anscheinend aus einer bedingten Selbstsegnung und Selbstverwünschung, die von den Vereidigten (nach-)gesprochen wurde. ${ }^{4}$ Die enge Verbindung von Vertrag und Eid bleibt im 1. Jt. v. Chr. ebenso deutlich. Weinfeld versteht die gesamten VTE als Loyalitätseid, bestehend aus einer langen Beschwörung durch den König, in welcher die Bedingungen für das Eintreten der Flüche und die Flüche selbst genannt werden (VTE Z. 1-493), der in der 1. Person Pl. formulierten Verpflichtung, die wohl den nachzusprechenden Eid beinhaltet (VTE Z. 494-512), und anschließenden rituellen Flüchen, wie man sie auch in den Sefire-Verträgen und hethitischen Soldateneiden findet. ${ }^{5}$ Der Loyalitätseid des Volkes und seiner Führer zugunsten Assurbanipals, den Asarhaddons Mutter Zakutu vornahm, besteht nur aus der Eidesformel. Auch in hethitischen Beamteneiden tritt zum Loyalitätseid eine königlichen Vorrede, ähnlich wie in den VTE. Dabei spielen die Flüche eine immer wichtigere Rolle. In der assyrischen Zeit haben sie den Segen ganz verdrängt. Häufig werden sie durch rituelle

\footnotetext{
1 ,The exact contents of the mamitu oaths are not stated in any document, but it was obviously a solemn self-curse, powerful enough, so it seemed, to prevent any transgression." TADMOR, „Treaty,“ 134; vgl. KOROšEC, Staatsverträge, 22f; SCHÄCHTER, Fluch, 68f; WATANABE, Thronfolgeregelung, 25: „adê wird - ähnlich wie māmītu - vergöttlicht bzw. dämonisiert. mämïtu bedeutet zugleich ,Eid“ und ,Bann“ ... . In dem Begriff adê sind ebenfalls diese beiden Elemente zu finden. Der Eid birgt nämlich in sich furchterregende Kräfte, die, im Falle des Eidbruchs, den betreffenden Menschen heimsuchen ... . Der Eid kann somit als Fluch wirken."

2 Vgl. WeInFELD, „Heritage,“ 176f, TADMOR, „Treaty,“ 132f; ZACCAGnINI, „Forms,“ 66f; vdTOORN, $\operatorname{Sin}, 50$.

${ }^{3}$ Vgl. KITCHEN, „Fall,“' 131; McCARTHY, Treaty 1978, 174-176. Zu aramäisch 'dn, 'dy und hebräisch 'dūt, 'dim vgl. GREENFIELD, „Studies,“'111.

${ }^{4} \mathrm{Vgl}$. KoROŠEC, Staatsverträge, 92f, 97: „Bei der Selbstsegnung für die Erfüllung des Vertrages wird das Vorsprechen der Eidesformel ausdrücklich bezeugt: (...), Also (spricht) Mattiwaza, der Königssohn, also (sprechen) auch die Hurrileute." Vgl. PEDERSEN, Eid, 108-118; HoRST, „Eid,“ 305/376; TADMOR, „Treaty,“'132f; MENDENHALL, Recht, $37 \mathrm{f}$.

5 Vgl. WeINFELD, „Loyalty,“ 379-381; WATANABE, Thronfolgeregelung, 26.
} 
Handlungen dramatisiert. Derartige rituelle Flüche fehlen aber in den altorientalischen Gesetzen und in Dtn 28. ${ }^{1}$

Der Zusammenfluß charakteristischer Elemente von Gesetz und Vertrag im Deuteronomium erschwert die Festlegung, wer in Dtn 28 eigentlich segnet und flucht. In den Gesetzen nämlich kommt das dem Gesetzgeber zu - ganz unabhängig von den Normadressaten. Hammurapi segnet bzw. verflucht potentielle Gesetzesbefolger und -brecher ${ }^{2}$ unabhängig davon, ob seine Gesetze überhaupt zur Kenntnis genommen werden. Die Normadressaten des Gesetzes werden nicht um Zustimmung gefragt. Man trug scheinbar wenig Sorge um die juristische Rezeption des KH. In den mesopotamischen Rechtstexten gibt es kaum Bezugnahmen auf Paragraphen des $\mathrm{KH}$, als ob er für die konkrete Rechtsprechung irrelevant gewesen wäre. ${ }^{3}$ Betrachtet man das Deuteronomium als Gesetz, stellt sich die Frage, ob Mose oder Gott der Gesetzgeber sei. Die sogenannte Promulgationsformel verstärkt die Mehrdeutigkeit, da sie von den Anordnungen Gottes spricht (מצותיו), die der im Deuteronomium sprechende Mose anordnet (מנכי מצוך beide Male die Wurzel צוה). Mose spricht von JHWH meist in der dritten Person. Er gibt die Gebote weiter, die Gott ihm am Horeb geoffenbart hatte (Dtn 5,27-31). ${ }^{4}$ Dient er nur als Stimme Gottes, dann gibt JHWH das Gesetz und fügt im Epilog Segen und Fluch an, die damit aber eigentlich zu Belohnungsversprechen und Strafandrohungen werden. Während Hammurapi seine Götter zur Sanktion aufruft, wäre im Deuteronomium Legislative und Exekutive in JHWH vereinigt. ${ }^{5}$

Das betonte der Promulgationsformel läßt auch eine andere Rolle des Mose zu. Er ordnet zwar die Gesetze JHWHs an, stellt selbst aber das handelnde Subjekt der Promulgation dar. ${ }^{6}$ Mose promulgiert seine Tora,

\footnotetext{
1 Vgl. Weinfeld, „Loyalty,“ 397-400; SeITZ, Studien, 283; Fensham, „Trends,“ 173f.

2 Anders McCarTHY, Treaty 1978, 124 Anm. 6; AsSMANN, „Fluchinschriften,“ 242. Doch widersprechen ihre Ansichten BORGERs Übersetzung der Einleitungen, die die Beachtung der Gesetze von jedem verlangen, „Codex,“ 77: Kol. XLIX „ "Wenn dieser Mensch ${ }^{2}$ auf meine Worte ... ${ }^{5}$ achtet ... . ${ }^{18}$ Wenn dieser Mann auf meine Worte ... ${ }^{21}$ nicht achtet ... 39dieser Mann, ${ }^{40}$ sei er König, ${ }^{41}$ Fürst, ${ }^{42}$ Stadtfürst ${ }^{43}$ oder, ${ }^{44}$ eine beliebige Person -."

3 Vgl. vSOdEN, Einführung, 128; OTTO, „Bedeutung,“ 146. RiEs, Prolog, 51-55, arbeitet Hammurapis Anliegen heraus, geltendes Recht festzulegen.

4 Vgl. LOHFINK, „Jahwegesetz,“ 389; SCHÄFER-LICHTENBERGER, „Autorität,“ 133.

5 Vgl. McCARTHY, Treaty 1978, 11; FEnSHAM, „Trends,“"174f.

6 „Das Deuteronomium selbst bietet ... einige interessante Phänomene. So redet hier beim Bundesschluß (außer natürlich im Dekalog) nicht mehr Jahwe, sondern Mose in der ersten Person. Mose erscheint nach Art eines Königs; ihm hat Jahwe die Angelegenheiten der Gesetzgebung anvertraut, und ihm ist die Wahrung des Rechts direkt übertragen ... ." MENDENHALl, Recht, 51. MENDENHALl pendelt zwischen „Bundesschluß“ und „Gesetz-
} 
eine Art Vermächtnis, das durch die Verschriftlichung zu einem testamentarischen Dokument wird. Assmann wies darauf hin, daß die Tora nach Dtn 27,8 zu einem Monument werden soll. Hier kommt die Textsorte der Inschriften und Denkmäler zum Tragen, die im AO gewöhnlich mit Flüchen und gelegentlich mit Segen versehen wurde. ${ }^{1}$ Folglich wäre Dtn 28 nicht am Horeb offenbartes Gotteswort, sondern Segen und Fluch des Mose, der damit sein Volk zur Beachtung der Gesetze motivieren will, da er in ihnen den Weg des Lebens sieht (Dtn 11,21; 30,15). Mose würde in Dtn 28 tatsächlich segnen und fluchen. Er als Mensch spräche Segens- und Fluchformeln aus, in die Zukunft gerichtete Wünsche, die JHWH bei Eintritt der Bedingungen für Segen und Fluch Wirklichkeit werden lassen soll. ${ }^{2}$ Fällt es auch schwer, sich einen Israel verfluchenden Mose vorzustellen, so muß man berücksichtigen, daß die Flüche auf den altorientalischen Dokumenten gerade nicht in Erfüllung gehen sollten. Sobald ihre zerstörende Kraft wirksam wird, ist das Schützenswerte, die Rechtsvereinbarung, das Gesetz, oder was auch immer der Fluch sichern sollte, bereits vernichtet. Segen und Fluch zielen in den hier herangezogenen Textsorten immer auf den Schutz des Positiven. ${ }^{3}$

Die Stellung des Mose verändert sich, wenn man Dtn 28 als Bestandteil des Vertragsformulares versteht. Ein Vertrag oder Bundesschluß geschieht im Gegensatz zur Gesetzespromulgation grundsätzlich bilateral. Auch der ohnmächtigste Vasall muß dem Vertrag zustimmen, damit er zustande kommt. ${ }^{4}$ Damit der Vertragspartner zustimmen kann, muß er den Inhalt der Vereinbarung kennen. Daher schrieb man ausdrücklich vor, die Verträge

gebung“. Die königliche Funktion eines Gesetzgebers kommt Mose aber nicht zu, wenn er Bundesmittler ist, denn dann setzt Gott als Vertragsherr die Stipulationen fest.

1 Vgl. „Fluchinschriften,“ 33, 246.

2 Vgl. MørstaD, Stimme, 7, 23. Bis zur semantischen Untersuchung der Begriffe „Segen“ und „Fluch“" in Kapitel 5.4 werden diese Ausdrücke nach dem deutschen Sprachgebrauch verwendet, der den Aspekt des Wunsches impliziert und diese Textsorte von reiner Heilsoder Unheilsansage abhebt. „FLUCH, m. exsecratio, imprecatio, maledictum, ... dem fluch, der verwünschung steht der wunsch, der segen, dem verwünschen, devovere das wünschen, vovere gegeniiber, ein heiles wunsch ... schlieszt dasselbe ein, was der fluchende wunsch ... abspricht." GRIMM, Wörterbuch, Sp. 1827.

${ }^{3} \mathrm{Vgl}$. POMPONIO, Formule, 7. Er nennt die hier besprochenen Flüche präventive Flüche und unterscheidet sie von punitiven.

4 ,... A legal act became binding only if the parties took upon themselves the jurisdiciton of the supreme powers. This meant the acceptance of their blessings for faithful compliance, but also, perhaps primarily, the subjugation to their curses for breaches of commitments. Thus the element of curses and blessings performed an essential function in giving binding force to various contractual relationships ... ." LEHMANN, „Oaths,“ 74. 
öffentlich vorzulesen und regelmäßig in Erinnerung zu bringen. ${ }^{1}$ Doch auch hier bleibt die altorientalische Terminologie zweideutig, da Bund und Eid sowohl bilaterale Vereinbarungen als auch unilaterale Auferlegungen und feierliche Versprechen bezeichnen können. ${ }^{2}$ Das Formular für den Vertrag zwischen Großkönig und Vasall wurde von der hethitischen Staatskanzlei aus der Kombination des paritätischen Vertrages und den einseitigen Treueiden von Beamten und Soldaten entwickelt. ${ }^{3}$ Bei der Formulierung eines derartigen Vertrages bestanden verschiedene Abstufungen der Verhältnisbestimmung von hethitischem König und untergeordnetem Partner, von scheinbarer Gleichwertigkeit bis deutlicher Unterordnung. ${ }^{4}$ Besitzt der Bundesschluß auch nicht immer den Charakter völliger Freiwilligkeit, so doch immer ein willentliches Element. ${ }^{5}$ Dieses willentliche Element findet im Vertragseid Ausdruck und stellt die Einverständniserklärung mit den Vertragsklauseln und mit den Konsequenzen von Vertragseinhaltung und Vertragsbruch dar. Enthält die Vereinbarung Segen oder Fluch als Sanktionen, so impliziert die Zustimmung zum Vertrag auch die Zustimmung zum Segen und Fluch. ${ }^{6}$ Altorientalischer Vertragsschluß enthält die Selbstsegnung oder -verwünschung, unabhängig davon, ob die Segens- und Fluchformeln nun im Rahmen der Vertragsschlußzeremonie von den Vereidigten tatsächlich ausgesprochen werden oder von dem Leiter der Vertragsschlußzeremonie wie in den VTE zusammen mit dem Vertragsinhalt vorgetragen und von den Vereidigten nur durch eine kurze Erklärung ratifiziert werden. ${ }^{7}$ Mose fungiert in dieser Sicht als Vermittler zwischen

1 Vgl. KOROšEc, Staatsverträge, 14, $101 \mathrm{f}$.

2 Vgl. WeINFELD, ,Heritage,“ 182.

3 Vgl. LIVERAN, ,Terminologia," 116.

${ }^{4}$ Vgl. ZACCAGNINI, „Forms,“ 67-79; zu königlichen Schenkungen als unilateraler Verpflichtung des Oberherrn in Parallele zur einseitigen Verpflichtung der Untertanen in den Instruktionen vgl. WEINFELD, „Heritage,“ 184. Im hethitischen Vasallenvertrag konnte auch der Oberherr Verpflichtungen eingehen. Vgl. TADMOR, „Treaty,“ 142. Götteranrufung, Fluch- und Segensformel beziehen sich jedoch nur auf den Vasall. Vgl. KorošEc, Staatsverträge, 96.

5 Vgl. Fensham, „Trends,“ 158.

6 ,Moreover, the texts are not merely documents: they reflect ceremonies. They are the 'words' of the king ... laying down his will to the lesser prince. And the invocations of the gods, the curses and blessings of the treaties look to the answering movement on the part of the vassal, the oath by which he accepts under divine sanctions the stipulations of the sovereign." McCARTHY, Treaty 1978, $122 \mathrm{f}$.

${ }^{7}$,The curse inherent in every oath (adê, māmītu) or the curse in action (arratu) becomes immediately effective and hits the person who breaks his oath. (...) Oath and curse, mämitu and $a r r a t u$, therefore are two sides of the same thing ... ." FranKENA, „Vassal-Treaties,“ 137. „Da man unter Anrufung des Lebens eines Gottes oder Königs schwur, wurde nǐsu ,Leben' zum terminus technicus für den Eid. Die Tatsache, daß mit nǐsu dann weiterhin die 
JHWH und Israel beim Abschluß des Bundes. Altorientalische Texte belegen die verantwortungsvolle Rolle königlicher Gesandter beim Abschluß zwischenstaatlicher Verträge. ${ }^{1}$ Dabei stellt Mose den mit der Durchführung des Vertragsrituals beauftragten Liturgen dar, der den Vertragsinhalt samt dem sie sanktionierenden Fluch und Segen vorträgt.

Durch das Einbinden von Dtn 28 in einen Vertragsabschluß verändert sich das Subjekt von Segen und Fluch. Mose spricht den Israeliten Segen und Fluch vor, die eigentliche Segnung und Verfluchung geschieht aber nicht durch ihn, sondern durch die ratifizierende Zustimmung der Israeliten zum Bund, der die in Segen und Fluch genannten Sanktionen einschließt. ${ }^{2}$ Eigentliches Subjekt des Segnens und Fluchens wären damit die Israeliten selbst. Dies entspricht dem Verständnis, das Kottsieper für den Schwur bei altorientalischen Verträgen und Eideszeremonien herausarbeitet. ${ }^{3}$ Mose spricht in Dtn 28 die an Israel in der 2. Person adressierten Konsequenzen des Bundesschlusses vor, die das Volk durch seine Zustimmung zum Bund als seine zukünftige Schicksalsbestimmung akzeptiert oder akzeptiert hat. Dies wiederum hängt davon ab, wo man die zustimmende Antwort der Israeliten im Deuteronomium lokalisiert. Sie könnte vor Dtn 28 zwischen den Aussagen von Dtn 26,16-19 bzw. in 27,1 liegen, oder nach dem Segens- und Fluchvortrag durch das in Dtn 29,11 angekündigte Ritual angedeutet werden. ${ }^{4}$ Mose rückt damit im Gegensatz zu seiner Rolle bei der Gesetzespromulgation eher auf die Seite der Israeliten. In Segens- und Fluchwünschen formuliert er das der göttlichen Macht vom sich verpflichtenden Volk anheimgestellte Geschick.

Konnotation ,Fluch“ verbunden wurde, zeigt, daß für den akk. Raum zwischen Fluch und Schwur keine klaren Grenzen bestehen.“ KOTTSIEPER, „Etymologie,“ 164.

1 Vgl. MunN-Rankin, „Diplomacy,“ 87f, 96.

2 „Wie die im Deuteronomium vorliegende Tradition andeutet, mag Segen und Fluch nicht als ein Element im Bundestext angesehen worden sein, sondern als eine Handlung, die die Ratifizierung des Bundes begleitete." MENDENHALL, Recht, 43.

3 ,Man wird sich den Vorgang in Analogie zu den heth. Militäreiden vorzustellen haben. So gibt z. B. der Leiter der Eideszeremonie im sogenannten ,Ersten Militärischen Eid“ den zu Vereidigenden nacheinander verschiedene Dinge in die Hand und spricht jeweils einen Fluch in der 3. $\mathrm{Sg}$., der Eigenschaften dieser Dinge als Vergleich heranzieht, über denjenigen, der den Eid übertritt. Die Eidesleistenden antworten dann $a-p a-a-a t e-e s ̌-d u$ ,Das soll sein'. (...) Es handelt sich bei diesen Eiden also um eine Verfluchung des Eidbrechers, an der der Eidleistende durch Rede und symbolische Handlung teilnimmt. Dies bedeutet natürlich letztendlich eine Selbstverfluchung durch den Schwörenden, ist aber de facto als Verfluchung eines anderen stilisiert.“ KOTTSIEPER, „Etymologie,“ 165.

${ }^{4}$ Vgl. Braulik, Deuteronomium II, 198f zu 26,17-19, 27,1.9; 213 zu 29,11; LoHFINK, „Fabel,“ 70f, 73; „Ältesten,“ 34, 36. 
Die Entscheidung, welchen rechtlichen Vorgang man hinter den im Deuteronomium geschilderten Ereignissen erblickt und welche altorientalische Textsorte man zum Vergleich heranzieht, verändert also vom Grundansatz her die Interpretation von Dtn 28. Nach diesem Einordnungsversuch in altorientalische Traditionsbereiche gilt es nun, die schriftliche Gestalt der Flüche zu beachten, die sich in verschiedene Gattungen ausdifferenziert.

\section{2. Die altorientalischen Fluchgattungen}

Da gleich gestaltete Flüche in den verschiedensten altorientalischen Textgattungen zu finden sind, erscheint die Einteilung der Fluchgattungen nach den Textsorten, in denen sie auftreten, für die Erfassung einer altorientalischen Fluchtradition sinnlos. Wenn Hillers daher von Treaty Curses spricht, kann damit keine Gattung von Flüchen, die für Verträge besonders typisch wären, gemeint sein, sondern nur eine Herkunftsangabe des von ihm herangezogenen Textmaterials.

Der Zweck der Flüche liefert kein geeignetes Einteilungskriterium, um die Charakteristika von Gattungen herauszuarbeiten. Pomponio unterscheidet präventive und punitive Flüche. ${ }^{1}$ Dtn 28 gehört zur Gruppe der präventiven Flüche, da Israel vom Verstoß gegen das Gesetz abgehalten werden soll. Auch die altorientalischen Flüche zum Schutz von Monumenten, Inschriften, Gesetzen und Rechtsvereinbarung gehören in diese Gruppe. Darüber hinaus schlägt Pomponio eine Einteilung bezüglich der Betroffenen vor. Die Flüche betreffen entweder einen anderen Menschen oder in den Vereidigungen den Verwünschenden selbst, wenn er die Vereinbarung verletzt. ${ }^{2}$ Doch dieser Unterschied schlägt sich nicht in der Fluchform nieder, da gleiche Flüche sowohl im KH, der den Gesetzesbrecher oder Inschriftenzerstörer verflucht, wie im Vertrag zwischen Marduk-zakir-šumi I. und Šamši-Adad V. verwendet ${ }^{3}$ werden konnten, wo die den Eid Leistenden durch ihren Schwur die Verwünschungen als Vertragsbruchkonsequenzen für sich selbst akzeptieren.

\footnotetext{
${ }^{1} \mathrm{Zu}$ den punitiven Flüchen zählt er ,la punizione invocata da un re sconfitto, Uruinimgina di Girsu, sul distruttore del suo regno ... e le maledizioni che fanno parte del racconto in alcuni testi lettrari ... o quello di una profezia ex eventu ... . Gli scongiuri della serie maqlû ... , composti contro gli effetti della magia nera, mirano alla punizione della strega o del maliardo colpevoli (maledicione punitiva) e, contemporaneamente, a evitare altre sofferenze per la vittima della malia (maledizione preventiva)." POMPONIO, Formule, 7.

$2 \mathrm{Vgl}$. Formule, $7 \mathrm{f}$.

3 Vgl. BRINKMAN, ,Covenants,“ 107, 111.
} 
Mehr textimmanenten Kriterien folgt Watanabe, indem sie die Subjekte der Flüche unterscheidet. Sie findet eine Einteilung nach folgenden Subjekten:

(1.) Gottheiten. Götter werden zur Verwirklichung eines Fluchwunsches angerufen. Das Prädikat steht hier normalerweise im Prekativ.

(2.) Die Verfluchten selbst. Die Auswirkung des Fluches auf die Verfluchten kommt zur Sprache. Das Prädikat steht im Indikativ oder Imperativ. In der Verneinung kann jedoch nicht unterschieden werden, ob ein negiertes Präsens oder ein negierter Imperativ (Prohibitiv) vorliegt.

(3.) Sonstige Personen oder Tiere, Gegenstände und Dämonen. Hier steht das Prädikat wieder im Prekativ. ${ }^{1}$

Der Nachteil der bisher dargestellten Klassifizierungsvorschläge liegt darin, daß inhaltliche mit formalen Gesichtspunkten vermischt werden. Dies erschwert die Suche nach einer Traditions- und Formgeschichte der Flüche. Deshalb orientiert sich die vorliegende Untersuchung an den mehr formalen Gattungskriterien, die Hillers aufgestellt hat, um Flüche aus altorientalischen Verträgen mit Passagen der biblischen Prophetenbücher zu vergleichen. Hillers erkennt unter den Vertragsflüchen verschiedene Formen:

(1.) Der Fluch bei den Göttern oder bei einem einzelnen Gott. Diese Flüche stellen eine Bitte an die Gottheit dar. ${ }^{2}$ Sie sind bereits in sumerischen Texten belegt. Das angesagte Unheil entspricht dem Wirkungsbereich der genannten Gottheit, deren Stellung im Pantheon auch den Platz für die Einordnung des Einzelfluches in größere Fluchreihen bestimmt. ${ }^{3}$

(2.) Der Vergleichsfluch. Hier besteht das Unheil in der Übertragung eines durch einen Vergleich beschriebenen Vorganges oder Zustandes auf den Verwünschten. Ursprünglich wurde der Vergleich dramatisiert, indem man an einem vorhandenen Vergleichsobjekt, z.B. einer Puppe oder Tierteilen, die Unheilshandlung rituell vollzog. Derartige Ritual- oder Zeremonialflüche lassen ihre Verankerung in der Vereidigungszeremonie erkennen. ${ }^{4}$ Später wurde in den Vergleichsflüchen auf die rituelle Dramati-

\footnotetext{
${ }^{1} \mathrm{Vgl}$. Thronfolgeregelung, 31f. Aus dieser Einteilung nach den Subjekten fallen die Vergleichsflüche heraus, in denen die Verfluchung durch einen Vergleich bisweilen sogar in zeremonieller Form dramatisiert wird. Deshalb nennt WATANABE sie gesondert.

${ }^{2}$ Vgl. Treaty-Curses, 12. Seine Formulierung impliziert den Bittcharakter solcher Flüche: "Curses in which all the gods or a selection of them are asked to bring evil on the man who breaks his oath... ."

3 ,The distinctive form ... contains these parts, typically: (1) the name of the deity; (2) an epithet of the deity; (3) the curse to be inflicted." HiLlers, Treaty-Curses, 13.

4 Vgl. Treaty-Curses, 18-21.
} 
sierung verzichtet, was Hillers aus dem Wegfall des Demonstrativpronomens vor dem Vergleichsobjekt erschließt. ${ }^{1}$

(3.) Die einfache Verfluchung. Sie enthält die Ansage eines üblen Geschicks für den, der den Eid bricht, ohne Anrufung einer Gottheit oder einen Vergleich. Auch in dieser Fluchgattung tauchen immer wieder traditionelle Motive auf, z.B. die Verfluchung von Speise und Trank. ${ }^{2}$

Schließlich beschreibt Hillers die futility curses, die antithetischen Vergeblichkeits-, Nichtigkeits- oder Frustrationsflüche. Diese Gattung findet er in Dtn 28,30-31.38-40; Lev 26,26. Doch auch Propheten bedienten sich dieser Form und ihrer Motive. ${ }^{3}$

\section{3. Der Fluch der Gottheit}

Wenn in altorientalischen Flüchen Gottheiten angerufen wurden, so erscheinen diese Anrufungen als Bitten an die Götter, im Sinne der Verfluchung aktiv zu werden, jedoch nicht als Gotteswort oder als prophetische Vorhersage ihres Wirkens. In der Bibel wie im AO gibt es aber auch die Vorstellung, daß Gott selbst flucht.

Mythen erzählen, wie die Götter sich untereinander verfluchen. Im sumerischen Epos „Enki und Ninhursag” verflucht Ninhursag Enki, weil er die Schöpfung zerstört hat. Daraufhin wird Enki krank. Der Fluch der Ninhursag richtet sich nicht an eine höhere Instanz, wie die menschlichen Flüche mit Anrufung der Gottheit, sondern birgt in sich eine Macht, die den Gott krank werden läßt und anscheinend von keinem anderen Gott aufgehoben werden kann. Ninhursag selbst muß Enki wieder heilen. ${ }^{4}$ Hier ähnelt das Fluchwort dem Zauber, der auferlegt und wieder weggenommen werden kann. Male-dictio birgt die male-factio in sich. Scheinbar entspricht die Mächtigkeit des Fluches der Wirkmacht der Gottheit. So schafft es die Göttin Ninmah im sumerischen Epos „Enki und Ninmah” nicht, Enki durch ihren Fluch in die Unterwelt zu versetzen. Hatte Enki schon dadurch Ninmah überlegen gezeigt, daß er auch behinderten Menschen ein lebens-

\footnotetext{
${ }^{1} \mathrm{Vgl}$. Treaty-Curses, 26. HIILERS sieht in Jer 34,18 die Anspielung auf einen Vergleichsfluch, der in den Eidesformeln des Vertrages zur Sklavenfreilassung enthalten gewesen sei.

2 Vgl. Treaty-Curses 26f mit Verweis auf VTE Z. 490-493 und den Vertrag zwischen Asarhaddon und Mati'ilu von Arpad Rs. Kol. IV Z. 14-15.

3 Vgl. Treaty-Curses, 28f; QUEEN SUTHERLAND, Futility Curse, 46-48; FALES, ,Istituzioni,“ 163. „Es handelt sich ... um ... Hos 4,10; 5,6; Am 4,8; 5,11; 8,12; (Hag 1,6), Zeph 1,13; Mi 3,4a; 6,14-15." PODElla, „Nichtigkeitsfluch,“" 428 Anm. 5. WungaARDS, Deuteronomium, 307 , spricht treffend von ,frustratiefloeken".
}

4 Vgl. BENTTO, Enki, 5. 
wertes Schicksal zuwies, so entkräftet Enki den Fluch der Ninmah einfach, indem er ihn nicht akzeptiert. ${ }^{1}$

Die Worte der Göttin erhellen eine Formel, die in mesopotamischen Flüchen weit verbreitet ist. Im Epos „Enki und Ninhursag” verflucht die Göttin Enki, indem sie sagt, sie werde auf ihn nicht mehr mit dem Auge des Lebens blicken. ${ }^{2}$ Dieses Versagen des heilbringenden göttlichen Blicks bringt Krankheit. Hier liegt wohl die Wurzel des bösen Blicks in den Fluchformeln. Der böse Blick der Gottheit kann sogar den Tod bringen. Im sumerischen Epos „Fluch über Akkade” wird davon gesprochen, daß Enlils zorniger Blick die Städte Kiš und Uruk tötete. ${ }^{3}$ Dementsprechend wünscht die Fluchformel GN + lirur $(\bar{u})(+$ ePP), daß die Gottheit(en) zum Subjekt des Verfluchens werden. Göttlicher Fluch wird also nicht bloß als mündliche Äußerung aufgefaßt, sondern als negative Wirkmacht. Wenn Götter einen Menschen verfluchen, dann geht es ihm schlecht.

Die Beschreibung des Mardukfluchs in den Königsinschriften Asarhaddons zeigt, daß der Fluch der Gottheit, wenn er Menschen betrifft, nicht als Zauber verstanden wurde, sondern als Urteilsspruch, für dessen Verwirklichung der göttliche Richter dank seiner Macht gleich selbst sorgt:

${ }^{8}$.... Enlil sah es, sein Herz ergrimmte und sein Gemüt tobte; ${ }^{9}$ der Enlil (Herr) der Götter, der Herr der Länder, sann Böses, um Land und Leute zu vernichten; 10 in seinem zornigen Herzen entschloß er sich, das Land niederzuwerfen und seine Bewohnerschaft zu verderben, und ein schlimmer Fluch wurde in seinem Munde gefunden." 4

Das Epitheton „Enlil (Herr) der Götter” meint den babylonischen Hauptgott Marduk, der nach der Darstellung Asarhaddons Babylon dem assyrischen König Sanherib zur Zerstörung übergibt. Götterfluch bedeutet hier Krieg, Überflutung und wohl auch Deportation:

,38 Der Arahtu, ein Fluß des Überflusses, ${ }^{39}$ eine wütende Flut, ein wildes Gewoge, ${ }^{40}$ ein geschwollenes Hochwasser, ein Ebenbild der ${ }^{41}$ Sintflut, trat über;

1 „... Ninmalı curses Enki 'on earth you shall not dwell.' (...) Ninmah continues her speech explaining why he will not live on the earth anymore. His words will not be heard and his appearence on the land disturbs her. (...) Although Enki begins his speech by recognizing that nobody can alter her words, her curse seems not to be decisive. (...) Instead of accepting the curse he tells Ninmah what has to be done." BENTTO, Enki, 17f, vgl. ebd. 42-44.

2 Vgl. BENTTO, Enki, 17 auch Anm. 9.

3 „Als der zornige Blick Enlils Kiš wie den Himmelsstier getötet hatte, das Haus des Ortes Uruk wie einen riesigen Stier geschlagen hatte, $(\mathrm{da} \beta \mathrm{es})$ im Staube liegt, ... ." FaLKENSTEIN, „Fluch,“ 65.

${ }^{4}$ Borger, Inschriften, 13, Bab. B. (Haupttext) + G. Die Formulierung ar-rat ma-ru-uš-ti iššá-kin ina pi-i-šú greift den verbreiteten an die Götter gerichteten Fluchwunsch arrat marušta līrur( $\bar{u})$ auf. 
die Stadt, ${ }^{42}$ ihre Wohnstätte und ihre Kulträume überschwemmte er ${ }^{43}$ und machte sie zur Wüstenei." 1

.2bObgleich er 70 Jahre ${ }^{3}$ als Frist seiner Entvölkerung ${ }^{4}$ (auf die Schicksalstafeln) geschrieben hatte, hat der barmherzige ${ }^{5}$ Marduk, nachdem sein Herz alsbald ${ }^{6}$ zur Ruhe gekommen war, ${ }^{7}$ die Ziffern vertauscht ${ }^{8}$ und seine Wiederbebauung im 11. Jahre ${ }^{9}$ befohlen."

Sanherib hatte nach der Eroberung Babylons die Stadt durch Umleitung der Kanäle überfluten lassen. Asarhaddon rechtfertigt die Tat seines Vaters mit dem Zom Marduks und sein Wiederaufbauprogramm für die babylonische Hauptstadt mit dem vorzeitigen Erbarmen des Gottes. Die Feinde als Vollstrecker des göttlichen Zorns und die 70 Jahre dauernde Zeit der Strafe gleichen Aussagen, die sich in prophetischen Büchern des AT im Zusammenhang mit dem babylonischen Exil finden (Jer 25,8-12; 29,10; Jes 47,6). Sollte im Fluchabschnitt von Dtn 28 auf die Eroberung durch Nebukadnezar und das Exil angespielt werden, so fänden sich hier ähnliche $\mathrm{Ge}$ danken wie im Gottesfluch der assyrischen Königsinschrift. Die Verse ab Dtn 28,45, die, wie später dargelegt wird, aus der Zeit des babylonischen Exils stammen, wären dann als Urteilsspruch Gottes im Munde des Mose zu verstehen. Mose kündet göttliche male-factio an, die wie bei Marduk darin besteht, daß die Stadt, die JHWH sonst immer schützte, den Feinden überlassen wird (Dtn 28,49). Mose ist das Sprachrohr göttlicher Entscheidung. Auch die assyrische Geschichtstheologie in der Königsinschrift, die historische Ereignisse auf Zorn und Erbarmen Marduks zurückführt, war wohl nicht nur ein rhetorischer Kunstgriff der Verfasser, sondern dürfte sich auf Offenbarungen durch Omina oder Prophetien stützen. Vor und während Sanheribs Feldzugs gegen Babylonien waren sicherlich die für solche Ereignisse üblichen Götterbefragungen durchgeführt worden.

$\mathrm{Daß}$ der göttliche Fluch als Urteilsspruch verstanden wurde, wird in einem Kudurru aus der Zeit des Nabu-šuma-iškun (760-748 v. Chr.) explizit festgehalten. In dieser Schenkungsurkunde schenkt nicht der König, sondern die Gottheit selbst das Land. Daher verfolgt ihr Fluch eigene Interessen. Er bezieht sich nicht auf den Inschriftenschutz, sondern auf eine Änderung oder Vindikation der göttlichen Satzungen. So wird auch das Eingreifen nicht von der Gottheit mit einem Prädikat im Prekativ erbeten, sondern ihr Tätigwerden im Nominalsatz als sicher festgestellt:

${ }^{1}$ BORGER, Inschriften, 14, Bab. A (Haupttext) + B + D.

2 BORGER, Inschriften, 15, Bab. A (Haupttext) + D; vgl. ebd. Bab. B.e; zu dem Zahlenspiel SHAFFER, „Notes,“ 188. 
Kol. III 1 amāt Nanna u Mar-būti 2 innû upaqqaru 3 Nanna u Mar-bīti 4 bèè̄e dīnišu

${ }^{1}$ Wer das Wort des Nanna und des Mar-biti ${ }^{2}$ ändert oder vindiziert, ${ }^{3}$ Nanna und Mar-biti ${ }^{4}$ (sind) seine Gerichtsherren. ${ }^{1}$

Im Akkadischen drückt der Prekativ also den menschlichen Wunsch an die Gottheit aus, während deren eigenständiges Fluchen im Nominalsatz oder Indikativ formuliert wird. Für den Indikativ gibt es einen Beleg in einem Kudurru aus der Zeit des Königs Kaštiliaš IV. (1245-1225), wo der König sich der Parteinahme seiner persönlichen Götter sicher zu sein scheint:

\section{1 ana èlî u pāqiri ša eqla annâ ileqqû ilū ša šarri irrarū̌su}

Den Anspruch Erhebenden oder Vindikanten, der dieses Feld wegnimmt, werden die Götter des Königs verfluchen. ${ }^{2}$

Vor dem Hintergrund dieser wenigen Beispiele für den Fluch der Gottheit im AO werden nochmals die Fragen deutlich, die an Dtn 28 zu richten sind. Findet man in Dtn 28 Segen und Fluch JHWHs? Dann wäre Mose sein Sprecher, der das Gotteswort vom Horeb weitersagt, wobei er wie auch bei der Gesetzesverkündigung (Dtn 12-26) von JHWH (meistens) in der 3. Person spricht. Dtn 28 könnte im Blick auf die Konditionalsätze $(28,15.58)$ als Strafandrohung oder in bezug auf die begründenden $k \hat{\imath}$-Sätze $(28,45.62)$ als göttliche Urteilsverkündigung verstanden werden, die so feststeht, daß sie im Indikativ vorgetragen wird. Waren aber Teile von Dtn 28 als Segen und Fluch des Mose konzipiert, der als Leiter einer Bundesschlußzeremonie die Selbstsegnung und Selbstverfluchung des Volkes vorträgt, dann wären Segen und Fluch Worte des Mose. Sie wären formulierungsmäßig in das Beziehungsgefüge zwischen JHWH, von dem in der 3. Person gesprochen, und Israel, das in der 2. Person angeredet wird, eingepaßt. Die Jussivformen in $\mathfrak{K}$, der Optativ in $\mathfrak{B}$ und der Konjunktiv in $\mathfrak{D}$ könnten als Anzeichen dafür gelten, daß zumindest Teile von Dtn 28 als menschliche Flüche verstanden wurden. ${ }^{3}$

\footnotetext{
1 Vgl. Thureau-Dangin, „Donation,“ 142f. „,bēl dinni ... Prozeßgegner, ... in Göttertiteln 'Gerichtsherr'... ."AHw, 119.

2 Vgl. UNTERLECHNER, Fluchformeln, 81, 101, 150 (MDP 2, 95f).

${ }^{3}$ Auch göttlicher Fluch kann als Wunsch formuliert sein, jedoch nur dann, wenn sich die Götter an höhere Instanzen wenden. Dementsprechend wird der Götterfluch über Akkade im Epos „Fluch über Akkade“ zunächst nicht als Gottesurteil formuliert, sondern als ein Gebet dargestellt, das die Götter an Enlil richten. Vgl. FALKENSTEIN, „Fluch,“ 72 Z. 212-224, 211.
} 


\section{FLUCHTRADITIONEN IN DEN THRONFOLGE-ADE ASARHADDONS}

\section{1. Der Aufbau der Thronfolge-adê}

\section{1. 1. Zum Verständnis der šumma-Sätze}

Die Flüche in VTE $\S \S 37-56$ (Z. 414-512) gehören zur Gattung der Verfluchung durch Anrufung von Gottheiten. ${ }^{1}$ Der genannte Abschnitt enthält aber nur die Fluchwünsche, also die Apodosis der Flüche. Uneinigkeit besteht darüber, wo die Bedingung ausgedrückt wird, unter der die Flüche eintreffen sollen. Die Lokalisierung der Protasis hängt zusammen mit der Diskussion um das Verständnis der šumma-Sätze in VTE Z. 49-82, 92-413, 513-634. Wiseman gab sie in seiner Übersetzung als Eidesformeln wieder. ${ }^{2}$ Der akkadische Eid gilt jedoch bereits als verkürzte Selbstverwünschung. ${ }^{3}$ Wenn also schon die šumma-Sätze als Eidesformeln die Verfluchung implizieren, wird die Funktion der anschließenden Flüche unklar. ${ }^{4}$

Frankena erklärte dagegen, der ganze Vertrag sei ein einziger langer Satz, dessen Protasis in Z. 413 ende und dessen Apodosis in Z. 414 beginne. šmma fungiert also als Konjunktion von Konditionalsätzen und nicht als Eideinleitung. ${ }^{5}$ McCarthy folgte zunächst Wiseman ${ }^{6}$, schloß sich in der 2. Auflage aber Frankena an. VTE $\S \S 37-56$ (Z. 414-512) sei am besten als Götterliste zu verstehen, die mit Flüchen angereichert wurde. Nach den Stipulationen erwarte man gemäß dem Vertragsschema eine Götterliste, und außerdem enthalte erst $\S 58$ (Z. 513-518) die eigentliche Flucheinleitung, wie sie auch in Dtn 28,1f.15 zu finden sei. Die folgenden Flüche VTE $\S \S 58-106$ (Z. 519ff) seien der eigentliche Fluchabschnitt des Vertrages. ${ }^{7}$ McCarthy hat jedoch übersehen, daß VTE $\S 57$ (Z. 494-512) nicht zur Fluchsektion gehört, sondern die Aussage der Vereidigten enthält, in welcher sie den Stipulationen und ihren göttlichen Sanktionen, also Protasis

\footnotetext{
$1 \mathrm{Vgl}$. HiLlers, Treaty-Curses, 12-18.

2 Vgl. „Vassal-Treaties,“ 34 Z. 63: „(You swear) that you will protect... ." usw.

$3 \mathrm{Vgl}$. GAG $\S 185 \mathrm{a}, \mathrm{g}, \mathrm{h}$.
}

${ }^{4}$ WISEMAN, „Vassal-Treaties,“ 25 , sah die Flüche durch die ihnen vorausgehenden $§ \S 35 f$ mit dem übrigen Vertrag verknüpft: „They swore that they would neither alter, destroy or bury the treaty-tablet (ll. 410-413) nor break their oath (11. 399-400). Should they do so the curses of the gods, ... are pronounced upon them." Gerade der von WISEMAN hier formulierte Konditionalsatz zur Flucheinleitung fehlt im assyrischen Text. Er ergänzt ihn in seiner Übersetzung, ebd. 60, Z. 414: „(If you do,) may Ashur ... .“

5 Vgl. „Vassal-Treaties,“ 125

$6 \mathrm{Vgl}$. Treaty 1963, 75.

7 Vgl. Treaty 1978, 115-117. 
und Apodosis der vorangehenden Periode (Z. 49-493), zustimmen. Nach diesem Redetext in der 1 . Person folgen ab $\S 58$ neue Einleitungen in der 2. Person und Zeremonialflüche.

Watanabe betrachtete Frankena folgend den ersten Fluchabschnitt ( $\S$ 37-56) als Apodosis zu den Stipulationen (Z. 49ff), welche die Protasis (Z. 49ff) bilden. Sie betonte, daß der Modus der šumma-Sätze zwischen Subjunktiv und Indikativ wechselt. Die šumma-Sätze im Subjunktiv besagen, daß das Genannte aus der Sicht des Sprechers nicht geschehen soll. Sie lehnte es ab, darin bereits den Eid zu sehen. ${ }^{1}$ Diese šumma-Sätze bilden vielmehr die Protasis zu den Flüchen. Davon abzuheben seien šummaSätze im Indikativ, die als Konditionalsätze, vom Sprecher gesehen, neutral mögliche zukünftige Ereignisse beschreiben. ${ }^{2}$ Die Vereidigung bestand nach Watanabe darin, daß den Vereidigten die zu beschwörenden Inhalte im Indikativ vorgelegt wurden (Z. 25-40, 46-49, 83-91, 198-211, 377-384), auf die sie anschließend den Eid leisteten (Z. 494-512). Dieser Eid ist aus einem in der 1. Person formulierten šumma-Satz (Z. 494-510) und einer Selbstverfluchung (Z. 511f) zusammengesetzt. Die Flüche in $\$$ 37-56 und $\S \S 58-106$ verstand Watanabe als Strafandrohungen, die von der Selbstverfluchung in Z. $511 \mathrm{f} \mathrm{zu}$ trennen seien. ${ }^{3}$

Wenn jedoch der in der 1 . Person formulierte Abschnitt ( $\$ 57$ ) die Eidesformel darstellt, durch die die Vereidigten sich für den Fall des Vertragsbruches selbst verfluchen, so ratifizieren sie damit nicht nur die im Indikativ formulierten Forderungen, sondern alles Vorhergehende, auch die Fluchklauseln. Die Flüche als die Strafe, unter die man sich stellt, falls man den Eid bricht, scheinen zu dem Sachzusammenhang der Bindung zu gehören, die die Vereidigten übernehmen. Für diese Sicht spricht im Schwurwort (§ 57) das Demonstrativpronomen (,diese Götter“ Z. 494), das wohl auf die vorher in den Fluchformeln (\$§ 37-56) angerufenen Götter und

\footnotetext{
1 „Nicht nur im Akkadischen, sondern auch in den anderen semitischen Sprachen wird eine eidliche Aussage sehr häufig als Bedingungssatz formuliert, wobei der Nachsatz, der den Fluch für den Fall des Eidbruchs, nämlich die Selbstverfluchung, beinhaltet, weggelassen werden kann. Dies gilt jedoch lediglich, wenn die eidliche Aussage mit der 1 . Person konstruiert ist. (...) Der šumma-Satz im Subjunktiv mit der 2. Person kann aber nicht als eine eidliche Aussage mit der (implizierten) Selbstverfluchung dienen, sondern nur als eine Androhung. (...) Da im VTE-Text tatsächlich die Flüche als Nachsätze folgen, sollte man die šumma-Sätze im Subjunktiv (2. Pl.) als Protasis der Fluchklausel gegenüber der Apodosis, den Flüchen, betrachten." WATANABE, Thronfolgeregelung, 29.

$2 \mathrm{Vgl}$. Thronfolgeregelung, 29f.

3 Vgl. Thronfolgeregelung, 27-29, 28f: „Möglicherweise haben die zu Vereidigenden bei der Zeremonie der Vereidigung diesen Paragraphen nachgesprochen ... . Wie auch immer die Zeremonie verlaufen sein mag, ergibt sich jedenfalls daraus, daß der VTE-Text eine Form des Dialogs zwischen beiden Parteien darstellt.“
} 
nicht etwa auf die Götterliste in $\S 2$ furückweist und sie zu Wächtern der Eidestreue einsetzt (lidgulū „sie mögen zuschauen“). Die Selbstverfluchung (Z. 511f) spricht aus, daß die Götter von den Vereidigten und ihren Nachkommen Rechenschaft fordem sollen. Wie diese Rechenschaftsleistung aussieht, steht in den Flüchen $\S \S 37-56,58-106{ }^{1}$

Parpola verstand die šmma-Sätze in den VTE vornehmlich als Schwüre und schloß sich damit Wiseman an. Sie seien nicht als Konditionalsätze wiederzugeben, sondern als dialektbedingte Form feierlicher Aussagen zu verstehen. $\mathrm{Zu}$ solchen feierlichen akkadischen Eidesleistungen gehöre das Prädikat im Subjunktiv und der Ausdruck positiver Sachverhalte durch Negationen und negativer Aussagen durch bejahte Formulierungen. Die Vertragsstipulationen bezog er auf eine vorausgehende Schwurformel (Z. 25) zurück und übersetzte sie als Aufforderungen. ${ }^{2}$ Krebernik folgte Parpola, ohne auf Watanabe einzugehen, bemerkte aber, daß die Verteilung der Modi in den šumma-Sätzen der VTE nicht konsequent ist. So gebe es auch šumma-Sätze im Subjunktiv, die wie jene im Indikativ reine Bedingungen ausdrücken (Z. 108, 119, 130, 134f, 147-149, 162, 166f, 513-517) Die restlichen šumma-Sätze im Subjunktiv seien jedoch als Gebote wiederzugeben. ${ }^{3}$ Bei den Flüchen brachte Krebernik diachrone Aspekte ins Spiel. VTE $\S \S 37-56$ gehörten ursprünglich in die Tradition der Flüche zum Inschriftenschutz. Im Mittelpunkt stand der respektvolle Umgang mit den Texten selbst. Erst die Flüche in $\$ \S 58-106$ sanktionierten nach Krebernik eigentlich die Beachtung der Stipulationen. Doch wies er selbst darauf hin, daß dieser unterschiedlichen Sinnfestlegung der beiden Fluchsektionen vom Text der VTE selbst widersprochen wird, da die Einleitung zur ersten Fluchpassage (Z. 373-413) nicht nur den Schutz des Dokumentes, sondern auch Verstöße gegen den Inhalt der

1 „ ${ }^{494}$,Diese Götter mögen zuschauen! Sollten wir gegen Asarhaddon, ... ${ }^{498}$ Rebellion und Aufstand unternehmen, unseren Mund nach ${ }^{499}$ seinem Feind richten, sollten wir ${ }^{500}$ Aufwiegler, Verbreiter von Flüstergerüchten, ${ }^{501}$ welche böse, schlechte und unschöne Worte ${ }^{502}$ und lügnerisches, unwahres Gerede sind, ${ }^{503}$ die sich gegen Assurbanipal ... ${ }^{505}$... richten, hören und verheimlichen, ${ }^{506}$ (es) Assurbanipal ... ${ }^{507}$ nicht sagen, sollte - solange wir, unsere Söhne ${ }^{508}$ und unser Enkel leben - Assurbanipal, ... ${ }^{509}$ nicht unser König, nicht

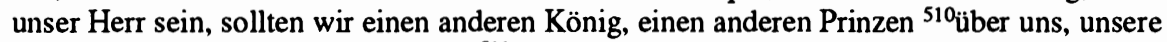
Söhne und unsere Enkel einsetzen, ${ }^{511}$ (dann) sollen die Götter, soviele (hier) namentlich genannt sind, von uns, ${ }^{512}$ unserer Nachkommenschaft (und) der Nachkommenschaft unserer Nachkommenschaft Rechenschaft fordern!"“ WATANABE, Thronfolgeregelung, 167. Diesen Abschnitt deutete schon WisEmaN, „Vassal-Treaties,“ 26, als Zustimmung der Vereidigten, die dem „Amen“ in hethitischen Soldateneiden und biblischen Bundeszeremonien entspricht. Vgl. WEINFELD, „Loyalty,“ 379-381; FRANKENA, „Vassal-Treaties,“, 132.

2 Vgl. Parpola / Watanabe, Treaties, IX, XXXVIII-XL, L Anm. 21.

${ }^{3}$ Vgl. „Deuteronomiumskommentar,“ 29. 
Loyalitätseide thematisiert. Die Verfasser der VTE verbanden offensichtlich Elemente unterschiedlicher traditioneller Herkunft zu einer neuen Einheit, die vor allem dem wesentlichen Ziel des Dokumentes, nämlich die Durchsetzung der Thronfolgeregelung dienen sollte.

Es scheint in der Diskussion um die šumma-Sätze weniger um das Verständnis der sprachlichen Phänomene selbst, als vielmehr um verschiedene Auffassungen über Art und Aufgabe einer Übersetzung zu gehen. Parpola hat recht, insofern er herausstellt, was die VTE meinen. Die šumma-Sätze bringen die Verpflichtungen des Eides feierlich zur Sprache. Er schafft mit seinen Aufforderungen und Verboten eine dynamisch-gleichwertige Übersetzung. Allerdings steht dies nicht so im assyrischen Text. Darüber hinaus verwischt diese Weise der Wiedergabe die Unterschiede zu Formulierungen in anderen neuassyrischen Dokumenten. In Asarhaddons Vertrag mit Baal von Tyrus gibt es nämlich Stipulationen, die nicht als šumma-Sätze strukturiert sind, d.h. die Schreiber hätten auch die VTE anders aufbauen können, entschieden sich aber für eine Gestalt, deren Charakteristikum nivelliert wird, wenn man šumma nicht als Einleitung eines Konditionalsatzes übersetzt. ${ }^{1}$ Die akkadischen Formulierungen in den VTE lassen noch die Verbindung zwischen Eid und Verfluchung durchschimmern, wenn man sie in einer formalen Übersetzung (Wort-für-Wort) wiedergibt. Da nicht nur das signifiant, die akkadischen Formulierungen, sondern auch das signifié, Vereidigungen mit Flüchen, unserer Zeit fremd sind, scheint es sinnvoller, das sachlich Ungewohnte in einer Weise wiederzugeben, die den originalen Formulierungen möglichst nahe kommt. ${ }^{2}$ Der akkadische Text legt es nahe, in den šumma-Sätzen die Bedingungen für das Eintreffen der Flüche der ersten Fluchsektion zu sehen.

1 „The Vassal Treaty of Esarhaddon is an example of an extensive piece of conditionally introduced second-person address. (...) There are also a number of unconditionally introduced prohibition forms in Esarhaddon's vassal treaty with the King of Tyre (verso col. 3:12-13).“ MORROW, „Discrepancy,“ 140f. Man vergleiche z.B. die Übersetzung dieser Passage in SAA 2 (Nr. 2), 25 (assyrische Vetitive = ,must not“) mit VTE Z. 180-187, SAA 2 (Nr. 6), 34 (šumma + positive Prädikate im Subjunktiv = ,shall not“).

${ }^{2} \mathrm{Zu}$ den Begriffen ,formale Übersetzung“ und ,dynamisch-gleichwertige Übersetzung“ vgl. EGGER, Methodenlehre, 65-67. WISEMAN schreibt, daß es ihm in der Wiedergabe der Stipulationen als Eidsätze um eine verdeutlichende Übersetzung geht. Impliziert ist also ein Vorverständnis, was die Übersetzung leisten soll, und wie die untergeordneten Sätze juristisch zu verstehen sind: „The main clauses literally begin 'Thou shalt ... Thou shalt not ..., ' but the translation ..., by using the form '(You swear that) you will ... you will not ... ,' seeks to bring out the sense of the subordinate clauses with their juridical force.“ „VassalTreaties,“ 23. 


\subsubsection{Gliederung der Thronfolge-adê und Fluchinhalte}

Versteht man die šumma-Sätze als Protasis des ersten Fluchabschnitts, ergibt sich folgende Gliederung der VTE: ${ }^{1}$

§ 1: Einleitung (Z. 1-12); § 2: Liste der göttlichen Zeugen (Z. 13-24); § 3: Götterliste der Vertragsgaranten (Z. 25-40); § 4: Rekapitulation der Vereidigungsumstände (Z. 41-45); Vereidigungssubjekt (Z. 46-49); §§ 4-34: Protasis der Vereidigung: šumma-Sätze mit dem Vereidigungsinhalt (Z. 49a-396); §§ 35f: Relativsatz bezüglich der māmīt tuppi (Z. 397-402), königlicher Statuen und Siegel (Z. 402-406), šumma-Sätze zum Inschriftenschutz (Z. 406-413);

$\S \S$ 37-56: Apodosis Flüche (Z. 414-493) ${ }^{2}$

Assur (böses Schicksal: šìmat lemutti lā tạabti lišìm-, kein langes Leben); Mullissu (Diffamierung); Anum (Krankheit); Sin (saḩaršubbû + Exkommunikation: kīma serēme șabūti șêru rupdā); Šamaš (Rechtlosigkeit: dīn kitti mēšari aji idīn-, Blindheit, Dunkelheit); Ninurta (Niederlage, Leichen als Tierfutter); Delebat (Schändung der Gattinnen; Feindberaubung); Jupiter/Neberu (Kultausschluß, Tod: lihalliqa napšătî-); Marduk (Strafe: hîțu kabtu, Bann: māmīt lā pašāri); Zarbanitu (Vernichtung von Name und Samen: šum- zēr- (ina māti) lihalliq); Belet-ili (kein Gebären); Adad (keine Bewässerung, kein Getreide, Sintflut, Heuschrecken, keine Gerste, kein Teig, Kannibalismus, Hunger, Menschenfleisch als Tierfutter, keine Totenpflege: etemma- pāqidu nāq mê aji irši); İ̌tar (Entwaffnung: ina tāhāzi danni qašatlišbir, Gefangenschaft: ina šapal nakr- lišēsib-); Nergal (Schwert, Seuche: mūtā̄nu); Mullissu (glühendes Schwert); Ištar (Erbarmungslosigkeit: rēmu gimillu lū lā išakkan ...); Gula (Krankheit, Wunde: simmu lazzu); Sebetti (Niederlage: ina kakki- ... našpanta- liškun-) ; Aramis (?); Bajjati-ili + AnatiBajjati-ili (Menschen von Löwen gefressen); Kubaba (rimț-Krankheit); die großen Götter des Himmels und der Erde (Schläge, böser Blick: (aggiš) likkelmû-, Fluch: arratu maruštu ... lïrurū-, Tod, keine Totenpflege, Ortlosigkeit, Hunger, Seuche, keine Beerdigung, Leichen als Tierfutter, Dunkelheit, Mühsal, Schlaflosigkeit, Sintflut + Niederwerfung, Krankheit, Verwünschung von Speise-Trank-Salbe-Kleidung-Heimstatt); § 57: Eidesformel, die von den Vereidigten zu sprechen ist (Z. 494-512);

\footnotetext{
1 Vgl. Frankena, „Vassal-Treaties,“ 124.

${ }^{2}$ Es folgen die Götter und Themen der Flüche stichwortartig. Zu charakteristischen Flüchen wurden die akkadischen Formeln hinzugefügt. Damit soll der Vergleich mit den in der Liste der Vergleichstexte zusammengestellten Flüchen erleichtert werden. Gleiche Stichwörter geben gleiche oder sehr ähnliche Formeln an. Die Bindestriche am Ende akkadischer Wörter zeigen die Leerstelle für ein dem Kontext entsprechendes enklitisches Personalpronomen.
} 
§ 58: Bedingungssatz (Protasis) und Apodosis:

Assurfluch (Niederlage);§§ 59-63: Palil/Igištu (Leichen als Tierfutter); Ea (tödliches Wasser, Wassersucht: aganutillâ limalli-); die großen Götter des Himmels und der Erde (Wasser + Öl = Bann); Girra/Gibil (Verbrennung von Name und Samen);

$\S 64$ Dito $=$ Wiederholung der Protasis

$\S 64$ Götter der Tafel (Boden = Ziegel/Eisen, keine Pflanzen); §§ 65-67: Vergleichsflüche (kein Regen, Regen = Kohlen, Niederlage, keine Nachkommenschaft); § 68: Šamaš (Umpflügen der Wohnstätten);

$\S 69$ Dito (vgl. § 64)

$\S \S 69 f:$ Ritualflüche (Kannibalismus, Füße mit Eingeweiden umwickelt)

§ 71: Bedingungssatz (Protasis) Vergleichsfluch (Zwietracht in der Familie)

$\S \S 72 \mathrm{f}$ : Dito $=$ Wiederholung der Protasis

$\S 73$ Vergleichsflüche (Eid in die Eingeweide, Frauen und Kinder weggeblasen, Vertrocknen der Wasserläufe);

§ 74: Dito (vgl. § 72) Götter/sie (Brot teuer wie Gold);

$\S \S 75 f:$ Dito (vgl. § 72)

Vergleichsflüche (Kannibalismus, Madenfraß an Lebenden);

§ 77: Dito (vgl. § 72) genannte Götter (Entwaffnung, Gefangenschaft);

$\S \S 78-80$ : Dito (vgl. § 72) Vergleichsflüche (Mord, keine Rückkehr);

$\S \S 80 f:$ Dito (vgl. § 72) Götter/sie (Mord, Fleisch schwarz);

§ 82: Dito (vgl. § 72) Vergleichsfluch (Gefangenschaft);

$\S$ 83: Dito (vgl. § 72) einfache Verfluchung (Verfärben des Fleisches);

$\S \S$ 84-86: Dito (vgl. § 72)

Götter (sie) (Löcher in Menschen, Ungeziefer, Zerquetschung); § 87: Vergleichsfluch (schlechter Atem vor Gott, König und Menschen: ina pān ilī / iläni u šarri amēlutte);

§ 88: Dito (vgl. § 72)

Götter(sie) (Erwürgen); § 89: Vergleichsfluch (Verbrennen, im Wasser versenken);

§ 90: Bedingungssatz (Protasis)

Vergleichsfluch (Streitwagen mit Blut bespritzt); §§ 91-95: genannte Götter (Herumwirbeln, Geschlechtsumwandlung: $k \bar{\imath}$ issi ina pān nakrī-, Rückwärtsgehen, Bosheit, Feuer, Übel, Eindringen des Eides, Vernichtung, Schwanken, Herausgezogenwerden durch den Feind);

$\S 96$ : Bedingungssatz (Protasis)

einfache Verfluchung (Schwerter, ?);

$\S 97$ Dito (vgl. § 96)

$\S \S 97-100$ : Vergleichsflüche (Ruhelosigkeit, Verstopfung, keine Wundversorgung, Zwietracht in der Familie); 
$\S 101$ Dito (vgl. § 96)

Samaš (in Vogelfalle gefangen, Tod); § 102f: Vergleichsflüche (kein Wasser im Durstland, keine Schuhe im Dornland); § 104f: Enlil (Thronverlust); Nabu (Vernichtung von Name und Same); \& 106: Vergleichsfluch (?)

Kolophon (Z. 664-670).

Es zeigt sich, daß manche Gottheiten mehrmals mit verschiedenen Fluchthemen angerufen werden: Assur (Z. 414-416; 518), Mullissu (Z. 417f, 457f), Šamaš (Z. 422-424, 545f, 649-651), Ištar (Z. 453f, 459f), Götterkollektiv ( $\S 56, \S 61, \S 63, \S 77, \S 91 \mathrm{f}$ ). Es gab also zumindest in diesen Fällen keine zwingende Verbindung von Gottheit und Fluchthema. Die Formkritik der näher besprochenen Flüche wird dies noch deutlicher machen und auch zeigen, daß manche Fluchthemen mit verschiedenen Gottheiten verbunden werden konnten. Die Reihenfolge der Götter legt also nicht automatisch die Reihenfolge der Fluchthemen fest. Es war offenbar dem Verfasser überlassen, welches zum Wirkungsbereich der Gottheit passende Thema er anschnitt. Borger fand in den VTE Formulierungen aus dem Vertrag Asarhaddons mit Baal von Tyrus (Kol. IV Z. 1-5) wieder. Es handelt sich um die Sequenz des Mullissu-, Ištar-, Gula-, Sebetti- Bajjati-ili und Anati-Bajjati-ilifluchs (VTE $\$ \S 50-54 \mathrm{~A}$ ), die in den VTE jedoch durch die Einschaltung des Aramisfluchs (§ 54) unterbrochen wird, sowie VTE Z. 430 aus dem Delebatfluch ( $\$ 42)$, die im Vertrag mit Baal dem Astartefluch (Kol IV Z. 19) entspricht. Hier wurde also eine Passage von den Schreibern Asarhaddons mehmals verwendet. Sie variierten den Text jedoch durch den Einschub des Aramisfluchs. ${ }^{1}$ Es handelt sich bis auf das Delebat- und das Gulamotiv nicht um Themen, die auch mit Dtn 28 in Verbindung gebracht wurden. Bemerkenswert ist, daß die Göttin in VTE $\S 42$ (Z. 430) und dem Baalvertrag Kol. IV Z. 19 verschieden heißt und das Motiv in den VTE vor, im adê mit Baal aber nach den restlichen parallelen Flüchen steht. Für den Vergleich mit Dtn 28 gilt es auch, die Textunterschiede zwischen den erhaltenen Handschriftenfragmenten zu achten. ${ }^{2}$ Das in Jerusalem vorhandene Exemplar stimmte kaum völlig mit dem heute zugänglichen Haupttext überein.

Deutlich wird auch die strukturelle und inhaltliche Andersartigkeit der zweiten Fluchreihe nach dem Eid. Dort wird die Protasis regelmäßig wiederholt und die Fluchgattung mit Anrufung der Götter ist seltener. Dafür gibt es mehr Vergleichsflüche.

\footnotetext{
1 Vgl. „Nimrud,“ 187-190; WatANABE, Thronfolgeregelung, 196.

2 Vgl. BORGER, „Nimrud,“ 187-196 (Z. 418a-c, 422, 599f, 613, 618, 624, 664, 668, 673); WATANABE, Thronfolgeregelung, 192, 195f, 200, 202, $204 \mathrm{f}, 207$.
} 


\section{2. Die Ähnlichkeiten mit Dtn 28 in der Forschungsgeschichte}

Die in der Forschung vertretenen Auffassungen zu diesem Thema wurden bereits in der Einleitung kurz dargestellt. Nun wird zuerst auf die Befürworter literarischer Abhängigkeit, anschließend auf die ablehnenden Meinungen genauer eingegangen und deren Argumentationsweise auf ihre Aussagekraft hin befragt.

Borger hatte sich nur auf Dtn $28,23 \mathrm{f}$ und VTE $\S 63 \mathrm{f}$ beschränkt. ${ }^{1}$ Frankena dagegen suchte im ganzen Kapitel 28 und in allen VTE-Flüchen nach Parallelen, was der methodologischen Forderung entspricht, beim Vergleich alttestamentlicher und altorientalischer Texte den Kontext zu berücksichtigen. ${ }^{2} \mathrm{Er}$ stellte folgende Abschnitte nebeneinander:

Dtn 28

V. 20

V. 27

V. 28

V. 30-34

V. $38-57$
VTE

Assurfluch Z. 414-416

V. 29b

Sinfluch Z. 419-421

Šamašfluch Z. 422-424

V. 26

Delebat/Venusfluch Z. 428-430

Adadfluch Z. 440-452

V. 25

V. 21

V. 35
Ninlilfluch Z. 417f

Ninurtafluch Z. 425-427
Ištarfluch Z. 453f

Nergalfluch Z. 455f

Gulafluch Z. 461-463.

Seine nach Motiven geordnete Liste orientiert sich an den VTE und berücksichtigt nicht die Abfolge der Flüche in der Bibel. Je nach Anordnungsvorzug verlieren entweder der assyrische oder der biblische Text die eigene Struktur. Die Abweichungen in der Reihenfolge sind in der Tabelle oben eingerückt. Die Parallelität der Reihung Assur bis Adad ist dennoch deutlich.

Allerdings klingt es wenig überzeugend, wenn Frankena den Adadfluch zum motivischen Vorbild für Dtn 28,38-57 erklärt. Er muß zugeben, daß fast allgemein ein Konsens über eine literarkritische Trennlinie innerhalb von 28,44-47 besteht. ${ }^{3}$ Sollten sich zwei Redaktionsstufen an derselben auBerbiblischen Vorlage orientierten? Dann wäre zu erklären, warum man zu späterer Zeit einem ersten Abschnitt mit Motiven aus dem Adadfluch einen

\footnotetext{
1 Vgl. „Nimrud,“ $191 \mathrm{f}$.

2 Vgl. „Vassal-Treaties,“ 145f; MALUL, Method, 29f Anm. 19, 45-47, 82f;

${ }^{3}$ Vgl. ,Vassal-Treaties,“ 146, 149f.
} 
zweiten Teil aus demselben Adadfluch hinzufügte. Es wäre zu erwarten, daß man gleich alle passenden Motive übernahm, wenn man schon Anleihen aus einem sowieso umzuformenden polytheistischen Text machte. Die Verbreitung des Kannibalismusmotivs in assyrischen und biblischen Texten verschiedenster Gattungen widerrät anzunehmen, daß der biblische Verfasser für die Ausgestaltung derartiger Motive eine Vorlage verwendete. ${ }^{1}$

Zu 28,36f setzt Frankena den Deportationsfluch aus dem Vertrag Asarhaddons mit Baal von Tyrus (Kol. IV Z. 14f), ohne die literarkritische Problematik dieser Verse überhaupt zu erwähnen. Weil in diesem Vertrag die syrischen Lokalgötter Milqart und Ešmun angerufen werden, meint er, ein Vertrag zwischen Assur und Juda habe im Deportationsfluch JHWH als den Heimatgott des Landes gebeten, die Vertragsbrecher zu vertreiben. ${ }^{2}$

Frankena räumt die abweichende Anordnung der Flüche ein, plädiert jedoch dafür, die Reihenfolge nicht zu wichtig zu nehmen, da sie sogar in den Versionen der VTE voneinander abweiche. So sei in ND 4329 der Assurfluch kürzer, in ND 4329, 4335 und 4350S der Anufluch vor den Sinfluch eingefügt und in ND 4329 die Fluchfolge Jupiter, Delebat/Venus, Ninurta. ${ }^{3}$

Anu repräsentiert den Himmel überhaupt, seine Stellung vor einer mit Sin, dem Mondgott, beginnenden Aufzählung einzelner Himmelskörper in drei VTE-Manuskripten erscheint sinnvoll. Sin / Mond kommt vor seinem Sohn Šamaš / Sonne, gefolgt von Venus, der dritten bereits altsemitischen Gottheit der Hauptgestime. ${ }^{4} \mathrm{Zu}$ dieser astralen Trias gesellen sich Jupiter und Ninurta, der Gott des Sirius. ${ }^{5}$

Die direkte Abhängigkeit des Bibeltextes von einer assyrischen Vorlage erkennt Frankena aus der Parallele zwischen Dtn 28,28-34 und dem Šamašbis Delebatfluch VTE $\S \S 40-42$ (Z. 422-424, 428, 430). Der biblische Schreiber habe jedoch in Dtn 28,30 Weinberg, Ochse, Esel, Schaf, Söhne, Töchter und die Frucht des Landes hinzugefügt, um die Aussage der assyrischen Vorlage zu spezifizieren. ${ }^{6}$ Allerdings verschweigt Frankena,

\footnotetext{
${ }^{1} \mathrm{Vgl}$. HilleRs, „History,“ 159.

2 Vgl. „Vassal-Treaties,“"146, 150. Ištar von Arbela-Fluch und den Fluch der Siebengottheit.

4 Vgl. vSODEN, Einführung, 169f; WEINFELD, „Traces,“ 420 Anm. 3.

5 vSODEN, Einführung, 172.

6 Vgl. „Vassal-Treaties,“' 148f.
}

${ }^{3}$ Vgl. „Vassal-Treaties,“, 146f. Flüche der VTE, die zu sehr den assyrischen Hintergrund durchscheinen ließen, habe der judäische Schreiber ausgelassen. Keine Parallelen in Dtn 28 findet er daher für den Jupiter-, Marduk-, Zarbanitu-, Belet-ili, Ninlil-, Ištar von Ninive-, 
$\mathrm{da}$ seine als so beeindruckend zitierte Parallele durch den Ninurtafluch VTE $\S 41$ (Z. 425-427) gestört wird. ${ }^{1}$ Die Nennung des Manasse in Listen assyrischer Vasallen in den Annalen von Asarhaddon und Assurbanipal führt Frankena zu der Vermutung, in Jerusalem habe man nicht nur assyrisch-judäische Verträge, sondern auch die VTE besessen und bei der Zusammenstellung des Deuteronomiums die Gestalt des assyrischen Vertrages nachgeahmt, um die Ablösung des Bündnisses mit Assur durch den unter Joschija erneuerten Bund mit JHWH zu verdeutlichen. Die Entstehung dieser Stufe des Deuteronomiums könne also zwischen 672, dem Jahr der Thronfolgevereidigung in Assyrien, und 622, dem Beginn der joschijanischen Reform, datiert werden. ${ }^{2}$

Weinfeld hob die mesopotamische Kombination des Sin- und des Šamašfluchs hervor. ${ }^{3}$ Die Serie der Flüche in VTE Z. 419-430 sei identisch mit der von 28,26-35. Zwischen dem Sinfluch (VTE Z. 419f) und Dtn 28,27 besteht sogar ein Vokabelbezug. Die von Sin verhängte Krankheit wird SAHAR.ŠUB- $b u$ genannt, das vom sumerischen SAHAR.ŠUB.BA abgeleitet ist, wofür lexikalische Listen als Äquivalent garābu angeben. Dessen hebräische Entsprechung גרב ;steht in Dtn 28,27. ${ }^{4}$ Neben diese lexikalische Parallele stellt er noch eine motivgeschichtliche zwischen der Bedeutung des sumerischen Wortes und der Verwendung des Begriffes .i.ü:S:שין; im AT. ${ }^{5}$ Der einzige Unterschied in der Abfolge der Sequenzen sei die Voranstellung des Motivs der unbegrabenen Leichen, doch die Stellung des Ninurtafluchs variiere in den verschiedenen Ausgaben der VTE sowieso. V. 26, der Ninurtafluch, sei nach vorne gewandert, weil er mit dem ähnlichen V. 25a verbunden werden sollte, welcher in Antithese zu V. 7 zwei thematisch parallele Gruppen von Segen (V. 7-12a) und Fluch (V. 20-25) zu einem chiastischen Schluß bringe. ${ }^{6}$ Während die Abfolge der

\footnotetext{
1 Vgl. „Vassal-Treaties,“ 148.

2 Vgl. „Vassal-Treaties,“ 151-153.

${ }^{3}$ Auf die Verbindung von Sin-; Šamaš- und Gulafluch in den VTE und altorientalischen Kudurrus wies zwei Jahre vor WEINFELDs „Traces“ schon FENSHAM, „Trends,“ 160f, 161 Anm. 40, hin.
}

4 Vgl. „Traces,“ 418 Anm. 3, 4; = School, 117 Anm. 4; WaTANABE, „Überlieferung,“ 110 , wo zusätzlich zu dem von WEINFELD angegebenen Beleg in igi.duh.a = tāmartu, Kurze Fassung [AfO 18 (1957) 82,172] noch igi.duh.a = tämartu, Assur-Fragment [AfO 18 (1957) $87,5]$ angeführt ist.

5 ,sahar correspondens to Akk. epru, 'earth, dust'; šub to Akk. nadû, 'to throw'; the idea of throwing earth actually lies behind the description of the prom among the ten plagues (Exod. 9:8ff): Moses throws soot toward the sky. This becomes dust throughout Egypt and causes the prTe." WeINFELD, School, 117f Anm. 6.

6 vgl. „Traces,“ 420 Anm. 1. WEINFELD sieht in der Niederstreckung durch Ninurtas Pfeil, die die Steppe mit Leichen oder Blut füllt, einen Hinweis auf eine Seuche, doch war Ninurta 
Flüche in Dtn 28 keinen inneren Sinn ergebe, folge sie in den VTE der Hierarchie des assyrischen Pantheons. ${ }^{1}$

Jeremias meinte, die meisten Flüche in 28,20-44 seien vom Deuteronomium aus vorliegendem Traditionsgut aufgenommen worden. Dtn 28,2324ba.25a.26a.32-33a $\beta_{1}$ und V. 53-57 stammen aus den VTE. ${ }^{2}$ Die mit dem Verb „schlagen“ beginnenden Verse 22.27.28.35 führte er auf den Sin-, Šamaš- und Gulafluch der VTE ( $\S 39,40,52)$ zurück. Die futility curses aus 28,30f.38-40.(41) hielt er wegen der formalen Parallele zu Sefire und zu alttestamentlichen Propheten des 8. Jhs. für älter als den Rest von 28,20$44{ }^{3}$ Die Verfütterung der Leichen an Tiere aus dem Ninurtafluch VTE $\S$ 41 (Z. 425-427), der Dtn 28,26 ähnelt, steht gleichlautend im Palil/IgištuFluch $\S 59$ (Z. 520) und ähnlich in $\S 56$, dem Fluch der Götter (Z. 483f). Gleichartige Fluchmotive konnten also mit verschiedenen Gottheiten verbunden werden, jedoch nicht beliebig, denn Palil ist eine Denomination Ninurtas oder Nergals. ${ }^{4}$

Für Dion stammt die Motivkomposition von Hautkrankheiten (Dtn 28,27), Blindheit (V. 28-29a) und Ungerechtigkeiten (V. 29b-33a) aus der Reihung der assyrischen Götter, denen derartige Flüche in den VTE zugesprochen werden. Bei der Übernahme dieser Fluchreihe aus dem assyrischen Original beseitigte man die verschiedenen Götternamen. Der Ninurtafluch (VTE Z. 425-427) wurde zu V. 25f, da er dort besser in den

bei den Assyrern Jagd- und Kriegsgott. Vgl. vSODEN, Einführung, 175; BORGER, „Vasallenverträge,“ 170 Anm. 425 a): „Ninurta, ... ursprünglich ein Vegetationsgott, erscheint hier als kriegerischer Gott ... ."

${ }^{1}$ In die Textlücke des Sinfluchs von UET I, 165 Kol. II Z. 23-25 restituiert WEINFELD, School, 120f, den Wunsch, die Krankheit möge unheilbar sein. Dies führt ihn zur Parallele zwischen 28,27+35. Das Motiv der Unheilbarkeit gehört jedoch zum Gulafluch. WATANABE, „Überlieferung,“ 101-105, bearbeitet diesen Sinfluch. Ihr Text Nr. 14 ist UET I, $165 \mathrm{Kol}$. II Z. 23-27 und enthält keinen Hinweis auf ein derartiges Motiv.

2 JEREMIAS stellte VTE Z. 528-531 zu 28,23f; VTE $\S 48$, den Ištarfluch, zu V. 25a; VTE $\S$ 41 , den Ninurtafluch und $\S 56$, den Götterfluch (Z. 483f) sowie $\S 59$, den Palil/Igištufluch, zu 28,26; VTE §.42, den Venusfluch, und den Vergleichsfluch § 82 (Z. 588-590) zu 28,3233; VTE § 47, den Adadfluch (Z. 448-450), sowie die Vergleichsflüche § 69 (Z. 547-550), § 75 (Z. 568-570) zu 28,53-57. Vgl. Kultprophetie, 163 Anm. 4. Der Ištarfluch hat aber außer der Kriegsthematik nichts mit 28,25a gemein. Der Kannibalismus im Adadfluch mit den Ernteschäden unterscheidet sich von 28,53-57 mit der Belagerung als Ursache. Auch die Vergleichsflüche VTE $\$ 69$ und 75 haben mit 28,53-57 nur den Kannibalismus, aber nicht die Belagerung gemein. 28,32-33a entsprechen VTE $\S 42$ nur in der Aufteilung des Gutes durch die Feinde. $\S 82$ spricht im Gegensatz zu 28,33a nicht von der Deportation, sondern der Gefangennahme der Söhne und Töchter durch den Feind. Genuin israelitisch erscheint die Wendung von V. 25a, die 28,7 entspricht.

${ }^{3} \mathrm{Vgl}$. Kultprophetie, 169f.

${ }^{4}$ Die andere Form hinderte JEREMIAS offenbar daran, 28,30 neben VTE $\$ 42$ zu stellen. Vgl. Kultprophetie, 168 Anm. 4. 
Kontext paßte. V. 27-35 gestaltete der biblische Verfasser zu einem konzentrischen Gefüge. Dion postulierte die direkte Abhängigkeit des Bibeltextes von den VTE. ${ }^{1}$ Die Einbindung von V. 25 in die Betrachtung ist bedeutsam. Dtn 28,25a +26 entsprechen gemeinsam den Inhalten des Ninurtafluchs. ${ }^{2}$

In seiner vergleichenden Behandlung der Prologe und Epiloge in Gesetzen des Altertums erkannte Ries, daß die Ähnlichkeit zwischen Dtn 28,30 und VTE Z. 428f sowie zwischen Dtn 28,23 und VTE Z. 530-532 im Rahmen altorientalischer Fluchtexte nicht selbstverständlich ist. ${ }^{3}$ Preuß sprach sich nach einer Auflistung der Parallelen, die der von Frankena ähnelt, für die Abhängigkeit von den VTE oder einem ähnlichen Text aus. ${ }^{4}$

Unter den Forschern, welche die Abhängigkeit einer assyrischen Vorlage ablehnten, bezog sich Hillers in Auseinandersetzung mit Borger nur auf Dtn 28,23f und VTE $\S 63 f .^{5}$ Wenn Vertreter dieser skeptischen Richtung umfangreicheres Fluchmaterial aus dem AO zusammenstellten, dann geschah dies in einer Weise, die Malul „Inventorial Approach" ${ }^{6}$ nennt. In Listen, die Inventaren gleichen, werden Flüche ähnlicher Motive oder Themen zusammengestellt, ohne auf den literarischen Kontext der angeführten Texte, auf die Identität der angerufenen Götter oder charakteristische Wortverbindungen zu achten. Mit anderen Worten, altorientalische Motiv- und Traditionsgeschichte spielt in solchen Listen keine Rolle. ${ }^{7}$ McCarthy versuchte, mit seiner Liste zu zeigen, daß die Ähnlichkeit zwischen Dtn 28 und den VTE nicht auf direkter Abhängigkeit beruht, sondern allein die Vertrautheit der Verfasser von Dtn 28 mit der Fluchtradition Mesopotamiens beweist. Es seien höchstens gemeinsame Themen auszumachen, die in ihren Formulierungen jedoch bereits unter mesopotamischen

\footnotetext{
1 Vgl. „Aspects,“ 46-49.

2 Vgl. Wächter, Tod, 134 Anm. 44. Sumner, Study, 53, 56f, hatte Dtn 28,25 als Parallele zum Fluch der Siebengottheit des Baal von Tyrus-Vertrags (Rs. Kol. II Z. 5) aufgelistet und dazu, ähnlich wie JEREMIAS, aus den VTE den Ištarfluch (VTE Z. 453) sowie den Vergleichsfluch § 65 (VTE Z. 534) gestellt.

${ }^{3}$ Vgl. Prolog, 77. Er zitiert als Gottesnamen im Delebatfluch VTE Z. $428 \mathrm{f}$ dštar.

4 Vgl. Deuteronomium, 72f.

5 Vgl. HiLlers, Treaty-Curses, $40 \mathrm{f}$.

6 Malul, Method, 32.

7 Vgl. MaLUL, Method, 32-35. Er beklagt, daß solche Studien nicht klar machen, welchen Zweck die listenartigen Zusammenstellungen verfolgen. Dies gilt für die Listen von SCHÄCHTER, Fluch, 163-170; SUMNER, Study 48-57. Das verschiedenartige Vergleichsmaterial verstellt den Blick für Textbezüge, die unter MALULs Kriterium uniqueness fallen würden. So verwundert ihr abschlägiges Urteil über einen assyrischen Einfluß auf Dtn 28 nicht.
} 
Texten deutlich voneinander abweichen. ${ }^{1}$ Doch in McCarthys Inventar sind Flüche verschiedener altorientalischer Fluchsequenzen nebeneinandergestellt, ohne daß der literarische Kontext oder der Aufbau der jeweiligen Quelle berücksichtigt wurde. ${ }^{2}$ Ein Beispiel soll verdeutlichen, wohin eine derartige Vorgehensweise führt. Um den Vergleich zu erleichtern werden die Passagen, die McCarthy aus dem Vertrag zwischen Assurnirari V. und Mati'ilu und aus dem KH angibt, aus Borgers Übersetzungen zitiert.

VTE
"19So möge Sin, ...
euch in Aussatz
${ }^{420}$ hüllen und
veranlassen, daß ihr
vor den Göttern und
dem König nicht
erscheinen könnt.
${ }^{421}$ Lauft umher auf
der Steppe wie ein
Wildesel oder eine
Gazelle!"33

Assurnirari
IV „ ${ }^{4}$ So möge Sin, ...
Mati'ilu, seine Söhne,
${ }^{5}$ seine Großen und
die Leute seines Lan-
des in Aussatz wie
in ein Gewand hüllen,
sie mögen auf der $_{\text {sie }}$
Steppe umherlaufen,
er möge ihnen kein
Mitleid angedeihen
lassen."4

KH
LI " 50 Ninkarrak, ...
55 möge eine schwere
Krankheit, 56 einen
bösen Krankheitsdä-
mon, ${ }^{57}$ eine
schmerzliche Wunde,
58 die nicht abheilt,
${ }^{59}$ deren Wesen kein
Arzt ${ }^{60}$ erkennt, ${ }^{62}$ die
er nicht 61 mit Ver-
bänden ${ }^{62}$ zur Ruhe
bringt, ... ${ }^{64}$ in seinen
Gliedern ${ }^{65}$ ihm
hervortreten las-
sen... . ${ }^{5}$

$\mathrm{KH}$

LI „50 Ninkarrak, ...

55 möge eine schwere

Krankheit, S6einen

bösen Krankheitsdämon, ${ }^{57}$ eine

schmerzliche Wunde,

${ }^{58}$ die nicht abheilt,

${ }^{59}$ deren Wesen kein

Arzt ${ }^{60}$ erkennt, ${ }^{62}$ die

er nicht ${ }^{61}$ mit Ver-

bänden ${ }^{62}$ zur Ruhe

bringt, ... ${ }^{64}$ in seinen

hervortreten lassen.... ."

Neben Dtn 28,27f stellte McCarthy die Sinflüche der VTE und des Assurnirari-Vertrags. Der Mondgott Sin schlägt die Vertragsbrecher mit Aussatz. Mit dem sumerisch-akkadischen Begriff saharšubbû ist eine Hautkrankheit gemeint, für die typisch schien, daß sie den ganzen Körper überziehen konnte. Deswegen wird sie mit einem Gewand verglichen, in das der Gott den Verfluchten hüllt. Der etwa 1000 Jahre ältere KH sprach im Sinfluch von der schweren Strafe und der großen Sühne, die aus dem Leib des Verfluchten nicht verschwinden soll (KH L 49-65). Bei dieser Strafe, die im Leib steckt und das Leben zum Tode macht, kann es sich ebenfalls nur um eine Krankheit handeln. ${ }^{6}$ Der Sinfluch wäre also der angemessene Vergleichspunkt im KH gewesen und hätte verdeutlicht, daß die Jahrtau-

\footnotetext{
$1 \mathrm{Vgl.} \mathrm{Treaty} \mathrm{1963,} 123$.

2 Vgl. Treaty 1963, 122; Treaty 1978, $173 f$.

3 BORGER, ,Vasallenverträge,“ 170.

4 BORGER, ,Mati'ilu,“ 156.

5 BORGER, „Codex,“ 79f.

6 Vgl. vdTOORN, $\operatorname{Sin}, 75$.
} 
sende alte mesopotamische Fluchtradition Wandlungen unterworfen war. Statt dessen gibt McCarthy aus dem KH den Ninkarrakfluch an, in welchem als Hauptmotiv die Unheilbarkeit der Krankheit genannt wird. Das Leiden wird einerseits als Dämon verstanden, was auf eine Geisteskrankheit hinweisen könnte, andererseits aber durch den Ausdruck simmu „Wunde“ auf bestimmte Körperpartien begrenzt im Gegensatz zur Umhüllung des ganzen Körpers im Sinfluch. Die Krankheitsbilder der hebräischen Begriffe in Dtn 28,27 bezeichnen großflächige Veränderungen an der Körperoberfläche ohne offene Wunden. ${ }^{1}$ In Dtn 28,34b.35 dagegen findet sich zunächst ein Hinweis auf den Wahnsinn und anschließend die Beschreibung von Krankheitsbildern, die auf bestimmte Körperteile, nämlich Knie und Schenkel, beschränkt sind und als böse und unheilbar charakterisiert werden. Dtn 28,34b.35 ähnelt also motivisch eher dem Ninkarrakfluch, V. 27 eher dem Sinfluch. An die Stelle des Ninkarrakfluchs trat später der Gulafluch. Zur Tradition des Gulafluchs gehört das Motiv der Unheilbarkeit und ein Krankheitsbild mit simmu lazzu, der ,unheilbaren Wunde“, die blutet und eitert. McCarthy vermischt in seiner Liste demnach Flüche, die in Mesopotamien deutlich voneinander abgegrenzt waren und eine eigene Motiv- und Formulierungsgeschichte besaßen. ${ }^{2}$

Noch deutlicher wird die zweifache Tradition von Krankheitsflüchen, die sich in Dtn 28 niedergeschlagen hat, wenn man die Stellung der Flüche betrachtet. Der Sinfluch steht in mesopotamischen Fluchsequenzen meist zusammen mit dem Šamašfluch ziemlich am Anfang, der Ninkarrak- oder Gulafluch dagegen eher am Ende der Fluchreihe. So besitzen die mesopotamischen Fluchsequenzen ein gewisses chiastisches Element, denn die beiden Krankheitsflüche schließen zumeist Kriegsflüche und vor allem den Adadfluch ein. Statt die Struktur der altorientalischen Fluchabschnitte zu berücksichtigen, arbeitete McCarthy in Dtn 28 eine Klimax heraus, auf die das ganze Kapitel zulaufe. In seiner Argumentation scheinen direkte Bezugnahmen auf eine altorientalische Vorlage und die strukturelle Einheitlichkeit von Dtn 28 unvereinbare Positionen zu sein. ${ }^{3}$ Schließt aber die Aufnahme von Flüchen aus einem assyrischen Vertrag die planvolle Gestaltung von Dtn 28 aus? Hauptargument zur Ablehnung direkter Bezie-

${ }^{1}$ Vgl. KINNIER WILSON, „Medicine,“ $355,360-363$.

2 Vgl. Watanabe, Thronfolgeregelung, 35-49; „Überlieferung,“ 99-119; Preuss, Deuteronomium, 73.

${ }^{3}$ Vgl. McCarThy, Treaty $1978,175 . \mathrm{Zu}$ den von FrankeNA und Weinfeld gezeigten Parallelen: „What, then, do the parallels say about the text as such? Do they show that $\mathrm{Dt}$ 28 , rather than simply belonging to a common ancient near eastern tradition, actually derived from a Vorlage, an Assyrian treaty?" Eine Antwort auf diese Frage sucht man vergeblich. Der Aufweis der Struktur von Dtn 28 soll wohl die verneinende Antwort geben. 
hungen zwischen den VTE und der Bibel sind die Unterschiede, die im Detail zwischen den Texten bestehen. ${ }^{1}$

Auch wenn Tadmor bezweifelt, daß jemals ein Vasallenvertrag zwischen Assyrien und Juda existierte, folgt daraus nicht unbedingt, daß die königliche Kanzlei in Jerusalem zur Zeit des Manasse keine Kopie der VTE besaß. ${ }^{2}$ Das im ardūtu-Verhältnis an Assyrien gebundene Juda mußte von der Thronfolgeregelung und der Aufteilung des assyrischen Hegemonialgebiets unter die beiden Thronfolger informiert werden.

Nicholsons Kritik an Hillers, Weinfeld und McCarthy richtete sich nicht direkt gegen eine assyrische Vorlage für Dtn 28 , zumal Hillers und McCarthy sich ebenfalls dagegen aussprachen, sondem bestritt deren Thesen von der weitgehenden literarischen Einheitlichkeit des Kapitels 28 und vom Aufbau des Deuteronomiums nach dem Vertragsformular, die sie mit dem Hinweis auf altorientalische Fluchtexte bekräftigten. ${ }^{3}$ Nicholson verwies auf die literarkritischen Ergebnisse von Plöger und Seitz und die Fluchlisten in anderen altorientalischen Textgattungen wie Kudurrus und Gesetzen. Dies schließt aber nicht von vornherein assyrischen Einfluß auf Dtn 28 aus. Assyrisches Material könnte auch im Rahmen redaktioneller Ergänzungen in den biblischen Text eingeflossen sein. ${ }^{4}$ Wie ernst man nun seinen Einspruch gegen das Vertragsformular nehmen mag5, die Frage nach der Struktur des gesamten Buches gehört nicht zum Thema dieser Untersuchung. Sie läßt sich aufgrund von Dtn 28 allein auch nicht beantworten. Sollten nämlich tatsächlich Flüche aus den VTE übernommen worden sein, ergibt sich daraus allein noch nicht das Vertragsschema für das ganze Deuteronomium. Doch spricht Dtn 28,69 vom Abschluß eines ברית. Das Stichwort Bundesschluß fällt im Kontext von Dtn 28, und es ist

\footnotetext{
1 Vgl. Treaty 1978, 175; SEITZ, Studien, 256. Da Frankena auf McCarTHYs Treaty 1963 Bezug nahm und McCARTHY sich in Treaty 1978 wiederum mit FRANKENA auseinandersetzte, spiegelt diese Diskussion die Interpretationsmöglichkeit der von beiden beschriebenen Textphänomene innerhalb der Alternative literarischer Abhängigkeit oder des Einflusses einer allgemeinen Tradition wider.

2 Vgl. TADMOR, „Treaty,“ 151. In der jüngeren Fassung des Artikels, ,Alleanza,“ 35, fehlt der Abschnitt über Manasse mit dem Schluß auf das Nichtvorhandensein der VTE in Jerusalem.

3 Vgl. Nicholson, God, 73-78.

4 Vgl. PlOGER, Untersuchungen, 158 Anm. 97, der zur Stützung seiner diachronen Ausgrenzung von Dtn 28,23f auf BORGER, „Nimrud,“ 181 verwies, wo dieser eine assyrische Vorlage für den Bibeltext vermutete.

5 ,... Nicholson (...) geht ... in seiner Ablehnung jeglichen Zusammenhangs sogar des Deuteronomiums mit der altorientalischen Vertragspraxis weit und scharf über Perlitt hinaus, wobei er sich freilich ... nicht gerade als profunder Kenner des neuassyrischen Vertragswesens ausweist.“ ZENGER, „Bundestheologie,“ 24.
} 
nicht unbesehen auszuschließen, daß V. 69 das Kapitel in einen Zusammenhang rückt, der die Anleihe an den Flüchen des assyrischen adê denkbar macht. ${ }^{1}$

Houtman bezog sich hauptsächlich auf Dtn 28,23f und schritt in der Ablehnung der Thesen von Borger, Fensham, Frankena und Weinfeld hinter den Argumentationsstand von Hillers zurück. ${ }^{2}$ Während Hillers mündliche Tradition als Band zwischen Dtn 28,23f; Lev 26,19 und den VTE postulierte, und somit unter den von MALUL definierten Kategorien zwar nicht „direct connection "3, aber zumindest „common tradition “4 vertrat, stellte Houtman einen Traditionsstrom von Fluchmotiven überhaupt in Frage. Die Gemeinsamkeiten resultieren nicht aus einer Überlieferung, sondern aus gleichen Lebenserfahrungen. Doch diese Ansicht mag vergleichbare Einzelmotive erklären, läßt aber die parallele Anordnung der Fluchthemen unerwähnt. Houtmans Auffassung impliziert, daß die altorientalische Lebenswelt ihre Erfahrungen in gleichen Formulierungsreihen zum Ausdruck brachte. Das kann jedoch nicht unhinterfragt angenommen werden. Ergibt sich die Reihenfolge der Flüche sachlich aus möglichen Leiderfahrungen des AO, dann sollten auch andere altorientalische und biblische Texte, die derartige Leiderfahrungen widerspiegeln, eine mit Dtn 28 und den VTEFlüchen zumindest teilweise identische Themenreihung aufweisen.

Der Forschungsüberblick bestätigt für das weitere Vorgehen die bereits definierten Kriterien. Nicht der Vergleich von Einzelmotiven kann eine befriedigende Klärung herbeiführen, sondern es gilt, den literarischen Kontext, die mesopotamischen Traditionslinien und die Baustrukturen altorientalischer Fluchsequenzen zu berücksichtigen.

\section{3. Methodische Überlegungen}

Um die VTE- Flüche in ihrer Gestalt und Tradition zu untersuchen, werden die herangezogenen Paragraphen auf der synchronen Ebene analysiert. Die diachrone Analyse tritt demgegenüber zurück, da kaum mit einer Redak-

1 Vgl. Nicholson, God, 147f; WeInFeld, Deuteronomy, 6-9; LoHFINK, „Fabel,“ 68-72.

2 Vgl. Himmel, 147f; Pentateuch, $311 \mathrm{f}$.

${ }^{3}$ Method, 89.

${ }^{4}$ Method, 91. 
tionsgeschichte der VTE zu rechnen ist und nach der Verwendung in der Vereidigungszeremonie keine Ergänzungen mehr zu erwarten sind. ${ }^{1}$

Die Flüche werden nach Präsentation der Umschrift und dem Zitat der Übersetzung Watanabes auf Abweichungen in den erhaltenen Versionen gesichtet, was ungefähr dem Arbeitsschritt Textkritik entspricht. In den Publikationen wurden die Fragmente der Manuskripte zu einem zusammengesetzten Text vereinigt, der mit keiner der originalen Versionen völlig übereinstimmt.

In der sprachlich-syntaktischen Analyse geht es um Aufbau und Gliederung des Textes, besondere Stilmerkmale und den Wortschatz. Bei der Untersuchung des Wortschatzes wurde anhand der Konkordanz der Ausgabe von SAA 2 überprüft, ob die in den Flüchen vorkommenden Wörter auch in den Stipulationen vorkommen, oder ob in den Flüchen lexikalisch feststellbar eine andere Sprache gesprochen wird. Ebenso dient die Konkordanz zur Feststellung, ob Begriffe nur den Flüchen bestimmter Gottheiten zugeordnet werden oder auch in anderen Flüchen anzutreffen sind. Wenn lexikalische Verknüpfungen zu den Stipulationen festgestellt werden können, zeigt dies, daß die Flüche nicht als erratischer Block überliefert und beliebig an Texte angefügt wurden, sondem ihre konkrete sprachliche Gestalt erst zusammen mit dem Text erhielten, zu dem sie gehören. Ebenso zeigt das Auftreten derselben Wörter in unterschiedlichen Flüchen, welche Motive nicht fest mit Gottheiten oder Vergleichen verknüpft waren, sondern variiert werden konnten.

Die semantische Analyse blickt über den Rahmen der VTE hinaus auf das gesamte Korpus der erhaltenen neuassyrischen Staatsverträge und Vereidigungen. Die in SAA 2 gesammelten dürfen als offizielle staatliche Dokumente angesehen werden und entstammen bis auf den Vertrag zwischen Marduk-zakir-šumi I. und Šamši-Adad V., der ein babylonischer Text ist ${ }^{2}$, der assyrischen Hofkanzlei. Im Rahmen dieser Texte kann nach neuassyrischen Eigentümlichkeiten geforscht werden. Außerdem geht es in der semantischen Analyse um die Bedeutung der angerufenen Gottheit und der im Fluch angesprochenen Übel.

Die Strukturanalyse soll den Aufbau des Textes sowie die Funktion der einzelnen Glieder schematisch zusammenfassen. Ihr folgt die Analyse der Textsorte, d.h. die Formengeschichte des Fluches in diachronem Aspekt.

\footnotetext{
${ }^{1}$ Zur Datierung der VTE siehe oben $15 f$. $\mathrm{DaB}$ der Text vom 16. Ajjar kaum von den Fragmenten des 18. Ajjar abweicht, berechtigt zu der Annahme, daß auch am 12. Ajjar der gleiche adê-Text verwendet wurde, obwohl keine Fragmente erhalten sind, die dieses Datum tragen. Vgl. WATANABE, Thronfolgeregelung, $3 \mathrm{f}$.

2 Vgl. ParPola / Watanabe, Treaties, XXVIf; BRINKMAN, „Covenants,“ 107-112.
} 
Innerhalb der übergeordneten Gattung des Fluches mit der Anrufung von Göttem, werden die erhaltenen Flüche mit Anrufung derselben Gottheit zusammengestellt und verglichen. Da es hier nur um die in die VTE eingeflossenen Traditionen geht, wird der Untersuchungszeitraum auf die etwa 1000 Jahre vom KH bis zu den VTE beschränkt. ${ }^{1}$ Unberücksichtigt bleiben die Flüche auf Privaturkunden sowie auf Texten, die außerhalb Babyloniens oder Assyriens entstanden. ${ }^{2}$ Auf den Vergleich mit Flüchen, bei denen mehrere Gottheiten gemeinsam angerufen werden, wird verzichtet, weil in diesen Fällen die Fluchmotive der Götter miteinander vermischt sind, während in den VTE-Flüchen nur jeweils eine Gottheit pro Fluch genannt wird.

Um im Zeitraum zwischen dem KH und den VTE möglichst alle Flüche auf veröffentlichten und bearbeiteten staatlichen Texten aus Babylonien und Assyrien zu erfassen, wurden zusätzlich zum Korpus der in SAA 2 gesammelten Dokumente die neuassyrischen Königsinschriften bis zu denen Asarhaddons durchgesehen. Die älteren Königsinschriften stehen in RIMA zur Verfügung. Die Königsinschriften der Sargoniden sind durch jeweils eigene Textausgaben zugänglich. Damit wäre die neuassyrische Linie mesopotamischer Flüche weitgehend erfaßt. Die Erhebung babylonischer Kudurruflüche erleichtern die nicht publizierte Dissertation von Gwendolyn Leick und die Diplomarbeit von Petra Unterlechner. Zusammen mit den Flüchen des KH und der in RIME und RIMB bisher veröffentlichten Königsinschriften ergibt sich eine umfassende Sammlung der babylonischen Flüche. Zweifellos bleibt der Vorbehalt des fragmentarischen Charakters der gefundenen altorientalischen Texte, von denen wiederum nur ein Bruchteil veröffentlicht und damit dieser

\footnotetext{
1 Ältere Inschriften besitzen, vom Kodex Lipit-Ištar und Texten Jahdun-lims von Mari abgesehen, kurze Flüche, die für die Tradition der VTE-Flüche nichts ergeben, was nicht auch in den untersuchten 1000 Jahren feststellbar wäre. $\mathrm{Zu}$ den Flüchen auf älteren Königsinschriften vgl. POMPONIO, Formule, 17-31; LEICK, Fluchformeln, 4-9; CHARPIN, „Inscriptions,“ 60-65; RIME 4; KUPPER, „Formules“. Neubabylonische Königsinschriften enthalten keine Flüche mehr. Zu Flüchen in literarischen Texten vgl. POMPONIO, Formule, 79-92.

2 Flüche auf Privaturkunden sind meist formelhafter und kürzer als auf den staatlichen Texten. Vgl. die Inschrift des Bel-eriš, Ass 1758 GRAYSON, Inscriptions II, 73 § 347: Samnuha, Gubaba (Fluch/Tod); „Caillou Michaux“ (I R 70), eine private Landschenkung als Mitgift aus der Regierungszeit des Marduk-nadin-ahbe: Anu, Enlil, Ea und Ninmah, die großen Götter (Fluch, Entwurzelung); Marduk (aganutilla); Šamaš (Rechtlosigkeit); Sin (saharšubbâ); Ištar (Böses); Ninurta (Grenze); Gula (simmu lazzu); Adad (Überschwemmung, Vernichtung der Ernte); Nabu (Hungersnot); genannte große Götter (Fluch, WegstoBen der Nachkommen); für neubabylonische Privaturkunden OWEN / WATANABE, „Gartenkaufurkunde,“ 38, für Kolophone HUNGER, Kolophone, Nr. 91, 92, 96, 97, 106, 115, 182, $193,195,200,210,233,234,235,236,238,239,240,241,256,271,291,314,318,319$, $320,333,351,352,353,355,356,357,359,360,375,424$.
} 
Untersuchung zugänglich ist. Trotzdem kann auf der Grundlage des bekannten Textmaterials erkannt werden, inwiefern die in dem Thronfolgeadê auftauchenden Formulierungen und Motive durch die mesopotamische Tradition vorgegeben waren und damit auch in einen judäischen Text als Überlieferungsgut einfließen konnten.

\subsection{Die zum Vergleich herangezogenen Texte}

Die Texte werden nach den Herrschern Babyloniens und Assyriens von Hammurapi (1792-1750) bis Asarhaddon (680-669) ${ }^{1}$ datiert und geordnet. Der Königsliste sind Codes für die aus der Regierungszeit des Herrschers stammenden staatlichen Dokumente mit Flüchen beigefügt. Der Code gibt in Analogie zu dem Numerierungssystem von RIMA und RIMB die Herkunft des Textes mit dem Buchstaben A für Assyrien und B für Babylonien an. Dem folgt die Herrschernummer, die das Regierungsende des Königs angibt, unter dem der Text entstand. Spätestens zu diesem Zeitpunkt hat das Dokument existiert. So sind die Belege für die Entwicklung der mesopotamischen Fluchtradition in ihrem diachronen Verhältnis zu anderen Texten leicht einzuordnen. Nach der Herrschernummer steht die Textnummer.

Die Textliste gibt die Publikation ${ }^{2}$ und die Textsorte an. Dann werden die angerufenen Götter mit dem von ihnen erbetenen Wirkbereich aufgezählt. Dies erlaubt einen Überblick über die Stellung des Fluches und der Motive im Aufbau der einzelnen Sequenzen. So kann gesehen werden, ob die Götter die Reihenfolge der Flüche bestimmen, oder ob die Fluchmotive selbst in einer festgelegten Reihenfolge tradiert wurden.

\footnotetext{
${ }^{1}$ Die Jahreszahlen folgen dem chronologischen Schema der Royal Inscriptions of Mesopotamia, vgl. GRAYSON, RIMA 1, 3.

2 Die Publikation des akkadischen Textes ist nur dann ins Literaturverzeichnis aufgenommen, wenn sie tatsächlich zur Erstellung einer Umschrift und/oder Ubersetzung verwendet wurde. Sind mehrere Publikationen aufgeführt, wurde die jüngere benutzt.
} 


\subsubsection{Königsliste}

BABYLONIEN

Hammurapi (1792-1750)

Samsuiluna (1749-1712)

Abi-Esuh (1711-1684)

Ammiditana (1683-1647)

$<\ldots>$

Agum II. kakrime

Bumaburiaš I. (um 1540)

Kaštiliaš III.

Ulamburiaš

Agum III.

Kara-indaš (um 1413)

Kadašman-Harbe

Kurigalzu I.

Kadašman-Enlil I.

Burnaburiaš II. (1359-1333)

Karaindaš (1333)

Nazi-Bugaš (1333)

Kurigalzu II. (1332-1308)

Nazi-Maruttaš (1307-1282)

Kadašman-Turgu (1281-1264)

Kadašman-Enlil II.

(1263-1255)

Kudur-Enlil (1254-1246)

Šagarakti-Šuriaš (1245-1233)

Kaštiliaš IV. (1232-1225)

Enlil-nadin-šumi (1224)

Kadašman-Harbe II (1223)

Adad-šuma-iddina (1222-1217)

Adad-šuma-uṣur (1216-1187)

Melišihu / Meli-Šipak

(1186-1172)

Marduk-apla-iddina /

Merodach-Baladan I. (1171-1159)

Zababa-šuma-iddina (1158)

Enlil-nadin-ahi (1157-1155)

Marduk-kabit-aḩhešu (1158-1141)

Itti-Marduk-balațu (1140-1133)

Ninurta-nadin-šumi (1132-1127)

Nebukadnezar I. (1126-1105)

Enlil-nadin-apli (1104-1101)
B.1155.1

B.1105.1-2 Aššur-reša-iši I. (1133-1116)

A.1116.1-2

B.1750.1-2

ASSYRIEN

$<\ldots>$

Enlil-nașir II . (1430-1425)

Aššur-nirari II. (1424-1418)

Aššur-bel-nišešu (1417-1409)

Aššur-ra'im-nišešu (1408-1401)

B.1374?.1-3

Aššur-nadin-aḩ̧̧ II. (1400-1391)

Eriba-Adad I. (1390-1364)

Aššur-uballit (1363-1328)

Enlil-nirari (1327-1318)

B.1282.1-4 Arik-den-ili (1317-1306)

A.1306.1-2

Adad-nirari I. (1305-1274)

A.1274.1-45

B.1255.1-2 Salmanassar I. (1273-1244)

A.1244.1-12

B.1246.1 Tukulti-Ninurta I.

(1243-1207)

A.1207.1-14

B.1225.1

Aššur-nadin-apli

(1206-1203)

A.1203.1

Aššur-nirari III. (1202-1197)

Enlil-kuduri-usur (1196-1192)

B.1172.1-4 Ninurta-apil-Ekur (1191-1179)

B.1159.1-6 Aššur-dan I. (1179-1134)

B.1101.1 Tiglat-Pileser I. (1115-1077)

A.1077.1 
Marduk-nadin-abhe

(1100-1083)

Marduk-šapik-zeri

(1082-1070)

Adad-apla-iddina (1069-1048)

Marduk-ahbe-eriba (1047)

Marduk-zer? (1046-1035)

Nabu-šumu-libur (1034-1027)

Simbar-Šipak (1026-1009)

Ea-mukin-zeri (1009)

Kaššu-nadin-ahi (1008-1006)

Eulmaš-šakin-šumi (1005-989)

Ninurta-kudurri-uṣur I. (988-986)

Širiqti-Šuqamuna (986)

Mar-biti-apla-ușur (985-980)

Nabu-mukin-apli (979-944)

Ninurta-kudurri-uṣur II. (944)

Mar-biti-ablhe-iddina (943)

Šamaš-mudammiq (-900)

Nabu-šuma-ukin (899-888)

Nabu-apla-iddina (887-855)

Marduk-zakir-šumi I.

(854-819)

Marduk-balassu-iqbi (818-813)

Baba-aha-iddina (812)

Marduk-bel-zeri

Marduk-apla-uṣur ( -770)

Eriba-Marduk (769-761)

Nabu-šuma-iškun (760-748)

Nabu-nasir (747-734)

Nabu-nadin-zeri (733-732)

Nabu-šuma-ukin II. (732)

Nabu-mukin-zeri (731-729)

Pulu/Tiglat-Pileser III. (728-727)

Ululaia/Salmanassar V. (726-722)

Marduk-apla-iddina /

B.711.1

Merodach-Baladan II. (721-711)

Sargon II. (710-705)

Bel-ibni (702-700)

B.700.1

Aššur-nadin-šum (699-694)

Nergal-ušezib

Mušezib-Marduk (693-689)

Asarhaddon (689-669)

B.1047.1
B.1083.1-3 Ašared-apil-Ekur (1076-1075)

B.1070.1-2 Ašur-bel-kala (1074-1057) A.1057.1-2

Eriba-Adad II. (1056-1055)

Šamši-Adad IV. (1054-1051)

Aššurnașirpal I. (1050-1032)

Salmanasser II. (1031-1020)

Aššur-nirai IV. (1019-1014)

Aššur-rabi II. (1013-973)

B.944.1 Aššur-reša-iši II (972-968)

Tiglat-Pileser II. (967-935)

Aššur-dan II. (934-912)

A.912.1

Adad-nirari II. (911-891)

A.891.1

B.855.1-2 Tukulti-Ninurta II. (890-884)

A.884.1-2

B.819.1-2

Aššurnașirpal II. (883-859)

A.859.1-10

Salmanasser III. (858-824)

A.824.1-2

Šamši-Adad V. (823-811)

Adad-nirari III. (810-783) A.783.1-4

Salmanasser IV. (782-773)

A.773.1

Aššur-dan III. (772-755)

B.748.1 Aššur-nirari V. (754-745)

A.745.1

Tiglat-Pileser III. (744-727)

Salmanasser V. (726-722)

Sargon II. (721-705)

A.705.1-8

A.681.1-37

Sanherib (704-681)

B.699.1-6 Asarhaddon (680-669)

A.669.1-7 


\subsection{Mesopotamische Texte mit Flüchen}

B.1750.1: Borger, Lesestücke, 43ff.

Kodex Hammurapi; Kol. XLIX Z. 45 - Kol. LI Z. 91:

Anu (Herrschaftsverlust, Fluch); Enlil (Wirren, Verzweiflung, leidvolle Regierung, wenige Tage, Hungersnot, Finsternis, Untergang der Stadt, Zerstreuung der Leute, Thronwechsel, Tilgung von Name und Gedenken); Ninlil (Diffamierung, Zerstörung des Landes, Untergang der Leute, Seelenverlust); Ea (Verwirrung, Dürre); Šamaš (Herrschafts- und Rechtsverlust, Verwirrung, böse Omina, unheilvolles Wort. Tod und Durst des Totengeistes); Sin (Herrschaftsverlust, Strafe, Widersacher, todesgleiches Leben); Adad (Dürre, Hungersnot, Sintflut); Zababa (Entwaffnung, Niederlage); Ištar (Fluch, Entwaffnung, Verwirrung, Aufruhr, Tod der Soldaten. Deportation): Nergal (Verbrennen und Zerschmettern); Nintu (Vernichtung von Erbsohn, Namen und Samen); Ninkarrak (Krankheit); Götter des Himmels und der Erde (Fluch); Enlil (Fluch).

B.1750.2: Frayne, RIME 4, E.4.3.6.11 (BM 96952).

Königsinschrift; sumerisch, Z. 53-70:

Meslamtiea (?) ... (Wehklage, Verkürzung der Lebenszeit, Ausreißen des Fundaments, Vernichtung des Samens).

B.1580?.1: Pinches, V R 33; Leick, Fluchformeln, 21.

Zylinderinschrift; Kol. VI Z. 443-45:

Assur und Belet (Ablehnung, Vernichtung von Name und Samen).

B.1374?.1: Boissier, RA 29, 96ff.

Königsinschrift; Rs. 17-19:

große genannte Götter (Fluch, Nahrungs- und Wassermangel).

B.1374?.2: King, BBS Nr. 2 (BM 102588).

Kudurru; Z. 11-24:

Anu, Enlil und Enki (Ea), Nanna (Sin), Šamaš und Marduk, Nusku und Sardarnunna, Nergal und Las (Vernichtung von Fundament, Samen und Nachkommenschaft, Tod); Šamaš (Tod, Unterwelt); Tišpak und Sebetti (?).

B.1374?.3: Gadd, CT 36, Taf. 6-7 (BM 108982).

Landschenkung an einen Ištartempel; Z. 26ff:

Ištar (Niederlage). ${ }^{1}$

B.1282.1: Arnaud, $R A$ 66, 163ff (L 7072).

Kudurru; Z. 35-50+x:

1 Vgl. UNTERLECHNER, Fluchformeln, if. 
Anu, Enlil und Ea (Fluch); Ninurta (Grenze); Sin (saharšubbû); Herrin der Götter (Kinderlosigkeit); Gula (Krankheit); futility curses (Trockenheit, Ackerlandzerstörung, Obdachlosigkeit).

B.1282.2: Scheil, MDP 2, 86ff, Taf. 16-19; (SB 21 = Susa Nr. 2); Hinke, Kudurru, $1 \mathrm{ff}$.

Kudurru; Kol. IV Z.31-36:

die großen Götter (Fluch, Vernichtung von Name und Samen); Marduk (Vernichtung des Lebens).

B.1282.3: Delaporte, $C C B N$ I, 179 A 821.

Königliches Siegel:

Šamaš und Adad (Zerstörung des Namens). ${ }^{1}$

B.1282.4: Falkenstein, UVB 12, 43f.

Königsinschrift; sumerisch, Z. 9-16:

Anu und Inanna (Ausreißen des Fundaments, Vernichtung des Samens, Tod).

B.1255.1: King, $B B S$ Nr. 1 (BM 91036).

Kudurru; Kol. II Z. 9-12:

Ninurta (Grenze); ? (Ausreißen des Fundaments).

B.1255.2: Pinches, IV R ${ }^{2} 12$.

Weiheinschrift eines Kampfwagens entweder aus der Regierungszeit des

Kadašman-Enlil II. oder aus der Zeit Burnaburiaš II; ${ }^{2}$ Bilingue, Z. 32-47:

Marduk (böser Blick, Tod, Vernichtung von Name, Same, Sproß, Familie und Nachkommen, kein Wasserspender); Ninlil (Diffamierung); Ninurta (Entwaffnung, Niederlage); ? (Deportation) ... .

B.1246.1: Amaud, RA 66, $169 \mathrm{ff}$.

Kudurru; Rs. Z. 67-77:

Anu, Enlil und Ea und genannte Götter (Fluch); Ninurta (Grenze); Nanaja (?); Zababa (Vernichtung des Namens); Nabu und Marduk (?); Sin (saharšubbû); Adad (Überschwemmung, Hungersnot); Gula (Kinderlosigkeit, simmu lazzu). ${ }^{3}$

B.1225.1: Scheil, MDP 2, 95f, Taf. 20.

Kudurru; Z. 11:

Götter des Königs (ilū ša šarri irarū̌š kein Prekativ!). ${ }^{4}$

B.1172.1: King, $B B S$ Nr. 3 (BM 90827).

Kudurru; Kol. V Z. 48 - Kol. VI Z. 25:

${ }^{1} \mathrm{Vgl}$. POMPONIO, Formule, 36.

2 Vgl. ZimMERN, Neujahrsfest, 153-156; BRINKMAN, ,Texts,“ $249 \mathrm{f}$.

${ }^{3} \mathrm{Vgl}$. WATANABE, Thronfolgeregelung, 36-38.

${ }^{4} \mathrm{Vgl}$. CAD 1/A II, 235 arāru A1b1'. 
Anu, Enlil und Ea (böser Blick); Sin, Šamaš, Adad und Marduk (Ausreißen des Fundaments); Ningirsu und Ba'u (freudloses Schicksal); Šamaš und Adad (Rechtlosigkeit); Panigarra (Zerstörung des Grenzsteins); Uraš und Nin-E-gal (Böses); Šuqamuna und Šumalija (Demütigung vor König und Prinzen); Ištar (Niederlage); genannte Götter (Vernichtung des Namens).

B.1172.2: King, BBS Nr. 4 (BM 90829).

Kudurru; Kol. III Z. 9 - Kol. IV Z. 14:

Anu (Fluch); Enlil (Strafe); Ea (übles Schicksal); Šamaš (Vernichtung des Namens); Marduk (Böses); Nabu (?); Anunitum (Entwurzelung); Ninurta (Entwaffnung); Ninkarrak (Vernichtung der Nachkommenschaft); Adad (?); Nergal (Tod des Nachkommen); Šuqamuna und Šumalija (Diffamierung); genannte Götter (Fluch, Tod, Vernichtung des Verfluchten und der Nachkommen, lang andauernde Hungersnot, königliche Ungnade, böses Ende).

B.1172.3: Scheil, MDP 2, 99ff, Taf. 21-24 (SB 22 = Susa Nr. 3); Hinke, Kudurru, 4ff.

Kudurru; Kol. VI Z. 1 - Kol. VII Z. 51:

Anu, Enlil, Ea und Ninhursag, die großen Götter (böser Blick, Fluch); Marduk (Hunger); Sin (saharšubbû); Ninurta (Vernichtung der Nachkommenschaft, kein Wasserspender); Gula (Krankheit); genannte Götter (Blindheit, Taubheit, Stummsein).

B.1172.4: Scheil, MDP 10, 87ff, Taf. 11-12 (SB 23).

Kudurru: Kol. IV Z. 9 - Kol. V Z. 3:

Anu, Enlil und Ea, die großen Götter (böser Blick, Fluch, üble Tage, wenige Jahre); Sin (Strafe); Ninurta (Grenze, Kinderlosigkeit).

B.1159.1: King, BBS Nr. 5 (BM 90850).

Kudurru; Kol. III Z. 26-44:

Anu, Enlil und Ea, Ninurta und Gula (böser Blick, Fluch, Ausreißen des Grenzsteins, Vernichtung des Samens, Übel, lā țüb širi, Tod); Šamaš und Marduk (keine Erhörung).

B.1159.2: Scheil, $M D P$ 6, 31ff, Taf. 9-10 (SB 26); Hinke, Kudurru, $14 \mathrm{ff}$.

Kudurru; Kol. V Z. 10 - Kol. VI Z. 27:

Anu, Enlil, Ea, Ninhursag, Sin, Ningal, Šamaš, es folgen 42 weitere Götternamen, die großen Götter (Fluch, sahıaršubbû, Exkommunikation, Wehklagen, aganutillû, keine Totenpflege, baldiger Tod, Vernichtung des Namens, Ausreißen des Fundaments, Vernichtung von Samen und Lieblingskind).

B.1159.3: Borger, AfO 23, 1ff.

Teheraner Kudurru; Kol. II Z.20 - Kol. IV Z.10:

Anu und Enlil (Fluch); Sin (saharšubbû) Belet-Ili (Kinderlosigkeit); Ištar (Exkommunikation); Adad (Dürre); Marduk und Zarpanitu (Niederlage); Ninurta 
(Grenze): Šuqamuna und Šumalija (Fluch); Gula (Vernichtung des Samens); große genannte Götter (Kinderlosigkeit).

\section{B.1159.4: Page, Sumer 23, 45ff (IM 67953).}

Kudurru; Kol. III Z. 6 - Kol. V. Z. 9:

Anu, Enlil, Ea und Ninmah, (böser Blick, Fluch); Sin. Šamaš, Adad und Marduk, (Krankheit, Unwohlsein als lebenslängliches Schicksal); Nabu, Nanaja und Tašmetum (Böses, Unglück); Uraš, Nin-E-gal, Nusku, Sadarnuna, Šuqamuna, Šumalija, (Ungnade und Zorn der Götter, königliche Ungnade); Gula (simmu lazzu).

B.1159.5: Scheil, MDP 6, 39ff, Taf. 11,1 (SB 33, 6018 = Susa Nr. 14); Borger, AfO 23, 11ff.

Kudurru: Kol. III Z. 3 - Kol. IV Z. 17:

? (Fluch); Šamaš (Schwindel, Taubheit, Lähmung); Sin (saharšubbû); Adad (Salpeter auf Felder, keine Vegetation); Marduk (Vernichtung von Sohn, Namensträger, Samen und Nachkommen, Exkommunikation); Gula (simmu lazzu); Nusku, Nin-E-gal, Šuqamuna, Šumalija, die Götter des Königs (Mißgunst, Feindschaft von Gott und König); genannte Götter (keine Erhörung).

B.1159.6: Scheil, MDP 6, Taf. 42-43 (SB 169, 6035); Borger, AfO 23, $17 \mathrm{ff}$. Kudurru; Kol. III Z. 1 - Kol. IV Z. 17:

? (Krankheit, Exkommunikation); Šamaš (Schwindel, Taubheit, Lähmung); Adad (Vegetation); Marduk (aganutillû, keine Beerdigung); Ninurta und Gula (?); Nusku und Nin-E-gal, Šuqamuna und Šumalija (Feindschaft); genannte Götter (keine Erhörung).

B.1155.1: Gadd, CT 36, Taf. 13 (BM 11389).

Kudurrufragment:

Anu, Enlil und Ea (Vernichtung des Namens); Ninhursag und Ba'u (?); Marduk (?).

B.1105.1: Hinke, BER 4, 142ff.

Hinke Kudurru; Kol. IV Z. 3-26, Kol. V Z. 5-7:

Anu (Fluch, Tod); Enlil (übles Schicksal, Unheil, Unglück); Ea (Unwohlsein); Sin (Trübsal); Šamaš und Adad (Rechtlosigkeit); Ninurta (Grenze); Gula (simmu lazzu); Ištar (Beschwerlichkeit); Nusku (rābișu, Entwurzelung); große genannte Götter (Fluch, Ausreißen des Fundaments, Vernichtung des Samens).

\section{B.1105.2: King, $B B S$ Nr. 6 (BM 90858).}

Kudurru; Kol. II Z. 37-60:

die großen Götter (Fluch, böser Blick); Ninurta und Gula (Grenze, Vernichtung des Samens); Adad (Verschlammung, Hungersnot, Unterdrückung, Ruin); Šumalija, Adad, Nergal, Nanaja, die Götter von Namar, Nirah, Sin, die Herrin von Akkad, die Götter von Bit-Ȟabban (Böses, Obdachlosigkeit, Niederlage, kein Erbarmen, Tod, Erniedrigung, Sorge, Vernichtung des Samens). 


\section{B.1101.1: King, BBS Nr. 11 (BM 102485).}

Kudurru; Kol. II Z. 23 - Kol. IV Z.13:

Anu, Enlil, Ea und Ninmah, die großen Götter (Fluch, Ausreißen des Fundaments); Sin (saharšubbû); Nabu (Lebensverkürzung); Gula (simmu lazzu); Ninurta (Niederlage); Marduk (Strafe); Ninmah (?); die Götter (?).

\section{B.1083.1: King, BBS Nr. 7 (BM 90841).}

Kudurru; Kol. II Z. 13-39:

Anu, Enlil und Ea (böser Blick, Fluch); Sin (saharšubbû, Exkommunikation); Šamaš (Schläge, Dunkelheit); Ištar (Zerstörung der Wohnstätten, Obdachlosigkeit ${ }^{1}$, Vertreibung); Marduk (aganutillû); Ninurta (Grenze); Gula (simmu lazzu); Adad (Überschwemmung); Nabu (Hungersnot, Fluch); große genannte Götter (Böses, Vernichtung des Namens und der Nachkommen).

\section{B.1083.2: King, BBS Nr. 8 (BM 90840).}

Kudurru; Kol. III Z.23 - Kol. IV Z. 35:

genannte Götter (Fluch); Anu, Enlil und Ea, die großen Götter (Ausreißen des Fundaments, Vernichtung der Nachkommenschaft); Marduk (aganutillû); Nabu (Grenze); Adad (Verschlammung); Sin (saharšubbû); Šamaš (Rechtlosigkeit); Ištar (Böses); Gula (simmu lazzu); Ninurta (keinen Erben, keine Totenpflege); Nergal (Entwaffnung); Zababa (Hilflosigkeit); Papsukkal (versperrtes Tor); Išhara (keine Erhörung); Anu (Ausweglosigkeit); genannte Götter (böser Blick, Fluch). Beischrift Z. 6f: genannte Götter (Fluch).

\section{B.1083.3: Al-Admi, Sumer 38, $121 \mathrm{ff}$ (IM 90585).}

Kudurru; Kol. IV Z. 1 - Kol. V Z. 32:

Anu, Enlil, Ea und Ninmah (böser Blick, Vernichtung von Namen, Samen und Nachkommen, keine Totenpflege); Sin (Wunde, Exkommunikation, Krankheit, göttlicher Zorn, Ruhelosigkeit); Šamaš (Rechtlosigkeit, Niederlage); Adad (Hungersnot, Durst); Nergal (Niederlage); Ninurta (Grenze); Zababa (Niederlage, Familienstreit, Mißfallen); Marduk (aganutillû); Nabu (Lebensverkürzung); Gula (Krankheit); Ningirsu (Dämon, statt Vegetation Salpeter, statt Getreide Dornen); Dumuzu, Ištar und $\breve{s} \bar{e} d u$ (Vernichtung der Pläne); große genannte Götter (Fluch).

B.1070.1: Reshid / Wilcke, ZA 65, 34ff (IM 74651).

Kudurru; Z. 52-87:

Anu, Enlil, Ea, Belet-ili, die großen Götter (böser Blick, Fluch); Sin (Exkommunikation); Šamaš (Fluch, Taubheit, Blindheit, Lähmung); Adad (Hungersnot); Marduk (aganutillû); Ningirsu (statt Vegetation Salpeter, statt Getreide Dornen); Gula (simmu lazzu); große genannte Götter (böser Blick, Krankheit, Depression, Wehklagen, Mangel, Mühsal, Trübsal, unaufhörliches Weinen).

\footnotetext{
${ }^{1} \mathrm{Vgl} . \mathrm{CAD}$ 10/M II, 321 mu'â B.
} 
B. 1070.2: Rashid, Sumer 36, 124ff (IM 80908).

Kudurru; Kol. III Z. 29 - Kol. IV Z. 26:

genannte Götter (Fluch, Entfernung von Namen, Samen, Wurzel und Nachkommen, Besitzlosigkeit, unbefriedigende Gattin, Feindschaft, Verfluchung durch alle, die ihn sehen).

\section{B. 1047.1: Hinke, BER 4, 188-195.}

Kudurru: Kol. II Z. 14 - Kol. III Z. 10:

große genannte Götter (Fluch); Anu, Enlil und Ea (böser Blick, Vernichtung von Leben, Erbsohn und Samen); Marduk (Versperrung des Kanals); Zarpanitu (Diffamierung); Ninurta und Gula (simmu lazzu); Sin (saharšubbû); genannte Götter (Tod).

B.944.1: King, $B B S$ Nr. 9 (BM 90835).

Kudurru; Kol. I Z. 37 - Kol. II Z. 30:

Anu, Enlil und Ea, die großen Götter (Fluch); Marduk (aganutillû); Zarpanitu (Diffamierung); Nabu (Hungersnot); Sin (saharšubbû); Šamaš (Rechtlosigkeit); Nergal (Tod in der Schlacht); Zababa (?); Adad (Hunger und Durst); Ninurta (Grenze, Vernichtung von Namen und Nachkommen, keine Totenpflege); Gula (simmu lazzu, keine Beerdigung); Ninmah (Furcht vor der Geburt seines Viehs und seiner Sklaven, Dämon, königliche Ungnade). Zusatz Kol. V Z. 6f: genannte Götter (Tod).

B.855.1: King, BBS Nr. 29 (BM 90936).

Kudurru; Kol. III Z. 13-15:

Šamaš und Marduk (Fluch, böser Blick, Vernichtung der Nachkommen).

B.855.2: King, $B B S$ Nr. 36 (BM 91000).

Landgeschenk an den Samaštempel von Sippar; Kol. VI Z. 47-55:

Šamaš, Aja und Buene, .... , die großen Götter (Vernichtung von Name und Samen, Hungertod, keine Beerdigung).

B.819.1: Thureau-Dangin, $R A$ 16, 117ff (AO 6684).

Kudurru; Kol. III Z. 27 - Kol. IV Z. 15:

Anu, Enlil, Ea und Belet-ili, die großen Götter (Fluch); Marduk und Zarpanitu (böser Blick, Untergang, Gefangenschaft); Nabu und Nanaja (Ausreißen des Fundaments, Vernichtung des Samens); Sin, Šamaš und Ištar (saharšubbû, Exkommunikation); Ninurta, Zababa und Nergal (Tod); Nabu (Anklage).

B.819.2: Weidner, AfO 8, 27ff; Parpola / Watanabe, SAA 2 (Nr.1), 4f; Brinkman, „Covenants,“" 107ff (Rm. 2,427).

Vertrag zwischen Marduk-zakir-šumi I. und Šamši-Adad V.; Z. 16-35:

Marduk (Krankheit, Zerstreuung des Volkes, Ausgießung des Lebens, Tod, Hunger, Verfolgung); Nabu (Dämonen); Anu (Herrschaftsverlust); Enlil (Mühsal, Lebensverkürzung, Hunger); Ninlil (Diffamierung); Ea (Austrocknen der Flüsse); 
Šamaš (Herrschaftsverlust, Rechtlosigkeit); Sin (Strafe, Mühsal, Stöhnen); Adad (Dürre, Hunger, Ruinenhügel) ... .

B.748.1: Thureau-Dangin, $R A$ 16, $141 \mathrm{ff}$.

Schenkungsurkunde für einen Beamten des Nabutempels in Borsippa; die Gottheit selbst ist der Geschenkgeber; Kol. III Z. 3f, Kol. VI Z. 2f:

Nanaja und Mar-biti (Prozeßgegner); genannte Götter (Vernichtung der Nachkommenschaft).

B.711.1: Messerschmidt / Ungnad, VS I 37 (VA 2663).

Kudurru; Kol. V Z. 36-47:

Anu, Enlil und Ea, die großen Götter (Fluch, Blindheit, Taubheit, Lähmung, Übel); Marduk und Zarbanitu (Strafe, aganutillû, Tod); genannte Götter (Vernichtung von Samen und Nachkommen, keine Zukunft).

B.700.1: Frame, RIMB 2, B.6.26.1.

Tontafel mit Privilegien für Ša-uṣur-Adad; Z. 28-34:

Marduk (übles Schicksal, Thronverlust, Not und Hunger für die Untertanen); Nabu (Lebensverkürzung, Tod).

B.669.1: Frame, RIMB 2, B.6.31.11.

Zylinder aus Nippur; Z. 21:

dUN.GAL.NIBRU.KI (böser Blick, Zerstörung von Name und Samen).

B.669.2: Frame, RIMB 2, B.6.31.12.

4 Zylinderfragmente aus Nippur, Exemplar 3 Z. 40f:

Enlil (böser Blick, übles Schicksal, Zerstörung von Name und Samen, kein Erbarmen).

B.669.3: Frame, RIMB 2, B.6.31.15.

Tonzylinder aus Uruk; Z. 41:

Ištar (böser Blick, Zerstörung von Name und Samen).

B.669.4: Frame, RIMB 2, B.6.31.16.

Zylinder aus Uruk; Z. 24f:

Ištar (böser Blick, übles Schicksal, Zerstörung von Name und Samen, kein Erbarmen).

B.669.5: Frame, RIMB 2, B.6.31.17.

3 Tonzylinder; Z. 24f:

Nanaja (böser Blick, übles Schicksal, Zerstörung von Name und Samen, kein Erbarmen).

B.669.6: Frame, $R I M B$ 2, B.6.31.18.

Tonzylinder; Z. 23:

Nanaja (böser Blick, übles Schicksal, Zerstörung von Name und Samen). 
A.1306.1: Grayson, RIMA 1, A.0.75.1 (VA 5917).

Bauinschrift aus Assur; Z. 71-77:

Šamaš (Herrschaftsverlust, Hunger).

A.1306.2: Grayson, RIMA 1, A.0.75.2 (BM 91059).

Steinzylinder; Z. 8-11: Ähnlicher Fluch wie A.1306.1.

A.1274.1-38, Grayson, RIMA 1, A.0.76.2.

38 Exemplare von Bauinschriften Adad-niraris enden folgendermaßen:

Assur, Anu, Enlil, Ea und Ninmah, die großen Götter, die Igigu und Anunnaku (böser Blick, Fluch, Vernichtung von Name, Samen, Familie und Stamm, im Land, Verteilung des Landes, Vernichtung der Untertanen und des Erbsohns); Adad (Flut, Überschwemmung, Orkan, Rivalität, Aufstand, Sturm, Not, Mangel, Armut, Hunger, Ruinenhügel); Ištar (Niederlage); Adad (Blitzschlag, Hunger).

A.1274.39: Grayson, RIMA 1, A.0.76.4.

Steinplatte aus Assur; Z. 48-53:

Assur (Herrschaftsverlust); Ištar (Niederlage); Adad (Blitzschlag, Hunger).

A.1274.40: Grayson, RIMA 1, A.0.76.9.

Bauinschrift aus Assur; Z. 25-33:

Assur (Herrschaftsverlust); Adad (Blitzschlag, Hunger, Tod für Verfluchten, Heer und Same, Niederlage, Ruinenhügel).

A.1274.41: Grayson, RIMA 1, A.0.76.11.

Bauinschrift auf Steinen; Z. 30-34:

Assur (Herrschaftsverlust, Vernichtung von Name und Samen); Ištar (Niederlage).

A.1274.42: Grayson, RIMA 1, A.0.76.14 (IM 60819).

Steintafel aus Assur; Z. 29-39:

Assur (Herrschaftsverlust, Schlagen von Verfluchtem, Volk und Same, Niederlage); Ištar (Niederlage); Adad (Blitzschlag, Hunger).

A.1274.43: Grayson, RIMA 1, A.0.76.15.

Bauinschrift aus Assur; Z. 39-48:

Assur (Herrschaftsverlust, Vernichtung von Name und Samen); Ištar (Niederlage); Adad (Blitzschlag, Hunger).

A.1274.44: Grayson, RIMA 1, A.0.76.17 (Ass 2198).

Bauinschrift aus Assur; Z. 20-29:

Assur, Anu, Adad (Herrschaftsverlust, Vernichtung von Name und Same, Verteilung des Landes, Vernichtung der Untertanen und des Erbsohns); Adad (Blitzschlag, Hunger).

A.1274.45: Grayson, RIMA 1, A.0.76.18. Z. 17f:

Assur (?). 


\section{A.1244.1: Grayson, RIMA 1, A.0.77.1.}

Bauinschrift; Z. 164-167:

Assur, Igigu, Anunnaku (böser Blick, Fluch, Zerstörung von Name und Samen, Thronverlust, Regentschaft eines fremden Königs vor den Augen des Verfluchten).

A.1244.2: Grayson, RIMA 1, A.0.77.2.

Bauinschrift; Z. 23f:

Assur (Herrschaftsverlust, Zerstörung von Name und Samen).

A.1244.3: Grayson, RIMA 1, A.0.77.3 (Ass 2708).

Bauinschrift; Z. 44-46: gleicher Fluch wie A.1244.2.

\section{A.1244.4: Grayson, RIMA 1, A.0.77.4.}

Bauinschrift; Z. 51-55:

Assur (Herrschaftsverlust, Zerstörung von Name und Samen, Thronverlust, Regentschaft eines fremden Königs vor den Augen des Verfluchten).

A.1244.5: Grayson, RIMA 1, A.0.77.8 (Ass 984).

Steintafel; Z. 6f: gleicher Fluch wie A.1244.2.

A.1244.6: Grayson, RIMA 1, A.0.77.6.

Bauinschrift aus Assur; Z. 24-31:

Assur (Herrschaftsverlust, Zerstörung von Name und Same); Ištar (Niederlage); Adad (Blitzschlag, Hunger).

A.1244.7: Grayson, RIMA 1, A.0.77.13 (Ass 13001).

Tontafelfragment aus Assur; Rs. Z. 1-4:

? (Thronverlust, Regentschaft eines fremden Königs vor den Augen des Verfluchten).

A.1244.8: Grayson, RIMA 1, A.0.77.1008 (Ass 17138, 17411).

Fragmente einer Alabastertafel aus Assur, Zuschreibung an Salmanassar unsicher; Kol. VI Z. 7-9:

Enlil (?).

A.1244.9: Grayson, RIMA 1, A.0.77.9 (BM 115691, Ass 18601).

Steintafel; Z. 25f:

Assur (Herrschaftsverlust, Hunger).

A.1244.10: Grayson, RIMA 1, A.0.77.10 (Ass 13081, Ass 7450b).

Bauinschrift; Z. 24-27: gleicher Fluch wie A.1244.9.

A.1244.11: Grayson, RIMA 1, A.0.77.17.

20 Tonkegel aus Ninive: Exemplar 3,4,9,17,20 Z. 12f:

Assur (Herrschaftsverlust, Zerstörung von Name und Samen, Gottverlassenheit); Adad (Blitzschlag, Hunger). 
A.1244.12 Grayson, RIMA 1, A.0.77.18.

5 Tonkegel aus Ninive; Exemplar 2,3 Z. 12f:

Assur (Herrschaftsverlust, Zerstörung von Name und Samen); Adad (Blitzschlag, Hunger).

A.1207.1: Grayson, RIMA 1, A.0.78.1.

Königsinschrift; Kol. V Z. 32 - Kol. VI Z. 22:

Assur, Adad, Götter des Himmels und der Erde (Herrschaftsverlust, Not, Hunger, Mangel, Thronverlust, Regentschaft eines fremden Königs vor Augen des Verfluchten, ..., Vernichtung der Nachkommenschaft, Volk); Ištar (Geschlechtsumwandlung, Niederlage, Schwäche, Schlachten, ..., Auslieferung).

A.1207.2: Grayson, RIMA 1, A.0.78.5.

Steintafel, Palastbau; Z. 111-126:

Assur, Adad, Götter des Himmels und der Erde (Herrschaftsverlust, Zerstörung von Name und Same, Thronverlust, Regentschaft eines fremden Königs vor den Augen des Verfluchten); Ištar (Niederlage, Schwäche, Auslieferung).

A.1207.3: Grayson, RIMA 1, A.0.78.6.

3 Steintafeln, Palastbau; Exemplar 1,2 Z. 41f:

Assur (Herrschaftsverlust, Zerstörung von Name und Samen).

A.1207.4: Grayson, RIMA 1, A.0.78.7.

2 Tonkegel; Z. 8f: ähnlicher Fluch wie A.1207.3.

A.1207.5: Grayson, RIMA 1, A.0.78.19.

4 Tonkegel; Z. 10: gleicher Fluch wie A.1207.3.

A.1207.6: Grayson, RIMA 1, A.0.78.10.

Steinplatte aus Assur; Z. 66f:

Assur (Vernichten der Herrschaft, Zerstörung von Name und Samen).

A.1207.7: Grayson, RIMA 1, A.0.78.11.

10 Exemplare einer Bauinschrift aus Assur; Z. 77-81:

Ištar (Entwaffnung, Auslieferung).

A.1207.8: Grayson, RIMA 1, A.0.78.13.

Steintafel aus Assur; Z. 59-65:

Ištar (Vernichtung der Herrschaft, Entwaffnung, Geschlechtsumwandlung, Auslieferung).

A.1207.9: Grayson, RIMA 1, A.0.78.14.

6 Exemplare einer Bauinschrift; Z. 39-43:

Dinitu (Entwaffnung, Auslieferung).

A.1207.10: Grayson, RIMA 1, A.0.78.16 (BM 114263).

Steintafel; Z. 71-79: 
Dinitu (Vernichtung der Herrschaft, Entwaffnung, Geschlechtsumwandlung, Auslieferung).

A.1207.11: Grayson, RIMA 1, A.0.78.18.

Steintafel aus Assur, Z. 41-43:

Sin, Šamaš (Herrschaftsverlust, Zerstörung von Name und Same).

A.1207.12: Grayson, RIMA 1, A.0.78.22 (BM 98494).

Bauinschrift aus Kar-Tukulti-Ninurta; Z. 62-67:

Assur (Herrschaftsverlust, Entwaffnung, Niederlage, Gebietsverkleinerung, Ende der Herrschaft, dunkle Tage, Beeinträchtigung der Jahre, Zerstörung von Name und Samen).

A.1207.13: Grayson, RIMA 1, A.0.78.23.

Bauinschrift aus Kar-Tukulti-Ninurta; Z. 135-146:

Assur, Enlil und Šamaš (Unglück, Entwaffnung, Gefangenschaft, Deportation, Herrschaftsverlust, Vernichtung von Name und Samen).

A.1207.14: Grayson, RIMA 1, A.0.78.28 (K 2673).

Kopie einer Siegelinschrift aus kassitischer Beute; Z. 3+11:

Assur, Adad (Zerstörung des Namens) zweimal dieselbe Formel.

A.1203.1: Grayson, RIMA 1, A.0.79.1 (YBC 2246).

Tontafel aus Assur; Z. 38-40:

Assur (Herrschaftsverlust, Zerstörung von Name und Samen).

A.1116.1: Grayson, RIMA 1, A.0.86.1.

29 Tonzylinder aus Ninive, Z. 13:

Ištar (Verlust von Herrschaft und Regierung, baldiger Tod).

A.1116.2: Grayson, RIMA 1, A.0.86.4.

2 Tonzylinderfragmente aus Ninive; Z. 10 :

die großen Götter (böser Blick, Fluch, Zerstörung von Name und Samen).

A.1077.1: Grayson, RIMA 2, A.0.87.1.

42 Exemplare, Annalentext; Kol. VIII Z. 74-88:

Anu, Adad (böser Blick, Fluch, Herrschaftsverlust, Ausreißen der Thronfundamente, Aussterben der Linie, Entwaffnung, Niederlage, Gefangenschaft); Adad (Blitzschlag, Elend, Hunger, Not, mütänu, baldiger Tod, Vernichtung von Name und Samen).

A.1057.1: Grayson, RIMA 2, A.0.89.3.

Bauinschrift, Z. 14:

Assur ... (... Thronverlust) ... . 
A.1057.2: Grayson, RIMA 2, A.0.89.10 (BM 124693).

Torso einer Frauenstatue, Ninive; Z. $6 f$ :

Sebetti (Schlangenbiß).

A.912.1: Grayson, RIMA 2, A.0.98.1.

Annalentext aus Assur; Rs. Z. 39ff:

Assur (... Augen, Not, Mangel, Hunger).

A.891.1: Grayson, RIMA 2, A.0.99.2.

Annalentext; Z. 133:

Assur, Gula (Herrschaftsverlust, Zerstörung von Name und Samen).

A.884.1: Grayson, RIMA 2, A.0.100.3.

Bauinschrift; Z. 16f:

Assur, Adad (Zerstörung von Name und Samen).

A.884.2: Grayson, RIMA 2, A.0.100.5.

Bauinschrift, 2 Exemplare; Z. 146: gleicher Fluch wie A.844.1.

A.859.1: Grayson, RIMA 2, A.0.101.17 (BM 118805).

Nimrud Monolith; Kol. V. Z. 89-95, 96-103:

Assur (Fluch, Erfolglosigkeit, Vernichtung der Herrschaft, Ausrottung des Volkes, Not, Hunger, Elend); Anu, Enlil und Ea (Unglück, Krieg).

A.859.2: Grayson, RIMA 2, A.0.101.26.

Königsinschrift, 16 Exemplare, 4 davon lassen den Fluch aus; Z. 70-72:

Assur, Ninurta (böser Blick, Herrschaftsverlust, Thronverlust, Gefangenschaft, Zerstörung von Name und Samen).

A.859.3: Grayson, RIMA 2, A.0.101.29.

Bauinschrift, Kalah; Z. 25:

Ištar (?).

A.859.4: Grayson, RIMA 2, A.0.101.32 (BM 118895).

Löwe vom Šarrat-niphi-Tempel; Rs. Z. 19-21:

Ninurta, Ištar (Herrschaftsverlust, Thronverlust, Gefangenschaft, Elend, Not, Hunger, Zerstörung von Name und Samen).

A.859.5: Grayson, RIMA 2, A.0.101.36.

Bauinschrift aus Kalaḩ; Z. 6-8:

Ninurta, Assur (Herrschaftsverlust, Thronverlust, Gefangenschaft, Elend, Not, Hunger, Zerstörung von Name und Samen).

A.859.6: Grayson, RIMA 2, A.0.101.38 (BM 92986).

Bauinschrift aus Kalah; Z. 44-49:

Assur, Adad, Erra (Herrschaftsverlust, Thronverlust, Gefangenschaft, Elend, Not, Hunger, Zerstörung von Name und Samen). 
A.859.7: Grayson, RIMA 2, A.0.101.40.

'Standard Inscription' aus Kalaḩ; 31 Exemplare; Z. 42-44:

Adad (Blitz, Elend, Not, Hunger).

A.859.8: Grayson, RIMA 2, A.0.101.50.

4 Tafeln aus Imgur-Enlil/Balawat, 1 Exemplar läßt den Fluch aus; Z. 42f:

Ištar (Entwaffnung, Thronverlust).

A.859.9: Grayson, RIMA 2, A.0.101.56.

viele Tonzylinder aus Ninive; $Z$. 19:

Ištar (Entwaffnung, Thronverlust, Gefangenschaft).

A.859.10: Grayson, RIMA 2, A.0.101.70.

Silber- und Goldtafel aus Apqu; Z. 16-18:

Assur (Entwaffnung, Thronverlust, Zerstörung von Name und Samen).

A.824.1: Fadhil, BM 21, 461ff (IM 125000).

Grabinschrift ${ }^{1}$ der Jabâ; Rs. Z. 15-22:

einfache Verfluchung (oben: durstiger und ruheloser Totengeist, unten: keine Totenpflege); Ningišzida und Bițūti-dugul (Leichnam besessen von ziqūtu-Geistern).

A.824.2: Fadhil, $B M 21,471 \mathrm{ff}$.

Grabinschrift der Mulissu-mukannišat-Ninua:

A) Grabdeckelinschrift: einfache Verfluchung (keine Totenpflege). B) Steintafelinschrift: einfache Verfluchung (keine Totenpflege; keine Wasserspende).

A.783.1: Postgate, $N R G D, 115-117$ + Reade / Walker, AfO 28,117f. Stele; Rs. Z. 17f, 28-34 (AfO 28: Rs. Z. 31-34):

Marduk (böser Blick, schlimmes Schicksal ...); ... Assur, Šamaš, Nabu, Marduk, Enlil, Ninurta, Nergal, Ištar, die großen Götter (böser Blick, Vernichtung des Samens, saharšubbû).

A.783.2: Unger, PKOM 2; Pomponio, Formule, $42 \mathrm{f}$.

Saba'a Stele; Z. 26-33):

Assur und die Götter (Fluch, Vernichtung von Same und Name); Marduk (Herrschaftsverlust); Šamaš (Finsternis); Adad (Entwurzelung, Heuschrecken).

A.783.3: Donbaz, ARRIM 8, 7 (Env. Nr. 11832).

Antakya Stele; Z. 17-19:

Assur, Adad, Ber, Sin, die großen Götter Assyriens (keine Gebetserhörung).

A.783.4: Donbaz, ARRIM 8, 9.

Pazarcik Stele; Vs. Z. 21f:

Assur, Marduk, Adad, Sin, Šamaš (Rechtlosigkeit).

${ }^{1}$ Zur Datierung beider Grabinschriften vgl. FADHL, „Grabinschrift,“ 479. Zu Flüchen auf Grabinschriften vgl. SOMMERFELD, „Flüche,“ 451. 
A.773.1: Donbaz, ARRIM 8, 9f.

Pazarcik Stele; Rs. Z. 15-19:

Assur, Marduk, Adad, Sin, Šamǎ̌ (Rechtlosigkeit, keine Gebetserhörung, Zerschmetterung des Landes wie ein Ziegelstein, kein Ratgeber).

A.745.1: Parpola / Watanabe, SAA 2 (Nr. 2), 8-13.

Vertrag des Assurnirari V. mit Mati'ilu, König von Arpad; Vs. Kol. I Z. 11 - 35, Rs. Kol. IV Z. 4-28, Kol. V. Z. 5-7, 9-15, 17-23, 25 - Kol. VI 5:

Siehe unten 172-173.

A.705.1: Fuchs, Inschriften, 29-44, 289-296.

Inschrift auf den Tonzylindern; Z. 77:

Assur, Šamaš, Adad, Götter (Ausrottung von Name und Samen, Gefangenschaft).

A.705.2: Fuchs, Inschriften, 45-48, 296-298 (AO 21370).

Inschrift auf der Bronzetafel; Z. 59-60:

Assur, Ningal, Adad, die großen Götter (Ausrottung von Name und Samen; Gefangenschaft).

A.705.3: Fuchs, Inschriften, 48-50, 298f (AO 21370).

Inschrift auf der Silbertafel; Z. 50f:

Assur (Vernichtung von Name und Samen).

A.705.4: Fuchs, Inschriften, 51f, 299f (AO 19933).

Inschrift auf der Goldtafel; Z. 39f: gleicher Fluch wie A.705.3.

A.705.5: Fuchs, Inschriften, 60-74, 303-307.

Inschrift auf den Stierkolossen; 28 Exemplare und Fragmente; Z. 104-106: Sin, Šamaš, Adad, Götter (Ausrottung von Name und Samen, Gefangenschaft).

A.705.6: Fuchs, Inschriften, 75-81, 307-312.

Die „Kleine Prunkinschrift“ des Saales XIV; Z. 86f:

Assur (Herrschaftsverlust, Vernichtung von Namen, Samen, kein Erbarmen).

A.705.7: Fuchs, Inschriften, 82-188, 313-342.

Annalen; Z. 467: gleicher Fluch wie A.705.6.

A.705.8: Messerschmidt / Ungnad, VS I 71; Winkler, Keilschrifttexte, 184f (VA 968). Stele; Z. 64-74:

große genannte Götter (Fluch, Vernichtung von Name und Samen, Erbarmungslosigkeit, Not, Hunger, Krankheit, Gefangenschaft, Herrschaftsverlust).

A.681.1: Luckenbill, Sennacherib, 84f.

Bavian Inschriften; Z. 57-60:

große genannte Götter (Fluch, Herrschaftsverlust). 
A.681.2: Luckenbill, Sennacherib, 66.

Felsinschrift auf dem Judi Dagh:

Assur und die großen Götter (böser Blick, Zerstörung).

A.681.3: Luckenbill, Sennacherib, 139 (VA 8248).

Königsinschrift:

Assur und die großen Götter (Fluch, Herrschaftsverlust, Tod, Vernichtung von Name, Samen, Nachkomme und Sproß).

A.681.4: Luckenbill, Sennacherib, 147 (VA 8254).

Gleicher Fluch wie A.681.3.

A.681.5: Luckenbill, Sennacherib, 148 (VA 1635).

Gleicher Fluch wie A.681.3.

A.681.6: Parpola / Watanabe, SAA 2 (Nr. 3), 18 (VAT 11449).

Thronfolge-adê für Asarhaddon; Vs. Z. 7-12, Rs. Z. 2-8:

Assur, Mullissu, Šerua, Sin, Nikkal, Šamaš, Nur, Anu, Antu, Enlil, Adad, Šala, Kippat-mati, Ištar des Himmels, Ištar von Ninive, Ištar von Arbela, die assyrische Ištar, Zababa, Babu, Ninurta, Nusku, ... die Götter des Akitutempels (Fluch ...); ... Assur, Mullissu, Šerua, Sin, Nikkal, Šamaš, Nur, Anu, Antu, Enlil, Adad, Šala, Kippat-mati, Ištar des Himmels, Ištar von Ninive, Ištar von Arbela, die assyrische Ištar, Zababa, Babu, Ea, Belet-ili, Kakka, Nergal, die Götter des Akitutempels (Fluch ....) ... .

A.681.7-37: Galter, ARRIM 5, $11 \mathrm{ff}$.

31 Zylinder aus Halbedelstein:

Assur und/oder Sin, Šamaš, Adad, Ninlil, Innin, Nabu, Uraš (Vernichtung von Name und Samen).

A.669.1: Parpola / Watanabe, SAA 2 (Nr. 4), $22 \mathrm{f}$.

Thronbesteigungs-adê Asarhaddons; Rs. Z. 16-28:

Assur (Strafe, keine Audienz bei Gott und König); Mullissu (Diffamierung?); Ištar (Entwaffnung, Kriegsgefangenschaft), Šamaš (falsche Gewichte); Nikkal (Diffamierung); Nergal (Pest) ... .

A.669.2: Parpola / Watanabe, SAA 2 (Nr. 5), 24-27.

Vertrag mit Baal, König von Tyrus; Rs. Kol. IV 1-19:

Mullissu (flammendes Schwert); Ištar (Erbarmungslosigkeit); Gula (Krankheit, Wunde); Sebetti (Niederwerfung); Bet-ili und Anat-bet-ili (Löwe); die großen Götter (Fluch); Baal Šameme, Baal Malage und Baal Șaphon (Schiffskatastrophen, Sturmflut); Milqart und Ěsmun (Zerstörung des Landes, Deportation, Entwurzelung, Nahrung-Kleidung-Salbe); Astarte (Entwaffnung, Plünderung).

A.669.3: Borger, Inschriften, 6.

Königsinschrift Ass. A VIIIa: 
Assur (böser Blick, Herrschaftsverlust, Zerstörung von Name und Nachkommenschaft, Erbarmungslosigkeit).

A.669.4: Borger, Inschriften, 28f, 92.

Königsinschrift A (Haupttext), C+AC, Fassung a':

Enlil der Götter (böser Blick, Untergang, Diffamierung, Tod).

A.669.5: Borger, Inschriften, 29.

Königsinschrift Fassung b, E:

Marduk (böser Blick, Vernichtung von Name und Samen, kein Erbarmen).

A.669.6: Borger, Inschriften, 99.

Sendscheli Stele; Rs. Z. 53-56):

Ištar (Fluch).

A.669.7: Parpola / Watanabe, SAA 2 (Nr. 14) 77-79.

Adê-Inschrift; Kol. II Z. 10-26:

die großen Götter (übles Schicksal, Fluch, Härte); Assur, Anu und Antu (Auslieferung an den König, Selbstmord); Šerua (Lebensverkürzung); Anu und Antu (Strafe); Enlil und Mulliltu (Unglück); Marduk und Zarpanitu (?). ${ }^{1}$

Die Vergleichstexte zeigen, daß die meisten mesopotamischen Flüche, vor allem die in Königsinschriften, kurz und wenig abwechslungsreich sind. Es wird deutlich, daß der Umfang des Fluchabschnitts der VTE jeden anderen altorientalischen Fluchtext quantitativ übertrifft. ${ }^{2}$ Selbst wenn man den meist fragmentarischen Erhaltungszustand der anderen neuassyrischen Fluchtexte einkalkuliert, zeigt die Beschreibung der Tafeln bei Parpola und Watanabe, daß auf den anderen neuassyrischen Inschriften von Anfang an weniger Flüche standen. Dies gilt vor allem für die Thronfolge- bzw. Thronbesteigungs-adê von Sanherib, Asarhaddon und Zakutu. Die folgende Tabelle stellt Parpolas Schätzung der ursprünglichen Tafelgrößen neben sich daraus ergebende Umfangberechnungen für die Fluchsektionen:

\footnotetext{
${ }^{1}$ Einige Kudurrus können nicht datiert werden. Die Flüche von MDP 2, 113ff, MDP 6, 46, MDP 6, 47 sind nur fragmentarisch erhalten und bieten nichts Neues. Vgl. UNTERLECHNER, Fluchformeln, 36f. Nur IM 5527: Sommerfeld, UF 16, 299ff, besitzt einen umfangreicheren Fluchabschnitt: ? (Vernichtung der Vegetation); Nabu (Abscheu); Ninurta (Kinderlosigkeit, Mittellosigkeit); Zababa und Ištar (Niederlage); Nergal (Vernichtung der Nachkommen); Sin (Vernichtung der Nachkommen); Šamaš und Adad (?); ? (Tod); Išum (Vertreibung); Illat (unglückliche Reise); Igigu (astrologisches Unheil); Anunnaku (Ortlosigkeit); Šuqamuna und Šumalija (Böses, königliche Ungnade).

2 Vgl. SOMMERFELD, „Flüche,“ 450: „,... die längste Fluchformel in der keilschriftlichen Literatur überhaupt ... ." TADMOR, „Treaty,“ 148: „Outstanding as literary and legal masterpieces, these adê documents of Esarhaddon, with their lengthy exorbitant maledictions, should not be considered typical examples of the Assyrian vassal treaty. On the contrary,
} 


\begin{tabular}{lccccc} 
Text & Tafelgröße & $\begin{array}{c}\text { Kolumnen } \\
(\text { Vs.+Rs. })\end{array}$ & Fluchzeilen & $\begin{array}{c}\text { Wörter pro } \\
\text { Zeile }\end{array}$ & $\begin{array}{l}\text { Wortzahl } \\
\text { der Flüche }\end{array}$ \\
\hline KH & - & 51 & 256 & 1,65 & ca. 422 \\
A.745.1 & $22 \times 15 \mathrm{~cm}$ & 6 & $203^{1}$ & 6,24 & ca. 1266 \\
A.669.2 & $26 / 9 \times 19,4 \mathrm{~cm}$ & 4 & $72^{2}$ & 6,15 & ca. 461 \\
A.669.1 & $22 \times 13 \mathrm{~cm}$ & 2 & $30^{3}$ & 6,4 & ca. 192 \\
A.681.6 & - & 2 & $(13)^{4}$ & 7,1 & ca. 92 \\
Zakutu- & $10,2 \times 6,3 \mathrm{~cm}$ & 2 & 6 & 3 & ca. 18 \\
ade & & 8 & 246 & 6,1 & ca. 1500 \\
VTE & $45-30 \mathrm{~cm}$ & 8 & &
\end{tabular}

Wenn die Schätzungen Parpolas stimmen, nähert sich dem Umfang der VTE höchstens der Vertrag A.745.1.5 Doch selbst hier ließe sich in der Differenz der Wortanzahl fast der ganze Fluch des KH unterbringen. Da der Vertrag A.669.2 deutlich kürzer ist, kann man nicht vermuten, die Fluchsequenzen von A.745.1 und der VTE hätten zum assyrischen Standard gehört. Im Gegenteil, gerade die gattungsmäßig den VTE näher stehenden Thronfolge- und Thronbesteigungsvereidigungen zeichnen sich durch erheblich kürzere Fluchsektionen aus. Zakutu kommt in der fast

they were born of necessity, resulting from an extraordinary situation - an exception rather than the rule."

1 ,The beginning of col. I, now lost, contained the treaty preamble and divine witnesses; the rest of the column is devoted to ceremonies accompanying the conclusion of the treaty. (...) Col. IV 4 through VI 5, in all 161 lines ... contained the curse section, of which $38 \%$ (62 lines) is extant." PARPOLA / WATANABE, Treaties, XLVI. Ca. 42 Zeilen Zeremonialflüche + 161 Zeilen $=203$ Zeilen.

${ }^{2}$ Höchstwert, wenn die ganze Kol. IV mit Flüchen beschrieben gewesen wäre. Erhalten sind 20 Fluchzeilen auf der unteren Hälfte der Kol. IV. Die untere Hälfte von Kol. III existiert ebenfalls und enthält noch keine Flüche. Vgl. Parpola / WATANABE, Treaties, XLIV.

${ }^{3}$ PARPOLA schätzt pro Kol. 51 Zeilen. Das mittlere Stück ist erhalten mit 28 Zeilen. Es können höchstens 20 Zeilen folgen, von denen etwa 3 Zeilen für das Kolophon abgerechnet werden müssen. Vgl. Parpola / Watanabe, Treaties, XLVII.

${ }^{4}$ Absicht und Größe des Textes sind ungeklärt. PARPOLA hält den Text für die Thronfolgeregelung Sanheribs zugunsten Asarhaddons. Da fast dieselbe Fluchformel zweimal vorkommt, wäre es möglich, daß die Tafel Exzerpte aus zwei adê enthält. Vgl. PARPOLA / WATANABE, Treaties, XLVIf.

5 Auch der Vertrag Asarhaddons mit dem Araberstamm Qedar war nicht lang. PARPOLA schätzt die ursprüngliche Größe der einkolumnig beschriebenen Tafel auf $12,6 \times 5,9 \mathrm{~cm}$ mit insgesamt etwa 62 Zeilen Text, von denen 27 Zeilen $(=43 \%)$ erhalten sind. Vgl. PARPOLA / WATANABE, Treaties, XLIX. Die beiden von Asarhaddon erhaltenen Verträge mit ausländischen Mächten lassen vermuten, daß auch ein Vertrag Assyriens mit Juda, sollte er wirklich existiert haben, nicht sehr lang war. Dann wäre zu bezweifeln, daß in seiner Fluchsektion tatsächlich Platz war für alle parallelen Motive, die zwischen Dtn 28 und den VTE ausgemacht werden können. Auf die quantitative Auswertung der Sefire-Verträge wurde verzichtet, weil nicht klar ist, um wieviele Dokumente es sich eigentlich handelt, und weil die aramäische Wortanzahl mit der akkadischen kaum aussagekräftig verglichen werden kann. 
vollständig erhaltenen Vereidigung zugunsten ihres Enkels Assurbanipal mit einer einzigen Fluchformel aus, die mehrere Götter gemeinsam anruft. Dieser Formel gleicht der Fluch in A.681.6 zur Regelung der Thronfolge für Asarhaddon. Derartig kurze Formeln scheinen in solchen Vereidigungen die Regel gewesen zu sein. Die VTE stellen also bereits aufgrund der Länge ihrer Fluchsequenz innerhalb der mesopotamischen Tradition etwas Einzigartiges dar.

\title{
3. 5. VTE § 38A-43 Himmel und Himmelskörper
}

\section{5. 1. VTE $§ 38 A$, der Anufluch}

418a Anum šar ilān̄i

murṣu tānēhnu di'u diliptu

418b nissatu lā tūu šìri

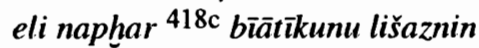

\author{
"18a Anum, der König der Götter, \\ möge Krankheit, Mühsal, \\ Kopfkrankheit, Schlaflosigkeit, \\ 418bJammern, Unwohlsein des Körpers \\ auf alle ${ }^{418 c}$ eure Häuser regnen lassen." ${ }^{1}$
}

\subsubsection{Textvarianten}

Der Anufluch (Z. 418a-c) fehlt in ND 4327. Die Möglichkeit, ihn auszulassen, zeigt, daß keine Tradition sein Auftauchen an dieser Stelle zwingend vorschrieb. Er besitzt in den Texten, in denen er steht, eine einleitende Funktion für die folgenden Flüche der Astralgottheiten.

Z. $418 \mathrm{~b} l \bar{a} t \bar{u} \bar{b}$ širi $i$ so ND $4335+4408 \mathrm{~S}$, der einzige weitere Textzeuge dieser Zeile, ND 4329, hat DÜG.GA NUMUN = țüb zēri „Gutes des Samens" ${ }^{*}{ }^{2}$ Dieser Ausdruck ist im Akkadischen ungewöhnlich. ${ }^{3}$

\subsection{2. Sprachlich-syntaktische Analyse}

Der $\S 38$ A besteht aus einem Satz. Dem Gottesnamen als Subjekt folgt das Epitheton MAN DINGIR.MEŠ (šar ilāni). Daran schließt als Akkusativobjekt eine Aufzählung von fünf Substantiven und einem negierten Ausdruck an. Den Schluß bilden eine Ortsangabe mit enklitischem Personalpronomen der 2. Person Pl. und das Prädikat zanānu/Š im Prekativ.

Vom Wortschatz sind di'u und nissatu in assyrischen Verträgen nicht mehr belegt. Die Verbindung la $t \bar{u} u \bar{b}$ šĭri kommt zwar in den VTE sonst nicht vor, wird aber im akkadischen Schrifttum als feststehende Verbin-

\footnotetext{
${ }^{1}$ WatANABE, Thronfolgeregelung, 163, vgl. ebd. 111, 162.

2 Vgl. BORgER, „Nimrud,“ 187; PARPOLA / WatANABE, Treaties, 45 Anm. 418A-C, LIX; WATANABE, Thronfolgeregelung, 111.

3 Vgl. AHw, 1393 țūbu(m) 10); 1521 zēeru(m) II.
} 
dung bezeugt. ${ }^{1}$ Verneint steht DÙG.GA (tiabu, țābtu) noch in VTE Z. $621 .{ }^{2}$ UZU ( širu) ist im Wortschatz der VTE-Flüche fest verankert. ${ }^{3}$ GIG (murșu) steht in den VTE noch in einer zu den Stipulationen gehörenden Ermahnung (Z. 389) sowie im Gulafluch ( $\$ 52$ Z. 461) und im Fluch bei den großen Göttern des Himmels und der Erde ( $\$ 56$ Z. 490), tānēhhu kommt in den VTE nur noch im Gulafluch (Z. 461) und in $\S 56$ (Z. 487) vor, diliptu nur noch in $\S 56$ (Z. 487). Das Verb zanānu steht, allerdings im G-Stamm, noch im Vergleichsfluch $\S 64$ (Z. 530, 531), der die zu Dtn 28,23f parallelen Motive enthält.

Zusammen mit der Ortsangabe und dem Objekt stellt die Aussage des Prädikats eine Metapher dar. Krankheiten regnen nicht und Häuser werden nicht krank. Die Häuser vertreten die Vereidigten. Durch das enklitische Personalpronomen wird die Beziehung zwischen dem Bild und den angesprochenen Menschen sprachlich festgelegt.

Im Epitheton steht das Wortzeichen MAN. Das gleiche Epitheton MAN DINGIR.MEŠ begegnet auch VTE Z. 401, 407 innerhalb eines mit ša (Z. 397) beginnenden indirekten Fragesatzes jeweils mit der Schreibung daššur. Im eigentlichen Assurfluch (§37 Z. 414ff) steht jedoch AN.ŠUR (Aššur) LUGAL DINGIR.MEŠ. Die Schreibung MAN für šarru wird in den VTE stereotyp in der Formel MAN KUR aš+šur (ki) als Titel des Königs von Assyrien verwendet (Z. 44, 46 und öfter). Das Wortzeichen LUGAL dagegen bezeichnet in den Stipulationen ebenso stereotyp einen fremden König, zu dem die Vereidigten eventuell abfallen könnten (Z. 71, $72,129,196,301,509)$. Ohne diese Differenzierung überinterpretieren zu wollen ${ }^{4}$, scheint hier ein Unterschied in der Bezeichnung des eigenen assyrischen und des fremden bzw. irgendeines Königs (so im Sinfluch § 39 Z. 420 und im Vergleichsfluch $\S 87$ Z. 604) zu bestehen. ${ }^{5}$ Ansonsten

$1 \mathrm{Vgl}$. AHw, 1393.

2 , ${ }^{621}$ Sie mögen euch wie mit Feuer mit Bosheit und Übel umgeben." WATANABE, Thronfolgeregelung, 173. Subjekt sind alle „" ${ }^{618 a}$... Götter, deren Namen auf dieser Tafel der adêVereidigung genannt sind ... .” Der von WATANABE mit „Bosheit“ übersetzte Ausdruck lautet la DÜG.GA-tú.

${ }^{3}$ Z. 426 Ninurta, Z. 519 Palil und in Vergleichsflüchen Z. 450f, 571, 585, 591, 596, 622f.

${ }^{4}$ Z. 209 steht LUGAL für den assyrischen König und Z. 320 schreiben verschiedene Versionen LUGAL neben MAN.

5 Die unterschiedlichen Wortzeichen für „König“ könnten ein Hinweis darauf sein, daß die assyrischen Schreiber vor der mit Z. 414 beginnenden Fluchsequenz Assur als den eigenen Götterkönig (MAN) herausstellten, während sie im Fluch den vereidigten Nichtassyrern den Himmelsgott Anu als Götterkönig (MAN) zuordneten, der über ihre Treue wacht, während Assur (Z. 414ff) den Charakter irgendeines Königs (LUGAL) erhielt. 
begegnet das Wortzeichen noch im Epitheton dé.A MAN ZU.AB ( $60 \mathrm{Z}$. 521).

\subsection{3. Semantische Analyse}

Anu gilt als der personifizierte Himmel. Er wird häufig als König der Götter, des Himmels oder der Länder bezeichnet. Zusammen mit Enlil und Ea bildet er in Götteraufzählungen eine Trias, bei der er in Babylonien meistens die erste Stelle einnimmt. In Assyrien wurde er von Assur verdrängt, taucht aber auch dort bisweilen auf dem ersten Platz auf. Man verehrte ihn unter anderem im Rahmen einer nächtlichen Feier, in der man das Aufleuchten seines Gestirns erwartete. Er stellt also nicht nur den Himmel allgemein dar, sondern ihm wurde auch ein Himmelskörper zugeordnet. ${ }^{1}$

Von den nur im Anufluch vorkommenden Wörtern bezeichnet $d^{\prime}{ }^{\prime} u$, von Borger und Watanabe „Kopfkrankheit”, von Parpola „malaria“ übersetzt ${ }^{2}$, eine Krankheit, die häufig mit diliptu kombiniert wird. Sie wird in einem jungbabylonischen Text als Attribut Nergals genannt und in altbabylonischen Texten sowie in der Beschwörungssammlung Šurpu ausdrücklich mit dem Kopf in Beziehung gebracht. ${ }^{3}$ Auch vSoden schlägt als Übersetzung „Kopfkrankheit“ vor. ${ }^{4}$ Der Bezug zum Unterwelt- und Pestgott läßt weniger Geistesgestörtheit vermuten als vielmehr eine todbringende Erkrankung, die mit Kopfschmerzen verbunden war. Das zweite nur hier vorkommende Wort nissatu gibt Borger mit „Wehklage“, Parpola mit ,worries" wieder. ${ }^{5}$ Das Nomen wird von dem Verb nasāsu I ,jammem, wehklagen" abgeleitet, kommt ebenfalls in Šurpu vor und wird in Verbindung mit dem Herzen bezeugt. Es weist also wohl auf seelische Vorgänge hin. ${ }^{6}$

Die Verbindung murșu tānēh̆u taucht als neuassyrische Ausnahmeerscheinung im Gulafluch der VTE und des Vertrags zwischen Asarhaddon

\footnotetext{
1 Vgl. EBELING, „Anu,“'115-117.

2 Vgl. Borger, „Vasallenverträge,“ 170; PARPOla / W ATANABE, Treaties, 45.

3 Vgl. AHw, 170. „In der ... Götterliste CT 24,41,68ff werden mehrere Unterweltgottheiten niederen Ranges ... mit Nergal identifiziert, wobei der Begriff ,Nergal' durch verschiedene Zusätze erläutert wird. Es handelt sich ... um Krankheitsbezeichnungen: šibtu „Plage‘(?); $u z$-zu ,Zorn'; ri-ša-ti; di'u ,Kopfkrankheit'. Hier werden also vorwiegend Kopf(=Geistes?)Krankheiten genannt." vWEIHER, Nergal, 85f.

$4 \mathrm{Vgl}$. AHw, 174.

5 Vgl. Borger, „Vasallenverträge,“ 170; PARPOla / WATANABE, Treaties, 45.

$6 \mathrm{Vgl}$. AHw, 795.
} 
und Baal von Tyrus auf. ${ }^{\perp}$ murșu allein bezeichnet in den Stipulationen ( $Z$. 389) eine Krankheit, die die Vereidigten über sich selbst bringen, wenn sie den Eid nur mit den Lippen schwören und ihre Nachkommen nicht über die Eidesverpflichtungen belehren. Watanabe meint, daß die Vereidigten die Krankheit simulieren, um nicht zur Vereidigungszeremonie antreten zu müssen. ${ }^{2} \mathrm{Da}$ der VTE-Text während der Vereidigungszeremonie gesprochen wird, wo die Vereidigten bereits anwesend sind, wirkt dies aber sinnlos. Die Krankheit, die Auswirkung des Eidbruchs, scheint vielmehr mit der geheuchelten Annahme der Vereidigung parallelisiert worden zu sein. Denn ana libbi adê ... erēbu, wörtlich „zur Mitte der adê eintreten“ vSoden übersetzt ,,in das Eidesverhältnis eintreten“3 - meint weniger die Zeremonie als vielmehr die innere Haltung gegenüber dem Zustand des Verpflichtetseins, den die Vereidigung schafft. ${ }^{4}$ Den Eid zu brechen, bedeutet zugleich, den Fluch auf sich zu ziehen. Verursacher der Flüche sind letztlich die Vereidigten, die ihren Eid brechen. Stimmt diese Interpretation, steht murșu lä pațru hier als pars pro toto für die Flüche überhaupt. ${ }^{5}$ Vom Verb marāṣu „krank, beschwerlich sein, werden“6 abgeleitet, kann sich murșu auf die verschiedensten Körperteile und in Verbindung mit libbi auch auf das Gemüt beziehen. ${ }^{7}$ tānēhu „Seufzen, Mühsal, Leid’8 steht bereits im Enlil- und Sinfluch des Vertrags B.819.2 (Z. 22ff, 29ff) ${ }^{9}$ sowie

${ }^{1}$ VTE Z. 461 und Text A.669.2 Kol. IV Z. 3; vgl. WATANABE, Thronfolgeregelung, 37 Anm. Ib.

2 Vgl. Thronfolgeregelung, 189.

$3 \mathrm{AHw}, 14$.

${ }^{4}$ Für diese Interpretation spricht auch, daß das abgelehnte Verhalten der Vereidigten in $\mathrm{Z}$. 386 ein „Eid des Lippenbekenntnisses“ genannt wird, also etwas nur Vorgetäuschtes, zu dem man innerlich nicht steht (Z. 387f).

${ }^{5}$ Eine aufschlußreiche Stelle für das Verständnis der Fluchverursachung sind die Ermahnungen, die die Vereidigten ihren Nachkommen mit auf ihren Lebensweg geben sollen: „... Bewahrt diese adê-Vereidigung! ${ }^{292}$ Sündigt nicht gegen eure adê-Vereidigung! ${ }^{293}$ Vernichtet nicht (dadurch) euer Leben! ${ }^{294} \mathrm{Gebt}$ euer Land nicht der Zerschlagung, euer Volk ${ }^{295}$ nicht der Verschleppung preis!" WATANABE, Thronfolgeregelung, 157. Die Vertragsbrüchigen selbst sind die grammatischen Subjekte der Fluchwirkungen, die sie treffen.

${ }^{6} \mathrm{AHw}, 609 ;$ hebräische Belege für מרץ: 1 Kön 2,8; Mi 2,10; Ijob 6,25; 16,5/H.

$7 \mathrm{Vgl}$. AHw, 676.

${ }^{8} \mathrm{Vgl}$. AHw, 1319. Das hebräische Äquivalent der Wurzel lautet ח2x, Nomen:

922 ... Ellil bēlum mušìm šĭmāti ša qibīssu 23 lā uttakkaru palê tānēhi ūmī ișūti šanät hušahhi 24 ana š̃mti liššmšu Ellil, der die Geschicke festsetzt, dessen Wort nicht geändert werden kann, möge ihm eine Regierungszeit voller Seufzer, wenige Tage, Jahre der Hungersnot als sein Geschick festsetzen. Der Enlilfluch folgt sowohl im KH als auch im Vertrag B.819.2 direkt auf den Anufluch. Vgl. BORGER, „Marduk-zakir-šumi,“ 168. 
VTE $\S 56$ Z. 487 in dem Fluch der Götter und kann daher nicht der Fluchtradition einer bestimmten Gottheit zugeordnet werden.

Der Ausdruck $t \bar{u} b$ šìri bezeichnet körperliches Wohlbefinden oft in ausdrücklicher Parallele zu seelischem Wohlergehen oder Herzensfreude $t \bar{u} b$ libbi. Beide Begriffe stehen auch verneint häufig zusammen. ${ }^{1}$

zanānu/Š ,regnen lassen“" wird gemeinhin den Göttern Adad und Enlil zugeschrieben. Die Bildersprache kennt das Regnen des Bannes auf ein Feld, das Regnen von Feuer, Brandpfeilen, Kampf und Waffen sowie das Regnen des Leides (tanēhu). ${ }^{2}$

\subsubsection{Strukturanalyse}

Der Wunschsatz des Anufluchs besteht aus zwei Bildebenen. Die erste besagt: Der Himmel (Anu) läßt auf die Häuser regnen. Die zweite Bildebene umfaßt die Akkusativobjekte des Satzes und macht aus dem Motiv des Regens eine Metapher für das Senden von Krankheiten. Die Akkusativobjekte sind in drei Ausdruckspaaren angeordnet, die jeweils die körperliche Dimension der Krankheit mit der geistig-seelischen verbinden.

Struktur Thema

Z. 418a Epitheton

Subjekt

Z. 418ab

Objekt

Krankheit + Seufzen

Kopfkrankheit +

Schlaflosigkeit

Sorgen + körperliches

Unwohlsein

\begin{tabular}{|lll|}
\hline Lexemverbindungen & VTE Z. & Gottheit \\
\hline MAN DINGIR.MEŠ & 401 & Assur \\
& 407 & \\
\hline
\end{tabular}

\begin{tabular}{|lll|}
\hline murșu + tānēhu & 461 & Gula \\
\hline \hline murșu & 490 & Götter \\
tānēhu + diliptu & 487 & Götter \\
\hline
\end{tabular}

Z. 418c Prädikat

\section{5. 1.5. Formengeschichte des Anufluchs}

Aus den Vergleichstexten lassen sich folgende Anuflüche zusammenstellen:

B.1750.1: Kodex Hammurapi:

Kol. XLIX (Rs. XXVI) ${ }^{45}$ Anum rabûm ${ }^{46}$ abu ili ${ }^{47}$ nabû palêja ${ }^{48}$ melemmi šarrütim ${ }^{49}$ lìteršu ${ }^{50}$ hatṭtašu ${ }^{51}$ lišbir $^{52}$ šimātišu līrur

$1 \mathrm{Vgl}$. AHw, 1393, tūbu(m) negiert 10g.

2 Vgl. AHw, 1509; vgl. AHw 1319; CAD 21/Z, 42f zazānu verbunden mit Adad, Marduk, Enlil, Nin-Gubla, niemals aber mit Anu! 
,${ }^{45}$ Der große Anu, ${ }^{46}$ der Vater der Götter, ${ }^{47}$ der mich zur Regierung berufen hat, ${ }^{48}$ möge ihm den Glanz des Königtums ${ }^{49}$ wegnehmen, ${ }^{50}$ sein Szepter $51_{\text {zerbrechen, }}{ }^{52}$ seine Geschicke verfluchen."

B.1172.2: BBS (Nr. 4), 22:

Kol. III ${ }^{9}$ Anum abi ilāni nakriš lïruršu

Anum, der Vater der Götter, möge ihn in feindlicher Weise verfluchen.

B.1105.1: BER 4, 150:

Kol. IV ${ }^{3}$ Anu šarru abi ilāni aggiš līruršuma napšatuš liballi

Anu, der König, der Vater der Götter, möge ihn wütend verfluchen und sein Leben vernichten.

B.1083.2: BBS (Nr. 8), 47:

${ }^{30}$ Anu rabî bēlu rabî ḩarrāna ${ }^{31}$ parīka lišes șissu

„Der große Anu, der große Herr, möge ihn (den Verfluchten) einen Irrweg, eine Sackgasse einschlagen lassen."

B.819.2: SAA 2, (Nr. 1) 5:

${ }^{22}$ (Rs. ${ }^{3}$ ) Anum abi ilāni ḩațašu lišbir

Anum, der Vater der Götter, möge sein Zepter zerbrechen.

In den Flüchen des Vertrags B.819.2 werden Formulierungen des KH aufgegriffen. ${ }^{3}$ Es fehlen aber das erste und das letzte Motiv des Anufluchs des $\mathrm{KH}$, die Wegnahme des Glanzes des Königtums und die Verfluchung der Geschicke. Außerdem hat sich die Stellung des Anu im Gesamtgefüge des Fluchabschnitts verändert. Im KH stand er an erster Stelle, in B.819.2 kommen davor Marduk und Nabu. Die Übernahme eines Fluches aus einer älteren Vorlage bedeutet also nicht, daß man alles abschrieb. Die Version des Vertrages greift zwar wörtlich die Formulierungen des $\mathrm{KH}$ auf, läßt aber Passagen weg, und zwar nicht einfach am Anfang oder Schluß des Fluches, sondern verstreut im Epitheton (KH Kol. XLIX Z. 45) sowie vor (KH Kol. XLIX Z. 48f) und nach (KH Kol. XLIX Z. 52) dem übernommenen Abschnitt.

Häufig bilden Anu, Enlil und Ea eine Trias, denen gemeinsam ein Fluch zugesprochen wird, der meistens die allgemeine Formel enthält: arrat $l \bar{a}$ napšuri ... tirurüǔu ,sie mögen ihn mit unlösbarem Fluch verfluchen“, oder den bösen Blick androht:

\footnotetext{
${ }^{1}$ Borger, .Codex,“ 77; vgl. Lesestücke, 45.

2 UNTERLECHNER, Fluchformieln, 179.

3 26. Vgl. BORGER, „Marduk-zakir-šumi,“' 168f; BRINKMAN, „Covenants,“ 111.
} 
B.1172.1: BBS (Nr. 3), 17:

Kol. V ${ }^{48}$ Anu Enlil u Ea Kol. VI ${ }^{1}$ ilāni rabûti ina aggi ${ }^{2}$ libbišunu likkilmûšu ${ }^{48} \mathrm{Anu}$, Enlil und Ea Kol. VI ${ }^{1}$ die großen Götter, mögen ihn im Zorn ${ }^{2}$ ihrer Herzen böse anblicken.

Aber auch mit anderen Göttern geht Anu eine Verbindung ein, so daß bisweilen sehr lange Aufzählungen von Götternamen zu finden sind, bevor der eigentliche Fluchspruch kommt. Genannt sei hier nur noch ein Beleg für die Anrufung Anus zusammen mit seiner Gemahlin Antu, der vergöttlichten Erde in einer Inschrift Asarhaddons.

A.669.7: SAA 2, (Nr. 14) 78 enthält zwei Anuflüche:

Kol. II ${ }^{16}$ Ǎ̌šur a-gu-um? Anum Antum [ ... $]^{17}$ ana qātē šarrišu liṣbatū šaniššū [ ... ] ${ }^{18}$ pataršu likšussu

${ }^{16}$ Assur, Agum (?), Anum (und) Antum [ ... $]^{17}$ mögen (ihn) für die Hände seines Königs ergreifen (?), zweitens [ ... ] möge ${ }^{18}$ sein eigenes Schwert ihn umbringen.

Kol. II ${ }^{21}$ Anum u Antum annašu 22 lā ipațtar [ ... ]

${ }^{21}$ Anum und Antum mögen [seine] Sünde ${ }^{22}$ nicht lösen. ${ }^{1}$

Nur selten wurde Anu in Flüchen alleine angerufen. Die Motive des VTEFluchs sind in den übrigen erhaltenen Anuflüchen des Untersuchungszeitraumes nicht belegt. Weder Regen noch Krankheit scheinen in traditioneller Weise mit dem Himmelsgott verbunden gewesen zu sein. Die Lexembezüge zum Gulafluch und zum Fluch der großen Götter des Himmels und der Erde lassen vermuten, daß der Anufluch nicht aus der Tradition übernommen wurde, zumal die entsprechenden Worte auch im Gulafluch assyrisches Eigengut sind.

\section{5. 2. VTE § 39, der Sinfluch verglichen mit VTE § 52, dem Gulafluch}

419 Sîn

nannar šamê u erșeti

saharšubbî ${ }^{420}$ lihallipkunu

ina pān(ē) ilānī u šarri erābkunu aji iqbi

421 kī serrāme șabūi ina șêri rupdā
"419Sin,

die Leuchte des Himmels (und) der Erde

möge euch mit saharšubbû-Krankheit 420 bekleiden, eurer Erscheinen in der Gegenwart ... der Götter ... und des Königs verbieten! ${ }^{421}$ Lauft wie Wildesel (und) Gazelle in der Steppe umher!“"2

\footnotetext{
${ }^{1}$ Zusammenhängende Umschrift nach der Erstveröffentlichung GRAYSON, „Treaties,“ 136, anders PARPOLA / WATANABE, Treaties, 78.

2 WatanaBe. Thronfolgeregelung, 163. vgl. ebd. 111f, 162.
} 


\subsubsection{Textuarianten}

Der oben zitierte Text folgt ND 4356.

Z. 420 ilānī] ND 4335+4408 hat den Singular DINGIR = ili, des Gottes. eräbkunu] So auch ND 4329, ND 4335+4408 bietet die Form $e<r>\bar{e} b k u n u$. kì serrāme] ND 4327 und ND 4335+4408 schreiben kìma serrēme.

ina șéri] alle anderen Manuskripte, in denen der Sinfluch erhalten ist, schreiben nur EDIN = șerru. In den von Watanabe gesammelten Sinflüchen ist der Ausdruck ohne ina noch in den Kudurrus B.1172.3 (se-ra), B.819.1 (EDIN) und in dem Vertrag A.745.1 belegt. Mit ina kommt die Formulierung nur in ND 4356 vor. ${ }^{1}$

\subsection{2. Sprachlich-syntaktische Analyse}

Der Sinfluch besteht aus zwei Verbalsätzen. Im ersten Satz steht nach dem Subjekt und seinem Epitheton das Objekt und das Prädikat im Prekativ (Z. 420). In der zweiten Satzhälfte ist das Prädikat verneint und mit Vetitivpartikel versehen (Z. 420). Der zweite Satz (Z. 421) enthält als Prädikat einen Imperativ, der die Verfluchten direkt anspricht. Das Vokabular besteht zum Großteil aus traditionell zum Sinfluch gehörenden Worten ohne weitere Belege in den VTE. Dazu gehören saharšubbû, halāpu/D ,kleiden“, rapādu „laufen“, serrēme „Wildesel“, MAŠ.DA / șabitu „, Gazelle“. Hier interessieren jedoch die lexikalischen Bezüge zu anderen Passagen der VTE. Diese finden sich im Epitheton, denn nannāru „leuchten“ kommt auch im Fluch der Götter ( $\$ 56$ Z. 486) vor, wo eine nicht erhellbare ( $l \bar{a}$ namāri) Finsternis als Schicksal bestimmt wird. Vielfältige Verknüpfungen ergeben sich in Z. 420: ina IGI/pane findet sich in Verbindung mit DINGIR.MEŠ in der Götterliste Z. 41, den Stipulationen Z. 153, 296 sowie in dem Vergleichsfluch $\S 87$ Z. 604 verbunden mit LUGAL. Das Verb erēbu ,eintreten“ begegnet in den Stipulationen Z. 183, 392, in den Vergleichsflüchen $\S 71$ Z. 556, § 72 Z. 560, 562, § 94 Z. 622, 625. Im Neberu/Jupiterfluch $\S 43$ dient es Z. 431 (e-rab EN) zum Ausdruck einer dem Sinfluch ähnlichen Thematik. Es geht ebenfalls um den Ausschluß vom Kult, obgleich sich das Eintreten dort nicht auf den Verfluchten, sondern auf die Gottheit bezieht. ${ }^{2}$ Ganz ähnlich findet sich die Formel von Z. 420 bereits im Thronbesteigungs-adê A.669.1, dort allerdings im Assurfluch

1 Vgl. WatanaBe, Thronfolgeregelung, 111f; „Überlieferung,“ 101, 104.

2 „431 Jupiter, ... möge euch das Eintreten Bēls in den Esangila-Tempel ${ }^{432}$ nicht zeigen, ... .“ WATANABE, Thronfolgeregelung, 165. 
und verbunden mit heftiger „Strafe“, ${ }^{1}$ der Krankheitsmetapher aus dem Sinfluch des KH. Die Belege für EDIN / șeeru „Steppe“ werden im Ninurtafluch behandelt.

Nennenswerte lexikalische Bezüge zum restlichen VTE-Text finden sich also nur in Z. 420. Nun zeigt aber Watanabes Zusammenstellung der Sinflüche, daß dieser Satz im Sinfluch der VTE erstmalig belegt ist und nur noch in leicht abgewandelter Form in zwei jüngeren neuassyrischen Texten auftaucht. ${ }^{2}$ Dieser Befund bestätigt wohl die hier angewandte Methode, anhand der Wortverknüpfungen mit dem VTE-Korpus traditionelle Fluchformeln von Neuschöpfungen der VTE-Schreiber zu trennen. Vorgegebene Formulierungen wie sie in Z. 419+421 zu finden sind, wurden offenbar durch die assyrische Hofkanzlei ergänzt. Der Zusatz tritt zwischen die beiden alten Formeln. Dabei bedienten sich die Schreiber in Z. 420 eines Motivs, das man ähnlich bereits im Assurfluch des Thronbesteigungs-adê für Asarhaddon verwendet hatte. Der so erweiterte Sinfluch wurde auch in spätere Staatstexte übernommen.

\section{5. 2. 3. Semantische Fragen und Formenkritik}

Watanabe hat sämtliche Sinflüche mit dem saharšubbû-Motiv untersucht. Mit dieser Krankheit wird in der Tradition des Fluches konsequent das Thema Exkommunikation verknüpft. Der Kranke darf den Tempel nicht betreten. Er wird kultunfähig. Außerdem bekommt er keine Audienz beim König mehr, wird also vom Palast ausgeschlossen. Z. 421 legt das Los des Kranken fest, Wildtieren gleich lebt er außerhalb der menschlichen Gemeinschaft.

SAHAR.ŠUB.BA wird in lexikalischen Texten mit garābu und epqu gleichgesetzt, was man mit „Lepra“ oder „Aussatz“ wiedergibt. Es scheint sich um eine Hautkrankheit zu handeln, da sie den Kranken wie ein Kleid umhüllt. Doch dachte man aufgrund einer Gleichsetzung von garābu mit GIG.HAB / būšānu ,übler Geruch“ auch an Pellagra, eine Vitamin-BMangelkrankheit, die mit Hautveränderungen einhergeht. Mit Pellagra tritt

${ }^{1}$,[May Aššur, father of the gods, and king] of the totality of heaven and earth, [impose a heavy] punishment [upon him ... and forbid his ent]ering into the presence of god and king." SAA 2 (Nr. 4), 22 (ina mahar ili u šarri erēbšu aja iqbi).

2 ,Die neuassyrischen Texte 24, 25 und 27 fügen hinzu, dass die Verfluchten vom Tempel und Palast ausgeschlossen sein sollen. Text 24 hat die Kombination von Gott/Götter und König statt Tempel und Palast wie in den Texten 25 und 27. Trotz der babylonischen Vetitivform aj iqbi (statt der neuassyrischen lü lä iqabbi) in Text $24 \mathrm{e} . .$. kann dieser Zusatz als eine neuassyrische Erweiterung gelten.” WATANABE, „Überlieferung,“ 112 (Text $24=$ VTE); vgl. Thronfolgeregelung, $191 \mathrm{f}$. 
häufig Skorbut auf, der einen schlechten Atem verursacht. ${ }^{1}$ Wie der Aussatz der Bibel galt saḩaršubbû nicht als unheilbar. ${ }^{2}$

Der Sinfluch bietet ein Beispiel für feststehend tradierte Formeln. Die inhaltliche Konzeption des Fluches ist bereits im KH erkennbar, obgleich noch andere Formulierungen und Bilder verwendet wurden. Bis zum 14./13. Jh. wurde der Fluch formalisiert und über 700 Jahre in die neubabylonische und neuassyrische Zeit kaum verändert weitergegeben. In der chaldäischen Zeit (7. Jh.) hört die Tradition jedoch scheinbar auf. Aus dieser und späteren Epochen sind keine Sinflüche bekannt. In seiner Formelhaftigkeit und Fixierung auf den Mondgott entspricht der Sinfluch den Erwartungen an eine Tradition, die Motive und Gottheit so fest verbunden weitergab, daß diese Kombination im gesamten $\mathrm{AO}$ als gängiges Fluchthema bekannt gewesen sein dürfte. ${ }^{3}$ Doch selbst der Sinfluch war kein erratisches Traditionsgut. Watanabe listet zwei neuassyrische Texte auf, wo saharšubbû Ištar zugesprochen wird. Auch Einzelmotive, wie der Ausschluß aus der Tempelgemeinde, sind mit anderen Göttern bezeugt. ${ }^{4}$ Die Formulierung und Motive mußten demnach nicht unbedingt mit Sin verbunden werden. Darüber hinaus gibt es auch Sinflüche, die nicht von Krankheit und Exkommunikation sprechen. ${ }^{5}$ Wenn saharšubbû auch von Ištar bewirkt werden konnte, scheint kein innerer Bezug zwischen der Krankheit und dem Mond zu bestehen.

Krankheit und Gottheit bilden auch in der Tradition des Gulafluchs eine feststehende Kombination. Das Thema Krankheit, verbunden einerseits mit dem Mondgott und andererseits mit der Oberärztin, umschloß bereits im KH andere Flüche. ${ }^{6}$ In den VTE steht dem Sinfluch als $§ 39$ dem Gulafluch in $\S 52$ gegenüber.

461 Gula azugallatu rabītu murșu tānēhnu [ina libbikunu?]
" ${ }^{461}$ Gula, die große Oberärztin, möge [in euer Herz(?)] Krankheit und Mühsal,

\footnotetext{
1 Vgl. KINNIER WILSON, „Medicine,“ 355-357; W ATANABE, „Überlieferung,“ $110 \mathrm{f}$.

2 Vgl. WATANABE, „Überlieferung,“ 111; UNTERLECHNER, Fluchformeln, 211.

3 Vgl. WATANABE, „Überlieferung,“ 115.

${ }^{4} \mathrm{Vgl}$. „Überlieferung,“ 109, 112.
}

${ }^{5}$ Z.B.: „16) d ZUEN a-hu-um ra-bu-um 17) i-na i-li ah-ḩi-šu 18) er-re-ta-am ra-bi-ta-am 19) li-ru-ur-šu, ,Sin, der älteste Bruder unter seinen göttlichen Brüdern, möge ihn mit einem großen Fluch verfluchen-Syria 32, 17 v 16-19 (Jahdunlim, Mari, aB); 13) d30 EN AGA na$m e-r u-t i$ 14) bu-ni-šu lit-țè-š-ma lil-li-<da>a+a TUK, ,Sin, der Herr der leuchtenden Krone, möge sein Antlitz verfinstern, und er [= der Verfluchte] möge keinen Nachwuchs bekommen- Hinke-Kudurru iv 13f. ... ." WATANABE, „Überlieferung,“116f Anm. 7.

${ }^{6} \mathrm{Zu}$ Gulaflüchen mit anderen Themen vgl. WATANABE, Thronfolgeregelung, 35. 
462 simmu lazzu ina zumrīkunu liškun

[dāmu u šarku] ${ }^{463}$ kīma $m \hat{e} r u[m k \bar{a}]$
462 auf euren Körper eine anhaltende Wunde le[gen]!

${ }^{463}$ Badet [in Blut und Eiter] wie in Wasser!" 1

Der Gulafluch wurde von Watanabe in ihrer Bearbeitung der VTE untersucht. Das Subjekt des ersten Teils des Gulafluchs bildet die Göttin, das Subjekt des zweiten Teiles die Verfluchten. Ähnlich wie im Sinfluch findet man auch im Gulafluch der VTE eine Ergänzung, die nicht zur Tradition gehört und nur in Texten Asarhaddons belegt ist. Es handelt sich um murșu tānēhu ina libbīkunu. Diese Worte verbinden den Gulafluch in den VTE mit dem Anufluch ( $\S 38 \mathrm{~A}$ ) und dem Fluch der großen Götter ( $\$ 56$ ). Wieder stellt gerade die lexikalische Verknüpfung zu anderen Passagen der VTE einen Hinweis auf die schöpferische Tätigkeit der assyrischen Schreiber dar. Doch hier scheint die Einfügung nicht bei der Komposition der VTE geschehen zu sein. Dieselbe Erweiterung steht nämlich bereits im Vertrag des Asarhaddon mit Baal von Tyrus (A.669.2). ${ }^{2}$

Die typische Krankheit der Gula lautet simmu lazzu. In Kudurruflüchen wird davon gesprochen, daß die „Wunde“ sich ausbreitet. Gula und ihr Gatte Ninurta werden im Zusammenhang der Gesundung des ganzen Körpers vom Scheitel bis zu den Zehennägeln genannt. So steht im Kolophon eines Textes aus der Bibliothek Assurbanipals:

„4) Heilungsverfahren vom Scheitel bis zu den ...nägeln, nicht zur Serie gehörige Exzerpte, die kunstvolle Lehre, 5) die Großarztschaft des Ninurta und der Gula, soviel (davon) gebildet ist, 6) habe ich auf die Tafeln geschrieben, geprüft, kollationiert und, 7) um sie zu lesen und mir vorlesen zu lassen, im Innern meines Palastes aufgestellt."3

$\mathrm{Zu}$ der eiternden und blutenden Wunde im Gulafluch tritt als Eigengut der Asarhaddontexte mit den Wörtern tānēhu „Mühsal“ und libbu „Herz" eine seelische Komponente.

\footnotetext{
${ }^{1}$ WaTANABE, Thronfolgeregelung, 165, vgl. ebd. 116, 164.

2 Vgl. Watanabe, Thronfolgeregelung, 37; Parpola / Watanabe, Treaties, 27.

3 Hunger, Kolophone, 103 Nr. 329. Hunger übersetzt Fingernägel. Das CAD 16/Ṣ, 251 șupru A 2' Zehennägel: „bulti TA muhhi adi UMBIN liqti mašmăši remedies (to be used) from head to toe ... " Das Sumerogramm bedeutet nur Nägel, doch läßt die Erwähnung des Scheitels an Dtn 28,35 denken: Von der Sohle bis zum Scheitel bist du krank. Das hebräische Wort für (Finger-)nagel צברן kommt im AT nur Dtn 21,12 vor, in Jer 17,1 bedeutet es "Spitze".
} 
3. 5. 3. VTE § 40, der Šamašfluch

\section{$422 \check{S}$ amaš}

nūr šamāmī u kaqqari

dīn kitti mēšari ${ }^{423}$ aji idīnkunu

nțil ìnīkunu lēšīma

424 ina ekleti itallakā
"422 Šamaš

das Licht des Himmels und der Erde möge für euch keine wahrhaftige gerechte Rechtshandlung ${ }^{423}$ vollziehen die Sicht eurer Augen verwirren! ${ }^{424}$ Wandelt in Dunkelheit umher!"1

\subsubsection{Textvarianten}

Z. $422 u$ ] ND 4356 reiht šamāmī und kaqqari asyndetisch nebeneinander.

Z. 422] mēšari steht in ND 4327, der Vereidigung des Ramatja von Urakazabanu, nicht jedoch in ND 4335+4408, ND 4329 und ND 4356, bei denen keine Zuordnung zu einem der Vereidigten möglich ist.

Z. 423 lêšìma] Diese zusammenhängende Umschrift resultiert aus li-ši(ma) in ND 4329, ND 4335+4408 und ND 4356. ND 4327 hat jedoch lišši-ma, das in zusammenhängender Umschrift zu liššima wird. Parpola bevorzugt die Lesung liš-ši-ma $<l(u$-)i[n] und die Aufhebung des Sehvermögens bedeutet. ${ }^{2}$ li-ši-ma kann von demselben Verb stammen, da Konsonantenverdopplung nicht geschrieben werden muß. ${ }^{3}$ Watanabe nimmt jedoch die Einfachschreibung ernst und tran-

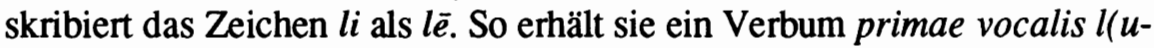
$\left.\left[i^{\prime}\right]\right) \bar{e} \breve{s} i=m a$. vSoden stellt $e s ̌ \hat{u} \mathrm{~V}$ zum arabischen agaršija ,verhüllen“ und ordnet dem Verb das Nomen ašû II zu, das eine Kopfkrankheit bezeichnet. ${ }^{4}$ Z. 424 ekleti] In ND 4356 steht dafür eklette.

\section{5. 3. 2. Sprachlich-syntaktische Analyse}

Der Fluch besteht aus zwei Sätzen. Das Subjekt des ersten Satzes bildet der Gottesname, ergänzt durch ein Epitheton. Ihm werden zwei Prädikate zugeordnet, von denen das erste durch die Vetitivpartikel verneint wird ${ }^{5}$, während das zweite im Prekativ steht. Die Prädikate beziehen sich jeweils auf ein Akkusativobjekt, das aus einer Constructus-Verbindung besteht.

\footnotetext{
1 WatANABE, Thronfolgeregelung, 163; vgl. ebd. 112, 162.

2 „May he remove your eyesight.“ PARPOLA / WATANABE, Treaties, 45; vgl. ebd. $98 \mathrm{zu}$ našâ.

$3 \mathrm{Vgl}$. GAG § 7d.

$4 \mathrm{Vgl}$. AHw, 85, 259, 383.

5 Je nach Transkriptionsweise wird sie $a-a$, ajja oder $a i$ wiedergegeben. Vgl. GAG $\$ 81 \mathrm{~h}-\mathrm{j}$
} 
Das erste Prädikat und das nomen regens der zweiten Constructus-Verbindung schaffen durch die ihnen angefügten enklitischen Personalpronomen einen Bezug zu den Textadressaten. Das Prädikat des zweiten Satzes ist ein Imperativ. Sein Subjekt sind die Textadressaten selbst. ${ }^{1}$

Zum eigentümlichen Wortschatz des Šamašfluchs gehören ConstructusVerbindungen, die sonst in den VTE nicht mehr belegt sind. nūru und šamāmu kommen in den erhaltenen neuassyrischen Verträgen nicht mehr vor. Allerdings taucht im Vertrag A.745.1 sowie im Thronfolge-adê A.681.6 die Gottheit A.A auf, für die Parpola die Lesung Nur vorschlägt. Dieser Gott erscheint als Gefolgsmann des Šamaš. In den Götterlisten, in denen Nur zusammen mit Šamaš in den assyrischen Verträgen aufgezählt wird, ist der Mondgott Sin jeweils durch Nikkal vom Sonnengott getrennt. ${ }^{2}$ Die syllabische Schreibung $\check{s} a-m a-m i$ weicht von dem sonst üblichen Begriff $\check{s} a m \hat{e} \mathrm{ab}$, der meist mit dem Wortzeichen AN geschrieben wird. ${ }^{3}$ kaqqaru dagegen begegnet häufig in den VTE. In den Stipulationen bezeichnet es den Ort der Vereidigung (Z. 385), im Kubabafluch fällt von Krankheit hervorgebrachte Flüssigkeit auf den Boden ( $\$ 55 \mathrm{Z} .471$ ), im Vergleichsfluch $\S 63 \mathrm{Z}$. 527f wird der Boden mit einem Ziegelstein und Bronze verglichen, im Vergleichsfluch $\S 67$ Z. 544 steht der Begriff in der Metapher Angesicht der Erde, in $\S 102$ Z. 653 bezeichnet das Wort einen Landstrich, wo man Durst bekommt, und Z. 657 für ein Gebiet, wo dornige Pflanzen wachsen. kaqqaru bezeichnet also im Gegensatz zu erșetu nicht die Erde schlechthin, sondern den Boden als konkreten Lebensraum, der je nach Beschaffenheit dem Leben des Menschen zuträglich sein kann oder nicht. Jedenfalls vermeidet das Epitheton die sonst geläufige Kombination šamê u erșeti. Der Ausdruck dīn kitti mēšari steht in den VTE nur hier, gehört aber zu den geprägten Wendungen altorientalischer Texte. Bisweilen steht wie in den meisten erhaltenen VTE-Manuskripten dieser Stelle nur eine der beiden Appositionen zu dīnu, kommen beide vor, werden sie häufig durch die Konjunktion u verbunden. ${ }^{4}$ ni-țil IGI.2.MEŠ-kunu kommt in den VTE so zwar nicht mehr vor, begegnet aber in der festen Wendung ina ni-til IGI.2-kunu im Delebatfluch ( $\$ 42$ Z. 428) und im Fluch bei den großen Göttern ( $\$ 56$ Z. 482). Die Verben nadānu, našû und alāku gehören schon bedeutungsbedingt zum vielfach belegten Vokabular der VTE. ${ }^{5}$

\footnotetext{
1 Vgl. WatanaBe, Thronfolgeregelung, 112.

2 Vgl. Parpola / Watanabe, Treaties, 111; zu Nur ebd. 13 Kol. VI Z. 9, 18 Z. 8', Rs. Z. 2'.

3 VTE Z. 21, 40, 42, 419, 440, 472, 523, 530

$4 \mathrm{Vgl}$. AHw, 659f.

5 Vgl. AHw, 171; AHw, 494f; AHw, 659.
} 
ekletu kommt im Rahmen der neuassyrischen Flüche nur noch im Fluch bei den großen Göttern vor ( $\$ 56$ Z. 485).

\section{5. 3. 3. Semantische Analyse}

Šamaš, der Sonnengott, wird in Mesopotamien zugleich als Gott der Gerechtigkeit und des Gerichts verehrt. Demgemäß bestimmen zwei Themen seinen Fluch: der Verlust der Gerechtigkeit und der Verlust des Sonnenlichts. Die Gerechtigkeit entzieht der Vetitiv. dīnu bedeutet „Rechtsspruch“. Der an sich ambivalente Urteilsspruch des Gerichtes wird durch die Nomina kittu „Stetigkeit, Wahrheit, Treue“ und mī̌aru / mēšaru „Gerechtigkeit“ positiv bestimmt. Alle drei Begriffe gehören zu den traditionellen Charakteristika des Šamaš. Das Thema „Licht“ kommt dreifach zur Sprache. Bereits das Epitheton drückt die Licht schaffende Funktion des Sonnengottes aus. Der Begriff nūru (ZALÁG, IZI.GAR) begegnet nicht selten in Epitheta ${ }^{1}$. Auch die beiden abschließenden Aussagen thematisieren das Licht und die Möglichkeit zu sehen. nitllu „Blick, Sicht“ bezeichnet meistens den Sehvorgang, es kann sich aber auch auf das Aussehen dessen beziehen, was man sieht. ${ }^{2}$ Verschiedenartige Interpretation der Schreibweisen in den Versionen der VTE entscheidet, ob die Verfluchten noch etwas sehen. Im Akkadischen führte ein Euphemismus zur Verdrängung des Wortes für „Blindheit“. Statt dessen negierte man das „Sehen“. 3 Die Aufhebung des Gesichtsinns mit der von našû abzuleitenden Lesung bedeutet also Erblindung. Setzt man jedoch das Verb ešu an, werden die Verfluchten nicht blind, sondern verwirrt. Eine derartige Verwirrung des Blickes kann durch Sonneneinwirkung hervorgerufen werden, z.B. als Fata Morgana oder Halluzination infolge eines Sonnenstichs.

Der Imperativ in Z. 424 zeigt das Interesse des Sprechers am Unheil. Es wird nicht als Folge göttlichen Wirkens beschrieben, sondern als Aktivität der Verfluchten ausgedrückt. Der Gtn-Stamm bezeichnet Dauer, das Umhergehen in Dunkelheit (ekletu) währt lange.

\subsubsection{Strukturanalyse}

Der Aufbau des Fluches ergibt mit seinen Themen und Verbindungen zu anderen VTE-Abschnitten folgendes Schema:

\footnotetext{
$1 \mathrm{Vgl}$. AHw, 805.

2 Vgl. AHw, 798.

${ }^{3}$ LANDSBERGER, „Wort,“ 320: „... ein eigentlich superstitiöser Euphemismus ist die Vermeidung des Wortes für blind, das zur völligen Ausdrängung dieser Wurzel aus dem Akk. geführt hat: sum. igi-nu-tuk = lä nätilu.“
} 
Struktur Thema

1. Satz

Z. 422

Z. $422 \mathrm{f}$ Gerechtigkeit

Z. 423 Sehmöglichkeit

2. Satz

Z. 424

Finstemis
Lexemverbindungen VTE Z. Gottheit

\begin{tabular}{|c|c|}
\hline Šamas & 545,649 Šamaš \\
\hline kaqqaru & $\begin{array}{l}385,471 \\
527 f, 544, \\
653,657\end{array}$ \\
\hline
\end{tabular}

\begin{tabular}{|lll}
\hline niṭil IGI.2-kunu 427,482 & $\begin{array}{l}\text { Delebat, } \\
\text { Götter }\end{array}$ \\
\hline
\end{tabular}

Die Entfaltung des Themas Licht und Sehvermögen nimmt gegenüber der Rechtssicherung eine dominierende Stellung ein. Nur durch Worte dieses Motivbereichs wird der Paragraph mit anderen Passagen der VTE verknüpft.

\section{5. 3. 5. Formengeschichte des Šamašfluchs}

Die VTE enthalten zwei weitere Šamašflüche. Der erste dieser Šamašflüche steht unvermittelt nach einer Reihe von Vergleichsflüchen in § 68:

545 Šamaš ina epinni ̌̌a parzilli âliku[nu] nagîkunu 546 lu[šab]alkit

"545 Šamaš möge mit einem eisernen Pflug eure Stadt und euren Bezirk ${ }^{546}$ umwenden!"1

Es folgen weitere Vergleichsflüche und Flüche mit Anrufung der Götter, die auf der Tafel der Vereidigung genannt sind, und schließlich in § 101 als sechsletzter Fluch überhaupt:

${ }^{649}$ Šamaš huhāru ša siparri ina muhhikunu (mar'ēku[nu]) ${ }^{650}$ ([mar]'ātēèunu)

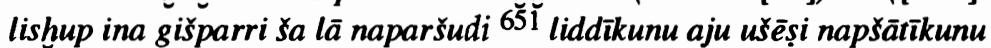

"649 Dito, möge Šamaš eine Vogelfalle aus Bronze auf euch, (eure Söhne) ${ }^{650}$ (eure Töchter) stürzen, euch in eine Falle, aus der es kein Entfliehen gibt,

${ }^{651}$ werfen! Er möge euch nicht mit dem Leben davonkommen lassen!“‘2

Während schon VTE § 40 im Epitheton Himmel und Erdboden erwähnte, symbolisieren die beiden anderen Samašflüche den Wirkbereich des Gottes durch Arbeitsgeräte, die Erde und Himmel menschlicher Nutzung dienstbar machen. Den Bereich der Erde behandelt das Bodenbearbeitungsgerät „Pflug“ (VTE § 68) und die himmlische Sphäre vertreten die „Vogelfallen“ (§ 101). Die Sorge des Šamaš für Himmel und Erde mag aus seinem

1 WaTANABE, Thronfolgeregelung, 169; vgl. ebd. 168.

2 WATANABE, Thronfolgeregelung, 175; vgl. ebd. 174. 
Sonnencharakter herrühren. Doch sind auch mythologische Wurzeln für diesen doppelten göttlichen Wirkungsbereich zu finden. Die „Falle“ (gišparru) des Šamaš spielt in der neuassyrischen Version des EtanaMythos in dem Fluch eine Rolle, der das Bündnis zwischen dem Adler und der Schlange bekräftigt:

${ }^{10}$ ina mahar Šamaš qurādi māmit itt[mū] ${ }^{11}$ ša itā ša Šamaš [ittiqu] ${ }^{12}$ Šamaš lemniš ina qāt māhiși [limallī̌su] ${ }^{13}$ sa itā ša Šamaš [ittiqu] ${ }^{14}$ lissûšuma nere[btašunu šadû] ${ }^{15}$ kakku murtappidu elišu $\left[\right.$ lī̌sir ${ }^{16}$ gišparrū māmit Šamaš libbalkitūšuma [libārūušu]

${ }^{10}$ Vor Šamaš, dem Held, schworen sie einen Eid: ${ }^{11}$,wer den Bund des Šamaš [übertritt], ${ }^{12}$ den fülle Šamaš zum Bösen in die Hand eines Schlagenden, ${ }^{13}$ wer den Bund des Šamaš übertritt, ${ }^{14}$ dem mögen die Berge ihre Pässe verwehren, ${ }^{15}$ eine unstete Waffe möge auf ihn [losgehen], ${ }^{16}$ die Fallen, der Eid des Šamaš, mögen bei ihm zuschnappen und [ihn fangen].“1

Die Falle wird mit dem Eid māmitu parallelisiert. Der Eid selbst wird zur Falle für den Übeltäter. Die beiden Tiere, die vor dem Sonnengott das Bündnis miteinander schließen, repräsentieren die Bereiche Himmel und Erde. ${ }^{2}$ Šamaš tritt im Mythos besonders als Garant des Rechtes hervor, da beide Tiere die Ungerechtigkeit des Vertragspartners vor ihm beklagen. Die fabelartigen Teile des Mythos bilden nur eine Nebenhandlung. Eigentlich geht es um Etanas Suche nach dem ewigen Leben. Diese Suche führt Etana auf dem Rücken des Adlers himmelwärts in die Nähe der Götter. Doch er stürzt wieder auf die Erde hinab. Thematisiert wird also die Stellung des Menschen zwischen Himmel und Erde. Šamaš umfängt beide Bereiche mit seinen Entscheiden für Mensch und Tier. ${ }^{3}$ Im Šamašhymnus (BWL, 126-138) ist von der kupfernen Vogelfalle šurāru (Z. 94) die Rede, in der Übeltäter gefangen werden. Der Text ist lückenhaft, doch darunter scheint sich auch jemand zu befinden, der Eide (Z. 85) nicht ernst nimmt. Der palindromisch aufgebaute Hymnus ahmt den Lauf der Sonne am Himmel nach und ordnet dem Sonnengott verschiedene Aktivitäten auf der Erde zu. ${ }^{4}$ Nach VTE $§ 101$ fängt der Sonnengott die Eidbrüchigen wie Vö-

${ }^{1}$ Vgl. GeVIrTZ, Motifs, 33f; CAD 10/M II, 228 murtappidu b); PrTTCHARD, Texts, 114; zur Verbindung von Himmel, Falle und Fluch ebd. 116 Text C-2 Z. 39, Text C-3 Z. 11.

2 Der Adler, der Herr der Lüfte, steht für den Himmel, und im Mythos trägt er Etana tatsächlich bis über den zweiten Himmel hinaus. Die Schlange dagegen ist mehr als die anderen Tiere mit dem Erdboden verbunden (vgl. auch Gen 3,14), und tatsächlich gelingt es ihr im Mythos, den Adler mit ausgerissenem Flügel in eine Grube zu werfen, also im tieferen Erdbereich festzuhalten.

3 Vgl. vSODEN, Einführung, 208f.

4 Vgl. CASTELlino, „Hymn,“ 72f; JANOWSKI, Rettungsgewißheit, 37f, 41; zur kupfernen Vogelfalle als Symbol des Šamaš vgl. CAD 6/H, 225 hurüäru (2). 
gel, während er nach § 68 ihre Städte und Siedlungsgebiete zerstört. Damit ist der Mensch ebenfalls zwischen Himmel und Erde dem Recht schaffenden Wirken des Šamaš ausgesetzt.

Für die Formengeschichte des Šamašfluchs können folgende Flüche herangezogen werden:

B.1750.1: Kodex Hammurapi:

L 14 Šamaš dajjānum rābium 15 ša šame ${ }^{16} u$ erșetim ${ }^{17}$ mušt tēer šer 18 šaknat napištim ${ }^{19}$ bēlum tukultī 20 šarrussu liskip ${ }^{21}$ dīnšu ${ }^{22}$ aji idīn ${ }^{23}$ uruhšu lišši

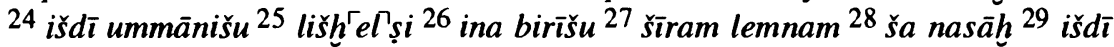
šarrūtī̌š ${ }^{30}$ u halāq mātī̌su liškunšum ${ }^{31}$ awātum maruštum ${ }^{32}$ ša Šamaš arhiš 33 likšussu ${ }^{34}$ eliš 35 ina ba[l]!̣̆tim 36 lissuhšu 37 šapliš 38 ina erșetim 39 etemmī̌su ${ }^{40}$ mê lišașmi

. ${ }^{14}$ Der Sonnengott, der große Richter ${ }^{15}$ des Himmels 16 und der Erde, ${ }^{18}$ der die Lebewesen ${ }^{17}$ recht leitet, ${ }^{19}$ der Herr, meine Zuversicht, ${ }^{20}$ möge sein Königtum stürzen, ${ }^{22} \mathrm{ihm}$ nicht ${ }^{21} \mathrm{zu}$ seinem Recht ${ }^{22}$ verhelfen, ${ }^{23}$ seinen Weg verwirren, ${ }^{24}$ die Füße seiner Truppen ${ }^{25}$ ausgleiten lassen, ${ }^{26}$ bei seiner Opferschau ${ }^{27}$ ein böses Vorzeichen, ${ }^{28}$ das Entwurzelung ${ }^{29}$ seines Königtums ${ }^{30}$ und Untergang seines Landes bedeutet, ihm bescheren; ${ }^{31}$ ein unheilvolles Wort ${ }^{32}$ des Sonnengottes möge eilends ${ }^{33}$ ihn treffen, ${ }^{34}$ oben ${ }^{35}$ möge er ihn aus den Lebendigen ${ }^{36}$ entfernen, ${ }^{37}$ unten, ${ }^{38}$ in der Unterwelt, ${ }^{39}$ möge er seine Totengeister nach Wasser dürsten lassen." 1

B.1374?.2: BBS (Nr. 2), 6:

19 Šamaš dajjān kīnāti elenu linîršu 20 šaplānu arūtašu mê kașūti aju ušamhir ${ }^{19}{ }^{2}$ amaš, der gerechte Richter, möge ihn auf der Erde töten, ${ }^{20}$ unter der Ërde seinen Schattenleib kein kühles Wasser empfangen lassen. ${ }^{2}$

A.1306.1: RIMA 1 (A.0.75.1), 120:

${ }^{71}$ Šamaš $^{72}$ bēli ${ }^{73}$ šarrussu ${ }^{74}$ liskip ${ }^{75}$ ana mātǐ̌su ${ }^{76}$ hušahh̆a ${ }^{77}$ liddi Šamaš, mein Herr, möge sein Königtum stürzen, auf sein Land Hungersnot werfen.

A.1306.2: RIMA 1 (A.0.75.2), 122:

${ }^{8}$ Šamaš bè ${ }^{9}{ }^{9}$ šarrusu liskip ${ }^{10}$ u huušahhăa ${ }^{11}$ ana mātišu liddi

${ }^{8}$ Šamaš, mein Herr, ${ }^{9}$ möge sein Königtum stürzen ${ }^{10}$ und Hungersnot ${ }^{11}$ auf sein Land werfen.

\footnotetext{
1 BORGER, „Codex,“ 78; zusammenhängende Umschrift nach BORGER, Lesestücke, 44. Das Geschick des etemmu (Z. 38-40) gehört zu den Šamašfluchmotiven. Etwa 1000 Jahre später finden sich in einem neubabylonischen Privatvertrag ähnliche Formulierungen (BASOR 91, 37f; BE 8/1, 4): Rs. 3-6 Šamaš dajjān šamê u erșetim aplu nāqa mê līkinšuma ina x [x] DU erșetim ețemmašu lizammâ kipsū Samaš möge ihm den Erbsohn, den Wasserspender, rauben. In ... der Unterwelt möge er seinen Totengeist nach einem Totenopfer dürsten lassen. Vgl. GeVIRTZ, Motifs, 44; UNTERLECHNER, Fluchformeln, 156; zu likinšuma AHw, 194.

2 Zusammenhängende Umschrift und Übersetzung nach CAD 4/E, 84 elēnu la1'.
} 
B.1172.2: BBS (Nr. 4), 22:

Kol. III ${ }^{12}$ Šamaš dajjān šamê u erșeti lihalliq šumšu

Šamaš, der Richter des Himmels und der Erde, möge seinen Namen vernichten.

B.1159.5: AfO 23, 14:

Kol. III ${ }^{5}$ Šamaš dajjānu rabû ša ilāni rabûti ${ }^{6}$ sūd pāni sakāk uzni ${ }^{7}$ u ubbur mešrēti ${ }^{8}$ [ana šijrikti lišrukšu

„Šamaš, der Oberrichter der großen Götter, möge ihm Schwindelanfall, Taubheit und Lähmung der Glieder bescheren."

B.1159.6: AfO 23, 17ff: Kol. III Z. 3-6 = B.1159.5.

B.1083.1: BBS (Nr. 7), 41:

Kol. II ${ }^{19}$ Šamaš dajjān šamê u erșeti panī̌u limhașma ${ }^{20}$ ūmušu namru ana da'ummati litūršu

${ }^{19}$ Šamaš, der Richter des Himmels und der Erde, möge sein Gesicht schlagen, ${ }^{20}$ sein heller Tag möge sich für ihn in Dunkelheit wenden.

B.1083.2: BBS (Nr. 8), 47:

Kol. IV ${ }^{10}$ Šamaš diqungal šamê u erșeti ${ }^{11}$ lū dikkuldî̌uma ina par[ik]ti lizzissu

${ }^{10}$ Šamaš, der Großrichter des Himmels und der Erde, ${ }^{11}$ möge sein Gegner bei Gericht sein, als sein Widersacher ihm entgegentreten. ${ }^{2}$

B.1083.3: Sumer 38, 125:

Kol. IV ${ }^{24}$ Šamaš dajjānu șīru ša šamê u erșeti ${ }^{25}$ muštēšer ilì u amīli 26 ana dīnišu aji iqūlšu ${ }^{27}$ dīnšu purussâ ${ }^{28}$ aju ušarši issu lišamți ${ }^{29}$ ajjābšu elīšu lizziz

${ }^{24}$ Šamaš, der erhabene Richter des Himmel und der Erde, ${ }^{25}$ der Befehlshaber von Gott und Mensch, ${ }^{26}$ möge sich um seine Rechtssache nicht kümmern, ${ }^{27}$ für sein Gerichtsverfahren möge er keine Entscheidung ${ }^{28}$ fällen, seine Kraft möge er schwächen. ${ }^{29}$ Sein Feind möge auf ihn treten. ${ }^{3}$

B.1070.1: ZA 65, 57:

Kol. II ${ }^{57}$ Šamaš dajjānu rabû ša šamê u erseti ${ }^{58}$ ina pî̌su elli lā mušpêli 59 lizzuršuma turti ìni ${ }^{60}$ šakāk uzni u ubbur mešrēti ${ }^{61}$ liš̄im isquššu

„57. Šamaš, der große Richter von Himmel und Erde 58. möge inn mit seinem reinem unwandelbaren Munde 59. verwünschen und ... der Augen, 60. Ver-

\footnotetext{
${ }^{1}$ Borger, „Grenzsteinurkunden,“ 14.

2 Paralleltext: I R 70 (Caillou Michaux). Zu di-qu!-un-gal vgl. AHw, 173; vSoden, „Wörterbuch,“ 380f; zu Z. 11 vgl. CAD 3/D, 137 dikkuldî; AHw, 833 pariktu(m) 4).

${ }^{3} \mathrm{Zu} \mathrm{Z}$. 26 vgl. AHw, 895 qâlu(m) I, 4; zu Z. 28 vgl. die ähnliche Wendung AHw, 365 $i d u(m) 6$.
} 
stopfung der Ohren und Lähmung der Gliedmaßen 61. als sein Los bestimmen."1

B.944.1: BBS (Nr. 9), 62:

Kol. II ${ }^{1}$ Šamaš dajjānu ša šamê $u^{2}$ erșeti dīnšu u purussā̄̌su ${ }^{3}$ aji iprus

1Šamaš, der Richter des Himmels und ${ }^{2}$ der Erde möge sein Gerichtsverfahren und seine Entscheidung ${ }^{3}$ nicht entscheiden.

B.855.2: BBS (Nr. 36), 126f:

Kol. VI ${ }^{46}$ ina amat Šamaš Aja ${ }^{47}$ u Bunene 48 bēlē purussî 49 ilāni rabûti 50 šumšu lihliq ${ }^{51}$ lillaqit zēršu 52 ina unși u bubūtu ${ }^{53}$ napištuš liqti ${ }^{54}$ limqut šalmassuma ${ }^{55}$ qēbira aji irši

${ }^{46}$ Auf das Wort von Šamaš, Aja ${ }^{47}$ und Bunene ${ }^{48}$ den Herren der Entscheidung ${ }^{49} \mathrm{der}$ großen Götter, ${ }^{50}$ möge sein Name zugrunde gehen, ${ }^{51}$ möge seine Saat vernichtet werden, ${ }^{52}$ in Bedrängnis und Hunger ${ }^{53}$ möge sein Leben zu Ende gehen, ${ }^{54}$ möge sein Leichnam fallen, ${ }^{55}$ einen Bestatter bekomme er nicht. ${ }^{2}$

B.819.2: Brinkman, „Covenants,“ 109f:

Rs. ${ }^{8}$ Šamaš dajjānn rabû ša šamê u erșeti mu[štēěser] ${ }^{9}$ šiknat napištim bēlu tukultī šarrussu liskip dīnšu aji idīn

${ }^{8}$ Šamaš, der große Richter des Himmels und der Erde, der die ${ }^{9}$ Lebewesen recht leitet, der Herr, meine Zuversicht, möge sein Königtum stürzen, ihm nicht zu seinem Recht verhelfen.

A.783.2: Saba'a Stele:

30 ... Šamaš dajjānu ša šamê u erșeti ${ }^{31}$ ekletu ina mātišu lišabšīma aji iț̣ulū ahāmiš

${ }^{30}$...Šamaš, der Richter des Himmels und der Erde, ${ }^{31}$ möge Finsternis auf sein Land legen, so daß der eine den anderen nicht sehen kann. ${ }^{3}$

A.669.1: SAA 2 (Nr. 4), 23:

Rs. ${ }^{22}$ [Šamaš] zībānitum lā kitti $[\mathrm{xxx}]^{23}$ [xxx l]ak ina rēbit āališsu $[x x x]$

22ك̌amaš möge keine rechte Waage ... ${ }^{23}$... inmitten seiner Stadt ... .

In den Šamašflüchen Mesopotamiens ist ein charakteristisches Epitheton verbreitet, das die Richterfunktion des Sonnengottes betont: Šamaš dajjānu (rabû) ša šamê u erșeti. In VTE $\S 40$ wird Šamaš jedoch davon abweichend nicht in seiner Funktion als Richter (dajjānu), sondern als Licht (nūru) angesprochen. Vor dem Aspekt des Lichtes und der Sehfähigkeit

\footnotetext{
${ }^{1}$ RESCHID / WILCKE, „Grenzstein,“ 57.

2 Da neben Šamaš noch andere Götter angerufen werden, gehört dieser Fluch eigentlich nicht zum Untersuchungsmaterial für die Formgeschichte des Šamašfluchs. Man beachte jedoch die sorgfältig gestalteten chiastischen Passagen (Z. 50f, 53f).

${ }^{3}$ Zusammenhängende Umschrift und Übersetzung nach WATANABE, Thronfolgeregelung, 192. Zu Z. 31 vgl. AHw, 767 naṭālu(m) 3)a).
} 
tritt in den VTE die Rechtsfunktion zurück. Das Augenlicht wird auf Kolophonen im Samašfluch mehrfach thematisiert. ${ }^{1}$

Abschließend sei die Stellung des Šamašfluchs (VTE § 40) nach dem Sinfluch besprochen. Die Vorordnung des Mondes vor die Sonne zur Reihenfolge Sin - Šamaš scheint ein sumerisches Erbe zu sein. ${ }^{2}$ Sie kann aber selbst für Mesopotamien nicht als feste Regel festgestellt werden. Der KH, das Kudurru B.1159.5, die private Landschenkung des Caillou Michaux aus der Zeit des Marduk-nadin-ahhe (1098-1081) und der Vertrag B.819.2 ordnen Šamaš vor Sin. Offensichtlich schrieb keine Tradition die Kombination von Sin und Šamaš zwingend vor. In den 1000 Jahren des Untersuchungszeitraums gibt es neun Texte, die einen Šamaš- aber keinen Sinfluch enthalten ${ }^{3}$ sowie neun andere, die nur einen Sinfluch enthalten ${ }^{4}$. Gerade in den assyrischen Verträgen mit den westlichen Partnern Mati'ilu von Arpad und Baal von Tyrus fehlt die Kombination von Sin- und Samašfluch. Das verringert die Wahrscheinlichkeit, daß ein möglicherweise zwischen Assur und Juda geschlossener Vertrag diese Kombination enthielt. Außerdem steht in der syrisch-kanaanäischen Religion sowie im AT die Sonne (der Sonnengott) immer vor dem Mond(gott). ${ }^{5} \mathrm{Da}$ die Reihenfolge Sin - Šamaš gerade in den Verträgen mit westlichen Partnern fehlt, kann man die Reihung der Themen in Dtn 28,27-29 kaum mit einer altorientalischen Tradition erklären. Die Kombination Sin - Šamaš war noch nicht einmal in Mesopotamien zur allgemeingültigen Norm geworden, um wieviel weniger sollte sie bei einem Judäer zu erwarten sein, zumal sie seiner Tradition, die Gestime zu reihen, zuwiderläuft. Es kann aber sein, daß in Israel die

1 Vgl. zu Šamašflüchen auf Kolophonen HuNGER, Kolophone, 79 Nr. 234, Z. 6-10; 235, Z. 13f, 85 Nr. 256, Z. 3; 111, Nr. 356, Z. 5 (Augenlicht), 112 Nr. 360, Z. 4 (Augenlicht), 116, Nr. 375, Z. 7f (Augenlicht) (doch 113, Nr. 361, Z. 2 Ea + Augenlicht). Šamaš bringt also in den Kolophonflüchen die Blindheit. Aber auch Ea wird mit diesem Motiv verbunden. Vgl. zum Thema Blindheit bei Šamaš noch die außerhalb des hier untersuchten Textmaterials belegten Flüche ABL 1105 Rs. Z. 10' und ND 5550 Z. 29, die WATANABE, Thronfolgeregelung, 192 zitiert.

2 Vgl. JANOwSKI, Rettungsgewißheit, 36.

${ }^{3}$ B.1282.3, B.1172.2, B.1159.1, B.855.1, B.855.2, A.1306.1, A.1207.13, A.783.2, A.669.1. Selbst wenn Tafeln nicht vollständig erhalten sind, kann bei diesen Texten ausgeschlossen werden, daß ein Sinfluch in der Nähe des Šamašfluchs stand, da die Passagen davor und danach erhalten sind.

${ }^{4}$ B.1282.1, B.1246.1, B.1172.3, B.1172.4, B.1159.3, B.1105.2, A.745.1 sowie die neubabylonischen Immobiliarkurkunden VS I 70 und FLP 1386; vgl. OWEN / WATANABE, „Gartenkaufurkunde," 38, 40f. Z. 29-32.

5 Vgl. NiEHR, Gott, 142-147, die einzige Ausnahme ist Palmyra, wo der Mondgott als höchster Gott Züge des Sonnengottes annimmt; Gen 37,9; Dtn 17,3; Jos 10,12.13; 2 Kön 23,5; Jes 13,10; 60,19f; Jer 8,2; 31,35; Ez 32,7; Joel 2,10; 3,4; 4,15; Hab 3,11; Ps 72,5.7; $89,37 f ; 148,3$. 
Motive selbst in einer festgelegten Reihenfolge überliefert wurden. Daher muß im Rahmen des AT abgeklärt werden, ob die Motive „Aussatz, Geschwür" und „Blindheit, Verwirrung“ in fixierten Kombinationen begegnen, die sich in Dtn 28 niederschlugen.

\section{5. 4. VTE § 41, der Ninurtafluch}

\section{Ninurta}

ašarēd ilānī

ina šiltāh̆išu šamri lišamqitkunu

426 dāmīkunu limalli șēru

šìrkunu arû zību 427 lišākil

\author{
"425Ninurta, \\ der Allererste der Götter, \\ möge durch seinen wütenden Pfeil \\ euch zu Fall bringen, \\ ${ }^{426}$ mit eurem Blut die Steppe anfüllen, \\ Adler und Geier euer Fleisch \\ ${ }^{427}$ fressen lassen!“"1
}

\subsubsection{Textvarianten}

In ND 4329 folgt auf den Šamašfluch (§ 40) der Jupiterfluch (§ 43). Die Schreibvariationen bei den Verben im $\breve{S}$-Stamm beruhen auf Dialektunterschieden. Die babylonischen Formen lišamqitkunu und lišākil stehen in ND 4327, 4329 und 4335+4408. Die assyrischen Schreibungen lušamqitkunu und lušākil findet man in den Fragmenten ND 4356 und 4328B. ${ }^{2}$

Z. 426 limalli] Im Manuskript 4335+4408 scheint die Verbform li-mal-la mit einem Ventiv zu enden. Das ist eine Abweichung von den sonst bekannten Belegen dieser Wendung.

šĭrkunu] ND 4327 und 4329 haben šīr $=k a$ (UZU.MEŠ- $k a$ ), was einen Numeruswechsel des enklitischen Personalpronomens zu dem in 4327 erhaltenen lišamqit $=k u n u$ bedeutet. $^{3}$

\section{5. 4. 2. Sprachlich-syntaktische Analyse}

Der Fluch besteht aus einem einzigen Satz, dessen Subjekt der Gottesname ist. Von ihm hängen drei Prädikate $a b$, die im Prekativ stehen. Beim ersten Prädikat bildet das angefügte enklitische Personalpronomen der 2. Person Pl. das Akkusativobjekt. Ihm geht eine adverbielle Bestimmung der Tätigkeitsweise voraus. Das zweite Prädikat regiert den doppelten Akkusativ. Der erste Akkusativ nimmt durch das enklitische Personalpronomen die

\footnotetext{
${ }^{1}$ WatanaBe, Thronfolgeregelung, 163; vgl. ebd. 112, 162.

2 Die Prekativpartikel $l \bar{u}$ kontrahiert im Babylonischen mit dem $u$-Anlaut des Verbs im Präteritum zu $l \hat{\imath}-$, assyrisch und neu/spätbabylonisch jedoch zu $l \hat{u}$-. Vgl. GAG § 81c.

3 Vgl. WatanABE, Thronfolgeregelung, 112; Parpola / WatanaBe, Treaties, 46.
} 
Textadressaten in den Blick. Das dem Verb folgende Nomen stellt das Akkusativobjekt dar. Abweichend von der gewöhnlichen Satzstellung steht das Prädikat nicht am Schluß, sondern wird von seinen beiden Akkusativen umschlossen. Auch das letzte Prädikat regiert einen doppelten Akkusativ. In Parallele zum vorhergehenden Satzabschnitt trägt der erste Akkusativ das enklitische Personalpronomen. Der Fluch enthält zwei auffällige Reihen von Zischlauten, die durch die Verben im Š-Stamm verstärkt werden:

\section{...ŠittāhiŠu Šamri liŠamqitkunu ... Ṣēru Šìrkunu ... Zibu lišăkil}

Die Lautgestalt und der Einschluß des limalli durch seine beiden Akkusative lassen bei diesem Fluch das Bemühen um kunstvolle Sprache erkennen.

Bereits der Wortschatz des Epitheton führt zu einem Charakteristikum des Ninurtafluchs in den VTE. Das Wort ašarēdu „Erster“ kommt nämlich in den VTE nur noch im Palilfluch vor ( $\$ 59$ Z. 519), der mit Teilen des Ninurtafluchs übereinstimmt:

519 Palil bēlu ašarēdu š̃ [rkunu] ${ }^{520}$ arû zību [lišăkil]

„519 Palil/Igištu, der allererste Herr, [möge euer Fl] eisch ${ }^{520}$ Adler (und) Geier [fressen lassen]!“1

Palil wird in der mesopotamischen Mythologie sowohl als „Ninurta von Elam" bezeichnet wie auch mit dem Gott Nergal identifiziert. ${ }^{2}$ Während Á.MUŠEN und $z i-i-b u$ nur in Z. 426 und 530 in den VTE belegt sind und auch sonst in den erhaltenen assyrischen Verträgen nicht mehr vorkommen, begegnet $a k a \bar{a} l u / S ̌$ mehrmals. In den Stipulationen bezeichnet es einen Vergiftungsversuch an Asarhaddon (VTE Z. 262) und in den Vergleichsflüchen zielt es auf den Kannibalismus ( $\$ 69 \mathrm{Z} .550$ ) oder beschreibt Ungezieferplagen ( $\$ 85 \mathrm{Z}$. 600).

Das Vokabular des ersten Wunsches führt zu einem Fluch, der dem zitierten Palilfluch unmittelbar vorausgeht. maqātu/Š kommt nämlich nur noch in $\S 58$ Z. 518 vor, einem Assurfluch, der die Zeremonialflüche einleitet:

518 Aššur abi ilānī ina kakkī[šu] ezzūti li[šam]qit[kunu]

„... möge Assur, der Vater der Götter, mit [seinen] zornigen Waffen [euch nie]der[werfen]!“3

\footnotetext{
1 WaTANABE, Thronfolgeregelung, 169; vgl. ebd. 121, 168.

2 ,Während in CT 25,12,17: 'palil(IGI.DU) mit ,Ninurta von Elam ' gleichgesetzt wird, steht 'IGI.DU in der Götterliste CT 24,36,52 ff., wo alle Nergalgestalten aufgezählt sind, an zweiter Stelle nach dnérgal (U.GUR)." vWEIHER, Nergal, 93.

3 WATANABE, Thronfolgeregelung, 169; vgl. ebd. 121, 168.
} 
Die Worte šiltāhu „Pfeil“ und šamru „wütend“ stehen in den VTE nur im Ninurtafluch. Der Ninurtafluch erscheint als Zusammensetzung aus dem Assur- und dem Palilfluch oder umgekehrt, der Ninurtafluch wurde in einen Assur- und einen Palilfluch aufgespalten. Jedenfalls können die im Ninurtafluch auftauchenden Motive nicht ausschließlich mit dieser Gottheit verbunden gewesen sein. So bleibt als Eigentümlichkeit die mittlere Aussage, doch deren Vokabular begegnet ebenfalls anderswo. MÚD.MEŠ steht in den Vergleichsflüchen, wo das Blut der Frauen, Söhne und Töchter süß wie Honig ( $\$ 75 \mathrm{Z}$. 568) und der Kampfwagen mit Blut getränkt sein soll ( 90 Z. 613, 615). Die syllabische Schreibung dam-me findet man in den Stipulationen, wo die Vereidigten Blut für Blut vergießen sollen (Z. 256) sowie im Gulafluch (§52 Z. 402). malû/D „füllen“ kommt noch im Eafluch ( $\S 60)$ vor, der dem zitierten Palilfluch folgt. ${ }^{1}$ EDIN / șeru „Steppe“ steht auch im Sinfluch ( 39 Z. 421). Nur die Bezeichnung der Waffe Ninurtas gehört demnach zum eigentümlichen Wortschatz dieses Fluches. Besondere sprachliche Beziehungen verweisen auf den Beginn der Zeremonialflüche nach der Eidesformel. Dort folgen ein Assur-, ein Palil/Igištu- und ein Eafluch (\$§ 58-60) aufeinander. Danach kommen ein kurzer Fluch bei den großen Göttern ( $\$ 61$ Z. 523), ein Girra/Gibilfluch mit der Vernichtung von Namen und Nachkommenschaft ( $\$ 62$ Z. 524) und § 63, der die Motive von Dtn 28,23f enthält. In dieser Sequenz können Palil und Girra/Gibil als Personifikationen des Nergal verstanden werden, welcher zu den „Ninurta-Göttem“ gehört. ${ }^{2}$ Die Flüche mit den auffälligen lexikalischen Bezügen zum Ninurtafluch zeigen ihm gegenüber einen einfacheren Aufbau. Obwohl teilweise dieselben Formulierungen verwendet werden, läßt sich nicht die gleiche Sorgfalt bei der sprachlichlautlichen Gestaltung feststellen.

\section{5. 4. 3. Semantische Analyse}

Ninurta gehörte als Kriegsgott und Sohn Enlils bereits in das sumerische Pantheon. Diese Funktion teilte er schon früh mit seinem Bruder Nergal. ${ }^{3}$ Bei den Assyrem war er zuständig für Krieg und Jagd. ${ }^{4}$ Er ist der Gott des

\footnotetext{
1 ,521Ea, der König der Wassertiefe, der Herr des Grundwassers, möge tödliches Wasser 522 euch zu trinken geben, mit Wassersucht euch füllen!" WATANABE, Thronfolgeregelung, 169.

2 Vgl. vWEIHER, Nergal, 72, 75.

3 Vgl. vWeIHER, Nergal, 12, 73 Anm. 5.

4 Vgl. vWEIHER, Nergal, 101.
} 
Sirius. Ihm war ein großer Tempel in Kalah geweiht. ${ }^{1}$ Auf bildlichen Darstellungen symbolisierten ihn der stehende Vogel und die Doppellöwenkeule. Verschiedene Waffen wurden besonders mit Ninurta in Beziehung gebracht, z.B. kakku „Waffe“,imittu, eine Lanze mit Hüftstütze, mittu, eine hölzerne Götterwaffe, die auch Anu beigegeben wird, gamlu, e in Krummholz. ${ }^{2}$ Ninurta stand neben Marduk im Mittelpunkt monolatrischer Tendenzen. Ein babylonischer Hymnus preist Ninurta als Krieger und erklärt nacheinander die Sonne zu seinem Antlitz, den Mond zu seinem Scheitel, Enlil und Ninlil zu seinen Augen, Gula und Belet-ili zu seinen Pupillen, Sin und Šamaš zu deren Iris, den Glanz der aufgehenden Sonne zu deren Augenlidern, die Ištar der Sterne zur Form seines Mundes und Anu und Antu zu seinen Lippen. Es folgen die Ausfaltung des mit Anu begonnenen Themas Mund und weitere Körperteile mit anderen Gottheiten. Bemerkenswert scheint, daß Gesicht und Gesichtssinn des Gottes mit Himmelserscheinungen gleichgestellt werden, wobei die Himmelskörper Sonne und Mond neben deren Vergöttlichungen Sin und Šamaš auftauchen. ${ }^{3}$

Die Vorrangstellung des Ninurta wird in seinem Epitheton häufig durch SAG.KAL / ašarēdu ausgedrückt. ${ }^{4}$ Unter diesem Aspekt wird Ninurta auch mit Marduk identifiziert. ${ }^{5}$ Daneben kommt das Wort aber auch in den Epitheta anderer Götter und Göttinnen vor. ${ }^{6}$

Der Begriff für Ninurtas Waffe, šiltăhu, bezeichnet einen Pfeil, gleichzeitig jedoch auch den Stern Sirius und in den Annalen Assurbanipals sogar den Kriegsgott selbst. ${ }^{7}$ šamru charakterisiert im Vertrag A.669.2 die Hochflut, die Baal Šameme, Baal Malage und Baal Șaphon bringen. ${ }^{8}$ maqātu/Š kommt auch im Mardukfluch des Vertrags B.819.2 vor. ${ }^{9}$ dämu

\footnotetext{
1 vSodEN, Einführung, 172, 175. Die Zuordnung der Planeten zu den Göttern änderte sich anscheinend im Laufe der Zeit. Aus der 2. Hälfte des 2. Jts. ist bezeugt: „Jupiter (=Marduk), Saturn (=Ninurta), Merkur (=Nabû) und Mars (=Nergal), denen die vier ,Weltränder ${ }^{*}$, das sind die vier Himmelsrichtungen entsprachen." vWEIHER, Nergal, 81.

2 Vgl. SEIDL / Hrouda / KRECHER, ,Göttersymbole,“ 487f, 497.

3 Vgl. LABAT / CAQUOT / SZnYCER / VIEYRA, Religions, 93; LAMBERT, Gott, 546.

4 Vgl. CAD 1/A II, 416f ašaridu 1.a)2'.

5 ,ašarēdu-ut-ka dninurta ... (...) dein allererster Platz ist Ninurta." vWEIHER, Nergal, 67.

6 Vgl. CAD 1/A/II, ašaridu 416 1.a)1', 1.a)2'.

$7 \mathrm{Vgl}$. AHw, 1237 šiltāhu(m) 2), 3); 1265 šuküdu(m) 2).

${ }^{8}$ Kol. IV Z. 13 „... eine wütende Hochflut möge gegen euch [...].“ BORGER „Baal,“ 159. Flut steht bereits in sumerischen Texten im Epitheton Nergals zur Charakterisierung seines Heldentums und seiner kriegerischen Aktivität. Vgl. vWEIHER, Nergal, 17f, $70 f$.

${ }^{9}$ Möge er sein Volk mit Tod (?) und Hungersnot niederwerfen. ,(19') [... ina] BAD $u$ hu [šah]-hni UN.MEŠ-šú li-šam-qit" BRINKMAN, „Covenants,“ 108.
} 
„Blut" steht außer im Gulafluch noch im Nergalfluch eines sonst kaum mehr erhaltenen Vertrags Sin-šar-iškuns. ${ }^{1}$ șēru bedeutet neben „Rücken, Oberseite“ auch „Steppe, offenes Land“ und bildet den Gegenbegriff zur Stadt. Im Sinfluch bezeichnet es den Ort der Exkommunikation, in den die saharšubbû-Krankheit führt. Doch haftet dem Wort nicht unbedingt die Bedeutung trostloser Einsamkeit an. Im Vertrag A.745.1 bezeichnet das Wort einfach das Ackerland, dem trostlose Unfruchtbarkeit durch den Fluch erst zugesprochen werden muß. ${ }^{2}$ Das offene Land bietet sich als Schlachtfeld an. ${ }^{3}$ In diesem Sinne wird wohl das Epitheton des Palil in dem Vertrag Assurbanipals mit den Babyloniem zu verstehen sein. ${ }^{4}$ In Kriegsbeschreibungen wird meist davon gesprochen, daß Leichenhaufen auf dem Schlachtfeld zurückbleiben. Blutvergießen im offenen Land wird seltener thematisiert. ${ }^{5}$

šîru bedeutet nicht nur „Fleisch“, sondern auch „Leib“" oder „Person“" 6 Während das erste der beiden Tiere, die das Fleisch zu fressen bekommen, durch das sumerische MUŠEN eindeutig als Vogel zu identifizieren ist, besitzt das syllabisch geschriebene $z \bar{\imath} b u$ mehrere Bedeutungen. Die etymologisch verwandten Worte anderer semitischer Sprachen bedeuten meistens Wolf. Daher sollte auch das im akkadischen gemeinte Tier ein Säugetier sein. vSoden schlägt Schakal vor und führt die hier besprochene VTEStelle unter den Belegen für diese Bedeutung an. Die neueren Übersetzungen ziehen jedoch wohl wegen der Parallele zum vorhergehenden Vogel die Übersetzung Geier vor. Die im AHw gesammelten Belege für die Bedeutung „Geier“ zeigen jedoch, daß bei dieser Bedeutung meist das Sumerogramm MUŠEN gesetzt wird, das in VTE Z. 426 fehlt. Es bleibt dem Belieben des Übersetzers anheimgestellt, ob man den Vogel oder das Säuge-

\footnotetext{
${ }^{16}{ }^{\text {Nergal bèlu gitmalu }}{ }^{7}$ dāmekunu ina harri $[n] a d a[b] a k[i]$... ${ }^{6}$ Nergal, der vollkommene Herr, ${ }^{7}$ möge euer Blut in den Abwasserkanal (Kanal der Hinschüttung) [füllen]. Umschrift und Übersetzung nach SAA 2 (NR. 12), 73.

2 IV ,... ${ }^{19}$ so möge sein Bauer auf dem Felde kein Lied anstimmen, ${ }^{20}$ das Grün des Feldes möge nicht aufgehen und die Sonne nicht erblicken.“ BORGER, „Mati'ilu,“ 156.

3 Vgl. AHw, 1093-1095.

${ }^{4}$ Rs. 20 , "IGI.DU LUGAL EDIN i-na x[xxx ..." SAA 2 (Nr. 9), 67. Vom Krieg spricht auch der Ištarfluch des KH: Kol. L (Rs XXVII) ," ${ }^{92}$ Ischtar ... ${ }^{105}$ möge..." LI (Rs. XXVIII) ,${ }^{8}$ seine Krieger ${ }^{9}$ niederstrecken, ${ }^{10}$ mit ihrem Blut ${ }^{11}$ den Erdboden tränken, ${ }^{13}$ die Leichen ${ }^{14}$ seiner Truppen ${ }^{15}$ auf dem Felde ${ }^{12}$ zu einem Hügel ${ }^{16}$ aufschichten ... ." BORGER, „Codex,“ 79. Der Ištarfluch dient hier nur als Beleg für die Konnotation „Schlachtfeld“" im Wort șēru. Die Ištarflüche VTE Z. 453f, 459 enthalten zwar ebenfalls Kriegsthematik, aber andere Motive.

5 Vgl. CAD 3/D, 75-80 dāmu 1c; CAD 16/Ṣ, 146 șēru A9i)1'.

${ }^{6} \mathrm{AHw}, 1328 \mathrm{f}$.
} 
tier vorzieht. ${ }^{1}$ Ähnliche Formulierungen kommen in der Beschwörungssammlung Maqlû und in Kriegsbeschreibungen assyrischer Könige vor. ${ }^{2}$ Derartige Fluchmotive besitzen also einen Hintergrund in konkreten Erfahrungen der Opfer assyrischer Kriegführung.

\subsubsection{Strukturanalyse}

Das folgende Schema zeigt, wie der Aufbau des Ninurtafluchs Formulierungen aus zwei weiteren in den VTE aufeinander folgenden Flüchen kombiniert:

Struktur

1. Satz Z. 425

Thema

Lexemverbindung VTE Z. Gottheit

Epitheton

Niederschlagung

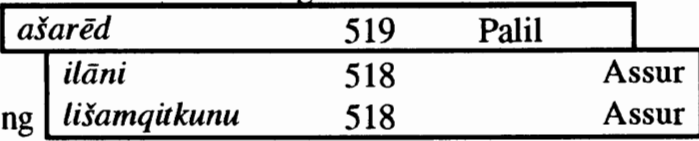

2. Satz Z. 426 Blut in der Steppe

3. Satz Z. 426f Leichen als Tierfutter

\begin{tabular}{|c|c|}
\hline $\begin{array}{l}\text { šīrkunu arû zību } \\
\text { lišākil }\end{array}$ & \\
\hline
\end{tabular}

Der Ninurtafluch enthält in chiastischer Anordnung Bezüge zu den Epitheta und Motiven der beiden Flüche, die am Anfang der Fluchreihe nach dem Eid ( $\$ 57$ ) stehen. Dies sind also Motive, die innerhalb der assyrischen Fluchtradition eine Fluchreihe anführen konnten, obwohl $\S 41$ mitten in eine Reihe von Gestirnflüchen eingebettet ist. Stellung, Motive und Verbindung mit den Gottheiten waren in der mesopotamischen Tradition für den Ninurtafluch demnach nicht fest vorgeschrieben und daher auch nicht in allgemeingültiger Verbindlichkeit verbreitet.

\subsubsection{Formengeschichte des Ninurtafluchs}

Zur Erhebung einer Ninurtafluchtradition können folgende Vergleichstexte angeführt werden:

B.1282.1: RA 66, 166:

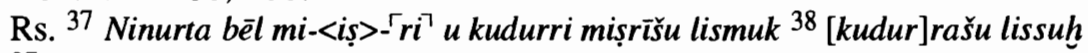

${ }^{37}$ Ninurta, der Herr von Grenze und Grenzstein, möge seine Grenze unkenntlich machen, ${ }^{38}$ seinen Grenzstein ausreißen.

${ }^{1} \mathrm{Vgl}$. AHw, 1525; CAD 21/Z, zību, 106; WATANABE, Thronfolgeregelung, 192.

2 Nin A Kol. V „66 pa-gar qu-ra-di-šú-un ina la qe-bé-ri ú-šá-kil zi-i-bu ... Die Leichen ihrer Helden beerdigte ich nicht, sondern ließ die Schakale sie auffressen." BORGER, Inschriften, 57f. Vgl. Maqlû Kol. VII Z. 85; SCHÄCHTER, Fluch, 99f. 
B.1255.1: BBS (Nr. 1), 4:

Kol. II ${ }^{9}$ Ninurta bēl kudurri ${ }^{10}$ kudurrašu linakkir

${ }^{9}$ Ninurta, der Herr des Grenzsteins, ${ }^{10}$ möge seinen Grenzstein ausreißen.

B.1255.2: IV R 12 Z. 40-43:

${ }^{40}$ Ninurta bèlu māru rēštu ša Enil bēl kakki kak dannutišu aji iddinšu ašar qabli u tahāzi ${ }^{42}$ kakkašu lišbir likmi birkišu u birkī qurāddīšu ${ }^{43}$ nakaršu elišu lizziz ${ }^{45}$...[kim]tišu me-[xxx] qāt nakirišu limallû̌̌u ${ }^{47}$ [...] ana māt nakirišu lišlulū

40Ninurta, der Herr und der erstrangige Sohn des Enlil, der Herr der Waffe, möge (ihm) die Waffe seiner Stärke nicht geben, am Ort der Schlacht und des Kampfes möge er ${ }^{42}$ seine Waffe zerbrechen, binden seine Knie und die Knie seiner Helden. ${ }^{43}$ seinen Feind möge er über ihm stehen lassen. ${ }^{45}[. .$. sei]ne $\mathrm{Fa}$ milie ... [...] die Hand seines Feindes mögen sie (mit) ihm füllen. ${ }^{47}[\ldots]$ ins Land seines Feindes mögen sie (Beute von ihm) fortführen. ${ }^{1}$

B.1255.1: RA 66, 173: Rs. Z. 69 = B.1282.1 Rs. 37-38.

B.1172.2: BBS (Nr. 4), 23:

Kol. III ${ }^{16}$ Ninurta ina tah[āzi kakkas']u lišbir

Ninurta möge in der Schlacht seine Waffe zerbrechen.

B.1172.3: MDP 2, 99ff; Hinke, Kudurru, 13:

Kol. VII ${ }^{5}$ Ninurta ${ }^{6}$ bèl apli ${ }^{7}$ Yumi $u^{8}$ kudurri $^{9}$ aplam ${ }^{10}$ nāq mê ${ }^{11}$ lïkimšuma ${ }^{12}$ zèra u pìra ${ }^{13}$ aju ušaršišu

${ }^{5}$ Ninurta, ${ }^{6}$ der Herr des Erbsohns, ${ }^{7}$ des Namens und ${ }^{8}$ des Grenzsteins, ${ }^{9}$ möge den Sohn, ${ }^{10}$ den Wasserspender, ${ }^{11^{1}}$ imm rauben, ${ }^{12}$ Samen und Sproß ${ }^{13}$ ihm nicht zu eigen geben.

B.1172.4: MDP 10, 92:

Kol. IV ${ }^{20}$ Ninurta bēl pulukki ${ }^{21}$ šarh̆u gitmālu ilitti É.KUR V 1 kisuršu liskip zēram aja ibni [kur]bassu lizzirma

IV ${ }^{20}$ Ninurta, der Herr des Grenzpfahls, ${ }^{21}$ der stolze, vollkommene, abstammend von Ekur V ${ }^{1}$ möge sein Gebiet zu Fall bringen, Samen möge er nicht schaffen, seine Scholle? möge er verfluchen.

B.1159.3: AfO 23, 1ff:

Kol. III ${ }^{3}$ Ninurta kudurrašu linakki[r]

„Ninurta möge seine Grenze ändem.“2

${ }^{1}$ Die sumerische Version hat ${ }^{~} U D . U_{18}$.LU, das Uta'ulu zu lesen ist. „Uta'ulu ... is normally an epithet of Ninurta ... (...) ux.lu is the storm ... which arrives from the south ... and darkens the day ... ." CAPLICE, „Namburbi,“" 161. Z.45 + 47 rufen wohl mehrere Götter an.

2 BORGER, „Grenzsteinurkunden,“ 3. 
B.1105.1: BER 4, 150:

Kol. IV ${ }^{19}$ Ninurta bēl miṣri u kudurri kudurrašu lissuh

„Ninurta, der Herr der Grenze und des Grenzsteins, möge seinen Grenzstein ausreißen."1

B.1101.1: BBS (Nr. 11), 79:

Kol. IV ${ }^{1}$ Ninurta bēl kudurr[ēti $]^{2}$ kakkē ašar tahāzi [... ${ }^{3}$ liksu'ma kamissu [...] 4 [li] צziz

${ }^{1}$ Ninurta, der Herr der Grenzsteine ${ }^{2}$ möge die Waffen auf dem Schlachtfeld [...] ${ }^{3}$ binden und ihn gefangen [...] ${ }^{4}$ hinstellen.

B.1083.1: BBS (Nr. 7), 41:

Kol. II ${ }^{27}$ Ninurta bēl mișri u kudurri kudurrašu lissuh ${ }^{28}$ mișiršu likabbis pilikšu tini

${ }^{27}$ Ninurta, der Herr von Grenze und Grenzstein, möge seinen Grenzstein ausreißen, ${ }^{28}$ seine Grenze niedertreten und sein Gebiet ändern.

B.1083.2: BBS (Nr. 8), 47:

Kol. IV ${ }^{19}$ Ninurta bēl kudurrēti ${ }^{20}$ apilšu nāq mều lišēli

${ }^{19}$ Ninurta, der Herr der Grenzsteine, ${ }^{20}$ möge seinen Erbsohn, seinen Wasserspender entfernen.

B.1083.3: Sumer 38, 125:

Kol. V ${ }^{11}$ Ninurta supû 12 mär Enlil qardu ${ }^{13}$ bēl miṣri ${ }^{14}$ u kudurri annî ${ }^{15}$ kudurrašu liss ${ }^{\top} h^{7}{ }^{16}$ pulukkašu ${ }^{17}$ linaqqir ${ }^{18}$ kisurrašu liḩalliq

${ }^{11}$ Ninurta, der Herrliche, ${ }^{12}$ der Sohn des Enlil, der Held, ${ }^{13}$ der Herr der Grenze 14 und dieses Grenzsteins, möge ${ }^{15}$ seinen Grenzstein ausreißen ${ }^{16}$ seinen Grenzpfahl ${ }^{17}$ zerstören, ${ }^{18}$ seine Grenze niederreißen.

B.944.1: BBS (Nr. 9), 62:

Kol. II ${ }^{14}$ Ninurta ${ }^{15}$ bēl kudurrēti kudurrašu ${ }^{16}$ lissuh šumšu zēršu per'ašu ${ }^{17} u$ nannabšu in pî niš̄e ${ }^{18}$ lihalliq apla u ${ }^{19}$ nāq mê aju ušaršišu

${ }^{14}$ Ninurta, ${ }^{15}$ der Herr der Grenzsteine, möge seinen Grenzstein ${ }^{16}$ ausreißen, seinen Namen, seinen Samen, seinen Sproß ${ }^{17}$ und seine Nachkommenschaft möge er im Mund der Menschen ${ }^{18}$ niederreißen, einen Erbsohn und ${ }^{19}$ Wasserspender möge er ihn nicht bekommen lassen.

B.?: UF 16, 299ff:

Kol. IV ${ }^{8}$ Ninurta ${ }^{9}$ aplam ${ }^{10}$ u mēreštam lizammi

"Ninurta möge (ihn) des Erbsohns und des Bedarfs berauben.“2

Die meisten Belege des Ninurtafluchs zeigen den Gott mit Grenze, Grenzstein und Erbsohn betraut. Nur B.1255.2 und B.1101.1 ordneten ihm krie-

\footnotetext{
${ }^{1}$ UNTERLECHNER, Fluchformeln, 216.

2 SOMMERFELD, „Grenzsteinurkunde,“ 303.
} 
gerische Motive zu. Dazu kann noch ein Lugalgirra-Fluch aus einem Kolophon gestellt werden: Lugalgirra ina kakkēe ezzūti lišgiš „Lugalgirra möge (ihn) mit seinen wütenden Waffen niedermetzeln."1

Niemals mehr ist in einem Ninurtafluch das Motiv der Leichenverfütterung belegt. Keine festgeschriebene Ninurtafluchtradition stand also Pate für die konkrete Gestalt des Fluches der VTE. In Anbetracht der Parallelen zum Assur- und Palilfluch scheint der Ninurtafluch vielmehr aus Traditionsstücken zusammengesetzt, die mit verschiedenen Göttern verbunden werden konnten. In den Götteraufzählungen der neuassyrischen Königsinschriften und königlichen Briefe steht Ninurta meist hinter Ištar, beide jedoch getrennt von Sin und Šamaš. Die Reihung Sin, Šamaš, Ninurta, Delebat/Ištar, die sich in VTE § 39-42 findet, kann nach Maßgabe sonstiger mesopotamischer Texte nicht als Überlieferungsgut angesehen werden. ${ }^{2}$ Eine engere Verbindung zwischen Sin, Šamaš und Ninurta belegt eine literarische Stelle. Es fehlt allerdings Ištar / Delebat:

„,Šamaš möge vor mich, Sîn hinter mich treten, Nergal möge zu meiner Rechten treten, Ninurta möge zu meiner Linken treten. ““3

\footnotetext{
${ }^{1}$ HuNGER, Kolophone, 114 Nr. 353. Lugalgirra ist eine der Erscheinungsformen Nergals. Vgl. vWeIHER, Nergal, 26, 80.

2 „Die gewöhnliche, große Götterreihe ist: Assur - Sîn -Šamǎ - Adad - Bēl - Nabû - Ištar von Ninive - Ištar von Arba'ili - Ninurta - Nergal - Nusku ... (...) Kürzere Götterreihen sind die folgenden: Assur - Šamaš - Bēl - Nabû - Nergal ... ."vWEIHER, Nergal, 102.

3 vWeIHER, Nergal, 47 Anm. 3.
} 
3.5. 5. VTE $\S 42$, der Delebatfluch

\section{Delebat \\ nabât kakkabāni}

ina nițil ìn̄kunu hīrātīkunu

429 ina sūn nakrïkunu lišanīl

mārīkunu ${ }^{430}$ aji ibēèù bütkun

nakru ahû liza"iza mimmûkun
${ }^{428}$ Venus,

die unter den Sternen (besonders) strahlend ist, möge vor euren Augen eure Gattinnen ${ }^{429}$ im Schoß eures Feindes liegen lassen! Eure Söhne mögen ${ }^{430}$ euer Haus nicht besitzen!

Ein fremder Feind möge all eure Habe aufteilen!"1

\section{5. 5. 1. Sprachlich-syntaktische Analyse}

Der Fluch besteht aus drei Sätzen. Das Subjekt des ersten bildet die Göttin. Nach deren Epitheton folgt ein einfacher Wunschsatz, dessen Prädikat im Prekativ am Schluß steht. Das Akkusativobjekt mit enklitischem Personalpronomen der 2. Person Pl. (hīrātī =kunu) wird von einer Zustandsangabe und einer Ortsangabe umschlossen. Die Zustands- und die Ortsangabe bilden durch ihre Struktur ina + Nomen regens + Nomen rectum + ePP 2. Person Pl. einen Parallelismus (ina niṭil ìn $\bar{\imath}=k u n u / /$ ina sūn nakrī $=k u n u$ ). Das dreifache enklitische Personalpronomen stellt den Bezug zu den Adressaten her. Die beiden anschließenden Wunschsätze besitzen zwar unterschiedliche Subjekte, bilden aber einen Parallelismus membrorum mit der von der üblichen Satzstellung abweichenden Form Subjekt - Prädikat Objekt. ${ }^{2}$ Dieser Parallelismus wird sprachlich dadurch verstärkt, daß die Worte mit ähnlichen Lauten beginnen:

$\begin{array}{llll}\text { mAr- } & A- & I- & \text { bIt- } \\ \text { nAk- } & A- & \text { II- } & \text { mIm- }\end{array}$

Das Objekt trägt das verkürzte enklitische Personalpronomen der 2. Person $\mathrm{Pl}$., welches für den hymnisch-epischen Dialekt und die spätbabylonische Aussprache typisch ist. ${ }^{3}$ Der Parallelismus membrorum, die Abweichung von der üblichen Satzstellung und die apokopierten Personalpronomina am Schluß weisen auf dichterische Sprache hin.

\footnotetext{
${ }^{1}$ WatanABE, Thronfolgeregelung, 165; vgl. ebd. 112f, 164.

$2 \mathrm{Vgl}$. GAG $\$ 130$ b.c. Die Umstellung begegnet häufig in der Dichtung.

3 Vgl. GAG § 42g Anm. 16, § 42j Anm. 5; Watanabe, Thronfolgeregelung, 192f. Das verkürzte ePP der 2. Pers. Pl. steht noch VTE Z. 418, 432, 439 und 460, bis auf den Jupiterfluch (Z.432) immer in Flüchen von Göttinnen.
} 
Der Gottesname ddil-bat begegnet innerhalb der VTE noch in der Nennung der göttlichen Zeugen, allerdings dort versehen mit dem Determinativ für Sterne MUL. Gegenüber den Flüchen erscheint die Reihenfolge in den göttlichen Zeugenlisten umgestellt. Dort geht gewöhnlich Jupiter der Delebat/Venus voraus. ${ }^{1}$

Besonderheiten des Wortschatzes innerhalb der VTE sind die Constructus-Verbindungen im Epitheton und im ersten Fluchwunsch sowie die Verben der beiden anschließenden Sätze. ${ }^{2}$ Der Ausdruck ina niṭil ìnīkunu wurde bereits im Šamašfluch (Z. 430) behandelt. hīrtu „Ehefrau“ gehört zum Epitheton der Mullissu. ${ }^{3}$ LÚ.KÚR/nakru „Feind“ kommt im Delebatfluch zweimal vor (Z. 429, 430) und verbindet den Fluch mit den Stipulationen (Z. 111, 127), dem Eid (§57 Z. 499), dem Ištarfluch (§ 48 t:) und einem fast gleichlautenden Fluch bei den Göttern der Tafel $(\S 77 \mathrm{Z}$. 573 ) sowie mit den beiden Vergleichsflüchen $\S 65 \mathrm{Z} .535$ und $\S 86 \mathrm{Z}$. 601f, wobei Z. 535, die dem Himmel/Erde-Bronze / Eisen-Vergleich (VTE § 63f) folgt, bisweilen als Entsprechung zu Dtn 28,25 angesehen wurde. ${ }^{4}$ Das Prädikat des ersten Satzes niälu/ŠS ,liegen lassen“ kommt nur noch im Grundstamm in einem Vergleichsfluch mit Schlange und Mungo vor ( $\$ 71$ Z. 559), der wie $\S 42$ den normalen Kontakt des Mannes mit seiner Ehefrau verflucht:

${ }^{558}$ so sollt ihr und eure Frauen nicht in éin Haus eintreten, ${ }^{559}$ nicht (zusammen) auf éinem Bett liegen! Trachtet danach, euch gegenseitig die Kehle durchzuschneiden." 5

Wie in einem Text, der die Thronfolge von Söhnen eines Königs regelt, zu erwarten, findet man das Wort DUMU.MEŠ / $m \bar{a} r \bar{r}$,,Söhne“ überall in den VTE. ${ }^{6}$ Auch É / bìtu „Haus, Familie“" verbindet den Delebatfluch mit den Stipulationen. ${ }^{7}$

1 VTE Z. 13; Zakutu-Vereidigung: SAA 2 (Nr. 8), 62 Z. 25; Vertrag Sin-š ar-iškunBabylonier: SAA 2 (Nr. 11), 72 Z. 6.

2 nabiu „hell“, MUL.MEŠ „Sterne“, ÚR „Schoß“, biālu „,beherrschen“ sind in allen überlieferten assyrischen Verträgen nur hier zu finden. zuāzu/D ,verteilen" steht in fast wörtlich gleicher Formulierung im Astartefluch des Vertrags A.669.2 Z. 19; vgl. AHw, 1518.

3 Vgl. VTE \& 38 Z. 417; A.669.1 Rs. Z. 18.

4 Vgl. Preuss, Deuteronomium, 72 offenbar mit Druckfehler 533 statt 535; SUMNER, Study, 57 ebenfalls mit falscher Zahl (1. 534), doch mit dem richtigen Zitat.

5 WatanaBe, Thronfolgeregelung, 171.

${ }^{6}$ Es bezeichnet in den Stipulationen und der Vereidigung die Söhne der Vereidigten VTE Z. 4, 9, 116, 228, 383, 387, 395, 507, aber auch die Söhne des Asarhaddon Z. 83, 237, 497, 516, vor allem formelhaft die Söhne derselben Mutter wie Assurbanipal Z. 94, 103, 171, $270,285,341,343,363$, doch auch einfach die Bürger Assyriens Z. 163, 222, 321, 338 oder eines anderen Landes Z. 164, 222f, 322, 339. In den Flüchen begegnet es häufig innerhalb 


\subsection{2. Semantische Analyse}

Der Name Delebat bezeichnet die Göttin Ištar als Venusstern. Der Bezug zum Sternenhimmel wird auch durch die Nennung der Sterne (MUL.ME ̌ / kakkābu) im Epitheton klargestellt. Zur Bezeichnung der Frau verwendete man nicht MÍ.MEŠ wie VTE Z. 558, sondern das syllabisch geschriebene hīrtu, das die „ebenbürtige Gattin“ meint ${ }^{1}$ und auch für die Gattin des Assur gebraucht wurde. Im Epitheton der Mullissu wird dieser Begriff durch naramtu ,geliebt“ ergänzt, was die emotionale Komponente der Wertschätzung, die das Wort enthält, zum Ausdruck bringt. Der $\breve{S}$-Stamm des Verbs niälu impliziert eine Fremdbestimmung des Liegens. Die Gattinnen erliegen nicht den Verführungskünsten der Feinde, sondern werden gezwungen. ${ }^{2}$ Die Feinde spielen im Delebatfluch schon aufgrund ihrer zweifachen Nennung eine besondere Rolle, obwohl im Gegensatz zum eigentlichen Ištarfluch VTE Z. 453f kriegerische Ereignisse nicht direkt geschildert werden, sondern eher deren Folgen zur Sprache kommen. Wendungen, wie den Thron, den Palast oder das Haus beherrschen, sind im Akkadischen bezeugt. ${ }^{3}$

Der letzte Satz des steht fast wörtlich auch im Astartefluch des Vertrags A.669.2 verbunden mit dem Motiv des Bogenzerbrechens, das die VTE im Ištarfluch (Z. 453f) bringen:

"18' So möge Astarte in schwerem Kampfe euren Bogen zerbrechen und euch zu Füßen [eures Feindes] ${ }^{19}$ 'sitzen lassen, ein fremder Feind möge euer Gut verteilen.“4

des Kannibalismusmotivs Z. 446, 449 (Adad), 549, 569, allgemeinem Verschwinden der Söhne Z. 538, 543, Behandlung durch Feinde Z. 577, 581, 583, 589, Veränderungen ihres Fleisches Z. 572, 586, 592, die Söhne werden zur Verantwortung gezogen Z. 510, von den Vereidigten nicht ergriffen Z. 535, vom Eid durchdrungen Z. 562, 624, ausgenommen Z. 553, ausgeblasen Z. 564, stranguliert Z. 606, 636. Sie gehen rückwärts Z. 618, finden keinen Schlaf Z. 638, ihr Schicksal ist bitter Z. 647.

${ }^{7}$ In VTE Z. 272, 275 werden damit Häuser Assurbanipals und seiner Söhne bezeichnet. In den Flüchen begegnet es im bereits besprochenen Anufluch sowie im Adadfluch, wo Mühle und Ofen in den Häusern fehlen sollen ( $\$ 47$ Z.444), im Götterfluch, wo Dämonen von den Häusern Besitz ergreifen ( $\$ 56$ Z. 493) und im schon beim Stichwort ,liegen“ zitierten Vergleich mit Schlange und Mungo ( $\$ 71$ Z. 558).

$1 \mathrm{Vgl}$. AHw, 348.

$2 \mathrm{Vgl}$. AHw, 784.

${ }^{3} \mathrm{Vgl}$. AHw 121, in B.1105.2 Kol. Il Z. 53 der Wunsch, daß ein anderer das Haus beherrschen solle, siehe unten 127 .

${ }^{4}$ BORGER, „Baal,“ 159. „18' das-tar-tú..... 19' LÚ.*KÚR a-hu-u li-za-i-za mim-[mu-ku-nu]“" PARPOLA / W ATANABE, Treaties, 27. 
In A.669.2 kann eine Anpassung an die Traditionen der fremden Vertragsparteien festgestellt werden. Der assyrische Text nennt die Göttin nicht Ištar, sondern mit ihrem westsemitischen Namen Astarte. Astarte wurde in Tyrus und Sidon als Gemahlin des phönizischen Baal verehrt. ${ }^{1}$ Man kannte also im westsemitischen Tyrus, nicht weit entfernt von der Grenze Israels, im 7. Jh. einen Fluch, der Formulierungen mit Astarte verband, die auch im Ištar- und Delebatfluch der VTE auftauchen. Es wäre möglich, daß sie in Juda bekannt waren. Doch erklärt dies noch nicht, warum das Motiv aus Z. 19 in Dtn 28,33 steht. Man müßte dazu einen Traditionsfluß der Motive von Ištar / Astarte zu JHWH postulieren. In Juda und Israel hatte man aber als göttliche Paredros JHWH/Els nicht Astarte, sondern, wenn überhaupt, Aschera verehrt, eine Göttin, die nicht einfach mit Astarte gleichgesetzt werden kann. Für die Umwandlung des Ištar/Astarte-Motivs in einen JHWH-Fluch fehlt im Rahmen der Tradition der Anknüpfungspunkt. Erst im frühen 6 . Jh. finden sich in Juda vermehrte Zeugnisse für die Verehrung einer Himmelskönigin, in der eine Verbindung zwischen Aschera und der assyrischen Ištar angenommen werden kann. ${ }^{2}$ Die Himmelskönigin fand jedoch keinen Eingang in den offiziellen Kult, sondern eher in die Familienfrömmigkeit. ${ }^{3}$ Aus der Familienfrömmigkeit dürfte Dtn 28,31.33 aber kaum stammen. Anders verhält es sich, sollten die Motive von Dtn 28,31.33 durch den Delebatfluch der VTE nach Juda gelangt sein. Delebat stellt, im Gegensatz zum Aspekt des Krieges und der Liebe bei Ištar/Astarte, die astral-kosmische Komponente in den Vordergrund, was eine Übertragung des Fluches auf JHWH erleichtern konnte.

\footnotetext{
1 Vgl. KeEl / UehLINGER, Göttinnen, 298.

2 Vgl. KEEL / UEHLINGER, Göttinnen, 386-390.

${ }^{3} \mathrm{Vgl}$. KeEL / UEHLINGER, Göttinnen, 388.
} 


\subsection{3. Strukturanalyse}

Das folgende Schema zeigt, wie der Delebatfluch mit den anderen überlieferten assyrischen Vertragsflüchen verbunden ist:

Gottheit

1. Satz Z. 428

Z. 429

2. Satz Z. 429f

3. Satz Z. 430

\begin{tabular}{|lll|}
\hline ina niṭil ìnīkunu & VTE Z.482 & Götter \\
hïrtu & VTE Z.417 & Mullissu \\
\hline
\end{tabular}

allgemein verbreitete Lexeme

\begin{tabular}{|ll|}
\hline $\begin{array}{l}\text { nakru ahû liza"iza } \\
\text { mimmî=ePP }\end{array}$ & A.669.2 Kol. IV Astarte \\
\hline
\end{tabular}

Ein weiterer Delebatfluch ist nicht bekannt. So stellt der Fluch in mehrfacher Hinsicht eine Besonderheit dar. Zusätzlich zu dem häufigen Ištarfluch mit seinen Kriegsaussagen greifen die Verfasser der VTE die astrale Komponente der Göttin unter einem eigenen Namen heraus. Die zahlreichen lexikalischen Bezüge zum Textkorpus der VTE lassen vermuten, daß dieser Fluch als solcher nicht Bestandteil der mesopotamischen Fluchüberlieferung war. Er scheint vielmehr von den assyrischen Schreibern aus vorgegebenen Traditionsstücken, für die der Astartefluch des Vertrags A.669.2 ein Beispiel liefert, zusammengebaut worden zu sein.

\subsection{VTE § 43, der Jupiterfluch}

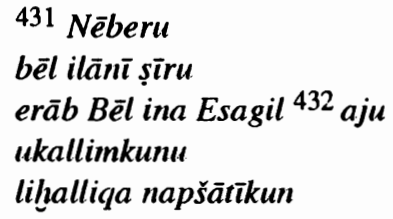

431 Nēberu

bēl ilānī șïu

erāb Bēl ina Esagil ${ }^{432}$ aju

"kallimkunu

liḩalliqa napšātīkun

\author{
${ }^{431}$ Jupiter, \\ der erhabene Herr der Götter \\ möge euch das Eintreten Bēls in den \\ Esangila-Tempel ${ }^{432}$ nicht zeigen, \\ euer Leben vernichten!“"1
}

Der Jupiterfluch wird hier nur behandelt, weil er zur Reihe der Gestirnsflüche gehört. In der Forschungsgeschichte wurde er niemals mit einer Passage aus Dtn 28 verglichen. Deshalb kann auf die Untersuchung seiner Sprache und Tradition verzichtet werden. Watanabe stellt fest, daß der Neberufluch keine lange feststellbare Tradition besitzt, sondern typisch für Asarhaddon sei. ${ }^{2}$ So bestätigt der Jupiterfluch die bereits beim Sin- und Gulafluch vermerkte Beobachtung, daß die VTE neben traditionell vorgegebenen Motiven und Formulierungen untypische, offenbar unter Asarhaddon aufgekommene und verbreitete Ergänzungen der Flüche enthalten. In

\footnotetext{
1 WatanaBE, Thronfolgeregelung, 165; vgl. ebd. 113, 164.

2 Vgl. Thronfolgeregelung, 32, 193.
} 
den erhaltenen assyrischen Verträgen kommt kein weiterer Fluch mit dem Gottesnamen SAG.ME.GAR / Nebēru vor. Doch steht Jupiter in den Götterlisten der VTE sowie des Zakutu-adê und einem adê des Sin-šar-iškun, allerdings immer vor Venus/Ištar/Delebat. ${ }^{1}$ Watanabe zitiert einen Sternfluch aus einer neubabylonischen Rechtsurkunde. Er enthält das alte und weit verbreitete Motiv der Vernichtung des Namens:

„,Alle [Gö]tter, deren Namen genannt sind, (und) Jupiter, Venus, Sirius und Mars mögen seinen Namen zugrunde richten', ABL 1169, 13'-r.1 ... ."2

Mit den Stemen werden die Gottheiten Ištar (Venus), Ninurta (Sirius) und dessen Bruder Nergal (Mars) identifiziert. ${ }^{3}$ In den VTE wird Nergal nicht in die Sternreihe eingefügt, sondern sein Fluch kommt erst in $\S 49$ nach dem Ištar- und vor dem Mullissufluch. Watanabes Zitat zeigt die Verbindung zwischen der Formel ,alle Götter, deren Namen ... genannt sind,“ und der Sternenreihe. In den VTE läßt sich diese Kombination zwar nicht belegen, doch die Flüche des Himmels- und der astralen Gottheiten $\S 38 \mathrm{~A}-42$ zeigen einige Lexemverknüpfungen zum Fluch der großen Götter des Himmels und der Erde, in dem die besagte Formel auftaucht.

Der Inhalt des Neberufluchs ähnelt dem assyrischen Zusatz zum Sinfluch der VTE ( $\$ 39$ Z. 420). In beiden Fällen wird Exkommunikation thematisiert. Im Sinfluch wird der Gottesdienst im Tempel und das Erscheinen vor dem König ausgeschlossen, im Jupiterfluch die Teilnahme an der kultischen Marduktheophanie im Haupttempel zu Babylon. Beide Flüche sind ausgerichtet auf den Ausschluß eines Individuums oder einer bestimmten Gruppe aus einer größeren Gemeinschaft, eben derjenigen, die im Tempel beten und eine Audienz beim König bekommen.

Im Blick auf Dtn 28 fällt auf, daß für diese assyrischen Ergänzungen zu den traditionellen Fluchelementen mit ihrem Exkommunikationsthema Entsprechungen im Bibeltext fehlen. Daraus könnte die Folgerung gezogen werden, daß die Ähnlichkeit zwischen Dtn 28 und den VTE tatsächlich nur auf der Überlieferung von Fluchmotiven beruht. Die traditionellen Elemente besitzen ihre Entsprechung, die assyrischen Eigenheiten kennt der Bibeltext anscheinend nicht.

Betrachtet man jedoch den historischen Kontext der VTE, so wird das Fehlen der Exkommunikationsmotive in Dtn 28 verständlich. Der Ausschluß einzelner aus der Volks- oder Kultgemeinschaft erscheint im Sinund Neberufluch der VTE sinnvoll, da die Vereidigten tatsächlich Indivi-

1 Vgl. Parpola / Watanabe, Treaties, 62 Z. 25; 72 Z. 6, 111 unter Sagmegar.

$2 \mathrm{Vgl}$. Thronfolgeregelung, 192.

3 Vgl. zu Nergal vWeiHer, Nergal, 76-83. 
duen oder eine Gruppe im Rahmen der größeren Gesellschaft des assyrischen Reiches waren. In Dtn 28 dagegen wird Israel als Ganzes anvisiert. Segen und Fluch enthalten keine Ächtung bestimmter Volksteile. Immer gelten die Aussagen für das angesprochene kollektive „Du“. Gegenüberstellungen geschehen nur im Blick auf Menschen, die nicht zu Israel gehören, dem Feind, den Fremden.

Wie also hätte eine Exkommunikation Gesamtisraels in der Bibel formuliert werden sollen? Der Ausschluß vom Kontakt mit dem Machthaber (Sinfluch) wird sinnlos, wo der König selbst zu den Verfluchten gehört (Dtn 28,36). Die Exkommunikation des ganzen Volkes vom Kult (Sin- und Jupiterfluch) könnte für Israel nur die Rücknahme der göttlichen Gegenwart im Tempel bedeuten. JHWH würde den Tempel verlassen oder der Tempel würde zerstört oder dem Volk wäre der Zugang zum Tempel in Jerusalem verwehrt. Eine derartige Exkommunikation von den Heilsgütern Land und Tempel geschah durch die Zerstörungen und Deportationen im Zuge der Eroberung Jerusalems durch Babylon 586 v. Chr. In der exilischen Literatur taucht nach diesem Zeitpunkt auch die Auseinandersetzung mit diesem Faktum auf (z.B. Klgl. 2,5-7; Ez 10,18-22). In Dtn 28 spricht den Ausschluß vom JHWH-Kult und vom Leben im Land in V. 36.64 an. Beide Verse werden häufig in exilische Zeit datiert. ${ }^{1}$

Dtn 28,36 wurde jedoch von Frankena und Weinfeld als vorexilisch und mit assyrischen Fluchtexten parallelisierbar befunden. ${ }^{2}$ Hier soll ihre These von einem Vertrag zwischen Assyrien und Juda nicht diskutiert werden, in deren Zusammenhang sie hinter Dtn 28,36 den JHWH-Deportationsfluch aus einem solchen Vertrag vermuteten. Bemerkenswert ist aber, daß die Deportation von König und Volk, die Götzendienst und damit den Ausschluß vom JHWH-Kult impliziert, in Dtn 28,36f genau an der Stelle des Jupiterfluchs in den VTE steht. In der Analyse von Dtn 28 wird nach dem diachronen Verhältnis von V. 36 zum Kontext zu fragen sein.

Impliziert Exkommunikation bei Übertragung des Sin- und Neberufluchthemas in den religiösen und politischen Kontext Judas die Deportation, so ergeben sich zwei Schwierigkeiten. Einerseits gibt es in Dtn 28 auch ein anderes Konzept der Deportation, das V. 36.64 widerspricht. In V. 32.41 werden nämlich nur die Kinder verschleppt, während die Eltem trauernd zurückbleiben. Deportation ist hier nur das Schicksal einzelner, die Existenz des Volkes im Land bleibt erhalten. Kultische Konsequenzen werden bei der Deportation der Kinder nicht angesprochen. Kommt es einer Nation in den Sinn, ihre Liquidierung als Gesamtheit zu thematisieren,

\footnotetext{
1 Vgl. Braulik, Deuteronomium II, 207f; Preuss, Deuteronomium, 86.

2 Vgl. Frankena, „Vassal-Treaties,“130f; 150. WeINFELd, School, 123.
} 
solange ihre politischen und religiösen Institutionen noch bestehen? Man muß damit rechnen, daß der Verlust des Landes durch die Deportation und der Verlust des Tempels als Ort der Gottesbegegnung erst zum Thema wurden, als das historische Faktum eingetreten war. Selbst in der (nach?)exilischen Endgestalt von Dtn 28 fehlt jeder Hinweis auf den Tempel bzw. den Ort. den JHWH sich erwählte, um seinen Namen dort wohnen zu lassen. Ausschluß vom JHWH-Kult wird nur indirekt als (erzwungene) Verehrung der Götter aus Holz und Stein behandelt. Andererseits kommt dieses Thema in den Flüchen der VTE überhaupt nicht vor. Deportation begegnet nur in einer Ermahnung der Vereidigten in $\S 25$. Wieso wünscht man in den VTE die Deportation nicht einmal seinem Feinde? Dafür dürfte es einen delikaten Grund geben. Asarhaddon selbst war nämlich an die Regierung gekommen, weil Sanheribs ältester Sohn, Assur-nadin-šumi, sein Statthalter in Babylon, von den Babyloniern gefangen und nach Elam deportiert worden war. ${ }^{1}$ Das assyrische Königshaus selbst war also von einem Schicksal geschlagen, das dem in Dtn 28,32.41 dargestellten gleicht. Bei einem Vertrag mit Ausländem, wie Baal von Tyrus, konnte das Thema Deportation relativ unverfänglich verwendet werden, doch in den VTE, wo die Vereidigten Assyrien viel näher sind und es um die Enkel Sanheribs geht, wären die Untergebenen bei einem Deportationsfluch wohl ins Grübeln geraten, wie solch ein Fluch das assyrische Königshaus treffen konnte.

Jerusalemer Hofkreisen dürfte der Zugang zu einem Exemplar der VTE möglich gewesen sein. ${ }^{2}$ Ihr Manuskript lagerte im Zentrum der politischen und kultischen Institutionen des Staates Juda, die durch eine Exkommunikation des gesamten Volks in Frage gestellt wären. So wird verständlich, daß Hofschreiber die Exkommunikationsmotive wohl ausgespart hätten, wenn sie die assyrischen Astralflüche in den JHWH-Text übernehmen wollten.

1 Vgl. WaTANABE, Thronfolgeregelung, 2.

$2 \mathrm{Vgl}$. KREBERNIK, ,Deuteronomiumskommentar," $35 \mathrm{f}$. 
3. 6. VTE $§ 56$, der Fluch bei den großen Göttern

\author{
472 ilā[nì ra]bûti \\ ša šamê erșeti \\ āšibütu kibrāti \\ 473 mala \\ ina țuppi annê šumšunu zakr[u] \\ 474 limhaṣūkumu \\ likkelmûkumu \\ 475 arratu maruštu aggiš līrurükunu \\ $476 \alpha$ eliš \\ ß baltūiti lissahūkunu \\ $\gamma$ šapliš ina erșeti \\ $477 \alpha$ etemmakunu mê lizammu
}

B șillu u șētu ${ }^{478 \beta}$ liktaššidūkunu

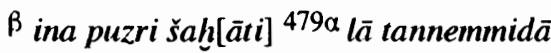

ß aklu u mê līzibūkunu

480 sunqu h̆ušalhhu

bubūtu miütānu

$481 \alpha$ ultu mahlin̄kunu aji ippițir

ß sissī ša ardātēkumu

482 matnāti ša eṭlütīkunu ina niṭil

inīkunu kalbī šahî;

483a ina rebīt Aššur lindaššarū

${ }^{\beta}$ pagrīkunu erșetu ${ }^{484 \alpha}$ aji imḩur

ß ina karši kalbī šalhî lū naqbarkunu

$485 \alpha$ ämīkun[u lü] eṭ̂̀

$\beta$ šanātīkunu lū eklā

Y ekletu

486 lã namār [i]

ana šīmtīkunu liš̄imū
, ${ }^{472}$ Die großen Gö[tter]

des Himmels und der Erde,

welche die Weltgegenden bewohnen, 473 alle,

deren Namen auf dieser Tafel genannt sind

${ }^{474}$ mögen euch schlagen,

euch böse anblicken

475 mit einem bösen Fluch euch zornig verfluchen,

${ }^{476}$ oben

euch aus den Lebendigen herausreißen, unten in der Unterwelt,

${ }^{477}$ euren Totengeist des Wassers berauben!

Schatten und Glut ${ }^{478}$ mögen euch immer wieder vertreiben!

In Verborgenheit und Ecken ${ }^{479}$ sollt ihr euch nicht verkriechen können!

Brot und Wasser mögen euch abhanden kommen!

480 Not, Mangel,

Hunger und Seuche

${ }^{481}$ mögen von euch nicht losgelöst werden!

${ }^{\beta}$ Die Zöpfe! eurer jungen Frauen und ${ }^{482}$ die Locken! eurer jungen Männer mögen im Anblick eurer Augen die Hunde und Schweine

483 auf dem Hauptplatz der Stadt Aššur hin und her schleifen!

Die Erde möge eure Leichen ${ }^{484}$ nicht empfangen!

BIm Bauch der Hunde und Schweine möge eure Grabstätte! sein!

${ }^{485}$ Eure Tage mögen finster sein, eure Jahre mögen dunkel sein!

Die Finsternis, ${ }^{486}$ die nicht erhellt wird, mögen sie ... als euer Schicksal bestimmen! 
487 ina t[änēḥi d] $]$ ilipti napištakunu liqti

488 bubbulu abūbu lā mahru; ultu erṣeti ${ }^{489 \alpha}$ lîlâma

B našpantakunu liškun

Y mimma tậbtu lū ikkibkunu

490a mimma marṣu lū šimatkunı

ß qiru kupru lū mākalākunu

$491 \alpha$ šināt imēeri lū mašqitkunu

$\beta_{\text {naptu lū piššatkunu }}$

492 elapî’a ša nāri lū taktīmkunu

493 šêdu utukku rābiṣu lemnu biātīkunu liḥīiū
${ }^{487}$ In M[ühsal? und Sch]laflosigkeit möge euer Leben zu Ende gehen! ${ }^{488}$ Eine Hochflut, eine unwiderstehliche Sintflut möge aus der Erde ${ }^{489}$ emporsteigen und eure Niederwerfung bewirken! Alles Gute möge euch verboten sein! ${ }^{490}$ Alles Krankhafte möge euer Schicksal sein!

Asphalt und Trocken-Asphalt mögen eure Speise sein!

${ }^{491}$ Eselsurin möge euer Getränk sein! Naphta möge eure Salbung sein! ${ }^{492}$ Die elapû(a)-Pflanze des Flusses möge eure Decke

493šêdu-, utukku- und böser rābișuDämon mögen sich eure Häuser als Wohnstätte auswählen!"1

\subsection{Textvarianten}

Z. 488 lā mahru] so ND 4337. ND 4350C läßt diesen Ausdruck aus, bietet aber in derselben Zeile ul-tu ŠÁ KI-tim / ultu libbi erșetim, so daß die Zeile in diesem Manuskript lautet: [Hochflut] (und) Sintflut mögen aus der Mitte der Erde em[porsteigen].

Z. 492 elapû'a] so ND 4337. ND 4352F hat nur elapû. ${ }^{2}$

\section{6. 2. Sprachlich-syntaktische Analyse}

Der erste Satz verbindet das Subjekt mit drei Epitheta (Z. 472f) und fünf Wünschen, die jeweils mit einem Verb im Prekativ schließen (Z.474$477 \alpha$ ). Die ersten drei dieser Prädikate drücken durch das enklitische Personalpronomen der 2. Person Pl. den Bezug zu den Angesprochenen aus, während im letzten Wunsch (lizammu) die Kette der ,-kunu"-Schlüsse abgebrochen wird, weil das Akkusativobjekt das enklitische Personalpronomen trägt. Darauf folgen kurze Verbalsätze mit unterschiedlichen Subjek-

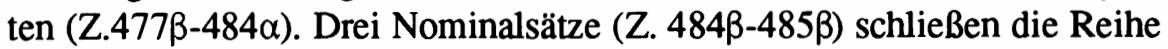
der vorangehenden Verbalsätze $a b$ und leiten zu einem Verbalsatz über, dessen Prädikat (lišim ū) wieder die großen Götter aus dem ersten Satz zum

1 WatanaBe, Thronfolgeregelung, 167; vgl. ebd. 117f, 166.

2 Vgl. Watanabe, Thronfolgeregelung, 118. 
Subjekt hat, ohne sie allerdings explizit zu nennen (485 $\gamma-486)$. Die beiden folgenden Verbalsätze besitzen eigene Subjekte. Von den beiden Subjekten bubbulu abūbu in Z. 488 hängen in Z. 489 zwei Prädikate ab. Darauf folgen sechs Nominalsätze (Z. $489 \gamma-492)$ und als Abschluß wieder ein Verbalsatz mit dem Prädikat im Prekativ (lihīrū Z. 493).

Einzelne Sätze von VTE § 56 wurden strukturell und lexematisch miteinander verknüpft. Zunächst verbindet der Verbalsatz in Z. $485 \gamma+486$ durch seinen impliziten Rückgriff auf das Subjekt des ersten Satzes (Z. 472-477 $\alpha$ ) die Mitte des Fluches mit dem Beginn, obgleich die Sätze dazwischen eigene Subjekte besitzen. Die Tätigkeit der großen Götter am Anfang und in der Mitte des Paragraphen umklammert so das in Z. 477ß$485 \beta$ Beschriebene. Das Stichwort erșetu „Erde“ zieht sich durch die erste Hälfte des Fluches (Z. 472, 476, 483, 488). Die zweite Hälfte des Paragraphen wird durch weitere Wortwiederholung ineinander verwoben. kalbī šahi „Hunde und Schweine“ verbindet Z. 482 mit Z. 484; šimtīkunu bzw.

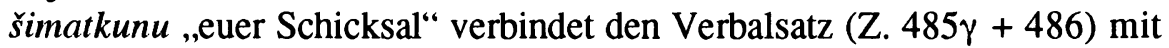
dem Nominalsatz Z. 490 und verknüpft so die ganze sich an Z. 490 anschließende Nominalsatzkette (Z. 490-492) mit dem Zentrum des Fluches. Das verneinte imhur (Z. 484) schlägt eine Brücke zum ebenfalls verneinten mahru (488). Das Finsternismotiv bildet in zwei hintereinanderliegenden Sätzen (485 eklā ,dunkel“, ekletu „Finsternis“) eine Dopplung, um die sich die anderen zweimal vorkommenden Worte herumlagern, wie folgendes Schema veranschaulicht:

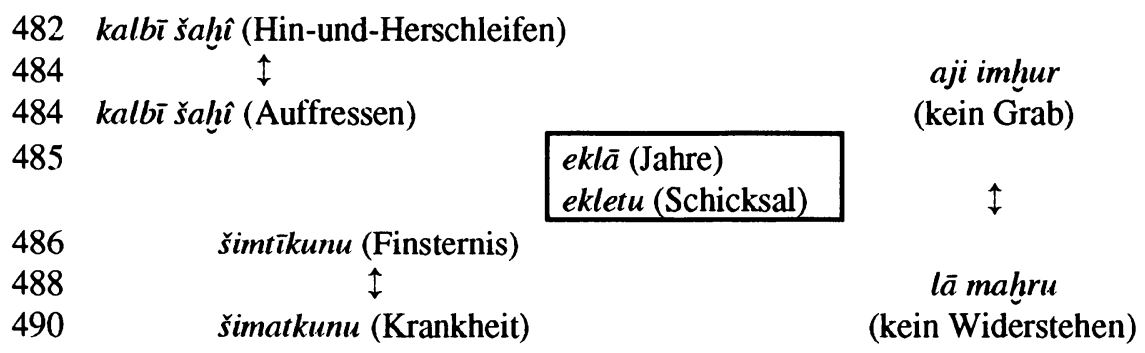

Motivisch umschließen das Hin-und-Herschleifen der jungen Frauen und Männer und das Auffressen den Wunsch, die Verfluchten mögen nicht in der Erde begraben werden. Ebenso umschließen das Motiv der Finsternis und das der Krankheit als Schicksalsbestimmung den Wunsch, eine unwiderstehliche Flut möge aus der Erde aufsteigen. Dies alles scheint aber nur die Ausgestaltung des mittleren Wunsches zu sein: Dunkelheit über alle Jahre und das ganze Geschick!

Das Vokabular des Fluches zeigt, daß er weitgehend aus Formulierungen zusammengesetzt ist, die auch sonst in den VTE und in den Flüchen 
anderer mesopotamischer Texte vorkommen. Den Beginn des Fluches ( $Z$. 472) findet man auch in der Rekapitulation des Vertragsinhalts Z. $41 \mathrm{f}^{1}$ so- $^{-}$ wie in dem Fluch Z. 523:

„ilāni rabûti ša šamê erșeti mê šamnu [ana?]kunu liškunü ${ }^{\star 2}$

"Die großen Götter des Himmels und der Erde ... mögen Wasser und Öl für euch [zum Bann(?)] machen!“3

Das Partizip von wašăbu ,wohnen“ steht ebenfalls bezogen auf die großen Götter in VTE Z. 21, dort bewohnen sie aber den Himmel und die Erde. Der in Z. 472 genannte Wohnort kibrāti „Horizont“ dient in Z. 14, 22 zur Bezeichnung des Herrschaftsbereichs Asarhaddons.

Die Formel von Z. 473 begegnet nicht nur in vielen mesopotamischen Fluchinschriften, sondern auch mehrmals in den VTE, so z.B. im $\S 63$ (Z. 526f), aber auch t:Z. 573f:

573 ilāni mala ina tuppi adê annî šumšunu zakru qašatkunu lišbirū ina šapal nakrīkunu 574 lušešsibūkunu qaštu ina qātēènu lušabalkitū ${ }^{575}$ narkabātēkunu ana qinniš lušadillū

"573(Dito,) mögen alle Götter, deren Namen auf dieser Tafel der adê-Vereidigung genannt sind, euren Bogen zerbrechen und euch zu Füßen eures Feindes 574sitzen lassen, den Bogen in euren Händen umwenden, ${ }^{575}$ eure Streitwagen nach rückwärts fahren lassen." 4

Ebenso beginnt $\S 91$ Z. 616a:

616a ilāni mala ina tuppi adê annê šumšunu zak [ru] ${ }^{616}$ kī pilaqqi lušaṣbirūkunu 617 kī issi ina pān( $\bar{e})$ nakrīkunu lēpašūkunu

"( ${ }^{616 a}$ Alle Götter, deren Namen auf dieser Tafel der adê-Vereidigung genannt sind,) ${ }^{616}$ mögen euch wie eine Spindel herumwirbeln, ${ }^{617}$ sollen euch wie eine Frau vor eurem Feind machen $!^{5}$

Auch in den $\S \S 92 \mathrm{f}$ werden die Götter angerufen (Z. 618a-621):

618a ilāni mala ina tuppi annî šumšunu zakru 618 ana kâšunu aḩhēekunu mar'ēekunu ${ }^{619}$ mar'ātēkunu kì allutti ana qinnišs ${ }^{620}$ lušadillūkunu ${ }^{621}$ kī išāti lā tābtu lā de'iqtu lušalbûkunu

"( ${ }^{618 a}$ Alle Götter, deren Namen auf dieser Tafel genannt sind,) ${ }^{618}$ mögen euch, eure Brüder, eure Söhne ${ }^{619}$ und eure Töchter wie einen Krebs nach rückwärts

1 ,... ina pān(ē) ilānì rabûti ša šamê (u) erșeti ..." WATANABE, Thronfolgeregelung, 146.

2 WatANABE, Thronfolgeregelung, 168.

3 WATANABE, Thronfolgeregelung, 169.

${ }^{4}$ WATANABE, Thronfolgeregelung, 171; vgl. ebd. 170.

5 WATANABE, Thronfolgeregelung, 173; vgl. ebd. 134, 172. 
${ }^{620}$ gehen lassen! ${ }^{621}$ Sie mögen euch wie mit Feuer mit Bosheit und Übel umgeben!"1

Sogar in der Eidesformel werden die Götter auf der Tafel angesprochen ( $\S$ 57 t:Z. 511). Der böse Blick (likkelmûkunu Z. 474) steht häufig in Flüchen auf Kudurrus und am Ende assyrischer Königsinschriften meist mit der Nennung Assurs. Z. 475 enthält die Fluchformel schlechthin (arratu ... ťrurūkunu). Sie kann mit verschiedenen Gottheiten verbunden werden und begegnet in den Fluchtexten Mesopotamiens sehr oft. ${ }^{2}$

Obwohl die Formulierung bereits im Šamašfluch des KH belegt ist, finden sich im erhaltenen Textkorpus der assyrischen Verträge für VTE Z. 475-477 $\alpha$ nur jüngere Parallelen. In Assurbanipals Vertrag mit babylonischen Verbündeten gehört sie zum Eafluch ${ }^{3}$, in Sin-šar-iškuns Vertrag mit babylonischen Verbündeten ist der Gottesname im betreffenden Fluch nicht erhalten. ${ }^{4}$ Z. 477 besitzt auch im Adadfluch der VTE eine Entsprechung:

" ${ }^{452}$ Euer Totengeist möge keinen Betreuer, keinen Wasserspender bekommen!"5

Mit dem Vergleichsfluch § 78 wird Z. 478 durch das Verb kašădu verbunden. Während es in Z. 478 im iterativen Dtn-Stamm (,vertreiben“) steht, begegnet es in $\S 78 \mathrm{Z}$. 576+578 im D-Stamm (,jagen, verfolgen“). ${ }^{6}$ Ebenfalls zu den Vergleichsflüchen führt das Wort NINDA.MEŠ / aklu „Brot“. In Z. 560 wird es mit dem Eid verglichen und gemäß Z. 561 soll es so teuer wie Gold werden.

Eine weitere Beziehung zum Adadfluch der VTE ergibt sich durch die Begriffe ḩušah̆hu und bubūtu. In Z. $449 \mathrm{f}$ heißt es:

${ }^{449} \mathrm{E}$ Bt wegen eures Hungers das Fleisch eurer Söhne! In Hungersnot ${ }^{450}$ und Mangel möge ein Mensch das Fleisch eines (anderen) Menschen essen, ... ."7

1 WatanaBE, Thronfolgeregelung, 173; vgl. ebd. 135, 172.

2 Vgl. UNTERLECHNER, Fluchformeln, 147-149.

${ }^{3}$ Vgl. SAA 2 (Nr. 9), 67 Rs. Z. 13'-14'.

4 Vgl. SAA 2 (Nr. 11), 72 Rs. Z. 9'-10'.

5 WaTANABE, Thronfolgeregelung, 165; , , ${ }^{452}$ etemmakunu pāqidu nāq mê aji iřši" ebd. 164.

${ }^{6}, 576$ Dito, wie ein Hirsch gejagt und getötet wird, ${ }^{577}$ mögen eure [Mör]der euch, eure Brüder, eure Söhne ${ }^{578}$ jagen und töten! (Var. ${ }^{577}$ mögen sie (= die Götter) euch den Händen eu[rer] Mörder ${ }^{578}$ überantworten!)“"WATANABE, Thronfolgeregelung, 171.

${ }^{7}$ WATANABE, Thronfolgeregelung, $165 ;,{ }^{449}$ (ina būrīkunu) šìr märīkunu aklā ina bubūti ... ${ }^{450}$ hušahhi amīlu šîr amilli līkul“ ebd. 164. 
Der Kannibalismus des Adadfluchs wird bereits im Vertrag A.745.1 durch huš̌ahhu ausgelöst, das dort mit sunqu kombiniert ist:

IV „ ${ }^{8}$ Adad, der Deichgraf des Himmels und der Erde, möge durch Elend, ${ }^{9}$ Hungersnot und Mangel dem Lande Mati'ilus und den Leuten seines Landes ${ }^{10}$ den Garaus machen. Sie mögen das Fleisch ihrer Söhne und Töchter essen, ${ }^{11}$ und es möge ihnen wohlschmecken wie das Fleisch eines männlichen und weiblichen Frühjahrslamms."

Doch der Hunger muß nicht mit Adad oder dem Kannibalismus verbunden sein. Im Vertrag B.819.2 stehen die Begriffe im Marduk- (Vs Z. 19), Enlil(Rs. Z. 4), aber auch im Adadfluch (Rs. Z. 14). Der Begriff NAM.ÚŠ / mutānu „Seuche“ dagegen gehört zum Nergalfluch (VTE Z. 456):

,${ }^{455}$ Nergal, der Gottesheld, möge mit seinem schonungslosen Schwert euer Leben ${ }^{456}$ auslöschen, Mord und Seuche in euer Inneres legen!“"

Das verneinte Verb paṭāru ,lösen“ schlägt in der Verbindung mit Krankheit einen Bogen zurück zu den Stipulationen in VTE Z. 389. Sollten die Vereidigten versuchen, den Schwur nur zu heucheln oder den Eid ungültig zu machen, trifft sie eine Krankheit, die ebenfalls nicht gelöst werden kann. In Z. 389 scheint die Krankheit mit dem Eidbruch identifiziert und als dessen unmittelbare Konsequenz dargestellt. ${ }^{3}$ Die in $\mathrm{Z}$. 482+484 genannten Tiere, UR.KU / kalbu „Hund“ und ŠAH.MEŠ / šahu „Schwein“, kommen innerhalb der VTE wieder im Adadfluch vor:

" ${ }^{451}$... Euer Fleisch mögen Hunde und Schweine fressen!“4

Der Ausdruck ina niṭil in̄̄kunu wurde bereits im Šamaš- und Delebatfluch besprochen, ina rebit (Z. 483) steht im Belet-ili-Fluch ( $\$ 46$ Z. 439), erșetu und mahāru stehen nicht nur mehrfach in $\S 56$, sondern kommen auch sonst in den VTE recht häufig vor. üme „Tage“ kommen in den VTE oft vor, šattu „Jahr“ dagegen nur Z. 485. Z. 486 enthält die Formel ana šìmtīkunu lišīin, die auch im Mardukfluch (Z. 434) steht:

.433 Marduk, der erstgeborene Erbsohn, möge eine schwere Strafe und einen unlösbaren Bann ${ }^{434}$ als euer Schicksal bestimmen. ${ }^{\circ 5}$

1 BORgER, „Mati'ilu,“ 156.

2 WATANABE, Thronfolgeregelung, 165; „... šagaštu mūtānu ina libbīkunu liškun“ ebd. 164. Ähnlich lautet auch der Nergalfluch im adê A.669.1 Rs. Z. 26.

3 Vgl. zu Z. 398 WaTANABE, Thronfolgeregelung, 198.

${ }^{4}$ WATANABE, Thronfolgeregelung, 165; ,.... širkunu kalbī šahì lïkulü“ ebd. 164.

5 WATANABE, Thronfolgeregelung, 165. Ähnlich steht die Formel bereits im Enlilfluch des KH und des Vertrags B.819.2 Rs. Z. 3. In VTE Z. 660 kommt NAM.MEŠ / šimtu im Epitheton des Nabu vor. 
ekletu wurde bereits im Šamašfluch behandelt, tanēhu diliptu im Anufluch. napšatkunu bzw. napšātīkun steht noch im Jupiterfluch (§ 43 Z. 432), im Nergalfluch ( $\$ 49$ Z. 455) in einem Vergleichsfluch $(\S 71$ Z. 557+559), wo Kehlen durchgeschnitten werden, sowie im Šamašfluch $\S 101$ (Z.651):

„... Er möge euch nicht mit dem Leben davonkommen lassen."1

Die Formel našpantakunu liškun (Z.489) steht auch im Sebettifluch (Z. 464f):

"464Sebetti, die [kriegerischen] Götter, mögen [mit ihren] wütenden [Waffen] 465 [euch] eine Niederwer[fung beifügen]!“次

tabtu „Gutes“ steht oft in den VTE, ikkibu „Verbotenes, Tabu“ jedoch begegnet innerhalb des assyrischen Vertragskorpus nur noch im Adadfluch des Vertrags A.745.1 in der Einleitung einer Sequenz, die Z. 490-492 gleicht:

"12Das Getöse des (Wettergottes) Adad mögen sie entbehren, ${ }^{13}$ Regen möge ihnen verwehrt sein. ${ }^{14}$ Staub möge ihnen zum Essen, Asphalt zum Salben, ${ }^{15}$ Eselsurin zum Trinken und Papyrus zur Kleidung ${ }^{16}$ gereichen. Ihr Lager möge in einem Loch sein.“3

Aus dieser traditionellen Sequenz von Flüchen sind die Begriffe qiru „Pech, Asphalt" noch im Vergleichsfluch § 81 Z. 587, šīnāti „Urin“ noch im Kubabafluch ( 55 Z. 470) und naptu ,Naphta“ im Vergleichsfluch § 81 Z. 587 bezeugt. Z. 490 bricht mit dem Stichwort marșu aus der Parallele des Vertrags A.745.1 aus und knüpft an den Anu- und Gulafluch der VTE an. ${ }^{4}$

1 WaTANABE, Thronfolgeregelung, 175; „... aju ušeși napšātīkunu“ ebd. 174.

2 WaTANABE, Thronfolgeregelung, 165; ${ }^{464}$ Sebetti ilānī [qardūti ina kakküšunu] ... ${ }^{465}$ ezzūti našpan[takunu liškunū] vgl. ebd. 164.

${ }^{3}$ BORGER, „Mati'ilu,“ 156. Rs. Kol. IV ${ }^{12}$ ikkil Adad lizamme'üma ${ }^{13}$ zunnu ana ikkibišunu liššakin ${ }^{14}$ eprū ana akālšunu qīru ana piššatišunu ${ }^{15}$ šināt imãri ana šatêšunu niaru ana lubuštišunu ${ }^{16}$ liššakin ina tubkinni lū majālšunu.

${ }^{4}$ Nur in $\S 56$ und auch nicht in den anderen erhaltenen assyrischen Verträgen oder den Fluchabschnitten assyrischer Königsinschriften stehen folgende Ausdrücke: șillu u șêtu "Schatten und Glut" (Z. 477), ina puzri šahäti ,in Verborgenheit und Ecken" (Z. 478), $e m \bar{e} d u / \mathrm{N}$,angelehnt werden“ (Z. 479), sissi ša ardātēkunu „Zöpfe eurer jungen Frauen“ (Z. 481), matnāti ša eṭlūtikunu „Locken eurer jungen Männer" (Z. 482), mašāru/Gtn „herumschleifen“, pagru „Leiche“ (Z. 483), ina karši ,im Magen“ (Z. 484), naqbāru „Grab“ (484), bubbulu abūbu „Hochflut und Sintflut“ (Z. 488), mašqītu „Getränk“ (Z. 491), elapâ eine Pflanze (Z. 492), taktīnu „Bedeckung“ (Z. 492), utukku rābiṣu Dämonen, hiāru ,auswählen“ (Z. 493). 


\subsection{Semantische Analyse}

Da $\S 56$ weitgehend aus traditionell vorgegebenem Material besteht, dessen Bedeutungsgehalt kaum Verständnisprobleme bietet, genügt es, hier nur jene Begriffe genauer zu untersuchen, die zum Sondergut des $\S 56$ gehören. sillu bedeutet „Schatten, Schirm, Schutz", seẹtu „Glut, heller Schein, Hitze". In metaphorischer Sprache werden Schatten und Hitze zu den Subjekten des Vertreibens. puzru emëdu bedeutet „sich verkriechen“. ${ }^{2}$ Damit scheint einerseits die Ruhe- und Ortlosigkeit der Verfluchten ausgesagt. Weder im Schatten noch in der Sonne sollen sie Ruhe finden. Andererseits kann im Wunsch, sich zu verkriechen oder zu verstecken, auch der Versuch gesehen werden, den Flüchen zu entkommen. Dann wird hier die Unmöglichkeit ausgesprochen, den Fluchwirkungen zu entgehen. Hier fehlt eine chronologische Entwicklung. Ort- und Rettungslosigkeit setzt in der Gegenüberstellung von Schatten und Hitze die Existenz der Verfluchten auf der Erde voraus, steht aber nach dem Todesfluch und der Versagung einer ordnungsgemäßen Totenpflege durch Libationen .

Unvermittelt wechselt das Thema von der Schutzlosigkeit zum Hunger. Drei Begriffe, sunqu, hušah̆hu und bubūtu, bezeichnen die „Hungersnot“. sunqu in Z. 480 wird von dem aramäischen Fremdwort sanāqu II „,bedürfen“ abgeleitet. ${ }^{3}$ Bei bubütu verweist vSoden auf das in Silbenschrift fast gleich geschriebene bubuttu ,Eiter". ${ }^{4}$ Tatsächlich steht in Z. 480 nicht das eindeutig zuzuordnende Sumerogramm, sondern die syllabische Schreibung $b u-b u-t u$, in dem sich beide Worte erkennen lassen. Die Textbearbeitungen übersetzen wegen der vorhergehenden beiden Begriffe für „Hunger, Mangel“ und der in anderen Texten belegten Kombinationen von sunqu oder h̆ušahhhu mit bubütu in Z. 480 mit „Hunger". Blickt man jedoch auf die anschließende Nennung von mutānu „Seuche, Pest“, eine von mūtu „Tod" hergeleitete Krankheitsbezeichnung5, so wirkt die dreifache Nennung des Mangels gegenüber der einmaligen Nennung von todbringender Krankheit unausgeglichen. Würde man bubuttu ,Eiter" lesen, stünden der zweifachen Nennung der Hungersnot zwei Begriffe für krankhafte Erscheinungen gegenüber. Eine eindeutige Festlegung zugunsten einer der beiden Lesarten läßt sich nicht treffen. Vielleicht stellt die Doppeldeutigkeit der Schreibung $b u-b u-t u$, ausgerechnet zwischen der Hungersnot und der Pest

\footnotetext{
${ }^{1} \mathrm{Vgl}$. AHw, 1101.

$2 \mathrm{Vgl}$. AHw, 211.

$3 \mathrm{Vgl}$. AHw, 1022.

$4 \mathrm{Vgl}$. AHw, 135.

$5 \mathrm{Vgl}$. AHw, 687.
} 
plaziert, die Raffinesse dieses Satzes dar. Beim Leser, der nicht durch Sumerogramme auf eine Bedeutung festgelegt wird, oder beim Hörer kann beides anklingen: eine dritte Form des Hungers oder der Eiter.

Die Bedeutung der Worte sissi und matnāti läßt sich nicht exakt bestimmen. ${ }^{1}$ Dennoch scheint der Sinn des Fluches klar, Hunde und Schweine schleifen menschliche Körperteile hin und her. Da das mitten in Assur geschieht (Z. 483), kann es sich bei den Jugendlichen, mit deren Leichenteilen die Tiere spielen, nicht um Opfer einer Hungersnot oder einer Seuche handeln, da dann die Hauptstadt Assyriens selbst der Schauplatz dieser Katastrophen wäre. Das Thema hat von Hunger und Krankheit zu Folgen des Krieges oder der Gewaltanwendung gewechselt. Die von dem Fluch Getroffenen sind entweder nach Assur gebrachte und dort zu Tode gekommene Kriegsgefangene, oder, falls man die Auffassung teilt, die VTE seien eine eher innenpolitische Vereidigung von Medern in assyrischen Diensten, in Assur zur Rechenschaft gezogene Eidbrüchige. Die Leichen, die die Tiere gemäß Z. 484 fressen sollen, sind nicht die Leichen, mit denen sie gemäß Z. 481 $\alpha-483$ spielen. Gefressen werden nämlich die Leichen der im Fluch Angesprochenen (pagri=kunu), doch im vorhergehenden Fluch sind nicht die Adressaten selbst die Betroffenen, sondern nur die jungen Männer und Frauen aus ihrer Gruppe. Die Adressaten selbst, deren Leichen nach dem Tod im Bauch der Tiere enden sollen, müssen noch als Lebende dem zusehen (ina niṭil ìnī $=k u n u$ ), was die Tiere mit den Körperteilen ihrer Nachkommen machen. Z. 484 stellt also nicht die logische Folge des in Z. 482f Beschriebenen dar. Es handelt sich um zwei voneinander unabhängige Geschehnisse.

Die beiden Begriffe für „Hochflut“ bubbulu und $a b \bar{u} b u$ stehen nicht im Adadfluch der VTE, obwohl auch dort von zerstörerischer Überschwemmung die Rede ist. bubbulu kann auch ,Neumondtag“ bedeuten und als 29. Tag des Monats in Beziehung zum Mondgott Sin, als 28. Tag des Monats in Zusammenhang mit Nergal stehen. ${ }^{2}$ Ebenfalls mit Nergal verbunden erscheint $a b \bar{u} b u$ in seinem Epitheton šăkin abübi. Da der Begriff auch in den Götterepitheta von Nabu, Ninurta und Ištar auftaucht, scheint hier eine kriegerische Konnotation vorzuliegen. Das Wort kann eine mythische Waffe Ninurtas bezeichnen. ${ }^{3}$ Die kriegerische Konnotation verstärkt sich, wenn man bedenkt, daß die Flut gemäß Z. 489 Niederwerfung bewirken soll, wobei eine Formulierung aus dem ebenfalls militärischen Sebettifluch

1 Vgl. Watanabe, Thronfolgeregelung, 196; Parpola / Watanabe, Treaties, 49 Anm. $481 f$.

$2 \mathrm{Vgl}$. AHw, 135.

3 Vgl. AHw, 8. 
aufgegriffen wird. Daraus ergibt sich der Schluß, Z. 488f sprechen eigentlich von einem Feindeinfall, der wie eine Flutwelle über die Betroffenen hereinbricht.

Der letzte Abschnitt von $\S 56$ enthält ab Z. 490 einen Fluch über Nahrung, Getränk, Salbe, Kleidung und Heimstatt, der einem festgelegten Schema folgt und offensichtlich in der mesopotamischen Fluchtradition verbreitet war. ${ }^{1}$ Die auch in der Bibel häufig belegte Reihung Korn, Wein, Öl, die oft durch Wolle ergänzt ist, zeigt, daß diese fundamentalen Bedürfnisse altorientalischen Lebens auch in Palästina in einer festen Verbindung genannt wurden. In diesen Aufzählungen kann tatsächlich ein Element einer gemeinsamen Sprach- und wohl auch Fluchtradition gesehen werden. Dennoch scheint zumindest die mesopotamische Überlieferung der Flüche weder die genaue Reihenfolge noch die Dinge, die im Fluch zu Nahrung, Trank, Salbe, Kleidung und Heimat werden, fixiert zu haben. Im Adadfluch des Vertrags A.745.1 lautet die Reihenfolge nämlich abweichend von den VTE: Speise, Salbe, Trank, Kleidung, Lager. Salbe und Getränk wurden also bei der Verwendung dieser Motivkomposition in den VTE vertauscht. Während die Speise in A.745.1 aus Staub besteht, werden in den VTE Pech und Asphalt genannt. Der Asphalt wiederum dient in A.745.1 zum Salben, während in den VTE dafür Naphta steht. Als Kleidung dient einmal Papyrus, das andere Mal eine Flußpflanze. Die Verfluchung des Zuhauses wird in A.745.1 unter dem Blickwinkel des Schlafplatzes abgehandelt, in den VTE dagegen als Enteignung des Hauses durch Dämonen beschrieben. Nur zum Ausdruck des Trankes steht in beiden Texten der Eselsurin.

Die Dämonen, die gemäß Z. 493 das Haus besetzen sollen, stellen keineswegs an sich böse Kräfte dar. Den assyrischen Königsinschriften zur Folge scheinen sie im Gegenteil durchaus gem gesehene Hausbewohner gewesen zu sein. Asarhaddon wird nicht müde, in seinen Palästen die Bildnisse der $\breve{S} e d u$ aufzustellen, damit sie zum Schutz der Gebäude als „Wächter“ darin wohnen. ${ }^{2}$ Der utukku ist ebenfalls an sich nicht bösartig, wird doch auch der Freund des Gilgameš, Enkidu, nach seinem Tode mit diesem Wort bezeichnet. ${ }^{3}$ Die eindeutige Negativbestimmung der im Fluch genannten Kräfte bewirkt erst das Adjektiv lemnu „,böse“. ${ }^{4}$

\footnotetext{
$1 \mathrm{Vgl}$. Watanabe, Thronfolgeregelung, 197.

218 šedê lamassê rābișê ... 19 šût bît $[\hat{\imath}]$... , "18 Die šêdu- und lamassu-Kolosse, die Wächter des ${ }^{19}$ Hauses ..." (Bab. A) BORGER, Inschriften, 23. Vgl. ebd. 62f, 64, 69; FUCHS, Inschriften, 247, 355: „Große Prunkinschrift“ Sargons II. Z. 189.

${ }^{3}$ Vgl. Gilgameš-Epos 12. Tafel, Z. 80, 84; AHw, 1445.

${ }^{4} \mathrm{Vgl}$. den Ištarfluch des Kudurru B.1083.3 Kol. VI Z. 20-28; UNTERLECHNER, Fluchformeln. 182.
} 


\subsubsection{Strukturanalyse}

Bereits bei der Besprechung der Wortwiederholungen war die Struktur um Z. 485 beschrieben worden, wo das Stichwort „Finsternis“ von den Stichwörtern „Schicksal“ und „Hunde und Schweine“ sowie von der Negation des Wortes mahăru umschlossen war. Die strukturelle Darstellung des § 56 wird zeigen, daß abgesehen von der Einleitung des Fluches (Z. 472-475) der gesamte Abschnitt palindromisch aufgebaut ist, so daß gleichartige Themen am Anfang und am Ende des Fluches einander entsprechen. Die Mitte, um die die palindromische Struktur kreist, bildet das schon durch die Wortwiederholungen herausgehobene Thema ,Finsternis“.

A) Tod + Totengeist Z.476f

Einleitung Z. 472-475

B) Glut + Schatten Z. 477-479

C) Hunger + Durst Z. 479f

D) Seuche Z. 480-481

E) Hunde + Schweine Z. $481 \beta-484$

a) Leichenschändung

b) Kein Begräbnis nach dem Tod

F) FINSTERNIS Z. 485f

E') Hochflut + Sintflut Z. 487-489

b') Leid vor dem Tod

a') Niederlage

D') Krankheit Z. 490

C') Speise + Getränk Z. 490f

B') Salbe + Decke Z. 491f

A') Heimatlosigkeit + Dämonen Z. 493

In A) wird der Mensch durch den Tod aus der Lebenswelt ausgeschlossen. Der Verlust ordnungsgemäßer Totenpflege läßt seinen Totengeist zum ruhelos dahinschweifenden Gespenst werden. A') dagegen spricht vom Ausschluß des Menschen aus seiner kleinen Lebenswelt Heimat. Gespenster und Dämonen nehmen sein Haus in Besitz. Gemeinsames Thema beider Abschnitte ist also der Ausschluß aus dem naturgemäßen Lebensraum und die Nennung von Geistern und Dämonen.

B) thematisiert das Getriebensein des Verfluchten durch Schatten und Glut und das Fehlen jeglicher Schutzräume, wo er sich verkriechen könnte. Zum Schutz gegen die Glut der Sonne diente im Alten Orient die Salbung mit Öl. Die Decke oder Kleidung schützt den Menschen in der Kühle des Schattens. Als Salbe und Decke zum Schutz gegen Glut und Schatten, Hitze und Kälte, dienen in B') nur mehr die unzulänglichen und abstoßenden Mittel Naphta und Flußpflanze. Verbindendes Thema beider Ab- 
schnitte ist die Schutzlosigkeit der Verfluchten gegenüber Witterungseinflüssen.

Dem Abhandenkommen von Brot und Wasser in C) entspricht die Ernährung durch Asphalt und Eselsurin in C').

Der Pest und dem Eiter, wenn man diese Interpretation der syllabischen Schreibung zuläßt, in D) entspricht der Wunsch in D'), den Verfluchten möge alles Krankhafte zuteil werden. Man kann auch eine Verbindung zwischen den jeweils davor stehenden Flüchen ziehen. Not und Mangel in Z. 480 sind das Ergebnis, wenn dem Menschen alles Gute verboten wird (Z. 489).

Die Verbindung zwischen E) und $E^{\prime}$ ) leuchtet durch die schon besprochenen Lexemverknüpfungen hervor. In Z. 483 geht es um eine Bewegung in die Erde (ersetu) hinein, die nicht stattfinden soll. Die Leichen sollen nicht in die Erde kommen. In Z. 488 dagegen wird von einer Bewegung aus der Erde heraus gesprochen. Die Flut steigt aus der Erde empor. E) beginnt mit den Leichen jugendlicher Eidbrüchige in Assur, die offenbar eines gewaltsamen Todes starben und nicht begraben wurden (a). Darauf folgt das Geschick der Vereidigten selbst, die zusehen müssen, wie die Tiere mit den Körperteilen ihrer Nachkommen spielen und schließlich selbst keine Beerdigung erhalten, sondern den Tieren zum Fraß überlassen werden. Es endet mit dem Schicksal nach dem Tod (b). Logisch vorgeordnet erscheint das, was E') anspricht. Die Themen von E) werden chiastisch aufgenommen. Dem Geschick nach dem Tod entspricht das Leben bis zum Tod, das in Mühsal und Schlaflosigkeit zu Ende geht (b'). Der Feindeinfall, der in der Metapher einer Hochflut die Eidbrüchigen überspült und ihre Niederlage bewirkt (a'), ist die Voraussetzung für Greuel, wie sie Z. $482 \mathrm{f}$ beschreibt (a). Die Unterlegenen werden nach Assur geschleppt, wo schließlich Tiere ihr Spiel mit ihnen treiben. So erzählt E') die Vorgeschichte für das in E) Beschriebene.

Das Zentrum des ganzen Paragraphen bildet der dreifache Wunsch finsterer Tage, dunkler Jahre und der Finsternis als Schicksal. Dunkelheit und Finsternis stehen hier wohl als Metaphern für alles, was ein Leben unglücklich machen kann. VTE § 56 erweist sich somit als eine kunstvolle literarische Komposition, die in palindromischer Weise Kernbegriffe des Šamašfluchs umschließt.

\section{6. 5. Formengeschichte des Fluchs bei den Göttern}

Als Vergleichsmaterial kommen Flüche in Betracht, die jeweils Götter (DINGIR.MEŠ) ohne genauere Namensnennung anrufen, sie aber unterschiedlich charakterisieren. Manchmal heißen sie die großen Götter des 
Himmels und der Erde, manchmal die (großen) Götter, alle, deren Name auf dem Dokument (Tafel, Stein) genannt ist. Beide Einleitungsformeln kommen auch in den VTE vor.

B.1750.1: Kodex Hammurapi:

Kol. LI ${ }^{70}$ ilū rabûtum ${ }^{71}$ ša šamê ${ }^{72}$ u erșetim ${ }^{73}$ Anunnaku ${ }^{74}$ ina napharǐšunu

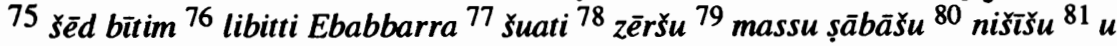
ummānšu 82 erretam ${ }^{83}$ maruštam lïrurū

"70 Die großen Götter ${ }^{71}$ des Himmels ${ }^{72}$ und der Erde, ${ }^{73}$ die Anunnaku ${ }^{74}$ in ihrer Gesamtheit, ${ }^{75}$ der Schutzgott des Tempels ${ }^{76}$ und das Ziegelwerk des Ebabbara ${ }^{77}$ mögen ihn selbst, ${ }^{78}$ seine Nachkommenschaft, ${ }^{79}$ sein Land, seine Truppen, ${ }^{80}$ seine Leute ${ }^{81}$ und sein Heer ${ }^{83}$ mit einem unheilvollen ${ }^{82}$ Fluch ${ }^{83}$ verfluchen .... . 1

B.1374?.1: RA 29, 99:

Rs. ${ }^{17}$ ilāni ša ina ṭuppi šuati zakrū līrurǚ̌su ${ }^{18}$ [...] akala u mê lizzemmi [...]-li $\check{s u}{ }^{19}[$...]-ra-su amassu li[l]mad

${ }^{17}$ Die Götter, die auf dieser Tafel genannt sind, mögen ihn verfluchen ${ }^{18}[\ldots]$ Brot und Wasser möge er entbehren, ${ }^{19}[. .$.$] sein Wort möge er lernen. { }^{2}$

B.1282.2: MDP 2, 86:

Kol. III ${ }^{16}$ ilāni rabûti mala 17 ina eli narê ${ }^{18}$ annî ${ }^{19}$ šumšunu zakru ${ }^{20}{ }^{2}$ akkū̌šnu kullumū ${ }^{21}$ u šubātušunu ${ }^{22}$ udda ${ }^{23}$ arrat lemutti ${ }^{24}$ lìrurūšu 25 šumšu lihalliqu ${ }^{26}$ zēršu ${ }^{27}$ ana šuli ${ }^{28}$ aji iršñ ${ }^{29}$ nidahi $^{3}$

${ }^{16}$ Die großen Götter, alle, ${ }^{19}$ deren Name auf ${ }^{18}$ diesem ${ }^{17}$ Stein ${ }^{19}$ genannt ist, ${ }^{20}$ deren Waffen gezeigt sind ${ }^{21}$ und deren Symbolsockel ${ }^{22}$ bezeichnet sind, ${ }^{23}$ mögen ihn mit einem bösen Fluch ${ }^{24}$ verfluchen, ${ }^{25}$ seinen Namen zerstören, ${ }^{26}$ seinen Samen ${ }^{27}$ zu entfernen ${ }^{28}$ mögen sie nicht ${ }^{29}$ nachlässig werden.

B.1172.1: BBS (Nr. 3), 18:

Kol. VI. 21 ilāni mala ina muh kudurri 22 annî šumšunu zakru 23 šumšu lihalliqu ${ }^{24}$ ana mimma lā bašê 25 lišălikū̌su

${ }^{21}$ Alle Götter, deren Name auf diesem Kudurru ${ }^{22}$ genannt ist, ${ }^{23}$ mögen seinen Namen zerstören, ${ }^{24}$ ihn zu völligem Nichtsein ${ }^{25}$ gehen lassen.

\footnotetext{
${ }^{1}$ BORGER, „Codex,“ 80. „Anunnaku wurden genannt die Götter der seit langem im Lande Ansässigen, vor allem der Sumerer, Igigu aber die Götter der später vor allem als Arbeiter ins Land gekommenen Nord- und Nordwestsemiten (Amurriter). Die nachaltbabylonische Theologie hingegen unterschied oft die Igigu als Götter des Himmels von den Anunnaku der Erde und Unterwelt.“ vSODEN, „Mottoverse,“ 236/207 Anm. 3.

${ }^{2}$ Wahrscheinlich wird Z. 19 einem anderen Gott zugesprochen. Zu Z. 18 vgl. AHw 1536 zummû(m) II 1).

${ }^{3}$ Vgl. LEICK, Fluchformeln, 21; AHw 209 elu(m) IV 9) a); 780 nīdu(m) B 1; 1258 šubtu(m) B 1 .
} 
B.1172.2 BBS (Nr. 4), 54:

Kol. IV ${ }^{5}$ ilāni mala ina muhhi narî annî [šum] šunu zakru ${ }^{6}$ arrat lā napšuri lìrurūšum $[a]^{7}$ ūma išten lā balāssu liqbû ${ }^{8}$ šâsu šumšu u zēršu aju ušabšn̂

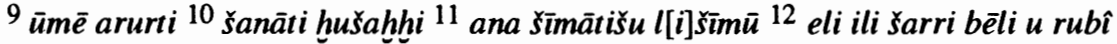
${ }^{13}$ lišemrișǚruma ${ }^{14}$ ina lemutti liklâ

${ }^{5}$ Alle Götter, deren Name auf diesem Stein genannt ist, ${ }^{6}$ mögen ihn mit einem unlösbaren Fluch verfluchen und ${ }^{7}$ befehlen, daß sein Leben nicht einen Tag (länger dauert). ${ }^{8} \mathrm{Ihn}$ selbst, seinen Namen und Samen mögen sie nicht bestehen lassen. ${ }^{9}$ Tage des Fluches ${ }^{10} \mathrm{Jahre}$ des Hungers ${ }^{11}$ mögen sie als sein Schicksal bestimmen. ${ }^{12}$ Vor Gott, König, Herr und Prinz ${ }^{13}$ mögen sie ihn mißfallen lassen. ${ }^{14} \mathrm{Im}$ Bösen möge er enden. ${ }^{1}$

B.1172.3: MDP 2, 99ff:

Kol. VII ${ }^{26}$ ilāni rabûti ${ }^{27}$ mala ina ${ }^{28}$ narî annî ${ }^{29}$ šumšunu zakru 30 šubātušunu uddâ ${ }^{31}$ kakkūšunu ${ }^{32}$ kullumū ${ }^{33}$ u ușurātušunu ${ }^{34}$ ușșurā

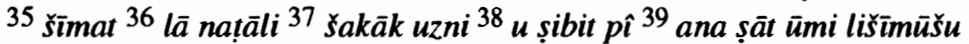

${ }^{26}$ Die großen Götter, ${ }^{27}$ alle, ${ }^{29}$ deren Name ${ }^{27}$ auf ${ }^{28}$ diesem Stein ${ }^{29}$ genannt ist, ${ }^{30}$ deren Symbolsockel gekennzeichnet, ${ }^{31}$ deren Waffen ${ }^{32}$ gezeigt, ${ }^{33}$ und deren Zeichnungen ${ }^{34}$ gezeichnet sind, ${ }^{35}$ ein Schicksal ${ }^{36}$ des Nichtsehens, ${ }^{37}$ Verstopfung der Ohren ${ }^{38}$ und Mundlähmung ${ }^{39}$ mögen sie für immer ihm bestimmen. ${ }^{2}$

B.1159.1: AfO 23, 1ff:

Kol. IV „8. DINGIR-MEŠ GAL-tum ma-la i-na 9. UGU DUR za-ak-ru 10. IBILA $u$ MU la $u(?)-x(-x)$

(...) Die großen Götter, welche auf ... genannt sind, mögen seinen Sohn und Namensträger ... ."3

B.1159.5: AfO 23, 16f:

Kol. IV ${ }^{15}$... ilāni mala ${ }^{16}$ ina narî annî šumšunu $z a[k r] u^{17}$ ina arrat arru pit [i] uzni aji irš̂̂

${ }^{15}$ Alle Götter, ${ }^{16}$ deren Name auf diesem Stein genannt ist, ${ }^{17}$ mögen wegen des Fluches, mit dem er verflucht ist, kein offenes Ohr (für ihn) haben. ${ }^{4}$

B.1105.1: BER 4, 152:

Kol. V 5 ilāni rabûti mala ina narî ${ }^{6}$ annî šumšunu zakru arrat lemutti ${ }^{7}$ lìrurūšu išissu lissuh̄u u zēršu lih̆alliqū

${ }^{1}$ Zu Z. 13 vgl. vSODEN, „Wörterbuch,“ 382 Anm. 1.

2 Zusammenhängende Umschrift nach STEINMETZER, „Schenkungsurkunde,“ 9.

${ }^{3}$ BORGER, „Grenzsteinurkunden,“ 3. ebd. 11: „IV,9. statt des in diesem Zusammenhang eigenartigen Zeichens DUR erwartet man entweder NA $\mathrm{NA}_{4}$-NA-RÚ-A = narú oder kudurru. Die Lesung DUR = riksu kommt wohl nicht ernstlich in Frage. IV, 10. Kollationsbedürftig. Man erwartet am ehesten la ú -šab-[šu(-ú)], aber für -[šu(-ú)] ist kein Raum vorhanden. Oder dürfte man etwa $u$-pa-lu (von uppulu ,zum Erben einsetzen', Kodex Hammurapi § 178) lesen??".

${ }^{4}$ Wörtlich: „keine Ohrenöffnung bekommen“. BORGER, „Grenzsteinurkunden,“ 17. 
${ }^{5}$ Die großen Götter, alle deren Name auf diesem Stein ${ }^{6}$ genannt ist, mögen ihn mit einem schlimmen Fluch ${ }^{7}$ verfluchen, sein Fundament ausreißen und seinen Samen vernichten.

B.1105.2: BBS (Nr. 6), 36:

Kol. II 51 ilāni rabûti annûtu ina uzzat libbi 52 ana lemutti lihtasassūšsma 53 būt ìpušu libēl šanûma ${ }^{54}$ ultu patru ina kišădišu u quppû ina ìnišu ${ }^{55}$ ana șābitānišu appašu lilbimma ${ }^{56}$ unninī̌su aji imhuršu 57 ḩantiš likkisa napšassu

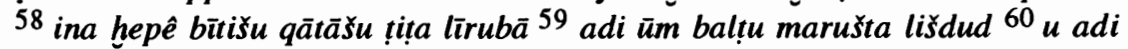
šamê u erșetu bašu zèrršu lihliq

${ }^{51}$ Diese großen Götter mögen im Zorn ihrer Herzen ${ }^{52}$ zum Bösen an ihn denken! ${ }^{53}$ Das Haus, das er baute, möge ein anderer beherrschen! ${ }^{54} \mathrm{Um}$ (zu vermeiden, daß ihm) ein Schwert in seinen Nacken und ein Messer in sein Auge (gestoßen werde, ${ }^{55}$ möge er sich vor seinem Fänger auf sein Angesicht werfen, ${ }^{56}$ und der möge sein Flehen nicht annehmen! ${ }^{57}$ Schnell möge er sein Leben abschneiden! ${ }^{58}$ Beim Zusammenbruch seines Hauses mögen seine Hände in den Lehm eindringen! ${ }^{59}$ Während der Tage seines Lebens möge er Böses erfahren ${ }^{60}$ und solange Himmel und Erde existieren möge sein Same zugrunde gehen.

B. 1083.1: BBS (Nr. 7), 42:

Kol. II ${ }^{36}$ ilāni rabûti mala ina narî annî sumšunu zakru ${ }^{37}$ ana lemutti u lā tâbti lirteddûšu 38 šumšu zērš̌ per'ešu nannabšu ${ }^{39}$ ina pî nišēe dišāti lihalliqū ${ }^{36}$ Alle großen Götter, deren Name auf diesem Stein genannt ist, ${ }^{37}$ mögen ihn zum Bösen und nicht Guten lenken, ${ }^{38}$ seinen Namen, seinen Samen, seinen Sproß und seinen Nachkommen ${ }^{39}$ im Mund der weit verbreiteten Menschen vernichten!

B.1083.2: BBS (Nr. 8), 48 Kol. IV Z. 32-35 = B.1172.2 Kol. IV Z. 5f. BBS (Nr. 8), 48 Beischrift Z. 6 f entspricht ebenfalls fast genau B.1172.2 Kol. IV Z. $5 f$.

B.1083.3: Sumer 38, 126 Kol. V Z. 29-32 = B.1172.2 Kol. IV Z. 5 f.

B.1070.1: ZA 65, 59:

Kol. II 76 ilū rabûtu mala ina narî annî 77 šumšunu zakru šuniršunu uddû 78 uṣurātušunu ușṣurā 79 u šubātušunu bašmā 80 ina bunīšnnu ezziš 81 likkilmûšunu ${ }^{82}$ ina murṣi di’i dilipti ${ }^{83}$ qüli kūri nissāti ${ }^{84}$ imtî tanehi lā țūb libbi lā țūb širi 85 idirti gerrāni ${ }^{86}$ u bikīit ümi ulā naparkâ lištabrûšu

„76. Alle großen Götter, deren Name auf dieser Stele 77. genannt ist, deren Embleme gekennzeichnet sind, 78. deren Bilder gezeichnet sind, 79. deren Symbolsockel geformt sind, 80. mögen ihn mit ihrem Antlitz 81. in wildem Zorn anschauen, und 82. ihn in Krankheit, Kopfschmerz, Schlaflosigkeit, 83. Schweigen, Ohnmacht, Jammern, 84. Mangel, Klage, Unglück, Mißbehagen, 
85. Trübsal, Wehklage 86. und Weinen ohne Unterlaß 87. die Tage verbringen lassen."1

B.1070.2: Sumer 36, 133:

Kol. III ${ }^{29}$ ilū rabûtu IV ${ }^{1}$ mala ina narî annî ${ }^{2}$ šumšunu zakru ${ }^{3}$ arrat lemutti ša lā napšuri līrurūšu ${ }^{4}$ šumšu lihalliqū ${ }^{5}$ zēršu lilqutū ${ }^{6}$ išissu per'ešu lissuh̄ū ${ }^{7}$ bissu u kudurrašu lispuhū ${ }^{8}$ aja iršî aššata simat lălišu ${ }^{9}$ apla zākir šūmi ${ }^{10}$ aha talima ${ }^{11}$ ana ahi ah̆u litūrš̌u ${ }^{12}$ lizammi rû̀a ${ }^{13}$ mammana itbāra ${ }^{14}$ ina

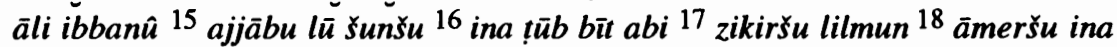
sūqi ${ }^{19}$ arrata libilšu ${ }^{20}$ nišēšu lirmumāšu

III ${ }^{29}$ Die großen Götter, IV ${ }^{1}$ alle, ${ }^{2}$ deren Name ${ }^{1}$ auf diesem Stein ${ }^{2}$ genannt ist, ${ }^{3}$ mögen ihn mit einem bösen Fluch, der nicht gelöst werden kann, verfluchen, ${ }^{4}$ seinen Namen mögen sie vernichten, ${ }^{5}$ seinen Samen mögen sie einsammeln, ${ }^{6}$ sein Fundament und seinen Nachkommen mögen sie ausreißen, ${ }^{7}$ sein Haus und seinen Grenzstein mögen sie zerstreuen, ${ }^{8}$ er soll nicht besitzen: eine Frau, die Zugehörige seiner Lust, ${ }^{9}$ einen Erbsohn, den Nenner seines Namens, ${ }^{10}$ einen bevorzugten Bruder; ${ }^{11}$ der Bruder möge sich zum Fremden verwandeln; ${ }^{12} \mathrm{er}$ sei des Gefährten beraubt; ${ }^{13}$ jeder Freund, ${ }^{14} \mathrm{der}$ in der Stadt geschaffen war, ${ }^{15}$ sei sein Feind; ${ }^{16}$ im Guten des Vaterhauses ${ }^{17}$ möge sein Andenken schlecht werden; ${ }^{18}$ wer ihn auf der Straße sieht, ${ }^{19}$ möge ihm Fluch bringen, ${ }^{20}$ seine Leute sollen ihn anbrüllen.

B. 1047.1: BER 4, 194:

Kol. III ${ }^{9}$ ilāni kališunu mala క̌umšunu ${ }^{10}$ zakru kî ištēen ùmi lā balāssu ${ }^{11}$ liqbû ${ }^{9}$ Die Götter, ihre Gesamtheit, alle, deren Name ${ }^{10}$ genannt ist, mögen ihm nicht für einen einzigen Tag Leben ${ }^{11}$ gewähren.

B.944.1: BBS (Nr. 9), 69 Kol. V Z. 6-7 = B.1172.2 Kol. IV Z. 5+7.

B.748.1: RA 16, 143:

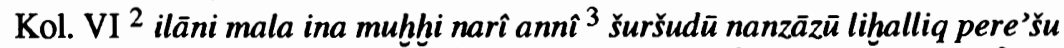
${ }^{2}$ (Jeder einzelne) aller Götter, ${ }^{3}$ deren Ehrenplätze ${ }^{2}$ auf diesem Stein ${ }^{3}$ fest gegründet sind, möge seinen Sproß ausreißen. ${ }^{2}$

B.711.1: VS I 37 Kol. V Z. 45-47:

Kol. $\mathrm{V}^{45}$ ilāni rabûti mala ina narî annî 46 šumšunu zakru šumšu zēršu pere’šu 47 ina pî nišē lihalliqū likkisū arkassu

${ }^{45}$ Alle großen Götter, ${ }^{46}$ deren Name ${ }^{45}$ auf diesem Stein ${ }^{46}$ genannt ist, mögen seinen Namen, seinen Samen, seinen Sproß ${ }^{47}$ im Mund der Menschen vernichten, sein Erbe mögen sie abschneiden. ${ }^{3}$

1 RESCHID / WILCKE, „Grenzstein,“ 59.

2 Vgl. CAD 11/N I, 262 manzāzu 2. a); AHw 732 nanzāzu 3.

$3 \mathrm{Vgl}$. CAD 1/A Il arkatu 3. d). 
A.705.8: VS I 71:

Kol. II (IV) ${ }^{65}$ [ilāni rabû] ti mala ina narî ${ }^{66}$ [annî] šumšunu nabû u ilāni 67 [āš̄ib] ūt qereb tâmti rapašti 68 [...? lī]rurūǔsuma šumšu zēršu 69 [ina mā]ti lih̆alliqū ${ }^{70}$ [aji iršûšu] rēmu ina sunqi hušahhi ${ }^{71}$ [bubūti] lipit erra 72 [lișah] hirūu nišešsu ${ }^{73}$ [ina šapal n] akrišu kamiš lišēešibūšuma ${ }^{74}$ [ina niṭil] ēnēš māssu lištappar

${ }^{65}$ [Alle großen Götter], ${ }^{66}$ deren Name auf [dieser] Stele genannt ist, und die Götter, ${ }^{67}$ die mitten im weiten Meer [wohnen], ${ }^{68}$ mögen ihn [...? ver]fluchen, seinen Namen und seinen Samen ${ }^{69}$ [aus dem Land] vertilgen. ${ }^{70}$ [Sie mögen ihm gegenüber] kein Mitleid [haben]. Durch Not, Hungersnot, ${ }^{71}$ [Hunger] (und) Pest ${ }^{72}$ [mögen] sie seine Untertanen (wörtlich: Menschen) [ver]ringern. ${ }^{73}$ [Zu Füßen (wörtlich: unter)] seines Feindes mögen sie ihn gefesselt sitzen lassen. ${ }^{74}$ Auf Dauer möge dieser - [vor seinen] Augen - sein Land beherrschen. ${ }^{1}$

A.681.1: LUCKENBILL, Sennacherib, 85:

59 ilū rabûti mala ina narî annî šumu nabû ina șīt pišu $[n u]{ }^{60}$... ša lā nakāri arrat lemutti līrurūšuma liskipū palêšu

${ }^{59}$ Alle diesen großen Götter, deren Name auf dieser Stele genannt ist, mögen ihn durch einen Ausspruch ihres ... Mundes, ${ }^{60}$ der nicht aufgehoben werden kann, mit einem bösen Fluch verfluchen, seine Herrschaft stürzen. ${ }^{2}$

A.681.3: LUCKENBILL, Sennacherib, 139:

${ }^{68}$ Aššur šar ilāni u ilāni rabûti ša samê u erșeti ${ }^{69}$ arrat [lā] napšuri marušti lïrurū̌šma ${ }^{70}$ šarrussu liškipū balassu līkimūšu ${ }^{71}$ šumšu zēršu per'ešu u nannabšu 72 ina naphar mātăti lihalliqū

${ }^{68}$ Assur, der König der Götter, und die großen Götter des Himmels und der Erde ${ }^{69}$ mögen ihn mit bösem, unlösbarem Fluch verfluchen und ${ }^{70}$ sein Königtum umstürzen! Sein Leben mögen sie ihm rauben, ${ }^{71}$ seinen Namen, Samen, Sproß und Nachkommen ${ }^{72}$ in jedem Land vernichten.

A.681.4: LUCKENBILL, Sennacherib, 147 Z. 35*-39 entspricht A.681.3, nur der Schluß variiert:

${ }^{39}$ per'ešu u nannabšu ina pî niše liḩalliqū

seinen Sproß und Nachkommen im Mund der Menschen vernichten.

A.681.5: LUCKENBILL, Sennacherib, $148=$ A.681.3.

A.669.2: SAA 2 (Nr. 4), 24ff:

Kol. IV ${ }^{8}$ ilāni rabûti ša šamê u erșeti ilāni māt Aššur ilāni māt Akkad ${ }^{9}$ ilāni Ebir-nāri arrat lā napšuri tīrurǚrku'nu

\footnotetext{
${ }^{1} \mathrm{Zu}$ Umschrift und Übersetzung von $\mathrm{Z} .70 \mathrm{vgl}$. CAD 15/S, 386b sunqu; zu $\mathrm{Z} .73$ vgl. CAD 8/K, 122 kamiš A; zu Z. 74 vgl. CAD 17/Š I, 447 šapāru 3. b) 2' und AHw, 1171.

2 Vgl. CAD 16/Ṣ, 219 șītu 2c.
} 
„8'So mögen die großen Götter des Himmels und der Erde, die Götter von Assyrien, die Götter von Akkad, 9' die Götter von Eber-nari euch mit einem unlösbaren Fluche verfluchen."1

A.669.7: SAA 2 (Nr. 14), 78:

Kol. II ${ }^{10}$ ilāni rabûti bēl eš[rēti? lišīmū̌šu] ${ }^{11}$ Y̌ìmā[ti arrāti] ${ }^{12}$ mala ina libbi $a d\left[\hat{e}\right.$ šuati ${ }^{13}$ šuršudū na[-xxx] ${ }^{14}$ marušta ša dūr ūmé li $[-\mathbf{x x x}]^{15}$ zamar $l \bar{a}\left\ulcorner_{i}{ }^{1}\right.$ ? $-\mathbf{x x x}$

${ }^{10}$ Die großen Götter, die Herren der Sch[reine mögen für ihn bestimmen] ${ }^{11}$ die Geschi[cke, Flüche,] ${ }^{12}$ alle die inmitten [dieses] adê ${ }^{13}$ fest gegründet sind [...] ${ }^{14}$ (alle) Tage dauernde Krankheit mögen sie [...] ${ }^{15}$ schnell nicht [...].

Als ein illustratives Beispiel für die Zusammenstellung von Fluchmotiven mit Anrufung mehrerer Götter sei das Kudurru B.1159.1: BBS (Nr. 5), 29 zitiert:

Kol. III ${ }^{26}$ Anu Enlil u Ea ${ }^{27}$ Ninurta u Gula ${ }^{28}$ bēlū erșeti šuatum ${ }^{29}$ u ilāni mala ${ }^{30}$ ina narî suatum ${ }^{31}$ ešrētušunu uddâ ${ }^{32}$ ezziš likkilmûšu ${ }^{33}$ arrat lā

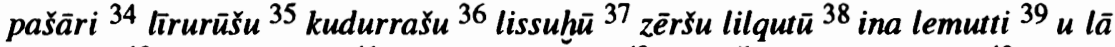
țūb širi ${ }^{40}$ adi ūmī ișüti ${ }^{41}$ sa balța liqtima ${ }^{42}$ ema Šamaš u Marduk ${ }^{43}$ išassû ${ }^{44}$ aji $[i \grave{s}]$ mûšu

${ }^{26} \mathrm{Anu}$, Enlil und $\mathrm{Ea},{ }^{27} \mathrm{Ninurta}$ und Gula, ${ }^{28}$ die Herren des besagten Landes ${ }^{29}$ und alle Götter, ${ }^{31}$ deren Heiligtümer ${ }^{30}$ auf besagtem Stein ${ }^{31}$ verzeichnet sind, ${ }^{32}$ mögen ihn böse anblicken, ${ }^{33}$ mit einem unlösbaren Fluch ${ }^{34}$ verfluchen ${ }^{35}$ sein Kudurru ${ }^{36}$ ausreißen, ${ }^{37}$ seinen Samen aufpicken. ${ }^{38} \mathrm{Im}$ Bösen ${ }^{39}$ und in Unwohlsein des Körpers ${ }^{40}$ mit geringen ${ }^{41}$ Lebenstagen ende er! ${ }^{42}$ Wenn er zu Šamaš und Marduk ${ }^{43}$ schreit, ${ }^{44}$ sollen sie ihn nicht hören!

Die folgende Tabelle zeigt, welche Motive aus $\S 56$ auch in Flüchen unter Anrufung anderer Gottheiten oder in den Inschriften unter Nennung der großen bzw. genannten Götter vorkommen. So wird ersichtlich, daß der § 56 aus verschiedenen traditionellen Formeln und Motiven zusammengesetzt ist, die von ihrer Bindung an eine bestimmte Gottheit gelöst wurden. ${ }^{2}$ Die assyrische Hofkanzlei verwendete offenbar traditionelles Material, um daraus einen unter den bekannten mesopotamischen Texten einmaligen palindromisch strukturierten Fluch zu schaffen.

${ }^{1}$ BORGER, „Baal,“ 159 Anm. 9’a) zu Eber-nari: „D. h. ,Transpotamien“ = Syrien“.

2 Vgl. WATANABE, Thronfolgeregelung, 196. 


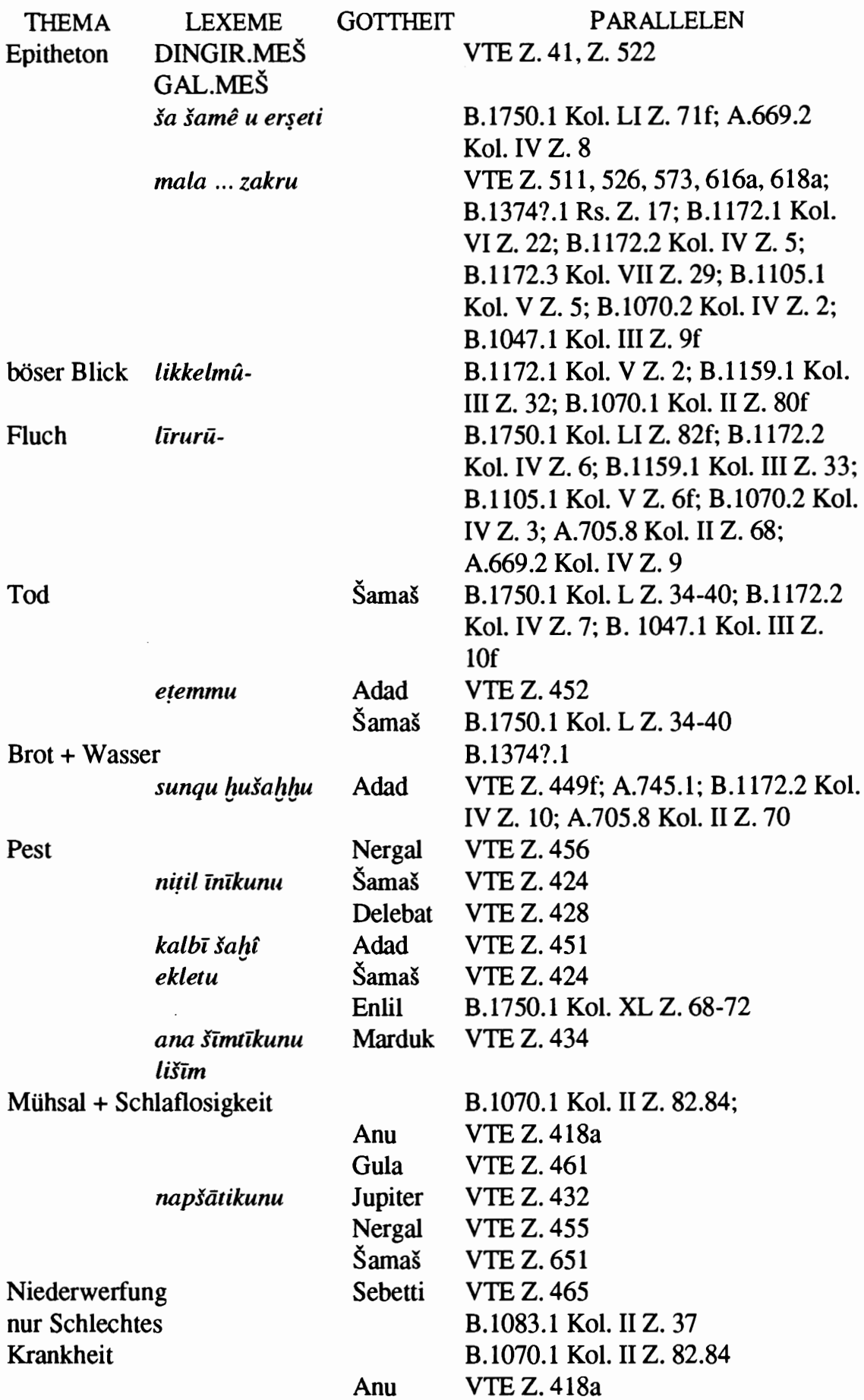




$\begin{array}{lll}\text { Nahrung } & \text { Gula } & \text { VTE Z. 461 } \\ \text { Getränk } & \text { Adad } & \text { A.745.1 Kol. IV Z. 14 } \\ \text { Salbe } & \text { Adad } & \text { A.745.1 Kol. IV Z. 15 } \\ \text { Kleidung } & \text { Adad } & \text { A.745.1 Kol. IV Z. 14 } \\ \text { Heim } & \text { Adad } & \text { A.745.1 Kol. IV Z. 15 } \\ & \text { Adad } & \text { A.745.1 Kol. IV Z. } 16\end{array}$

Die meisten Bezüge bestehen zu Flüchen der Götter Adad und Šamaš. Die Reihenfolge der Fluchmotive orientiert sich nur teilweise an einer Götterhierarchie. Die Motive böser Blick und Fluch bilden in der mesopotamischen Tradition häufig den Anfang von Fluchsequenzen. Dieses überlieferte Bauelement mag bei der Komposition der Einleitung von $\S 56$ Pate gestanden haben. Allerdings zeigen die gesammelten Flüche bei den großen Göttem, daß beide Fluchmotive in der mesopotamischen Tradition auch als Einleitungsformeln verwendet wurden. Die Motive gehörten offenbar an den Anfang eines umfangreicheren Fluchs. Das nächste Motiv, das einer Gottheit zugeordnet werden kann (Z. 476f), kommt in Šamašflüchen vor. Šamašflüche stehen in den meisten Fluchsequenzen der Kudurrus ziemlich am Anfang. Zumindest der Beginn von $\$ 56$ wurde also nach traditionellen Bauprinzipien konstruiert. Die Anordnung der übrigen Motive des $\S 56$ läßt keine Orientierung an einem Pantheon erkennen. Nur ein Strukturelement, das auch in anderen Fluchsequenzen erkennbar war, zeigt sich noch. Das Thema Krankheit / Mühsal wird dort mehrmals angesprochen, meist unter Anrufung von Sin und Gula, und umklammert andere Themen. Die Verteilung der Bezüge zum Gula- und Anufluch zeigt, daß dieses Bauprinzip auch in $\S 56$ angewandt wurde. Die markante Schlußpassage mit der Verwünschung der Grundbedürfnisse menschlichen Daseins gehörte offenbar zum vorgegebenen Textmaterial assyrischer Staatsschreiber, wie der Adadfluch im Vertrag A.745.1 zeigt. Dort bilden diese Elemente allerdings nicht den Schluß eines Textabschnittes. Sie konnten also an beliebiger Stelle eingebaut und unterschiedlichen Göttem zur Ausführung anheimgestellt werden.

Die Einleitung mit den Motiven böser Blick und Fluch (Z. 472-475) fügt sich nicht in die Palindromie und steht gewissermaßen als Vorbau vor dem in sich geschlossenen Rest des Paragraphen. Während man also in Mesopotamien bei der Lösung der Fluchmotive von den Einzelgöttern eine vom Pantheon abstrahierte Palindromie schuf, gleicht der allein auf JHWH konzentrierte Bibeltext in der Themenfolge von 28,27-30 dem Aufbau polytheistischer Fluchsequenzen Mesopotamiens. Da die Autoren von $\S 56$ überkommene Formeln und Motive aus ihren traditionellen Bindungen an einzelne Götter lösten und nach literarischen Gesichtspunkten neu kombinierten, kann die altorientalische Konvention zur Gestaltung von Flüchen 
nicht so dominierend gewesen sein, daß der Verfasser des Bibeltextes sich genötigt sah, seine Fluchmotive in der beschriebenen Weise zu reihen.

\section{7. VTE § 63-65, die Parallele zu Dtn 28,23(-25?)}

$\S 63526$ do. (do.) ilānī mala ina țuppi adê an[nî šumšunu zakru] ${ }^{527}$ ammar libitti kaqquru lusiqqūnekkunu ${ }^{528}$ kaqqarkunu k̄̄ parzilli lēpušù mēmēni 529 ina libbi lū lā iparru'a

$\S 64{ }^{530} k \bar{c}$ ša issu libbi šamā'ē ša siparri zunnu lā izannunūni ${ }^{531}$ kī hanni’e zunnu nalšu ana libbi eqlātīkunu ${ }^{532}$ tamerātîkunu lū lā illak kūm zunni 533 pe'nāte ana mätīkunu liznunā

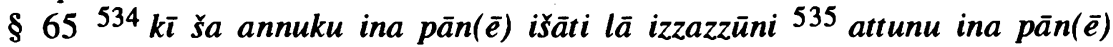

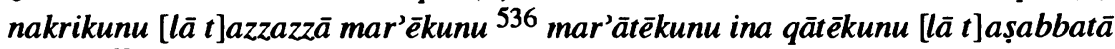
„§ $63{ }^{526}$ Dito, mögen alle Götter, [deren Namen] auf dieser Tafel [genannt sind], ${ }^{527}$ euch den Boden eng wie einen Ziegel machen, ${ }^{528}$ euren Boden wie (aus) Eisen machen! Nichts ${ }^{529}$ möge daraus aufgehen!

$\S 64{ }^{530}$ Wie es vom Himmel aus Bronze nicht regnet, ${ }^{531}$ so mögen Regen und Tau auf eure Felder ${ }^{532}$ und eure Fluren nicht kommen! Statt Regen (Var. Tau) ${ }^{533}$ möge (es) Kohlen auf euer Land regnen!

$\S 65{ }^{534}$ Wie Zinn dem Feuer nicht widerstehen kann, ${ }^{535}$ so sollt ihr vor eurem Feind nicht standhalten können! Ihr sollt eure Söhne ${ }^{536}$ und Töchter [nicht (mehr)] mit euren Händen packen können!"1

\subsection{Textvarianten}

Watanabe vermerkt, daß von den erhaltenen Textzeugen nur das Manuskript ND 4327 zwischen $\S 63$ und 64 einen Trennungsstrich hat. ND 4328A läßt die Z. 526 aus.

Z. 527 lusiqqūnekkunu] diese assyrische Form bezeugen ND 4328A und 4331, ND 4327 und 4335+ haben das babylonische lisi-.

Z. 532 küm zunni] ,statt Regen“" schreibt ND 4328C. Dagegen hat ND 4327 kūm [na]lši ,statt Tau“, während ND 4328A das Sumerogramm ŠÈG bietet, das sowohl zunnu als auch nalšu gelesen werden kann, und ND 4331 diesen Satz ganz ausläßt und erst mit Z. 534 fortfährt.

Z. 533 pe'nāte] so ND 4328A und 4335+4408. ND 4327 bietet statt dessen pehn[äte.$^{2}$

\footnotetext{
1 WatanaBE, Thronfolgeregelung, 169; vgl. ebd. 168.

2 Vgl. WatanaBE, Thronfolgeregelung, 122f, $198 \mathrm{f}$.
} 


\subsection{Sprachlich-syntaktische Analyse}

Am Anfang von $\S 63$ steht das „Dito“-Zeichen KIMIN.KIMIN. Borger und Watanabe nehmen an, daß damit die Fluchbedingungen aus Z. 513-517 wiederholt werden sollen. ${ }^{1}$ Durch das Wiederholungszeichen wird der zweite Fluchabschnitt (ab Z. 513) in Untereinheiten eingeteilt, die jedesmal mit der ermeuten Nennung der Bedingung gedacht werden sollten. Die erste Untereinheit umfaßt die explizite Protasis Z. 513ff sowie die sich anschließenden Assur- (Z. 518), Palil- (Z. 519), Ea- (Z. 521), Götter- (Z. 523) und Girraflüche (Z. 524). Die Bezüge zum Ninurtafluch wurden bereits behandelt. Wassersucht (aganutillû Z. 521) ist die Strafe für den Meineid und normalerweise in Mesopotamien mit Marduk verbunden. ${ }^{2}$ Auch die großen Götter des Himmels und der Erde wurden bereits behandelt und die Belege für den Namens- und Nachkommenschaftsfluch (Z. 524) sind fast unzählbar. In diesen Abschnitten stehen also allgemein verbreitete Fluchmotive, teilweise mit Rückbezug zum ersten Fluchabschnitt der VTE, teilweise mit Bezug zu anderen Texten der mesopotamischen Fluchtradition. Das KIMIN-Zeichen in $\S 63$ leitet eine zweite Einheit ein, die sich bis $\S 68$, einem Šamašfluch, erstreckt. Sie umfaßt neben den hier besprochenen Flüchen in $\S 66$ einen Vergleichsfluch, der die menschliche Unfruchtbarkeit im Vergleich mit dem Maulesel heraufbeschwört, und in $\S 67$ einen Vergleichsfluch, der dasselbe Thema im Vergleich mit dem Malzkeimling in der Biermaische ausdrückt.

$\S 63$ beginnt mit einem langen Satz, dessen Subjekt das durch einen Relativsatz erweiterte ilāni bildet, von dem im Hauptsatz zwei Prädikate ( $Z$. 527, 528) abhängig sind. Beide Prädikate beziehen sich auf ein gleichlautendes Akkusativobjekt. Z. 527f weist einen Chiasmus auf, bei dem das Prädikat zwar jeweils am Satzende steht, dafür aber das enklitische Personalpronomen chiastisch wechselt:

Vergleichspartikel + tertium comparationis - kaqqaru - Prädikat + ePP kaqqaru + ePP - Vergleichspartikel + tertium comparationis - Prädikat

\footnotetext{
${ }^{1} \mathrm{Vgl}$. Borger, „Vasallenverträge,“ 173 Anm. 526a. ${ }^{513}$ Solltet ihr gegen „diese adêVereidigung, die Asarhaddon, König von Assyrien, euer Herr, ${ }^{514}$ [be]treffs Assurbanipals, des Groß-Prinzen des Nachfolgehauses, ${ }^{515}$ seiner [Brüder], der Söhne [der Mutter Assurbanipals], des Groß-Prinzen des Nachfolgehauses, ${ }^{516}$ und der übrigen leiblichen Söhne Asar[haddons, Königs von] Assyrien, ${ }^{517}$ (eures Herrn), mit euch [vorgenommen] hat, sündigen, ..." WATANABE, Thronfolgeregelung, 167, 169; vgl. ebd. 198.

2 Vgl. WATANABE, Thronfolgeregelung, 193; OETTINGER, Eide, $71 \mathrm{f}$.
} 
In Z. 528 fängt der zweite Satz des Fluches mit dem neuen Subjekt $m \bar{e} \bar{m} \bar{e} n i$ an, das im negierten Wunsch ,nichts“ 'bedeutet. ${ }^{1}$

Z. 526 enthält eine Einleitungsformel, die aus vielen mesopotamischen Inschriften bekannt ist und in den VTE hier erstmalig vorkommt. Dieselbe Formel steht auch in $\S 77 \mathrm{Z}$. 573 sowie in einigen Texten in $\S 91 \mathrm{Z} .616 \mathrm{~A}$ und $\S 92$ Z. 618A. ${ }^{2}$ Wo immer die Formulierung außerhalb von $\S 63$ in den VTE auftaucht, geht es um das Thema Niederlage bzw. Rückzug vor dem Feind. Geschlechtsumwandlung ( $\$ 91)$ macht die Männer zu Frauen vor dem Feind und das Bild vom zurückweichenden Krebs ( $\$ 92)$ scheint eine militärische Konnotation zu implizieren. Aus Z. 527 führt das syllabisch geschriebene kaqquru „Boden, Grund, Erde“ zum Epitheton des Ša mašfluchs (Z. 422), wo der Gott ausdrücklich nicht Licht der Erde (in den VTE meist $\mathrm{KI}^{\text {-tim }}$ für erșeti(m)), sondern genau genommen Licht des Erdbodens (kaqqaru) genannt wird. Die übrigen Worte aus Z. 527 kommen in den VTE nur hier vor. Auch AN.BAR / parzillu „Eisen“ in Z. 528 verknüpft $\S 63$ mit dem Sonnengott. Das Wort kommt in den VTE nur noch in $\S 68$ Z. 545, dem bereits zitierten Šamašfluch, vor. Während in $\S 63 \mathrm{der}$ Boden zu Eisen wird, pflügt Šamaš dort Stadt und Bezirk der Verfluchten mit eisernem Pflug. Dazu würde die Übersetzung Borgers für Z. 529 passen, der iparru'a von parä'u I ,durch-, abschneiden“ ableitet: , ,... so daß niemand ${ }^{529}$ ihn pflügen kann."3 Watanabe dagegen setzt parä’u II ,aufgehen (von Pflanzen)“ an. ${ }^{4}$ Ob nun der Boden keine Pflanzen hervorbringt oder ob er nicht bearbeitet werden kann, gemeinsam bleibt beiden Deutungen die landwirtschaftliche Nutzlosigkeit. Das Motiv des Šamašfluchs hat seine Wurzeln wohl in den Vemichtungsritualen an eroberten Städten (umpflügen, mit Salz bestreuen). Gleichzeitig bildet er aber den Abschluß der durch das Wiederholungszeichen in $\S 63$ eingeleiteten Untereinheit. So ist die Verbindung beider Paragraphen durch die landwirtschaftliche Bildwelt und die Anordnung innerhalb der Fluchsequenz unübersehbar. In Z. 541 ist parä'u ,sprossen“ aus Z. 529 nochmals belegt. Es steht im Vergleichsfluch mit dem Malzkeimling in der Biermaische, gehört also ebenfalls zum Abschnitt §§ 63-68. § 63 enthält demnach Lexemverbindungen zu anderen Flucheinleitungen durch die Formel in Z. 526 sowie zu den Šamašflüchen $\S 40$ und in $\S 68$.

$\S 64$ beginnt wie die folgenden Paragraphen 65, 66 und 67 mit der Vergleichspartikel ki ša, ein Wort, das in Aufbau und Funktion dem hebräi-

\footnotetext{
1 Vgl. WatanaBe, Thronfolgeregelung, 198.

2 Vgl. Watanabe, Thronfolgeregelung, 205.

3 BORGER, ,Vasallenverträge,“ 173.

4 Vgl. WatANABE, Thronfolgeregelung, 199.
} 
schen כאשי entspricht. An den Vergleichssatz (Z. 530) schließen sich zwei Wunschsätze (Z. 531-533) an, von denen der erste verneint ist und durch $k \hat{\imath}$ hanni'e „genauso“ an den Vergleichssatz anknüpft.

Der Kernbegriff des $\S 64$ lautet A.AN / zunnu ,Regen“ und kommt in jedem der drei Sätze vor (Z. 530, 531, 532), sonst aber in den VTE nicht mehr. Dagegen begegnete das Verb zanānu (Z. 530, 533) bereits im Anufluch (VTE Z. 418c). ${ }^{1}$

Das Wort UD.KA.BAR / siparru „Bronze“ findet sich in den VTE nur noch in einem Šamašfluch. In Z. 649 beginnt mit $\$ 101$ der letzte der durch das Dito-Zeichen eingeleiteten Unterabschnitte des zweiten Fluchteils. Dort dient das Metall zur Qualifizierung einer göttlichen Vogelfalle durch eine Genitivverbindung (huhăāru ša siparri). Wie bei § 68 führt der Vergleich zu Šamaš, wieder steht dieser Šamašfluch an exponierter Stelle, diesmal als Einleitung der letzten Unterabteilung der Flüche, wieder besteht das Arbeitsgerät des Gottes aus dem Material des tertium comparationis der Vergleiche aus $\S \S 63 \mathrm{f}$. Die Verknüpfungen der $\S \S 63 \mathrm{f} \mathrm{mit} \mathrm{den}$ Šamašflüchen $\S \S 68$ und 101 scheinen nicht zufällig zu sein. In der mesopotamischen Literatur fehlen jedoch bisher Hinweise auf eine besondere Verbindung des Sonnengottes mit den Metallen Eisen und Bronze ebenso wie auf eine Verantwortlichkeit dieses Gottes für Regenmangel und Bodenaustrocknung.

Dem syllabisch aus Z. 530 aufgenommenen Regen wird in Z. 531 nalšu „Tau“ beigeordnet, das im ganzen Korpus der assyrischen Verträge nur hier und in der folgenden Zeile vorkommt. Man würde erwarten, daß der Regen und der Tau auf den „Boden“ fallen und so eine lexikalische Verknüpfung zum vorhergehenden Paragraphen geschaffen würde. Dies geschieht jedoch nicht. Statt dessen wird das Objekt, welches Regen und Tau nicht empfangen soll, mit zwei Ausdrücken genauer festgelegt: A.ŠÀ / eqlu „Feld" und tamertu „Flur". Auch in Z. 533 stellen die Verfasser keine lexikalische Lexemverbindung zum vorhergehenden Paragraphen her. Das wäre leicht möglich gewesen, wenn es auf den „Boden“ (kaqqaru) statt auf das , Jand“ (mätikunu) regnen würde. Tatsächlich ist $\S 64$ durch kein einziges Wort mit dem vorhergehenden Paragraphen lexikalisch verknüpft, sieht man von dem Allerweltswort Š̀̀ / libbu „Herz, Mitte“ ab, das zur Ortsangabe dient. Angesichts der Wiederholungen der Kernbegriffe kaqqaru und zunnu innerhalb der jeweiligen Paragraphen, kann die lexika-

${ }^{1}$ In Z. 530 wird der Vergleich in Sumerogrammen ausgedrückt (TAŠ̀̀ AN ${ }^{-e} \zeta \check{a}$ UD.KA.BAR. A.AN). Das Sumerogramm für „Himmel“" sieht genauso aus wie in den anderen Belegen der VTE. Watanabe scheint es nur aufgrund der assyrischen Verbformen im as-

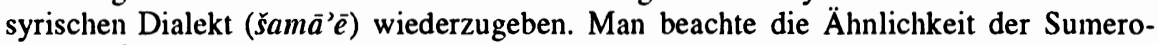
gramme ${ }^{\mathrm{d}} \mathrm{AN}=A n u$, der vergöttlichte Himmel, A.AN = Himmelswasser, Regen. 
lische Beziehungslosigkeit der beiden Flüche nicht damit erklärt werden, die Verfasser hätten nach dem Grundsatz variatio delectat formuliert. Es scheint vielmehr hier ein sprachlicher Hinweis dafür vorzuliegen, daß den Verfassern eine Parallelität beider Paragraphen nicht bewußt war oder daß ihnen zumindest die Parallelisierung der Motive Boden / Eisen - Himmel / Bronze kein besonderes Anliegen war. Darauf wird in der Behandlung der Fluchgattungen noch zurückzukommen sein. In der Tat lautet vom Sprachbefund her die Gegenüberstellung beider Paragraphen nicht Erde Himmel, sondern Boden - Regen. In $\S 63$ werden Veränderungen des Bodens beschrieben, in $\S 64$ Veränderungen des Regens. Der Regen soll gemäß Z. 533 zu pe'nāte „Holzkohle“ werden. Der letzte Fluchsatz (Z. 532*, 533) bezieht sich nicht mehr auf den Vergleich von Z. 530 zurück, sondern stellt einen eigenständigen Wunsch dar.

$\S 65$ beginnt wie $\S 64$ mit einem Vergleichssatz, der in Z. 435 auf die Verfluchten angewendet wird. Abgeschlossen wird der Fluch wie im vorhergehenden Paragraphen mit einem selbständigen Wunschsatz, der das Fluchthema weiterführt, aber auch ohne den Vergleich in der ersten Zeile verständlich wäre. Im Vergleich Z. 534 geht es wieder um ein Metall. annuku ,Zinn"1kommt in den erhaltenen Teilen der assyrischen Verträge nur hier vor. IZI / išatu „Feuer" dagegen steht noch in den Flüchen $\S 89 \mathrm{Z}$. 608 , wo eine Wachspuppe geschmolzen wird, und $\S 93 \mathrm{Z}$. 621, wo die Verfluchten das Böse wie Feuer umgeben soll. ${ }^{2}$ Vokabular der Stipulationen wird mit qātu „Hand“ (Z. 536) aufgegriffen (Z. 5, 66, 105, 365, 374). Im Eid (§ 57) meint es die Hände der Vereidigten (Z. 511). In den Flüchen bezeichnet das Wort Löwenpranken ( $\$ 54 \mathrm{~A}$ Z. 468), die Hände der Verfluchten, denen der Bogen umgedreht wird ( $\$ 77$ Z. 574), und die Hände von Mördern ( $\$ 80$ Z. 583). Gefangenschaft drückt es in $\S 83$ aus (Z. 590).

$\S \S 65$ und 64 sind einander parallel aufgebaut. Der erste Satz enthält den mit $k i$ ša eingeleiteten Vergleich und ein verneintes Prädikat. Der zweite Satz wendet den Vergleich auf die Verfluchten an und enthält wieder ein verneintes Prädikat. Am Schluß steht ein einfacher Wunschsatz mit positivem Prädikat im Prekativ. Eine gleichartige Struktur weisen auch $\S \S 66 f$ auf. Die sprachliche Gestalt von $\S 64$ orientiert sich also nicht an $\S$ 63, sondern an den folgenden Paragraphen.

\footnotetext{
1 Vgl. WEIGL, ,Geschichte“.

2 izuzzu „stehen“. (Z. 534, 535) kommt in den VTE häufig vor. Die Belege für nakru „Feind“" wurden bereits im Delebatfluch (Z. 429, 430) besprochen.
} 


\section{7. 3. Semantische Analyse}

Hier soll nicht das gesamte Lexikon der untersuchten Paragraphen auf seinen semantischen Gehalt befragt werden. Die Bedeutung der Wörter wurde größtenteils bereits in der sprachlich-syntaktischen Analyse behandelt. Es werden nun Kernbegriffe herausgenommen, um den Hintergrund einiger Formulierungen genauer zu beleuchten.

Der Ausdruck ammar libitti kaqqaru lusiqqūnekkunu (Z. 527) findet sich ähnlich im Vertrag A.745.1:

Kol. I, ${ }^{4}$ 'sein Land wie eine Wüste [...]. ${ }^{5}$ 'Der Erdboden möge wie ein aufgerichteter Ziegelstein ${ }^{6}$ zum Stehen seiner Söhne, seiner Töchter, [seiner Großen] ${ }^{7}$ und der Leute seines Landes nicht ausreichen. ${ }^{1}$

Obgleich Z. 4 nicht ganz erhalten ist, wird die Thematik der unfruchtbaren Wüste deutlich, in deren Zusammenhang das Bild vom Ziegelstein auch in $\S 63$ steht. Der Ziegelstein dient jedoch nicht als Bild der Unfruchtbarkeit, sondern der Raumnot. Das Land wird so klein, daß die Menschen keinen Platz haben. ${ }^{2}$ Daß der Boden zu Eisen wird, kommt in der bekannten mesopotamischen Literatur nicht mehr vor. Der einzige Bezug des Eisens zum Erdboden könnte darin gefunden werden, daß es zur Zeit Salmanassars (1280-1261 v. Chr.) eine Rolle bei Grundsteinlegungen gespielt haben muß. ${ }^{3}$

Die Verbindung des Himmels mit Bronze kommt in der mesopotamischen Literatur nicht mehr vor. Zur Bestimmung des semantischen Gehaltes von šamû in Z. 530 muß man sich vor Augen halten, daß der Himmel nicht in Bronze verwandelt wird, sondern bereits Bronze ist. Es handelt sich um einen Vergleich, der offenbar nicht auf das Himmelsfirmament abzielt, sondern auf einen Gegenstand, der aus Bronze hergestellt wurde und den man ebenfalls šamû nannte. vSoden sieht in VTE Z. 530 übertragenen Sprachgebrauch und listet im AHw drei weitere Stellen auf, in denen Gegenstände namens šamû aus Gold hergestellt bzw. mit Gold überzogen sind. Es könnte sich um Baldachine handeln, die auch im Deutschen, wenn

\footnotetext{
${ }^{1}$ BORger, „Mati'ilu,“' 155. Vgl. WATANABE, Thronfolgeregelung, 198. „5' kaq-qa-ru ammar SIG $_{4}$ ina $u ́$-[zu-zi-šú] 6' a-na ú-zu-zi šá DUMU.MEŚ-š́ DUMU.MI.ME[Š-šú GAL.MEŚšsú] 7' ... " SAA 2 (Nr. 2), 8. BORGER restituiert Ende von Kol. I Z. 5' ,ina ú-[zu$z u$-ša?]“ „Mati'ilu,“" 155 Anm. I 5'a. Damit bezieht er ein fem. enklitisches Personalpronomen auf den Ziegelstein zurück, der aufrecht stünde. PARPOLA / WATANABE restituieren ein m. Personalpronomen und beziehen es auf Mati'ilu zurück, der keinen Platz zum Stehen findet.

${ }^{2}$ Zerstörbarkeit veranschaulicht der Ziegel in A.773.1 Z.18: „KUR-su ki-i SIG 4 lu-šá-x-x $u r-r u-u h$.... and may they quickly smash his country like a brick." DONBAZ, „Stelae," 9f.

3 Vgl. SCHACHERMEYR, „Eisen,“ 316-319.
} 
man sie bei Prozessionen herumträgt, bisweilen „Himmel“ genannt werden. ${ }^{1}$ In Z. 530 geht es also um ein Artefakt aus Bronze, das in übertragenem Sprachgebrauch als „Himmel“ bezeichnet wurde und aus dem selbstverständlich kein Regen fällt. Die Vergleiche der folgenden Flüche untermauern diese Interpretation. Auch das schmelzende Zinn (Z. 534), der zeugungsunfähige Maulesel (Z. 537) und der in der Biermaische gärende Malzkeimling (Z. 540) stellen anschauliche und nachvollziehbare Sachverhalte dar. Ebenso selbstverständlich dürfte der bronzene Himmel-Baldachin gewesen sein. Die Mehrdeutigkeit des Wortes šamû wird in $\S 64$ ausgenutzt. Vom Baldachin, aus dem unmöglich Regen kommen kann, wechselt der Blick zum Regen, der aus dem Himmelsfirmament eigentlich kommen sollte. Der Fluch besteht darin, daß der Regen ausbleibt und statt dessen Kohle vom Himmel fällt. Wie das Eisen vermittelt Bronze Festigkeit und Härte. Als Gebrauchsmaterial wurde es seit der Zeit Aššurnașirpals II. (885-859 v. Chr.) mehr und mehr vom Eisen verdrängt. ${ }^{2}$ Das Zinn wird in $\S 65$ gerade wegen seiner Weichheit und Schmelzbarkeit erwähnt.

Auch das Regnen von pe'ttu, pēntu „Holzkohle“ wird sonst nirgends beschrieben. Das Regnen dient bisweilen als Metapher für anderes, z.B. Kälte, Krankheit, Sterne, Tod, die größte Ähnlichkeit mit der in Z. 533 aufscheinenden Bildwelt findet sich in Belagerungsschilderungen, wo Feuer oder Feuerpfeile auf die Belagerten regnen. ${ }^{3}$ Das Ausbleiben des Regens wird in den anderen assyrischen Verträgen immer Adad zugeschrieben. ${ }^{4} \mathrm{Im}$ Adadfluch der VTE dagegen wird der Regen nicht thematisiert. Das Thema Regenmangel kommt explizit nur in $\S 64$ vor.

\section{7. 4. Formenkritik}

Da akkadische Vergleichstexte für $\S \S 63 \mathrm{f}$ fehlen, wird der Text nach den Fluchgattungen von Hillers aufgeschlüsselt. $\S 63 \mathrm{Z}$. 526-528 stellt einen Fluch unter Anrufung der Götter dar. Die angerufenen Götter sollen zwei Veränderungen des Bodens bewirken. Sie sollen ihn eng wie einen Ziegelstein und hart wie Eisen machen. Diese Veränderungen beinhalten den

$1 \mathrm{Vgl}$. AHw, 1160 šamû IB. Vgl. auch das deutsche Kompositum „Himmel“-Bett.

2 Vgl. SCHAWE, „Bronze,“ 68f, Singer, Metalle, 46.

3 Vgl. Vgl. CAD 21 Z, 41-43 zanānu 1.a)5', 1.b), 2.a)2'. 160-162 zunnu.

${ }^{4} \mathrm{Vgl}$. den Vertrag B.819.2: ,[32'-35'][May Adad deprive him of rai]n from heaven and flood waters at the(ir) source. May He destr[oy his land with famine and hunger...] May He $[$ turn] his [land] into [mounds left by a flood...].“ BRINKMAN, „Covenants,“ 110; und den Vertrag A.745.1: Kol. IV „" ${ }^{2}$ Das Getöse des (Wettergottes) Adad mögen sie entbehren, ${ }^{13}$ Regen möge ihnen verwehrt sein." BORGER, „Mati'ilu,“ 156. 
Fluchwunsch, d.h. sie sollen wirklich stattfinden. Z. 528*, 529 entspricht einer einfachen Verfluchung. Das Ergebnis der göttlichen Handlungen wird dargestellt.

§ 64-67 enthalten Vergleichsflüche. Der Vergleich am Anfang stellt jedoch noch nicht den Fluch dar. Es wird im Indikativ jeweils eine Tatsache festgestellt. Aus einem bronzenen Baldachin regnet es nicht. Hier wie in den folgenden $\S \S 65-67$ ist kein göttliches Eingreifen notwendig, um das tertium comparationis, an das der Fluch anknüpft, herbeizuführen. Es geht in $\S 64$ also nicht darum, daß der Himmel zu Bronze wird. Nicht der Himmel verändert sich, sondern der Regen. Der bronzene „Himmel“ dient nur als Einleitungsbild. Z. 531-533 enthält zwei einfache Verfluchungen.

Die gleiche Form erscheint in $\S 65$. Daß Zinn im Feuer schmilzt, ist noch nicht der Fluchinhalt. Der Fluch beginnt erst mit Z. 535. In zwei einfachen Verfluchungen wird das Bild der Anfangszeile auf die Eidbrüchigen angewandt.

\subsubsection{Strukturanalyse}

Der Abschnitt wurde durch Wortverknüpfungen ineinander verwoben. Die Themenfolge lautet Raumnot, Ernteausfall (§ 63), Trockenheit ( $\$ 64$ ), Feinde ( $\S 65)$, keine Nachkommenschaft ( $\S 66 f)$, Eroberungsrituale ( $\$$ 68). Damit greift der Šamašfluch am Schluß mit der Zerstörung der Siedlungen auch inhaltlich zur Raumnot in $\S 63$ zurück. Nimmt man noch die Feinde in $\S 65$ dazu, ergibt sich die Gliederung: Krieg $\S 63$ - landwirtschaftliche Unfruchtbarkeit $\S \S 63 \mathrm{f}$ - Krieg $\S 65$ - körperliche Unfruchtbarkeit $\S \S 66 f-$ Krieg $\S 68$.

Um die Eingebundenheit der besprochenen Paragraphen in die VTE zu zeigen, stellt das folgende Schaubild die Struktur des durch das Dito-Zeichen in $\S 63$ eingeleiteten Abschnitts und die Verknüpfung der $\S$ 63-65 mit anderen VTE-Flüchen dar. 


\begin{tabular}{|c|c|c|c|c|c|}
\hline Gattung & $\mathrm{Z}$. & Lexem & Parallele & Gottheit & in $\S \S 63-68$ \\
\hline$\S 63$ & & & & & \\
\hline Anrufung der & 526 & ilānì mala ... & VTE Z. 573, & & \\
\hline Gottheit & & zakru & $616 \mathrm{~A}, 618 \mathrm{~A}$ & & \\
\hline & 527 & libittu & $\begin{array}{l}\text { A. } 745.1 \mathrm{Kol} . \\
\text { I Z. } 5\end{array}$ & & \\
\hline & 528 & kagqaru & VTE Z. 422 & Šamaš & $\downarrow$ Z. 544 \\
\hline & & parzillu & & Šamaš & $\downarrow \mathrm{Z} .545$ \\
\hline einfache & $528 \mathrm{f}$ & & & & \\
\hline Verfluchung & & & & & \\
\hline$\S 64$ & & & & & \\
\hline Vergleich & 530 & siparru & VTE Z. 649 & Šamaš & \\
\hline Vergleichsfluch & $531 \mathrm{f}$ & & & & \\
\hline einfache & $532 \mathrm{f}$ & $m \bar{a} t u$ & VTE Z. 418c & Anu & $\downarrow Z .559$ \\
\hline Verfluchung & & zanānu & & & \\
\hline$\S 65$ & & & & & \\
\hline Vergleich & 534 & & & & \\
\hline Vergleichsfluch & 535 & nakru & VTE Z. 429f & Delebat & \\
\hline & & & VTE Z. 454 & Ištar & \\
\hline & & & VTE Z. 573, & & \\
\hline
\end{tabular}

$\S 66$

Vergleich

Vergleichsfluch

537

$\S 67$

538f mätu

个 Z. 533

Vergleich

Vergleichsfluch $543 \mathrm{f} \mathrm{kaqgaru}$

Z. 528

§ 68

Šamašfluch

545 parzillu

个Z. 528

Der Textbefund zeigt, daß die Motive vom eisemen Boden und bronzenen Himmel in den $\S \S 63$ und 64 keine Einheit bilden:

(1) Es findet sich keine lexikalische Verknüpfung zwischen beiden Paragraphen, sieht man von dem unbedeutenden libbu ab.

(2) Strukturell orientiert sich Z. 528 mit dem Motiv vom eisernen Boden in chiastischer Verknüpfung und lexikalischer Aufnahme von kaqqaru an der vorhergehenden Z. 527. Dagegen richtet sich Z. 530 mit dem Motiv vom bronzenen Himmel nach den ebenfalls mit $k i$ ša beginnenden $\S \S 65-67$ aus.

(3) Vom Standpunkt der Gattung gehört Z. 528 zu einem Fluch bei Anrufung von Göttem und stellt einen Fluchwunsch dar, dessen Verwirklichung erbeten wird (leppušŭ im Prekativ). Z. 530 dagegen gehört zu einem Vergleichsfluch und dient nur als tertium comparationis für den folgenden 
Fluchwunsch (Z. 531). Die Trennung beider Paragraphen ergibt sich aus der Textgestalt. Watanabe meint, die assyrischen Verfasser der VTE haben die Motive vom eisemen Boden und bronzenen Himmel aus dem Westen übernommen. ${ }^{1}$ Das bedeutet aber, sie hätten die dort zusammengehörenden Motive auseinandergerissen und ihnen in verschieden strukturierten Paragraphen unterschiedliche Bedeutung gegeben. Dies wirkt unwahrscheinlich. ${ }^{2}$

Die Verwendung der Motive vom eisernen Boden und vom bronzenen Himmel in den VTE zeigt, daß sie von den assyrischen Schreibern als eigenständige Bilder empfunden wurden. Ihr Zusammentreffen an der Grenze zweier Paragraphen wirkt fast zufällig. Jedenfalls erscheinen strengere Parallelisierungen beider Motive eher als Weiterentwicklung gegenüber den Formulierungen der VTE. Ob direkte Bezüge von den VTE zu Lev 26,19 und Dtn 28,23f vorliegen, kann erst eine Untersuchung der Bibeltexte im Vergleich zu den hier aufgezeigten Beobachtungen ergeben.

Nimmt man die Wortverknüpfungen zum ersten Fluchabschnitt der VTE zusammen, ergibt sich folgendes Bild:

$\begin{array}{llllll}\S 38 \mathrm{~A} & \text { Anu } & \text { zanānu } & & \S 63 & \text { kaqqaru 2x } \\ \S 39 & \text { Šn } & & & & \\ \S 40 & \text { Šamaš } & \text { kaqqaru } & & \S 64 & \text { zanānu 2x } \\ \S 41 & \text { Ninurta } & & & & \\ \S 42 & \text { Delebat } & \text { nakru 2x } & & \S 65 & \text { nakru }\end{array}$

Die $\S \S 38 \mathrm{~A}-42$ und 63-65 sind also nicht nur dadurch in den VTE hervorgehoben, daß für beide Stellen ähnliche Abschnitte in Dtn 28 gefunden werden können. Beide Stücke zeigen sich vielmehr innerhalb der VTE

1 „Vgl. Leviticus 26,19f; Deuteronomium 28,23f. (...) Literaturgeschichtlich gesehen sollte man hier ... eine Beeinflussung der assyrischen Literatur vom Westen her annehmen ... . (...) Beachte, daß nur Text 27 zwischen $\S 63$ und $\S 64$ einen Trennungsstrich aufweist, d. h. die beiden Paragraphen gehören zusammen. Unterschiede im Detail zwischen Dt 28 und Lev 26 einerseits und z. 528-533 andererseits zeigen aber auch, daß dieses Fluchthema nicht direkt aus der assyrischen Tradition in die biblischen Bücher entlehnt sein kann." WATANABE, Thronfolgeregelung, 198f. Sie sagt jedoch nicht, welche Unterschiede dies sind und inwiefern sie eine Beeinflussung der Bibel durch eine assyrische Vorlage unwahrscheinlich machen.

2 Man kann ein derartiges Auseinanderreißen einer vorgefundenen Motivkombination in den VTE nicht damit erklären, daß die Verfasser so innerhalb des Abschnitts §§ 63-68 einen verbindenden Übergang zwischen dem Fluch mit Götteranrufung in Parallele zum Šamašfluch $\S 68$ und den Vergleichsflüchen in der Mitte schaffen wollten. Warum machen sie dann die Verknüpfung nicht auch durch Wortwiederholungen bemerkbar? Außerdem wäre es im Vergleich mit dem kurzen $\S 68$ harmonischer gewesen, auch $\S 63$ kurz zu gestalten und sich auf den ersten Fluchwunsch, die Veränderung des Bodens zum Ziegelstein, zu beschränken. Dann hätte das Motiv vom eisernen Boden mit dem anschließenden Fluchwunsch der Unfruchtbarkeit in Parallele zu § 64 gestaltet werden können. 
durch Kernbegriffe miteinander verknüpft, die jeweils an exponierter Stelle $\mathrm{zu}$ finden sind.

Anhand dieser Feststellung kann die These dieser Arbeit umrissen werden. Sollte der biblische Verfasser für die Gestaltung von Dtn 28 Anleihen an den Flüchen der VTE genommen haben, so scheinen sich aufgrund der lexikalischen Bezüge von $\S \S 38 \mathrm{~A}-42$ und $\S \S 63-65$ die Gemeinsamkeiten der übernommenen Flüche herauszukristallisieren. Beide Abschnitte der VTE zeichnen sich durch eine gewisse Abstraktion in den Gottesvorstellungen aus. In $\S \S 38 \mathrm{~A}-42$ geht es um den Himmel und seine Gestime. In der Mitte steht Šamaš, die Sonne. In $\S 63$ geht es um die Götter der Tafel mit Lexembezügen zu Šamaš $(\S 40, \S 68)$. Es gilt festzuhalten, daß die Flüche, die die deutlichsten Parallelen zu Dtn 28 aufweisen, nicht irgendwelche Götter anrufen, sondern sich auf den Bereich des Himmels konzentrieren oder die Götter allgemein ansprechen. So scheinen die Auswahlkriterien auf, nach denen die polytheistischen VTE-Flüche einen auf JHWH bezogenen Text beeinflußt haben könnten. Der Blick des biblischen Verfassers dürfte - durch charakteristische Wortverbindungen in den VTE geleitet - zu Motiven der Himmelssphäre und Anrufungen eines Götterkollektivs gewandert sein. ${ }^{1}$

\section{8. Exkurs: Šamaš und JHWH}

Die palindromische Struktur von VTE $\S 56$, die Motive des Sonnengottes ins Zentrum rückt, weist den Text als literarische Schöpfung aus, die von religiösen und ideologischen Beweggründen geleitet ist. Im 2. Jt. v. Chr. erhielt der Šamašhymnus (BWL, 126-138) seine endgültige Gestalt, dem ebenfalls ein palindromischer Aufbau zugrunde liegt. ${ }^{2}$

Warum rückte man ausgerechnet Motive des Šamaš in die Mitte von VTE $§ 56$ ? Hier spielten religiöse Motive eine Rolle. Šamaš kam in der Frömmigkeit Mesopotamiens überragende Bedeutung zu. An keine andere Gottheit richtete man mehr Hymnen und Gebete. ${ }^{3}$ Der Gegensatz von Licht und Finsternis bedeutete im gesamten $\mathrm{AO}$ nicht nur den Widerpart von Hell und Dunkel, sondern die Gegenüberstellung von Chaos und Kosmos, Tod und Leben. Ihm kam daher eine grundsätzliche Ordnungsfunktion für

\footnotetext{
${ }^{1}$ Man könnte gegen diese Argumentation einwenden, daß die dargestellten Ergebnisse an Aussagewert verlieren, weil die analysierten VTE-Texte zuvor aufgrund der Parallelen zu Dtn 28 ausgewählt wurden. Doch die Verknüpfung durch die Begriffe zanänu und kaqqaru sowie die Beziehungen zu Šamaš in $\S 40+68$ wären auch bei einer Untersuchung der Lexemverbindungen des gesamten VTE-Textes zum Vorschein gekommen.

2 Vgl. JANOwsKI, Rettungsgewißheit, 38f; CASTELLINO, „Hymn,“71f.

${ }^{3} \mathrm{Vgl}$. JanOwSKI, Rettungsgewißheit, 32.
} 
das Daseinsverständnis und die Bestimmung der Stellung des altorientalischen Menschen in der Welt zu. ${ }^{1}$ Wenn man also im Zentrum des Fluches dem Menschen das Licht nahm und ihn in die Finstemis stürzte, so beraubte man ihn der lebenspendend Ordnung schlechthin, um ihn Chaos und Tod zu überantworten. Die übrigen darum gelagerten Fluchmotive anderer Gottheiten sind dann nur noch die Ausgestaltung dieser fundamentalen Vernichtung.

Die Finsternismetapher schließt also alles Übel ein. Šamaš kommen darüber hinaus in der mesopotamischen Religion Funktionen zu, die mit den meisten Motiven von VTE $\S 56$ korrespondieren. Šamaš übt Macht über die Dämonen aus, die Krankheit und Unheil bringen. ${ }^{2}$ Neben dem Schicksal des Einzelmenschen obliegt dem Sonnengott die Garantie der Rechtsordnung. Damit legt er die Grundlage menschlicher Gesellschaft. Sein Richterspruch schafft Ordnung in der Welt. Er verhilft zum Recht. ${ }^{3}$ Damit kommen die ideologischen Gründe für die zentrale Rolle des Šamaš im Fluch einer Thronfolgeregelung für Königssöhne in den Blick. Garantie von Recht und Ordnung, sowie Schutz und Gerechtigkeit für die gesellschaftlich Machtlosen gehört bereits im Epilog des KH zu den Prärogativen des Königs. Nach KH Kol. I Z. 40 haben die Götter Hammurapi dazu berufen, dem Šamaš gleich (kima dUTU) den Menschen aufzugehen und ihnen zu leuchten. Die rechte Regierung des Königs wird in der altorientalischen Königsideologie mit Šamaš verbunden und durch Lichtmetaphorik beschrieben. ${ }^{4}$

Nicht nur VTE $\S 56$ rückt Šamaš in den Mittelpunkt. Der Šamašfluch (VTE $\S 40$ ) steht in der Reihe der Astralgottheiten von $\S 38 \mathrm{~A}$ bis $\S 42$ in der Mitte. ${ }^{5}$ Außerdem sticht er aus den sonst auf staatlichen Dokumenten erhaltenen Flüchen dieses Gottes durch die Betonung des Lichtcharakters

\footnotetext{
1 Vgl. JANOwSKI, Rettungsgewißheit, 23-31; ebd. 26: „Im Alten Israel und seiner Umwelt hat die Lichtmetapher ihren (wenn nicht einzigen, so doch) besonderen Bedeutungsgehalt in Antithese zu den Phänomenen ,Finsternis', ,Chaos' und ,Tod(esgeschick) ' entfaltet. Als Kategorien, die Erfahrung von Welt leiten bzw. allererst ermöglichen, sind ,Licht * (// Leben) und ,Finsternis' (// Chaos, Tod) Kategorien ursprünglicher Daseinsorientierung: Das Licht, das die distinkten Konturen der Dinge, ihre Form und Unterschiedenheit, hervortreten läßt, ist nicht einfach die ,unbestimmbar allgegenwärtige Helle', sondern die ,vordringende Entmachtung der Finsternis', die kosmosschaffende Eingrenzung des Chaos.“

2 Vgl. JANOWSKI, Rettungsgewißheit, 65, 83.

3 Vgl. JANOwSKI, Rettungsgewißheit, 84-86; LANGER, Gott, 212.

4 Vgl. JANOwSK1, Rettungsgewißheit, 86.

${ }^{5}$ Dabei ist vom Jupiterfluch $\S 43$ abzusehen, dessen Exkommunikationsmotiv im Kontext Israel als Ganzes betreffender Flüche schwierig nachzuvollziehen ist. Die Himmelsflüche finden sich in Dtn 28 in einer veränderten Reihenfolge wieder: Ninurta $(28,26), \operatorname{Sin}(28,27)$, Šamaš $(28,29)$, Delebat $(28,30-33)$ und Anu [Gula] (murṣu) $(28,34 \mathrm{f}$.).
} 
hervor. Sogar in $\S \S 63 \mathrm{f}$ zeigten sich bemerkenswerte lexikalische und kontextuelle Bezüge zu Šamašflüchen. Es ergab sich, daß die beiden Dtn 28 am meisten ähnelnden Abschnitte $\S \S 39-42$ und $\S \S 63 \mathrm{f}$ bereits innerhalb der VTE durch Begriffe aus dem Wortbestand der Šamašflüche verknüpft sind. Dies und die im Aufbau von $\S 56$ aufscheinende religiöse und ideologische Bedeutung des Šamaš legt es nahe, in den Bezügen zum Sonnengott ein Kriterium zu sehen, nach welchem Passagen aus den VTE zur Einfügung in Dtn 28 ausgewählt wurden. Daher sind die historischen Bedingungen zu reflektieren, unter denen in Juda eine Auswahl von VTEFlüchen nach deren Bezügen zum Sonnengott denkbar ist.

Gegen eine solche Auswahl sprechen die Verbote der Verehrung der Sonne, des Mondes und der Gestirne in Dtn 4,19; 17,3. Wie sollte ein Verfasserkreis, der den Sonnenkult als von Gott verboten betrachtet, aus einem paganen Text von der Šamašideologie geleitete Anleihen entnehmen? Das Verbot der Gestirnsverehrung in Dtn 4,19 steht jedoch in einem Kapitel, das als späte exilische Einfügung ins Deuteronomium betrachtet wird. ${ }^{1}$ Dtn 17,3 gehört zu einem Modellprozeß innerhalb der exilischen Ämtergesetze. ${ }^{2}$ Beide Bestimmungen stammen also erst aus der Zeit des Exils und es gab einmal ein Deuteronomium, das die Verehrung von Sonne, Mond und Gestimen nicht explizit verurteilte.

Um die einzigartige Beziehung zwischen JHWH und seinem Volk auszudrücken, greift das Deuteronomium auf alte Traditionen aus vorisraelitischer Zeit zurück. So enthält die Zentralisationsformel (z.B. Dtn 12,11) die bereits im Akkadischen der Jerusalemer Amarna-Korrespondenz belegte Formulierung „den Namen anbringen“ (שכן, šakānu šuma). ${ }^{3}$ Zur Tradition des vorisraelitischen Jerusalem gehörte die Verehrung einer Sonnengottheit. Auch der Abendstern (Šalim) und die Morgenröte (Šaḥar) besaßen religiöse Bedeutung. ${ }^{4}$ Die solare Gottheit hieß wahrscheinlich Ședeq, wie Königsnamen nahelegen (Jos 10,1.3; Gen 14,18; Ps 110,4). Der Gottesname macht deutlich, daß sie für צד צGerechtigkeit" sorgte. ${ }^{5}$ Als mit David auch JHWH in Jerusalem eingezogen war, widmete sich der aus der Stadt stammende Oberpriester Zadok dessen Kult. JHWH wurde Schutzgott der Dynastie (2 Sam 7) und nahm solare Züge an. ${ }^{6}$ Sein Tempel in Jerusa-

\footnotetext{
1 Vgl. BrauliK, „Monotheismus,“ 280/138; Mittel, 36f; TAYLOR, Sun, 108f.

2 Vgl. LOHFINK, ,Sicherung,“ 306, 313; TAYLOR, Sun, 110f. Zur Datierung von Versen mit Personenwechsel wie in Dtn 17,3 vgl. LOHFINK, ,Jahwegesetz,“ 390 Anm. 21.

3 Vgl. BrauliK, Deuteronomium, 98.

4 Vgl. KeEL/UEHLINGER, „Sonnengottheit,“ 275-278.

5 Vgl. KeEL / UEHLINGER, „Sonnengottheit,“ 280f; KeEL, „Sturmgott,“ 87.

6 Vgl. KeEL/ UEHLINGER, „Sonnengottheit,“ 281; UEHLINGER, „Kultreform,“ 68, $76 \mathrm{f}$.
} 
lem war geostet, ein leerer Thron stand darin, wie er auch in Syrien und Mesopotamien für den Sonnengott bezeugt ist, und es gab Pferde und Wagen für die Sonne (2 Kön 23,11). ${ }^{1}$ Archäologische Zeugnisse belegen, daß JHWH durch solare Motive symbolisiert wurde. ${ }^{2}$ Biblische Texte sprechen von ihm in Lichtmetaphern (Jes 18,4; Dtn 33,2) gerade dann, wenn sie seine Rolle als Richter betonen (Gen 19; Hos 6,5; Zef 3,5). Auch sein rettendes Eingreifen im Krieg wird so beschrieben (Ex 17,12b; Jos 10,12f.; 1 Sam 11,9.13). ${ }^{3}$ Von JHWHs Macht, Krankheiten zu heilen (vgl. Hab 3,4f), berichtet das DtrG im Zusammenhang mit einer Sonnenuhr auf dem Obergemach des Ahas. Bei dieser Sonnen-, bzw. besser Schattenuhr, haben sich von Judas Königen (nicht von Manasse!) errichtete Altäre befunden, die wohl einem Sonnen- oder Astralkult gewidmet waren (2 Kön 23,12). ${ }^{4}$

Gerade der Rückhalt in eigenen religiösen Traditionen ließ einem judäischen Schreiber, der in einem assyrischen Text nach verwendbaren Motiven suchte, möglicherweise jene Passagen ins Auge springen, in denen der mesopotamische Šamaš eine Rolle spielt. Šamaš und JHWH konnten am ehesten zueinander in Beziehung gesetzt werden, da ihre Sorge für Gerechtigkeit, Abwehr von Krankheit, Rettung aus Not, Spendung des Lichts und ihre Stellung in der Königsideologie sich weitgehend deckten.

\footnotetext{
1 Vgl. KeEL, „Sturmgott,“" 85; KeEL / UeHLINGER, „Sonnengottheit,“" 287-293, 301; UEHLINGER, „Kultreform,“ 74-77; TAYLOR, Sun, 176-179.

2 Vgl. TAYloR, Sun, 24-37; LANGER, Gott, 205, 215; zur Darstellung JHWHs als Sonne auf Siegeln des 8. Jhs. und der Reformkönige des 7. Jhs. vgl. McKAY, Religion, 52f; Niehr, Gott, 157; TAYLOR, Sun, 165; KEEL/ UEHLINGER, „Sonnengottheit,“ 294.

3 Vgl. NiEHR, Gott, 149-154; JANOWSKI, Rettungsgewißheit, 180-191; LANGER, Gott, 149 152, 209-211, 214f; KEEL/ UEHLINGER, „Sonnengottheit,“ 295-298, 302.

4 Vgl. TAYLOR, Sun, 65-168; UeHLINGER, „Kultreform,“ 79f. Die wundersame Zeitangabe auf der Uhr dient dazu, göttliches Eingreifen im Krankheitsfall zu beweisen (2 Kön 20,6-11; Jes 38,7-8). JHWH handelt in 2 Kön 20,11 synchron am Schatten und der Krankheit.
} 


\subsection{Ergebnisse: Der altorientalische Hintergrund von Dtn 28}

\subsection{Die VTE-Parallelen zu Dtn 28}

Es konnten über 200 Texte staatlicher Kanzleien aus 1000 Jahren gesammelt werden, um zu erforschen, ob die Parallele zwischen VTE §§ 39-42 und Dtn 28,25-33 auf ein überliefertes Bauschema zurückgeht, das im AO verbreitet war (coincidence). Die Tabelle auf der nächsten Seite stellt gleichartige Motivfolgen mesopotamischer Sequenzen zwischen die Themenfolge von Dtn 28,25-33 und VTE $\S \S 38 \mathrm{~A}-42$ Von den zur Verfügung stehenden Inschriften weisen nur acht Übereinstimmungen mit der Reihenfolge der Motive in den VTE und Dtn 28 auf.

In der Tabelle wurde die Zuordnung zu den Göttern vernachlässigt, weil in Juda die Motive kaum an verschiedene Gottheiten gekoppelt waren. $\mathrm{Zu}$ den acht aufgeführten Texten kommen noch zwei weitere, in denen nur zwei Motive zu VTE und Dtn 28 parallelisiert werden können, und die aus Platzgründen ausgespart wurden. Es sind B.1159.6, mit der Sequenz Sin(?) (Krankheit - Exkommunikation) Šamaš (Schwindel, Taubheit, Lähmung) und B.1070.1 mit der Folge Sin (Exkommunikation) Šamaš (Fluch, Taubheit, Blindheit, Lähmung). Keine einzige Sequenz der 1000 Jahre vor den VTE entspricht der Abfolge von Dtn 28 oder VTE 38A-42 völlig. Man findet kleine Abschnitte, die verschiedenen Inschriften gemeinsam sind, aber der größere Kontext differiert erheblich.

Die deutlichste Themenparallele zu VTE $\S 38 \mathrm{~A}-41$ bietet das HinkeKudurru B.1105.1, wo Unwohlsein (vgl. VTE § 38A lā țūb širi), Trübsal und Rechtlosigkeit miteinander verbunden sind. Dabei kann sogar eine Entsprechung zur Götterfolge der VTE gefunden werden. Das Unwohlsein wird Ea zugesprochen, der häufig zusammen mit Anu in Fluchanrufungen auftaucht. Dann folgen Sin und Šamaš. An diese Götterreihe schließt sich wie VTE $\$ 41$ Ninurta an. Doch bringt er nicht die Niederlage, sondern zerstört die Grenze und Sin verursacht nicht die Hautkrankheit saharšubbû, sondern bewirkt Trübsal. Im Detail weicht also auch B.1105.1 von den VTE ab. In den anderen Texten, die in Parallele zu den VTE oder Dtn 28 gesetzt werden können, fehlen ebenfalls Glieder, die der Bibel und dem adê gemeinsam sind. 


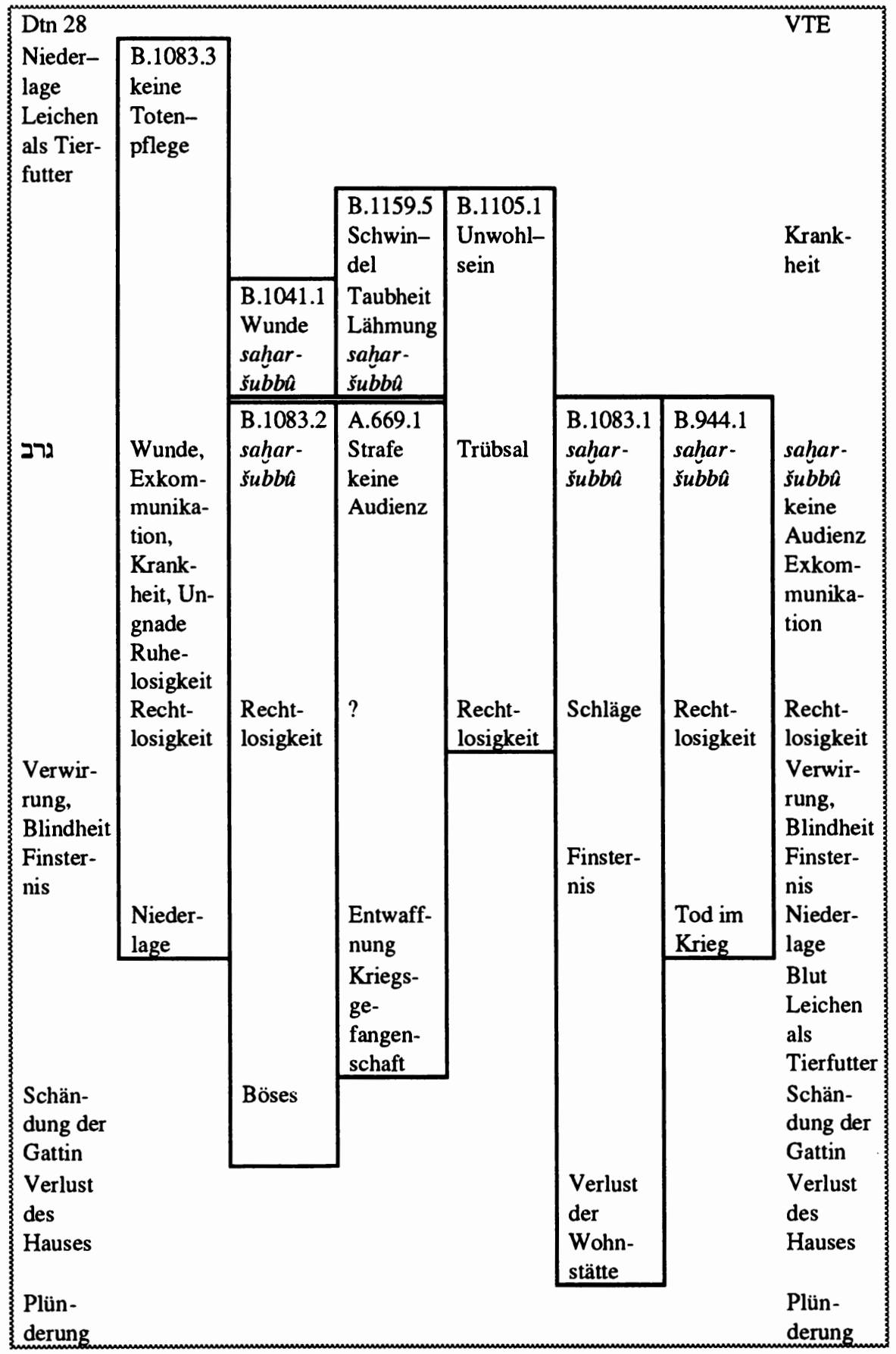


Es ergibt sich also, daß die altorientalische Fluchtradition keine längeren Muster für Motivanordnungen überlieferte. Man findet vielmehr Motivbausteine, die unterschiedlich miteinander kombiniert werden konnten. Dafür, daß keine größeren Muster fixiert wurden, spricht auch, daß die meisten Inschriften nur kurze Flüche mit zwei oder drei Anrufungen besitzen. ${ }^{1}$ Allerdings gab es offenbar beliebte Kombinationen der Motivbausteine, die mehrmals belegt sind. Dazu gehören die Folge saharšubbû + Rechtlosigkeit und Exkommunikation + (Blindheit) / Taubheit / Lähmung (B.1159.6; B.1070.1). Auch das Motiv Krankheit vor saharšubbû, wie es VTE $\S 38$ A bezeugt, ist mehrfach belegt (B.1159.5; B.1105.1; B.1047.1). Niemals aber findet man in mesopotamischen Texten das Motiv der Niederlage und der Verfütterung der Leichen, das in Dtn 28,25f auftaucht und in der Forschung durch das Vorrücken von VTE $\$ 41$ an den Anfang der Sequenz erklärt wurde, vor saharšubbû. Die Abfolge von Dtn 28,25-27, wo die Niederlage vor der Hautkrankheit steht, entspricht also keiner altorientalischen Tradition, während die Folge Krankheit + saharšubbû von VTE $\S \S 38 \mathrm{~A}+39$ auch in anderen mesopotamischen Texten belegt ist.

Anders sieht es mit dem Motiv aus, das der Kombination Hautkrankheit und Rechtlosigkeit / Blindheit / Dunkelheit von Dtn 28,27-29 und VTE §§ 39+40 folgt. Die VTE bieten hier den Ninurtafluch (\$ 41). Im Deuteronomium folgen aber sogleich die Motive Schändung der Gattin + Verlust des Hauses (Dtn 28,30), die die VTE erst im folgenden Delebatfluch (§ 42) bieten. Im Untersuchungszeitraum findet man drei Fluchsequenzen, in denen die Reihung der Götter der in Dtn 28,27-33 implizierten Reihenfolge Sin - Šamaš - Ištar (Delebat) entspricht. Es handelt sich um die babylonischen Kudurrus B.1083.1; B.1083.2 und B.819.1. In B.819.1 werden Sin, Šamaš und Ištar gemeinsam in einem einzigen Fluch angerufen, welcher nur die typischen Sinmotive saharšubbû und Exkommunikation enthält. Der Fluch liefert den Beleg, daß die drei Gottheiten in der mesopotamischen Fluchtradition miteinander verbunden werden konnten.

Auf dem Kudurru B.1083.2 unterscheidet sich der Kontext des Fluchs, die parallelisierbare Passage Sin-Šamaš-Ištar ausgenommen, von den VTE: Nach einem Fluch mit Anrufung der Götter, werden Anu - Enlil - Ea, Marduk, Nabu und Adad genannt. Dann kommen: Sin (saharšubbû), Šamaš

\footnotetext{
${ }^{1}$ Die Zahl der Vergleichstexte vergrößert sich erheblich, zählt man die Exemplare gleichlautender Inschriften auf Tafeln, Zylindern und Tonkegeln jeweils extra. Für das Überlieferungsgut der Flüche Mesopotamiens ist bezeichnend, daß gerade die Formeln auf Bauinschriften vielfach kopiert wurden. Variationsfreude läßt sich nicht feststellen.
} 
(Rechtlosigkeit), Ištar (Böses) ${ }^{1}$, Gula (Wunde), Ninurta (kein Erbe, keine Totenpflege). Es folgen Flüche mit Nergal, Zababa, Papsukkal, Išhara, Anu und den Göttern. In zwei Punkten ähnelt diese Abfolge Dtn 28. Der Sinfluch enthält nur das Aussatzmotiv, es fehlt die sonst traditionell dazugehörige Exkommunikation. Im Anschluß an Ištar folgt Gula mit ihrem Krankheitsmotiv, was Dtn 28,34f. entsprechen würde. Abweichend von Dtn 28 bringen aber Šamaš und Ištar nicht Dunkelheit, Blindheit und Beraubung, sondern Rechtlosigkeit und Böses vor den Augen der Götter und des Herrschers. B.1083.1 ähnelt Dtn 28 mehr. Die Fluchsektion beginnt mit Anu, Enlil und Ea, von denen die allgemeine Verfluchung gefordert wird. Die dann folgenden Flüche seien in Übersetzung zitiert:

„Sîn, die Leuchte des reinen Himmels, möge mit saļaršubbû-Krankheit, die nicht fortgeht, seinen ganzen Körper bekleiden, ... und auf die Dauer seiner Lebenszeit möge er [ $=$ der Verfluchte] nicht rein werden... und er möge wie ein Wildesel im Aussenbezirk seines Wohnsitzes(?) ständig umherlaufen.“2 Šamaš, der Richter des Himmels und der Erde, möge sein Gesicht schlagen, sein heller Tag möge sich für ihn in Dunkelheit wenden. Ištar, die Herrin, die überaus tüchtige Fürstin der Götter, möge ihm schicken die flimmernde Dämonin, die Botschaft ihres Zorns, und möge niederwerfen seine Wohnstatt. Wie ein Hund möge er die Nacht verbringen auf dem Platz seiner Stadt. ${ }^{3}$

Es folgen Flüche mit Marduk, Ninurta, Gula, Adad, Nabu und den großen Göttern. Zwar enthält der Sinfluch abweichend von Dtn 28,27 das Exkommunikationsmotiv, doch das Thema Krankheit wird im Kudurru durch den außergewöhnlichen Zusatz der Unreinheit auf Lebenszeit besonders ausgestaltet. ${ }^{4}$ Dies entspricht der Unheilbarkeit der Krankheit in Dtn 28,27. Außerdem bietet das Kudurru einen der seltenen Belege für das Motiv der Dunkelheit in der mesopotamischen Šamašfluchtradition. Darin ähnelt es Dtn 28,29.

In der Kanzlei des Marduk-nadin-ahhe (1100-1083 v. Chr.) wurden also Fluchsequenzen geschaffen, die in der Reihenfolge der Götter und in ihren Motiven am deutlichsten der Abfolge von Dtn 28,27-30 entsprechen. Doch angesichts der vielen Texte, die anders angeordnet sind, belegen die beiden Kudurrus nicht, daß diese Sequenz zum allgemein verbreiteten Überliefe-

\footnotetext{
${ }^{1}$ Kol. IV ${ }^{12}$ Ištar bèlet šamê u erșeti ${ }^{13}$ ana mahri ilāni u šar Bābili ${ }^{14}$ ana lemutti lirteddišu ${ }^{12}$ Ištar, die Herrin des Himmels und der Erde, ${ }^{13}$ möge ihn vor den Göttern und dem König von Babylon ${ }^{14}$ zum Bösen geleiten.

2 WATANABE, „Überlieferung,“ 107.

${ }^{3}$ Kol. II ${ }^{21}$ Ištar bēltu rubāt ilāni telītu ${ }^{22}$ lišpuršuma Baririta našpartaša ša uzzi ${ }^{23}$ urra u muša lima"î dadmišu ${ }^{24}$ kima kalbi libıa"ita ina rēbit âlišu.

${ }^{4}$ Vgl. WATANABE, „Überlieferung,“ 105 unter (*7).
} 
rungsgut gehörte. Wenn diese Götter- und Motivfolge schon in Mesopotamien nur vereinzelt auftritt, kann man nicht damit rechnen, daß sie in Juda bekannt war. Die deutlichsten mesopotamischen Parallelen zu B.1083.1 und B.1083.2 bieten innerhalb der gesammelten Fluchinschriften die VTE $\S \S 38 \mathrm{~A}-42$ mit ihrer Abfolge Anu - Sin - Šamaš - Ninurta - Delebat/Ištar. Abweichend von den Kudurrus steht jedoch in den VTE-Ausgaben zwischen Šamaš und Delebat der Ninurtafluch. Allerdings besitzen nicht alle VTE-Versionen diese Reihenfolge. In ND 4329 steht der Jupiterfluch an der Stelle des Ninurtafluchs. Der Jupiterfluch aber scheint eine neuassyrische Schöpfung zu sein. Da die Einordnung des neuassyrischen Fluches nur auf neuassyrische Schreiber zurückgehen kann und diese mit dem Ninurtafluch variiert, ergibt sich, daß auch die Stellung Ninurtas zwischen Šamaš und Delebat eine neuassyrische Besonderheit darstellt. Dafür spricht auch, daß der Ninurtafluch aus Formeln besteht, die in den VTE auch noch in einem Assur- und Palilfluch vorkommen. Offenbar haben sich die Verfasser der VTE-Flüche strukturell und sprachlich an babylonischen Fluchsequenzen orientiert, wie sie B.1083.1 und B.1083.2 enthalten, ihre Vorgaben aber in eigentümlich assyrischer Weise verändert. ${ }^{1}$ Bieten jedoch bereits die erhaltenen neuassyrischen Versionen bezüglich dieser Assyrismen kein einheitliches Bild, so wird man auch in der aramäischen Version der VTE mit Abweichungen rechnen müssen. Gleiches gilt auch für eine weitere assyrischen Eigenheit, den Ausschluß von Königsaudienz und Kult im Sinfluch VTE § 39. Die Reihe VTE 38A-43 kann also als schöpferische Leistung der VTE-Verfasser betrachtet werden, die traditionelle Formeln mit eigenen Ergänzungen kombinierten.

Festzuhalten gilt, daß einige Parallelen zu Dtn 28 gerade in den neuassyrischen Zusätzen der VTE zu den sonst bekannten mesopotamischen Flüchen zu finden sind. Im Šamašfluch der VTE und in Dtn 28,28 geht es um Verwirrung, Blindheit und Finsternis, eine Zusammenstellung, die so in keinem der mesopotamischen Flüche mehr auftaucht. Vom Ninurtafluch (VTE § 41) finden sich in Dtn 28,25f gerade die Motive der Niederlage und Leichenverfütterung, die auch im Assur- und Palilfluch der VTE vorkommen, obgleich sonst in Mesopotamien kein Fluch gefunden werden kann, in dem Ninurta etwas mit Leichen fressenden Tieren zu tun hat. Auffällig ist die Gemeinsamkeit zwischen Bibel und dem Delebatfluch (VTE § 42), wo Schändung der Gattin und Plünderung durch Feinde

${ }^{1} \mathrm{Vgl}$. die assyrische Veränderung des Sinfluchs nach WATANABE, Thronfolgeregelung, $191 \mathrm{f}$ und überhaupt die Benennung Ištars als Delebat. 
zusammengestellt sind. Weder diese Kombination noch ein Delebatfluch kommen in den erhaltenen mesopotamischen Texten noch einmal vor. ${ }^{1}$

Im Vergleich mit dem Aufbau der meisten mesopotamischen Fluchsequenzen und im Blick auf die neuassyrischen Eigentümlichkeiten läßt sich sagen: Die Paragraphen 38A-42 bilden im Rahmen der erkennbaren mesopotamischen Tradition einen außergewöhnlichen Fluch (uniqueness). AuBergewöhnlich ist der Fluch nicht nur deshalb, weil kein einziger weiterer mesopotamischer Text mit einer derartigen Götter- und Motivfolge in seiner Fluchsektion erhalten ist, sondern auch, weil der Umfang der VTE-Flüche den aller anderen mesopotamischen Texte weit übersteigt. Von allen neuassyrischen Verträgen reichen die erhaltenen Fragmente aus, um festzustellen, daß dort keine Fluchreihe wie VTE $\S \S 38 \mathrm{~A}-42$ enthalten war, weil Gottheiten aus dieser Fluchreihe mit anderen Göttern verbunden sind. Sprachlich und umfangmäßig dürfen die VTE also für die mesopotamische Tradition als außergewöhnlicher Text gelten. Diese Besonderheiten sind durch den außergewöhnlichen Anlaß begründet, für den die VTE geschaffen wurden. Immerhin regeln sie die Thronnachfolge für zwei Königssöhne in zwei bereits damals geschichtsträchtigen Reichen, Assyrien und Babylonien. Außerdem hatten die Bürgerkriege, mit denen Asarhaddon nach seiner Thronbesteigung trotz des Sanherib-adê zu kämpfen hatte, wohl zu der Erkenntnis geführt, daß die bisherigen Vereidigungen nichts nützten. ${ }^{2}$ Um den Herrschaftswechsel zu sichern, mußte etwas Besseres her! Asarhaddon empfand sein Vorgehen wohl selbst als außergewöhnlich, denn eine seiner Inschriften gilt als Rechtfertigungsversuch. ${ }^{3}$ Assurbanipals Königsinschriften und die erhaltenen VTE-Versionen bezeugen Vereidigungszeremonien an mindestens drei verschiedenen Tagen. Der Aufwand überstieg offenbar alles bisher Dagewesene. Zu diesem Aufwand gehörte auch der VTE-Text selbst. Die Zusatzvereidigung der Großmutter, die sich besonders an Šamaš-šum-ukin und assyrische Honoratioren richtete, konnte wieder zum sonst üblichen Umfang zurückkehren. ${ }^{4}$

Da das assyrische Reich niemals mehr die Macht der Zeit Asarhaddons erreiçhen sollte, niemals mehr die Thronfolge für Assyrien und Babylonien zugleich geregelt wurde und weder aus früherer noch aus späterer Zeit ein Text mit Flüchen gleichen Umfangs bekannt ist, verringert sich die Wahr-

${ }^{1}$ Mögliche Gründe für das Fehlen des Exkommunikationsmotivs von VTE $\S 39$ in Dtn 28,27 wurden bereits im Zusammenhang des Jupiterfluchs reflektiert.

2 Vgl. Parpola / Watanabe, Treaties, XXVIII.

3 Vgl. PARPola / Watanabe, Treaties, XXXIV.

4 Vgl. Parpola / Watanabe, Treaties, 62-64; ebd. XXXIf., XLVIII. 
scheinlichkeit, daß es in Mesopotamien weitere Fluchsequenzen gab, die in Aufbau und Umfang neben die VTE gestellt werden können.

Die Besonderheiten der VTE im Rahmen der mesopotamischen Fluchüberlieferung beweisen jedoch noch nicht die direkte literarische Abhängigkeit der Parallele in Dtn 28. Prinzipiell wäre es vorstellbar, daß die offensichtlich in Mesopotamien überlieferten Motivbausteine auch in Juda bekannt waren und durch Zufall in beiden Ländern zu gleichartigen Texten kombiniert wurden. Damit würden die Ähnlichkeiten zwischen Dtn 28,2533 und VTE $\$ \S 39-42$ doch ausschließlich auf der Tradition beruhen (coincidence). Hier ergeben sich Aufgabenstellungen für die Analyse von Dtn 28. Sollten die VTE die schriftliche Vorlage für Dtn 28 geliefert haben (uniqueness), wird auch zu fragen sein, welche Stellung das Motiv von VTE $\S \S 63 f$, Dtn 28,23f und Lev 26,19 in der Überlieferung des AO besaß und warum die Themen von VTE $\S 41$ in Dtn 28,25f an den Anfang der sonst parallelen Reihe gerückt sind.

\section{9. 2. Der Aufbau von VTE §56}

Die bei der Untersuchung von VTE § 38A-43 gewonnene Erkenntnis, daß keine größeren Anordnungsmuster, sondern nur kleinere Motivbausteine überliefert wurden, die von den Schreibern schöpferisch ergänzt und verschieden kombiniert werden konnten, bestätigt sich auch in VTE § 56.

Der Fluch bei den großen Göttern des Himmels und der Erde ist der längste bekannte mesopotamische Fluch, bei dem nicht einzelne Gottheiten angerufen werden, die nach ihrer hierarchischen Stellung im Pantheon geordnet sind. Die Analyse des Textes ergab, daß die Verfasser der VTE zwar einige Anordnungselemente hierarchisch strukturierter Fluchreihen verwendeten, insgesamt $\S 56$ jedoch eine palindromische Gestalt gaben, wobei sie Fluchmotive, die traditionell mit verschiedenen Gottheiten verbunden sein konnten, um das Šamašthema der Finsternis gruppierten. VTE $\S 56$ liefert den Beweis, daß man sich in Mesopotamien bei der Konstruktion von Flüchen außerhalb der Götterhierarchie nicht an eine implizit vom Pantheon bestimmte Ordnung der Fluchmotive hielt. Dieses Ergebnis macht es unwahrscheinlich, daß man in Juda nur aus Gründen der Tradition solcher Texte die Motivfolge nach der Hierarchie des mesopotamischen Pantheons reihte. 


\section{4. ,ÜBERSETZUNGEN“ VON FLÜCHEN}

Vergleicht man biblische Texte mit altorientalischen, so stimmen bisweilen Themen und Motive überein, die konkreten Formulierungen weichen jedoch voneinander ab. Diese Abweichungen bilden meist die Grundlage, literarische Abhängigkeiten zwischen altorientalischen und biblischen Texten abzulehnen. Nur ganz selten setzt sich wie beim biblischen Buch der Sprichwörter und der ägyptischen Weisheitssammlung des Amenemope die Ansicht durch, Abschnitte der Bibel seien teilweise aus einer fremdsprachigen Vorlage übernommen. ${ }^{1}$ Sollten fremdsprachige Texte bei der Abfassung biblischer Texte Pate gestanden haben, so mußte man sie ins Hebräische übersetzen. Wenn unterschiedliche Formulierungen als Argument für jeweilige Eigenständigkeit angeführt werden, ist zu prüfen, ob derartige Abweichungen nicht aus dem Übersetzungsvorgang stammen können. Wie genau hat man im AO übersetzt? Für Dtn 28 muß die Frage noch konkretisiert werden: Wie genau hat man im AO Flüche übersetzt?

Um diese Frage zu beantworten, werden nun die Fluchsektionen mehrsprachig erhaltener Verträge und Inschriften auf ihre Übersetzungstreue überprüft. In bezug auf Dtn 28 verschärft sich das Argumentationskriterium. Die Verfasser mehrsprachiger Verträge oder Inschriften erhoben den Anspruch, in beiden Versionen denselben Text wiederzugeben. Wo dieser Anspruch nicht besteht, kann man nicht von einer Bilingue sprechen. Wenn in mehrsprachigen Inschriften jedoch Unterschiede zwischen den Versionen festgestellt werden können, bedeutet dies, daß die Übersetzungsgenauigkeit selbst dort, wo man denselben Text auf ein und demselben Dokument wiedergeben wollte, nicht groß war. Ein biblischer Verfasser, der einen fremdsprachigen Text aufnimmt, will keine Bilingue schaffen, oder einen Vertrag, der mit der anderssprachigen Variante verglichen werden sollte. Er legt keinen Wert darauf, daß man seine fremdsprachige Vorlage erkennen kann. Die Anforderungen an Übersetzungsgenauigkeit und Vorlagentreue vermindern sich also, wenn man aus den Ergebnissen der folgenden Untersuchung Rückschlüsse auf die Übersetzung eines biblischen Textes aus einer fremdsprachigen Vorlage zieht.

Das Untersuchungsmaterial ist gering, da einerseits mehrsprachige Texte nicht übermäßig häufig sind, andererseits nur wenige davon Flüche enthalten und drittens nur noch bei einem Bruchteil die Flüche tatsächlich in beiden Versionen erhalten sind. Nicht untersucht werden die Flüche auf

1 Vgl. LOPRIENO, „Amenemope,“ 47-76. 
sumerisch-akkadischen Bilinguen. ${ }^{1}$ Es ist unsicher, wie lange sumerisch überhaupt eine gesprochene Sprache war und die sumerische Version daher Zeugnis für ein eigenständiges Sprachgefühl gibt. ${ }^{2}$ Seit dem Aussterben des Sumerischen wurden die in dieser Sprache tradierten und neu verfaßten Inschriften zunehmend formal und fehlerhaft. ${ }^{3}$

Ein Zeugnis für die Schwierigkeit, in zweisprachigen Texten eigene sumerische Traditionen herauszufiltern, liefert das Tontafelfragment CBS 1511, welches eine sumerische Version des Epilogs des KH enthält. Wurden die Flüche des KH ins Sumerische übersetzt, wie Sjöberg meinte ${ }^{4}$, oder besaßen sie ein sumerisches Vorleben und wurden zum Einbau in den $\mathrm{KH}$ ins Babylonische übertragen, wie Oelsner einwandte? ${ }^{5}$ Hat man es also mit einem Zeugnis der sumerischen oder der babylonischen Fluchüberlieferung zu tun? Zur Klärung dieser Frage mag die Beobachtung beitragen, daß die sumerischen Flüche in den Götterepitheta Rückbezüge auf den königlichen Auftraggeber der Inschrift enthalten, wie sie auch im KH stehen. So heißt Nintu, die Mutter, meine Gebärerin, und Ninkarrak, die Sprecherin meines guten (Leumunds). ${ }^{6}$ Es ist aber unwahrscheinlich, daß CBS 1511 eine Liste sumerischer Flüche darstellt, die wie ein Bausatz schon gleich mit Bezügen auf den Auftraggeber der Inschrift überliefert wurden. Daher dürfte es sich tatsächlich um eine Passage des KH handeln, die ins Sumerische übersetzt wurde. Anhand des bekannten sumerischen Vergleichsmaterials ist jedoch nicht zu beurteilen, ob die Abweichungen vom $\mathrm{KH}$ und die akkadischen Glossen über manchen sumerischen Ausdrücken auf diesem Tontafelfragment Übersetzungsschwierigkeiten oder idiomatische sumerische Wendungen belegen. ${ }^{7}$

\footnotetext{
1 Vgl. VEENHOF, „Curse,“ 142f; HIRSCH, „Inschriften,“ 37, 68f; GELB / KIENAST, Königsinschriften, 160, 216, 344f.

2 Vgl. vSODEN, „Zweisprachigkeit,“ 7; COOPER, „Sumerian,“ 239-241, 243.

${ }^{3}$ Vgl. CAPLICE, „Bilinguismo,“136-138; vSODEN, ,Zweisprachigkeit,“ 10.

4 Vgl. ,Version,“ 219f.

5 Vgl. „Gesetze,“ 56.

${ }^{6}$ KH Kol. LI (XXVIII) Z. 43 „AMA ba-ni-ti“" SJOBBER,, „Version,“ 221, = CBS 1511 Z. 11 ,ama-dim2-ma-mu“ ebd. und KH Kol. LI (XXVIII) Z. 53 f qá-bi-a-at dum-qí-ia vgl. ebd. = CBS 1511 Z. 13 ,"mig -sa $_{6}$-ga-mu inim bal-bal-e“" ebd.

7 Vgl. SJÖBERG, „Version,“ 222f; OelSNER, „Gesetze,“ 56.
} 


\section{1. Zweisprachige Verträge des Hattireiches}

\section{1. 1. Der Vertrag zwischen Hattušili III. und Ramses II.}

Dieser paritätische Vertrag wurde etwa 1278 v. Chr. zwischen Hattušili III., dem König des Hattireiches, und Ramses II., dem Pharao Ägyptens, geschlossen. Der Vertrag ist in einer ägyptischen und einer babylonischen Version erhalten. Eigentlich handelt es sich nicht um einen zweisprachigen Vertrag. Beide Vertragsurkunden waren ursprünglich auf babylonisch abgefaßt. Die in babylonischer Sprache verfaßte Urkunde des Pharao wurde nach Hुattuša gebracht und in Boghazköy gefunden (CTH 91). Die ägyptische Variante ist Übersetzung der hethitischen Urkunde, die ebenfalls auf

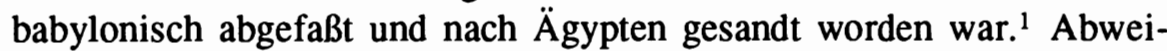
chungen der ägyptischen Übersetzung vom babylonischen Text und Umstellungen einzelner Paragraphen können auf Übersetzungsschwierigkeiten und auf dem Versuch beruhen, trotz der gleichrangigen Formulierungen eine Unterordnung des hethitischen Königs unter den göttlichen Pharao durchklingen zu lassen. Doch hier interessieren nur die Segens- und Fluchabschnitte, die in deutscher Übersetzung einander gegenübergestellt werden.

\section{BABYLONISCHE VERSION CTH 91 \\ (aus der Kanzlei des Pharao) \\ „\$2 22 Fluch bzw. Segen für Hattusili bei Verletzung bzw. Einhaltung des Vertrags (abgebrochen)}

$\S 23$ Fluch bzw. Segen für Ramses bei Verletzung bzw. Einhaltung des Vertrags

Rs. 1' [Und wenn Reamasesa MaiAmana und die Söhne des Landes Ägypten diesen Vertrag nicht halten, so sollen die männlichen Gottheiten und] 2' die weiblich[en] Gottheiten [des Landes Ägypten und die männlichen Gottheiten und die weiblichen Gottheiten des Landes Hatti den Samen] 3' des Reama[sesa Mai-Amana,
ÄGYPTISCHE VERSION (aus der Kanzlei von Hattuša) ,(\$§ $22+23$ der babylonischen Fassung sind ohne Entsprechung in der ägyptischen Übersetzung.)

1 Vgl. Kestemont, „Accords,“ $15,17$. 
des Großkönigs, des Königs des Landes Ägypten, vernichten. Und wenn Reamasesa Mai-Amana] 4' und die Söhne <des Landes> Ägy[pten diesen Vertrag halten, so sollen die Eidesgötter sie beschützen] 5' und ih[r] Antlitz [...]

\$24 Segen für jeden Partner bei Einhaltung des Vertrags

[Was den angeht, der die Worte hält, die auf dieser Silbertafel stehen], 6' so sollen die [großen] Götter [des Landes Ägypten und die großen Götter des Landes Hatti ihn leben lassen und ihn] 7 ' gesund sein lassen [mitsamt seinen Häusern, seinem Land und seinen Dienern].

$\S 25$ Fluch für jeden Partner bei Verletzung des Vertrags

[Was den angeht, der die Worte nicht hält, die auf dieser Silbertafel stehen, so sollen] 8' die gro[Ben] Götter [des Landes Ägypten sowie die großen Götter des Landes Hatti sein Haus, sein Land und seine Diener vernichten]."1
$\S 24$ Fluch für jeden Partner bei Verletzung des Vertrags

Was diese Worte angeht, 31 die auf dieser Silbertafel des Landes Cheta und des Landes Ägypten stehen, und was den angeht, <-seien es Hethiter oder seien es Ägypter-> der sie nicht halten wird, so sollen die 1000 Götter des Landes Cheta sowie die 1000 Götter des Landes Ägyp[ten] sein Haus, sein Land und seine Diener vernichten.

$\S 25$ Segen für jeden Partner bei Einhaltung des Vertrags

Was (aber) den angeht, - seien es Hethiter oder seien es Ägypter - der diese Worte hält, die auf dieser Silbertafel stehen, 32 und sie nicht außer Acht läßt, so sollen die 1000 Götter des Landes Ägypten ihn gesund sein lassen und ihn leben lassen mitsamt seinen Häusern und mitsamt seinen Dienern.“2

Neben den strukturellen Abweichungen des Ausfalls zweier Paragraphen, der Umstellung des Segens- und Fluchabschnitts und der nur im ägyptischen (ursprünglich aus Hatti stammenden) Text stehenden Floskel ,,seien es Hethiter oder seien es Ägypter" sei auf ein Detail hingewiesen, das noch in der deutschen Übersetzung erkennen läßt, wie unterschiedliche Formulierungstraditionen zweier Staatskanzleien einen Fluch verändern. Die signifikante Abweichung kann nicht auf den Einfluß ägyptischer Sprachgewohnheiten bei der Übersetzung der hethitischen Urkunde ins Ägyptische entstanden sein, da die ägyptische Kanzlei in dem in Boghazköi gefundenen Text eine andere Formulierung verwendet hatte. Es handelt sich um das Attribut der angerufenen Götter. Die Version aus Ägypten spricht von

\footnotetext{
1 EDEL, „Friedensvertrag,“ $142 \mathrm{f}$.

2 EDEL, „Friedensvertrag,“ $150 \mathrm{f}$.
} 
den großen Göttern. Dahinter steht die Formulierung DINGIR.MEŠ GAL.MEŠ, mit ihrer in Mesopotamien weit verbreiteten Tradition des Fluchs bei den großen Göttern. ${ }^{1}$ Die ägyptischen Verfasser der für Huattuša bestimmten Tafel schrieben nicht nur Fremdsprache Babylonisch, sie glichen sich auch der babylonischen Fluchtradition an, indem sie einen Fluch (und Segen) bei den großen Göttern schufen.

Die Sumerogramme DINGIR.MEŠ GAL.MEŠ sind in hethitischen Verträgen nicht üblich. Statt dessen wurden in der für Ägypten bestimmten Version aus Hatti die 1000 Götter angerufen. Die Hethiter verwendeten dabei ebenfalls die Fremdsprache Babylonisch. Sie besaßen jedoch zur Zeit des Vertragsschlusses zwischen Hattušili III. und Ramses II. bereits eine Jahrhunderte alte Tradition in der Abfassung zweisprachiger Verträge. Sie verwendeten nicht den Begriff DINGIR.MEŠ GAL.MEŠ, sondern bestimmten die Götter entweder durch Ländemamen genauer oder schrieben li-im DINGIR.MEŠ ,,die 1000 Götter“.

Im Blick auf Dtn 28 kann vermerkt werden:

(1.) Die Reihenfolge einzelner Textabschnitte - hier konkret von Segen und Fluch - konnte variieren.

(2.) Die Übersetzer ins Ägyptische veränderten den Inhalt aus ideologischen Gründen.

(3.) Die Schreiber in den Staatskanzleien hatten unterschiedliche idiomatische Wendungen ausgebildet. Diese voneinander abweichenden Formulierungen wurden trotz ihrer Unterschiede offensichtlich als gleichwertig empfunden. ${ }^{3}$

\subsection{Die syro-hethitischen Verträge}

Eine Reihe von Verträgen des Hattireiches vor allem mit westlichen Nachbarstaaten sind zweisprachig in einer babylonischen Version für den syri-

1 Vgl. VTE $\$ 56$.

2 Vgl. z. B. den Vertrag zwischen Muršili II. von Hattuša und Niqmepa' von Ugarit CTH 66 Z. 86. DEL MONTE, Trattato, 26, oder auch den Vertrag zwischen Muršili II. und Manapa¿U vom Land des Flusses Šeha CTH 69 A Z. 48'. DEL MONTE, „Bruchstücke,“ 62, 64.

${ }^{3}$ Die Schreiber, die die babylonische Version aus Hattuša ins Ägyptische übersetzten, hatten Verständnis- und Übersetzungsschwierigkeiten, weil sie hethitische und babylonische Religionstraditionen offenbar nicht ausreichend kannten. Mesopotamische und kleinasiatische Propria werden durch kanaanäische Äquivalente wiedergegeben, die in Ägypten scheinbar geläufiger waren. So wird aus der babylonischen Ištar die kanaanäische Astarte. Doch nicht einmal in Kanaan bekannte Formulierungen konnten die Ägypter richtig übersetzen. So wird aus einer Ištar der Herde, wie sie das hebräische עשתרות in Dtn 7,13; 28,4.18 noch anklingen läßt, im Ägyptischen die „Göttin von Șen“. Vgl. EDEL, „Friedensvertrag," 150 besonders Anm. 28, 29d. 
schen Vertragspartner und in einer hethitischen Version für das Archiv in Hattuša abgefaßt worden. ${ }^{1}$ Es blieb kein einziger Vertrag erhalten, der den Segens- oder Fluchabschnitt in beiden Sprachen enthält. Stellt man jedoch die Fluchabschnitte zweier verschiedener Verträge nebeneinander, von denen der eine auf babylonisch, der andere auf hethitisch erhalten ist, so läßt sich erkennen, daß der in diesem Kapitel unternommene Versuch, Übersetzungen miteinander zu vergleichen, auch zum Scheitem verurteilt wäre, wenn von ein und demselben Vertrag ein Fluch in beiden Sprachen erhalten wäre. Zur Verdeutlichung wird die Fluchformel des in babylonischer Sprache erhaltenen Vertrages zwischen Muršili II. und Niqmepa' von Ugarit neben den Fluch der hethitischen Version des Vertrages zwischen Muršili II und Tuppi-Tešub geschrieben:

Muršili II. - Niqmepa‘

CTH 66:

Vertrag in akkadischer Sprache "112' mi-nu-um-me-e $a$-ma-te.MEŠ ša [(ri)-ik-sí ù ša ma-mi-ti ša (i-na lib-bi tup-pi)] 113' an-ni-ti šaț-rat.at sum-ma I.níq-[m(e-pa a-ma-te.MEŠ an-n)a-ati ša ri-i(k-sí)] 114' ù ša ma-mi-ti la-a i-n[(a-șár ù nê)-eš DINGIR.MEŠ (an-nu-ú-ti

I.niq-me-pa qa-du)

SAG.DU-šu] 115' DAM.MEŠ-šu

DUMU.MEŠ -š

DUMU.DUMU.MEŠ-š[u

É-(šu URU-šu KUR-šu

mim-mu-šu)

$l(u-h a l-l i-q u-\check{s} u)]^{“ 2}$
Muršili II. - Tuppi-Tešub

CTH 62 II:

Vertrag in hethitischer Sprache „21 [(MI-NU-UM) -ME A-WA-TE.MEŠ ŠA RI-IK-SI Ù MA-ME-TI 22 [I-NA LÌB-BI] TUP-PÍ AN-NI-TI ŠAT-RAT-E ŚUM-MA I.tup-pi-d.U-up 23 [(A-WA-TE).MEŠ AN-NA-T]I?(ras.) ŠA RI-IK-SI Ù ŠA MA-ME-TI 24 [LA-A IN-NA-ṢA-AR] Ù NI-IŠ DINGIR.MEŠ AN-NU-TI

I.tup-pi-d.U-up 25 [QA-DU SAG.DU-ŠU DA]M-ŠU DUMU-ŠU DUMU.DUMU-ŠU

É-TI-ŠU 25 [(URU-LI-ŠU KUR-ŠU Ù QA-DJU MIM!-MU!-ŠU LU-HAL-LI-QÚ-ŠU“3

In beiden Texten steht wörtlich derselbe Fluch und er ist auch im hethitischen Vertrag auf babylonisch verfaßt. Die Hethiter schrieben also in den sonst hethitischen Verträgen die Flüche (und auch den Segen) in der Fremdsprache, deren Schriftsystem sie übernommen hatten. Es sind nur leichte orthographische Abweichungen festzustellen, z.B. der Wegfall des Pluralzeichens MEŠ in CTH 62 II Z. 25 gegenüber CTH 66 Z. 115. Die

\footnotetext{
${ }^{1}$ Eine Liste dieser Verträge bietet DEL MoNTE, ,Traduzione,“ $103 \mathrm{f}$.

2 Del MonTe, Trattato, 30.

${ }^{3}$ Del MonTE, Trattato, 174, 176.
} 
Verwendung derselben babylonischen Wendungen in verschiedenen Verträgen zeigt, daß die hethitischen Fluch- und Segensformeln festgelegt waren und stereotyp wiederholt wurden. Inhaltlich sei hervorgehoben, daß nicht die Götter, sondern die Eide selbst als Vollstrecker der Flüche angesprochen werden. Die Übersetzung der Fluch- und der sich meist anschlieBenden Segensformel lautet:

Alle Worte des Vertrages und des Eides, die auf dieser Tafel geschrieben sind, wenn PN diese Worte des Vertrages und des Eides nicht hält, so mögen diese Eide bei den Göttern den PN, sein Haupt, seine Frauen, seine Söhne, seine Enkel, seine Stadt, sein Land (seine Habe) vernichten. Wenn PN diese Worte des Vertrages und des Eides, die auf dieser Tafel geschrieben stehen, hält, so mögen die Eide bei den Göttern den PN, sein Haupt, seine Frauen, seine Söhne, seine Enkel, (sein Vieh), sein Haus, seine Stadt, sein Land (und seine Habe) beschützen.

Die in Klammern gesetzten Segens- oder Fluchobjekte können hinzugefügt oder weggelassen werden und es sind auch Hinzufügungen mit einem Umschlag in die 2. Person Sg. bekannt. Im allgemeinen aber wurde die hier Formel in fixierter Form tradiert. Ein anderes Bild zeigt sich in den Loyalitätseiden, wo Ritualflüche belegt sind, die Ähnlichkeiten mit den Ritual- und Vergleichsflüchen des Vertrags A.745.1 oder der VTE aufweisen. Im Gegensatz zu den Vertragsflüchen sind sie in hethitischer Sprache verfaßt. Sie enthalten aber auch Passagen, die der allgemeinen Formel der Verträge ähneln. ${ }^{1}$

\subsection{Die Bilinguen von Tell Fekheriye und Karatepe}

1979 fand man in Tell Fekheriye im Haburgebiet an der Nordgrenze Syriens die Statue eines Gouverneurs von Guzana namens Hadad-yis'i. Die Statue stammt wohl aus dem 9. Jh. v. Chr. und enthält eine assyrisch-aramäische Bilingue, welche sie als Votivgabe an den Gott Adad ausweist. Mehrere Flüche sollen die Figur und ihre Inschrift schützen.

Der Text bezeugt eine assyrisch-aramäische Zweisprachigkeit im nördlichen assyrischen Herrschaftsbereich. Assyrischer und aramäischer Text

\footnotetext{
${ }^{1}$ Vgl. OetTINGER, Eide, 7-21, 17: „... dessen Stadtbewohnersch[aft 8'[ mit Enke]l und Urenkel, des Menschen Rinder und Sch[afe ] [ ] mit Weingarten und Gemüsegar[ten ] 10' [ soll(en)] für (alle) Zukunft hinweg[ ... ] ...".

${ }^{2} \mathrm{Vgl}$. ABOU-ASSAF / BoRDREUl / MillaRd, Statue, 1, 18, 22. Zu weiterer Literatur über die Tell Fekheriye-Inschrift vgl. VATTIONI, „Bilingue,“ 349-353.
} 
entsprechen einander nicht immer. ${ }^{1}$ Zum Beispiel bezeichnet sich Hadadyis'i im aramäischen Teil als mlk „König“ von Guzana, während er sich im assyrischen nur šaknu ,Gouverneur" nennt. ${ }^{2}$

Die Inschrift besteht aus zwei Teilen, die beide den Zweck der Weihegabe ausdrücken. Der erste Teil (A4) endet bereits mit einem kurzen Fluch: ${ }^{3}$

16 mannu ša šume $\bar{e}^{17}$ unakkaru

Derjenige, der meinen Namen

beseitigt,

u šumšu išakkanu

und seinen Namen einsetzt,

18 Adad qardu lü bèl dīnišu

Adad, der Held sei sein Ankläger!
11 wzy yld šmy mnh

Und der meinen Namen auslöscht,

12 wyšym šmh

und seinen Namen einsetzt,

hdd gbr lhwy qblh

Adad, der Held sei sein Ankläger!

Der Fluch am Schluß des zweiten Teiles (B4) ist viel ausführlicher:

${ }^{26}$ mannu ša šumē issu libbi ${ }^{27}$ unūte

Derjenige, welcher meinen Namen aus

diesem Gegenstand

ša bīt Adad bēlīja ${ }^{28}$ ipaššituni

des Hauses Adads, meines Herm tilgt, ${ }^{4}$ Adad bēlī

Adad, mein Herr, akālšu ${ }^{29}$ mêšu lā imah̆haršu

nehme weder seine Speise noch seinen

Trank an!

Šala bēssì

Šala, meine Herrin,

30 akālšu mêšu KI.MIN

weder seine Speise noch seinen Trank dito
16 mn yld šmy mn m'ny'

Wer meinen Namen löscht von diesem

Gegenstand

17 zy bt hdd mr'y

des Hauses Hadads, meines Herrn,

mr'y hdd

mein Herr Hadad

lhmh wmwh'l ylqh mn 18 ydh

nehme weder seine Speise noch seinen

Trank aus seiner Hand an!

swl mr'ty

Sawl, meine Herrin,

lhmh wmwh'l tlqh mn ydh

nehme weder seine Speise noch seinen

Trank aus seiner Hand an!

${ }^{1}$ Vgl. Abou-Assaf / Bordreul / Millard, Statue, 9; Dion, „Bilingue,“ 141-147; Fales, „Bilinguisme,“ 249f.

${ }^{2}$ Vgl. FALES, „Istituzioni,“ 150. Der Statue fehlen die in der assyrischen Bildkunst üblichen Herrscherembleme. Die dargestellte Person scheint aus assyrischer Sicht kein König gewesen zu sein. Vgl. Abou-AsSAF/ Bordreull / Millard, Statue, 9.

3 Transkription und Übersetzung nach ABOU-AsSAF / BORDREUIL / MiLlARD, Statue, 63, 65f; GREENFIELD / SHAFFER, „Notes,“ 51-58. Einen vokalisierten aramäischen Text bieten ANDERSEN / FREEDMAN, „Orthography,“ 11, eine deutsche Übersetzung beider Versionen DELSMAN, „Inschriften,“ 634-637.

${ }^{4}$ Die assyrischen Sätze (Z. 16.26) beginnen gleich, während im Aramäischen von Konjunktion und Relativpronomen (Z. 11) zum Fragepronomen gewechselt wird. Dafür behielt man dort die Wurzel lwd Uauslöschen" bei, während der assyrische Text von nakäru/D mit babylonischem Subjunktiv (Z. 17) zu pašăṭu und assyrischem Subjunktiv wechselt (Z. 28). 
lìriš lū lāa ${ }^{31}$ eșidi

Er säe, er möge nicht ernten.

1 lim tîriš

Tausendfach möge er säen, 1 sūtu 32 lișbat nur 1 Sutu möge er erhalten!

$1 m \bar{e}$ lahrū

100 Mutterschafe

lā ušabbâ ${ }^{33}$ h̆urāpu

sollen nicht ein Lamm sättigen!

1 mē lâtu

100 Kühe

lā ušabbâ mūri

sollen nicht ein Kalb sättigen!

${ }^{34} 1$ mè alidāte

100 Mütter

lā ušabbâ māru

sollen nicht ein Kind sättigen!

351 mê apiāte

100 Bäckerinnen

la $u<s ̌ a m>l a{ }^{36}$ tinūru

sollen nicht einen Backofen füllen!

eli tupkinnāte $e^{5}$ $w^{19} z r^{\prime} w^{\prime} l$ yhṣd

Und er säe, aber ernte nicht!

w'lp s'ryn lzr'

Und tausend $\mathrm{Maß}$ säe er ${ }^{1}$

wprys l'hz mnh

nur ein prys möge er davon erhalten! ${ }^{2}$

${ }^{20}$ wm'h s'wn

100 Mutterschafe

Ihynqn 'mr w'l yrwh

sollen ein Lamm stillen,

aber es wird nicht satt! ${ }^{3}$

wm'h swr

100 Kühe

lhynqn 21 ' $g$ l w'l yrwy

sollen ein Kalb stillen,

aber es soll nicht satt werden!

wm'h nšwn

100 Frauen

lhynqn 'lym w'l yrwy

sollen einen Säugling stillen,

aber er soll nicht satt werden!

22 wm'h nšwn

100 Frauen

l'pn btnwr lhm w'l yml'nh

sollen in einem Backofen Brot backen, aber sie sollen ihn nicht füllen! ${ }^{4}$ wmn qlqlt'

1 Vgl. GREENFIELd / SHAFFER, „Notes,“ 53.

${ }^{2}$ Sutu und wprys sind kleine Maßeinheiten. Auch šryn wird als Maßangabe angesehen. Vgl. ABou-ASSAF / BordREUIL/ Millard, Statue, 34f.

${ }^{3}$ Der feminine Pl. ušabbâ bezieht sich auf die 100 Muttertiere, während die Form im Sg. maskulin $y r w h / y$ das eine Jungtier meint. Vgl. ABOU-ASSAF / BORDREUIL / MILLARD, Statue, 49. Zum Jussiv mit Präfix ,l-“ oder als apokopiertes Imperfekt vgl. ebd. 58f. Bei negierten Verben steht das Jussiv-Präfix , ,l-“ nicht. Vgl. HuEHNERGARD, „Jussive,“ 269 Anm. 13. In Z.20 wurde am Ende des Verbums tertiae infirmae „yrwh" ein He geschrieben, das normalerweise den Indikativ bezeichnet, in Z. 21 zweimal Jod, welches den Jussiv angibt. Vgl. ARISTAR, „Jussive,“ 159.

${ }^{4} \mathrm{Zu}$ w'l yml'nh schreibt HUEHNERGARD, „Jussive,“ $268 \mathrm{Anm}$. 9: „The final - $h$ of this form is not part of the verbal ending but a $3 \mathrm{~ms}$ objekt suffix referring back to $t$ wwr 'oven'. That the suffix is $-h$ only, not $-n h\left({ }^{*} y m l^{\circ} n n h\right)$, is further evidence that the verb form is jussive ...".

5 GREENFIELD / ShAFFER, „Notes,“ 57, vergleichen tupkinnāte mit „'ina tubkinni lū mayālšunu' 'may their bed be on a dung-heap'." aus dem Assurnirari-Vertrag A.745.1 Kol. VI Z. 6 und Klgl. 4,5. 
Auf Abfallhaufen

laqūte $\bar{e}^{37}$ lilqutē

sollen die Kornsammler sammeln!

di'u šibțu ${ }^{38}$ dilipte

Krankheit, Seuche, Schlaflosigkeit issu mātišu lā ipparrasū

mögen aus seinem Land nicht entfernt werden!
Und vom Abfallhaufen

llqtw' 'nšwh šrn l'klw

sollen die Menschen Gerste sammeln, um sie zu essen!

${ }^{23}$ wmwtn šbt zy nyrgl

Und Pest, die Seuche Nergals,

'l ygtzr mn mth

möge aus seinem Land nicht entfernt werden!

Der zitierte Ausschnitt zeigt, daß man keineswegs immer wörtlich übersetzt hat. Manchmal steht in der assyrischen, manchmal in der aramäischen Version mehr. Der assyrische Text wechselt in Z. $13 \mathrm{f}$ von der 3 . in die 1 . Person, die aramäische Entsprechung in den Z. 9 f macht diesen Wechsel nicht mit. Z. 17f der aramäischen Fassung weicht durch die Erwähnung der Hände ('l ylqh mn ydh) von der assyrischen ab (Z. 28f). Die Hände scheinen jedoch zu einer im Aramäischen festgelegten Formulierungsgewohnheit zu gehören, wie fast gleichlautende Formeln in der Inschrift Panamuwa I. (wmt yqhw mn ydy / KAI Nr. 214 Z. 12) ${ }^{1}$ und Sefire III (wtqh mly' $m n$ $y d h /$ Z. 2) $)^{2}$ zeigen. Die Frustrationsflüche, aus denen wie im Deuteronomium Reihen gebildet werden, stehen genau genommen nur im aramäischen Text (Z. 19-22). Ihre Struktur besteht aus einer Beschreibung der Tätigkeit $+w+$ Negation + Verb der Präfixkonjugation und entspricht genau den futility curses nach Hillers. ${ }^{3}$ Im assyrischen Gegenstück dagegen stehen keine Antithesen, sondern nur verneinte Wünsche. ${ }^{4}$ Dieser Unterschied führte Dion und Fales zu der Auffassung, der futility curse stamme aus dem aramäischen Sprachbereich. ${ }^{5}$ Dies impliziert die Annahme einer von der assyrisch-babylonischen differenzierbaren westsemitischen Fluchtradition, die eigene Formen hervorbrachte. Man verzichtete darauf, die aramäischen Antithesen durch entsprechende assyrische Formulierungen wiederzugeben, obwohl derartige Gestaltungsmuster auch im Assyrischen bekannt waren. ${ }^{6}$ Diese Abweichung läßt erkennen, daß einfache ak-

1 Vgl. Dion, „Bilingue,“ 146; Tropper, Zincirli, 72 (S 68 = H:12).

2 Vgl. GREENFIELD / SHAFFER, „Notes,“ 52.

${ }^{3}$ Vgl. Hillers, Treaty-Curses, 28, 35; Podella, „Nichtigkeitsfluch,“ 428, $435 \mathrm{f}$.

4 Vgl. Fales, „Bilinguisme,“ 249.

5 Vgl. Dion, „Bilingue,“ 146; PoDELLA, „Nichtigkeitsfluch,“ 437; FALES, „Istituzioni,“ 164: „ne postuleremo pertanto un'origine tutta aramaica.“ ABOU-ASSAF / BORDREUIL / MILLARD, Statue, 76, weisen auf die leicht abweichende Verwendung der Zahl sieben in einem Fluch des Kapara von Guzana hin. Dort fehlt aber die Antithese. Vgl. auch GreENFIELD / SHAFFER, „Notes,“ 53f. 
kadische Wunschsätze und westsemitisch futility curses als gleichwertig empfunden wurden, wobei letztere offenbar dem Geschmack westsemitischer Schreiber eher entsprachen. ${ }^{1}$

Während Dtn 28 den Frustrationsfluch vom Zahlenspiel Vielzahl zu eins trennt, kennt das AT auch die Verbindung beider Elemente. Dazu gehört Lev 26,26:

Ich entziehe euch dann euren Vorrat an Brot, so daß zehn Frauen euer Brot in einem einzigen Backofen backen, daß man euch das Brot abgewogen zuteilt und ihr euch nicht satt essen könnt (ואכלתם ולא תששעו).

Auch prophetische Texte kennen das Motiv Vielzahl zu eins und Antithesen (z.B. Jes 5,10; Hag 1,6). ${ }^{2}$

Im Blick auf Dtn 28,21f fällt auf, daß die assyrische Version drei verschiedene Krankheiten aufzählt (Z. 37f vgl. Dtn 28,22a), denen in der aramäischen nur der Pestfluch gegenübersteht (Z. 23 vgl. Dtn 28,21). Zweisprachige Texte müssen also bei Aufzählungen nicht unbedingt gleich viele Glieder anführen. Außerdem ist diliptu im Gegensatz zu di'u und šibtu nie im Kontext des Nergalfluchs belegt. Dem aramäischen $\check{s} b t$, das dem akkadischen šibtum entspricht, werden das Wort mwtn und die Nennung Nergals beigegeben. Die Pest war bei den Assyrem ein Attribut Nergals, der den Menschen mūtānu sandte. ${ }^{3}$

Die assyrische und aramäische Fassung der Inschrift von Tell Fekheriye zeigt, daß die übersetzende gleichzeitig eine gestaltende Hand war. Einfache Wünsche können in Antithesen umgewandelt, mehrgliedrige Aufzählungen in eine einzige Aussage zusammengefaßt werden. Für diese Bestandsaufnahme der „Übersetzungstreue“ bleibt es unerheblich, in welche Richtung man übersetzte, ob der jeweilige Einzelfluch also ursprünglich assyrisch oder aramäisch formuliert war. ${ }^{4}$ Bei aller gestalterischen Freiheit

6 Vgl. STRECK, Assurbanipah 76-79 (Rassam Prisma) Kol. IX Z. 65-67; ebd. 378 Kol. II Z. 14, B.1298.1 Rs. Kol. II Z. $44+x-47+x$.

1 Vgl. KREBERnIK, „Deuteronomiumskommentar,“ 36; ABOU-AssaF / BordREUIL / Millard, Statue, 79, lehnen wegen des geringen Textmaterials die Differenzierung eigenständiger west- und ostsemitischer Fluchtraditionen ab. Dennoch bezeugt das Fehlen der aramäischen Antithesen in den assyrischen Äquivalenten unterschiedliche Fluchstile; FALES, „Bilinguisme,“ 249, meint, die assyrischen Wunschsätze seien eine Vereinfachung der aramäischen Frustrationsflüche.

2 Vgl. ABou-AsSaF / Bordreuil / Millard, Statue, 78; Podella, „Nichtigkeitsflüche," $436 \mathrm{f}$.

3 Vgl. GreENFIELD / SHAFFER, „Notes,“ 58; FALES, „Bilinguisme,“ $247 \mathrm{f}$.

${ }^{4}$,We believe that along side this division one following the original language of composition can be made: Assyrian original - Assyrian 11. 1-26 = Aramaic 11. 1-16; Aramaic original - Assyrian 11. 26-38 = Aramic 11. 16-23. This last part ... contains the curse portion 
in der Wiedergabe des anderssprachigen Fluches wurde jedoch die Reihenfolge der Fluchthemen (göttlicher Ankläger, Ablehnung des Opfers, Saat, Schafe, Kühe, Menschen, Backofen, Abfallhaufen, Krankheit) treu bewahrt.

Sollte Dtn 28 tatsächlich von den Flüchen eines assyrischen Vertrages beeinflußt sein, so darf wohl nach Betrachtung der Bilingue von Tell Fekheriye kaum gefordert werden, daß man die VTE wortwörtlich übersetzt hätte. Im Hinblick auf den in $\mathbb{R}$ von Dtn 28 belegten Jussiv sei auf die Jussivformen in den aramäischen Flüchen hingewiesen: lšm, lhwy, $l z r^{\prime}, l^{\prime} h z$, lhynqn, llqtw usw. entsprechen dem akkadischen Prekativ. ${ }^{1}$

Der Vollständigkeit halber sei noch die phönizisch-hethitische Bilingue von Karatepe (KAI Nr. 26) erwähnt, die ebenfalls ins 9. Jh. v. Chr. datiert werden kann. ${ }^{2}$ Der phönizische Text wurde mehrfach bearbeitet. Eine Edition des hethitisch-bildluwischen Textes fehlt noch. Daher können die beiden Versionen der Flüche hier nicht verglichen werden. Allerdings gilt die luwische Version als freie Übersetzung des phönizischen Textes. ${ }^{3}$

Die Untersuchung der Differenzen zwischen dem phönizischen und dem hethitisch / bildluwischen Text, die Amadasi Guzzo und Archi durchführten, behandelt die Fluchformel nicht, wohl aber deren Einleitung. Die phönizische Flucheinleitung beginnt mit der Konditionalpartikel $w^{\prime} \boldsymbol{m}$, dem konditionalen Nominalsatz folgt ein Relativsatz mit dem Verb im Imperfekt. Eine derartige Konstruktion scheint typisch für phönizische Flucheinleitungen, denn sie ist ähnlich auch in den Inschriften des Ahiram (KAI Nr. 1), des Jeḥaumilk (KAI Nr. 10, Z. 13-15) und des Tabnit (KAI Nr. 13, Z. 6-8) zu finden. Die hethitisch-bildluwische Version dagegen wechselt innerhalb der Flucheinleitung in die direkte Rede. Zur Verdeutlichung wird der Übersetzung des Fluches von Müller die italienische Übersetzung der hethitischen Flucheinleitung durch Amadasi Guzzo und Archi gegenübergestellt.

... . The Aramaic is rich while the Assyrian equivalent is, except for the last curse, poor and secondary." GrEENFIELD/ SHAFFER, „Notes,“ 49.

1 Vgl. GreENFIELd / ShafFER, „Notes,“ 50; HuehnERGARD, „Jussive,“ 269 Anm. 13.

${ }^{2}$ Vgl. MULLER, „Inschriften,“ 641 Anm. 1a. Es wird aber auch eine Datierung ins 8. Jh. v. Chr. diskutiert.

${ }^{3}$ Vgl. MULLER, „Inschriften,“ 640-645, 640: „Die folgende Übersetzung folgt dem phönizischen Text der Fassung A, da die semitisch beeinflußte, wortschatzarme luwische Version von den meisten als relativ frei übersetzter Text angesehen wird." Dazu bemerkt eine ausdrücklich auf den Bilingualismus ausgerichtete Untersuchung: „Mentre la struttura d'insieme è comune alle due versioni, sono diversi i procedimenti adottati all'interno di tale struttura per esprimere lo stesso contenuto: con alcuni esempi di queste differenze si vuole mettere in evidenza l'indipendenza redazionale dei testi nelle due lingue." AMADASI GuZzo / ARCHI, „Bilingue,“ 89. 
Kol III „12Und wenn ein König unter Königen (ist) und ein Prinz unter den Prinzen oder ein ${ }^{13}$ (anderer) Mensch, der Ansehen besitzt, der den Namen Azitawaddas austilgt ... ${ }^{18}$ so möge der Baal des Himmels und El, der die Erde erschaffen hat, ${ }^{19}$ und der ewige Scham(a)sch und der ganze Kreis der Gottessöhne jenes Königtum und jenen König und jenen IV ${ }^{1}$ Menschen, der Ansehen besitzt, austilgen. Nur ${ }^{2}$ der Name Azitawaddas möge in Ewigkeit bleiben wie der Name ${ }^{3}$ des Scham(a)sch und Jarich."1

„Se qualcuno tra i re / o (se) egli (è) un uomo / e a lui (è) un nome virile / proclama ciò: / cancellerò il nome di Azatiwa ... / possa Tarhunza del cielo ... cancellare." 2

Der hethitische Fluch benennt die Götter anders, statt Baal des Himmels steht Tarhunza des Himmels. Satzkonstruktion und Gottesnamen können also im Fluchabschnitt von Bilinguen voneinander abweichen. Religionsgeschichtlich hervorzuheben ist die Nennung des El, der die Erde geschaffen hat. In dieser phönizischen Inschrift werden in den Epitheta des Fluchs Himmel (Baal) und Erde (El) erwähnt. Dazu treten der Sonnengott (Šamaš) und ein Götterkollektiv. Diese Zusammenstellung erinnert an die Stichwortverknüpfungen, die in den VTE zwischen den Passagen gefunden wurden, für die es Parallelen in Dtn 28 gibt. Auch dort ging es um Šamaš (VTE § 40, § 68 [Eisen], § 101 [Bronze]), den Himmel ( $\$ 64$ [Bronze]) und die Erde (kaqqaru $\S 40, \S 63$ [Eisen]), wobei in VTE $\S 63$ ebenfalls ein Götterkollektiv angerufen wurde. Sollte die Karatepe-Inschrift eine westsemitische Kombination von Motiven bezeugen, die auch einen Judäer bei der Suche nach passendem Material in einem assyrischen Text geleitet haben könnte?

Šamaš ist im Fluch den Göttern Baal und El nachgeordnet, im abschlieBenden Segen (Kol. IV Z. 2f) allerdings dem Mondgott Jarich vorangestellt. Die Voranstellung des Sonnengottes vor den Mondgott, der in der letzten Zeile der Inschrift zum ersten Mal genannt wird, während Baal, El und ein Götterkollektiv bereits in der Selbstsegnung des Azitawadda (Kol. III Z. 2-11) vorkamen, scheint typisch westsemitisch. ${ }^{3}$

\footnotetext{
${ }^{1}$ MÜlLeR, „Inschriften,“ 644f. Zu den Gottesnamen vgl. 644 Anm. 18b, 645 Anm. 3a.

2 Amadasi Guzzo / ARCHI, „Bilingue,“ 91.

${ }^{3} \mathrm{Im}$ neuassyrischen Sprachbereich wurde in solchen Segnungen der Mondgott $S$ in vor den Sonnengott gereiht, wie der Brief ABL 923 (K. 2701a) an den assyrischen König belegt: " ${ }^{4}$... [Mögen] Sin und Schamasch [meinem] königlichen [Herrn] Heil [erbitten]... ." HECKER, „Zukunftsdeutung,“ 79.
} 


\section{3. Die Bilingue von Kelišin}

Bisher kennt man zwei urartäisch-assyrische Bilinguen. Die ältere befindet sich auf der Stele von Kelišin und stammt von dem urartäischen König Išpuini (ca. 825-810 v. Chr.). Die jüngere, die Bilingue von Topzawa, stammt vom urartäischen König Rusa I. (ca. 730-714/713 v. Chr.) und ist, obwohl man im Zagros Teile eines Duplikates ihres assyrischen Textes gefunden hat, in einem so schlechten Erhaltungszustand, daß ein Vergleich zwischen der assyrischen und der urartäischen Version unmöglich ist. ${ }^{1}$ Die Inschrift von Kevenli, verfaßt von König Menua (ca. 810-785/780 v. Chr.), enthält zwar auch einen assyrischen und einen urartäischen Text, stellt aber keine Bilingue dar. In ihrem ersten Teil (Z. 1-3) verewigt sie nämlich auf assyrisch den Bau eines Kultgebäudes für den Gott Haldi, in ihrem zweiten Teil (Z. 4-6) auf urartäisch eine Segensformel für Menua und dessen Vater Išpuini. $^{2}$

Für den Vergleich zweisprachiger Fluchformeln kommt also nur die Bilingue von Kelišin in Betracht, welche im folgenden nach der Bearbeitung von Benedict zitiert wird. Die beiden urartäischen Fluchformeln lauten:

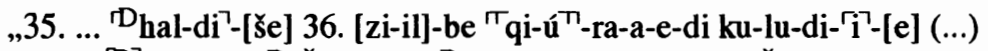

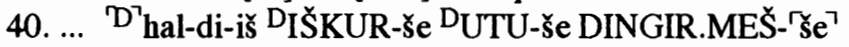

41. [URU ar]-'di-ni'-ni-na-še zi-l'i'-bi qi-ra-e-di 'ku-lu'-d[i-e]“3

„... may Haldi wipe out (his) seed on the earth ... whoever removes this inscription from this place, whoever breaks (it), whoever causes another (to do) these things, says 'go destroy (it),' may Haldi, Teisheba, Shiuini, (and?) the gods of the town of Ardini wipe out (his) seed on the earth." ${ }^{4}$

Die beiden assyrischen Formeln lauten:

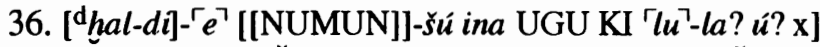

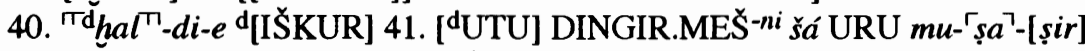

42. [NUMUN-ša] ina UGU $\mathrm{KI}^{-r i} \times \mathrm{x} \mathrm{x}^{75}$

„... may Haldi blot out(?) his seed(?) upon the earth. [Whoever disturbs(?)] this inscription from this place, whoever breaks (it), whoever says to anyone 'go

1 Vgl. SALViNI, „Uso,“ 173, 176.

2 Vgl. Salvin, „Uso,“ $175 f$.

3 BENEDICT, ,Inscription,“ 372.

4 BENEDICT, ,Inscription,“ 383.

5 Vgl. BENEDICT, „Inscription,“ 362. Die Sumerogramme wurden nicht in assyrische Wörter aufgelöst, um zu verdeutlichen, daß die assyrische Version fast nur aus Logogrammen besteht. Diese Schreibweise und das in Mesopotamien sehr verbreitete Fluchmotiv erwecken den Eindruck, die urartäischen Schreiber hätten den assyrischen Fluch bereits in fixierter Form übernommen. 
break (it), 'may Haldi, Adad(?), Shamash(?), (and?) the gods of Musasir [blot out(?)] his seed(?) upon the earth."1

Die Fluchformeln enthalten das weit verbreitete Motiv der Ausrottung des Samens und stimmen fast ganz überein. Die Götternamen wurden in beiden Versionen mit denselben Wortzeichen geschrieben. Allerdings heißen die zuletzt angerufenen Götter in der urartäischen Fassung die Götter der Stadt Ardini, in der assyrischen jedoch die Götter der Stadt Mușașir. Auch das Verb, durch welches die Ausrottung ausgedrückt wird, scheint in beiden Fassungen nicht bedeutungsgleich zu sein. Benedict versucht diese Unstimmigkeit durch die Worte ,wipe out“ und „,blot out" anzudeuten. Unzweifelhaft geht es in beiden Fällen um die Vernichtung des Samens. Leider ist das assyrische Verb beide Male unleserlich und muß sinngemäß aus der urartäischen Version ergänzt werden. Das letzte Wort der beiden urartäischen Fluchzeilen 36+41 war identisch, obgleich es in Z. 41 kürzer geschrieben sein dürfte. ${ }^{2}$ Dagegen müssen aufgrund der noch lesbaren Zeichenreste im assyrischen Text in beiden Fluchformeln verschiedene Worte gestanden haben. ${ }^{3}$

\section{4. Die Verträge mit Mati'ilu von Arpad und westsemitische Inschriften}

\section{4. 1. Die Sefire-Inschriften und der Assurnirari-Vertrag}

Von dem König von Arpad, der auf assyrisch Mati'ilu und auf aramäisch Mati'-Il genannt wurde, blieben Verträge in aramäischer und assyrischer Sprache erhalten, die ihm jeweils ein mächtigerer Herrscher auferlegte. Sie zeigen, wie ähnliche Inhalte in assyrischen und in aramäischen Verträgen abgehandelt wurden. So eröffnet sich ein Einblick in die unterschiedlichen Formulierungstraditionen beider Sprachen.

Die Stelen von Sefire sind mit aramäischen Verträgen beschrieben, die König Bar-Ga'yah von KTK mit Mati'-Il schloß. ${ }^{4}$ Trotz zahlreicher philo-

1 BENEDICT, ,Inscription,“ 383.

2 Vgl.' BeNEDICT, ,Inscription,“ 382.

${ }^{3} \mathrm{Zu} \mathrm{Z}$. 36 schreibt BENEDICT, „Inscription,“ 370: „The reading $l a$ is possible for the sign after $l u$. The next sign would be $u, g a, k i d, l a h$, or something similar, or the beginning of IL (našu $)$. (...) There seems no way of reading a form of haläqu into the visible wedges. The formula here should be something similar to that in 42 but cannot be identical ... " $\mathrm{Zu} \mathrm{Z} .42$ schreibt er 371: „We would expect here a phrase similar to that which stood in $36 \ldots$. However, it is clear that the wording, or at least the spelling, is quite different here."

${ }^{4}$ „Da Arpad um das Jahr 740 v. Chr. durch den Assyrerkönig Tiglatpileser III. erobert und zerstört worden ist, sind die Inschriften jedenfalls vor diesem Zeitpunkt entstanden." RÖSSLER, „Verträge,“ 178. Vgl. Lemaire / DuRAND, Sfiré, 3-5; PUECH, „Traités,“ 88; KAI Nr. 222-224. 
logischer und historischer Untersuchungen lassen diese Texte noch viele Fragen offen. ${ }^{1}$ So ist die Identität des Königs Bar-Ga'yah und die Lokalisierung seiner Hauptstadt KTK immer noch ungeklärt. ${ }^{2}$ Für den Vergleich der Sefire-Verträge mit der Bibel genügt die Quintessenz der historischgeographischen Einordnungsversuche. Die Stelen von Sefire stammen aus dem aramäischen Kulturraum Syriens, der jedoch massiv von assyrischmesopotamischem Gedankengut durchdrungen war. Sie entstanden etwa um 750 v. Chr. Die Frage, ob die Inschriften der drei Stelen denselben Vertrag in drei verschiedenen Versionen oder jeweils unterschiedliche Verträge enthalten, ist nicht geklärt. Puech meint, Stele I enthält zwei Vertragstexte, den ersten auf den Seiten $A+D$, den zweiten auf den Seiten $\mathrm{B}+\mathrm{C} .{ }^{3}$ Flüche blieben aber nur auf Stele I und II erhalten. ${ }^{4}$

Die Verwendung des Jussiv im Aramäischen von Sefire führt zu textimmanenten Aussagenuancen. Grammatisch erkennbar wird der Jussiv bei den starken Verben durch die Apokope des Nun in der 2. Person fem. Sg. sowie der 2. und 3. Person Pl. des Imperfekts. Bisweilen macht in Formen ohne Suffix, besonders bei Verben tertiae infirmae, ein orthographischer Unterschied den Modus deutlich. Im Indikativ schrieb man als mater lectionis für den Endvokal Aleph oder He, im Jussiv Jod. ${ }^{5}$ In den übrigen Verbformen kann kein Unterschied zwischen Imperfekt und Jussiv festgestellt werden. Huehnergard vertrat die These, Formen der 3. Person Pl. fem. wurden in Sefire immer mit Nun geschrieben. Modusdifferenzierung geschah durch die Aussprache: yvqtvln für Jussiv und yvqtvlān für Indikativ. ${ }^{6}$ Solche nach dem Schriftbild nicht eindeutig im Modus bestimmbare Formen werden im folgenden als ambivalent eingestuft. In diesen Fällen scheint der Kontext für die Modusbestimmung ausschlaggebend. ${ }^{7}$

Man findet in Sefire Formen, die nach den oben genannten Kriterien morphologisch eindeutig Jussive darstellen: ${ }^{8}$ thry IA Z. 21, thwy IA Z. 25,

${ }^{1}$ Zur Forschungsgeschichte vgl. LEMAIRE / DURAND, Sfiré, 5-21.

2 Vgl. FITZMYER, Inscriptions, 127-135; LEMAIRE / DURAND, Sfiré, 20f, 37-56; FALES, „Istituzioni,“" 152-154, 172f; ZADOK, „Background,“ 534.

3 Vgl. PUECH, „Traités,“ $88 \mathrm{f}$.

${ }^{4}$ Vgl. Lemaire / Durand, Sfiré, 56f.

5 Vgl. ARISTAR, „Jussive, 158f., Rosenthal, Grammar, $44 \S 108,52 \S 152$.

6 HuEhNERGARD, ,Jussive,“ 277.

7 Vgl. HuehneRgaRd, „Jussive,“ 267 Anm. 6; ebd. Anm. 5: „That $y^{\prime} r r n$ and yqhnn are indicative is assured by the parallel occurence, in the same set of curses, of the masculine indicative ygzrn 'they will be cut up,' KAI 222 A 40 ."

8 ,The inscriptions from Sefire ... may serve as a representative example. ... these show, with few exeptions, a consistent graphic distinction between the unsuffixed indicatives of IIIy verbs, where he is written as mater lectionis for the final vowel, e.g. IB: $28 y^{\prime}$ th 'he 
32, yṣrw IC Z. 15, hpkw IC Z. 21, wyšnw IC Z. 23, ytnšy IIA Z. 4. Die Jussivformen lassen sich auf bestimmte Abschnitte eingrenzen. Die Verben in der 3. Person Pl. mit apokopiertem End-Nun stehen alle im Segen und Fluch für das Bewahren der Inschrift (IC Z. 15-25). Dort begegnet kein Verb, das als Indikativ gelesen werden muß. Subjekt der Sätze sind die Götter. Es handelt sich offensichtlich um Wunschsätze. Die Götter sollen den respektvollen Umgang mit dem Vertrag belohnen, seine Mißachtung bestrafen.

Anders stellt sich die Verwendung der Modi in den eigentlichen Vertragsflüchen dar. Dort stehen die mit End-Jod geschriebenen Formen der Verba tertiae infirmae zwischen Formen mit Nun. Weil der Text viele Lücken aufweist und die Jussivmorpheme in der Semitistik immer wieder diskutiert werden ${ }^{1}$, bleibt vieles unklar. Doch scheinen in Sefire morphologisch eindeutige Indikative verwendet worden zu sein, um Abschnittsgrenzen zu markieren. Die folgende Tabelle gliedert den Fluchabschnitt von Sefire IA Z. 20-42 nach dem Modus der Verben:

\begin{tabular}{|c|c|c|}
\hline \multirow{2}{*}{$\begin{array}{l}Z . \\
{[14-18} \\
21\end{array}$} & \multirow[t]{2}{*}{ JUSSIV } & AMBIVALENT \\
\hline & & $\begin{array}{l}y m s ̌ h\left[?^{3}\right. \\
\text { thry }\end{array}$ \\
\hline 22 & & yhynqn / yšb \\
\hline 23 & & yhynqn / yšb \\
\hline $23 \mathrm{f}$ & & yhynqn / yšbc \\
\hline 24 & & $y h k n\left(y^{\prime} p n\right) / y$ \\
\hline$[24-25$ & & \\
\hline 25 & thwy & \\
\hline & & $y m l k$ \\
\hline 26 & & [wysk] / wysk \\
\hline 27 & & $y^{\prime} k l / t^{\prime} k l$ \\
\hline $27 f$ & & wysq / ypq \\
\hline 29 & & $y t \breve{s}^{\prime}$ \\
\hline
\end{tabular}

comes', and the jussives and imperatives, where yod is so used, e.g. IA:25 thwy 'may it become'.“ ARISTAR, „Jussive,“ 159.

${ }^{1}$ Vgl. HueHNERGARD, ,Jussive,“ 267 Anm. 3, 269 Anm. 13.

${ }^{2}$ Zur Rekonstruktion vgl. PUECH, „Traités,“ 90.

${ }^{3}$,The form $y$ mšh $[n]$, 'may they anoint' [KAI 222 A 21], because of its broken ending, is not significant for our discussion." HUEHNERGARD, ,Jussive," 267 Anm. 6.

${ }^{4}$ Vgl. HUEHNERGARD, ,Jussive,“ 267f. Statt yhkn und w'l yhrgn, könnte man vielleicht auch $y^{\prime} p n$ und $w^{\prime} l y m l^{\prime} n$ lesen ,on the basis of the parallel in Fakhariyah 22.... . Whatever the correct reading of these forms, however, it seems certain that they are ... third feminine plural jussives of the form y-...-n." ebd. 268 Anm. 6. PUECH, ,Inscriptions,“" 582: „yhrgn- la lecture est assurée ...." 
[y'kl? / ?] tht ?

$$
\text { wthwy }
$$

'mr

$$
\text { tqd / tqd }
$$$$
\text { wyzr / } t^{\prime} m r
$$$$
\text { tqd / yqd }
$$$$
\text { tšbr / yšbr }
$$$$
y^{\prime} r / y^{\prime} r
$$$$
\text { ygzr / ygzr }
$$$$
\text { [ } \left.t^{t} r r\right]
$$$$
\text { tqh / wymh' }
$$

wyšlḥn

$$
\begin{aligned}
& \text { wygzrn } \\
& \text { y'rrn } \\
& \text { yqhn }
\end{aligned}
$$

Die Tabelle zeigt, daß der Fluchabschnitt gegliedert ist. Am Beginn steht ein Konditionalsatz. Auf inn folgt nach einer unbestimmbaren Verbform eine morphologisch eindeutige Jussivform (Z.21), welche auch den Modus der folgenden ambivalenten Verben vorgibt, die Huehnergard aufgrund der Parallelen in Tell Fekheriye alle als Jussiv bestimmt. ${ }^{2}$ Der nächste Konditionalsatz eröffnet einen neuen Unterabschnitt. Wieder folgt ihm eine morphologisch eindeutige Jussivform, wieder kommen daraufhin ambivalente Verben bis schließlich in Z. 30 ein morphologisch unzweifelhafter Indikativ auftaucht. Nach zwei unbestimmbaren Verben begegnet wieder der morphologisch eindeutige Jussiv in Z. 32. Rein formal ähnelt diese Abfolge dem Beginn der Fluchsequenz, wo zwischen Konditionalsatz und dem ersten Jussiv auch eine unbestimmbare - wohl ambivalente - Form stand (Z. 18-21). Was liegt näher, als auch vor dem Jussiv in Z. 32 eine Abschnittsgrenze zu postulieren? Ein Blick in den Text bestätigt dies. Inhaltlich findet zwischen Z. 31+32 tatsächlich ein Themenwechsel statt. Vom Konditionalsatz in Z. 24f an ging es um Unheilsschläge, die Arpad treffen sollen, solange es noch besteht. Ab Z. 32 ist jedoch die Existenz Arpads selbst aufgegeben. Es soll zum Tell, ja völlig vergessen werden.

Der Moduswechsel zwischen Z. 29-33 ist eingebunden in eine weitere strukturelle Auffälligkeit. In Z. 29, 31, 32f, 34f stehen Sätze mit immer längeren Ketten von Nomina, die beim Lesen wohl immer schwerfälliger wirkten. In Z. 29f sind es nach Puechs Textrekonstruktion drei Ausdrücke, in Z. 30f sechs, in Z. 32f acht und in Z. $34 \mathrm{f}$ schließlich 13, die jeweils von

${ }^{1}$ „La fin de la 1.31 et le début de la 1.32 restent difficiles et discutés. (...) En fait, l'éxamen paléographique invite à lire wtht et non [ys]tht $; \ldots$. On peut donc rattacher tht t au verbe ht!t, 'arracher, gratter'.“ LEMAIRE / DURAND, Sfiré, 134.

2 Vgl. HuEHNERGARD, ,Jussive,“ 267 Anm. 6. 
einem Prädikat am Satzanfang abhängen. Hier ist sicherlich eine Klimax beabsichtigt, zumal Z. 34, die einzige Zeile in der Fluchsequenz auf IA ohne Verb, den Abschluß der Fluchwünsche vor den Ritualflüchen bildet. Doch noch nicht einmal an dieser strukturell einschneidenden Stelle ist ein Absatz im Schriftbild erkennbar. Z. 35 geht nahtlos von der Fortsetzung der Nomina aus Z. 34 zu den Zeremonialflüchen über. Die Gliederung muß also durch Stilmittel des Textes erfolgen, die beim (lauten) Lesen hervortreten. Der Wechsel von langen Ketten zu den Ritualflüchen mit ihrem formal strengen Aufbau aus Vergleich mit ' $y k$ und Anwendung mit $k n$ oder die Konditionalsätze (Z. 14-18.24f) bildeten wohl solche Gliederungsmarkierungen. Nun läuft die Klimax länger werdender Nominalketten aber über den Moduswechsel in Z. 30-32 hinweg. Der Inhalt der Aussage ändert sich jedoch. So scheint hier der Moduswechsel, ambivalentes Verb - Indikativ - ambivalente Verben - Jussiv, die Abschnittsgrenze zu bezeichnen. Die morphologisch ambivalenten Verben nach dem Indikativ in Z. 30 dürften bis zur nächsten deutlichen Jussivsetzung in Z. 32 als Indikative zu verstehen sein. Der Abschnitt vom Indikativverb bis zum Jussiv bildet nämlich auch inhaltlich eine kleine Untereinheit. In Z. 30 wird im Indikativ gesagt, daß die Götter „Fresser“ schicken. Dann folgt die Beschreibung deren Tätigkeit und schließlich die Feststellung, daß die ganze Vegetation des Landes zur Wüste geworden ist. ${ }^{1}$ Diese Untereinheit schließt aber nur eine bereits mit dem Konditionalsatz in Z. 25 einsetzende Folge von unterschiedlichen Katastrophen für Landwirtschaft und Bevölkerung ab. Demgegenüber bringt der mit dem Jussiv eingeleitete Wunsch, daß die Stadt Arpad zur Ruine werde, inhaltlich etwas Neues. Dieselbe Funktion der Markierung einer Abschnittsgrenze übt der Indikativ wohl auch in Z. 40-42 aus. Die Zeilen stehen am Ende der Seite A. Der Vertrag soll nach Puech auf Seite D weitergehen. D ist nicht erhalten, bot aber nur wenig Platz zum Beschreiben. ${ }^{2}$ Wenn A und D einen ganzen Vertrag enthielten, standen auf Seite D die Stipulationen, da sie auf Seite A fehlen. Mit anderen Worten, möglicherweise bilden Z. 40-42 überhaupt das Ende der Fluchsequenz des

\footnotetext{
${ }^{1}$ Der Indikativ kann nicht damit erklärt werden, daß hier das Subjekt im Pl. steht, während der $\mathrm{Sg}$. bei den ambivalenten Verben keine eindeutige Modusbezeichnung zuläßt. Dagegen spricht Z. 38, wo die Götter Inurta und Hadad ein Prädikat im Plural erhalten könnten, doch ein ambivalentes Verb im Singular bekommen. Warum gibt es hier Numerusinkongruenz, in Z. 30, 40-42 aber nicht? Z. 38 steht mitten in den Zeremonialflüchen. Offenbar wäre Indikativ Pl. hier Fehl am Platz gewesen, da es eine Abschnittsgrenze markiert hätte. In Z. 38 liegt aber keine Abschnittsgrenze vor.

2 ,Un des petits côtés (D) fait totalement défaut ayant emporté du même coup sur toute la hauteur le bord gauche de la face $A$ et le bord droit de la face $B$. Il est à peu près certain que le texte de la face A (minimum de 42 lignes) continuait sur la face D ... " PUECH, „Traités,“ 88.
} 
Vertrages auf Sefire I A+D. Wenn danach die Stipulationen folgten, würde das erklären, warum drei Indikativverben in diesen Zeilen zu finden sind. Damit wird das Ende der Ritualflüche und der Abschluß des gesamten Fluchteils markiert. ${ }^{1}$

Der Aufbau des Sefirefluchs erlaubt einen Ausblick auf Dtn 28,20-44. Dort gibt es eine gleichartige Reihe von Satzanfängen mit der Struktur $y i q t o l-x$, die in V. 21.36 Verben aufweist, die eindeutig als Jussiv punktiert sind. Das gleicht der Reihe von Satzanfängen mit Jussiven in Sefire. Daneben findet man auch in Dtn 28,20-44 viele modal ambivalente Verben. Den Schluß der Sequenz bildet eine Kette von antithetischen Flüchen (Dtn 28,38-44). Dort findet man keine morphologisch eindeutigen Jussive mehr. Die Sätze sind formal streng in These und Antithese (kî-Satz V. 38-41) gegliedert. Ähnlich formal streng ist in Sefire die Struktur der Ritualflüche (Z. 35-42), die wohl den Abschluß der ganzen Fluchsequenz von Stele IA bilden. Hier stehen sich immer Vergleich ('yk) und Anwendung $(k n)$ gegenüber.

Nach der Bestimmung der Modusformen kann nun eine Übersetzung von Sefire IA Z. 14-42 geboten werden. ${ }^{2}$

14... Und wenn Mati'-Il, der Sohn des 'Attarsumki, der König von Arpad, eidbrüchig wird gegenüber Bar-Ga'yah, ${ }^{15}$ den König von KTK, ... ${ }^{20} \ldots$ [Und $\operatorname{sie}^{21}$ ben Widder mögen ein Schaf be[springen], aber es soll nicht empfangen! Und sieben [Am]men mö[gen ihre Brüste salben], ${ }^{22}$ und sie mögen ein Kind säugen, aber es soll nicht satt werden! Und sieben Stuten mögen ein Fohlen säugen, aber es soll nicht satt [werden! Und sieben] ${ }^{23}$ Kühe mögen ein Kalb säugen, aber es soll nicht satt werden! Und sieben Schafe mögen ein Lamm säugen, ab[er es soll nicht satt] ${ }^{24}$ werden! Und sieben Bäckerinnen mögen gehen, um Brot zu backen, aber sie sollen nicht ....(?)! ${ }^{3}$

\footnotetext{
${ }^{1}$ Die Fluchsequenz auf Stele II A Z. 1-14 entspricht im wesentlichen dem auf Stele I. Er ist allerdings schlechter erhalten. Auch hier scheint der Indikativ Abschnittsgrenzen zu markieren. In Z. 3 beginnt mit dem Konditionalsatz eine neue Einheit. Es folgen Jussive (thwy?, $y$ tnšy) und schließlich ein Indikativ (wyhwh). In Z. 5 wird der Gott Hadad genannt. Anscheinend beginnt mit der Anrufung des Gottes ein neuer Abschnitt, denn das Verb in Z. 6 ist wieder der morphologische Jussiv thwy.
}

2 Die Übersetzung orientiert sich an der kommentierten Transkription von LEMAIRE / DURAND, Sfiré, 113-147, und an den Übersetzungen von ROSSLER, „Verträge, 180-182, und PUECH, „Traités,“ 90-92. Ergänzungen von Textlücken und unklaren Stellen sind PUECHs Übersetzung entnommen.

${ }^{3}$ Vgl. Sefire II A: „' $\left[\right.$... und es soll ni]cht satt werden, und sieben ${ }^{2}[\ldots$ werden ein ... säugen und es soll nicht satt werden, und sieben Ziegen werden] ein Böckchen [säugen] und es soll nicht satt ${ }^{3}$ [werden ...]. ROSSLER, „Verträge,“ 184. Vgl. HILlERS, Treaty-Curses, 28 , FITZMYeR, Inscriptions, 14; LEMAIRE / DURAND, Sfiré, 113. PUECH, „Inscriptions,“ 582, übersetzt: „et que ses sept boulangères s'en aillent tandis que brûle (grille) le pain, et qu'elles ne soient pas tuées!“ yhrgn kann von hrg „töten“ oder $r g g$,begehren“ abgeleitet 
Und wenn Mati['-II] eidbrüchig wird [gegenüber Bar-Ga'yah und] ${ }^{25}$ seinem Sohn und seiner Nachkommenschaft, so möge sein Königreich zu einem Traumkönigtum werden, in dem das Feuer alles beherrscht! Hadad ${ }^{26}$ möge Böses aller Art auf der Erde und im Himmel ausgießen und jede Art von Bedrängnis! Er gieße über Arpad [...] ${ }^{27}$ Hagel aus! Und sieben Jahre möge die Heuschrecke fressen! Und sieben Jahre möge der Wurm fressen! Und sieben [Jahre zei] ${ }^{28}$ ge sich Aussatz auf der Oberfläche seines Landes. Und es möge kein Gras wachsen und kein Grün soll sich zeigen und es soll [fehlen] ${ }^{29}$ (jegliche) Vegetation. Und es so[11] in Arpad kein Ton der Zither mehr gehört werden, sondern in seinem Volk Krankheitsgewimmere, Jam[merru ${ }^{30} \mathrm{fe}$ und Klagen. ${ }^{1}$ Und die Götter werden jede Art von Fressern nach Arpad schicken. Und in seinem Volk [frißt der Schlu] ${ }^{31}$ nd der Schlange und das Maul des Skorpions, und das Maul des Bären / der Wespe(?), und das Maul des Panthers/der Ameise(?) und die Motte und die Laus. Und nicht satt [wer] ${ }^{32}$ den wird der Schlund der Kobra. Und seine Vegetation wird ausgetilgt zur Wüste.

Und Arpad möge ein Tell werden, La[ger für Raubtier und] ${ }^{33} \mathrm{Gazelle}$, Schakal, Hasen, Wildkatze, Eule, Fasan und Elster! ${ }^{2}$ Und [diese Sta]dt möge nicht mehr genannt werden und ${ }^{34}$ auch nicht Madura, Murbbeh, Mazzeh, Nabbulah, Šaron, Tu'im, Bet-El, Daynan, [Muru, A $]^{35}$ rneh, noch Hazaz, noch Udum!

Wie dieses Wachs im Feuer verbrennt, so verbrenne Arpad und [seine Tochter ${ }^{36}$ städte]! Und Hadad säe auf sie Salz und Kresse, und dieser Räuber soll nicht mehr genannt werden, noch die Nachkommenschaft von ${ }^{37}$ Mati'-Il, und er selbst sei unterdrückt! Wie dieses Wachs im Feuer verbrennt, so verbrenne Ma[ti'-Il im Feu] ${ }^{38}$ er! Und wie dieser Bogen und diese Pfeile zerbrochen werden, so möge Hadad und Inurta [seinen] Bo[gen] ${ }^{39}$ und den Bogen seiner Großen zerbrechen! ${ }^{3}$ Und wie ein Mann aus Wachs blind ist, so erblinde Mati'-I[1! Und wi] ${ }^{40}$ e dieses Kalb in Stücke geschnitten wird, so wird Mati'-Il in Stücke geschnitten und so werden seine Großen in Stücke geschnitten. [Und wie die $]^{41}$ se (Figur) entblößt wird, so werden die Frauen des Mati'-Il entblößt werden und die Frauen seiner Nachkommenschaft und die Frauen seiner Gro[Ben. Und wie ${ }^{42}$ man diese Figur aus Wachs nimmt] und ihr ins Gesicht

werden. Vgl. ebd. 578. Beide Bedeutungen befriedigen nicht. Folgt man PUECH fehlt in dem Fluch der Bäckerinnen die Frustration vorhergehender Bemühung. Dies scheint angesichts der anderen Flüche mit der Zahl sieben jedoch kaum wahrscheinlich.

${ }^{1}$ Vgl. A.745.1 Kol. IV „" ${ }^{17}$ Wenn Mati'ilu, seine Söhne und seine Großen gegen den Vertrag ${ }^{18}$ Assurniraris, Königs von Assyrien, sündigen, ${ }^{19}$ so möge sein Bauer auf dem Felde kein Lied anstimmen, ${ }^{20}$ das Grün des Feldes möge nicht aufgehen und die Sonne nicht erblicken.“ BORGER, „Mati'ilu,“" 156.

2 Vgl. A.745.1 Kol. V „... 5so möge Assur, der Vater der Götter, der das Königtum verleiht, dein Land zum Ödland, ${ }^{6}$ deine Leute zu ..., deine Städte zu Trümmerhügeln und dein Haus 7 zur Wüste machen.“ BORGER, „Mati'ilu,“' 157.

${ }^{3}$ Vgl. A.745.1 Kol. V , , ${ }^{12}$.. [Ischtar], die Herrin der Männer, die Königin der Frauen, ${ }^{13}$ möge ihren Bogen wegnehmen und ihren ... bewirken.“ BORGER „Mati’ilu,“” 157. 
schlägt, so werden die Frauen des Mati'-Il genommen und ins Gesicht geschlagen [und die Frauen seiner Nachkommenschaft und die Frauen seiner Großen?]

Die Übersetzung zeigt, daß der Moduswechsel vom Wunsch zur indikativischen Zukunftsbeschreibung dem Inhalt größere Eindringlichkeit verleiht. Das Handeln der Götter in Z. 30 leitet den abschließenden Höhepunkt der zunehmenden Verwüstung des Landes ein, die zunächst in Wunschsätzen in den Blick kam. Ebenso besiegeln die indikativischen Aussagen in Z. 4042 das Schicksal des Mati'-Il und seiner Großen, nachdem ihnen zuvor noch im Wunschsatz - durch Hadad und Inurta die Möglichkeiten zur Verteidigung geraubt wurden. Die Tötung des Aufständischen mit der darauf folgenden Schändung der nun schutzlosen Ehefrauen scheint als Strafmaßnahme des Eidesherrn durchaus vorstellbar. Diese Strafe wird als feststehende Zukunftsperspektive dargestellt. Die Wunschsätze leiten somit Ereignisfolgen ein, die zu sicher, d.h. im Indikativ, vorherzusagenden Ergebnissen führen.

Assurnirari V. regierte Assyrien von 754-745 v. Chr. In den Berichten über seinen ersten Kriegszug wird Arpad erwähnt, später nicht mehr. Daher vermutet Parpola, der Vertrag mit Mati'ilu sei anläßlich dieses Feldzuges geschlossen worden. ${ }^{1}$ Im folgenden werden die Fluchsektionen nebeneinandergestellt. Die beiden Texten gemeinsamen Motive und Götternamen sind durch kursiv gesetzte Kapitälchen hervorgehoben. Im Aufbau weichen beide Sequenzen deutlich voneinander ab.

${ }^{1}$ Vgl. Parpola / Watanabe, Treaties, XXVIIf; Crawford, Blessing, 242 Anm. 183. 


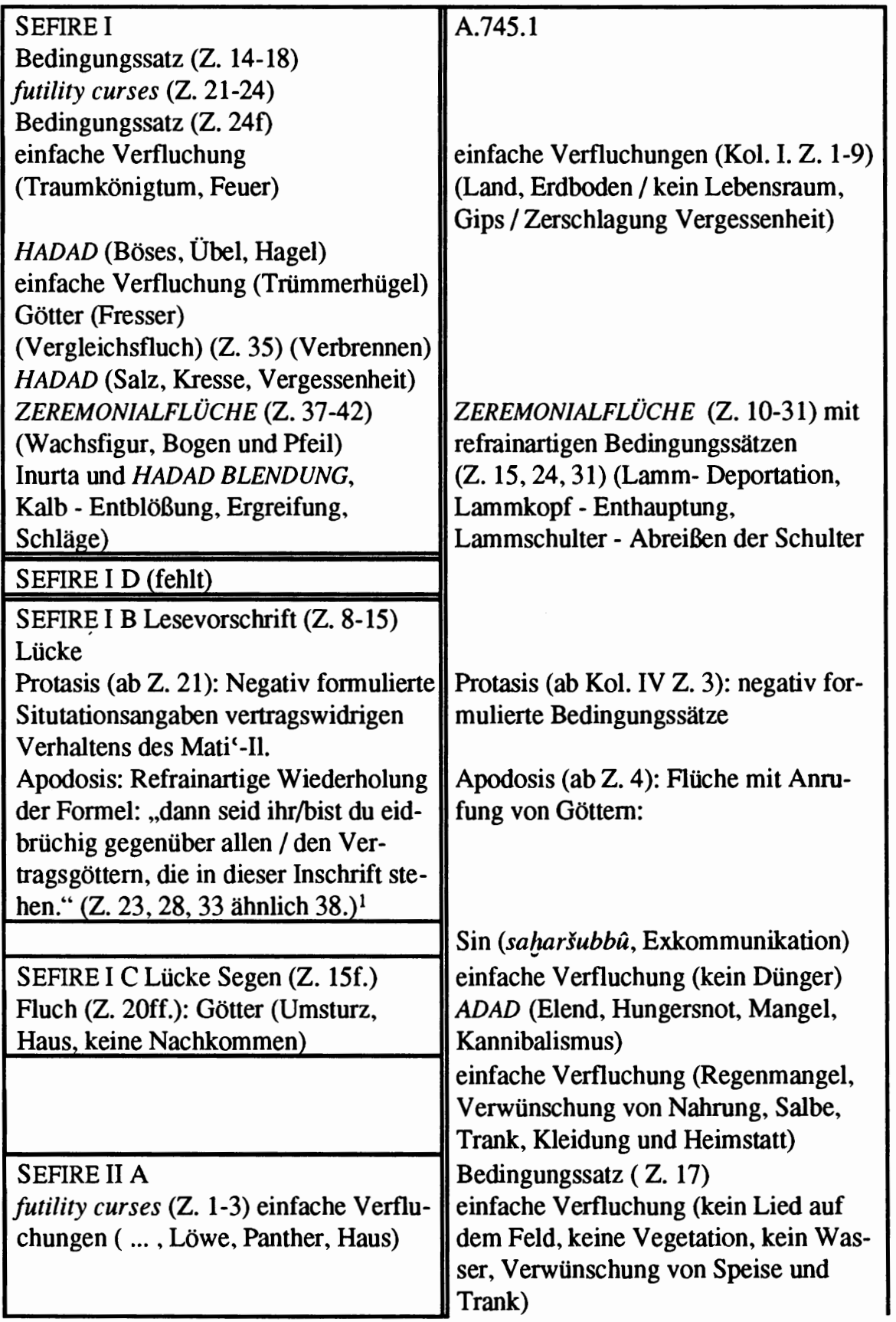

${ }^{1}$ RÖsSLER, „,Verträge,“ 183; vgl. CRAWFORD, Blessing, $261 \mathrm{f}$. 
SEFIRE II B

Vertragserfüllung kein Strafgrund (Z. 4ff)

Protasis (ab Z. 7): negativ formuliertes Verhalten

Apodosis: „so seid ihr eidbrüchig gegenüber allen Vertragsgöttern, die in dieser Inschrift stehen." $(Z .9,14)^{1}$
Protasis: Bedingungskehrvers

(Kol. V Z. 1-4, 8, 16)

Assur (Ödland, TRÜMMERHÜGEL, Wüste)

einfache Verfluchung (Geschlechtsumwandlung, Unfruchtbarkeit) Ištar (Entwaffnung); einfache Verfluchung (?, BLENDUNG, Zahlenfluch 1000 / 1 Entvölkerung der Häuser und Zelte $)^{2}$

SEFIRE II C

Fluch zum Inschriftenschutz: Vertragsgötter (Hinwegraffen des Mati'-Il und seines Volkes)

SEFIRE III

Protasis (ab Z. 1): positiv formulierte Klauseln; Apodosis: „sonst seid ihr eidbrüchig gegenüber allen Vertragsgöttern, die in dieser Inschrift stehen.“ (Z. 4, $14)^{3}$ oder: „,sonst bist du eidbrüchig gegenüber diesen Verträgen.“ $(Z .9,20 f)$ abwechselnd mit Protasis (ab Z. 6): negativ formuliertes vertragsbrüchiges Verhalten; Apodosis: „so seid ihr eidbrüchig gegen diese Verträge.“ (Z. 7) ${ }^{4}$ oder: „seid ihr eidbrüchig gegenüber allen Vertragsgöttern, die in dieser Inschrift stehen." (Z. 16, 23) $)^{5}$ oder: „bist du eidbrüchig gegenüber diesen Verträgen.“ $(Z .19,27)^{6}$

Beide Texte werden durch refrainartige Wiederholungen strukturiert. Im Assumirari-Vertrag taucht der formelhaft formulierte Bedingungssatz für die Flüche mehrmals auf, in Sefire I B, II B und III wird dagegen in stereotypen Wendungen der Vertragsbruch konstatiert. In beiden Fluchabschnitten kommen Zahlenkombinationen vor. Auf den Sefirestelen lautet die Kombination sieben zu eins, im Assurnirari-Vertrag $1000 \mathrm{zu}$ eins (Kol. VI Z. 3f). Beide Verträge enthalten Zeremonialflüche. Der Vergleich beider Texte zeigt die Gemeinsamkeit der altorientalischen Fluchtraditionen in gleichartigen Motiven, Zahlenspielen und Zeremonien. ${ }^{7}$ Doch es zeichnen sich Unterschiede ab, die aufzeigen, welche Gestaltungsmittel das Sprach-

${ }^{1}$ ROSSLER, „,Verträge,“ 185.

2 Vgl. BORGER, „Mati'ilu,“ 155-158.

${ }^{3}$ ROSSLER, ,Verträge,“ $186 \mathrm{f}$.

${ }^{4}$ ROSSLER, „Verträge,“ 187.

5 RÖSSLER, „Verträge,“ 188.

${ }^{6}$ ROSSLER, ,Verträge,“ $188 \mathrm{f}$.

7 Vgl. CRAWFORD, Blessing, 242-263. 
empfinden im west- und ostsemitischen Bereich zur Formulierung von Flüchen vorzog.

Sefire I C enthält einen kurzen Segen, dessen Einleitung nicht erhalten ist. Man kann nicht mit Sicherheit feststellen, ob der Erhalt der Inschrift oder ob die Vertragstreue mit Segen belohnt wird. Die folgende Flucheinleitung legt jedoch nahe, daß es nicht einfach um den Inschriftenschutz ging, sondern die Unverletzbarkeit der Inschrift mit der Vertragserfüllung verbunden war.

Sefire I C ${ }^{15}$ Mögen die Götter seine Lebens ${ }^{16}$ zeit und sein Haus bewahren! Und wer ${ }^{17}$ die Worte der Inschrift, die auf dieser Stele ist, nicht bewahrt ${ }^{18}$ und sagt: ,Ich will (etwas) tilgen von seinen Wor ${ }^{19}$ ten!' oder: ,Ich will das Gute umkehren und ${ }^{20}$ zum Bösen ${ }^{19}$ machen! ‘ ${ }^{20}$ an dem Tag, an dem er dies ${ }^{21}$ tut, sollen die Götter [die]sen [Ma]nn um ${ }^{22}$ stürzen, sein Haus und alles was [dar] ${ }^{23}$ innen ist, und sollen sein Unterstes [zu] ${ }^{24}$ [o]berst kehren, und seine $\mathrm{Li}^{25}$ [n]ie soll keinen Namen erben!"1

Die Verbwurzel der Formen yṣrw und lyṣr, welcher Rössler mit „bewahren“ übersetzt (Z. 16.17), entspricht dem akkadischen nașāru und beinhaltet das Halten, Beobachten und Erfüllen des Vertrages. Genauso wird das akkadische Wort im Vertrag zwischen Muršiliš von Hatti und Niqmepa' von Ugarit verwendet. Es deckt sich in diesem Sinn mit dem in Dtn 28 vorkommenden Verb שמר. ${ }^{2}$ Im Unterschied zu den üblichen Flüchen zum Inschriftenschutz wird nicht das Löschen des Namens oder das Vernichten oder Verstecken der Stelen geahndet, sondern das Nicht-Bewahren der Worte. Die Worte, die Vertragsinhalte, erhalten somit eine unveränderliche kanonische Bedeutung. Die biblische Kanonformel, die das Weglassen und Hinzufügen zum Text verbietet (Dtn 13,1), wird von solchen Inschriftenschutzklauseln hergeleitet. ${ }^{3}$ Ein ähnlicher Konditionalsatz findet sich in Sefire IB:

${ }^{24}[$ Wenn du aber hörst ...] ... diese Verträge und sagst: ,[Ich bin Vertragmann!' [dann kann ich meine] ${ }^{25}$ Hand nicht gegen dich [erheben] und mein Sohn kann die Hand nicht gegen [deinen] Sohn erheben, und meine Nachkommenschaft nicht gegen [deine] Nachkommenschaft. “4

Dem Bedingungssatz folgt kein Segen, sondern die Feststellung, daß bei Erfüllung des Vertrages kein Anlaß zum Krieg besteht. Während also zur

${ }^{1}$ ROSSLER, „Verträge,“ 184: andere Übersetzungmöglichkeit für Z. 15f.: „ ... mögen die Götter (alle Übel) von seinem Tag und von seinem Haus fernhalten.“

2 Vgl. FenshaM, „Malediction,“ 7; CRAWFORD, Blessing, 262-264, 288.

${ }^{3}$ Vgl. DOHMEN / OEMING, Kanon, 68-86, besonders 73-78, 82-85.

${ }^{4}$ ROOSSLER, ,Verträge,“ 183. 
Sanktion der Nichterfüllung göttliche Instanzen in den Flüchen angerufen werden, wird die Erfüllung des Vertrages durch Menschen belohnt. Der Vertragsherr hat keinen Grund zur Strafe. Wenn in den Sefirestelen den Flüchen ein kurzer Segen und menschliche Wohlwollensäußerungen gegenübergestellt werden, zeigt dies, daß die positiven Sanktionen im aramäischen Bereich nicht wie im assyrischen ungenannt bleiben. ${ }^{1}$ Dennoch besitzt der Segen gegenüber dem Fluch geringeres Gewicht und wird darüber hinaus in der Feststellung des Nichtangriffgrundes zum politischen Wohlwollen säkularisiert. Im Vergleich zu den fast parallelen Segens- und Fluchsektionen der hethitischen Verträge, darf man im Zurücktreten des Segens auf Verträgen eine ähnliche Säkularisierungstendenz sehen, wie man sie im Rückgang von Kudurruflüchen bis hin zum Aussterben der Kudurrus und bestimmter Flüche überhaupt festgestellt hat. ${ }^{2}$ Sobald eine menschliche Institution Beachtung und Nichtbeachtung von Vorschriften belohnen und ahnden konnte, verzichtete man anscheinend zunehmend auf die Verlegung der Sanktionen in den göttlichen Bereich. Friedliches Wohlwollen als positive Wirkung der Vertragserfüllung stellt dabei eine für den Vertragsherrn leicht zu erfüllende Belohnung dar. Viel mühsamer wäre dagegen die Verlegung der Strafe in den zwischenmenschlichen Bereich gewesen. Sie hätte den Krieg gefordert, dessen Ausgang vielleicht ungewiß, dessen Durchführung jedenfalls mühsam und kostspielig war. Für die negativen Sanktionen bemühte man also in zwischenstaatlichen Verträgen weiterhin die Götter.

Gegenüber dem in assyrischen Verträgen feststellbaren Verzicht auf den Segen scheinen die aramäischen Sefire-Inschriften konservativer. Erinnert deren Segen an die Segensformeln der hethitischen Verträge, so gleicht die refrainartig wiederholte Feststellung des Eidbruchs in Sefire I B, II B und III ebenfalls Formulierungen in hethitischen Verträgen. Auch dort war die Vertragsklausel bisweilen negativ formuliert und ein vertragsbrüchiges Verhalten mit dem Refrain kommentiert worden: ,so hat er den Eid über-

1 PUECH, „Traités,“ 97, 100, 106 rekonstruiert insgesamt drei Segensabschnitte auf den Sefirestelen.

2 Vgl. Brinkman, „Kudurru,“ 267-274, 274: „... Babylonia as a whole enjoyed much greater economic and political stability than it had in the immediately preceding centuries. Only a few kudurrus survive from this final period. (...) In the early 7 th cent., clay legal documents dealing with real estate became increasingly common ... and kudurrus died out just before 650 B.C., perhaps because they were no longer needed." Zum Aussterben des Sinfluchs in chaldäischer Zeit vgl. WATANABE, „Überlieferung,“ 115. 
treten". ${ }^{1}$ Der Refrain zur Feststellung des Eidbruchs weist darüber hinaus stilistische Variationen auf, die offenbar textgliedernde Funktionen besaBen. So wechseln lange und kurze Formeln und Formeln mit der Anrede im Singular und im Plural miteinander ab. Sefire kann als ein Beleg für die stilistische Bedeutung des Numeruswechsels gewertet werden, der nicht literarkritisch aufgelöst werden darf. ${ }^{2}$

Sefire und A.745.1 unterscheiden sich darin, daß im assyrischen Vertrag, obwohl von ihm ein wesentlich kürzeres Stück erhalten ist, vier Flüche an Götter gerichtet sind und zwar an Sin, den großen Herrn, der in Haran wohnt (Kol. IV Z. 4), an Adad, den Deichgraf des Himmels und der Erde (Kol. IV Z. 8), an Assur, den Vater der Götter, der das Königtum verleiht (Kol. V Z. 5) und an Ištar, die Herrin der Männer, die Königin der Frauen. In den umfangreicheren Sefirefluchabschnitten gibt es dagegen nur drei Flüche, bei denen Götter angesprochen werden. Sie stehen alle in Sefire IA. Es sind Hadad (Z. 25f), Hadad (Z. 36) sowie Inurta und Hadad (Z. 38). Hier zeigt sich die überragende Bedeutung des Gottes Hadad im Gebiet westlich des Euphrats. Nur Inurta wird noch genannt und selbst der zusammen mit Hadad. Während also in den assyrischen Fluchsektionen verschiedene Götter mit ihren jeweiligen Zuständigkeitsbereichen aufgelistet werden, gibt es im westsemitischen Vertrag eine Tendenz zur Vorherrschaft einer einzigen Gottheit, die an die alleinige Rückführung aller Flüche auf das Wirken JHWHs in der Bibel erinnert. Außerdem werden die Götter im assyrischen Vertrag mit Epitheta versehen, in Sefire dagegen nicht. Der Verzicht auf Götterepitheta im Fluch scheint ein differenzierendes Charakteristikum des westsemitischen Fluchs zu sein. In A.745.1 verdient die Reihenfolge der angerufenen Götter Beachtung. Während in der Götterliste Assur, Anu und Antu den Anfang machen, man also mit der Spitze des assyrischen Pantheons beginnt, steht in der Fluchsektion Sin an erster Stelle, dem durch die Lokalisation in Haran noch ein syrisches Kolorit gegeben wird. ${ }^{3}$ Im folgt Adad, das assyrische Pendant zum aramäischen Hadad, der als einziger im Fluch zweimal erwähnt wird (Kol. VI Z. 8, 12). Erst nach einer neuen Einleitungsformel folgen Assur und Ištar. Die Voranstellung eher in Syrien lokalisierter Gottheiten vor den assyrischen Staatsgott im Fluch scheint einen psychologischen Sinn im Blick auf die

1 Vertrag zwischen Šuppiluliuma und Tette CTH 53 Vs. Kol. II Z. 32, 47; Rs. Kol. III Z. 40. 51, vgl. WeIDNER, Dokumente, 63, 67; Vertrag zwischen Šuppiluliuma und Aziru CTH 49 Vs. Z. 36, vgl. ebd. 75; CRAWFORD, Blessing, 153.

$2 \mathrm{Vgl}$. CRAWFORD, Blessing, 153f.

${ }^{3}$ Das Epitheton für Sin in A.745.1 Kol. IV Z. 4 ašib URU.KASKAL (= Haran) ist in den erhaltenen assyrischen Verträgen nicht mehr belegt. URU.KASKAL kommt nur noch VTE Z. 36 vor, wo alle Götter Harans zu Schwurgöttern gemacht werden. 
Aramäer zu haben. Zunächst werden die von ihnen selbst verehrten Götter über den Vertrag wachen, in zweiter Linie treten erst die fremden Götter auf den Plan. ${ }^{1}$ Die dem assyrischen Pantheon widersprechende Reihung der Fluchgötter scheint jedoch unerklärlich, wenn die Sefire-Verträge tatsächlich die aramäische Fassung des Vertrags A.745.1 wären. Warum sollten im assyrischen Text, wenn er sowieso nur für den assyrischen Hof bestimmt war, die Flüche nach syrischen Gesichtspunkten gereiht werden, um dann in der aramäischen Version durch die Hadadpräferenz noch mehr den aramäischen Religionsvorstellungen zu folgen?

Wie in Dtn 28 gibt es auch in Sefire futility curses. Sie enthalten jedoch die Zahlenkombination sieben / eins, die man in Dtn 28,7.25 findet, dort aber ohne die Form des futility curse. Die Zahl sieben kommt in Sefire auch in einfachen Fluchwünschen vor, die formal eher der assyrischen Wiedergabe der antithetischen Flüche in Tell Fekheriye entsprechen. Die verwendeten Verben $(y k l, t k l, y s q)$ und Nomina ('rbh, $t w l ' h)$ erinnern an Dtn 28,38f. ${ }^{2}$ A.745.1 besitzt Flüche mit der Kombination 1000 / eins (Kol. VI Z. 3f). Sie sind aber keine Frustrationsflüche, sondern wie die assyrischen Übersetzungen der futility curses in Tell Fekheriye nur einfache Wunschsätze ohne Antithesen. Hieraus darf man schließen, daß zur Ausformulierung gleichartiger Motive, die assyrischen Schreiber eher Fluchwünsche, die westsemitischen Schreiber dagegen lieber futility curses verwendeten. ${ }^{3}$

\subsubsection{Vergleichbare Flüche anderer westsemitischer Inschriften}

Bei der Suche nach westsemitischen Fluchgewohnheiten, die sich von den mesopotamischen unterscheiden, genügt es nicht, nur Tell Fekheriye und Sefire heranzuziehen. Allerdings bieten die übrigen westsemitischen Inschriften nur wenig Vergleichsmaterial, da es sich meistens um recht kurze Fluch- und manchmal auch Segensformeln zum Inschriftenschutz handelt. Crawford hat sämtliche Segens- und Fluchabschnitte auf syro-palästinischen Inschriften der Eisenzeit untersucht. Er unterscheidet Segensformeln, שלמ und/oden שרכ un vom substantive blessing, d.h. inhaltlichen Segnungen ohne diese Begriffe. Ebenso trennt er bei den Flüchen solche

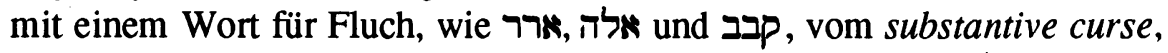
d.h. Flüchen mit inhaltlichen Unheilsansagen ohne ausdrückliche Nennung

\footnotetext{
${ }^{1}$ Man vergleiche dazu auch die westsemitischen Gottheiten im Fluch des Vertrages A.669.2 SAA 2 (Nr. 5), 27.

2 Vgl. SUMNER, Study, 49.

3 Vgl. KREBERNIK, „Deuteronomiumskommentar,“ 36.
} 
eines Wortes für Fluch. Crawfords Untersuchungen über die Inschriften mit terminus technicus für Segen und Fluch werden bei der Behandlung der entsprechenden Passagen von Dtn 28 herangezogen. Der größte Teil von Dtn 28 sowie die Sefirestelen gehören jedoch zur Kategorie des substantive blessing und substantive curse. Daher werden die Flüche der von Crawford unter diese Gruppe gereihten Inschriften hier chronologisch vorgestellt. ${ }^{1}$

(1.) Ahiram, Sarkophag, ca. 1000 v. Chr. Fundort: Byblos, Sprache: Phönizisch. Der Fluch wendet sich an einen fremden Usurpator, der die Herrschaft in Byblos übernimmt und das Grab des Königs schändet.

w'l. mlk. bmlkm. wskn. bs<k>nm. wtm'. mḥnt. 'ly. gbl. wygl. 'rn. zn. thtsp. hṭr. mšpth. thtpk. ks'. mlkh. wnht. tbrh.' 'I. gbl. wh' ymh sprh. lpp. šbl

„Wenn aber (?) ein König unter den Königen oder ein Statthalter unter Statthaltern oder der Befehlshaber eines Lagers gegen Byblos heraufgezogen ist und diesen Sarkophag aufdeckt, dann soll der Stab seiner Herrschaft entblättert werden, soll sein Königsthron umgestürzt werden und der Friede soll weichen von Byblos. Und was ihn angeht, (so) soll seine Inschrift ausgelöscht werden mit der Schärfe (?) des .... "3

Verlust von Herrschaft, Thron und Szepter findet sich auch in akkadischen Flüchen, z. B. im KH (Kol. XXVI 50f.; XXVII 40-44).

(2.) Zakkur, Basaltstele, erstes Viertel des 8. Jh. v. Chr., Fundort: Afis, etwa $45 \mathrm{~km}$ südwestlich von Aleppo. ${ }^{4}$ Vor dem Fluch steht eine Selbstsegnung Zakkurs. Bei derartigen guten Wünschen für den

\footnotetext{
${ }^{1}$ Manche Inschriften ermöglichen keine befriedigende Auswertung. Wahrscheinlich aus dem 9. Jh. stammt die phönizische Grabinschrift KAI Nr. 30. Ihr Erhaltungszustand macht eine Übersetzung des Fluches unsicher. Es scheint um die Auslieferung des Grabschänders an die Hand des Baal, der Menschen oder der Götterversammlung zu gehen. Vgl. CRAWFORD, Blessing, 156f Anm. 170. Die Übersetzung der Inschrift auf der Amman Zitadelle (Mitte 9. Jh., Fundort: Südwestecke des Jebel el-Qala'ah) macht große Schwierigkeiten und die Meinung der Forscher über ihren Inhalt differiert beträchtlich. Vielleicht enthielt der Text den Auftrag des Gottes Milkom an den König von Ammon, die Grenzen zu festigen, verbunden mit einem Fluch gegen Ammons Feinde und einer Zusage der Sicherheit und der Herrschaft für den König. Vgl. ebd. 226-232. Auch die Übersetzungen und Interpretationen der Inschrift von Deir'Alla (ca. 700 v. Chr.) unterscheiden sich so sehr, daß sie hier nicht herangezogen werden kann. Vgl. ebd. 173-176, 185-188; LAYTON, „Source,“ 183. Die Statue Panamuwas II. (KAI Nr. 215) scheint nicht mit einem Fluch, sondern mit einer Selbstsegnung zu enden. Vgl. TROPPER, Zincirli, 98-102; CRAWFORD, Blessing, 131; LAYTON, „Sources,“ 181. Auf dem hebräisch beschriebenen Elfenbeintäfelchen aus Nimrud (ND 10150) fehlen Verb der Verfluchung und Subjekt des Fluches. Vgl. CRAWFORD, Blessing, 171f.

2 Vgl. GeVirTZ, „Problem,“ 146; KAI Nr. 1.; CRAWford, Blessing, 161.

3 DONNER / ROLLIG, Inschriften 2.

${ }^{4}$ Vgl. LAYTON, „Sources,“ 177, 186 Anm. 11: „The spelling 'Zakkur', as opposed to the widely accepted 'Zakir', is assured by cuneiform writings ... ."
} 
Inschriftenurheber kann man nicht entscheiden, ob es sich wirklich um einen Segen oder um ein Gebet handelt. Der Fluch steht in Zakkur B:

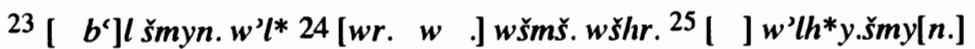

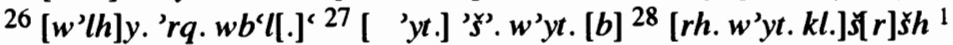

${ }^{23}\left[\mathrm{Be}^{\mathrm{r} e}\right]$ lschemayn und Ilu-24[Wer ...] und Schamasch und Sahar $25 . .$. und die Götter des Himme[ls] ${ }^{26}$ [und die Gött]er der Erde und Ba'al von ${ }^{27}$.. den Mann und ${ }^{28}$ seine Wurzel .... . 2

(3.) Kilamuwa 1, Reliefinschrift, 830-825 v. Chr., Fundort: Zincirli, phönizisch. ${ }^{3}$

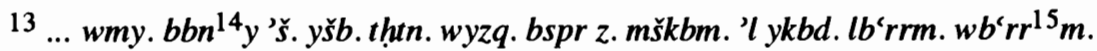

'l ykbd. lmškbm. wmy. yšḥt. hspr z. yšḥt. r’š. b'l. șmd. '̌̌. lgbr ${ }^{16}$ wyšḥt. r’š.

b'lhmn. ‘š. lbmh. wrkb'l. b'l. bt. ${ }^{4}$

${ }^{13}$... Und wer unter meinen Nachkommen ${ }^{14}$ an meiner Stelle sitzen wird, aber diese Inschriften beschädigt, (für dessen Regierung gilt:) Die Muškabim sollen die Ba'ririm nicht ehren und die Ba'ririm ${ }^{15}$ sollen die Muškabim nicht ehren. Und wer diese Inschrift verdirbt: Sein Haupt soll der Ba'al-ȘMD, der (dem Hause) GBR (zugehört), vernichten, ${ }^{16}$ und es sollen Ba'al-HMN, der des BMH und Rakab-'EL, der Herr des Hauses, sein Haupt vernichten."5

Der Fluch richtet sich gegen die Königssöhne und spricht wohl von einem Bürgerkrieg zwischen zwei Bevölkerungsgruppen. ${ }^{6}$

(4.) Hadad, Statue des Gottes, gewidmet von Panamuwa I., ca. 750 v. Chr., Fundort: ein Dorf nordöstlich von Zincirli. ${ }^{7}$

$22 \ldots w^{\prime} l^{*}[$.$] yrqy. bh[.] w^{*} m^{*} z^{*} .23$ yšl. 'l ytn. lh. $h^{\circ} d d . w^{*} h d d . h r^{\prime}$. $l y^{*} t^{*} k^{*} h^{*}[] \quad.\left[w^{\prime}\right] 1 . y t n . l h . l^{\prime} k l . b r^{*} g^{*} z .{ }^{24}$ wšnh. lmn', mnh. bly*l'.wdl*h*.

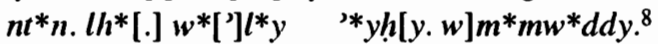

"22... und er soll kein Wohlgefallen an ihm haben, und was immer ${ }^{23}$ er erbitten wird, das soll ihm Hadad nicht geben, und Hadad soll Zorn ausgießen

1 Vgl. GevirTZ, „Problem,“ 144; KAI Nr. 202; Crawford, Blessing, 233; Delsman, „Inschriften,“ 626-628. Beschädigte Zeichen sind mit einem Asteriskus versehen.

2 Delsman, „Inschriften,“ 627f. Iluwer ist eine andere Bezeichnung für Adad. Vgl. EBELING, „Adad,“ 23.

3 Vgl. Tropper, Zincirli, 27-30; CRAWFORD, Blessing, 146; LAYTON, „Sources,“ 181f.

${ }^{4}$ Vgl. TropPer , Zincirli, 44-46; CraWford, Blessing, 147; KAI Nr. 24.

5 DONNER / ROLLIG, Inschriften, 31.

6 Vgl. CRAWFORD, Blessing, 148. Nach einem wohl weniger wahrscheinlichen Übersetzungvorschlag wären die Zeilen 14b, 15a als Segen zu verstehen. Ebd. 149-151.

7 Vgl. Tropper, Zincirli, 54-59; LAYTON, „Sources,“ 180f; CraWford, Blessing, $276 \mathrm{f}$.

8 Vgl. TROPPER, Zincirli, 82-86; CRAWFORD, Blessing, 277; vgl. KAI Nr. 214. 
[..............] soll ihm nichts zu essen geben im Zorn, ${ }^{24}$ und den Schlaf soll er in der Nacht von ihm fernhalten, und indem er ih[m] Angst macht ... ."

Ob der Beginn der Z. 18 dieser Inschrift als Segensaussage verstanden werden darf, ist fraglich. Nimmt man das an, so enthält der Schlußabschnitt nur eine Verwünschung des Nachkommen, der nicht für seinen Ahnen opfert und betet. Die Flüche nehmen Motive der vorausgehenden Darstellung des Lebens Panamuwas auf und kehren diese ins Gegenteil. ${ }^{2}$ Die Verweigerung göttlicher Erhörung in Z. 22b-23 findet eine positive Parallele in einem Segen aus Kuntillet 'Ajrud 6, wo es ebenfalls unter Verwendung des Verbs שאול heißt:

Alles, was er von einem Menschen erbittet, sei gnädig geschenkt ... und JHW gebe ihm nach seinem Willen (wörtlich: entsprechend seinem Herzen). ${ }^{3}$

(5.) Nerab 1, Basalttafel, Grabtafel des Sin-zer-ibni, ca. 700 v. Chr., Fundort: $7 \mathrm{~km}$ südöstlich von Aleppo. ${ }^{4}$ Der Fluch richtet sich gegen Bildoder Grabschänder. Am Schluß findet sich ein Segen:

9 šhr wšmš wnkl wnšk ysḥw ${ }^{10}$ šmk w'šrk mn hyn wmwt lḥh ${ }^{11} y k t$ lwk wyh'bdw $z r^{\prime} k$ whn ${ }^{12}$ tnșt șlm' $w^{\prime} r s t^{\prime} z^{\prime} 13$ 'hrh ynșr ${ }^{14} z y l b^{5}$

" 9 ŠHR, Šamaš, Nikkal und Nusku mögen ausrotten ${ }^{10}$ deinen Namen und deine Stätte aus den Lebenden, und mit einem bösen Tode ${ }^{11}$ mögen sie dich töten und deine Nachkommenschaft zugrundegehen lassen! Wenn du aber ${ }^{12}$ dieses Bild und diesen Sarkophag beschützest, ${ }^{13}$ (dann) möge hinfort beschützt werden ${ }^{14}$ das, was dir (gehört)! “6

(6.) Nerab 2, Basalttafel, Grabinschrift des Si'-gabbari, Zeit und Fundort wie Nerab $1 .^{7} \mathrm{Si}^{\prime}$-gabbari beteuert, er sei ohne Grabbeigaben, nur mit einem Gewand beigesetzt worden. Das sollte Grabräuber abhalten. Dennoch werden Grabschänder anschließend noch verflucht:

\footnotetext{
${ }^{1}$ DONNER / ROLLIG, Inschriften, 215; TROPPER, Zincirli, 84f, übersetzt Z. 24: „Und Schlaf soll er nachts von ihm fernhalten. (...) Und Verstörtheit möge ihm gegeben werden. (...) Und [ni]cht soll(en) ... (...) ... Brüder und Freunde."

2 Vgl. Crawford, Blessing, 278 Anm. 357, 281-283.

3 כל אשר ישאל מאש תצנ ... ונתג לה יהו כלבבה VI. CRAWFORD, Blessing, 281; DAvIES, Inscriptions (Nr. 8.022), 81.

${ }^{4}$ Vgl. LAYTON, „Sources,“"184f; CRAWFORD, Blessing, 283.

5 Vgl. GeVirTZ, „Problem,“ 148; CraWford, Blessing, 284; KAI Nr. 225.

6 DONNER / ROLLIG, Inschriftem, 275.

7 Vgl. LaYTON, „Sources,“ 185; CRAWFORD, Blessing, 155.
} 
9... šhr wnkl wnšk yhb'šw ${ }^{10}$ mmtth w'hrrrrth t'bd ${ }^{1}$

„9... ŠHR, Nikkal und Nusku mögen sein Sterben elend sein lassen, ${ }^{10}$ und seine Nachkommenschaft soll zugrundegehen!“"2

Für Dtn 28 gilt es festzuhalten, daß die Götter in den Inschriften Zakkur, Hadad, Nerab 1 und Nerab 2 ohne Epitheta angesprochen werden. Epitheta findet man nur in Kilamuwa 1. Die Inschriften bestätigen also die bei den Sefiretexten gewonnene Erkenntnis, daß im westsemitischen Bereich Götterepitheta in Flüchen eher unüblich waren.

\subsection{Exkurs: Der futility curse im Alten Orient}

Beim futility curse handelt es sich um eine Kombination von Form und Inhalt, die eng mit der Syntax westsemitischer Sprachen verknüpft ist. Den Mühen zur Erreichung eines Zieles in der These, steht die Vergeblichkeit und das Ausbleiben des Zieles in der Antithese gegenüber. These und Antithese werden meist durch die Verbindung von Konjunktion und Negation verknüpft. Die biblischen Beispiele wurden von Queen Sutherland untersucht, die altorientalischen Bespiele behandelte Fales, biblischen und altorientalischen Belegen widmete sich Podella. ${ }^{3}$

Auf der Bilingue von Tell Fekheriye sind die aramäischen futility curses genau nach dem Bauplan von Hillers gestaltet: Beschreibung der Tätigkeit $+w+$ Negation + Verb der Präfixkonjugation. ${ }^{4}$ Das assyrische Gegenstück dagegen enthält statt der ersten beiden aramäischen futility curses Antithesen, die sich genau betrachtet als zwei asyndetisch nebeneinander gestellte Wünsche erweisen:

\section{${ }^{30}$...Er säe, er möge nicht ${ }^{31}$ ernten.}

Tausend[fach] möge er säen, 1 Sutu möge er ${ }^{32}$ erhalten.

1 Vgl. GeVIRTZ, „Problem,“ 147; KAI Nr. 226; CrawFord, Blessing, 157.

2 DONNER / ROLLIG, Inschriftem, 276.

3 Vgl. QueEn Sutherland, Futility Curse, 46-81; Fales, „Sforza,“ 1-8; Podella, „Nichtigkeitsfluch," 428-438.

4 ,The formula consists of a statement concerning the future and of a second statement describing the frustration, usually introduced by the conjunction $w$ and a negation. These curses have been described ... as 'futility curses'... ." HILlers, Treaty-Curses, 35; vgl. PODELLA, „Nichtigkeitsfluch,“428, 432. 
Die restlichen vier aramäischen futility curses werden im assyrischen Text nicht als Antithesen wiedergegeben, sondem sind nur verneinte Wünsche. ${ }^{1}$

z.B. ${ }^{32}$... Mögen 100 Schafe nicht ${ }^{33}$ ein Lamm ${ }^{32}$ sättigen!

Hätte man im Assyrischen die These mit der Antithese syntaktisch verbinden wollen, so wäre es möglich gewesen, an das letzte Wort der These ein - $m a$ anzufügen oder vor das erste Wort der Antithese $u$ zu schreiben. Daß dies nicht geschah, muß als stilistisches Ausdrucksmittel im Assyrischen gewertet werden, das vom Aramäischen abweicht.

Die aramäische Vorliebe für futility curses kam auch in den Sefire-Verträgen zutage, wo sie mit dem Zahlenspiel sieben / eins verbunden sind. ${ }^{2}$ Damit kann man die Stellen vergleichen, wo der Frustrationsfluch zusammen mit der Zahlenfolge sieben / eins in assyrischen Texten vorkommt. Es handelt sich um fast gleichlautende Passagen in den Annalen Assurbanipals und einem Brief desselben Königs an den Gott Assur. Beschrieben wird in beiden Texten ein Feldzug gegen rebellierende Araber in der Palmyrene, den man von Damaskus aus führte. Assurbanipal deutet die Vernichtung seiner Feinde als Auswirkung der Flüche, die der von diesen gebrochene Vertrag enthalten hatte. Im Gottesbrief an Assur lautet diese Stelle:

„(6) Den Rest Arabiens, der vor meinen Waffen (7) geflohen war, warf der starke Era nieder. (8) Not brach unter ihnen aus, so daß (9) sie gegen ihren Hunger das Fleisch ihrer Kinder aßen. (10) Alle die Flüche, die im Eid(estext) (11) unter der Nennung meines Namens und (der Namen) der Götter, deiner Kinder, geschrieben stehen, (12) bestimmtest du ihnen genauso als schlimmes Geschick: (13) Ein Kamelfohlen, ein Eselfohlen, ein Kalb, ein Lamm (14) mochten an sieben Milchtieren saugen und (15) konnten doch ihren Bauch an Milch nicht sättigen. (16) Die Leute in Arabien (17) fragten einander gegenseitig: (18f.) ,Weshalb ist [Arabien] ein solches Un[heil widerfahren?]' (20) ,Weil wir [die großen] E[ide bei Assur nicht gehalten,] (21) [uns] gegen die Güte A[ssurbani]pals, (22) des [Königs na]ch dem Herzen Enlils, [vergan]gen haben! “ 3

Im Gegensatz zu Tell Fekheriye und A.745.1 macht der assyrische Text die Antithese hier grammatisch erkennbar:

1 Vgl. Fales, „Bilinguisme,“ 249.

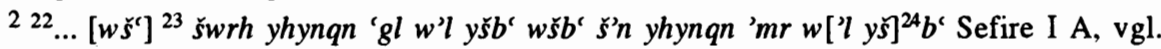
FITZMYER, Inscriptions, 14; LEMAIRE/ DURAND, Sfiré, 113.

${ }^{3}$ WeIPPERT, „Kämpfe,“ 82. VAT 5600 Kol II Z. 1-12; K 2802 (= Z. 21f). Vgl. ebd. 74. Zur fast gleichlautenden Parallele in den Annalen vgl. ebd. 47; STRECK, Assurbanipal, 76-79; 
${ }^{13}$ pakru suh̄iru būru ḩurāpu ${ }^{14}$ ina muhhi 7 ... mušēniqāti ìniqū=ma 15 šizbu lā ušabbû karassun (Annalen Kol. IX Z. 67: karašššsunu) ${ }^{1}$

Der Vordersatz (13f) spricht im Indikativ vom Saugen an sieben Muttertieren, der Nachsatz (Z. 15) erklärt mit seiner Negation $l \bar{a}$ die Erfolglosigkeit des Bemühens. Das Morphem - $m a$ am Ende von Z. 14 fungiert als Konjunktion, welche These und Antithese miteinander verknüpft und zusammen mit der Verneinung in Z. 15 dem aramäischen w'l oder dem hebräischen ולא entspricht. Besser könnte man die westsemitische Form der futility curses im Akkadischen kaum wiedergeben. Dieser assyrische Frustrationsfluch wurde etwa 200 Jahre nach den futility curses im aramäischen Teil der Tell Fekheriye-Inschrift verwendet. Es ist von den Flüchen des Vertrags mit dem arabischen Qedar-Stamm die Rede, der in der syrischen Wüste in engem Kontakt mit den Aramäern lebte. ${ }^{2}$ Bedenkt man, daß in den Flüchen assyrischer Verträge lokale Traditionen der Vertragspartner aufgegriffen wurden ${ }^{3}$, so scheint es möglich, daß auch der Frustrationsfluch als Teil des syrisch-arabischen Lokalkolorits in den Vertrag mit den Arabern geraten war und so in die Königsinschriften gelangte. Das Kannibalismusmotiv (vgl. Dtn 28,53-57) gehört zum Inventar assyrischer Vertragsflüche. ${ }^{4}$ Auf die Parallele des Motivs der "Strafgrunderfragung“ zu Dtn 29,19-23 haben viele Forscher hingewiesen. ${ }^{5}$

Dennoch gelangte diese Weise, These und Antithese durch Konjunktion zu verbinden und so mit den Mitteln der akkadischen Grammatik den futility curse zu gestalten, nicht erst durch den Qedar-Vertrag in die mesopotamische Literatur. Das etwa 600 Jahre ältere Kudurru B.1282.1 verwendet in seinen Flüchen genau das akkadische Schema des futility curse: These + $-m a+$ Antithese mit Negation $l \bar{a}$.

Rs. Kol. II ]x

$45+\mathrm{x}[$ när $] a\left(\mathrm{I}_{7}\right)$ lihrû

46+x [bī]t älim (URU.KI) lišu

$47+\mathrm{x}[$ tam] irta lilmû $=m a \quad$ tibnu (IN.NU) $l \bar{a}(\mathrm{NU})$ išaqqû̀ (UŠ-qú)

$=m a \quad m \hat{e}(\mathrm{~A} . \mathrm{MEŠ}) l \bar{a}(\mathrm{NU})$ udašš $(\mathrm{LU}-\mathrm{s} \mathrm{i})$

$=$ ma ina rati li!-bit

$=m a$ idru liṣbassi (DAB-si) ${ }^{6}$

1 VAT 5600 Kol. II. Vgl. Fales, „Sforza,“ 3; PODELla, „Nichtigkeitsfluch,“ 435.

2 Vgl. WeIPPERT, „Kämpfe,“ 66f, 40 Anm. 4.

${ }^{3}$ Vgl. A.669.2 Kol. IV Z. 10-17.

${ }^{4}$ Vgl. SUMNER, Study, 52; A.745.1 Kol. IV Z. 10 (Adadfluch), VTE Z. 449f (Adadfluch), VTE Z. 547, 570 (Vergleichsflüche).

5 Vgl. STRECK, Assurbanipal, 77 Anm. 11, 78 Anm. 3; WeIPPERT, „Kämpfe,“ 47 Anm. 34; HILLERS, Treaty-Curses, 65 Anm. 60, 86f Anm. 27; FRANKENA, „Vassal-Treaties,“ 153f; SKWERES, Rückverweise, 181-197; VARGYAS, „Cylindre,“157f, 162.

6 „44+x douteux UŠ-qú de šaqû, au sens de "hausser la tête', 'pousser' pour une plante?“ ARNAUD, „Kudurru,“ 169. Zur Lesung des Sumerogramms LU in Z. 45+x vgl. CAD 3/D, 
] $\mathrm{x}$

${ }^{45+x}$ Einen Kanal grabe man,

${ }^{46+x}$ Ein Stadthaus besitze er, $47+x$ Eine Feldflur umschreite man, aber Stroh sprieße nicht hervor.

aber mit Wasser soll er (die Felder) nicht versorgen.

aber in einer Wasserrinne übernachte er.

aber Salpeter möge sie in Besitz nehmen.

Die These beschreibt mit Verben im Prekativ teils eine positive Situation, den Besitz eines Hauses oder von Feldern, teils eine Bemühung, das Graben des Kanals. In der Antithese wird, ebenfalls im Prekativ, geschildert, daß die Verfluchten aus dem in der These Gesagten keinen Nutzen ziehen. Der Kanal nützt nicht zur Bewässerung, trotz des Hauses ist der Verfluchte obdachlos und obwohl er Land in Besitz nimmt, kann er keine Landwirtschaft betreiben. B.1282.1 widerrät, die futility curses auf aramäischen Ursprung oder das hethitisch-luwische Motiv des Essens, ohne satt zu werden, zurückzuführen. ${ }^{1}$ Bereits Jahrhunderte vor der Tell FekheriyeBilingue und auch vor dem Entstehen neuhethitischer Staaten in Syrien kannte man im akkadischen Sprachbereich futility curses. Gerade weil antithetische Formulierungsmuster zur Verfügung standen, muß die Tatsache, daß die Frustrationsflüche im assyrischen Text von Tell Fekheriye nicht adäquat wiedergegeben werden und diese Struktur im Akkadischen äußerst selten, in westsemitischen Flüchen dagegen häufiger belegt ist, als Differenz im Sprachstil hervorgehoben werden.

Für Dtn 28 ergibt sich: In westsemitischen Texten verwendete man den futility curse in Motiven, die im Akkadischen eher als einfache Verfluchungen gestaltet wurden. Hier zeigt sich ein unterschiedlicher Geschmack in der Formensprache, der dadurch verständlich wird, daß der westsemitische futility curse, bei dem Konjunktion und Negation aufeinanderprallen ( $w^{\prime} l, l$, ול ), prägnanter wirkt als sein akkadisches Äquivalent, wo Konjunktion und Negation auf These $(-m a)$ und Antithese $(l \bar{a})$ verteilt sind. Während in den aramäischen, assyrischen und auch manchen biblischen Frustrationsflüchen die Antithese von Aufwand zu Erfolg durch die Zahlenfolge Vielzahl / eins gesteigert wird, fehlen in Dtn 28,30f.38-42 die Zahlen. Dagegen enthalten Dtn 28,7.25 zwar die Gegenüberstellung sieben / eins, der antithetische Aufbau dieser Verse entspricht aber nicht dem Schema

130 dešâ $2 b$ versehen mit Flüssigkeiten (Bier und Wein); zu lawâ „umschreiten“ (Z. 47+x) im Sinne von „vermessen"vgl. AHw 541 4) a).

${ }^{1}$ Gegen FALES, „Istituzioni,“ 164; PODELLA, „Nichtigkeitsfluch,“ 441, 444f. Immerhin existierte B.1282.1 vor dem Entstehen der von PODELLA als Traditionsträger hethitischer Mythologeme betrachteten neuhethitischen Staaten seit dem ,ausgehenden 13. oder ... Anfang des 12. Jhs. v. Chr.“. „Nichtigkeitsfluch,“ 438. 
der futility curses. Dtn 28,7.25.30f.38-42 zeugen also von einem schöpferischen Umgang mit traditionellen Gestaltungsmustem.

\section{6. Übersetzungen aus persischer Zeit}

\subsection{Die Bisitun-Inschrift}

Darius I. (522-486 v. Chr.) ließ in Bisitun (Behistun, heute Bisotun) ein Felsbild mit einer dreisprachigen Inschrift einmeißeln. Diese Inschrift entstand zwischen 520 und $518 \mathrm{v}$. Chr. und enthält einen altpersischen, einen elamitischen und einen babylonischen Text. Darius diktierte persisch, das Diktat wurde jedoch elamitisch aufgezeichnet. Der elamitische Text gilt also als der älteste, obgleich er eine mündliche persische Version wiedergibt. Die zwei Segens- und Fluchformeln am Ende zeigen persischen Hintergrund, da als Gott Ahuramazda angerufen wird. In Ägypten fand man Fragmente einer aramäischen Übersetzung aus dem 5. Jh. v. Chr., die sich an die babylonische Version anlehnt. Die Versionen weichen in ihren Formulierungen teilweise voneinander $a b .{ }^{1}$ Die Übersetzung von Borger und Hinz gibt die Unterschiede zum persischen Text in Anmerkungen an. Hier wird die Übersetzung von Borger und Hinz so zitiert, daß die Abweichungen aus dem Anmerkungsteil zusammen mit dem Haupttext für jede Version nebeneinander geschrieben sind. Außerdem wurden die Segens- und Fluchsequenzen in der Originalsprache und die aramäischen Fragmente aus der Edition von Greenfield und Porten mit hinzugefügt.

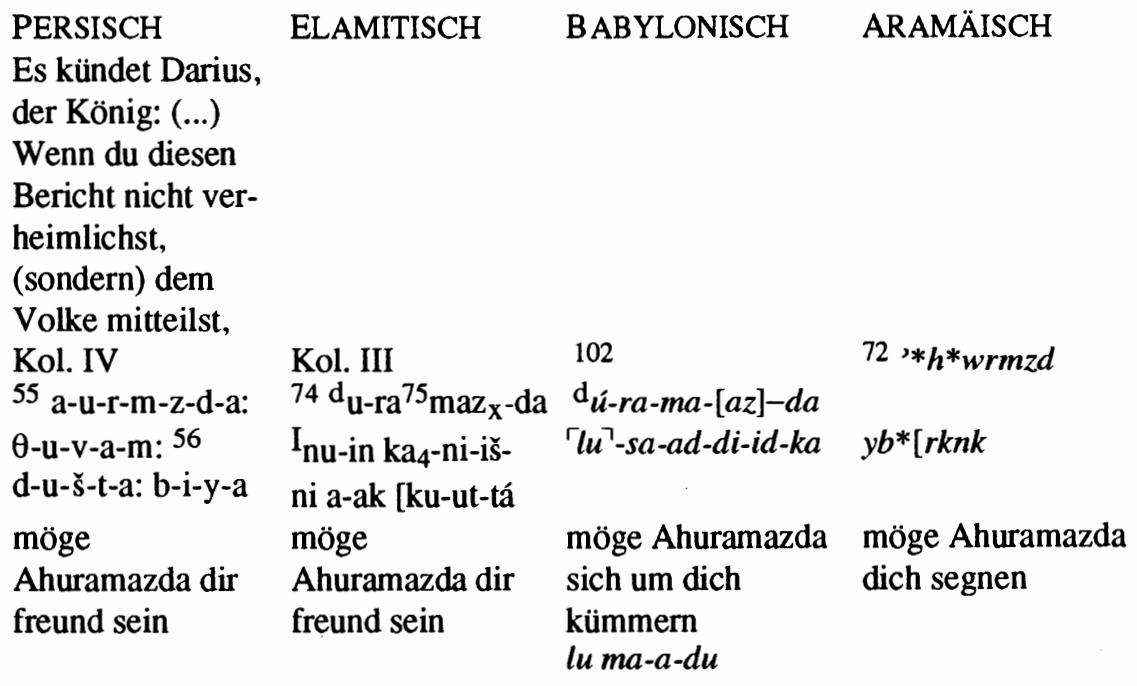

${ }^{1}$ Vgl. BORGER / HINZ, „Behistun-Inschrift,“" 419f. 


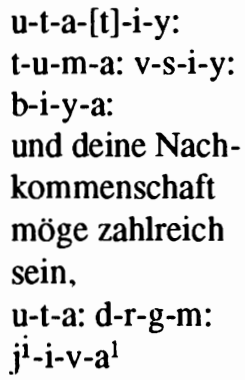

und du mögest lange leben!

Es kündet Darius der König: Wenn du diesen Bericht verheimlichst und dem Volke nicht mitteilst,

58 a-u-r-m-z-d-a-

$\mathrm{t}-<\mathrm{i}>-\mathrm{y}$ :

j-t-a: b-i-y-a:

möge

Ahuramazda dich schlagen

u-t-a-t-i-y:

t-u-m-59a:
INUMUN] $^{\text {meš-ni }}$ a-ak ku-ut-tá $I_{\text {nu }}$ me!-ul-li-ik-tá ka4-tak-ti-ni ${ }^{2}$ und deine Nachkommenschaft wie auch du selbst, ihr möget lange leben.

Es kündet Darius der König: Wenn du diesen Bericht verheimlichst und dem Volke nicht mitteilst,

76.

$\left.d_{u-r a-m a z}-d a\right]$ Inu-in hal-pi-iš-ni möge

Ahuramazda dich schlagen

a-ak ku-ut-tá INUMUN ${ }^{m e s ̌-n i ~}$ li-ra-[']-am-ka

und dich sehr

lieben

$r_{u}$ NUMUN-ka' wzr' $\left.y h w h l k\right] \check{s} g^{\prime}$

[li]-mi-id

und deine Nach-

und deine Nach-

kommenschaft kommenschaft möge zahlreich sein, wywmyk $y^{\prime *} r k w n^{4}$ sein,

UD.MEŠ- $[k a]$

li-ri-ku-’3

und deine Tage

mögen lang sein. ${ }^{5}$

und deine Tage

mögen lang sein.

Es kündet Darius der König: Wenn du diesen Bericht verheimlichst und deinem Volke das wahre Wort, das hier geschrieben ist, nicht mitteilst, 103

dú-ra-ma-az-da.

li-'ru'-ur-ka

Aber wenn du (es) verheimlichst,

73 'hwrmzd

möge Ahuramazda möge Ahuramazda

dich verfluchen dich verfluchen

NUMUN- $k a$

$w z r^{c}$

lu-ú

$l^{\prime}$

\footnotetext{
$1 \mathrm{Vgl.} \mathrm{SCHMITT,} \mathrm{Bisitun,} 42$.

2 Vgl. Grillot-Susini / HerrenschmidT / Malbran-Labat, „Version,“ 36.

3 Vgl. vVOIGTLANDER, Bisitun, 43.

4 Vgl. GreENFIELD / PORTEN, Bisitun, 50.

5 Vgl. BORGER / HINZ, „Behistun-Inschrift,“ 445.
} 


$\begin{array}{llll}\text { m-a: b-i-y-a } & \text { a-nu ki-ti-in-ti } & i a-a-n u^{3} & y h w h l k]^{4} \\ \text { und Nachkom- } & \text { und Nachkom- } & \text { und Nachkommen- } & \text { und Nachkommen- } \\ \text { menschaft mögest } & \text { menschaft mögest } & \text { schaft mögest du } & \begin{array}{l}\text { schaft mögest du } \\ \text { du nicht haben. }\end{array} \\ \text { du nicht haben. } & \text { nicht haben. } & \text { nicht haben. }\end{array}$

\section{PERSISCH}

Es kündet Darius der König: Wenn du diese Inschrift erblickst, ... sie erhältst

${ }^{74}$... a-u-r-m-z-d-a:

möge Ahuramazda

७-u-v-a-m: d-u-š-t-a: b-i$y-75 a:$

dir freund sein

u-t-a-t-i-y: t-u- m -a: v-s-i-y: b-i- y -a: und deine Nachkommenschaft zahlreich sein. u-t-a: d-r-g-m:

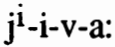

Und mögest du lange leben.

\section{ELAMITISCH}

Es kündet Darius der König: Wenn du diese Inschrift erblickst, ... sie erhältst

${ }^{86} \ldots$ d $_{\text {u-ra- }}$ maz $_{x}$-da möge Ahuramazda Inu-in ka4-ni-išs-ni a87ak ku-ut-tá dir freund sein
INUMUN $^{\text {meš-ni }}$

[ki-ti-in-ti a-ak und deiner Nachkommenschaft. mi]-ul-li-tá ka4-tuk-ti-ni a-ak ku-ut-tá Und mögest du lange leben.

ap-pa hu-ut-tan-ti hu-uh-pè du-ra-mazx-da

\section{BABYLONISCH}

Es kündet Darius der König: Wenn du dieses Denkmal erblickst, dich um sie kümmerst $107 . . .{ }^{\mathrm{d}} \tilde{u}-r a-{ }^{-} m a^{\top}-a z-d a$ möge Ahuramazda lu-sa-'ad'-[dak]-ka

sich um dich kümmern, 'dum?-qi $\ulcorner l i-i d$ ' $-[d a k]-k a$ dir Gutes geben, li-ra-r?-am-ka dich lieben u NUMUN!-ka lu-šá-am-'-id und deine Nachkommenschaft zahlreich machen. UD.MEŠ- $k a$ [lu-ur]-rik

Deine Tage möge er lang machen.

$\mathrm{d}_{u}$-ra-ma-az-da

lu-rab-bi-ka!

Ahuramazda möge dich groß machen.

u-t-a: t-y:

u k -u-n-v-a-h-y ${ }^{76}$ :

a-v-t-i-y: a-u-r-m-z-d-a:
108 u mi-im-ma

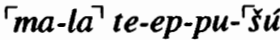

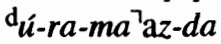

\footnotetext{
1 Vgl. SCHMIT, Bisitun, 43.

2 Vgl. Grillot-Susini / Herrenschmidt / Malbran-Labat, „Version,“ 36.

3 Vgl. vVOIGTLANDER, Bisitun, 44.

4 Vgl. GREENFIELD / PORTEN, Bisitun, 50.

5 Vgl. BORGER / HINZ, „Behistun-Inschrift,“ 445.
} 
$\mathrm{u}-\mathrm{c}-\mathrm{a}-\mathrm{r}-\mathrm{m}: \mathrm{k}^{\mathrm{u}}-\mathrm{u}-\mathrm{n}-\mathrm{u}-\mathrm{t}^{\mathrm{u}}-\mathrm{u}-\mathrm{v}^{1}$ ha-iz-za-iš-ni ${ }^{2}$

Und was du unternimmst, Und was du unterdas möge Ahuramazda nimmst, das möge dir wohlgelingen lassen. Ahuramazda dir wohlgelingen lassen.

Es kündet Darius, der König: Wenn du diese Inschrift erblickst oder diese Bildwerke, sie zerstörst und nicht solange du bei Kräften bist, sie erhältst, Kol. IV ${ }^{78} \ldots$...a-u-r-m-z-d-a-t-i-y j-t-a: b- ${ }^{79}$ i-y-a:

möge Ahuramazda dich

schlagen.

u-t-a-t-i-y: t-u-m-[a:] m-a: b-i'-[y-a]:

Und du mögest keine Nachkommenschaft haben

u u-t-a: t-y:

k u-n-v-a-h-y:

a-v-t-i-y:

$a-u-r-m-z-d-80 a$

Und was du unternimmst, das möge Ahuramazda

$\mathrm{n}-\mathrm{i}-\mathrm{k}-\mathrm{t}^{\mathrm{u}}-\mathrm{u}-\mathrm{v}^{5}$

dir zunichte machen.
Es kündet Darius, der König: Wenn du diese Inschrift oder diese Bildwerke zerstörst und nicht sie erhältst, $\mathrm{I}_{\text {nu-in hal-pi-iš-ni }}$ möge Ahuramazda dich

schlagen.

a-ak ku-ut-tá

$\mathrm{I}_{\text {NUMUN }}{ }^{\text {meš }}$-ni a-nu ${ }^{89}$ ki-ti-in-ti

Und du mögest deine Nachkommenschaft nicht behalten.

[a-ak ap-pa hu-ut-tá-in-ti hu-uh-pè] $\mathrm{d}_{\mathrm{u}-\mathrm{ra}-\mathrm{maz}_{\mathrm{x}}-\mathrm{da}}$

Und was du unternimmst, das möge Ahuramazda ri-ip-pi-iš-ni ${ }^{6}$

dir zunichte machen.
${ }^{88}$... d ${ }^{\text {u-ra-maz }}$ - da
$\left.\left.\Gamma_{i n a} \check{S ̌ U}^{I I I}\right\urcorner_{-k} k \Gamma^{\top} l u-u s ̌-t e\right\urcorner-s ̌ e-e r^{3}$

Und was du unternimmst, das möge Ahuramazda in deiner Hand wohlgelingen lassen. ${ }^{4}$

Es kündet Darius, der

König: Wenn du dieses

Denkmal

zerstörst und dich nicht darum kümmerst,

108 ... dú-ra-ma-az-da

li-ru-ur-[ka]

möge Ahuramazda dich

verfluchen.

$109 u$ NUMUN

NUMUN- $-k a ?$

lu ia-a- $\boldsymbol{n} \boldsymbol{u}$ ?

Und du mögest keine

Nachkommenschaft haben.

u mi-im-ma ma-la

te-ep-pu- Г̌sú

$\left.\mathrm{d} u \dot{u}-r a-m a-a z-\mathrm{da}^{\top}\right\urcorner$

Und was du unternimmst, das möge Ahuramazda

$u l-t u$ S̆UII $_{-k a}$

li-is- ${ }^{\top} s u^{\top}-u h^{7}$

aus deiner Hand entreißen. ${ }^{8}$

1 Vgl. SCHMITT, Bisitun, 44.

2 Vgl. Grillot-Susin / HerRenschmidt / Malbran-Labat, „Version,“ 37.

3 Vgl. vVoigtlander, Bisitun, 45f.

${ }^{4}$ Vgl. BORGER / HINZ, „Behistun-Inschrift,“ 446.

5 Vgl. SCHMITT, Bisitun, 44.

6 Vgl. Grillot-Susini / HerRenschmidt / Malbran-Labat, „Version,“ 37.

7 Vgl. vVOIGTLANDER, Bisitun, 46.

8 Vgl. BORGER / HINZ, „Behistun-Inschrift,“ 446. 
Während die elamitische Version meist mit der persischen übereinstimmt, weicht die babylonische häufig ab. Dabei zeigen sich die Unterschiede im Segen deutlicher als im Fluch. Im Segen Z. 101 erweitert die babylonische Fassung die erste Segnung um zwei Aussagen. Dies macht die aramäische Übersetzung nicht mit. Statt dessen benutzt sie das gattungsspezifische Verb brk im Indikativ, während im Babylonischen der Prekativ steht. Das Aramäische entfernt sich damit sowohl von der Metapher „Freundschaft Gottes" im persischen und elamitischen Text, wie auch von der babylonischen Dopplung ,kümmern“ und „lieben“. Das Motiv des langen Lebens umschreiben die babylonische und die aramäische Version mit dem in der semitischen Segenstradition verbreiteten Ausdruck ,Länge der Tage“. Im Segen Z. 107 nehmen die babylonischen Ergänzungen einen noch größeren Umfang an. Das Motiv der Gottesfreundschaft wird in drei Segnungen ausgestaltet. Nach der Lebensverlängerung wird ein Segen eingefügt, der im persischen und elamitischen Teil gar keine Entsprechung hat. Der letzte Wunsch enthält statt des Personalpronomens die semitische Metaphorik ,in / aus deiner Hand“.

Im Fluch übersetzen die babylonische und die aramäische Version „,schlagen“ mit „fluchen“. Der gattungsspezifische Terminus entspricht der weitverbreiteten Formel GN lìrur-ePP, obwohl es auch Belege für das seltenere mahāṣu ,schlagen“ im babylonischen Fluch gibt. ${ }^{1}$ Man verließ also die persisch / elamitische Bildwelt zugunsten der traditionellen akkadischen Fluchformel. Das nüchterne persisch / elamitische ,zunichte machen" wäre auch im Babylonischen etwa durch das in Flüchen häufige halāqu auszudrücken gewesen. Statt dessen verwendete man wieder die Metapher der Hände und das Verb nasāhu ,herausreißen“. Die Nennung der Hände als Haftpunkt des Erfolgs und Mißerfolgs (Z. 107, 108) erinnert an משלך ידך (Dtn 28,8.20).

Während die elamitische und persische Version gleiche Formulierungen wiederholen, ändert die babylonische die Segnungen ab. In Z. 107 wird gegenüber Z. 101 in der Mitte ,dir Gutes geben“ eingeschoben. In Z. 108 wird gegenüber Z. 103 das NUMUN-Zeichen verdoppelt.

Die Bisitun-Inschrift gibt Zeugnis für Segen und Fluch in nachexilischer Zeit. Obgleich zu Dtn 28 kein direkter Bezug besteht, erhellt sie doch einige Eigenarten der Übersetzungsweise im AO:

(1.) Metaphern werden durch abstrakte themenspezifische Ausdrücke wiedergegeben (schlagen $\leftrightarrow$ fluchen; kümmern + lieben $\leftrightarrow$ segnen).

(2.) Abstrakte Ausdrücke werden in Metaphern verwandelt (zunichte machen $\leftrightarrow$ aus deiner Hand entreißen).

${ }^{1}$ Vgl. B.1083.1 Kol. II Z. 19; VTE § 56 Z. 474. 
(3.) Es besteht ein Hang zu Erweiterungen. Aus einer Aussage wird eine Aufzählung mit mehreren Gliedern (freund sein $\leftrightarrow$ kümmern + Gutes geben + lieben). Eigenständige Ergänzungen ohne Entsprechung im Original werden hinzugefügt (Ahuramazda möge dich groß machen).

Die babylonische Version weicht so sehr von den beiden anderen ab, daß man sie wohl kaum ohne weiteres als deren Übersetzung erkennen würde, wenn nicht der Fundkontext und der Gottesname Ahuramazda die Identifizierung klären würde. Tatsächlich deuten Greenfield und Porten an, daß das aramäische Fragment mit dem Segen und Fluch aufgrund des Gottesnamens identifiziert und eingeordnet wurde. ${ }^{1}$ Wie schwer dürfte es daher sein, einen altorientalischen Segens- oder Fluchtext eindeutig als Wiedergabe einer fremdsprachigen Vorlage zu erweisen, wenn zusätzlich zu den in der Bisitun-Inschrift erkennbaren Übersetzungsdifferenzen auch noch die Namen der Götter geändert würden.

Die Bemerkung des Darius, er habe für die Übersetzung und Verbreitung seiner Inschrift gesorgt (persische Version Kol. IV Z. 88-91) zeigt, daß zur Zeit der Pentateuchredaktion ein Text im persischen Reich verbreitet war, der zwei Mal Segen und Fluch (in dieser Reihenfolge) gleichberechtigt nebeneinanderstellt und damit nicht nur den Erhalt der Inschrift, sondern auch dessen wahrheitsgetreue Verkündigung sanktionierte.

\section{6. 2. Eine Bilingue aus Sardes}

Die lydisch-aramäische Bilingue aus dem 10. Jahr des Artaxerxes wird hier nur zitiert, um einerseits die treue Tradierung von Fluchformeln festzuhalten, die schon in den Verträgen der Hethiter verwendet wurden und andererseits eine weitere Möglichkeit der Abweichung von Inschriften auf Bilinguen aufzuzeigen: die Umstellung von Textelementen. Es handelt sich um eine Grabinschrift aus Sardes, deren Fluchteil folgendermaßen übersetzt wurde:

\footnotetext{
1 ,Sachau already observed that the fragment Pl. 56, No. 4 must come at the end of the text because only there, in the blessing and curse formulae, does Ahuramazda occur in the sequence presumed here - at the beginning of two long sentences. In fact, neither he nor Cowley appreciated that the two preserved letters after each occurence of Ahuramazda yield $y b[r k n k]$, 'he will b[less you]' and $y q[l l n k]$ 'he will c[urse you]'." GREENFIELD / PORTEN, Bisitun, 49. Ein Grund dafür, daß man zunächst nicht auf die Idee kam, diese Verben zu rekonstruieren, dürfte gewesen sein, daß „fluchen“" weder im elamitischen noch im persischen Text vorkommt und ,segnen“ in überhaupt keiner der drei Bisitunversionen.
} 
Aramäisch: , ${ }^{6}$ wer immer das alles vernichtet oder zerstückelt: ${ }^{7}$ Die Artemis von Koloe und die (Artemis) der Epheser mögen seinen Hof, sein Haus, ${ }^{8}$ seine Habe, Erde und Wasser und alles, was sein ist, ihm zerstreuen und ihm zerbrechen!,",

Lydisch: „6 nun wer auch immer was auch immer beschädigt (?), nun ihm Artemis 7 (die) Ephesische und Artemis (die) Kolo'ische Hof und Haus, 8 Erde und Wasser, ländlichen Besitz und was auch immer seinig (?), oder (und) seinem (Erben)? soll(en)? zerstreuen (?).“2

Die Aufzählung vertauscht in Z. 8 den ländlichen Besitz mit Erde und Wasser. ${ }^{3}$ Obwohl die Bilingue recht genau übersetzt, können also bei Aufzählungen Umstellungen in der Motivfolge vorkommen.

\section{7. Die aramäische Sprache in der assyrischen Verwaltung}

Bildliche Darstellungen belegen, daß im nördlichen Herrschaftsbereich Assyriens Texte zugleich in einer keil- und einer westsemitisch-buchstabenschriftlichen Version verfaßt wurden. Ein Relief aus dem Palast Sargons in Khorsabad (Dur-Šarukkin) weist diese Zweisprachigkeit sogar für die assyrischen Feldzüge nach. In der Darstellung der Plünderung von Muṣașir ist nämlich ein assyrischer Beamter abgebildet, der die Beuteliste zugleich einem Schreiber mit Tontafel und einem mit den Schreibutensilien für die aramäische Schrift diktiert. ${ }^{4}$ Mitten in die Zerstörung der feindlichen Stadt postiert, wird diese Schreiberszene nicht von einer diplomatischen Korrespondenz berichten, sondern die alltägliche Buchhaltung wiedergeben. Das Relief scheint zu bezeugen, daß sogar gänzlich reichsinterne Angelegenheiten, wie Auflistungen der Kriegsbeute in assyrischer und aramäischer

\footnotetext{
${ }^{1}$ DONNER / RÖLLIG, Inschriften, 306.

2 KAHLE / SOMMER, „Bilingue,“ 81; vgl. KAI Nr. 260.
}

3 „In Z. 7ff. sind sinnentsprechend im Lydischen die paarweise geordneten Glieder durch ,und', die einzelnen Paare aber untereinander nicht zusammengefaßt, während Ar. bei seiner etwas anderen Gruppierung ,Hof, Haus, Grundbesitz ' wiederum asyndetisch gibt, das Paar ,Erde und Wasser" durch $\underline{u}$-kopuliert und schließlich das allgemeine ,was auch immer sein ist" dem Ganzen ebenfalls durch , und" anreiht. - Die polysyndetische Ausdrucksweise als Regel wird durch die anderen lydischen Inschriften ... bestätigt.“ KAHLE / SOMMER, „Bilingue," 82. Die Abweichungen ergeben sich also nicht einfach aus mangelnder Genauigkeit beim Übersetzen, sondern resultieren aus Sprachgewohnheiten der Zielsprache, die in die Übersetzung einflossen.

${ }^{4}$ „Auf dem Dach des Gebäudes links vom Tempel diktiert ein auf einem Klapphocker sitzender assyrischer Beamter einem Tontafelschreiber und einem aramäischen Schreiber die Beuteliste.“ MAYER, „Finanzierung,“ 593. Die auf dem Relief in Sargons Palast in Khorsabad dargestellten Ereignisse fanden auf seinem Feldzug im Jahre 714 statt. Vgl. ebd. 572. 
Sprache durchgeführt wurden. Inzwischen sind über 17 Darstellung bekannt, ausgehend von der Regierungszeit Tiglat-Pilesers III., die Schreiberpaare zeigen, von denen der eine in Keilschrift und der andere auf eine Pergamentrolle schreibt. ${ }^{1}$

Als weiteres Beispiel für die gemeinsame Verwendung der assyrischen und aramäischen Sprache zur Zeit des neuassyrischen Reiches sei auf die aramäischen Anmerkungen am Rand vieler neuassyrischer Rechtsdokumente hingewiesen. In ihnen war der Inhalt der Tafel zusammengefaßt. Die aramäischen Notizen dienten zur leichteren Identifizierung der Tafel oder als Hilfe für jene, die die Keilschrift nicht beherrschten. ${ }^{2}$ Die Symbiose beider Sprachen und Schreibsysteme dient Postgate auch zur Erklärung der dreieckigen Tonklumpen, die eine verknotete Schnur umkleideten und mit dem Keilschrifttext eines Getreidedarlehens oder eines Schuldscheins für Getreide beschrieben sind. Der Tonklumpen sollte das Öffnen des Knotens verhindern, durch den wohl eine Pergamentrolle zusammengehalten wurde. Diese aramäisch beschriebene Schriftrolle hat man auf dem Tonklumpen gesiegelt und mit einer Inhaltsangabe in Keilschrift versehen. Die Pergament- oder Papyrusrollen zerfielen und nur die Tonumschläge blieben übrig. In Ninive und Assur wurden derartige Tondreiecke gefunden, die auf aramäisch beschrieben sind. ${ }^{3}$

Gegen Ende des neuassyrischen Reiches nahm die Verwendung von Pergament als Schreibmaterial deutlich zu. Inschriften aus Ninive belegen das Ideogramm A.BA, das Schreiber und Übersetzer im königlichen Dienst bezeichnete, die auf Pergament schrieben und teilweise ausdrücklich Aramäer genannt wurden. Die Zunahme aramäisch sprechender Bevölkerung im Herrschaftsgebiet Assyriens ${ }^{4}$ hinterließ nicht nur grammatische Spuren

\footnotetext{
1 Vgl. HaRAN, „Book-Scrolls,“ 119f, ebd. 121 Anm. 17: „It ist noteworthy that the conventional duality of scribes appearing on the reliefs finds an explicit verbal echo in correspondence. Thus, for example, in a letter addressed to one of the last kings of Assyria the writer indicates that the king's father gave an order of payment registered in an Assyrian document and in an Aramaic document' ... ."

2 ,We have already remarked on the symbiosis of the Assyrian and Aramaic writing systems ... . A good number of Neo-Assyrian legal documents have notes added in Aramaic script on the edge, summarising the contents of the text; these had no legal significance, but served to identify the tablet quickly, or for those with little or no knowledge of cuneiform." Postgate, Documents, 11.

${ }^{3} \mathrm{Vgl}$. Postgate, Documents, 5f, 6: „As early as the reign of Sargon we hear of the palace scribe receiving rolls of papyrus (ABL 568), ... while not only from Tell Halaf in Syria, but also from Niniveh and Assur, we have triangular dockets of the very kind under consideration but inscribed entirely in Aramaic ... ."
}

4 Vgl. HARAN, „Book-Scrolls,“ 121; TADMOR, „Aramaization,“ 449-451. 
im neuassyrischen Dialekt ${ }^{1}$, sondem führte offenbar dazu, daß die Staatsverwaltung zweisprachig wurde.

Der assyrisch-aramäische Bilingualismus beleuchtet die Problematik einer direkten Beziehung zwischen assyrischen Verträgen und dem Deuteronomium. Einerseits bezeugen die Funde das Vordringen des Aramäischen im Rechtsverkehr, so daß man berechtigterweise annehmen kann, Staatsverträge mit Vertragspartnem im Westen seien nicht nur in einer assyrischen, sondern auch in einer aramäischen Version verfaßt worden und in dieser Form auch am Jerusalemer Hof bekannt gewesen. ${ }^{2}$ Andererseits kann die Existenz solcher aramäischer Versionen wegen der Vergänglichkeit von Pergament und Papyrus nicht bewiesen werden und muß daher ein Postulat $e$ silentio bleiben. Vor dem Hintergrund der in Nimrud gefundenen Papyrusgallerie ist anzunehmen, daß ein so bedeutender Text wie die VTE von Anfang an sowohl in einer assyrischen als auch in einer aramäischen Version existierte. ${ }^{3}$

Die Schreiber der vorisraelitischen kanaanäischen Städte des 2. Jts konnten Keilschrift schreiben, wie Schriftfunde in Palästina beweisen. Auch der König von Jerusalem korrespondierte damals mit seinem ägyptischen Herren in El-Amarna in babylonischer Keilschrift. ${ }^{4}$ Möglicherweise ging dieses Bildungsgut im 1. Jt. verloren. Rechnet man damit, daß das neuassyrische Reich seine diplomatische Korrespondenz mit den westlichen Nachbarn auf aramäisch durchführte, konnte man die VTE in Jerusalem verstehen, selbst wenn die judäischen Schreiber die Keilschrift nicht beherrschten.

\footnotetext{
1 Vgl. GAG § 196 b.c.
}

2 Vgl. KREBERNIK, „Deuteronomiumskommentar,“ 35f. Archäologische Funde beweisen, $\mathrm{da}$ man im assyrischen Staatsarchiv Dokumente aus Papyrus und Pergament aufbewahrte. Vgl. Parpola / Watanabe, Treaties, XIII Anm. 1. Die Assyrer wickelten offizielle Kontakte zu westlichen Staaten auf aramäisch ab. Vgl. TADMOR, „Aramaization,“ 452 mit Verweis auf ABL 872, Nimrud Letter 13 und 14.

3 ,The relative Schnittes of the extant material may indicate that many treaties, especially those concluded with Levantine rulers, were not recorded on clay but on papyrus or leather; note the evidence of treaties on papyrus from the 'Papyrus gallery' of Sennacherib's palace in Nineveh ... ." PARPOLA, „Treaties,“ 162 Anm. 7, vgl. ebd. 183; 2 Kön 18,26-28.

4 Vgl. MaLul, Method, 108f; MoRAN, Lettres, 506-520. 


\section{8. Ergebnisse: Übersetzungstreue in Fluchtexten des Alten Orients}

Für einige Fluchformeln läßt sich eine fast gleichlautende Verwendung in den Verträgen des Hattireiches (CTH 62 II, 66; 2. Hälfte des 2. Jts.) bis zu Texten aus der Perserzeit (KAI Nr. 260; 1. Hälfte des 1. Jts.) nachweisen. Solche Formeln verfluchten summarisch einen Menschen, dessen Frauen, Kinder, Stadt, Land, Haus, Hof, Vieh und Besitz und wurden in Übersetzungen sehr vorlagengetreu wiedergegeben. Auch der Fluch der Nachkommenschaftsvernichtung wurde in verschiedenen Sprachen fast wörtlich übersetzt (Bilingue von Kelišin). Doch in den verschiedenen Sprachen flossen auch eigene Ausdrucksweisen in die Fluchformeln ein. Sogar die gleichsprachigen Exemplare desselben Vertrages aus Ägypten und Huattuša wichen im Detail voneinander ab (CTH 91). Sobald eine Fluchsequenz nicht mehr aus traditionell festgelegten Formeln bestand, nahmen die Unterschiede zu. Hier scheint die Bezeichnung „Übersetzung“" weniger angebracht. Man sollte eher von einer „Übertragung“ in die Formulierungsgewohnheiten der Zielsprache reden. Folgende Abweichungen sind belegt:

(1.) Glieder einer Aufzählung werden vermehrt (Tell Fekheriye: Nergalfluch; Bisitun elamitisch $\leftrightarrow$ babylonisch) bzw. reduziert (Bisitun babylonisch $\leftrightarrow$ aramäisch).

(2.) Metaphem werden in Abstrakta verwandelt (Bisitun elamitisch $\leftrightarrow$ babylonisch, babylonisch $\leftrightarrow$ aramäisch), bzw. Abstrakta werden in Metaphem verwandelt (Bisitun elamitisch $\leftrightarrow$ babylonisch).

(3.) Einfache akkadische Fluchwünsche stehen aramäischen futility curses gegenüber (Tell Fekheriye; vgl. Sefire und A.745.1).

(4.) Götternamen werden geändert (Karatepe).

Immer gleich blieb die grundsätzliche Themenabfolge der Fluchsequenz. Bei der Übersetzung ins Hebräische ist also mit ähnlichen Abweichungen gegenüber der fremdsprachigen Vorlage zu rechnen. ${ }^{1}$

\footnotetext{
${ }^{1}$ Eine Beziehung zwischen den Literaturen zweier Sprachen kann nur festgestellt werden, wenn Form und Inhalt übereinstimmen. CRAIGIE, „Poetry,“ 26, 28-31, unterscheidet drei Möglichkeiten des Zustandekommens einer derartigen Beziehung: (1.) Direkte Entlehnung (2.) Adaption des fremden Materials und (3.) kreativer Gebrauch eines mündlich überlieferten Fundus poetischer Stilmittel. Für die altorientalischen Übersetzungsgewohnheiten treffen alle drei Kategorien zu. Die Übersetzung erweist sich als direkte Übernahme fremden Materials, das dabei zugleich adaptiert wird. CRAIGIE zählt bereits die Jahwesierung zur Adaption. Für die Adaption des Materials verwendet der Übersetzer idiomatische Wendungen aus dem Formulierungsfundus der Zielsprache, die mehr oder weniger vom Ausgangstext abweichen.
} 


\section{KONTEXT UND „FABEL“ VON DTN 28}

Die Interpretation von Dtn 28 muß den Kontext und die Stellung des Kapitels im Aufbau des Buches berücksichtigen. Die Forschungsgeschichte zeigt, daß der Zugang zum Text von der Perspektive beeinflußt wird, die man an das Deuteronomium als Ganzes heranträgt.

Im vorigen Jahrhundert wurde die Literarkritik zur Analyse des Deuteronomiums als Gesetz bestimmend. ${ }^{1}$ Man rekonstruierte ältere Vorstufen des Buches, deren Umfang und Gestalt aber hypothetisch bleiben. ${ }^{2}$ Um einen Grundbestand von Dtn 28 als Segen und Fluch in einem Gesetzeskorpus zu erhalten, mußte man das Kapitel 27 als sekundär ausscheiden. Erst dann bildet Dtn 28 den Abschluß der zweiten Moserede, die in 5,1 beginnt und in den Kapiteln 12-26 das Gesetz umfaßt. ${ }^{3}$ Doch auch nach hinten wurde der Kontext von Dtn 28 abgeschnitten. ${ }^{4}$

In Segen und Fluch am Schluß eines Gesetzbuches kann man kaum etwas anderes sehen, als Versprechungen und Drohungen. JHWH, der Gesetzgeber, sanktioniert Befolgung oder Mißachtung seiner Gesetze. Mose segnet und flucht nicht, sondem er informiert, bzw. er verspricht und droht im Namen Gottes. ${ }^{5}$ Die Textgestalt von Dtn 28 wird der aus der diachronen Analyse hervorgegangenen Verbindung mit dem Gesetz geopfert. Seine Jussivformen bleiben unbeachtet. ${ }^{6}$ Nur Noth übersetzt, vermutlich angeleitet durch seine altorientalischen Vergleichstexte, in Dtn 28 tatsächlich Wunschsätze. ${ }^{7}$ Er unterläßt jedoch eine Funktionsbestimmung des Kapitels im Zusammenhang des Gesetzbuchs. Wie können am Ende des Gesetzes Segnungen und Verwünschungen stehen, die von JHWH, dem Ge-

1 Vgl. Preuss, Deuteronomium, 33-35; Houtman, Pentateuch, 301.

2 "Die klare Ausgrenzung eines Urdtn.s ... hat sich immer mehr als schwierig erwiesen, und wir wissen über dieses Buch kaum mehr als vor etwa 150 Jahren, wenn man wirklich den Versuch einer Ausgrenzung eines zusammenhängenden ,Buches“ als Gesetzescorpus mit Einleitungsrede und Schlußrahmen macht." PrEUSS, Deuteronomium, 43; vgl. HouTMAN, Pentateuch, 301-305.

${ }^{3}$ Vgl. in der Forschung dieses Jahrhunderts Noth, ,Fluch,“ 130/157 Anm. 5; CAZELLES, Deutéronome, 15; WRIGHT, „Deuteronomy,“ 312-315, 502; PENNA, Deuteronomio, 10, 236f; SEITZ, Studien, 223, 303 hielt noch nicht einmal die Verbindung zwischen Dtn 28 und Dtn 26 für ursprünglich.

4 Vgl. Preuss, Deuteronomium, 38, 158-173.

5 Vgl. z. B. CAZELleS, Deutéronome, 21: „Les bénedictions promises“.

6 Vgl. SErTZ, Studien, 279.

7 Vgl. NoTH, „Fluch,“138/165, 134/170 Anm. 41. 
setzgeber ${ }^{1}$, in der 3. Person sprechen und sein Eingreifen herbeiwünschen. Da die meisten Gesetze des AO ohne Segen und Fluch überliefert sind, können letztere keine zum Wesen des Gesetzes gehörende Funktion besitzen. ${ }^{2}$

Kontext und Funktion des Kapitels 28 erschienen in einem anderen Licht, sobald man das Deuteronomium als Zeugnis eines in Sichem gefeierten Bundeserneuerungsfestes betrachtete. ${ }^{3}$ In Dtn 27-30 waren keine literarkritischen Ausschlüsse mehr nötig, um Sinneinheiten zusammenzustellen, die zur Bundesschlußzeremonie gehören. Segen und Fluch wurden im Zusammenhang der deuteronomischen Gesetzespredigt gesehen und erhielten paränetischen Charakter. Segen und Fluch erschienen als Predigtthemen. Mose segnet und flucht nicht, sondern er predigt über Lohn und Strafe. ${ }^{4}$

Die synchrone Ebene der gegenwärtigen Textgestalt betonten auch jene Forscher, die im Deuteronomium die Struktur des Vertrages fanden. ${ }^{5}$ Assmann bestimmte Monumente und Verträge als die genuinen Orte für schriftliche Flüche. In beiden Fällen soll die Rezeption des geschriebenen Wortes in der Zukunft sichergestellt werden. Flüche bilden einen integralen Bestandteil der Verträge. Sie gehören zu dem Eid, in dem sich der den Eid Leistende dem Wirken der Gottheit, die über den Vertrag wacht, unterwirft. Assmann definierte Dtn 28 als Vertragsfluch. ${ }^{6}$

In der neueren Forschung setzt sich jedoch die Auffassung durch, das Deuteronomium könne nicht einfach als Gesetz, Bundeserneuerungszere-

1 "Denn das deuteronomische ... Gesetz ... leitet sich von Jahwe als Gesetzgeber her ... ." NOTH, „Fluch,“ 137/165.

2 Vgl. OTTO, „Bedeutung,“ 149; AssmanN, , Fluchinschriften,“ 241-244.

3 Vgl. vRAD, Deuteronomium-Studien, 9/111; RIDDERBos, Boek II, 78; BUIS / LECLERCQ, Deutéronome, 170f; ReNNES, Deutéronome, 118; WINGaARDS, Deuteronomium, 304, 312 314; Craigie, Deuteronomy, 24, 28; Houtman, Pentateuch, 299-301, 307, $314 \mathrm{f}$.

${ }^{4}$ Vgl. vRAD, Deuteronomium-Studien, 7-10/109-112; JUNKer, Deuteronomium, 531; KRÄMER, Numeri, 229, 506f; CUNLIFFE-JONES, Deuteronomy, 16, 24f; RIDDERBOS, Boek I, 34; Boek II, 81; Buts / LeClercQ, Deutéronome, 175; CraigIe, Deuteronomy, 340.

5 Vgl. KLINE, Treaty, 28, 37, 44, 124; THOMPSON, Deuteronomy, 18-21, 67f; SCHÄCHTER, Fluch, 214; MORAN, „Deuteronomy,“ 247, 256-259; WeINFELD, School, 7; Deuteronomy 111, 4-13, 55-57; PHIlliPS, Deuteronomy, 4-8.

6 „Beim Deuteronomium handelt es sich um Vertragsflüche. Den vertraglichen Aspekt hebt der Text selbst explizit hervor. Den langen Fluchkatalog beschließt der metatextuelle Vermerk: ,Dies sind die Worte des Bundes ...' $(28,69)$; und von den Flüchen heißt es später: ,gemäß allen Flüchen des Bundes, der in dem Buch dieses Gesetzes aufgeschrieben ist' $(29,20)$. Die Flüche sind ,Bundesflüche' oder ,Vertragsflüche', und als solche stehen sie im Buche (oder auf den Steinen am Ebal), geschrieben“. Der Ausdruck ,Bundesflüche“ verweist sowohl auf ihren schriftlichen wie auf ihren vertraglichen Charakter." AsSMANN, „Fluchinschriften,“ 238. 
monie oder Vertrag eingestuft werden, sondem stelle die Verbindung verschiedener Konzepte dar. Diese unterschiedlichen Strukturmodelle mögen teilweise diachron verschiedenen Entstehungsphasen des Buches zugeordnet werden, stehen synchron jedoch gleichberechtigt nebeneinander. ${ }^{1} \mathrm{Da}$ Segen und Fluch keinen wesentlichen Bestandteil von Gesetzen, sehr wohl aber von Bundesschlüssen und Verträgen bilden, scheint es angemessen, in der Auslegung von Dtn 28 den Vertragscharakter des Buches hervorzuheben und das Kapitel 28 als Bestandteil einer Vereidigungszeremonie Israels zu sehen. Dies greift auf Ausführungen von Kline, Buis, Leclercq und Braulik zurück, wonach der Bundesschluß in Dtn 26,16-19 beginnt, Segen und Fluch von Dtn 28 umfaßt und auch die rituellen Handlungen einschließt, welche in 29,9-14 angesprochen werden. ${ }^{2}$

Nachdem somit unter den verschiedenen möglichen Blickwinkeln auf das Deuteronomium als Ganzes der für die folgende Exegese bestimmende ausgewählt wurde, soll nun der Kontext von Dtn 28 in bezug auf die folgenden Kapitel betrachtet werden, wobei vor allem die Bedeutung und Funktion von Dtn 28,69 interessiert. Da in 28,69 der Erzähler zu Wort kommt, stellt sich die Frage, was im Deuteronomium erzählt wird. Was geschieht in Dtn 28? Wie fügt es sich ein in die „Fabel“ - des Kontexts? Der Erzähler spricht auch in Dtn 27. So können die Funktionsbestimmung von Dtn 28 in der „Fabel“"3 und die Kontextabgrenzung nach vorne, gegen Kapitel 27 hin, gemeinsam behandelt werden.

Zum Schluß ist vor der Auslegung des Kapitels zu klären, was man eigentlich unter einem Fluch versteht, was das hebräische Wort pללה bedeutet, und wie es bei der Auslegung von Dtn 28 adäquat wiedergegeben werden kann.

\section{1. Der Kontext nach hinten: Dtn 28,69}

Nach der Moserede Dtn 27,11-28,68 kommt in 28,69 der Erzähler zu Wort.

69a $a$ Dies sind die Worte des Bundes, אלדה רברי הברית

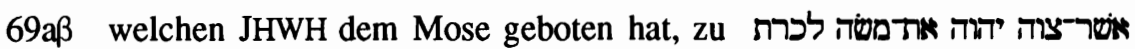

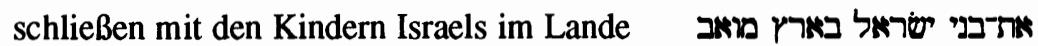
Moab,

\footnotetext{
1 Vgl. vRad, Buch, 15; Braulik, Testament, 5-13; Deuteronomium, 5-8, 12f; Plaut, Deuteronomy, XIXf, XXII, HALLO, ebd. XXVI-XXXIV; mit Betonung des Gesetzbuches MAYES, Deuteronomy, 28, 29f, 33, 41-48.

2 Vgl. KlIne, Deuteronomy, 29, 33, 120; BuIs / LeCLERCQ, Deutéronome, 170f; BraUliK, Testament, 65f, 72; Deuteronomium II, 197f, 210, 212-214.

3 ISER, Akt, 61. LOHFINK, „Fabel,“ 255.
} 
69ba zusätzlich zu dem Bund, מלבד דברית

$69 \mathrm{~b} \beta$ welchen er mit ihnen geschlossen hat am Horeb.

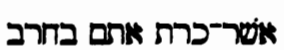

Was ist mit den Worten des Bundes gemeint? Ist der Vers eine Unterschrift unter Dtn 5-28 oder eine Überschrift über Dtn 29ff? m zieht den Vers zu Kapitel 28. Im Kodex Aleppo beginnt z.B. V. 69 nach Dtn 28,68 mit einem neuen eingerückten Absatz. Zwischen 28,69 und 29,1 ist jedoch eine Zeile freigelassen und an den linken Rand in Höhe von 29,1 wurde פרש geschrieben. V. 69 erscheint somit als Unterschrift unter Dtn 5-28 und qualifiziert diesen Text als die Worte, die Mose anläßlich des Bundesschlusses in Moab gesprochen hat. ${ }^{1} \boldsymbol{B}$ dagegen stellt den Vers zum folgenden Kapitel und zählt ihn als 29,1. Er gilt damit als Einleitung zu den Kapiteln 29ff. ${ }^{2}$ Die Zuordnung von 28,69 zum Folgenden wurde in der neueren Forschung maßgeblich, wenngleich über das Ende der mit diesem Vers eingeleiteten Einheit Uneinigkeit herrschte. ${ }^{3}$ Lohfink läßt den folgenden Abschnitt bis 32,47 reichen. Während Kapitel 29-30 einen liturgischen Ablauf andeuten, erweist besonders Dtn 31 den gesamten Text als literarische Kunstform. ${ }^{4}$ Er folgt Kleinert, der schon 1872 auf ein Überschriftsystem hingewiesen hatte, welches das ganze Deuteronomium durchläuft und zu dem Dtn 1,$1 ; 4,44 ; 28,69 ; 33,1$ gehören. $^{5}$

vRooy plädierte dafür, in V. 69 die Unterschrift unter Dtn 1,1-28,68 zu sehen. ${ }^{6}$ Sein Hauptargument war, daß der Ausdruck דברי הברית semantisch

\footnotetext{
${ }^{1}$ Dieser Ansicht folgen in den Kommentaren seit 1938 JUNKER, Deuteronomium, 531f; Penna, Deuteronomio, 236, CAZElles, Deutéronome, 117; CUnlIFF-Jones, Deuteronomy, 160; Rose, 5. Mose, 547f.
}

2 Dieser Sicht folgen Noth, „Fluch,“ 139f/166f; Studien, 29; WRIGHT, „Deuteronomy,“ 312; RIDDERBOS, Boek II, 86; MoRAN, „Deuteronomy,“ 256f, 247; KLINE, Treaty, 129f; vR AD, Buch, 128; WIJNGAARDS, Deuteronomium, 304-314; LAMPARTER, Aufruf, 144 Anm. 1, 146; MAYES, Deuteronomy, 358.

${ }^{3}$ Vgl. Preuss, Deuteronomium, 158f; vRAD, Buch, 128 Anm. 1; SEITZ, Studien, 25; vRooy, „Subscript,“ 219-221. LoHFINK, „Bundesschluß,“ 32/54 Anm. 4, resümiert die ältere Forschung und legt seinen Standpunkt fest: „28,69 ist nicht Unterschrift (so MT, Knobel, Kuenen, Westphal, Valeton, Driver, von Hummelauer, Junker u.a.), sondern Überschrift (so LXX, Ewald, Keil, Schröder, Oettli, Dillmann, Bertholet, Steuernagel, Puukko, Hempel u.a.). (...) Kleinert selbst nimmt an, 28,69 habe ursprünglich vor 27,9 als Überschrift zu 27,9f.; 26,16-19; 28,1-68 gestanden; die Annahme fällt mit ihrer Begründung: „Bund“ müsse die Segens- und Fluchtexte von Dt 28 meinen." KLEINERT, auf den sich LOHFINK stützt, bezieht den Vers also gerade auf Dtn 28.

4 Vgl. „Bundesschluß,“ 52-55/77-81.

5 Vgl. „Bundesschluß,“ 32-35/53-58; „Fabel,“ 69; MoraN, „Deuteronomy,“ 256.

${ }^{6} \mathrm{Vgl}$. „Subscript,“ 222; 220: „If Deut 28,69 should be regarded as a subscript, the question must be posed wether it should be linked to the introduction at the beginning of the book $(1,1-5)$ or to the superscript to the law corpus $(4,44-5,1 \mathrm{a})$. Again the question is not that important, because the section starting at 4,44 is included in the preceding section in both 
Stipulationen, also etwas, das man befolgen soll, und Sanktionen, nämlich Flüche, konnotiert. ${ }^{1}$ Nun enthalten Dtn 29-30 aber keine Stipulationen. Folglich kann 28,69 nur Unterschrift unter das Vorhergehende sein, wo in Dtn 12-26 Stipulationen und in Dtn 27f Segen und Fluch zu finden sind. bezeichnet nach vRooy keine Zeremonie, wie sie in Dtn 29 geschildert ist. ${ }^{2}$ Lohfinks Entgegnung bezweifelte, daß man die semantischen Inhalte an den Belegstellen des Ausdrucks דברי הברית AT auf Dtn 28,69 übertragen könne. ${ }^{3}$

Man kann bei der Zuordnung von V. 69 aber auch anders verfahren. Wright referierte die Gründe dafür, 28,69 zum Vorhergehenden oder zum Folgenden zu ziehen. Er stellte fest, daß beide Ansichten vertretbar sind. ${ }^{4}$ Krämer, Buis, Leclercq und Weinfeld schlugen dementsprechend vor, Dtn 28,69 als Charakterisierung des ganzen Deuteronomiums aufzufassen, das im wesentlichen die Worte enthält, die Mose im Zusammenhang des Bundessschlusses im Lande Moab sprach. Der Vers gilt für das Vorausgehende und für das Folgende und hat eine Brückenfunktion. ${ }^{5}$ Die Brückenfunktion

cases ... . Taking the semantic field of $d b r y$ hbryt into consideration, it is quite evident that Deut 28,69 can funtion as a subscript to the preceding section. Deut 12,1-26,15 comprises of stipulations and Deut 27,22-28,68 a long series of curses (as well as blessings). These correspond to the two facets of the expression dbry hbryt."

1 Vgl. „Subscript,“ $218 f$.

2 Vgl. „Subscript,“ 220f.

3 Vgl. „Überschrift,“ 46-49. Für Dtn 28 relevant wird jedoch vor allem ein anderes gegen vRooy aufgeführtes Argument Lohfinks, das Segen und Fluch von Dtn 28 aus der in Dtn 5,1 beginnenden Moserede in Moab ausschneidet. Das Kapitel 28 gehöre nicht nach Moab, sondern zu einer Anweisung an die Leviten, die in 27,11 beginne und ihnen einen FluchSegen-Fluchtext vorschreibe, den sie in Sichem nach der Landnahme ausrufen sollen. ${ }^{3}$ vRooys semantischer Inhalt von דברי הברית, der Stipulationen und Flüche umfassen soll, wäre in Dtn 5-28 gar nicht vorhanden. Vgl. ebd. 45. Inzwischen akzeptiert Lohfink aber auch die Interpretationsmöglichkeit, derzufolge mit 27,26 die Textanweisung an die Leviten beendet ist, und 28,1 wieder die in Moab versammelten Israeliten anspricht. Vgl. „Moab,“ 146-150.

4 „Deuteronomy,“ 501f. Nach BuIS, Deutéronome, 29, 387, könnte 28,69 einmal die Unterschrift einer Ausgabe des Buches gewesen sein, die sich als ein auf den Sinai folgender Bund präsentierte. Im jetzigen Zusammenhang sei der Vers aber eine Einführung des folgenden Abschnitts.

5 Vgl. Krämer, Numeri, 522; BuIS / LeCLERCQ Deutéronome, 181; WeINFELD, School, 66 68 . 
zeigt sich darin, daß Dtn 28,69 syntaktisch mit Dtn 4,45 verbunden ist. ${ }^{1} \mathrm{Zu}$ dieser syntaktischen Verknüpfung gesellt sich eine lexematische. In 4,45, dem vermutlich ältesten Teil der Überschrift 4,44-49, steht in herausgehobener Position ערות. Dieses Wort kann als hebräisches Äquivalent des aramäischen ' $d n$ / ' $d y$ und des akkadischen adê verstanden werden.' In der ברית Bedeutung „Eid, Vereidigungsinhalt“ wäre es das Pendant zu „Bundesschluß“ in 28,69. In 4,45 genauer definiert durch die folgenden Begriffe „Gesetze und Rechtsnormen“ bezeichnet es wohl die Stipulationen, auf die vereidigt wird, während ברית sich auf die zur Vereidigung gehörende Zeremonie ${ }^{3}$ beziehen dürfte.

Obwohl 28,69 vom Aufbau des Buches her zum Überschriftsystem gehört und Einleitungsfunktion hat, geschieht auf der Ebene der „Fabel“ des Buches ein Rückgriff. In 27,11 steht, daß Mose zum Volk spricht. Es ist also versammelt und hört zu. Kann man damit rechnen, daß es anschlieBend wegging, um in 29,1 wieder versammelt zu werden? Naheliegender scheint es, die Verkündigung der Tora (Dtn 5-28), die bereits zu diesem Zeitpunkt schriftlich vorliegt $(28,58.61)$ und den Bundesschluß, bei dem auf die schriftliche Tora verwiesen wird $(29,19.20 .26 ; 30,10)$, als zusammenhängende Ereignisse innerhalb einer einzigen Versammlung zu sehen. ${ }^{4}$ Dtn 4,45-28,68 und 28,69-30,20 sind sachlich ineinandergeschoben $\mathrm{zu}$ denken. Es handelt sich um thematisch unterscheidbare und deshalb im literarischen Aufbau des Buches getrennte Reden, die Mose auf der einen Versammlung Israels hielt, deren Einberufung in 5,1 und 29,1 vermerkt wird. Der Erzähler nimmt in 29,1 den Erzählfaden von 5,1 wieder auf. ${ }^{5}$ In der Vollversammlung Israels wird der Moabbund geschlossen. Die Zeremonie schließt mit der Einsetzung des Josua $(31,7 \mathrm{f})$. Danach ereignet sich eine Theophanie (31,14-23), es werden Repräsentanten des Volkes

\footnotetext{
${ }^{1} \mathrm{Vgl}$. DeReGT, Model, 58: „28:69a 'lh dbry hbryt These are the words of the covenant (...) 4:45a 'lh $h^{\text {'d }}$ dt whhqym whmšptym These are the testimonies, the statutes and the ordinances." DeREGT stellt die syntaktische Verbindung zwar letztendlich zwischen 4,44a und 28,69 her, weil noch eine Beziehungslinie zwischen 4,44a und 5,1a besteht, die durch den Neueinsatz einer Beziehungslinie zwischen 4,45 und 28,69 gestört würde. Er bezeichnet letzteres aber als ,a possible alternative“" ebd.

2 Vgl. LOHFINK, „„d(w)t,“ 87, 89, 91f; LemaIRE / DuRAND, Sfiré, 91-106;

3 ,Der Ausdruck dibrê habbrît muß ... jene Zeremonie ankündigen und alle die Worte meinen, die mit ihr verbunden sind, also die ,Gesetze', die bedingten Flüche und auch andere Worte. Man könnte dibrê habberît daher mit ,die rituellen Worte des Eides" wiedergeben." BRAULIK, „Ausdrücke,“44/16.

${ }^{4}$ „Die Ritualtexte von 29-30 könnten als solche gar nicht gesprochen werden, wenn nicht in der gleichen Zeremonie auch der Bundestext selbst vorgetragen würde." LOHFINK, „Überschrift,“ 51.

${ }^{5}$ Vgl. LoHFINK, „Fabel,“67, $71 \mathrm{f}$.
} 
einberufen und schließlich gibt es eine weitere Versammlung des ganzen Volkes $(32,44) .{ }^{1}$ Obgleich der explizite Bericht seines Vollzuges fehlt ${ }^{2}$, umfaßt das Bundesschlußritual, welches in 29,9-14 erklärt wird, einen performativen $\mathrm{Akt}^{3}$ Israels. Es soll durch Zeichen der Selbstverfluchung schreiten $(29,11)$. Was aber macht die in 29,11 erwähnten Symbole zu Zeichen der Selbstverfluchung? Was macht aus dem Hindurchschreiten den Bundesschluß? Der performative Akt muß von performativen Worten begleitet werden, die das Tun deuten und somit neue Wirklichkeit schaffen, die es vorher nicht gab. ${ }^{4}$ Nach dem Durchschreiten wird Israel im Bundesverhältnis sein. Nach dem Durchschreiten wird es sich selbst verflucht haben. Was liegt näher, als in den pלות von Dtn 28,16-44 die Verwünschung $\mathrm{zu}$ erblicken, die Mose als liturgischer Leiter der Bundesschlußzeremonie Israel in der 2. Person zuspricht und die es durch den Akt des Hindurchschreitens ratifizierend auf sich bezieht. ${ }^{5}$ In diesem Zusammenhang können durchaus auch die ברכות von Dtn 28,3-14 gesprochen worden sein, denn Segnungen sind wie die Flüche performative Äußerungen. ${ }^{6}$ Wer den Eid leistet, setzt sich den Flüchen aus. ${ }^{7}$ Innerhalb der „Fabel“" gehört Dtn 28 also zu Worten des Mose, die er spricht, während Israel die in 29,9-14 angedeuteten Vereidigungsrituale vollzieht. ${ }^{8}$

1 Vgl. LoHFINK, „Dtn 31-32,“ $269 f$.
2 Vgl. LoHFINK, „Überschrift,“ 49f.

3 ,... I argue, that ceremonies should not be thaught of as accompanying, or reinforcing, the making of treaties and covenants, but as operative, performative elements." HILLERS, „Ceremonies,“ 363.

4 „Austin's pioneering discussion of this aspect of human communication had to do primarily with speech - with 'performative utterances' - but his first example was of a ritual combining word and action: the christening of a ship ('I name this ship the Queen Elizabeth'), surly accompanied by the traditional bottle-smashing. Austin's point about this kind of speech - and I would say, ritual - was that it actually accomplishes what it states." HILLERS, „Ceremonies,“ 359f.

5 ,In den Staats- und Vasallenverträgen sind Eid und Fluchformeln integrale Bestandteile des Formulars. Nach der einleitenden Vorstellung der Vertragspartner und der detaillierten Auflistung der Abmachungen beginnt die meist sehr umfangreiche Eidesklausel mit der Anrufung der Götter zur Zeugenschaft; es folgt oft - nicht immer - der Segenswunsch bei Erfüllung des Vertrages; stets beschließen ausführliche Fluchformeln für den Fall der Vertragsverletzungen den Vertragstext.“ SOMMERFELD, „Flüche,“ 450. Vgl. ASSMANN, „Fluchinschriften,“" 238. Segen, vor allem aber Fluch gehören also zum Eid dazu!

6 Vgl. Mrtchell, Meaning, 7; MULler, „Segen,“6/225; KAISER, „Promise,“ 160.

${ }^{7}$ Als Selbstverfluchung beim Akt des Hinüberschreitens wurde Dtn 29,11 auch in Qumran verstanden. Vgl. FAHR / GLESSMER, Jordandurchzug, 122-126. Zum Unterschied zwischen den Flüchen in Dtn 27 und Dtn 28 vgl. AssMANN, ,Fluchinschriften,“ 233f, 237f.

8 Vgl. LoHFINK, „Fabel,“ 73. 


\section{2. Abgrenzung nach vorne: Dtn 27}

An seinem letzten Lebenstag, von dem das Deuteronomium erzählt, entwickelt Mose eine Fülle von Aktivitäten. Er schreibt die Tora auf, beruft zwei Vollversammlungen Israels ein, betraut Josua mit seiner Nachfolge, erlebt eine Theophanie, notiert und lehrt ein Lied. ${ }^{1}$ Vor allem aber hält er eine lange Rede (Dtn 5,1-26,19), eine Abschiedsrede, in der er zugleich ein Gesetz promulgiert. Außerdem schließt er einen Bund $(28,69)$. Manche Handlungen vollzieht Mose äußerlich sichtbar, z.B. das Aufschreiben der Tora. Vieles aber geschieht nur mit Worten, während und indem er spricht. Es sind gesprochene Handlungen, sogenannte Sprechakte. Doch bei Sprechakten ist nicht immer klar, was tatsächlich getan wird. ${ }^{2}$ Bevor jedoch die Sprechakte des Mose untersucht werden, ist der Anfang der Rede festzustellen, zu der Dtn 28 gehört.

In Dtn 27,12 beginnt Mose, nachdem er zuvor zusammen mit den Ältesten und den Leviten performative Bundeserklärungen $(27,1.9 f)^{3}$ abgegeben hatte, wieder allein zu reden. Diese Rede läuft bis 28,68 durch. Was enthält sie? 27,14-26 umfassen Anweisung und einen zu rezitierenden Text für das Ritual in Sichem. Gehört auch 28,1-68 zu dieser Ritualanordnung für die Leviten, was bedeutet, daß Segen und Fluch erst in Sichem proklamiert würden, oder wandert der Blick in 28,1 wieder zur Moabversammlung, vor der Mose redet? Zwei Antworten sind möglich.

(1.) Dtn 28,1-68 gehört zur Rede der Leviten in Sichem, die in 27,14 beginnt. ${ }^{4}$ Dann spricht Mose nicht Segen und Fluch aus, sondern er fügt einen Bestandteil der Stipulationen hinzu. Er promulgiert einen Ritualtext, der in Sichem zu sprechen sein wird. Dtn 28,69 ist die Einleitung zur Verpflichtungszeremonie in Moab und die Beachtung der gesamten deuteronomischen Tora (Dtn 5-28) wird, von den Segenszusagen ${ }^{5}$ in Dtn 7,12-16; 14,$29 ; 15,4-6.10 .18 ; 23,21 ; 24,19$ und den Flüchen ${ }^{6}$ in 8,$20 ; 11,16 f$ abgesehen, im Moabbund nur motiviert durch den halben Segensvers 30,16b

1 Vgl. LoHFinK, ,Dtn 31-32,“ 270.

2 Vgl. Austin, Sprechakte, 50f, 118-122.

${ }^{3}$ Vgl. LoHFiNK, „Ältesten,“ 31f; „Fabel,“ 70. Diese performativen Erklärungen mit den Ältesten in Vertretung des Volkes $(27,1)$ und mit den Leviten als Stimme JHwHs $(27,9 \mathrm{f})$ entbinden das Volk aber nicht davon, selbst den Bundestext anzunehmen. Dies geschieht im Ritual von 29,11. Vgl. „Fabel,“ $72 f$.

4 Vgl. LOHFINK, „Moab,“ 142-146; KLOPPERS, „Deuteronomium 27,“ 244-245; RosE, 5. Mose, 544-547.

5 Vgl. BERGE, Zeit, 288-296.

6 Vgl. LohFINK, „Überschrift,“ 45. 
und sanktioniert durch die beiden Fluchverse 30,17f. Das wäre für das assyrische Vertragsmodell zwar ungewöhnlich, doch in der Endgestalt des Deuteronomiums kann die Vertragsstruktur sowieso nicht einfach als Schema für den Buchaufbau postuliert werden. ${ }^{1}$ In hethitischen Verträgen sind solch kurze Formeln auch in längeren Vertragstexten zu finden. Jedenfalls stehen Segen und Fluch hinter dem Verpflichtungsakt, den Dtn 29,11 erwähnt. Sie sind damit keine integralen Bestandteile der Selbstverpflichtung, sondern höchstens deren Dramatisierung wie die Flüche in VTE §§ 58-106 nach dem Eid in VTE $\$ 57$.

(2.) Die Moserede springt in 28,1 wieder in die Gegenwart der Moabversammlung und spricht die Israeliten, die zuhören, direkt an. Segen und Fluch in 28,1-68 gehören als Sanktionen zu den Stipulationen in Dtn 527. Dtn 5-28 ist die Tora auf die in Dtn 29-30 zurückverwiesen wird. Dtn 28,69 verbindet das Bundesdokument mit dem Bundesschlußritual. Dtn 30,15-20 enthält weder Segen noch Fluch im Sinne eines Sprechaktes, sondern ermahnende Ausführungen, in denen Israel nochmals aufgefordert wird, das Gute zu wählen.

Lohfink brachte diese alternativen Lösungsmöglichkeiten auf den Punkt und sammelte die Argumente für beide. Er entschied sich dafür, Dtn 28,168 zum Ritualtext der Leviten zu rechnen. ${ }^{2}$ Die Handlungen, die Mose vollzieht, unterscheiden sich je nach Sichtweise. Mose redet (seit 27,11) und spricht performativ, d.h., er handelt, indem er redet. Doch Mose erklärt nicht explizit, was er tut. Seine Rede ist implizit performativ. ${ }^{3}$ Nach Austins Theorie der Sprechakte vollzieht sich in jedem lokutionären Akt, jeder performativen Äußerung, ein illokutionärer Akt. Dieser illokutionäre Akt geht bei der implizit performativen Äußerung aus den gesprochenen Worten nicht direkt hervor, sondern hängt davon $a b$, wie man die Lokution benutzt. ${ }^{4}$ Darüber hinaus wirkt das Wort auch im Hörer. Damit schließt der lokutionäre Akt einen perlokutionären Akt im Blick auf den Empfänger

\footnotetext{
1 Vgl. LoHFink, „Fabel,“ 73f.

2 „Ich neige dazu, Dtn 28 noch als Fortsetzung des Zitats für die Zeremonie in Sichem anzusehen. Doch das ist fast schon eine Gefühlsentscheidung.“LOHFINK, „Moab,“ 150.

${ }^{3}$ Deshalb kann die Klärung dessen, was Mose tut, indem er spricht, nicht auf die Textanalyse von Kapitel 28 verschoben werden. Man kann noch nicht einmal immer konstative von implizit performativer Rede unterscheiden: "Die Kriterien, welche wir ... vorgeschlagen haben, machten sich die Syntax oder das Vokabular ... zunutze. Wir haben gezeigt, daß es sicher kein absolutes Kriterium dieser Art geben kann ... ." AUSTIN, Sprechakte, 88.

4 ,Den Vollzug einer Handlung in diesem neuen, zweiten Sinne habe ich den Vollzug eines »illokutionären« Aktes genannt, d. h. einen Akt, den man vollzieht, indem man etwas sagt, im Unterschied zu dem Akt, daß man etwas sagt ... ." AuSTIN, Sprechakte, 117.
} 
ein. ${ }^{1}$ Mit dem Hörer und Empfänger ist hier nicht ein Leser des Deuteronomiums gemeint, sondem die Mose zuhörenden Israeliten. Es geht um die Kommunikation, von denen die „Fabel“ erzählt, und die sich zwischen Mose und seinen Zuhörem in Moab vollzieht. ${ }^{2}$

Wenn man Dtn 28,1-68 als Fortsetzung der Levitensprüche (27,14-26) auffaßt, ergeben sich Sprechakte des Schemas A:

SCHEMA A:

Akt A Lokution: Mose sagt: ,gesegnet / verflucht bist / seist du ... ."

Akt B Illokution: Mose befiehlt (ein Ritual).

Akt C Perlokution: Mose verbindet die Israeliten mit dem Land, wo Segen oder Fluch ihr Leben bestimmen werden. ${ }^{3}$

Dtn 28 enthält in diesem Fall nicht Segen und Fluch, sondern den Inhalt eines Befehls. ${ }^{4}$ Mose erläßt diesen Befehl vor dem ganzen Volk $(27,11)$. Ausführende der Anweisung werden aber nur die Leviten sein, denn das Volk hat hier nicht mehr wie in 27,12-26 mit „Amen“" zu antworten. Man sollte erwarten, daß die Promulgationssätze in Dtn 28,1.13.14.15 das Volk, welches Mose gemäß 27,11 auch bei seinem Vortrag von Dtn 28 zuhört, wieder' in das היום, "heute“ der Moabversammlung zurückholt. ${ }^{5}$ Der Promulgationssatz in 28,1 markiert, daß der Rezitationstext für Sichem ab-

$1 \mathrm{Vgl}$. AUSTIN, Sprechakte, 118, 124f; WhITE, „Introduction,“ 3: „The fundamental feature of the perlocutionary act is that it refers to an effect upon the receiver (e.g. persuading) achieved by an illocutionary act (e.g. as promising, under the proper conditions, has the effect in its performance, of creating a promissionry relation between two parties).

${ }^{2}$ Kommunikationsvorgänge zwischen Verfasser, Text und Leser, wie sie IsER, Akt, 83-101 nach AUstins Modell der Sprachakte bei der Rezeption literarischer Texte beschreibt, würden eine pragmatische Analyse des Bibeltextes voraussetzen. Es geht in den Ausführungen oben rein um die Handlung in Dtn 28 selbst. Zu den Implikationen der Auffassung, der Text bzw. das Scheiben desselben sei selbst ein Sprechakt vgl. WHITE, „Introduction,“ 4-16; PATTE, „Speech,“" 88-92.

${ }^{3}$ Vgl. LoHFINK, „Moab,“ 151f. Die Ausrufung hypostasierter Segnungen und Flüche im Land verträgt ebensogut Indikativ- und Jussivformen. Ein solch magisches Verständnis selbstwirksamer Flüche, das Gottes Souveränität einschränkt, gehört jedoch eher in eine religionsgeschichtliche Frühphase. Vgl. ScHOTTROFF, Fluchspruch, 50.

4 ,Die Folge für den Endtext ist allerdings, daß in ihm auch Dtn 28 durch ויצו eingeleitet wird.“" LOHFINK, „Moab,“ 145.

${ }^{5}$ Es überzeugt nicht, wenn LoHFINK, „Moab,“ 145, schreibt, „nach Jos 8:34f hat Josua in Sichem die ganze Tora, also auch die Paränese und Gesetze, wörtlich vorgelesen. Daß also ein im ,Ich" des Mose formulierter Text auch nach Moses Tod ohne Ausmerzung seiner mosaischen Ich-Merkmale vorgetragen werden konnte, ist zumindest noch Jos 8 kein Problem." Wieso soll es ein Problem sein, wenn aus dem Deuteronomium vorgelesen wird? Das Problem besteht darin, daß die Israeliten entsprechend der nach LoHFINKs Auffassung in 27,11 grundgelegten „Fabel" ab 28,1 Mose vom „heute" sprechen hören und darunter anders als zuvor im Deuteronomium - „Sichem“ verstehen sollen. 
geschlossen ist und kehrt zur direkten Anrede der Israeliten zurück. Auch nach dem Gebet, das Mose in Dtn 26,13-15 vorschreibt, zeigt das exponierte היום in 26,16 die Rückkehr zur direkten Anrede der Zuhörer an. So scheint es angemessen, das Levitenritual mit 27,26 als beendet zu betrachten. Lohfinks Vorschlag, die Ritualanweisung weiterlaufen zu lassen, zwingt, zur Erklärung der Rückverweise auf Toraflüche in Dtn 29-30 mit dem noch nicht promulgierenden Vortrag als Ritualanweisung sowie der Verschriftlichung von 28,1-68 im ספר התורה, der Bundesurkunde, in Moab und dann noch mit der promulgierenden Rezitation in Sichem zu operieren. Das ist die kompliziertere Hypothese gegenüber der Auffassung, daß Dtn 28,1 in die Moabversammlung zurückkehrt.

Sieht man also in Dtn 28 direkt an Israel gerichtete Worte des Mose, so stellt sich die Frage nach seinen Sprechakten neu. Gehört Dtn 28 zu einem Deuteronomium, das als Gesetz, Landschenkungsurkunde oder Predigt verstanden wird, so ergeben sich Sprechakte des Schemas B:

SCHEMA B

Akt A Lokution: Mose sagt: „gesegnet / verflucht bist du .... “"

Akt B Illokution: Mose drängt (zum Halten der Gebote) und warnt (davor, sie zu übertreten).

Akt C Perlokution: Mose weckt (im Idealfall) die Neigung zum Gehorsam und ein Zurückschrecken vor der Übertretung der Gebote.

Schema B ergibt sich auch, wenn man das Deuteronomium als Vertrag betrachtet und Segen und Fluch im Indikativ übersetzt. Mose warnt. Segen und Fluch stellen nur paränetisch dramatisierend das Schicksal des untreuen Vertragspartners heraus. Sie sind kein integraler Bestandteil des Vertragsabschlusses, genauso wie die Flüche im Epilog von Gesetzen oder Landschenkungsurkunden kein integraler Bestandteil der Gesetzespromulgation oder der Schenkung sind. ${ }^{2}$ Es gibt im AO auch Gesetze und Landschenkungsurkunden ohne Flüche.

Mit der Mahnung ist der Aspekt der Information verbunden. Segen und Fluch sind hier nicht der Sprechakt des Mose, sondern der Inhalt seiner Mitteilung. Mose stellt in einer konstativen Äußerung ${ }^{3}$ das zukünftige Schicksal Israels dar, das an die Bedingung von Gehorsam oder Ungehorsam gebunden ist. ${ }^{4}$ Der Inhalt von Dtn 28 kann somit auf eine göttliche

${ }^{1}$ Die Kombination von Gesetz, oder Predigt mit Flüchen in Wunschform scheint bei Mose als Sprecher unsinnig, da er kaum Interesse haben dürfte, Israel zu verwünschen.

2 Vgl. AssmanN, „Fluchinschriften,“ 241.

3 Vgl. AuSTIN, Sprechakte, 150-161.

${ }^{4}$ Gegen AssmaNN, „Fluchinschriften,“ 240, 252f, der monumentalen Inschriften wie Kudurrus, Testamenten und Denkmälern einen impliziten Vertragscharakter zuschreibt sei 
Offenbarung an Mose zurückgehen, in der JHWH ihm seine zukünftigen Belohnungs- oder Bestrafungsvorhaben mitgeteilt hätte. Man kann dann davon sprechen, daß JHWH das Subjekt von Segen und Fluch ist, insofern er Israel mit dem Segen beschenkt $(28,8)$ und durch den Fluch züchtigt $(28,20){ }^{1}$

Etwas anderes geschieht, wenn man Segen und Fluch mit Wunschformen übersetzt:

SCHEMA C:

Akt A Lokution: Mose sagt: ,gesegnet / verflucht seist du ... “

Akt B Illokution: Mose segnet und verflucht.

Akt C Perlokution: a) Mose schützt die zukünftige Rezeption seiner Tora oder b) Mose vereidigt Israel, d.h. er läßt sie Segen und Verwünschung auf sich beziehen und zusammen mit den Vertragsstipulationen als Vertragssanktionen ratifizieren.

Nur in diesem Fall enthält Dtn 28 tatsächlich Segen und Fluch im Sinne performativer Sprechakte des Mose. ${ }^{2}$ Dann können die ברכות und pלות in Dtn 28 nicht als Gotteswort angesehen werden. JHWH kann nicht durch den Mund des Mose sein eigenes Eingreifen herbeiwünschen. Vielmehr ist Dtn 28 Menschenwort, genauer Mosewort. Für tatsächliche Segnung und Verwünschungen kann Mose nur zwei Gründe haben. Vielleicht wollte er seine Tora, die nach 27,8 zum Denkmal werden soll, als sein Vermächtnis an Israel schützen. ${ }^{3}$ Dagegen spricht allerdings, daß in Dtn 28 nicht die Tora selbst geschützt wird, sondern die darin enthaltenen מצות משת ח die zu befolgen nichts anderes bedeutet, als JHWH zu gehorchen $(28,1.15 .58)$. Der Gehorsam Gott gegenüber stellt aber den Inhalt des Moabbundes dar.

der dialogale Aspekt des Vertrages betont. Kein Vertrag kommt zustande, wenn der Vertragspartner nicht zustimmt. Der zukünftige Leser einer Inschrift wird aber nicht gefragt, ob er dem Text und den Verhaltensnormen zustimmt, die Segen und Fluch an ihn herantragen. Dieser Zug beherrscht aber „das Gottesbild, so wie es uns in den Rahmenpartien des Deuteronomiums entgegentritt ... . Hier wird ein - mittels Mose - mit Israel argumentierender und um es werbender Gott vorgestellt, der das Volk für sich zu gewinnen sucht ... , um seine Zustimmung für ein künftiges Leben mit und unter ihm zu erlangen." SCHÄFER-LICHTENBERGER, „Autorität,“ 127.

${ }^{1}$ Mose sagt das Verhalten JHwHs voraus. Der Charakter solcher Äußerungen bleibt mehrdeutig: „Ist eine Voraussage über das Verhalten anderer Leute wirklich eine Feststellung? Es ist wichtig, die Äußerungssituation als ganze zu betrachten." AusTIN, Sprechakte, 157.

2 „Moses selbst verflucht das Volk und verweist auf ,den Herrn, Deinen Gott“ als den Agenten der Bestrafung.“ ASSMANN, „Fluchinschriften,“ 234.

3 „Die Fluchformeln sind dazu gedacht, diese Rezeption in die richtigen Bahnen zu lenken. Sie sind meta-textuell, indem sie die Rezeption des ,Textes' steuern. Hier liegt der gemeinsame Nenner zwischen Verträgen und Denkmälern." ASSMANN, „Fluchinschriften,“ 246. 
So wird es sich in Segen und Fluch tatsächlich um eine Segnung und Verwünschung handeln, die Mose über Israel ausspricht, während es den in 29,11 angedeuteten Vereidigungsritus vollzieht. Mose gleicht einem Liturgen, der zu einem rituellen Akt Dritter die deutenden Worte spricht, welche zusammen mit deren rituellen Handlungen performativ Wirklichkeit setzen. Nachdem er Dtn 28 gesprochen hat, ist Israel gesegnet und verflucht!

Auch die VTE legen diese Interpretation nahe. Die 1. Fluchsektion (VTE § 37-56) enthält Verwünschungen, in welchen die Adressaten in der 2. Person angesprochen werden. Im Eid (VTE § 57) werden die Stipulationen, die Verhaltensforderungen, mit den Sanktionen, den Flüchen, zu einer Einheit verbunden und akzeptiert.

Die vorliegende Untersuchung rückt den Blickwinkel der Vereidigung Israels in Rahmen des Bundesschlusses im Lande Moab in den Vordergrund. Es wird sich jedoch zeigen, daß Mose in Dtn 28 nicht nur segnet und flucht, nicht nur vereidigt. Einige Passagen des Kapitels lassen sich besser als Feststellung oder Warnung deuten. Der Blick auf Dtn 28 wird so differenzierter. Eine solche Mehrschichtigkeit ist möglich, weil Dtn 28 vor allem Bestandteil einer Rede des Mose ist. Im Rahmen dieser Rede kann er verschiedene illokutionäre Akte setzen.

In der Kontextbestimmung nach vorne folgt die Arbeit jenen Forschern, die mit Dtn 26,16 den Beginn des Bundesschlusses ansetzten und Dtn 28 in eine inhaltlich-narrative Einheit einbezogen, die bis Dtn 30,23 reicht. 28,1 schließt logisch an 26,19, bzw. die performativen Erklärungen in 27,1.9f an. ${ }^{1}$ Eingeschoben sind auf der Ebene der Endredaktion in Dtn 27 verschiedene Exkurse mit Ausführungsbestimmungen für die Zeit nach der Landnahme, die zu den Stipulationen gehören.

Das folgende Kapitel handelt vom Inhalt des Begriffes „Fluch“ und beleuchtet, inwiefern die Mehrdeutigkeit dieses Wortes unterschiedliche Interpretationen von Dtn 28 hervorrufen kann.

\section{3. Wann ist ein Fluch ein Fluch?}

Der Inhalt von Dtn 28 wird zumeist mit den Begriffen „Segen“ und „Fluch“ umschrieben. Was wird impliziert, wenn die gängigen Übersetzungen und Kommentare die in $\mathbb{k}$ stehenden Begriffe mit „Segen“ und

\footnotetext{
1 "Alle zwei Deklarationen haben weder mit Torainschrift und sichemitischem Altarbau noch mit einer zukünftigen Segen-Fluch-Zeremonie bei Garizim und Ebal noch mit einem אור -Ritual etwas zu tun. Sie führen vielmehr das Ende von Kapitel 26 fort und das SegenFluch-Kapitel 28 herauf.“ LoHFINK, „Ältesten,“ 38. „Zugleich spricht nichts dagegen, schon an eine älteste, vermutlich joschijanische deuteronomistische Schicht zu denken.“ Ebd. 39.
} 
„Fluch“, „,blessing“ und „curse“ wiedergeben?1 ${ }^{1}$ Sobald das Bedeutungsspektrum der Begriffe in der Zielsprache abgeklärt ist, wird nach dem Bedeutungsrahmen der in 28,1 und 28,15.45 verwendeten Worte ברכה und קללה fragt, um zu entscheiden, inwiefern „Segen“ und „Fluch“ eine adäquate Weise darstellen, die hebräische Terminologie von Dtn 28 zu übersetzen. Da in der Gegenüberstellung von 28,1 und 28,15.45 קללה genauso als Gegenbegriff zu ברכה verwendet wird, wie in den Übersetzungen „Fluch“ als Gegenstück zu „Segen“ steht, beschränkt sich die folgende Wortuntersuchung auf die Begriffe קללה, ,Fluch“ und „curse“. Mitchell und Müller haben Untersuchungen zum Segen vorgelegt. Mitchell sah sich in ähnlicher Weise mit der Problematik konfrontiert, definieren zu müssen, was einen Segen eigentlich zum Segen macht. ${ }^{2}$

Der Bedeutungszusammenhang des deutschen Wortes „Fluch“ mit der Verwünschung, wie sie Grimms Wörterbuch (1854) angibt, bildete die Grundlage der Besprechung altorientalischer Flüche, die durch Verben im Prekativ oder Jussiv fast immer als Wünsche des Fluchenden zu erkennen sind. ${ }^{3}$ Die deutschen Wörterbücher kennen drei Verwendungsmöglichkeiten des Begriffes „Fluch“: (1.) im Zorn gesprochenes Kraftwort, (2.) ausgesprochener Unheilswunsch, (3.) Strafe, Unheil. ${ }^{4}$ Der Unheilswunsch

${ }^{1}$ Der MICROROBERT, 637, (1978) unterscheidet für das französische malédiction zwei Bedeutungen: „MALEDICTION ... $1^{\circ}$ Littér. Paroles par lesquelles on souhaite du mal à qqn. (en appelant sur lui la colère de Dieu, etc.). Condamnation au maleur prononcée par Dieu. II Contr. Bénédiction. II $2^{\circ}$ Maleur auquel on semble voué par la destinée, par le sort. ...Malédiction qui pèse sur qqn. II Contr. Bonheur, chance. I"“ Es wird zwischen dem menschlichen Fluch als Wunsch und dem göttlichen als Urteilsspruch unterschieden. Wie im Deutschen kann das Wort für „Fluch“" aber auch das Unheil selbst meinen. Zum Nomen קללה bemerkt LEVĖVRE „Malédiction,“ Sp. 747, 750, (1957) nur, daß es das von der Wurzel ארר abgeleitete מארה fast ganz verdrängt habe. Malédiction könne zum Synonym für Beraubung und Elend werden. Dementsprechend übersetzen die alten Versionen מארה mit $\varepsilon v \varepsilon เ \delta \varepsilon \alpha$, $\alpha \pi \circ \varrho \iota \alpha$, fames, egestas und penuria (Dtn 28,20; Spr 3,33; 28,27). Beim Bund erhielten Segen und Fluch den Charakter von Sanktionen.

2 Vgl. Mrtchell, Meaning, 165. Den Segen von Dtn 28 rechnet er zu den Covenantal Blessing Promises, ebd., 33-44. D.h. Mose spricht keinen Segen, sondern Versprechungen aus. Indem er Dtn 28 im Kapitel God Blessing Man behandelt, zeigt er, daß er seinen Inhalt als göttliche Offenbarung versteht. Gott selbst gibt die blessing promises, ebd. 36. MÚLLER dagegen sieht in Segen und Fluch ,ursprüngliche Zauberhandlungen“. „Segen,“ 8/227. Es ist „,der Mensch, dessen Wirkwort Gott zum Geber einer von ihm unterschiedenen Gabe macht“, ebd. 14/233. Dtn 28 bezeichnet er als „Segens- und Fluchfolgen am Ende von Gebotssammlungen", ebd. 17/236.

${ }^{3}$ Vgl. GRIMM, Wörterbuch, Sp. 1827.

${ }^{4} \mathrm{Vgl}$. Duden II, 867. Vgl. WAHRIG, Wörterbuch, 487. Die 3. Bedeutung muß keineswegs auf einen zuvor ausgesprochenen Fluch zurückgeführt werden. Es meint einfach: ,3. ... furchtbare Strafe ... ."Wörterbuch der deutschen Gegenwartssprache II, 1325. Vgl. Brockhaus-Enzyklopädie VII, 399. Einen zusätzlichen Aspekt nennt MACKENSEN, 
stellt einen Menschen oder eine Sache unter die Macht der Gottheit. ${ }^{1}$ Nimmt man die Verwendung als Schimpfwort heraus, scheint das Hauptgewicht im Gebrauch des deutschen Wortes den Wunsch zu implizieren, daß der Fluchinhalt zumindest unter den gegebenenfalls hinzugefügten Bedingungen tatsächlich Wirklichkeit wird. „Fluch“ synonym mit Strafe Gottes oder Unheil zu gebrauchen, scheint dem gegenüber sekundär, entspricht aber der aus altorientalischen Texten erarbeiteten Vorstellung, daß der Fluch der Gottheit einem Urteilsspruch gleichen kann und zur malefactio wird. ${ }^{2}$

Im Blick auf Dtn 28 lautet demnach die Frage: Versteht man das Wort „Fluch“ in der Fiktion der Moserede als performativen Sprechakt (Verwünschung) oder als deskriptive Feststellung (Unheilsbeschreibung), bzw. auf der Textebene als Gattungs- oder Inhaltsangabe ${ }^{3}$ Der folgende Überblick über Veröffentlichungen zum Thema „Fluch“ zeigt, daß die Mehrdeutigkeit des Wortes nicht immer beachtet wird.

In der Magie primitiver Religion sah Hempel (1925) die Wurzeln des Segnens und Fluchens auch im AT. ${ }^{4}$ Magische Selbstwirksamkeit gehört nach Hempel zur 'ārûr-Formel, der eigentlichen israelitischen Fluchformel. Aus dieser Formel habe sich das Rachegebet entwickelt, welches das Unheil nicht mehr selbst herbeiwünscht, sondern von Gott erfleht. Dazwi-

Wörterbuch, 765: „Fluch ... (Selbst-)Verwünschung; zorniges Kraftwort; ... Gotteslästerung; ... Gottesstrafe ... ."

1 Vgl. Brockhaus-Enzyklopädie VII, 399. „Die Ausgangsbedeutung ist wohl ,stoßen, schlagen'; daraus die deutsche Bedeutung (vgl. einen Fluch ausstoßen) und in einem anderen Bild , die Hände zusammenschlagen' im Englischen ... . Das germanische Verb geht zurück auf *pläg- ,schlagen" in l. plangere ,schlagen, an die Brust schlagen, trauern ' ... ." KLUGE, Wörterbuch, 223.

2 Man findet in der exegetischen Literatur Verwendungen des Wortes „Fluch“, die durch keine der drei Bedeutungsnuancen gedeckt sind, die die deutsche Sprache besitzt. Hier fragt man sich, was das Wort dann bedeuten soll. LoHFINK, „Bundesschluß,“41/63, schreibt z.B. zu Dtn 29,19: „Auch war der abschließende Fluch von V. 19 nur ein untergeordnetes Element innerhalb der Predigt 29,15-19 ... . In der Predigt 29,15-19 werden weder Kraftwort noch Verwünschung ausgesprochen. Das Wort Weigerung Gottes zu verzeihen. Es wird also kein Fluch ausgestoßen, sondern höchstens über den Fluch im Sinne göttlicher Strafmaßnahme gepredigt. Dann geht es hier aber nicht um einen „abschließenden Fluch“, sondern um die Erwähnung der Fluchwirkungen im Zusammenhang einer paränetischen Strafdrohung.

${ }^{3}$ Die gleiche Alternative sah MrTCHELL beim Segen: „Human blessings like God's blessings can consist of either a speech act (benediction) or a bestowal of material goods (benefaction). Benedictions can be either declarative or optative." Meaning, 79.

4 Vgl. „Anschauungen,“ 20, 26f: „Mit dem Zauber teilen Segen und Fluch die unbedingte, unwiderrufliche Auswirkung. Der Segen, den Jakob sich erschlichen, kann ihm nicht wieder genommen werden. Die Flüche von Dtn. 28 erfüllen sich; auch die Bekehrung des Josia vermag das Unheil nur hinauszuschieben, aber nicht abzuwenden (2 Reg. 22,19).“ 
schen stehe die Wunschform des Fluches. ${ }^{1}$ Die 'ārûr-Formel werde außer in Jos 6,26 und 1 Sam 26,19 nicht als Aufforderung an Gott formuliert. Damit unterscheide sich der israelitische Fluch von den Flüchen anderer semitischer Sprachen, in denen die Götter zum Verfluchen aufgefordert werden. ${ }^{2}$ Lev 26 ist im Gegensatz zu Dtn 28 nicht als Segen und Fluch, sondern als Verheißung von Gaben und Androhung von Strafen zu verstehen. ${ }^{3}$ Mit dieser Unterscheidung zwischen Lev 26 und Dtn 28 zeigt Hempel bereits einen Blick für Differenzierungen, die Erkenntnisse der Textlinguistik und Sprachphilosophie im Rahmen der Textpragmatik oder der performativen Sprechakte vorwegnimmt. ${ }^{4}$ Obwohl er nicht die hebräischen Begriffe einzeln untersucht, sondem das Phänomen des Fluches im AT allgemein erforschen will, verwendet Hempel das deutsche Wort sorgfältig. Seine Abgrenzung des Fluches vom Prophetenwort zeigt, daß für ihn zum Fluch ein Element des Willens im Sinn der Ver=wünschung gehört. Der Prophet, der JHWHs Unheilsdrohung auszurufen hat, flucht nicht, weil ihm das Interesse am Eintreffen des Unheils fehlt. ${ }^{5}$

Bei der Suche nach den rechten deutschen Wörtern, um das hebräische קללה wiederzugeben, ging Scharbert (1958) von den Ausdrücken „(ver)fluchen“, „,verwünschen“, „Fluch“, „Verwünschung“ aus ${ }^{6}$ und behandelte die möglichen hebräischen Äquivalente. Die Wurzel pל hat in allen semitischen Sprachen die Bedeutung ,leicht, klein, unbedeutend, gering, verächtlich sein"?. Für die Belege des Verbs im Pi'el und Pu'al geht er von der Grundbedeutung aus und findet meistens den Sinn ,schmähen“, „höhnen“. Fluchen oder Verwünschen bedeutet das Verb in Schimpfreden unter Berufung auf die Gottheit. ${ }^{8}$ Das Substantiv קללה übersetzt Scharbert

1 Vgl. „Anschauungen,“ 66.

2 Vgl. „Anschauungen,“ $68 \mathrm{f}$.

3 ,Für den alten Israeliten ist nun selbstverständlich Jahve der Gott, dessen Segen er erfleht und dessen Fluch er fürchtet. Auch wo, wie in Lev. 26 im Gegensatz zu Dtn. 28, an die Stelle des Segens und Fluches die Verheißung von Einzelgaben und die Androhung von Einzelstrafen getreten sind, ist es Jahve allein, der sie vollstreckt oder verleiht, ... ." HEMPEL, „Anschauungen,“ 71. Vgl.vRAD, Deuteronomium-Studien, 7/109, 17/119.

/ Es ist nicht dasselbe, ob jemand sagt: wenn du das tust, werden / sollen folgende קלות über dich kommen (Dtn 28); oder: wenn du das tust, werde ich folgendes tun (Lev 26).

5 Vgl. „Anschauungen,“ 81 .

6 Vgl. „Fluchen,“ 1.

7 Vgl. ,Fluchen,“ 8-10.

8 „Fluchen,“ 11. Weitere Stellen der Bedeutung mündliches oder schriftliches Fluchwort: Dtn 11,29; 23,6; 27,13; 30,1.19; Jos 8,34; Ri 9,57; Spr 26,2; 27,14; Neh 13,2. Vgl. ebd. Anm. 1. 
mit „Fluch“. Der Sinn „Beschimpfung“ sei höchstens in 1 Kön 2,8 auszumachen. Dtn 28,15.45 stellt er zu den Belegen für die Verwendung des Nomens im Sinne eines mündlich ausgesprochenen oder schriftlich niedergelegten Fluchwortes. ${ }^{1}$ Die Konsequenzen für das, was Mose in Dtn 28 tut, bleiben unerwähnt. Spricht er wirklich einen Fluch aus? Das wäre performative Rede! Jemand, der ein Fluchwort ausspricht, flucht! Ein Problem sieht Scharbert nur in der Metonymie, die קללה mit einer Person oder einem Ort identifiziert. Hier bedeutet das Wort nach Scharbert das schreckliche Schicksal. ${ }^{2}$ Ohne es explizit zu machen, wandert Scharbert bei der semantischen Festlegung der hebräischen Terminologie von der deutschen Verwendung des Wortes „Fluch“ im Sinne der „Verwünschung“ zur Bedeutung „Unheil““. ${ }^{3}$

Im biblischen Teil des LThK-Artikels über „Fluch“ unterscheidet Pax (1960) den göttlichen vom menschlichen Fluch. Von Gott her ist der Fluch Ausdruck seines Zorns, schließt aus seiner Gemeinschaft aus oder ist Strafandrohung im Fall des Bundesbruchs (Jer 11,3). Bei Gott wird also nicht von Verwünschung gesprochen, sondern die Bedeutung Strafurteil oder Unheilsdrohung hervorgehoben. Auch beim menschlichen Fluch ist öfters nicht zu entscheiden, ob ein Wunsch oder eine auf die Zukunft bezogene Drohung vorliegt. ${ }^{4}$

Für vImschoot (1968) gründete bei den Israeliten die Macht von Segen und Fluch wesentlich in Gott. JHWH kann seinen Segen dem menschlichen Fluch entgegenstellen (vgl. Dtn 23,6). Das Eintreffen des Fluches hängt im AT von der Schuld des Verfluchten ab und trifft nur nach dem Willen Gottes ein. Dadurch verliert der Fluch in Israel seinen magischen Charakter. $^{5}$

Keller (1978) übersetzt die Nomina der Wurzel pל pל mit „Schmähung“ (q'alālah) und „Schande“ (qülālōn). קללה kommt am häufigsten im Deuteronomium (elfmal) und in Jeremia (neunmal) vor. Von der Grundbedeutung ,leicht sein“ entwickelte sich die Bedeutung der Wurzel oppositionell zu כבד schwer sein“. Nur unter dem Gesichtspunkt, daß die Verächtlichmachung, Verwünschung und Beschimpfung das Gegenteil zum „bārûk-

1 „Fluchen,“ 8. Zwei weitere Bedeutungen des Wortes קללה, nämlich Unheil bringende Potenz und das Unheil selbst, lokalisiert er in anderen alttestamentlichen Stellen.

${ }^{2}$ Vgl. „Fluchen,“ 12. Als Stellen dafür gibt er Dtn 21,23; 2 Kön 22,19; 42,18; 44,8.12; Sach 8,13; Jer 26,6; 44,22; 49,13 an. Vgl. ebd. Anm. 4, 5.

3 ,Fluchen,“ $13 \mathrm{f}$.

${ }^{4} \mathrm{Vgl}$. „Fluch, Sp. 182. TRE und RLA verweisen unter dem Stichwort Fluch auf das Stichwort Segen. Die Bände zum Buchstaben $S$ sind jedoch noch nicht erschienen.

5 Vgl. „Fluch,“Sp. $486 f$. 


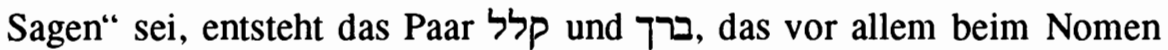

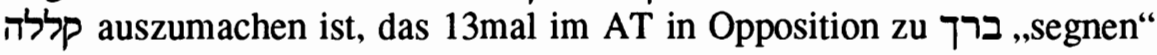
erscheint. ${ }^{1}$ Fluch impliziert auch für Keller die Verwünschung. Das Zusammenspiel von einem vorgefaßten Textverständnis und den unterschiedlichen deutschen Wiedergabemöglichkeiten von pללה zeigen Kellers Be-

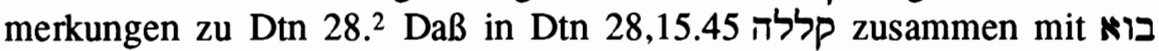
„kommen“ verwendet wird, bedeutet seiner Meinung nach, daß die Verwünschung sich erfüllt. ${ }^{3}$ Doch wer ver=wünscht in Dtn 28 ? Wer hat das zur Verwünschung gehörende Interesse, wenn er die 'ārûr-Formel spricht, an der Keller die Verwünschung festmacht? Obwohl die Formeln von Mose gesprochen werden, sieht Keller in JHWH den eigentlichen Autor des Fluches in Dtn 27-30. Die in dieser Deutung implizierten Anschauungen über das Zusammenspiel von Mose und JHWH, die Wertung der Flüche als Gesetzesflüche des Recht satzenden Souveräns und damit die Entscheidung über die Gattung des Deuteronomiums überhaupt, werden weder erwähnt noch begründet. Dtn 28 wird so, ähnlich wie der Fluch im KH, zur Verwünschung durch den Gesetzgeber, der das Interesse hat, daß seine Flüche Wirklichkeit werden, sobald der Rechtsadressat seinen Normen zuwiderhandelt. ${ }^{4}$

Wieder deutlicher in Verbindung mit der magischen Vorstellung einer materialisierten Schadensmacht sieht Schottroff (1991) den Fluch im AT. Weil der Fluch in sich selbst wirksam war, sei die 'ārûr-Formel ursprünglich im Modus des Indikativs zu denken. Der Fluch ist somit kein Wunsch, sondern ein Machtwort. Die Unterstellung des Fluches unter JHWH als Vollstrecker sei eine nachträgliche Entwicklung, die parallel zur Verwendung der Fluchwünsche in der polytheistischen Umwelt Israels ablaufe. ${ }^{5}$ Lev 26,14-38 und Dtn 28,15-68 versteht Schottroff als Fluchkataloge nach altorientalischem Vorbild, die wiederum den Hintergrund für Unheilsdrohungen der Propheten bildeten. Wenn er Dtn 28,16-19 im Indikativ über-

\footnotetext{
1 Vgl. „קלל,“'Sp. 645: „Im Dtn werden alle 'ärūr-Sprüche, d. h. Verfluchungen für den Fall des Ungehorsams, im Ausdruck $q^{e} l a \overline{l a}$ zusammengefaßt (Dtn 11,26.28.29; 27,13;28,15.45; 29,$16 ; 30,1.19$; Jos 8,34) und (außer Dtn 29,26) der $b^{e} r a \bar{k} \tilde{a}$ entgegengesetzt."

2 Vgl. ,קלק," Sp. 642-654.

3 Vgl. ,קלק," Sp. 645.

4 „Die Überzeugung, daß Jahwe »verächtlich machen, verwünschen« könne, liegt auch der dtn. Rede vom Fluch ( $\left.q^{2} l a \bar{l} \bar{a}\right)$ zugrunde, den Jahwe seinem Volke vorlegt, und der sich im Falle des Ungehorsams erfüllen werde (Dtn 27-30; 11,26ff.)." Keller, ,pל," Sp. 646.

5 „Die von Hause aus indikativische F.-Formel wandelt sich damit zum F.-Wunsch und zur F.-Bitte.“ SCHOTTROFF, „Fluch,“ Sp. 683.
} 
setzt, scheint er dort noch das Konzept des selbstwirksamen Fluches zu sehen. ${ }^{1}$

Obwohl er nicht von Sprechakten redet, differenziert Scharbert (1993) beim „Fluch“ zwischen ausgesprochenem Wort und Sachverhalt. Beide Bedeutungskomponenten sind auch im hebräischen pללה zu finden. Es kann das gesprochene Fluch=Wort bezeichnen, aber auch das in dessen Folge ausgelöste Unheil. In Dtn 28,1-13.15-45 sieht er Segens- und Fluchworte, woraus zu schließen ist, daß er בכרה tatsächlich als Gattungsbegriffe versteht. ${ }^{2}$

Die englische Sprache zeigt ähnliche Mehrdeutigkeiten. Crawley definierte (1911) curse und blessing als den ausgesprochenen Wunsch, daß jemandem Übles oder Gutes geschehe. Wenn dieser Wunsch von einem Gott oder Geist ausgesprochen werde, sei es Wunsch, Wille und Faktum in einem. ${ }^{3}$ Er führte also auch den göttlichen Fluch auf den Wunsch zurück, der Wunsch ist aber zugleich Wirklichkeit. Das primitive Denken lasse die Grenzen verschwimmen zwischen Gedanke, Idee, Wort, Handlung und mechanischer, psychischer und sprachlicher Macht. Daher bekommen Segen und Fluch einen energiegeladenen Selbstand. ${ }^{4}$ Bedingter Fluch sei eine übernatürliche Energie, die in einem latenten Zustand gehalten werde, solange bis die Handlung geschehe, gegen die er gerichtet sei. Ordal und Eid beruhen auf dem Konzept des bedingten Fluches. ${ }^{5}$

Mercer (1915) erklärte den englischen Begriff malediction fast mit denselben Worten, die Crawley für curse fand. ${ }^{6}$ Allerdings nahm Mercer nur das menschliche Subjekt in den Blick und verband das Wort eng mit dem Eid.

\footnotetext{
${ }^{1}$ Vgl. ,Fluch,“ Sp. 683f.
}

2 „Ebenso sind ... habberākăh we haqqe läläh ... die in 28,1-13.16-45 verzeichneten Segensund Fluchworte; mitgemeint sind aber zweifellos die dadurch ausgelösten Heilsgüter bzw. Unheilsfolgen." SCHARBERT, ,לי," Sp. 45.

3 Vgl. ,Cursing,“ 368.

${ }^{4}$,The indeterminate character of primitive thought makes interchange easy between thought, idea, word, and act, and also between mechanical, psychical, and verbal force. Thus a curse or blessing may be regarded now as a spirit, now as a thing, now as a word, but in each case it is charged with energy. Or, again, it may be regarded as travelling along a material or psychical conductor or as embodied in a material object, its ernergy then being potential, ready to become kinetic when discharged." CRAWLEY, ,Cursing,“ 368 .

5 Vgl. „Cursing,“ $372 \mathrm{f}$.

6 ,A malediction is the praying down of evil upon a person, and implies the desire or threat of evil declared either upon oath or in the most solemn manner.“ MERCER, „Malediction,“ 282. 
Blank untersuchte (1950/51) curse weniger inhaltlich als vielmehr formal. Meistens impliziere das Wort einen Wunsch. ${ }^{1}$ Dtn $28,16 \mathrm{ff}$ rechnete er zu den composite curses, die Gott zugesprochen werden. Er sah also in JHWH das eigentliche Subjekt bzw. den Urheber von Dtn 28,16-68. Allerdings unterschied Blank, ob der Inhalt des göttlichen curse angegeben wird oder ob nur Bezug nehmend auf ihn verwiesen wird. In letzteren Fällen sei nicht klar, ob Gott tatsächlich Worte ausspreche (Gen 12,3; Dtn 11,26-29; 30,19; Mal 2,2; Spr 3,33). Beim Menschen liege das Hauptgewicht auf dem als wirksam gedachten Wort, bei Gott dagegen auf der wirksamen Aktion. ${ }^{2}$ Den biblischen Eid bestimmte Blank als bedingten Fluch. Gott sei beim Eid involviert als derjenige, der den bedingten Fluch Wirklichkeit werden läßt. ${ }^{3}$

Auch für Gevirtz (1962) stellte der Fluch ursprünglich den Wunsch dar, Böses möge jemanden oder etwas befallen. ${ }^{4}$ Flüche begegnen im AT als abschreckende oder strafende Maßnahme, in Selbstverfluchungen besonders im Zusammenhang mit Eiden, als Gottesfluch, und schließlich als Vertragsflüche in Verträgen zwischen Menschen (Ri 21,18), sowie in der feierlichen Annahme des göttlichen Willens durch die Israeliten (Dtn 27,15-26; 28,15-19.20-36; Ri 9,15). ${ }^{5}$ Bemerkenswerterweise betrachtete er die Fluchsequenzen von Dtn 27f unter dem Aspekt der Aktivität Israels. Im Rahmen der angeführten Texte ratifizieren die Israeliten Gottes Vertragsbestimmungen. ${ }^{6}$

In seiner Untersuchung des Nomens קללה ging Brichto (1963) von der Mehrdeutigkeit des englischen curse aus. Es bedeute (1.) das Herbeirufen von Bösem oder Übel, (2.) das Übel, welches aufgrund dieser Herbeirufung komme und (3.) Böses und Unglück überhaupt. ${ }^{7}$ Brichto betonte die Verwirrung, die entstehen kann, wenn man einen mehrdeutigen Begriff wie קללה durch ein Wort übersetzt, das ebenfalls vieldeutig ist. Ein Mißverste-

1 ,The curse occurs in the Bible in three forms: (I) the simple curse formula, (II) the composite curse, and (III) curses freely composed. Forms I and II are, for the most part, profane wishes; form III usualy has the character of imprecatory prayer." BLANK, „Curse." 73.

2 Vgl. „Curse,“ 79.

3 Vgl. „Curse,“ $87,89$.

4 Vgl. „Curse,“ 749.

5 Vgl. „Curse,“ 749. Er vermutet, daß es in Israel auch Königsinschriften und Gräber gegeben habe, die durch einen Fluch geschützt waren.

6 „The curses were designed to protect the terms of contract by being directed at the future violator of the treaty. In the OT this appears in ... Israel's acceptance of the suzerainty of Yahweh (Deut. 27:15-26; 28:15-19, 20-36) ... ." GEVIRTZ, „Curse,“ 749.

7 Vgl. Problem, 180. 
hen der Intention und des Inhalts des untersuchten Textes ist die Folge. Der semantische Gehalt von קללה lasse sich auch nicht vom Qal oder Pi'el des Verbs ableiten. Seine Bedeutung erhalte das Wort meistens durch seine Gegenposition zu ברכה. Doch dieses Wort bedeute weniger eine mündliche Äußerung, sondern eher im materiellen Sinn ein gutes Schicksal, Freiheit von Bösem und Glück. Auch pללה sei ursprünglich materiell zu verstehen. Daher unterschied Brichto drei Bedeutungsebenen, in denen das Wort begegnen kann. ${ }^{1}$ Zuerst behandelte er die Stellen im AT, wo das Wort nicht im Sinn von Verwünschung verwendet wird. Es bedeute Strafe, Unglück oder Desaster (Dtn 11,26-29; Jos 8,32-34; Dtn 27,12f; 28,15.245; 29,16; 30,1.19); Beschimpfung, Denunziation und Verunglimpfung (2 Sam 16,12 und 1 Kön 2,8); in Jer 24,9 Unglück. In Spr 26,1 trete קללה in Gegenposition zu כבד und bedeute Schande, während es in Spr 27,14 Beschimpfung heiße. Dtn 21,22f schließlich enthält die Verbindung קללת אלדים im Sinne einer Beleidigung Gottes. ${ }^{3}$ Tatsächlich eine Verwünschung bezeichnet קללה nach Brichto in Dtn 23,6; Ri 9,56f (vgl. Ri 9,7-20); Jer 29,22; Sach 8,13 . In Ri 9,56f wird קללה synonym zu אלה, der bedingten Verwünschung, verwendet. ${ }^{4}$

Altorientalische Flüche lieferten Lewis, Harrison (1980) und Stuart (1992) den Hintergrund für die Behandlung des biblischen curse. Nach Stuart diente der Fluch zur Verstärkung der Bundesbestimmungen im Gesetz des Mose. Die Flüche seien Warnungen vor dem, was Gott tun werde, wenn Israel sündigt. ${ }^{5}$ Göttlicher Fluch wirkt nach Stuart, einmal angekündigt, automatisch, sobald der Mensch dessen Eintrittsbedingungen erfüllt. ${ }^{6}$

\footnotetext{
1 Vgl. Problem, 180-182.

${ }^{2}$ Dtn 28 bewertet er als ,,admonitions ... detailing the blessings attending obedience and the

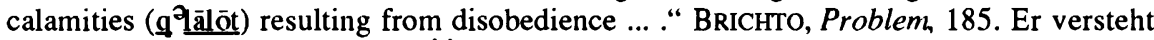
Dtn 28 also als Ermahnung und pל im Sinn von Katastrophen.
}

$3 \mathrm{Vgl}$. Problem, 182-195.

4 Vgl. Problem, 195f. In Gen 27,12-13; 2 Kön 22,19; Jer 25,18; 26,6; 42,18; 44,8.12; Ps $109,17 \mathrm{f}$ kann die verbale Äußerung der Verwünschung ebenso gemeint sein wie materielles Unglück. Vgl. ebd. 197-199.

5 Vgl. Lewis / Harrison, „Curse,“ 837f. STUART, „Curse,“ 1218: „Leviticus 26 and Deuteronomy 28-32 contain the sanctions portions of the covenant structure relative to their respective statements of the Law, and in these passages much is made of the many types of curses that will attend the Israelites if they abandon the covenant. Twentyseven types of curses are found in these contexts, representing virtually all the miseries one could imagine occurring in the ancient world ... . Such curses are warnings of what God will cause to happen to Israel if they sin."

6 ,When a divine curse has been announced as generally applicable ... violators of the warning automatically bring upon themselves the miseries implied in the curse (Deut 28:15; Zech 5:1-4; 2 Chr 34:24).“ STUART, „Curse,“ 1218. 
Eine mögliche Weise, pללה $^{1}$ in Dtn 28,15.45 zu verstehen, hat Brichto genannt. Es bezeichne Unglück, Katastrophe in materiellem Sinn und sei eingebunden in eine Ermahnung und prophetische Ankündigung. Bei der Wiedergabe durch das deutsche „Fluch" wäre also die Bedeutung „göttliche Strafe“ gemeint. ${ }^{2}$ Diese Auffassung scheint auch hinter den modernen Übersetzungen zu stehen, die Dtn 28 im Indikativ wiedergeben. Es handelt sich dann um Sachaussagen. Potentielle Zukunft wird beschrieben. Mose erhält die Rolle des Propheten. Gerade diese Sicht stößt jedoch auf Probleme, betrachtet man sie auf dem Hintergrund des altorientalischen Vertragsformulars. Dort besitzen die Flüche den Charakter von Verwünschungen. Ist die Verschiebung von Verwünschung zur Strafankündigung ausreichend damit erklärt, daß in der Bibel der Vertragspartner zugleich die Gottheit ist, die das Unheil verhängt, während im AO der menschliche Bündnispartner erst um göttliche Sanktion bitten muß?3

Sieht man im „Fluch“ schlimmes Schicksal infolge eines Fluchspruches, so kann Dtn 28,15-68 im magischen und automatischen Sinn verstanden werden, den Schottroff und Stuart ansprechen. Gott hätte irgendwann einmal - vielleicht am Horeb - Fluchsprüche ausgesprochen. Diese bedingten Verwünschungen wurden zu selbständigen Wirkmächten, die warten, bis sie durch den Eintritt ihrer Bedingung wirksam werden können. Gott gäbe in dieser Sicht ein Stück seiner Souveränität auf zugunsten selbständig handelnder Wirklichkeiten, die anschließend sogar ihn selbst zum Handeln zwingen. ${ }^{4}$ Mose trägt so keine prophetischen Unheilsverheißungen vor, sondern informiert die Israeliten über ihre Situation. Das Damoklesschwert der bereits potentiell existierenden Fluchmächte schwebt über ih-

1 „Fluch“, curse, malédiction für pללד bieten sich zunächst für die Übersetzungen an, weil der Übersetzer sich nicht entscheiden muß, ob das Wort im Sinne verbaler Verwünschung oder materiellen Unheils verwendet wird. Die Mehrdeutigkeit des hebräischen Originals setzt sich in die Übersetzungen fort. Dies kann einer ursprünglichen Intention des Verfassers entsprechen, der vielleicht das mehrdeutige hebräische Wort wählte, um mehrere Verständnismöglichkeiten offen zu lassen.

2 Vgl. ähnlich zu ברכה MrTCHELL, Meaning, 41.

3 „In den Verträgen und Gesetzen ist jedesmal ,der Herr des Bundes` ein anderer als die jeweiligen ,Herren der Flüche“. Das drückt sich in der jussivischen Fassung der Vertragsflüche aus. In Israel ist Jahwe der Geber der im Dt niedergelegten Ordnungen und Gesetze, die Mose nur in dessen Namen verkündigt, und zugleich ist Jahwe dieselbe Gottheit, die die Flüche sendet. Der Herr des Vertrags oder der Gesetze hat also ein unmittelbares Verhältnis zu Segen und Fluch. Das legt eine indikativische Übersetzung der Verbalformen nahe auch an den beiden defektiv geschriebenen und von den Massoreten (sic!) als Jussiv punktierten Stellen v. 21 und v. 36." SEITZ, Studien, 279.

${ }^{4}$ JHWH ist das Subjekt in Dtn 28,20.21.22.24.25.27.28.35.36.49.59.60.61.63.64. 65.68. Gott würde also von der selbständig kommenden $(28,15)$ pל pals Akteur mitgebracht. 
nen. Auch unter diesem Gesichtspunkt kommt Dtn 28,15-68 keine Funktion nach dem altorientalischen Vertragsformular $\mathrm{zu}$.

Betrachtet man sämtliche Belege von pללה im AT, läßt sich Dtn 28,15.45 auch ein anderes Verständnis finden. In beiden Versen wird das Wort mit dem Demonstrativpronomen verbunden. Es handelt sich also nicht um irgendwelche pללות, sondern um bestimmte. Das Demonstrativpronomen kann nun auf eine Liste von Katastrophen im Sinne Brichtos deuten. Es kann aber auch, wie Scharbert andeutete, eine Angabe über die Textsorte der dazwischen stehenden Verse sein. In der Moserede von Dtn 27,11-28,68 wäre damit das, was in Dtn 28,16-44 steht, ein Textsegment, welches zur Redegattung קללה im Sinne der Verwünschung gehört. Dtn 28,16-44 enthielte damit keine Unheilsbeschreibungen, sondern eine Reihe von Verwünschungen, die Mose tatsächlich ausstößt. Die Verse wären nicht der Sachverhalt, sondern der Text der pללות im Sinne von Sprechakten. In diesem Fall kann man zum Vergleich die beiden einzigen Stellen im AT heranziehen, wo ebenfalls der Text einer pללה mitgeteilt wird: Ri 9,20 und Jer 29,22.

Ri 9,20 wird von Jotam gegen Abimelech ausgesprochen. In Ri 9,56f wird das Eintreffen der קללה Jotams konstatiert und auf Gottes Wirken zurückgeführt:

So ließ Gott das Verbrechen, das Abimelech an seinem Vater begangen hatte, als er seine siebzig Brüder umbrachte, auf ihn selbst zurückfallen. Auch auf die Einwohner von Sichem ließ Gott alles Böse, das sie getan hatten, zurückfallen. So kam über sie der Fluch Jotams, des Sohnes Jerubbaals.

Jotam stellt seiner Verwünschung einen bedingten Segen voran (Ri 9,19f).

Wenn ihr also heute treu und redlich an Jerubbaal und seinem Haus gehandelt habt, dann sollt ihr eure Freude haben an Abimelech, und er soll seine Freude an euch haben. Wenn aber nicht, dann soll Feuer von Abimelech ausgehen und die Bürger Sichems und Bet-Millos fressen. Und von den Bürgern Sichems und von Bet-Millo soll Feuer ausgehen und Abimelech fressen.

Die konditionalen Einleitungen ähneln Dtn 28,1f.15 ebenso wie die Zusammenstellung von Segen und Fluch. Allerdings geht es in dieser Verfluchung nicht um einen Bundesschluß. Gott wird überhaupt nicht genannt. Es handelt sich schlicht um einen bösen Wunsch. Ri 9,57 sieht in dessen Verwirklichung aber dennoch Gottes Handeln, so daß auch in Ri 9,20 ein Appell an Gottes Wirken impliziert sein dürfte. ${ }^{1}$

\footnotetext{
${ }^{1}$ Die Einheitsübersetzung stellt in Ri 9,19+20 das Verb in die Wunschform. $m$ hat in V. 19

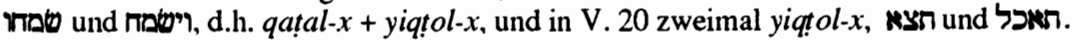


Jer 29,22 gehört zu einem Drohwort gegen die falschen Propheten Ahab und Zidkija. Die קללה wird nur in einer Nebenbemerkung genannt, um die Strafe Gottes zu beschreiben. Das Unheil, das die Lügenpropheten trifft, ist so schlimm, daß andere Menschen in ihren Verwünschungen auf die beiden falschen Propheten verweisen werden: ${ }^{1}$

Dann wird man bei allen Verschleppten Judas, die in Babel sind, von ihnen das Fluchwort herleiten: Der Herr mache dich Zidkija und Ahab gleich, die der König von Babel im Feuer rösten ließ. ${ }^{2}$

Die Verwünschung beginnt mit der Anrufung JHWHs und ähnelt damit den altorientalischen Flüchen unter Nennung der Gottheit. Eine Bedingung für das Eintreten der Verwünschung wird nicht genannt. Es gibt keinen Zusammenhang mit einem Bundesschluß.

Die „Verwünschungen“ in Dtn 28,16-44, die von der Gattungsbezeichnung pללות umschlossen sind, dürften jedoch zum Vertragsabschluß gehören. Der Text bekommt die Funktion der impliziten Selbstverwünschung Israels durch die Teilnahme an der Bundeszeremonie unter Ratifizierung der Vertragsstipulationen (Dtn 5-26) und der Sanktionen (Dtn 28). Mose trägt Verwünschungen vor, die das Volk im Bundeseid auf sich bezieht. ${ }^{3}$ Sollte Dtn 28,16-44 Verwünschungen enthalten, müßten die Verben der für Israel negativen Aussagen in der Wunschform begegnen. Genau dies ist in $\mathfrak{m}, \boldsymbol{O}$ und $\mathcal{D}$ der Fall. Es muß also eine Tradition gegeben haben, die Aussagen in Dtn 28,16-44 als Wünsche verstand, sie also als Verwünschungen betrachtete. Diese Interpretationslinie führte in prämasoretischer Zeit dazu, in $\mathfrak{G}$ Verben der Abschnitte 28,7-14.20-36 in den Optativ zu setzen. ${ }^{4}$ In protomasoretischer Zeit veranlaßte sie Hieronymus in seiner Vulgata, in

\footnotetext{
1 „Das bedeutet: Wenn man jemanden verflucht, wird man ihm dasselbe Schicksal wünschen, wie es Zidkija und Ahab erfahren haben. Die Formel entspricht der Wendung ,zu einem Segen werden/machen'... ." SCHARBERT, ,pל," Sp. 45.

2 Wieder übersetzt die Einheitsübersetzung im Konjunktiv. In hat prow, d.h. yiqtol-x.

3 ,Curses could accompany any sort of covenant, as part of the oaths made to bind all parties. Individuals who then broke such covenants would be subject to the curses they had agreed to in binding themselves to the covenant (Judg 21:18; Neh 10:29; cf. Matt 26:74; Acts 23:12)." STUART, .Curse,“" $1218 f$.

${ }^{4}$ „Form vv. 7 through 36 optatives are used whenever God is the subject ... ." WEVERS, Text, 83. Für die Unterscheidung prämasoretisch, protomasoretisch und masoretisch vgl. BARTHÉLEMY, Project, VIf. Prämasoretisch entspricht dort dem ,earliest attested text" ebd. VII, aus der zweiten Phase der Entwicklung des hebräischen Textes.
} 
Dtn 28,20-35 Verben im Konjunktiv zu verwenden. ${ }^{1}$ In masoretischer Zeit schließlich bewirkte sie die Punktation von Jussivformen in Dtn 28,8.21.36. ${ }^{2}$ Mit V. 36 hören die Wunschformen auf. Sie finden sich also nur in dem als קללות (V. 15.45) bezeichneten Abschnitt. In IT und 6 stehen sie auch in der ברכה. Für diesen Moduswechsel, den die ältesten Traditionen innerhalb von Dtn 28 vornehmen, muß es einen Grund geben. Es spricht alles dafür, daß man 28,1.15 tatsächlich als Angabe der Textsorte des folgenden Abschnitts verstanden hat, und somit in 28,16-44 Verwünschungen sah. ${ }^{3}$

Einen indirekten Hinweis auf diese Zusammenschau von Fluch und Schwur in hellenistischer Zeit liefert Dan 9,11. Daniel erklärt die Bedrängnisse Israels folgendermaßen:

Ganz Israel hat dein Gesetz übertreten und ist abgewichen, indem es nicht auf deine Stimme gehört hat. So hat sich denn der Fluch und Schwur (דאלה והשבעה), der im Gesetze Moses, des Knechtes Gottes, geschrieben steht, über uns ergossen, weil wir wider Gott gesündigt haben.

Der Ungehorsam gegenüber der Stimme JHWHs erinnert an Dtn 28,15.45. Auffälliger ist die Kombination דהאלה ודשבעה FFluch und Schwur“, die in der, dורת משדה, dem ,Gesetz Moses“, geschrieben stehen., שבועה ", kommt im Pentateuch, dem weitesten Bereich der Tora des Mose, nur in Gen 24,8; 26,3; Ex 22,10; Lev 5,4; Num 5,21; 30,3.11.14 vor. Niemals ist im Pentateuch die Rede davon, daß ganz Israel gegenüber Gott einen

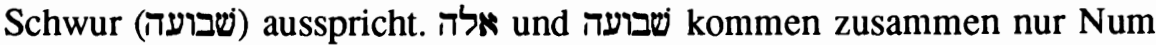
5,21f im Eifersuchtsordal vor:

... der Priester also soll das Weib den Fluch schwören lassen, indem er zu ihr sagt: Der Herr mache deinen Namen zum Fluch- und Schwurwort unter deinem Volke, indem er deine Hüfte schwinden und deinen Leib anschwellen lässt, und

\footnotetext{
${ }^{1}$ Dtn 28,21 adiungat, 22 percutiat, persequatur, 23 sit, 24 det, 25 tradat, 26 sitque, sit, 27.28 percutiat, 29 dirigas, sustineas, 30 accipias, dormiat, aedifices, plantes, immoletur, comedas, rapiatur, reddatur, dentur, sit, 32, tradantur, sit, comedat, sis, 35 percutiat; ab V. 36: Verben im Indikativ Futur.

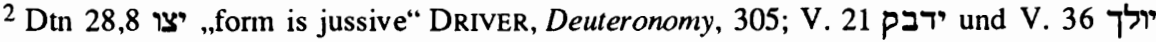
,pointed as jussive“" ebd. 308, 312.

${ }^{3}$ Die Optativformen in $\boldsymbol{B}$ können nicht theologisch begründet werden, weil man etwa Gottes Wirken modal vom menschlichen Tun trennen wollte. Dann dürfte nämlich in Dtn 28,49.59.64.65.68 nicht Indikativ Futur stehen, denn auch dort ist xv@เo S Subjekt. Der Modus ändert sich innerhalb von Dtn 28. Es kann auch nicht eine griechische Konvention zur Formulierung von Flüchen die Ursache für den Optativ sein. Dann müßte das ganze Kapitel den gleichen Modus aufweisen. Der Moduswechsel zeigt, daß sich für die Übersetzer von $\boldsymbol{B}$ der Charakter der Aussagen zwischen 28,16-44 von denen nach V. 45 unterscheidet. Zu griechischen Flüchen in Stiftungen und Gesetzen vgl. RiES, Prolog, 99 Anm. 84. Zu Segen und Fluch in griechischen Eiden und Verträgen vgl. WEINFELD, „Heritage,“ 187-189.
} 
dieses fluchwirkende Wasser dringe in deine Eingeweide, dass der Leib anschwelle und die Hüfte schwinde! Und das Weib soll sprechen: So geschehe es! So geschehe es! ${ }^{1}$

Der Priester läßt die Frau schwören, so lautet die Einleitung. Es folgt aber kein Eid, den die Frau zu sprechen hätte, sondern der Priester stößt eine Verwünschung gegen die Frau aus. Die Frau beantwortet den Fluch des Priesters mit Amen und bezieht ihn damit auf sich.2

Das zweite Wort in Dan 9,11, אלה, wird nur in Dtn 29-30 auf Israel bezogen. Es bezeichnet das Hindurchschreiten durch Tierhälften im Rahmen der Vereidigung. Wiederum ist kein Eid angegeben, den Israel auszusprechen hätte. Aber auch Mose spricht keine אל, die der Äußerung des Priesters in Num 5,21 gleichkäme. Die Aussagen des Mose werden vielmehr קללה genannt. Im ganzen Pentateuch gibt es also weder ausgesprochene שבועה noch eine niedergeschriebene אלה, die über das Volk kommen könnten. ${ }^{3}$ Es wird in Dan 9,11 offenbar auf die Ereignisse angespielt, um die es in Dtn 27-30 geht. Schwur und Fluch wären nach Num 5,21 die Verwünschung des Vereidigten durch eine autorisierte Person, die den Vereidigten in der 2. Person anredet, sowie die Annahme dieser Verwünschung durch einen Zustimmungsakt des Vereidigten. Derartiges steht in Dtn 27,14-26. Doch fehlen hier die Ausdrücke אלה und שבועה. Es scheint daher berechtigt, Dan 9,11 als eine Anspielung auf den Bundesschluß in Moab zu verstehen. Er bestand aus einer verwünschenden Anrede durch Moses und einer Zustimmung Israels, die im Ritual von Dtn 29 angedeutet wird. Doch wo steht im Pentateuch eine aufgeschriebene Verwünschung Israels durch Mose? Dafür kommt nur Dtn 28,15.16-44.45 in Betracht. קללה wäre synonym zu אלה verwendet, was nach Brichto durchaus möglich ist. ${ }^{4}$ Deshalb wird die Arbeitsübersetzung in Dtn 28,3-14.16-44 Wunschformen verwenden und sowohl ברכה als auch ptn 28 als Bestimmung von Sprechakten (segnen, verfluchen) verstehen.

\footnotetext{
${ }^{1}$ Die Lexemverbindung zwischen Dan 9,11 und Num 5,21f ist in der Zürcher Bibel (1942) treuer wiedergegeben als in anderen Übersetzungen. Deshalb wurde sie hier zitiert.

2 Vgl. vdToorn, Sin, 46f, 54, 76.

${ }^{3}$ Niedergeschrieben im Pentateuch als Tora des Mose findet sich weder ein Schwur שבועה noch ein Fluch אלה, מללות (Dtn 28,15.45; 29,16) im Wechsel mit הלה (Dtn 29,11.13.18.19.20).

4 Vgl. Problem, 195f, 198.
} 


\section{EXEGESE VON DTN 28}

Die Fülle der Analyseergebnisse in dem langen Kapitel 28 fordert eine Gliederung der Präsentation. Zur Grobeinteilung von Dtn 28 bietet es sich an, formale Kriterien zu verwenden. So findet man gleichgebaute Einleitungs- bzw. Schlußsätze mit fast identischen Formeln (28,1f.15.45f), die bärûk - und 'ārûr-Reihen (28,3-6.16-19), den Segensabschnitt (28,7-14), einen ersten Fluchteil (28,20-44), der von der V. 15 korrespondierenden Formel V. 45 abgeschlossen wird, und einen zweiten Teil des Fluchabschnitts (28,47-68). Da im Blick auf die Parallelen zu den VTE vor allem der Fluch interessiert, wird die Exegese des Kapitels nicht nach der Abfolge der großen Abschnitte in Dtn 28 dargestellt, sondern nach den Einleitungs- und Schlußsätzen gleich 28,20-44 besprochen, in dem sich die Bezüge zu den VTE befinden. Es folgt dann 28,47-68 und erst im Anschluß daran kommen die bārûk- und die 'àrûr-Formeln und der Segen an die Reihe. Damit ist am Ende das ganze Kapitel besprochen und es kann eine redaktionsgeschichtliche Zusammenschau versucht werden.

Bei jedem Unterabschnitt werden zuerst Text und Übersetzung in der Satzeinteilung von Richters BHt geboten. Die Benennung der Versteile folgt jedoch der masoretischen Einteilung (a $\alpha \beta \ldots$...b $\alpha . .$. ), damit eine terminologische Übereinstimmung mit der bisherigen Forschung zu Dtn 28 gewährleistet ist.

Nach der Textkritik setzt der traditionelle exegetische Methodenkanon die Literarkritik an. ${ }^{1}$ Doch neuere Vorschläge wollen die Literarkritik erst nach der synchronen Analyse durchführen. ${ }^{2}$ Bei der hier vorgelegten Bearbeitung ging die synchrone Analyse der diachronen voraus. Die bisherige Forschung zu Dtn 28 betonte aber vor allem den diachronen Aspekt. Es empfiehlt sich daher, in der Darstellung der Arbeitsergebnisse die diachrone Fragestellung der Literarkritik zusammen mit der Forschungsgeschichte abzuhandeln und erst danach die Ergebnisse der synchronen Untersuchungsschritte vorzustellen. Nur bei den Unterkapiteln zu 28,47-68 und 28,7-14 wird die synchrone Analyse vor die Behandlung der Diachronie gestellt, weil sich die hier vorgelegten Thesen zur diachronen Schichtung der Abschnitte auch auf Beobachtungen der synchronen Betrachtung stützen.

${ }^{1} \mathrm{Vgl}$. FOHRER, Exegese, 25f.

2 Vgl. EGGER, Methodenlehre, 25f, 74, 160f; WILLMES, „Exegese,“ 72-74. 
Die synchronen Untersuchungen bestehen aus sprachlich-syntaktischer und semantischer Analyse. ${ }^{1}$ Semantik wird als Wortsemantik durchgeführt, die nach der Bedeutung hervorstechender Ausdrücke und Wendungen fragt. ${ }^{2}$ Die Traditionsgeschichte beleuchtet anschließend vor allem den altorientalischen Hintergrund jeder Untereinheit von Dtn 28.

\section{1. Dtn 28,1 fowie 15 und $45 f$}

$\mathrm{la}_{1} \quad$ Und es wird geschehen,

$\mathrm{la \alpha}_{2 \mathrm{f}}$ wenn du gehorsam hörst auf die Stimme Jhwhs, deines

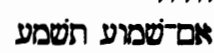
Gottes,

$1 \mathrm{a} \beta_{1} \quad$ indem du alle seine Gebote hältst בקול יהוה אלדהיך

1a $\beta_{1.2}$ und ausführst, ${ }^{3}$

1a $\gamma$ auf die ich dich heute verpflichte, lb dann wird JHWH, dein Gott, dich hoch über alle Völker der Erde erheben,

$2 \mathrm{a} \alpha$ und es werden alle diese Segnungen über dich kommen,

$2 a \beta \quad$ und dich erreichen

2b wenn du auf die Stimme JHWHs, deines Gottes hörst.

לשמר לעפות אתדכלדמצותיו אישר אנכי מצוך היום ונתנך יהוה אלהיך עליון על כלגויי הארץ עליץ כלדכות האלה כי תשמע בקול יהוה אלהיך

$15 \mathrm{a} \alpha_{1} \quad$ Und es wird geschehen,

$15 \mathrm{a \alpha}_{2 \mathrm{f}} \quad$ wenn du nicht hörst auf die Stimme JHWHs, deines Gottes,

$15 \mathrm{a} \beta_{1} \quad$ indem du alle seine Gebote und Gesetze [nicht] hältst

$15 \mathrm{a} \beta_{1.2}$ und ausführst,

15a $\gamma$ auf die ich dich heute verpflichte, $15 \mathrm{~b} \alpha$ dann werden אםלא תשמע בקול יהוה אלהיך

\footnotetext{
${ }^{1}$ Auf eine pragmatische Analyse wurde verzichtet, weil sie außertextliche Komponenten wie das Verfasser-Leserverhältnis und den Verwendungszweck einbezieht. Vgl. EgGER, Methodenlehre, 134, 136, 138. In vielen derartigen Fragen des Deuteronomiums dürften nur schwer konsensfähige Ergebnisse zu erzielen sein. Vgl. ROMER, „Book,“ 210.

2 Vgl. Kedar, Semantik, 33-50, 70-82, 98-113, 118-121. Andere Verfahren wie Textsemantik, narrative Analyse, Komponenten- und Wortfeldanalyse würden den Rahmen der Arbeit sprengen. Vgl. EGGER, Methodenlehre, 93-128.

${ }^{3}$ Der Infinitiv constructus hat die Bedeutung eines Gerundivs, das den Gedanken erklärt. Vgl. MilleR, „Construct,“" 224.
} 
alle diese Verwünschungen über dich kommen,

$15 \mathrm{~b} \beta \quad$ und dich erreichen.

$45 a \alpha_{1} \quad$ Und es werden ובאו עליך כלדהקלות האלה alle diese Verwünschungen über dich kommen,

$45 \mathrm{aa}_{2}$ und dich verfolgen,

$45 \mathrm{a}_{3}$ und dich erreichen

$45 \mathrm{a} \beta$ bis du vernichtet bist,

$45 \mathrm{~b} \alpha \quad$ denn du hast nicht auf die Stimme JHWHs, deines Gottes, gehört,

$45 \mathrm{~b} \beta \quad$ dadurch, da $\beta$ du seine Gebote und Gesetze [nicht] gehalten [hast],

$45 \mathrm{~b} \gamma \quad$ auf die er dich verpflichtet hat.

46 Und sie werden zum Zeichen und zum Wunder an dir und an dei-

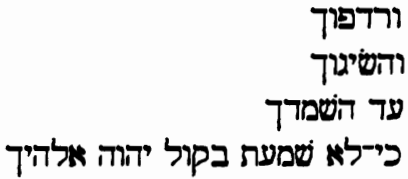

לשמר מצותיו וחקתיו

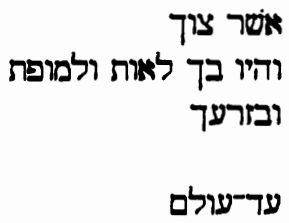

\subsubsection{Textkritik}

$1 \mathrm{a} \alpha$ ] außer 10 B 848, $426 b$ lat cod 100, Arm und $100 \mathfrak{U}$, die die ganze Passage auslassen, fügen die anderen 6 -Zeugen aus 27,2 hinzu: $\omega \varsigma$ $\alpha v \delta\llcorner\alpha \beta \eta \tau \varepsilon$

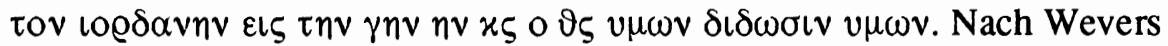
ist dies eine sekundäre Erweiterung des ursprünglichen $\boldsymbol{B}$-Bestandes, wo

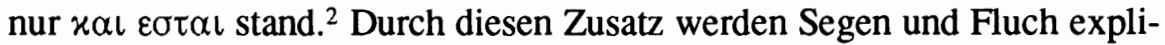
zit im Land lokalisiert. Vielleicht wollte man in der ägyptischen Diaspora den Geltungsbereich von Dtn 28 auf Palästina einschränken. ${ }^{3}$

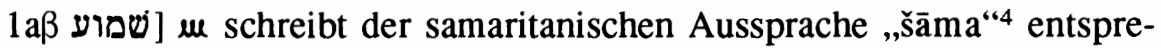
chend שמעy.

${ }^{1}$ Die Übersetzung ,Samen“ statt Nachkommen soll die lexikalische Berührung mit den altorientalischen Nachkommenschaftsflüchen verdeutlichen.

$2, \ldots$ Rahlfs in failing to follow the text of B was misled into accepting a lengthy expansion." WEVERS, „Attitude“, 504; vgl. Text, 122; DOGNIEZ / HARL, Bible, übersetzen die Rahlfs-Edition (vgl. ebd. 100) und geben in 28,1 auch die sekundäre Erweiterung aus 27,2 wieder.

${ }^{3}$ Zur Lokalisierung der LXX in Ägypten vgl. DognIEZ/ HARL, Bible, 19, 29.

${ }^{4}$ BEN-HAYYIM, Tradition, 145. 


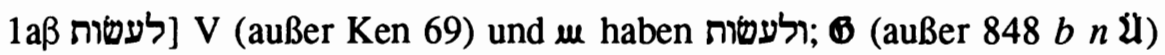
bietet $x \alpha \mathrm{l}$. Die asyndetische Verbindung scheint lectio difficilior zu sein. ${ }^{1}$ 1b גו In wenigen Handschriften und dem $\mu$ steht der Sg. Die Versionen übersetzen jedoch alle den Pl. Es handelt sich wohl um einen Schreibfehler.

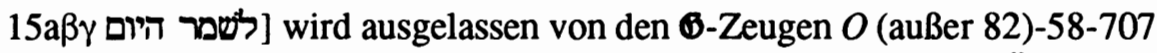
$b$ 106(mg) $n$ (außer 75') 85mg t18'-120-630' 407 LatLuc Athan I 8 ü Co Syh 71. Dies ist eine Abweichung innerhalb der Textüberlieferung von $\boldsymbol{G}$, denn die Handschriften haben für das enklitische Personalpronomen von im Plural $v \mu \omega v,{ }^{2}$ so daß der Blick des Schreibers von dort zu on $\mu \varepsilon \varrho o v$ gesprungen sein könnte.

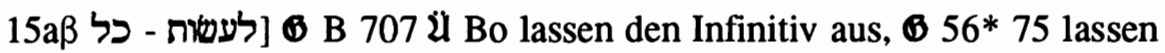
$\pi \alpha \sigma \alpha \varsigma$ aus, $\$ d$ (außer 106mg) und $\mu$ lassen die ganze Passage aus. Das von $\mu$ weggelassene Stück beginnt und endet mit einem ל. Die Auslassungen der griechischen Manuskripte beruhen wohl auf dem Einfluß gleichartiger Formulierungen des Deuteronomiums. $B$ (außer F) setzt vor den Infinitiv xal. Wie in 28,1 scheint die asyndetische Verbindung ursprünglich.

$15 a \beta$ וחקת VKen 69 wenige Manuskripte und 6 lassen das Wort wahrscheinlich aufgrund eines Homoioteleuton aus. ${ }^{3}$ Die in 4Q 42 / 4QDeut ${ }^{\circ}$ erhaltenen Passagen aus V. 15 stimmen mit $m$ überein. ${ }^{4}$

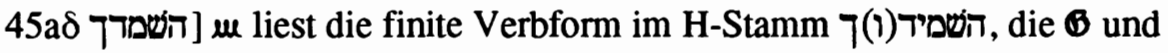
$\boldsymbol{L}$ übersetzen. ${ }^{5}$ Dagegen erscheint der Infinitiv des $\mathbf{N}$ - Stammes in $\mathfrak{l l}$ als lectio difficilior. Die Infinitive in $\mathfrak{m}$ bereiten allen Übersetzern Schwierigkeiten. $\mathcal{D}$ und $\mathcal{C O}$ paraphrasieren mit der 2. Person Sg. Aktiv donec intereas bzw. Passiv עד התישחתיצ' (šssy/hitpe'al „,beenden“). Solche übersetzungsbedingten Umwandlungen von Infinitiven in finite Verben werden im folgenden nicht mehr angeführt, es sei denn, $\mu$ bezeugt die finite Form als

1 Ploger, Untersuchungen, 140, und SeITZ, Studien, 261 Anm. 30, plädieren für die Kopula. Doch לעמות stehen im Deuteronomium nur noch 15,5; 28,13.15 und 32,46 unmittelbar beieinander. Außer in 28,13 fehlt immer die Kopula. Für jede dieser Stellen gibt es Textzeugen, die die Kopula bieten. 15,5: VKen 92 Mss w65; 28,15: VKen 69 pc Mss $B$ außer BFmin D; 32,46: pc Mss m65D. Bei 28,13 sind jedoch keine Zeugen angegeben, die die Kopula auslassen. Es bestand also eher die Tendenz, die Kopula zu ergänzen, als sie fortzulassen.

2 Vgl. WeVERs, Text, 11.

${ }^{3} \mathrm{Vgl}$. PLOGER, Untersuchungen, 139f. Er vermutet sekundäre Angleichung an 28,1. Anders SEITZ, Studien, 262, der aufgrund einer postulierten Parallelität zu 28,1 der Auslassung von (6) den Vorzug gibt. Vgl. MAYES, Deuteronomy, 353.

4 Vgl. García MartíneZ, „Manuscrits,“ 71 .

5 Vgl. PENNA, Deuteronomio, 233. 
hebräische Variante. Die Übersetzungen aus dem protomasoretischen Text, $\mathfrak{D}, \mathcal{S}$ und $\mathfrak{C}$, geben die Verse 1f, 15 und 45 paraphrasierend wieder, was ihren Wert für die Textkritik schmälert.

(6) übersetzt gleiche hebräische Formulierungen mit unterschiedlichen Begriffen oder Formen. So steht für לשמר in 28,1 $\varphi v \lambda \alpha \sigma \varepsilon \sigma \vartheta \alpha$ l, in 28,15

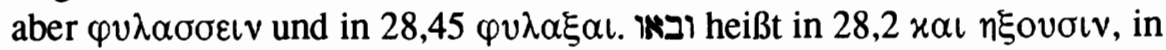

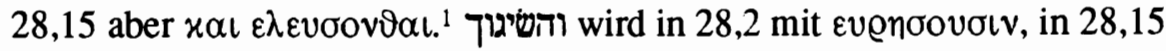
mit $x \alpha \tau \alpha \lambda \eta \mu \psi \sigma v \tau \alpha \iota$ wiedergegeben. Auch die Promulgationsformel unterscheidet sich durch ihr Relativpronomen. Derartige Formelunterschiede ergeben für die Septuaginta ein eigenes Formelgerüst, das Wevers zusammengestellt hat. Eine Promulgationsformel, die wie in 28,1 mit ö tet wird, steht in $\widetilde{\sigma}$ nur noch Dtn 19,9. In 28,15 beginnt die Promulgations-

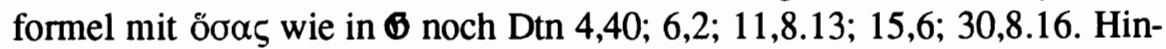
gewiesen sei auch auf die Übersetzung von $(28,1.15)$ und $(28,2)$ durch ẻòv, was für 28,2 die Wiederholung des Bedingungssatzes bedeutet. ${ }^{2}$

\section{1. 2. Forschungsgeschichte und Literarkritik}

Die Einleitungen von Segen und Fluch in Dtn 28 bestanden nach Noth ursprünglich aus einem Vordersatz, der die Voraussetzung angibt $(28,1 \mathrm{a}$; 15a) und einer allgemeinen Ankündigung der Segnungen und Verfluchungen $(28,2 \mathrm{a} ; 15 \mathrm{~b})$. Damit ist die Auffassung verbunden, daß Segens- und Flucheinleitung ursprünglich symmetrisch waren. Von dieser Ansicht geleitet wurde die Erhöhungsaussage von V. 1b mit ihrem Bezug zu Dtn 26,19 als nachträglicher Einschub bewertet. ${ }^{3}$ Kann aber die vermutete ursprüngliche Symmetrie beider Einleitungen und der Rückbezug auf 26,19 als literarkritisches Kriterium ausreichen, um 28,1b auszuscheiden? Es ist kein zwingender Grund ersichtlich, warum V. 1b jünger sein soll als 1a+2a.

Der $k \hat{k}$-Satz in V. $2 \mathrm{~b}$ erscheint gegenüber dem 'im-Satz in V. 1a als störende Dopplung. ${ }^{4}$ Zwischen die Ankündigung der ברכות in V. 2a und den $b \bar{a} r u \hat{k}$-Formeln in V. 3-6 schiebt sich ein retardierender Konditionalsatz. Der Segen wird im Gegensatz zum Fluch zweifach bedingt. Außerdem

\footnotetext{
${ }^{1}$ Es dürfte sich dabei um stilistische Variationen $\mathrm{zu}$ handeln. Eine inhaltliche Differenzierung scheint nicht erkennbar. $\varepsilon \lambda \varepsilon v 00 \mu \alpha \iota$ $\varepsilon \pi \iota$ nur noch Jos 16,$6 ; \mathrm{Ez} \mathrm{38,8;n \xi \omega}$ $\varepsilon \pi \mathrm{l}$ aber 1 Kön 10,7; Jes 2,2; 8,21; 32,19; 47,9; 47,11; 66,19; Jer 1,15; 3,18; 23,17.19; 31,8; 37(30),23; 38(31),12; Ez 38,11; Ijob 36,18; Spr 24,40(25); Da 4,20; $11,7$.

2 Vgl. WeVERS, Text, 91-95.

3 Vgl. „Fluch,“ 130/157f Anm. 8,9; PLOGER, Untersuchungen, 137f; MAYES, Deuteronomy, 351f; Rose, 5. Mose, 533f.

4 Vgl. NOTH, „Fluch,“ 130/157f; PLOGER, Untersuchungen, 137f; SCHÄCHTER, Fluch, 147 149; SEITZ, Studien, 267; MAYES, Deuteronomy, $351 \mathrm{f}$.
} 
scheint der Wechsel der Konjunktion von אם in V. 1a zu כ in V. 2b einen Perspektivenwechsel zu implizieren, auf den Penna hingewiesen hat, der im $k \hat{\imath}$-Satz die Feststellung einer Tatsache sieht, während der 'im-Satz zukünftige Möglichkeiten eröffnet. ${ }^{1}$ Berücksichtigt man außerdem, daß die Formel כי + שמע בקול יהוה אלהיך im gesamten Deuteronomium nur noch 13,$19 ; 28,45$ b. $62 ; 30,10$ vorkommt, wobei 28,$62 ; 30,10$ nach weit verbreiteter Auffassung nicht ${ }^{2}$ und wohl auch 13,19;28,45 kaum zu derselben redaktionellen Schicht gehören ${ }^{3}$ wie 28,1.2a.15, scheint es wahrscheinlich, daß 28,2b ein späterer Zusatz ist, aus einer Zeit, wo man den Gehorsam als Bedingung für den Segen besonders herausstellen wollte. Im Endtext bilden die Verse $1+2$ einen Chiasmus ${ }^{4}$ aus Konditionalsatz mit impliziter Gehorsamsforderung (1a) - Segensverheißung (1b) - Segensverheißung (2a) Konditionalsatz mit impliziter Gehorsamsforderung (2b), der in sich abgeschlossen wirkt, obgleich die Formulierung כלדהברכות האלה in V. 2a eine inhaltliche Füllung verlangt, die auf 28,3-14 vorausweist.

Plöger streicht in V. עד השמרך und ורדפוך als gegenüber den Vergleichssätzen 1a.2a überschüssig und beraubt sich so der Möglichkeit, den Vers in Beziehung zu 28,47-68 zu sehen. 28,45 korrespondiert chiastisch mit V. 15. Wie viele andere Exegeten meint er, Dtn 28 schloß ursprünglich mit V. 46. ${ }^{5}$ Irwin und Krämer verstehen V. $45 \mathrm{f}$ nicht als Abschluß der vorausgehenden Fluchpassage. Weil das Demonstrativpronomen אלד in V. 2.15 vorausweisende Bedeutung besitzt, fordert Krämer diese auch für 28,45. Er betont, daß der Ungehorsam nicht mehr als zukünftig betrachtet wird, wie in V. 1.2.13.14.15, sondern wie die Gesetzesmitteilung in V.

${ }^{1} \mathrm{Vgl}$. Deuteronomio, 226f. PENNA und die TOB übersetzen 28,2b als Kausalsatz.

2 Zur exilischen Datierung von Dtn 28,62 vgl. Preuss, Deuteronomium, 157; BRAULIK, Deuteronomium II, 203; zur spätexilischen Datierung von Dtn 30,10 vgl. BRAULIK, „Entstehung,“ 330-332.

${ }^{3}$ Dtn 13,19 setzt den Dekalog voraus. Dtn 5,9-10 werden in 13,18-19: ,neu gesehen: was geschieht, nachdem die Schuld da ist?" Braulik, Gesetze, 33. Wenn die Einfügung des Dekalogs ins Deuteronomium erst einer joschijanischen Schicht des DtrG zuzuordnen ist, vgl. LOHFINK, ,These,“ 105/371; BRAULIK, „Gedächtniskultur,“" 18, so wird die Aufnahme von $D$ tn 5,9-10 in 13,18f im Zusammenhang der Frage nach neuem göttlichen Erbarmen kaum vorexilisch sein.

${ }^{4}$ KONIG, Deuteronomium, 186, hatte in V. 1b-2b eine palindromische Struktur entdeckt und die Streichung von V. 2b abgelehnt; PLOGER, Untersuchungen, 137, nennt die heute vorliegende Form von $\mathbb{m}$ von $28,1 \mathrm{f}$ einen asymmetrischen Parallelismus.

5 Vgl. Untersuchungen, 137-140; NoTH, „Fluch,“" 130f/157f; SMITH, Deuteronomy, 314; CUNLIFFE-Jones, Deuteronomy, 156f; JUnKeR, Deuteronomium, 532; BUIS / LECLERCQ, B UIS / LeClercQ, Deutéronome, 179; vRA D, Buch, 124; BuIS, Deutéronome, 28; ThOMPSOn, Deuteronomy, 271; LAMPARTER, Aufruf, 141; CAZElles, Deutéronome, 114. 
45b $\gamma$ der Vergangenheit angehört. ${ }^{1}$ In diesen Ansichten wird bereits spürbar, daß 28,45f nicht nur den Abschluß von 28,15-44 bildet, sondern auch auf das Folgende vorausweist und deshalb erst vom Verfasser der Ergänzung ab V. 47 stammen kann. Seitz hat gezeigt, daß 28,45-48 als Zwischenstück komponiert wurde, durch das der bedingte Fluch 28,15-44 abgeschlossen und zur Drohung 28,47-57 übergeleitet werden sollte. ${ }^{2}$ Für die literarkritische Trennung vom Vorhergehenden nennt Seitz drei Gründe:

(1.) Im Gegensatz zur Flucheinleitung (V.15) enthält V. 45 einen die Fluchsanktionen begründenden $k \hat{\imath}-S a t z$, dessen Verb im Perfekt steht (שמעת). Vor dem Ungehorsam wird nicht mehr gewarnt, sondern er wird als Tatsache festgestellt. Das ist eine Sichtweise, die V. 47 entspricht. $^{3}$

(2.) Am Ende von 28,45.46.48 stehen jeweils mit עד verbundene Begriffe, die eine einheitliche Struktur erzeugen. Durch עד השמדך (45a) wird eine Brücke zu עד־השמידו אותך (48) geschlagen. V. 47 bildet die Einleitung zum begründeten Fluch. ${ }^{4}$

(3.) Das Perfekt צוך in 45b $\beta$ spiegelt nicht die sonst im Partizip ausgedrückte Gegenwart der Gesetzespromulgation durch Mose wider, sondem weist auf in der Vergangenheit verkündetes Gesetz JHWHs, das übertreten wurde. ${ }^{5}$

\section{1. 3. Zur Herkunft der Einleitungsformeln}

Mørstad versuchte nachzuweisen, daß die Einleitungsverse $1 \mathrm{f} .15$ bereits in einem vordeuteronomischen Textstadium zu den Segens- und Fluchformu-

1 Vgl. IRWIN, „Criterion,“ 342; KRÄMER, Numeri, 517.

$2 \mathrm{Vgl}$. Studien, 266; RUTterswÖrdEn, Dominium, $70 \mathrm{f}$.

${ }^{3}$ Die Redaktionsstufe, zu der 28,45-57 gehören, nennt SEITZ, Studien, 308f, deuteronomische Überarbeitung. Ihr Ergebnis sei ein Text, der im Wesentlichen Dtn 5-28, aber noch ohne Dtn 27, umfaßte. Dtn 5-11* wurden neu geschaffen, die sozialen Gesetze $15,1-18 ; 21,22 f ; 22,1-12 ; 23,1-9.16 .24$.(25-26?); 24,17-22 eingefügt und die Kultformulare und die Verpflichtungsformel von Dtn 26 vor das erweiterte Kapitel 28 gestellt. Dieser Schichtenzuweisung kann die vorliegende Arbeit nicht folgen. 28,45-68* dürfte einer deuteronomistischen Redaktion der Exilszeit entstammen.

4 Vgl. Studien, 262-264.

5 Vgl. Studien, 263f; Penna, Deuteronomio, 232; MA Yes, Deuteronomy, 349f, 356. BraUliK, „Ausdrücke,“ 42/14, bezieht das Perfekt der Promulgationssätze, in denen Mose der Sprecher ist, auf den Dekalog, den JHWH am Horeb verkündete oder auf die Anweisung an Mose, am Horeb zu bleiben. Diese Promulgationsformeln können also frühestens aus der Zeit des DtrG stammen. Wenn 28,45 „Rückverweis auf die Ratifizierung des durch Moses verkündeten ,Gesetzes " durch Jahwe in $26,16^{\text {" }}$ ist, und damit das ganze deuteronomische Gesetz als JHWH-Gesetz qualifiziert, ebd. 42/14 Anm. 12, dürfte hier eine noch spätere Reflektions- und Redaktionsstufe vorliegen. Eine Datierung von 28,45 ins Exil scheint daher plausibel. 
laren (V. 3-6.16-19) gehörten. Mit ihren Einführungen wirken die Formulare wie Rechtsfälle richterlicher Entscheidungen. Ein Mittler legt in der 1. Person redend einem angesprochenen „Du“ Gebote auf. ${ }^{1}$ Dafür gibt es auBerhalb des AT strukturverwandtes Material in den hethitischen Vasallenverträgen und in babylonischen Gesetzen. ${ }^{2}$ Die Epiloge des Kodex LipitIštar und des $\mathrm{KH}$ besitzen ebenfalls motivierte Heils- und Unheilsankündigungen, die denen der Verträge entsprechen. Zwar war die altorientalische Mittlerstellung des Gesetzgebers nicht analog zum Deuteronomium, dennoch aber liefern die Gesetzeskodizes einen Hinweis auf die Verankerung der Segens- und Fluchformulare samt ihrer motivierenden Einleitungen im Rechtsleben, besonders in der Gesetzespromulgation. ${ }^{3}$ Seitz schloß sich dem Urteil Mørstads an und sah in V. 1a.2a.15 die ursprünglichen Einleitungen zu den barûk- und 'ārûr-Reihen. ${ }^{4}$ Schächter versuchte, die Einleitungen aus dem forensischen Bereich der Vertragssprache herzuleiten. Von dort aus wurden sie zu kultischen Einführungen für Segen und Fluch, um schließlich den Sprachgebrauch der deuteronomischen und deuteronomistischen Literatur zu beeinflussen. ${ }^{5}$ Nach Plöger entstammen die Einleitungen und Schlußsätze nicht der Rechtssprache, sondern werden im kultischen „Heute“ gesprochen. Sie sind eine Schöpfung deuteronomischer Verfasser. ${ }^{6}$

Gesetzesproklamation, Vertragsschluß, Kult oder deuteronomischdeuteronomistische Literatur - die Überlieferungsgeschichte der Einleitungen bleibt umstritten. In der vorliegenden Form von Dtn 28,1.2a.15 jedoch setzten sie mit ihren Promulgationssätzen ein Deuteronomium voraus, das bereits als Moserede stilisiert war. Sie dürften also noch nicht in der Urkunde Joschijas gestanden sein, es sei denn, der Promulgationssatz habe sich ursprünglich auf jemand anderen als Mose - vielleicht den Liturgen der Zeremonie von 2 Kön 23,1-3 - bezogen. Sollten sich die Promulgationssätze von Anfang an auf Mose bezogen haben, wäre die Mosaisierung des Deuteronomiums anläßlich seiner Einführung in die deuteronomistische Landeroberungserzählung ein plausibler Anlaß für die Entstehung von

\footnotetext{
${ }^{1} \mathrm{Vgl}$. Stimme, 5-7.

$2 \mathrm{Vgl}$. Stimme, 18.

$3 \mathrm{Vgl}$. Stimme, 21.

${ }^{4} \mathrm{Vgl}$. Studien, 267. Seine Untersuchung enthält den Widerspruch, daß zwar literarisch die Einleitungsformeln 28,1a.2a.15 von Anfang an mit den barûk- und 'ārûr-Reihen verbunden waren, dennoch aber die barâk-Reihe älter sein soll als die 'ārâr--Reihe, die erst als Gegenstück zum Segen geschaffen worden sei, der zunächst ohne Bedingung existiert habe. Vgl. ebd. 273.
}

$5 \mathrm{Vgl}$. Fluch, $130 \mathrm{f}$.

$6 \mathrm{Vgl}$. Untersuchungen, 162-165. 
28,1.2a.15. ${ }^{1}$ Dtn 28,2b.45f gehören wohl in die Zeit des Exils. Nun stellt sich jedoch die Frage nach der Verbindung der Einleitungen mit den Segens- und Fluchpassagen. Hier kann die synchrone Analyse zur Antwort beitragen.

\section{1.4. Sprachlich-syntaktische Analyse}

V. $1 \mathrm{a} \alpha$ und $15 \mathrm{a} \alpha$ beginnen gleichlautend mit der Struktur $w=q a t a l(-x)$, die dazu dient, an zuvor Gesagtes anzuknüpfen. In Reden kann sie auf Zukunft bezogene Aussagen zusammenfassend weiterführen. ${ }^{2}$ Die durch $ם x$ bzw. eingeleiteten Konditionalsätze in $1 \mathrm{a} \alpha_{2}$ und $15 \mathrm{a} \alpha_{2}$ besitzen die Verbstruktur $x$-yiqtol, was einen Sachverhalt der Zukunft bezeichnet. Nach dem in 1a $\gamma$ und 15a $\gamma$ eingeschobenen partizipialen Relativsatz, der Gegenwart andeutet, folgen in $1 \mathrm{~b}$-2ab und $15 \mathrm{~b}$ wiederum Äußerungseinheiten mit der Struktur $w=q a t a l-x$, die Zukunft ausdrücken. ${ }^{3}$ Derselbe zukünftige Zeitaspekt mit $w=q a t a l-x$ steht auch in $45 \mathrm{a} \alpha$. In V. $2 \mathrm{~b}$ und in V. 45b schließen sich mit $כ$ und eingeleitete Sätze an. $2 \mathrm{~b}$ enthält dabei mit $x$-yiqtol einen Zukunftsaspekt, während 45b mit $x$-qatal sowohl im kî- als auch im Relativsatz Vergangenheit bezeichnet. ${ }^{4}$ Erst V. 46 blickt wieder in die $\mathrm{Zu}$ kunft mit $w=q a t a l-x .{ }^{5}$ Die hier besprochenen Verse sind kaum mit dem Rest des Kapitels verknüpft. Die Segenseinleitung $(28,1 \mathrm{f})$ weist mehr Verbindungen mit V. 3-14 auf als 28,15 mit dem Fluchteil (V. 16-44.47-68). ${ }^{6}$

\footnotetext{
${ }^{1}$ Vgl. MAYES, Deuteronomy, 351f, der 28,1f.15 wegen der deuteronomistischen Phraseologie auf einen deuteronomistischen Verfasser zurückführt, der das deuteronomische $\mathrm{Ge}$ setzbuch herausgegeben habe. In der vorliegenden Arbeit werden DtrL und Dtr I in die Regierungszeit Joschijas datiert. Vgl. ROMER, „Book,“ 188, 190.
}

2 Vgl. Gross, „Rössler,“ 65f; NICCACCI, Syntax, 182.

${ }^{3} w=$ qațal- $x$ kann nach Gross, „Rössler,“ 65 , auch „Injunktiv für dringenden Wunsch sowie ... individuelles wie generelles Gebot" ausdrücken. NICCACCI, Syntax, 182-186 sieht in $w=q a t a l$ zwar Befehle und Anweisungen, nicht jedoch volitive Aussagen. In der Rede drückt es häufig Futur als Konsequenz von zuvor Gesagtem aus. Keine der Versionen übersetzt V. 1b.2a.15b.45a volitiv. Die alten Übersetzer verstanden $w=q a t a l$ in Dtn 28 offenbar nicht als Wunschmodus.

4 Gross, „Satzfolge,“ 111 , bestimmt Dtn 28,2.9.13 als Konditionalsätze mit 'כ, die auf ihre Apodosis folgen. „... Dies ist ... außerhalb des Dtn ungebräuchlich; es ist somit eine stilistische Eigenart dieses Buches und findet sich in stark formelhaften Sätzen, jeweils mit PK(LF).“ Solche kî-Sätze gibt es auch in Dtn 4,29; 6,25; 12,25.28; 13,9; 22,8d; 30,10a.b. Vgl. ebd. Anm. 104.

5 Vgl. Gross, „Rössler,“ 63-68; ebd. 68: „In dem syntaktischen Teilbereich: verbum finitum nach $\mathrm{x}=$ Konjunktion kennt bereits das Althebräische ein fast ausnahmslos durchgeführtes 3-Stufen-System: SK für Vorzeitigkeit bzw. Vergangenheit, Partizip für Gleichzeitigkeit bzw. Gegenwart, PKLF für Nachzeitigkeit bzw. Zukunft.“

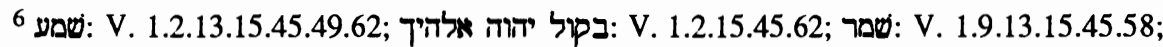

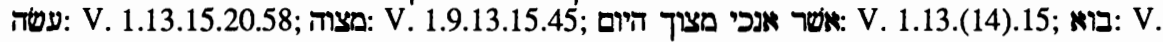


Das Verb בוא in einer der bārûk-Formeln, vor allem aber die formelhaften Wendungen von V. 9.13.14, verknüpfen den Segensabschnitt mit den Einleitungsversen (1f):

\section{9) כי תשמר אתזמצות יהוה אלהיך והלכת בדרכיו

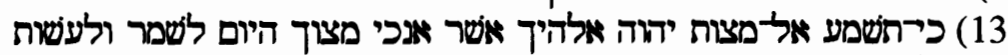

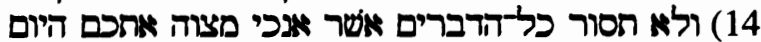

Dennoch gibt es beachtenswerte Unterschiede. Während in V. If die Stimme JHWHs das präpositionale Objekt des Hörens ist, hört man in V. 13 auf die Gebote. Werden die Gebote in V. 1 durch den angeschlossenen Relativsatz näher bestimmt, so geschieht dies in V. 9 durch eine Constructus-Verbindung, die in V. 13 sogar zwischen die Gebote und den Relativsatz tritt. ${ }^{1}$ Die ברכות von V. 2 tauchen am Ende des Segensabschnitts nicht mehr auf. Im Gegenteil, V. 14 sticht sowohl formal mit dem Numeruswechsel als auch inhaltlich mit der Verehrung fremder Götter aus seiner Umgebung heraus.

Im Fluchabschnitt kommt den Versen 15 und 45 durch Parallelität eine rahmende Funktion zu. 15b entspricht wörtlich $45 \mathrm{a} \alpha, 15 \mathrm{~b} \beta$ wörtlich $45 \mathrm{a} \alpha_{3}$, und auch die Gemeinsamkeiten zwischen $15 \mathrm{a} \beta$ und $45 \mathrm{~b} \alpha$ treten prägnanter hervor als es im Segensabschnitt (28,2b.9b.13b.14) der Fall war. Jedesmal wird gehört, jedesmal ist die Stimme JHWHs das Objekt. Nur der Relativsatz in 45by unterscheidet sich durch Subjekt und Zeitaspekt. Darüber hinaus fällt auf, daß V. 2aß.b durch wörtliche Übereinstimmungen mit $45 \mathrm{a} \alpha_{3}$ und von $45 \mathrm{~b} \alpha$ (außer dem Perfektverb) verbunden ist. Nimmt man noch die Entsprechung von $2 \mathrm{a} \alpha$ und $45 \mathrm{a} \alpha_{1}$ hinzu, so ergibt sich, daß die Parallelität zwischen V. 1f und 15.45 größer ist als die zwischen V. If und 13f. Mit anderen Worten, V. 13f besitzt gegenüber V. 1f nicht dieselbe wiederholende und rahmende Funktion, wie V. 45 gegenüber V. 15.

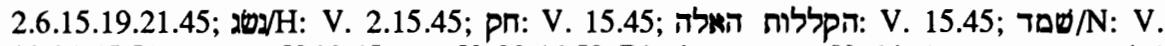

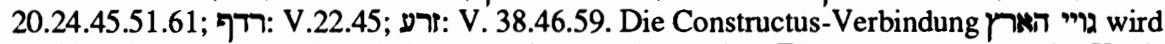

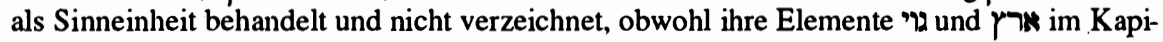
tel noch belegt sind. Die Wurzeln היה נת underden vernachlässigt, da sie zu den häufigsten Verben des Deuteronomiums gehören und auch in Dtn 28 derartig vorherrschen, daß aus ihrer Verteilung kaum Schlüsse gezogen werden können. Im Deuteronomium kommt נתן 169mal, in Dtn $2817 \mathrm{mal}$, המשה 158mal, in Dtn $2821 \mathrm{mal}$, das dritthäufigste Verb des Deuteronomiums (147mal), in Dtn 28 aber nur 5mal vor. Vgl. DeREgT, Supplement, 9.

${ }^{1}$ Die Verben der Gesetzesbeobachtung bilden in Dtn 4-28 Reihen. Vgl. LoHFinK, Hauptgebot, 69f, 299-302. 
Im Fluchteil gibt es einige formelhafte Wendungen, die Elemente aus V. 15.45 enthalten:

\section{8) אם־לא תשמר לעשות אתכלכדבברי התורה האהת

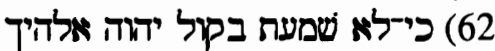

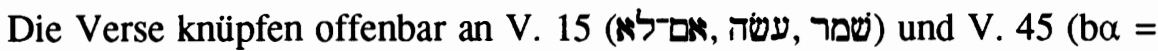
$62 \mathrm{~b})$ an. Darüber hinaus stimmt $62 \mathrm{~b}$ fast wörtlich mit V. 2b überein. V. 58 fällt aber dadurch aus dem Rahmen, daß nicht gehört, sondern bewahrt (שמר) wird und daß der Terminus מצות fehlt.

Als Leitwörter für Dtn 28 treten in den hier besprochenen Sätzen neben

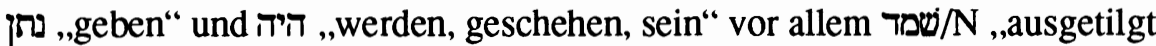
werden“ und das gegenüber ברכה ,Fluch“, hervor. Besondere Aufmerksamkeit verdient שמד/N. Das Wort fehlt in V. 15, der Flucheinleitung. Es begegnet erstmalig in V. 20, taucht dann in V. 24.45 auf und begegnet schließlich noch in V. 51.61. Nimmt man die beiden Belege שמד/H in 28,48.63 hinzu, so kommt die Wurzel im Kapitel 28 siebenmal vor. ${ }^{1} \mathrm{Da}$ auch die damit alliterierende Wurzel שמע ,hören“ in Dtn 28 siebenmal belegt ist, deutet auf redaktionelle Arbeit an einem späten Textstadium von Dtn 28 hin. Andere Siebenerreihen im Deuteronomium lassen auf eine numerisch akzentuierende Gestaltung schließen. Gehorsam und Vernichtung sind durch ein Zahlenverhältnis aufeinander bezogen, wobei der Gehorsam durch die Verwendung der figura etymologica in 28,1a ein leichtes Übergewicht bekommt. ${ }^{2}$

Betrachtet man auch רדף ,verfolgen“, so bestätigt sich die Beobachtung von Seitz, daß V. 45f eine Brückenfunktion zwischen 28,16-44 und 47ff zukommt. זרע ,Same“ verknüpft die Abschnitte zwar als Lexem, meint aber in 28,38 Saatgut, in 28,45.59 jedoch Nachkommenschaft. Im Unterschied zu V. 45 ist V. 15 mit 28,16-44 nur durch בוא in der 'ārûr-Formel

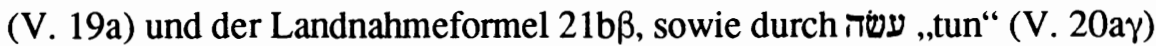
verknüpft. In 28,16-44 fehlen Wendungen aus V. 15. Es bestand offensichtlich kein Interesse, Dtn 28,16-44 durch das Vokabular enger mit dem Einleitungsvers zu verbinden. Demgegenüber bemühte man sich in 28,4768 durch die formelhaften Wendungen von V. 58.62 um eine Verknüpfung mit den Versen 1f.15.45. Darin ähnelt 28,47-68 dem Segensstück 28,3-14 mit seinen verknüpfenden Formeln in V. y:9.13f.

Diese Beobachtungen scheinen ein Licht auf die diachrone Schichtung des Kapitels zu werfen. Der Abschnitt 28,16-44 unterscheidet sich von

\footnotetext{
1 Vgl. LoHFINK, ,עמ, " Manuskript.

2 Obwohl es damit eigentlich acht עמ-Belege gibt, zählt die figura etymologica in Siebenergruppierungen nur einmal. Vgl. BRAULIK, „Funktion,“ 44.
} 
28,3-14 und 28,45-68 dadurch, daß er durch keine geprägten Wendungen mit dem Einleitungsvers verknüpft ist. 28,15 steht fast unverbunden vor 28,16-44. Es ist möglich, daß 28,1f.15 von Anfang an mit den $b \bar{a} r u ̂ k-$ und 'ārûr-Formeln (28,3-6.16-19) verbunden waren, wie Mørstad und Seitz meinten. Für 28,20-44 erscheint dies jedoch fraglich. Die nur zu zwei Ver-

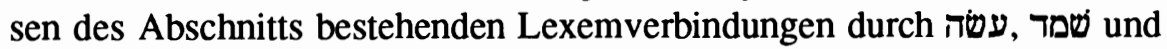
בוא wirken so aufgesetzt, daß es scheint, eine bereits ziemlich geschlossene Gestalt von 28,20-44 habe schon vorgelegen, als der Abschnitt durch die formelhaften Wendungen in V. 20a $\gamma .21 \mathrm{~b} \beta$ mit der Einleitung V. 15 verknüpft wurde.

\subsubsection{Semantische Analyse}

Der Ausdruck שמע בקול יהוה אלהיך stellt eine geprägte Wendung dar. Er steht besonders häufig im Deuteronomium und im Buch Jeremia. Im Deuteronomium findet man sechsmal שמע בקול בשק שמע בקול יהוה ${ }^{1}$ Die Formel scheint also durch redaktionelle Arbeit gezielt und unter numerischen Gesichtspunkten im Text plaziert worden zu sein. Die präpositionale Rektion beim Verb der Wahmehmung intensiviert den geistigen Kontakt. Das direkte Objekt bei שמע bezeichnet nur das akustisch Hörbare. Ein durch die Präposition $ל$ angeschlossenes Objekt impliziert eine gewisse innere Distanz zum Gehörten. Der Anschluß mit ב dagegen impliziert ein Hören als Willensakt, der zu einer positiven Aufnahme des Wahrgenommenen führt. קול ,Stimme“ ist dabei „das Gesagte“. Bezogen auf das Volk bezeichnet der Ausdruck den Gehorsam bzw. negiert den Ungehorsam. ${ }^{2}$ Die figura etymologica in Ex 15,26; 19,5; Dtn 15,5; 28,1; Sach 6,15 erhöht die Betonung des gewissenhaften Gehorchens. Die figura etymologica dient im AT zum feierlichen Abschluß oder zur feierlichen Eröffnung einer Perikope. ${ }^{3}$

Fenz wies darauf hin, daß die Formel mit dem Gottesnamen יהוה im Deuteronomium immer im Zusammenhang von Segen oder Fluch aufscheint. ${ }^{4}$ Geht man alle Belege durch, zeigen sich formale und inhaltliche Unterschiede. Mit $w=$ eingeleitet oder als Infinitiv steht sie in Gehorsamsforderungen oder -voraussagen (Dtn 4,30; 30,2: ושמעתבקולו 27, 27, 30,8:

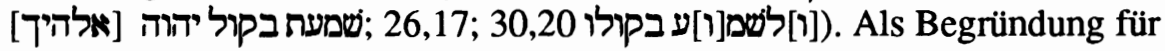

\footnotetext{
1 Vgl. FenZ, Stimme, 38f שממע בקול in Dtn 4,30;9,23;13,5;26,17;30,2.20. שמע בקול ידוה in Dtn 8,$20 ; 13,19 ; 15,5 ; 26,14 ; 27,10 ; 28,1.2 .15 .45 .62 ; 30,8.10$.

2 Vgl. JenNI, Präposition, 243-250.

3 Vgl. GolKA, „Figura,“ 417.

4 Vgl. Stimme, 39.
} 
Israels Untergang steht die negierte Formel außerhalb von Dtn 28 in Dtn 8,20 (עקב לאתשמעון בקול יהוה אלהיכם). Im Zusammenhang der Segenszusage steht die positive Formel in 15,5, wo sie fast wie in 28,1 lautet und mit a beginnt. Zweimal wird die Formel mit eingeleitet. In 13,19 geht es um die neue Zuwendung Gottes nach seinem Zorn und auch in 30,10 geht es um die erneute Freude Gottes an seinem Volk. Wo immer also die Formel שמע בקול יהוה außerhalb von Dtn 28 mit verbunden ist, geht es um neues Heil nach JHWHs Zorn.

Weitet man den Blick auf das ganze AT, so ergibt sich, daß שמע בקול יהוה in einem $k \hat{\imath}$-Satz überhaupt nur noch im Jeremiabuch auftaucht. In Jer 42,6 lautet die Wendung כי נשמע בקול יהוה אלדינו. Die bei der babylonischen Invasion übriggebliebenen Israeliten hoffen, daß JHWH ihnen wieder Gutes erweist. Auch diese Stelle steht also im Zusammenhang der Hoffnung auf neues Heil nach erfahrenem Unglück. Die drei anderen Jeremiabelege bieten die Formel negiert wie in Dtn 28,45.62. In Jer 3,25 gehört sie zu einem Sündenbekenntnis, das den Götzendienst als Ursache für JHWHs Gericht an Samaria herausstellt: ${ }^{1}$

Wir betten uns in unsere Schmach, und unsere Schande bedeckt uns. Denn (כ) wir haben gesündigt gegen den Herrn, unseren Gott, wir selbst und unsere Väter, von Jugend an bis auf den heutigen Tag. Wir haben nicht gehört auf die Stimme des Herm, unseres Gottes (ולא שמענו בקול יהוה אלדינ).

In Jer 40,3 geht es ebenfalls um Sünde. Der babylonische Kommandant stellt den Zusammenhang zwischen Ungehorsam und Deportation fest. JHWH hat seine Drohungen eintreffen lassen, die im Verlust des Landes gipfeln. Jer 42,6 erzählt, daß die Truppenführer der von den Babyloniern in Juda Zurückgelassenen zu Jeremia kommen und um ein Orakel bitten. Das Orakel besteht im Verbot, das Land zu verlassen und nach Ägypten zu gehen (Jer 42,13-19). Doch dieses Verbot findet keine Beachtung. Man zieht dennoch fort. Das wird ausdrücklich in einem $k \hat{\imath}$-Satz als Ungehorsam qualifiziert (Jer 43.7). ${ }^{2}$ Im Unterschied zu Dtn 28,68 geht die Initiative zum Zug nach Ägypten von Israeliten aus. Dennoch ziehen die meisten nicht freiwillig nach Ägypten, sondern werden gleichsam von ihren eigenen Landsleuten deportiert (Jes 43,5f).

Betrachtet man sämtliche Belege mit der Wendung שמע בקול יהוה in einem $k \hat{\imath}$-Satz außerhalb von Dtn 28, so scheint Jer 3,25 in einem authentischen an das Nordreich Israel gerichteten Jeremiawort aus der Frühzeitver-

\footnotetext{
1 Vgl. AlbERTZ, „Frühzeitverkündigung,“ 32.

2 Vgl. FENZ, Stimme, 60f. Jer 42,1-43,13 Orakelerfragung und Ungehorsam gehören zu einem Gedankengang, die um למע בקול יהוה herum gruppiert ist.
} 
kündigung ${ }^{1}$ der älteste Beleg zu sein. Jer 40,3; 42,6; 43,7 gehören zu Prosastücken. ${ }^{2}$ Jer 40,1-6 rechnet Stipp zur schafanidischen Redaktion, die jünger sei als die deuteronomistische und großes Interesse an der SchafanFamilie und an Baruch habe. Jer 42,1-9; 43,4-7b* einschließlich der hier interessierenden Wendung betrachtet er als Teil der ,Erzählung vom Untergang des palästinischen Judäertums", die er vor der deuteronomistischen Redaktion ansetzt. ${ }^{3}$ Lohfink bestimmte Jer 40,3; 42,6 als deuteronomistische Ergänzungen einer aus dem Umkreis der Schafaniden stammenden historischen Kurzgeschichte, die zum Ziel hatte, die ägyptische Gola gegenüber der babylonischen abzuwerten. Jer 43,7 scheint sogar zum ursprünglichen Bestand der Geschichte zu gehören. ${ }^{4}$ Die leicht abweichende Schichtenzuordnung von Stipp und Lohfink läßt einen für Dtn 28 wichtigen Schluß zu. Der kî-Satz kommt im Sprachgut des Propheten Jeremia vor und wurde dann in Kreisen verwendet, die Geschichten über sein Leben tradierten und redaktionell bearbeiteten. Diese Redaktionen können teilweise als deuteronomistisch qualifiziert werden. Eine Verbindung zu jenen Kreisen liegt nahe, die im Deuteronomium deuteronomistischen Passagen hinterließen. Dtn 30,10 gehört zu einer spätexilischen deuteronomistischen $\check{s} u b$-Redaktion und auch Dtn 13,19, das den erst in DtrG mit dem Deuteronomium vereinigten Dekalog uminterpretiert, dürfte aus der Exilszeit stammen. ${ }^{5}$ Inhaltlich kommt hinzu, daß sämtliche Belege dieser Wendung, wenn sie positiv formuliert ist, neues Heil nach erfahrenem Zorn thematisieren. Die negierten Formeln in Jer 40,3; 43,7 sprechen von Ungehorsam im Zusammenhang des Landverlustes, sei es im Wegzug nach Babylon oder nach Ägypten. Nur das Bußwort in Jer 3,25 spricht nicht explizit von Deportation, setzt sie aber als Schicksal des nach 722 angeredeten Nordreiches implizit voraus.

Dieser Befund aller alttestamentlichen Belege ergibt für Dtn 28, daß die negierte Formel in 28,45 möglicherweise auf das Thema des Landverlustes und der Rückkehr nach Ägypten $(28,63 f .68)$ vorausweist. Dies scheint vor allem deshalb plausibel, weil 28,47-57 auf Jer 5,15-17, ein Jeremiaorakel aus der Frühzeitverkündigung, bezug nimmt. ${ }^{6}$ Der Verfasser von Dtn 28,45 dürfte auch Jer 3,25 gekannt haben. Berücksichtigt man, daß die Formel

\footnotetext{
1 Vgl. AlBERTZ, „Frühzeitverkündigung,“ 32.

2 Vgl. HeRrmanN, Jeremia, 51.

3 Vgl. Parteienstreit, 204, 343; ,Probleme,“ 250.

4 Vgl. ,Gattung,“" 71f, 75, 79, 80f.

5 Vgl. BrauliK, „Entstehung,“ 330-332; Gesetze, 33; VANONI, ,Anspielungen,“ 389; PREUSS, Deuteronomium, 24, 82.
}

6 Vgl. SuMNER, Study, 167. 
שממע בקול יהוה numerisch gezielt $(2 \times 6)$ im Deuteronomium verteilt wirkt, scheint nach dem Willen der Redaktoren in $28,2 \mathrm{~b}$ wie in den beiden Formelbelegen 13,19; 30,10 die Bedingung für neues Heil nach erfahrenem Unheil genannt zu sein. ${ }^{1}$

In Dtn 28,2a.15.45a sind die ברכות und pלות die grammatischen Subjekte der Aktivität בוא ,kommen“. Sie handeln wie Lebewesen. Bedeutet das, daß Segen und Fluch zu selbständigen Seinsgrößen hypostasiert sind ${ }^{2}$, die als eigene Wirklichkeiten womöglich unabhängig von JHWH Heil und Unheil bewirken? Dann enthielten die Einleitungen Relikte magischen Denkens. Preuß betont, daß JHWH auch dann hinter dem Segen und der Kraft des Fluches steht, wenn dies wie in 28,2.15 nicht ausdrücklich gesagt ist. ${ }^{3}$ Eine Klärung wird möglich, wenn man überlegt, was die ברכות und קללות in 28,2.15.45 eigentlich sind. 28,15.45 enthalten die einzigen Belege im gesamten AT, wo das Nomen קללה im Plural steht. Die Pluralsetzung macht deutlich, daß es sich nicht um einen abstrakten Seinszustand handeln kann, sondem um Konkreta, die vereinzelbar sind, da sie einen Plural bilden können. Ähnliches zeigt sich bei dem Nomen ברכות. Im Deutschen kann man das Wort Segen nicht in den Plural setzen. Wenn der Plural verwendet wird, versteht man unter Segnungen entweder einzelne Segenssprüche oder einzelne Ereignisse, Errungenschaften oder Wohltaten. Ähnliches stellt Scharbert für Dtn 28,2 heraus. Zunächst sind mit ברכות die bārûk-Formeln gemeint, dann aber auch die von ihnen ausgelösten Segenspotenzen. ${ }^{4}$ Zunächst bezeichnen ברכות und קללות in 28,2.15.45 also Sprechakte, Sätze, Formeln. Die mit diesen Worten ausgelösten Potenzen sind demgegenüber sekundär. Man kann in den beiden hebräischen Begriffen Gattungsangaben für 28,3-13 und 28,16-44 sehen. Doch können Worte über jemanden kommen, wie es die Wendung בוא על על nahelegt?

בוא על Dird im AT häufig mit Personen verbunden und bedeutet in kriegerischem Kontext ,überfallen“ (Gen 34,25.27; Jos 11,7; Ri 18,27; 1 Sam 30,23; 2 Sam 17,2; 2 Kön 7,6; Jes 10,28; Jer 49,14; 51,51; Ez 23,$24 ; 38,18$ ). Dieser militärische Kontext ist aber in Dtn 28 nicht gegeben. Zumindest das Kommen der Segnungen dürfte kaum als „Überfall“ ver-

\footnotetext{
1 So deutet übrigens die chasidische Interpretation die Zahlenwerte des Kapitels. Vgl. Plaut, Deuteronomy, 312.

2 Vgl. Oetrli, Deuteronomium, 91, DognieZ / HaRL, Bible, $287 \mathrm{zu} 28,15$.

${ }^{3}$ Vgl. בוג,"Sp. 543; Theologie, 101.

4 Vgl. ScharberT, ,ברד: Sp. 830.
} 
standen worden sein. Eher mit 28,2.15.45 vereinbar scheinen Stellen, wo Abstrakta Subjekt des בוא על sind. ${ }^{1}$

Bei einer ganzen Reihe von Belegen drückt בוא על einfach räumliche Annäherung oder Berührung aus (Lev 11,34; 21,11; Num 6,6; 2 Sam 15,4; 2 Kön 24,11; Jes 47,13; Jer 14,3; Sach 12,9; 14,16; 1 Chr 12,23f; 2 Chr $20,2.24 ; 28,20$ ). Das Nahekommen ist zumeist mit einer Wirkung verbunden. Man macht sich unrein, empfängt Hilfe oder gerät in Gefahr. Im Gebot der Schwagerehe (Dtn 25,5) impliziert בוא על eine positive Zuwendung. Solche bis zur Berührung reichende und verändernde Nähe scheint der semantische Horizont der Wendung בוא על in Dtn 28,2.15.45 zu sein. Noch zweimal im AT besitzt der Ausdruck das Subjekt ברכה. An diesen beiden Stellen wird deutlich, daß solch eine verändernde Nähe Sprechakten, Worten, zugeschrieben wurde. In Dtn 30,1 heißt es ausdrücklich:

Und wenn alle diese Worte über dich gekommen sind, der Segen und der Fluch, die ich dir vorgelegt habe, wenn du sie dir zu Herzen nimmst ... .

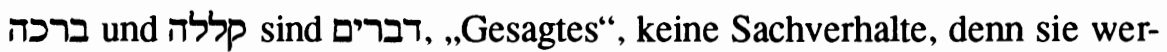
den von Mose vorgelegt und können beherzigt werden. In Ijob 29,13 wird der Segen in Parallele zu einer Metapher lautlicher Äußerung gesetzt:

Der Segen des Verlorenen kam über mich, und jubeln ließ ich der Witwe Herz.

Auch hier steht im Hintergrund, daß der Segnende etwas Lautliches von sich gegeben hat. Es ist bedeutungsvoll, in den Begriffen primär eine Qualifikation von Sprechakten zu sehen, weil damit 28,3-13 und 28,16-44 tatsächlich Segen und Fluch im Sinne von Textsorten enthalten und nicht Paränesen über Segen und Fluch als Predigtthemen. In den Einleitungsversen entscheidet sich, ob in Dtn 28 wirklich gesegnet und geflucht wird, oder ob nur über Segen und Fluch gesprochen wird. Die beiden anderen AT-Stellen mit בוא על + בכרה rechtfertigen die Interpretation, daß in 28,2.15.45 primär sprachliche Äußerungen angekündigt werden. ${ }^{2} \mathrm{Ob}$ aus den ברלות und täsächlich das Schicksal bestimmende Wirklichkeiten werden, hängt von JHWH ab, dem Spender des Segens $(28,8)$ und dem Sender des Unheils $(28,20)$. Hinter den Konditionalsätzen $28,2.15$ steht

${ }^{1}$ Man findet Unheil (רעה: 2 Sam 19,8; Jes 47,11; Jer 5,12; 23,17; Mi 3,11; Ijob 2,11), Bedrängnis (צרה: Ijob 27,9; Spr 1,27), den Tag des Verderbens und die Zeit der Bestrafung (Jer 46,21), den Tag des Zorns (Zef 2,2), das Zorngericht (2 Chr 32,26) oder einfach ,etwas" (Jes 47,13; Esra 9,13; Neh 9,33) und Gedanken (2 Chr 7,11). Für den Hintergrund von 28,2 auszuschließen sind Stellen, wo der שר/שרד ,Verwüster" kommt (Jer 6,22; 51,56; Am 5,9) oder das Schwert (Ez 33,3; 2 Chr 20,9). Daneben kann der Ausdruck den Sonnenuntergang (Dtn 24,15; Mi 3,6) bezeichnen, einen Grund angeben (Gen 30,33) und Menge ausdrücken (Ex 35,22; Ez 7,26).

2 Vgl. zu den pללות in Dtn 28,15.45; 29,26 als ,Fluchworte“" SCHARBERT, ,pל." Sp. 45. 
kein Automatismus von Ursache und Wirkung, sondern es wird der Geltungsbereich von Worten festgelegt und die Tätigkeitsweise JHWHs konzediert. Wenn Israel gehorcht - und Israel will ja beim Bundesschluß gehorchen - soll JHWH den Segnungen entsprechen, wenn es aber tatsächlich einmal ungehorsam werden sollte, dann mögen die Verfluchungen seine Handlungsprinzipien sein.

Auch das Verb ששג/H ,erreichen“ (28,2a $\beta .15 b \beta .45 a \gamma)$ wird im AT explizit auf sprachliche Äußerungen bezogen. In Sach 1,6 heißt es:

Meine Worte und meine Entschlüsse, die ich durch meine Knechte, die Propheten verkünden ließ, haben sie sich nicht an euren Vätern erfüllt (הלוא השיגו אבתיכם)?

Dazu kommen noch Stellen im hebräischen Sirach, die נשג mit Worten oder Segnungen verbinden. ${ }^{1}$ Auch im Deutschen sagt man, daß Worte einen Menschen verfolgen können (רדך 45ab), zumal wenn sie von einer Autorität wie Mose ausgesprochen werden. Die Begriffe ברכות und קללות legen die folgenden (דאהלה) Äußerungen des Mose als performative Segens- und Fluchworte fest. Das bedeutet, ברכות und מללות sind Menschenwort, nicht

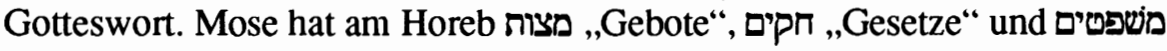
„Rechtsvorschriften“ empfangen (Dtn 5,31), aber keine Segens- oder תורתמשה zuchsprüche. Von Mose ausgesprochen, gehören sie jedoch zur und stehen auch in dem ספר התורה (28,61), das Mose schreibt (1,5).2

Natürlich sind dann sekundär mit den ברכות und קללות auch Wirklichkeiten gemeint, denn es beeinflußt und verändert das Leben eines Menschen, wenn er sich im Einklang mit dem Gottesgebot und unter dem Mosesegen stehend wissen darf, oder wenn er aufgrund seines Ungehorsams das Eintreffen der Flüche fürchten muß. Sind die Flüche einmal eingetrofאות ומופת fen, so können ihre Auswirkungen an den Betroffenen als „Zeichen und Wunder“ (V.46) haften.

Die Wortverbindung אות ומופת in 28,46 läßt den Exodus anklingen. Steht die Wendung im Plural, bezeichnet es immer die Machttaten Gottes bei der Herausführung Israels aus Ägypten (Dtn 4,34; 6,22; 7,19;26,8; 29,2; 34,11; Ps 135,9; Jer 32,20f). In Dtn 13,2f; 28,46; Jes 20,3 steht der Ausdruck im Singular. Es geht in Dtn 13,2f und Jes 20,3 um Zeichen und

1 Vgl. HausmanN, נמשג, “ Sp. 646: Sir 3,8; 12,12; 31,34; in Qumran: 1 Q 22,1,10 mit Flüchen.

2 „Der Ausdruck Tora kehrt ... wieder in den Teilen des Buches Dt, die um das ältere Mittelstück Dt 5-28 herumgelegt sind ... . Er meint immer das ganze Mittelstück - Paränese, Gesetze, Segen und Fluch zusammen." LoHFINK, Sicherung, 311. BRaUlIK, Ausdrücke, 38: ,tôräh bezeichnet ... zunächst das ,Gesetz' des Moses, wie es in den Kapiteln 5-26 und 28 vorliegt, meint aber dann Dtn 1-32.“ 
Wunder von Propheten. In Jes 20,3 ist Jesaja ein Zeichen für Ägypten, das von einem mesopotamischen König in die Gefangenschaft geschleppt werden wird. ${ }^{1}$ Auch V. 46 dürfte daher Ägypten und Deportation anklingen lassen, wie es in 28,63f.68 in der Umkehrung des Exodus zur Sprache kommt. Die Ausdrücke für Gesetz מצות מות bezeichnen das ganze Gesetz Dtn 5-26, also den paränetischen Teil und die Einzelgebote. Der

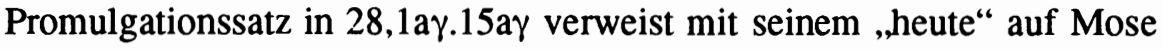
als denjenigen, der das Gesetz in Moab promulgiert. Der Promulgationssatz 45b $\gamma$ erinnert dagegen an die Verkündigung des Gesetzes, die durch JHWH am Horeb geschah. ${ }^{2}$

\section{1.6. Traditionsgeschichte}

28,1f.15 bilden konditionale Einleitungen für Segens- und Fluchtexte, wie sie auch im $\mathrm{AO}$ belegt sind. ${ }^{3}$ Fenz und Cazelles wiesen auf den altorientalischen Hintergrund der Wendung שממע בקול hin. Im KH findet man die

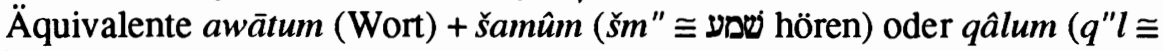
וp still und aufmerksam auf etwas achten). Sie stehen in den Einleitungen der Segens- und Fluchsequenzen. ${ }^{4}$ Cazelles meinte, der Ausdruck mit dem durch $ב$ angeschlossenen präpositionalen Objekt enthält einen Gehorsam heischenden weisheitlichen und moralischen Unterton. Daraus schließt er, daß der Ausdruck seine Wurzeln in Schreiberkreisen Ägyptens hatte. Deren Ausdrucksweise wurde aber wiederum beeinflußt von der alten akkadischhurritischen Wendung šemû ina pî, die in Nuzi belegt ist und die Haltung bezeichnet, mit der ein Sohn auf seinen Vater hört. ${ }^{5}$

\footnotetext{
1 Vgl. WAGNER, , صأِي, " Sp. 751-757.

2 Vgl. BraUliK, „Ausdrücke,“13f, 28-32.

3 Vgl. MørSTAD, Stimme, 18-21.

${ }^{4}$ Vgl. FenZ, Stimme, 75-78 (KH Rs. Kol. XXV Z. 14; Rs. Kol. XXV Z. 78f; Rs. Kol. XXVI

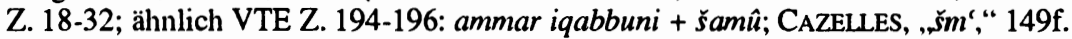

5 Vgl. CAZELLES, ,ک̌m?,“ 149f.
} 


\section{2. Dtn $28,20-44$}

20a $\beta$ JHWH schicke ${ }^{1}$ gegen dich ישלח ידוה בך

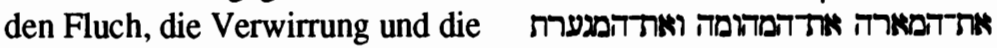
Bedrohung auf jedes Werk deiner Hände,

20a das du unternimmst,

$20 \mathrm{~b} \alpha \quad$ bis du vertilgt bist

$20 \mathrm{~b} \alpha_{2}$ und bis zu deinem schnellen Untergang

$20 \mathrm{~b} \beta \quad$ wegen der Bosheit deiner Taten,

$20 \mathrm{~b} \gamma \quad$ durch die du mich verlassen hast. ${ }^{2}$

21a JHWH klebe an dich die Pest

$21 \mathrm{~b} \alpha \beta \quad$ bis er $/ \mathrm{sie}^{3}$ dir ein Ende gemacht hat in dem Land,

21 by in das du kommst,

$21 b \delta \quad u m$ es in Besitz zu nehmen.

22a JHWH schlage dich mit

Schwindsucht und mit Fieber

und mit Brand und mit Entzündung und mit Hitze

und mit Getreidebrand und mit

Getreiderost,

$22 b a \quad$ und sie sollen dich verfolgen

$22 b \beta \quad$ bis zu deinem Untergang.

$23 \mathrm{a} \alpha_{1}$ Und es wird dein Himmel,

$23 \mathrm{a} \alpha_{2}$ der über deinem Kopf [ist],

$23 \mathrm{a} \beta \quad$ Bronze

$23 \mathrm{~b} \alpha_{1}$ und die Erde,

$23 \mathrm{~b} \alpha_{2}$ die unter dir [ist],

$23 \mathrm{~b} \beta$ Eisen.

24a JHWH mache den Regen [für] deine Erde zu Staub und Asche, בכל־מטסלח ידך

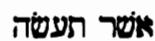
ער השמדך וער־אבדך מהר ער

מפני רע מעלליך

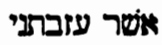

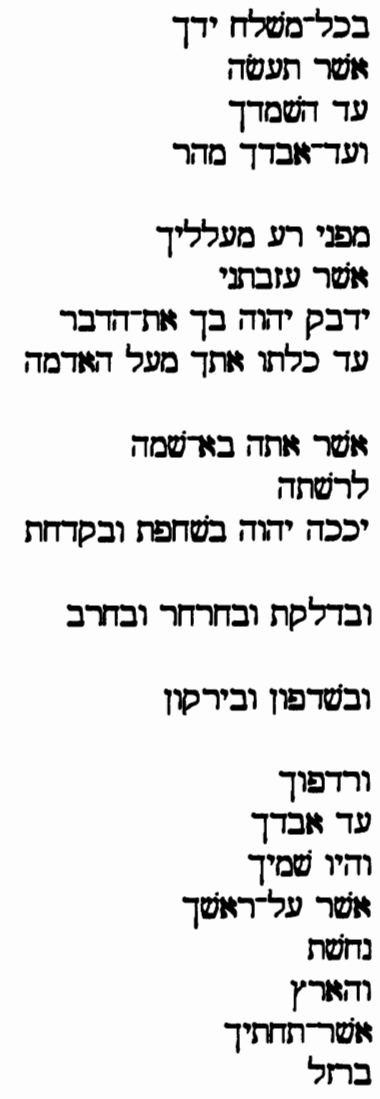

יתן יהוה את־מסר ארצך אבק ועפר

1 „A Yiqtol in the first position of a sentence is always jussive ... . “ NICCACCI, „Point,“ 7.

2 In 28,20 liegen in RICHTER, $B H t, 618 \mathrm{f}$, anscheinend Druckfehler vor. $20 \mathrm{~b} \alpha$ wird als ,aRI1“ und „aRI2“ definiert, so als ob es sich um Infinitivergänzungen des vorhergehenden

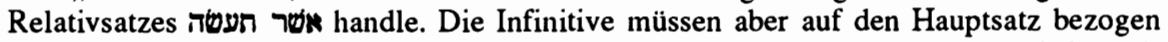

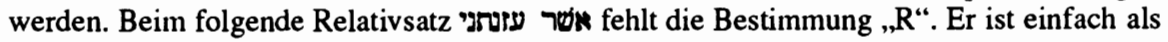
„b“, d.h. als neuer Satz bezeichnet.

${ }^{3}$ Das enklitische Personalpronomen kann sich auf JHWH oder die Pest beziehen. TOB, 399: „Le SEIGNEUR te fera attraper une peste qui finira par t'éliminer de la terre ... .“ 
24ba vom Himmel komme ${ }^{1}$ er herab auf dich

$24 \mathrm{~b} \beta \quad$ bis du vertilgt bist.

25a $\alpha$ JHWH gebe dich geschlagen vor deine Feinde,

$25 \mathrm{a} \beta \quad$ auf einem Weg mögest du ausziehen gegen sie,

25ay und auf sieben Wegen mögest du fliehen vor ihnen.

25b Und du wirst zum Schrecken für alle Königreiche der Erde.

26a Und dein Leichnam werde zur Nahrung für alle Vögel des Himmels und für das Getier der Erde,

26b und es gibt keinen, der sie verscheucht.

27a JHWH schlage dich mit dem Geschwür Ägyptens und mit Beulen und mit Hautkrankheit und mit Krätze,

$27 b \alpha \quad$ von denen du nicht geheilt werden kannst.

$28 \quad$ JHWH schlage dich mit Raserei und mit Blindheit und mit Verwirrung des Herzens.

$29 \mathrm{a}_{1} \quad$ Und du wirst am Mittag umhertasten

$29 \mathrm{aa}_{2}$ wie ein Blinder umhertastet im Dunkeln,

29aß und du wirst auf deinen Wegen keinen Erfolg haben,

$29 \mathrm{ba}$ und du wirst nur ausgebeutet und beraubt werden alle Tage,

$29 \mathrm{~b} \beta \quad$ und es gibt keinen Retter.

$30 \mathrm{a} \alpha_{1}$ Eine Frau heiratest du,

$30 \mathrm{aa}_{2}$ aber ein anderer Mann wird sie schänden.

30a $\beta \quad$ Ein Haus baust du,

30a $\gamma$ aber du wirst nicht darin wohnen.

$30 \mathrm{ba}$ Einen Weinberg pflanzt du,

$30 \mathrm{~b} \beta \quad$ aber du wirst ihn nicht einweihen.

מןדשטים ירד עליך

ער השמרך

יתצך ידוה נגף לפני היביך

בדרך אחד תצא אליו

ובששבעה דרכים תנום לפניו

והיית לזעוה לכל ממלכות הארץ

והיתה ובלתך

למאכל

לכלעוף השמים ולבהמת הארץ

ואין מחריד

יככה יהוה מצוה

כששחין מצרים ובעפלים ובגרב ובחרס

אשיר לאדתוכל להרפא

יככה יהוה

בשגעון ובעורון ובתמהון לכב

והיית ממששט בצדרים

כאטר ימששט העור באפלה

ולא תצליח אתדרכיך

והיית אך עשוק וגזול כל־דימים

ואין מושיע

אלשה תארט משין

ואיש אחר ישגלנה

בית תבנה

ולאדתשב בית בות

כרם תטע תלמת ביל

ולא תודלט תםט

1 ,The (Waw-x)-Yiqtol construction is jussive when it is preceded by a direct volitive form ... ." NicCACCI, „Point,“ 9. 
$31 \mathrm{a} \alpha_{1}$ Dein Ochse wird vor deinen Augen geschlachtet,

$31 \mathrm{a} \alpha_{2}$ aber du wirst nicht davon essen.

$31 \mathrm{a} \beta$ Dein Esel wird vor dir geraubt,

31ay und er wird nicht zu dir zurückkehren.

31b $\alpha$ Dein Kleinvieh wird deinen Feinden gegeben,

$31 b \beta$ und es gibt keinen, der dich rettet.

$32 \mathrm{a} \alpha_{1}$ Deine Kinder werden einem anderen Volk gegeben,

$32 \mathrm{a}_{2} \beta$ und deine Augen blicken und schmachten nach ihnen den ganzen Tag,

32b aber du vermagst nichts [daran $\mathrm{zu}$ ändern].

33a $\alpha \beta$ Die Frucht deines Landes und all deinen Gewinn ißt ein Volk,

33a das du nicht kanntest.

33b Und du wirst nur bedrückt und mißhandelt alle Tage.

34aba Und du wirst verrückt bei dem Anblick, der sich deinen Augen bietet,

$34 \mathrm{~b} \beta \quad$ was du [alles] mit ansehen mußt.

35a $\alpha$ JHWH schlage dich mit bösem Geschwür an den Knien und an den Schenkeln,

$35 \mathrm{a} \beta \quad$ von dem du nicht

וטין לאל ידך

ועיניך ראות וכלות אליהם כלדהיום

ולא תזכל ממנו

חמרך גזול מלפניך

ולא ישטב לך גור מדי

צאנך נתנות לאיביך

וזין לך מוֹשיע

בניך ובנתיך נתנים לעם אחר

פרי אדמתך וכל-יגיעך יאכל עם

ומשר לאידידעת

והיית רק עשטק ורצוץ כדדהימים

והיית משגע ממראה עיניך

יכוז

יככה יהוה ריוה

בשחין רע על־דברכים ועל־דשקים יכדים

אישטר לא־תוכל

35a geheilt werden kannst,

35b von der Fußsohle bis zu deinem Scheitel.

$36 \mathrm{a} \alpha_{1}$ JHWH lasse dich und deinen König,

$36 \mathrm{a} \alpha_{2}$ den du über dich erhebst,

36aß zu einem Heidenvolk gehen,

36a $\gamma$ das weder du noch deine Väter kannten,

36b und du wirst dort fremden Göttern dienen, [Götzen aus] Holz und Stein.

37aba Und du wirst zum Entsetzen zum Sprichwort und zum Spottlied bei allen Völkern werden,

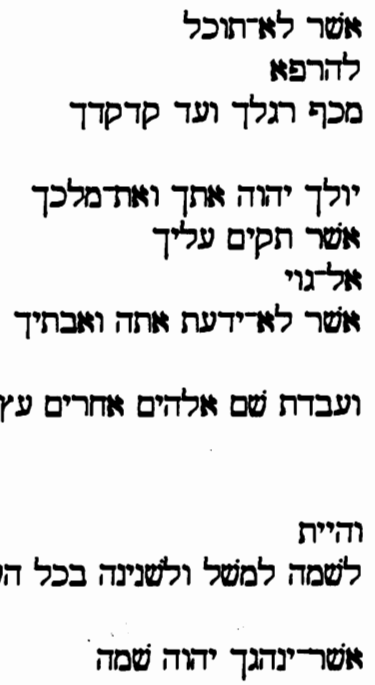


38a Viel Samen bringst du aufs Feld זרע רב תוציא השרה hinaus,

$38 \mathrm{~b} \alpha$ aber wenig wirst du ernten,

$38 \mathrm{~b} \beta$ denn die Heuschrecke wird alles abfressen.

39a Weingärten pflanzt du,

$39 \mathrm{a} \beta$ und du mühst dich,

$39 \mathrm{~b} \alpha_{1}$ aber Wein wirst du nicht trinken,

$39 \mathrm{ba}$ und du wirst keinen Vorrat anlegen,

$39 \mathrm{~b} \beta$ denn der Wurm wird alles fressen.

40a Ölbäume wachsen für dich auf deinem ganzen Gebiet ${ }^{1}$,

$40 \mathrm{~b} \alpha \quad$ aber mit Öl salbst du dich nicht,

$40 \mathrm{~b} \beta$ denn herunterfallen wird deine Olive.

41a Söhne und Töchter wirst du zeugen,

$41 \mathrm{~b} \alpha$ aber du wirst sie nicht behalten,

$41 \mathrm{~b} \beta \quad$ denn sie werden in die Gefangenschaft gehen.

42 Alle deine Bäume und die Frucht deines Landes nimmt die Grille in

כי יחסלטו הארבה תמסף

כרמים תטע

ועבדת

ויין לאדתשתחה המדות

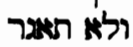

כי תאכלנו התלעת תואר

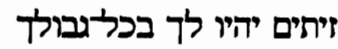

ושמן לא תסוך

כי ישל זיתך

בנים ובנות תוליר

ולה כיהם ובנות לך

כי ילכו בשירי

כלעצך ופרי אדמתך "ירש הצלצל

Besitz.

43a $\alpha_{1}$ Der Fremde,

$43 a_{2}$ der in deiner Mitte [wohnt]

$43 \mathrm{a} \beta \quad$ erhebt sich über dich, hinauf, hinauf,

43b du aber, du steigst hinab, hinunter, hinunter.

44a $\alpha$ Er, er leiht dir aus,

$44 \mathrm{a} \beta \quad$ aber du, du leihst ihm nicht aus.

$44 \mathrm{~b} \alpha \quad$ Er, er wird zum Haupt,

$44 \mathrm{~b} \beta \quad$ aber du, du wirst zum Schwanz.

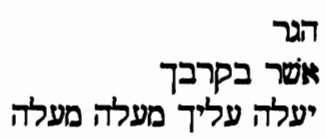

ואתה תרד מטה מטה

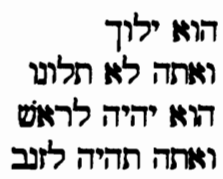

\subsubsection{Textkritik}

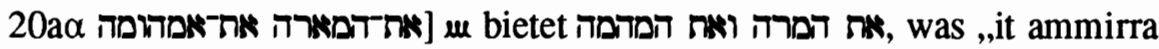
wit ammåmă“2 gesprochen wird. Das Verstummen des $*$ hat offenbar zu dessen Ausfall im ersten Nomen geführt. ואו dürfte Angleichung an das folgende וואתדהמגערת sein. ${ }^{3}$

1 Vielleicht ist גבול hier wie in 1 Sam 13,18 „Berg, Anhöhe“ zu übersetzen. Vgl. KEDAR, Semantik, 88.

2 BEN-HAYYIM, Tradition, 146.

${ }^{3}$ Vgl. HeMPEL, ,Wert,“ 230; RICHTER, $B H^{\prime}, 616$. 
20aß ידך ניד einige masoretische Handschriften und Hände“ CJ jdkwn ,eure Hand“. Das Jod vor dem Suffix muß nicht grammatischer Pluralanzeiger sein, sondern kann schlicht als mater lectionis dienen. Es handelt sich also vielleicht nur um eine Schreibvariante. ${ }^{1}$

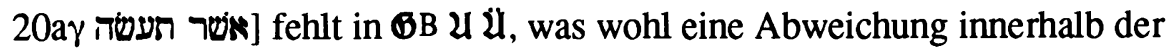

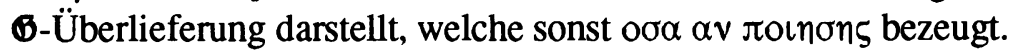

20b $\alpha$ [השמדך Nif al Inf. cstr. + ePP ,vertilgt werden“. u schreibt dagegen השמידך, Hif'il Inf. cstr. + ePP ,ausrotten“.

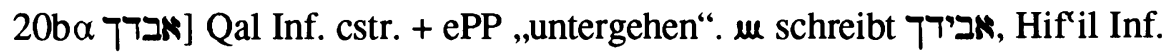
cstr. + ePP ,zugrunde richten“. Lohfink weist auf die Nif'al-Hif'il Schwankungen der beiden Formen von 20b $\alpha$ im Deuteronomium hin. Manchmal legen $\mu$ und $\boldsymbol{\sigma}$ ein ursprüngliches Hif ${ }^{\wedge}$ il nahe. Der ungewöhnliche Inf. cstr. des Hif'il wäre von $\mathfrak{M}$ als Nif'al vokalisiert worden. ${ }^{2}$

Doch die verschiedenen Verbstämme implizieren auch eine theologische Verschiebung. $\mathbb{m}$ macht die Verfluchten zum Subjekt des Untergangs. Durch שמד/N steht das passive Erleiden Mittelpunkt des Interesses. Israels Schicksal ist das Thema, dessen Ursachen nur aus dem Zusammenhang deutlich werden. Bei אבד/G wird Israel sogar zum aktiven Subjekt. Das enklitische Personalpronomen drückt in $\mathfrak{\mathbb { K }}$ jeweils einen genitivus subjectivus aus. Die Hif' ilverben des $m$ rücken dagegen die Aktivität einer von außen kausativ eingreifenden Macht in den Mittelpunkt. Das enklitische Personalpronomen wird zum genitivus objectivus, der auf das Opfer der Vernichtungsaktion hinweist. Die Infinitivformen verschleiern jedoch das Subjekt der Vernichtungsaktion. Daß JHWH als Letztursache dahinter steckt, wird nur aus dem Kontext klar. Die Haupttradition von $\mathbb{G}$ definiert dagegen Gott konkret als Subjekt der Vernichtung. $\varepsilon \xi \circ \lambda \varepsilon \vartheta \rho \varepsilon v \sigma \eta$ und $\alpha \pi 0 \lambda \varepsilon \sigma \eta$, Indikativ Futur 3. Person, kann nur auf das Subjekt des Hauptsatzes, xv@los, bezogen sein. So läßt sich von $\mathfrak{l}$ über $\mu$ zu $\mathbb{E}$ eine immer deutlichere Involvierung Gottes in die Vernichtung Israels feststellen. $\sigma 318$ U treiben diese Tendenz mit überdeutlichem $\varepsilon \xi \circ \lambda \varepsilon \vartheta \varrho \varepsilon v \sigma n$ xv@los auf die Spitze. $\mathfrak{D}$ ist ebenso klar mit donec conterat te. Abgesehen davon, daß die hebräischen Infinitive schwer ins Griechische oder Lateinische zu übersetzen sind, sind die finiten Verbformen wohl eine Vereinfachung gegenüber $\mathfrak{k}$.

(6 besitzt die Tendenz, die Logik der Zusammenhänge stärker zu verdeutlichen und dabei die Vernichtungsdrohungen zu verstärken. Außerdem enthält Dtn 27-34 insgesamt mehr Abweichungen von $\mathbb{R}$, die auf theologi-

\footnotetext{
${ }^{1}$ Vgl. Hempel, „Wert,“ 217-219; Penna, Deuteronomio, 229; Richter, $B H^{t}, 618$.

2 Vgl. ,שמד,“"Manuskript.
} 
sche Anliegen von $\boldsymbol{B}$ zurückgeführt werden können. ${ }^{1}$ Eine noch weiter von m entfernte theologische Vorstellungswelt zeigen Lesarten, die in Nebenüberlieferungen von $\mu$ und 6 aufscheinen. $\mu \mathrm{B} \mu \mathrm{B}$ השמידוך ועד דאטבידוך und (6509 $\varepsilon \xi \circ \lambda 0 \vartheta \varrho \varepsilon v \vartheta \omega \sigma \iota v$ stellen mit ihren finiten Pluralformen die drei Objekte von 20a $\alpha$ als selbst wirkende Subjekte der Vernichtung dar. Hinter diesen Formen dürfte eher die Angleichung an ורדפוך in 22b $\alpha$ und ähnliche Formulierungen in $2 \mathrm{a} \beta .15 \mathrm{~b} \beta .45 \mathrm{a} \beta . \gamma$ stecken als Reste eines älteren noch in magischem Denken verhafteten Textstadiums. Dieselben textkritischen Erwägungen gelten auch für die Formen in $22 \mathrm{~b} \beta$ und $24 \mathrm{~b} \beta$.

20by עזבתני] Der Wechsel in die erste Person ist gegenüber den Formulierungen von $6 \mathrm{~d}$ (außer 125) $t \varkappa v$ und $\mathbf{6} 75$ Bo avtov lectio difficilior.

21ba כלתו] In BHS2 fehlt, aufgrund eines Druckfehlers das Dagesch im Lamed. $m$ hat כלותו entsprechend der Aussprache „kallūtu“2. Aus herodianischer Zeit stammt 4 QDtg, das Dtn 28,21-24 in einer mit $\mathfrak{l}$ identischen Form enthält. ${ }^{3}$

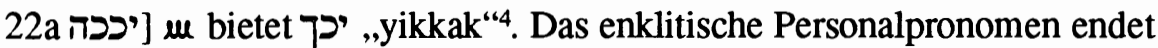
also im samaritanischen Dialekt nicht wie in $\mathfrak{k}$ auf $-k \bar{a}$. He als Anzeiger für den langen Vokal des Suffix ist für $\mathbb{m}$ außergewöhnlich. ${ }^{5}$ Doch wird dies die ursprüngliche Schreibung sein, da auch einige $\mu$-Handschriften יככה יכדיכה bezeugen ( $\mu \mathrm{d} 1 \mathrm{X} 1 *$ יככ.ה). Gleiches gilt für die Belege von יככה in 28,27.28.35.

22a ובחרב ûbaharaeb ,mit dem Schwert". D übersetzt aestu ,mit Hitze“ = ûbahorarb. Malusà zeigte, daß die Konsonantenfolge $h r b$ auch in den semitischen Versionen $\boldsymbol{C}$ und $\boldsymbol{S}$ mehrdeutig ist. Als klare Option für die Bedeutung "Schwert" führt er $\boldsymbol{6}$ an. ${ }^{6}$ Doch yov $\omega$ heißt nicht Schwert, sondern Mord. Das kann auf das Schwert als Mordinstrument zurückgehen ${ }^{7}$, kann aber auch die Hitze der Haßgefühle im Blick haben, aus denen Mordgedanken entspringen. Jedenfalls scheint in der griechischen Tradition hier eine Verständnisschwierigkeit gelegen zu haben. So schreiben $6344 \mathrm{mg} 407$

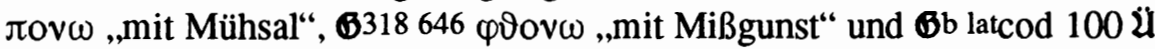
U $\varphi \circ \beta \omega$,mit Furcht“. Diese phonetisch ähnlichen Abweichungen beruhen vielleicht auf Hörfehlern. Sie lassen aber erkennen, daß pov $\omega$ nicht das

1 Vgl. DOGNIEZ / HaRL, Bible, 37, 39.

2 BEN-HAYYIM, Tradition, 146.

3 Vgl. WhITE, „Manuscripts,“ 23, 35, 41.

${ }^{4}$ BEN-HAYYIM, Tradition, 146.

5 Vgl. HEMPEL, ,Wert,“ 228.

6 Vgl. „Interpretazione,“259-261.

7 Vgl. DOGNIEZ / HaRL, Bible, 288. 
Wort war, das man in diesem Kontext erwartete. Barthélemy hält die Vokalisation abahaeraeb für eine Textvereinfachung und die Angleichung an parallele Passagen. Er schlägt vor, âbahorab zu lesen. ${ }^{1}$

22b ירדפוך עד אבידוך yirdåfok 'ad abbīdok“2, , s wnrdpwnk ' $d m$ ' d'bdwnk. $\mathcal{S}, \mathfrak{G}$ und $\mathfrak{D}$ bestätigen die Konjunktion am Anfang von 22b. Der Wechsel von Waw zu Jod dürfte ein Schreib- oder Lesefehler sein. $\sigma$ hat $\varepsilon \omega \varsigma \alpha v \alpha \pi 0 \lambda \varepsilon \sigma \omega \sigma \iota v \sigma \varepsilon$,bis sie dich verderben“ mit den Krankheiten als Subjekt, $6963^{*} \alpha \pi 0 \lambda \varepsilon \sigma \varepsilon \tau \varepsilon$,bis ihr verderbt“ mit Israel als Subjekt, ähnlich $\mathfrak{D}$ persequatur donec pereas ,er (Gott) möge dich verfol-

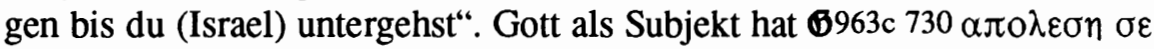
6319 $\alpha \pi 0 \lambda \varepsilon \sigma \varepsilon \iota \sigma \varepsilon$. $\mathbb{K}$ bietet gegenüber den finiten Verben lectio difficilior und lectio brevior.

IT verbindet unterschiedliche theologische Perspektiven miteinander. Einerseits agieren die Krankheiten als wirksame Fluchmächte (ורדפוך), andererseits ist das Subjekt des im Infinitiv ausgedrückten Untergehens (אבדך) Israel selbst bzw. JHWH, falls man das enklitische Personalpronomen in $21 \mathrm{a} \beta$ auf ihn beziehen soll. So ergibt sich in $\mathbb{k}$ ein Perspektivenwechsel, den die Versionen - bis auf $6963^{*}$ und $\mathfrak{D}$ - nicht nachvollziehen, da sie durch finite Verben im Singular oder Plural entweder Gott oder die Fluchmächte zum Subjekt der Vernichtungsaussagen machen. הבידוך in щD10 X2 $\vartheta \mathrm{X}^{*}$ dürfte auf samaritanischer Aussprache beruhen, denn die Gutturale Ajin, He, Het wurden Aleph angeglichen. ${ }^{3}$

23a $\alpha$ שמיך] Die meisten $\mathbb{G}$-Handschriften haben nur o ovgavos. Ein Pos-

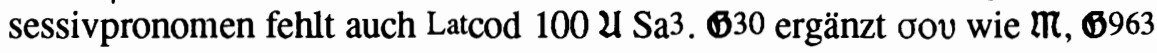
бol. $\mathbf{S}$ bietet nur šmj', $\mathfrak{D}$ nur caelum. Der Wegfall des Possessivpronomens scheint eine Angleichung an ודאמים in $23 b \alpha$ zu sein. Außerdem wird im AT nur selten mit einem enklitischen Personalpronomen versehen. ${ }^{4}$ Es kann sich also auch um Einfluß durch den sonst im AT verbreiteten Sprachgebrauch handeln.

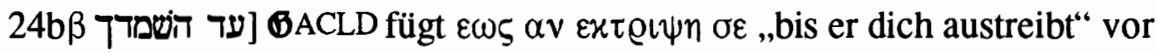

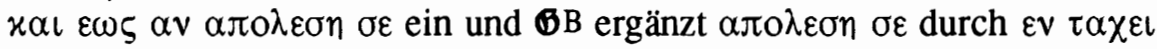
aus V. 20.

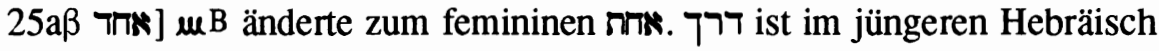
feminin.

\footnotetext{
1 Vgl. Report, 295.

2 BeN-HaYYiM, Tradition, 146.

3 Vgl. BEN-HAYYIM, „Observations,“ 14.
}

${ }^{4}$ Lev 26,19; Ps 8,4; 33,28; 144, 5. Das ist auffällig im Verhältnis zu אר, das im AT 38mal allein mit dem enklitischen Personalpronomen der 2. Person Sg. auftaucht. 
25b לזעוה] Die Konsonanten des seltenen Wortes werden in einigen Handschriften und im $\mu$ an Jes 28,19 angeglichen. $\mathbb{O}$ übersetzt $\varepsilon v \delta\llcorner\alpha \sigma \pi \circ \alpha, \mathcal{D}$ dispergaris. Das Wort wurde also als Zerstreuung interpretiert. Genauso wird das hebräische Wort auch Jer 34,17 = 11,17 wiedergegeben. An den

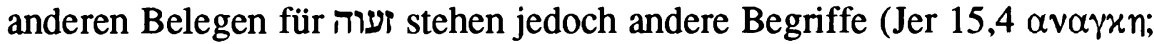

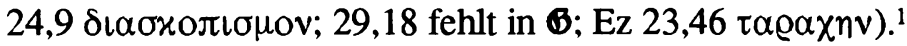

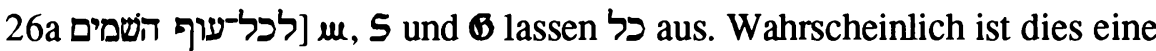
Angleichung an לבדמת (ל ס bezeugt cunctis. ${ }^{2}$

27a ובעפלים Statt des Ketib „Beulen“ setzt die masoretische Tradition das Qere טחרים

27a ובחרס ש M X1 schreiben ובהרס ,mit Zerstörung“ (vgl. Jes 19,18). Das Het bleibt im Samaritanischen stumm „wbērrås". ${ }^{4}$ So kam es wohl zu diesem Schreibfehler.

28 [ובעורון ובתמהום BB 963 b 509 lassen die Konjunktion xal aus. B verzichtet bis auf wenige Handschriften auf die Übersetzung des hebräischen $ב$ in den Krankheitsflüchen.

29a $\alpha$ בצהרים B vokalisierte bașāh ${ }^{a}$ rajim.

תצליח דרך 29a und einige Handschriften von 17 haben nur „,(nicht) gelinge der Weg“, 5 wl' $t s q$ 'wrhk $l r j s ̌ s$, ,und nicht führt dein Weg

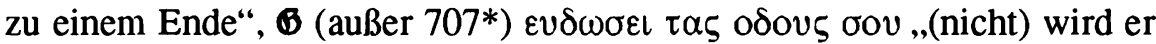
(der Blinde?) deine Wege gut führen“, $\$ 500$ ป̀ $\mathfrak{U} \varepsilon v \delta \omega \sigma \varepsilon\llcorner\varsigma$,,(nicht wirst du...". Die Versionen zeigen, daß die Formulierung von $\mathfrak{m}$ nur umschreibend übersetzt werden kann. Der Wegfall der Akkusativpartikel im Hebräischen ist eine Vereinfachung, da תצליח dann Subjekt vorden kann. Barthélemy empfiehlt, $\mathfrak{m}$ zu folgen. ${ }^{5}$

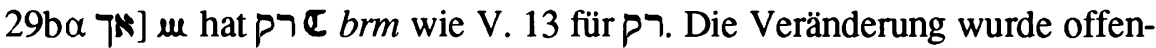
bar durch Parallelstellen beeinflußt (vgl. 33b).

30aa2 ישגלנה [ישל Einige Handschriften und $\mathbb{C}$ ersetzen das Ketib von $\mathfrak{m}$ durch

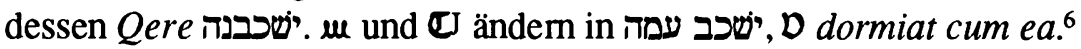

1 ,... Lorsque ce mot hébreu est appliqué à Israël, comme ici ou en Jr 34 (41), 17, le traducteur évite de le traduire exactement et lui substitue l'idée d'exil ou de dispersion ... . Le mot diasporá et un néologisme ... ." DOGNIEZ / HARL, Bible, 289.

2 Vgl. RicHTER, $B H t, 620$.

3 Vgl. RichTER, $B H t, 620$.

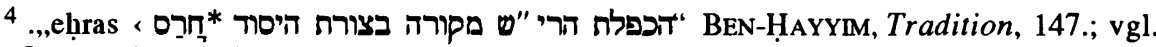
„Observations,“" 19.

5 Vgl. Report, 295.

6 Vgl. Nielsen, נתי, 21.24; Buts / LeClercQ, Deutéronome, 176; Penna, Deuteronomio, 231: „la possederà, il raro verbo ebraico, in forza della sua etimologia, non include qualcosa 
32b ידך] Viele masoretische Handschriften haben ידיך,, שJ bjdjkwn. Die Einfügung des Jod scheint denselben orthographischen Schwankungen zu unterliegen, auf die bereits unter $20 \mathrm{a} \beta$ hingewiesen wurde. BHK und BHS empfehlen unter Hinweis auf Gen 32,29, $\mathfrak{k}$ zu folgen (vgl. auch Neh 5,5).

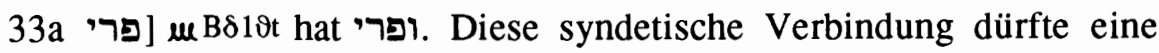
Angleichung an V. 18.42 sein.

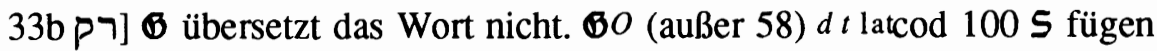

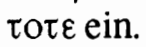

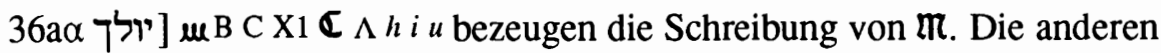
u-Handschriften haben jedoch יוליך, entsprechend der Tendenz des $\mu$, im Hif'il plene zu schreiben. ${ }^{1}$ Die $m$-Belege zeigen wohl keine Tradition, die in V. 36 den Jussiv nicht kannte, sondern eine orthographische Variante.

36a $\alpha$ מלכך] $\mathbb{C}^{\mathrm{J}}$ hat das enklitische Personalpronomen der 2. Person P1., G

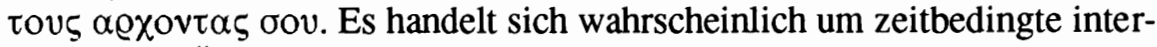
pretierende Übersetzungen. ${ }^{2}$

36b ועבדת Die Pluralbelege für $\lambda \alpha \tau \varrho \varepsilon v \sigma \varepsilon \tau \varepsilon$ in $ఠ d t$ latcod $100 \widetilde{C}^{\mathrm{J}}$ sind nur marginal. ${ }^{3}$

37a לשם מש לשמה למשל schreibt. Das ist vielleicht nur eine abweichende Form von $\mathfrak{m}$, doch es könnte auch den schlechten Namen oder ein

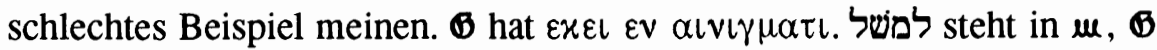
und $\mathbf{S}$ mit Konjunktion. Vielleicht resultiert dies aus dem Einfluß von Jer 24,9, wo das Wort in einer Aufzählung ebenfalls an zweiter Stelle steht. ${ }^{4}$

$39 \mathrm{~b} \alpha_{2}$ [תאג [ $_{3} \boldsymbol{\sigma} \mu$ unterlief scheinbar wegen der stummen Gutturale im Samaritanischen ein Schreibfehler: תגאר. ( 1 (außer 707) erweitert interpretierend $\varepsilon \cup \varphi \varrho \propto \vartheta n \sigma n \varepsilon \xi$ $\alpha \cup \tau o v$, du sollst dich daran (nicht) freuen“. 5

40b $\beta$ ישל של-Manuskripte schreiben samaritanischer Aussprache entsprechend ישעל ,yěšā'al"6. Ben-Ḥayyim erklärt, die samaritanische Tradition habe das Verb שעל bewahrt, welches nicht im AT, wohl aber in der tannaitischen Literatur auftaucht. Man kann aber nicht bestimmen, ob

di negativo (il sostantivo in Sal. 45,10 indica la regina), ma i masoretici suggeriscono sempre (cfr. Is. 13,16; Ger. 3,2; Zac. 14,2) l'equivalenza con (= gị (= giacere con una donna)".

1 Vgl. Ben-HAYYiM, „Observations,“ 15.

2 Vgl. BuIs / LECLERCQ, Deutéronome, 177.

3 Vgl. Penna, Deuteronomio, 233.

4 Vgl. Buts / LeCLERCQ, Deutéronome, 177.

$5 \mathrm{Vgl}$. Schultz, Differences, 14.

${ }^{6}$ BEN-HAYYIM, Tradition, 148. 
die Form Imperfekt Qal oder Pi'el ist. ${ }^{1}$ So entsteht die Doppeldeutigkeit ,abfallen“ mit dem Subjekt ז in 40b $\beta$, oder ,abwerfen“" mit dem Subjekt זית aus 40a und dem Plural des Verbs, wie ihn $\mu b d 1$ mit ישל mit ישעלו bieten. וית 40b 40 wäre dann Objekt. $\mu N \mathrm{~N}$ Q setzt auch das noch in den Plural. Die Pluralsetzungen dürfen gegenüber dem Numeruswechsel zwischen $40 \mathrm{a}$.b $\beta$ in $\mathrm{m}$ als Vereinfachungen gelten.

42 יירש = Hif'il. Der H-Stamm des Verbs ist häufig belegt (in der Bedeutung ,,in Besitz nehmen“ in Num 14,24; 33,53; Ri 1,14; Jos 8,7). Das Pi'el der Wurzel kommt jedoch im AT nur an dieser Stelle Dtn 28,42 vor. $\mathbb{M}$ ist daher lectio difficilior.

\section{2. 2. Forschungsgeschichte und Literarkritik}

\subsubsection{Beobachtungen zur Textstruktur}

Als beabsichtigtes Merkmal des Textes fielen Steuernagel die Parallelen zum Segen auf. ${ }^{2}$ Seitz entdeckte in den gemeinsamen Motiven von Segen und Fluch chiastische Anordnungen, die er ebenfalls auf bewußte Gestaltung zurückführte. Folgende Tabelle ergänzt die Zusammenstellung von Seitz mit der Angabe der chiastischen Verbindung und einem hebräischen Begriff zur Inhaltsbestimmung: ${ }^{3}$

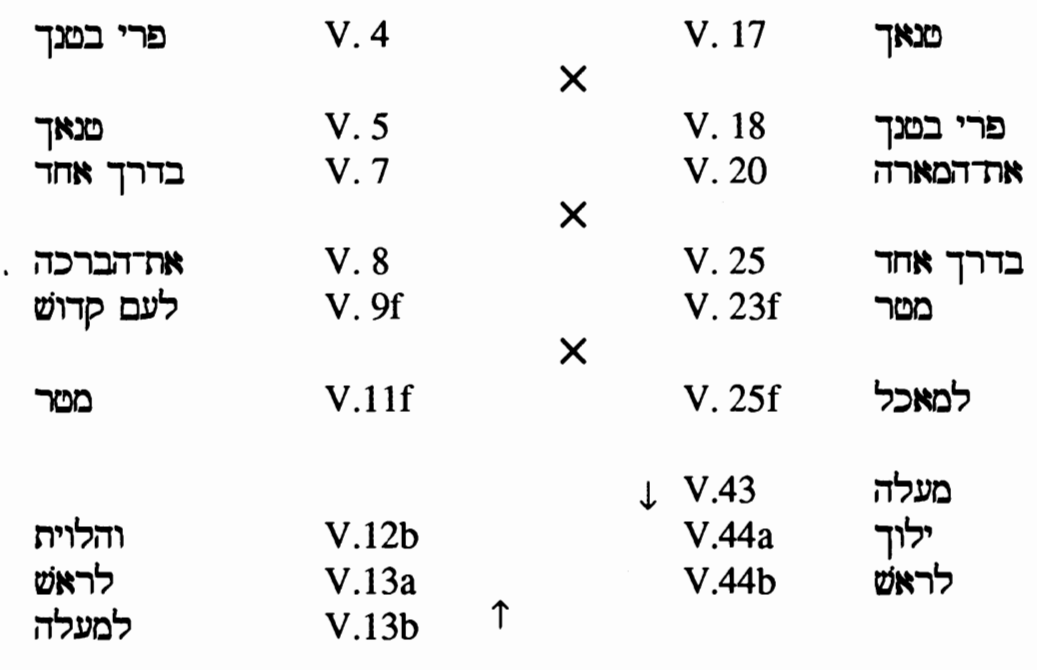

1 Vgl. „Observations,“" $16 f$.

2 Vgl. Übersetzung, 99.

${ }^{3}$ Vgl. Studien, 259. Die Tabelle macht deutlich, daß V. 3/16 und 6/19 nicht in die Chiasmen einbezogen sind, die Beziehung zwischen V. 9f/25.26 angesichts der deutlicheren Entsprechung von V. 7/25 ein wenig gezwungen wirkt und in V. 12f/43f ein Doppel(12b.13a/44) und ein Einzelmotiv chiastisch vertauscht sind. 
An Form, Rhythmus, Syntax und parallelismus membrorum erkannte Seitz, daß V. 23f und 43f für den entsprechenden Segen V. 12-13a als Vorlage dienten und demnach älter sind als der Segen. ${ }^{1}$

Als strukturelle Besonderheit arbeitete Hillers in 28,30-32.38-41 die futility curses heraus. Ihre rhythmische Sprache hebt sie vom Kontext ab. ${ }^{2}$ Plöger bestimmte 28,30f als eine Reihe antithetischer Flüche und teilte sie in eine Gruppe mit 2 Hebungen pro Stichos (V.30) und eine mit 3 Hebungen pro Stichos (V.31). Beide Verse sollen allein existiert haben. 28,38-41 besitzen zwar wie 30f Rhythmus und Antithesen, darüber hinaus aber einen motivierenden $k \hat{\imath}$-Satz. Am Ende der beiden Reihen erkannte er in 28,34+42 je eine Zusammenfassung. ${ }^{3}$

Von Hillers übernahm Seitz die Klassifizierung der Fluchformen. Der altorientalische Fluch mit Anrufung der Götter wurde in Israel zum Fluch bei JHWH. So ordnete er 28,20-22.24f.27f.35f.49 einer Reihe gleichartig gebauter Flüche $\mathrm{zu}^{4}$ Schächter wies darauf hin, daß die grammatische Struktur dieser Verse jeweils mit yiqtol- $x$ beginnt. ${ }^{5}$ Thompson arbeitete zwischen 28,25-37 eine palindromische Struktur heraus. ${ }^{6}$ Am Schluß (V. 36f) läßt sich die Palindromie nicht ganz durchhalten. Dies deutet auf nachträgliche Texteingriffe hin. Sumner identifizierte hier die Hand eines Interpolators, der das chiastische Orakel der Verse 27-35 nachträglich durch Jeremiazitate gerahmt hat. Während es nämlich innerhalb von V. 27 35 Wortverknüpfungen gibt, korrespondieren bei V. 25b im Hinblick auf V. 37 und bei V. 26 in Beziehung zu V. 36 nur die Ideen. Daß beide Abschnitte Ergänzungen einer einzigen Hand sind, erkannte Sumner daran,

1 Vgl. Studien, 259f; MAYEs, Deuteronomy, 350f; HILlERs, Treaty-Curses, 38-40, fand poetische Stücke in Dtn 28,23.24.25a.44.

2 Vgl. Treaty-Curses, 35-37.

${ }^{3} \mathrm{Vgl}$. Untersuchungen, 154-159. Ebd. 157 handelt es sich in dem Satz: „v. 43 ist eine rhythmische Zusammenfassung wie v. 34 in der antithetischen Reihe vv. 32-33." anscheinend um einen Druckfehler. Oben steht das wohl gemeinte V. 42. Zur Unterteilung der Frustrationsflüche nach syntaktischen Gesichtspunkten vgl. PODELLA, ,Nichtigkeitsfluch,“ 432.

${ }^{4}$ Vgl. Studien, 279-282. Bereits NoTH, „Fluch,“ 132/160, hatte gefragt, ob die Sätze mit dem Motiv des Schlagens (22.27.28.35) einmal eine Reihe bildeten und enger aneinander anschlossen. PLOGER, Untersuchungen, 154-159, nannte diese verbalen Fluchsätze in V.22.27.28.29.35 die ursprünglich eigenständige „Schlagen“- Reihe. Jeder Vers beginnt mit dem Verb נכל ,schlagen“.

5 Vgl. Fluch, $157 \mathrm{f}$.

6 ,We have the following items listed: $a$. defeat before enemies, 25a; $b$. Israel will become a horror and her corpses will be unburnt, 25b, 26; $c$. incurable diseases, 27; $d$. madness, 28; $e$. continual opression, 29; $f$. frustration, 30-32; $e^{1}$. continual oppression, 33; $d^{1}$. madness, 34; $c^{1}$. incurable disease, $35 ; a^{1}$. Israel defeated by an enemy, 36; $b^{1}$. Israel becomes a horror, 37. There is, in fact, a slight breakdown in the chiasmus at the end, for the elements $a$ and $b$ are reversed." THOMPSON, Deuteronomy, 273. 
daß Dtn 28,25b.37 zusammen auf Jer 24,9; 29,18 anspielen. ${ }^{1}$ Ein Schaubild veranschaulicht dies:?

Dtn 28.25b ודיית לזעוה לכל־ממלכות הארץ המוץ

Jer 24,9

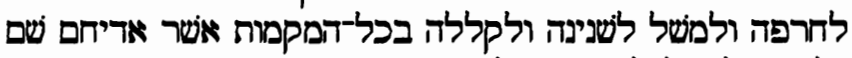

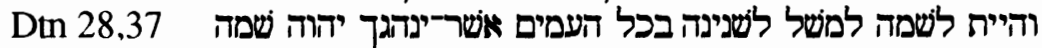

Die im Deuteronomium auf die Verse 25b und 37 aufgeteilten Stichwörter finden sich bei Jeremia innerhalb eines Verses.

Faßt man die referierten Erkenntnisse der bisherigen Forschung zusammen, läßt sich die Struktur von Dtn 28,20-44 in folgendem Schema darstellen:

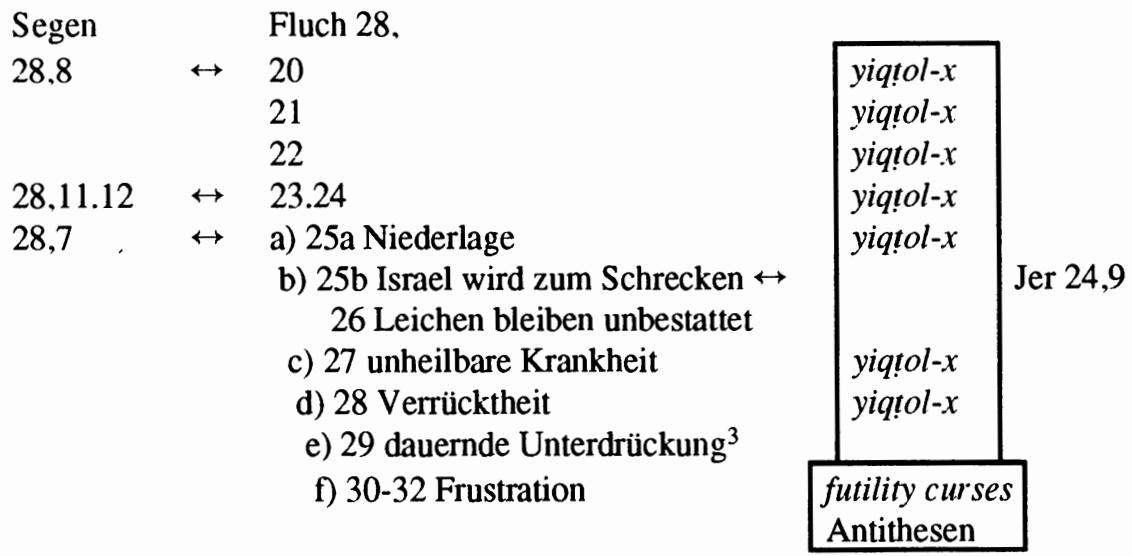

\footnotetext{
${ }^{1} \mathrm{Vgl}$. Study, 102-105, 113f, 115: „In the two Jeremiah passages, Deut. 28:25b and 28:37 appear in the same sentence as complementary to one another. In this respect, the chiastic nature of these two verses is increased by reference to Jeremiah."

${ }^{2}$ Auf die Wiedergabe von Jer 29,18 wird verzichtet, da die Passage 29,16-20 in 6 fehlt, wo der ältere Textumfang bewahrt ist. Vgl. Herrmann, Jeremia, 48, 148f; STIPP, Sondergut, 79; Person, Zechariah, 64, 79 Anm. 21. Die Parallele zwischen Din 28,25b und Jer 24,9 wird noch deutlicher, wenn man berücksichtigt, daß לרעה prämasoretischer Zusatz ist. Vgl. STIPP, Sondergut, 74f.

3 „Zusammengehalten wird das Ganze durch zwei beinahe gleichlautende Sätze: v. 29b

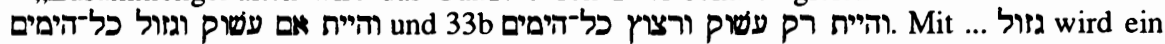
Wort aus einem der Gegensatzflüche (v.31) aufgegriffen, zum andern schlagen die Verbalformen im perfectum consecutivum eine Brücke zu den ... gleichgebildeten Formen in v. 29a und v. 34 (והיית)." SeItZ, Studien, 285. Vgl. Braulik, Deuteronomium II, 206.
} 
e') 33 dauernde Unterdrückung

d') 34 Verrücktheit

c') 35 unheilbare Krankheit

a') 36 Niederlage

b')- 37 Israel wird zum Schrecken $\leftrightarrow$ $38-41$

$28,12.13 \leftrightarrow 43.44$

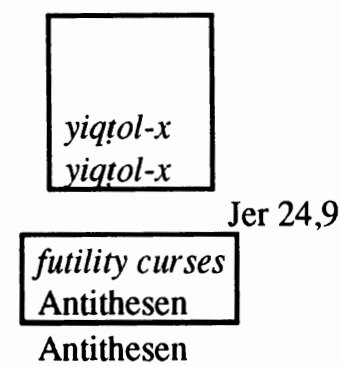

Einige Phänomene des Textaufbaus erwecken den Eindruck bewußter Gestaltung. Man erkennt, daß der gesamte Abschnitt 28,20-44 in den Frustrationsflüchen 28,30-32 eine Mitte besitzt, um die sich die palindromische Struktur von 28,25-37 lagert. Auch der Aufbau der übrigen Partien scheint nicht willkürlich. Die Bezüge zum Segen finden sich am Anfang und am Ende der Einheit. Allerdings besteht ein Übergewicht am Beginn. Dort sind aber nicht nur die Parallelen zum Segen vermehrt anzutreffen, sondern auch die Satzstruktur yiqtol-x. Dagegen überwiegen im zweiten Teil Sätze mit antithetischem Aufbau (28,38-41.43f). Beide Satzstrukturen, yiqtol-x und Antithesen, ähneln zwei Bändern, die in 28,30-36 ineinander verschlungen sind. Umfangmäßig halten sich die Abschnitte vor (V. 20-24) ${ }^{1}$ und nach (V. 38-44) ${ }^{2}$ dem palindromischen Mittelstück etwa die Waage. Keiner der oben angeführten Forscher arbeitete die ganze Struktur des Schemas heraus. Es wurde aus ihren unterschiedlichen Beobachtungen zusammengetragen. Man zog auch keine Schlußfolgerungen bezüglich eines Gestaltungsprinzips für den Abschnitt, das die verschiedenen Strukturmuster integriert, wie es hier durch die Metapher der zwei ineinander verschlungenen Bänder mit vorherrschenden yiqtol-x-Sätzen bzw. Antithesen vorgebracht wird. Im Gegenteil, die Strukturmerkmale dienten der Forschung bisher hauptsächlich als Ansatzpunkte für die Literarkritik.

\section{2. 2. 2. Zur Literarkritik}

Literarkritische Analysen von Dtn 28,20-44 sind bestimmt durch Prämissen, die von außen an den Text herangetragen wurden und auf die Bewertung von Spannungen, die die Einheitlichkeit in Frage stellen, einwirkten. So kann es nicht verwundern, daß neue Gesichtspunkte jeweils die literarkritischen Ergebnisse der Vorgänger samt deren Voraussetzungen in Frage stellten. Dabei gewann die Berücksichtigung altorientalischer Fluchsequenzen zunehmende Bedeutung.

\footnotetext{
174 Wörter.

268 Wörter.
} 
Die Prämisse, die Steuernagel und Hölscher an den Text herantrugen, war die Auffassung, Segen und Fluch seien ursprünglich parallel gewesen. Sie schieden in Dtn 28,20-44 alles als späteren Zusatz aus, was keine Entsprechung im Segen besitzt. ${ }^{1}$

Noth zog den $\mathrm{KH}$ als altorientalischen Vergleichstext heran. An ihm stellte er fest, daß Segen und Fluch im AO keineswegs parallel waren. Die literarkritischen Voraussetzungen von Steuemagel und Hölscher verloren daher ihre Plausibilität. Er konnte im Fluchabschnitt nicht mehr nur die Parallelen zum Segen als ursprünglich ansehen. Dennoch betrieb Noth Literarkritik und schied ohne nähere Begründung V. 29.34.36.37 als sekundär aus. Die ursprüngliche Zugehörigkeit von 28,38-41 schien ihm zweifelhaft. ${ }^{2}$ Nur bei V. $21 \mathrm{~b}$ gab er als Grund den Wechsel in die 1 . Person an. ${ }^{3}$ Der Segen entstand seiner Meinung nach größtenteils erst nach dem Fluch. Dies demonstrierte er vor allem an 28,43f und 28,12f. Den Fluch mit der Nennung des גempfand er als angemessen, den Segen mit seiner Ausweitung auf den internationalen Bereich (גוים) nicht. ${ }^{4}$

Plöger lehnte die These Noths vom Vorrang des Fluches vor dem Segen ab. Diese Einschätzung fußt aber nicht auf der Analyse von Dtn 28 selbst, sondern auf Erwägungen Reventlows zur Zusammengehörigkeit von Segen und Fluch im Bundesschlußschema, in Dtn 27 und in den Denkkategorien des Tun-Ergehen-Zusammenhangs. Er sah in V. 12f die Vorlage für 28,43f. ${ }^{5}$ Plögers eigener Literarkritik liegt die Arbeitshypothese zugrunde, $\mathrm{da}$ in den Rahmenstücken des Deuteronomiums Überlieferungseinheiten zusammengearbeitet wurden, die ursprünglich selbständig existierten. ${ }^{6}$ Eine zweite Prämisse seiner Literarkritik nimmt unhinterfragt für den Urbestand der gesuchten Überlieferungsstücke metrische Sprache an. Inhaltlich und formal ähnliche Passagen sezierte er zu ursprünglich selbständigen Reihen

1 ,.... In dem ersten Teil der Fluchrede (v. 15-46) entsprechen einige Sätze mehr oder weniger genau den Segenssprüchen ..., nämlich: v. 15-19. 20*. 23-24*. 25a.43-46. Man hat den Eindruck, dass dies Verhältnis ein beabsichtigtes ist, und wird darum alle übrigen Verse als spätere Zusätze ansehen müssen.“ STEUERNAGEL, Übersetzung, 99. Vgl. Rahmen, 40; HOLSCHER, „Komposition,“ 221; S MTTH, Deuteronomy, 307; RoSE, 5. Mose, 537.

$2 \mathrm{Vgl}$. NoTH, ,Fluch,“ 132f/160f.

${ }^{3} \mathrm{Vgl}$. „Fluch," 132/160. Die 1. Person in 20b diente auch STEUERNAGEL, Übersetzung, 101, schon als Argument für die Literarkritik. Er nannte aber noch mehr: ,פעלליך (bei Jer häufig) findet sich sonst im Dtn nicht; auch scheint Sg nicht einen schnellen Untergang gedroht zu haben, cf. zu 43f. ... ." Vgl. HolsCHER, „Komposition,“ 221 Anm. 2.

${ }^{4} \mathrm{Vgl}$. ,Fluch," 131f/159f.

5 Vgl. Untersuchungen, 133, 150; RevenTlow, Heiligkeitsgesetz, 144; Priorität des Segens auch bei EHRLICH, Randglossen, 332f; SCHÄCHTER, Fluch, 134f; THOMPSON, Deuteronomy, 273; BUIS, Deutéronome, 380; KRÄMER, Numeri, 516.

6 Vgl. Untersuchungen, 146. 
heraus und argumentierte oft metrici causa. ${ }^{1}$ In 28,20a $\beta$ störte ihn

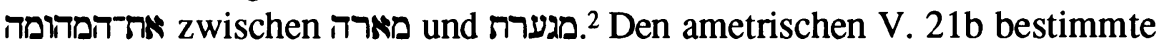
er ob seiner Anspielung auf das Exil als sekundär. 28,25b.26.29a.b.33f.37 nannte er durch והיתה oder והיית eingeleitete Erweiterungen, die die Fluchfolgen ausmalen. Wo das Thema Deportation auftaucht (28,32f.36.41), fand er exilische Ergänzung und auch V. 43f datierte er wegen der Umgestaltung der Parallele 28,12f ins Exil. ${ }^{3}$ Plögers eigene Terminologie offenbart die Problematik seiner Analyse. Er sucht Überlieferungsstücke. Ist das nicht Aufgabe der Überlieferungsgeschichte? ${ }^{4}$ Plöger kann nicht nachweisen, daß seine Überlieferungsstücke tatsächlich einen schriftlich fixierten Text bildeten. Darum geht es aber in der Literarkritik. Seine Reihen können ebensogut verschiedenartige mündliche Gestaltungsmuster für Flüche widerspiegeln, die von einem einzigen Autor verwendet wurden. Seine Analyse beweist nicht, daß die Reihen einen anderen Verfasser haben als den Urheber von Dtn 28,20-44 selbst.

Seitz wollte Formgeschichte und Literarkritik miteinander verbinden. ${ }^{5}$ Formgeschichtliche Argumente führten ihn zur Ausgliederung der Verse 24f.36. Die aus sechs Versen bestehende Reihe körperlicher Plagen $\left(20 a^{*} .21 \mathrm{ab} \alpha .22 \mathrm{a} \alpha^{*} .27 \mathrm{a} .28 .35 \mathrm{a}\right)$ habe eine andere Gestalt als diese drei Verse. ${ }^{6}$ Die einfachen Verwünschungen - eine von Hillers übernommene Gattungsbezeichnung - in V. 23.25b.26.29b.33b.34.37.42 betrachtete er als nachträgliche Entfaltungen der unmittelbar vorhergehenden Flüche. ${ }^{7}$ Gattungskritik diente als Ausgangspunkt der Literarkritik. In der Besprechung der futility curses urteilte er allerdings behutsamer als seine Vorgänger. V. 30-33 ist nach Seitz eine komponierte Einheit, bestehend aus den älteren Gegensatzflüchen V. 30.31 sowie der freieren Nachbildung deren strenger

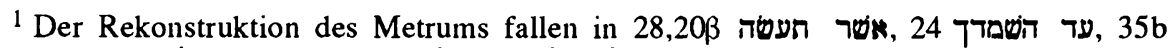

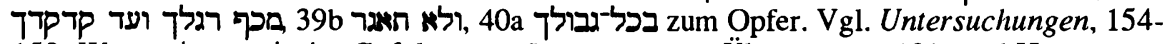
158. Wenn עשר תעשה im Gefolge von STEUERNAGEL, Übersetzung, 101, und HOLSCHER, „Komposition,“ 221, ausgeschlossen wird, weil es in $\boldsymbol{\sigma}$ fehlt, vermischt man Text- und Literarkritik.

${ }^{2} \mathrm{Vgl}$. Untersuchungen, 158. HOLSCHER hatte in 20a אתדהמהומה ואת־המגערת als asyndetischen Zusatz streichen wollen. Vgl. „Komposition,“ 221.

${ }^{3} \mathrm{Vgl}$. Untersuchungen, 158f. Bereits STEUERNAGEL, Übersetzung, 101f, hatte 28,25b.26 als Zusatz aus Jeremia bestimmt, 29a als Ausmalung von V. 28 qualifiziert und in 36.42 ein vaticinium ex eventu gesehen. In PLOGERs Analyse kommen also noch die Auffassungen STEUERNAGELs durch, deren Basis die Prämisse der Segen-Fluch-Parallelität bildete.

${ }^{4} \mathrm{Vgl}$. FoHrer, Exegese, 121.

$5 \mathrm{Vgl}$. Studien, 257.

6 Vgl. Studien, 282.

7 Vgl. Studien, 283. 
rhythmischer Form in V. 32-33a. Der gesamte Abschnitt V. 30-33a wurde durch die Verse 29b und 33b umklammert und erst später in den Kontext eingefügt. ${ }^{1}$ Die Umklammerung der Teilreihe in V. 30-33 durch beide Kehrverse ließ Seitz auf nachträgliche Eingriffe schließen, und diente ihm als Argument, die Gegensatzflüche in 28,38-40.43.44 für einen ursprünglichen Bestandteil von 28,20-44* zu halten, V. 30-33 jedoch als Ergänzung anzusehen. Der Weinbergfluch in 28,30 schien ihm eine Dopplung zum Weinbergfluch in 28,39. Den Deportationsfluch V. 41 und die Zusammenfassung der Frustrationsflüche (28,38ff) in V. 42 schrieb er demselben Redaktor zu, der auch V. 23f.25.29-34.36f eingefügt hat. ${ }^{2}$

Bei der Analyse der anderen Teile von Dtn 28,20-44 wiederholte er zumeist Beobachtungen von Steuernagel und Hölscher. ${ }^{3}$ Bei V. 21b grenzte er sich aber von Plögers Analyse ab. indem er עד כלתו beibehielt. Diese Formulierung kommt im AT meistens ohne Gebietsangabe vor. Den vergleichbaren Ausdruck in Ex 32,12 bestimmte er als deuteronomistisch. ${ }^{4}$

Man muß die der Gattungskritik entnommenen Voraussetzungen teilen, um die literarkritische Aussonderungen der Reihen verschiedener Formen durch Seitz zu akzeptieren. Altorientalische Texte zeigen jedoch, daß die von Hillers analysierten Fluchgattungen nebeneinander in Sequenzen stehen, die literarkritisch als einfache Einheit zu bewerten sind, da die altorientalischen Schreiber sie in einem zusammenhängenden Arbeitsgang schufen, wobei sie verschiedene Traditionen und Formen miteinander kombinierten.

Auch der Vergleich mit Flüchen des AO ist eine Prämisse, die von auBen an Dtn 28 herangetragen wird. Sie beeinflußte die Betrachtung des Kapitels auf der diachronen Ebene. Die von der Literarkritik hervorgebrachten Argumente verloren angesichts der Disparität altorientalischer Texte ihre Überzeugungskraft. ${ }^{5}$

\footnotetext{
$1 \mathrm{Vgl}$. Studien, $284 \mathrm{f}$.

$2 \mathrm{Vgl}$. Studien, 286f, 289.

${ }^{3}$ In V. 20 streicht SeITZ, Studien, 281, אתדדמהומה ואחדדמגערת. Beide Ausdrücke seien asyndetisch hinzugefügte Erklärungen zu אתדמארה, das an seinen anderen Belegstellen im AT auch keine Reihen bilde. Den Rest des Verses ab משלח ידך hält SEITZ für sekundär, weil משטר תעשה im Codex Vaticanus fehlt und sachlich nicht erforderlich sei, die Dopplung der Vernichtungsaussagen in $20 \mathrm{~b} \alpha$ den Eindruck der Überfüllung erweckt, מהר im Widerspruch zum länger währenden Unglück in V. 43 stehe und der Umschlag in die 1. Person sowie das Vokabular von $20 \mathrm{~b} \beta \gamma$ an Jeremia erinnere. Vgl. STEUERNAGEL, Übersetzung, 101f; HOLSCHER, „Komposition,“ 221.

${ }^{4} \mathrm{Vgl}$. SEITZ, Studien, 281, PLÖGER, Untersuchungen, 158. Die Möglichkeit einer nachträglichen Erweiterung des Verses 22 nach

${ }^{5}$ Zu Forschern, die Dtn 28 als Einheit ansahen, vgl. PREUSS, Deuteronomium, 154.
} 
Mørstad versuchte unter Hinweis auf altorientalische Parallelen im KH die Einheitlichkeit von Dtn 28 zu verteidigen und eine Literarkritik zu widerlegen, die sich auf postulierte Symmetrie zwischen Segen und Fluch, Dopplungen, als vaticinium ex eventu qualifizierte Exilsanspielungen oder Hinweise auf die schriftliche Tora stützte. Er hielt die ursprüngliche Symmetrie für unbeweisbar, da auch in den tatsächlich parallelen Abschnitten V.17/18, 25a/20a, 43a-44 Asymmetrien zu den entsprechenden Fluchversen bestehen. ${ }^{1}$ Wiederholungen und Verflechtungen der Fluchinhalte entsprechen der im AO herrschenden Norm für Umfang und Thematik der Flüche. Dieser mündlichen Fluchspruchnorm folgend flossen die thematisch gleichartigen Flüche 28,32.36.37.41.47-68 ins Urdeuteronomium ein. ${ }^{2}$ Auch im Epilog des KH herrscht ein Mißverhältnis zwischen dem 18 Zeilen umfassenden Segen und dem 294 Zeilen langen Fluch. Sein Fluchteil enthält wie Dtn 28 Themendopplungen und Variationen. ${ }^{3}$

Hillers behandelte Dtn 28 zusammen mit Lev 26. Der Vergleich mit anderen altorientalischen Verträgen widerlegt seiner Ansicht nach ein redaktionsgeschichtliches Wachstum des Textes, denn auch diese enthalten mehrere Schluß- und Einleitungsformeln wie 28,15.47.58, Hinweise auf die Schriftlichkeit des Dokuments $(28,58)$, Numeruswechsel (Sefire I B, Z. 23.38), eine Überlänge des Fluches gegenüber dem Segen, die Erwähnung von Deportation, Stilbrüche und das Fehlen eines logischen Gedankenfortschritts. Wie die Fluchlisten der Verträge so ist auch Dtn 28 eine Komposition, eine Sammlung und Anpassung traditionellen, mündlich überlieferten Materials. ${ }^{4}$

McCarthy arbeitete im gesamten Kapitel 28 eine Struktur heraus, die auf eine Klimax zuläuft. Diese Struktur kann erst durch die Dtr II-Redaktion endgültig ausgestaltet worden sein, der er 28,47-68 zuschreibt. 28,1-45 erscheint ihm als Einheit, die die Bedingungen für den Eintritt von Segen (V. 1f13b14) und Fluch (V.15.45f) den Resultaten (3-13a.16-44) gegenüberstellt. Unpersönliche Formulierungen (3-6.16-19) wechseln mit Aktivitäten JHWHs ab, die jeweils noch durch Aussagen mit anderen Handlungssubjekten weitergeführt werden (30-34.38-44). Er lehnt es ab, die Kriegsoder Deportationsmotive (28,30-34.37b.48-57.64-68) als vaticinium ex

\footnotetext{
1 Vgl. „Overveielser,“ 224-226.

2 Vgl. „Overveielser,“ 226-230. Er will nicht die Möglichkeit nachträglicher Zusätze, z. B. in 28,36f.41, leugnen, doch die Selbstverständlichkeit der Argumente der traditionellen Literarkritik in Dtn 28 in Frage stellen.

${ }^{3}$ Vgl. „Overveielser,“ 229f. Er nimmt bereits Auffassungen HILLERS bezüglich der Einheitlichkeit von Dtn 28 und der Rückführung der Gestaltungselemente des Kapitels auf eine mündliche Fluchtradition vorweg.
}

4 Vgl. Treaty-Curses, 26-28. 
eventu zu verstehen. Dtn 28 wuchs nicht einfach, sondern wurde aus der Intention heraus strukturiert, das besondere Verhältnis zwischen JHWH und seinem Volk unter dem Aspekt der Treue und des Gehorsams darzustellen. ${ }^{1}$

Jeremias meinte, das Deuteronomium übernahm V. 23-24ba.25a.26a. 32-33a $\beta_{1}$ sowie die gleichartigen mit "schlagen“ beginnenden Flüche V. 22.27.28.35 aus älterem - assyrischem - Traditionsgut. ${ }^{2}$ Die futility curses 28,30 und dessen Ergänzung V. 31 sowie V. 38-40 rechnete er zu vordeuteronomischem Material aus dem 8 . Jh. v. Chr., da futility curses auch bei Propheten des 8 . Jhs. begegnen. ${ }^{3}$

\section{2. 2. 3. Literarkritik}

Es herrschen in der Forschung verschiedene Auffassungen darüber, was Literarkritik leisten soll und wie methodisch vorzugehen ist. ${ }^{4}$ Sucht man bei der Frage, ob 28,20-44 eine einfache Einheit ist, nach störenden Wiederholungen und unvereinbaren Spannungen als Kriterien für Uneinheitlichkeit, so ergeben sich folgende Problemstellen:

(1.) In $28,20 \mathrm{~b} \beta \gamma$ bewirkt der Umschlag in die 1 . Person und ins Perfekt eine syntaktische Spannung. Außerdem liefert der Versteil die Begründung für das Eintreffen des Fluches aus der gleichen Sicht wie V. 45. Der Abfall, das böswillige Verlassen, ist bereits geschehen und nicht bloß zukünftige Möglichkeit wie in der Flucheinleitung (V. 15). Zur syntaktischen Spannung kommt also der inhaltliche Widerspruch im Verständnis der Fluchbedingung. V.20b $\gamma \delta$ scheint ein sekundärer Zusatz zu sein. JHWH-Rede, die beklagt, Israel habe ihn verlassen (עזב) (עב findet man im AT nur im DtrG und

\footnotetext{
1 Vgl. Treaty 1978, 179-181. Auch WEINFELD, School, $128 \mathrm{f}$ vertrat die Einheitlichkeit des Kapitels. Zur Kritik an HILLERS, McCARTHY und WeINFELD unter Berufung auf die literarkritischen Ergebnisse von PLOGER und SEITZ vgl. NICHOLSON, God, 74-77; zur Kritik an NICHOLSON vgl. LOHFINK, „Nicholson,“ $269 f$.

2 Vgl. Kultprophetie, 168.

$3 \mathrm{Vgl}$. Kultprophetie, 169f.

${ }^{4}$ Vgl. BrauliK, „Gedächtniskultur,“ 11; Werlitz, Studien, 42f; FoHRER, Exegese, 47f. „Einen Text, in dem sich weder unvereinbare Spannungen, noch störende Wiederholungen finden und der inhaltlich abgerundet ist, nennen wir einfache Einheit." ebd. 50.

5 עז Israel als Subjekt: Ex 23,5; Lev 19,10 = 23,22; Dtn 12,19; 14,27; 29,24 (Bund) = 31,16; Jos 24,20; Ri 2,12.13; 10,6.10.13; 1 Sam 8,8; 12,10; 31,7; 1 Kön 9,9; 11,33; 19,10.14 (Bund); 2 Kön 17,16 (Gebote); 22,17; Jer 1,16; 2,13; 9,18; 16,11; 19,4; 22,9 (Bund); 51,9; Ez 20,8; 24,21; Ps 37,8; Esra 9,10 (Gebote); Neh 5,10; 10,40; 1 Chr 10,7; 2 Chr 7,19 (Gebote).22; 17,5; 13,10.11; 15,2; 24,18.20; 34,25 משח אשיר עזבוני
} 
bei Jeremia. ${ }^{1}$ Immer gehört zu עזב die Verehrung fremder Götter. ${ }^{2}$ Jer 1,16

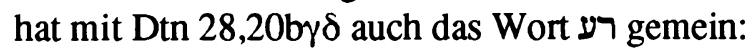

עer 1,16aßba עשר עזבוני

Dtn 28,20b

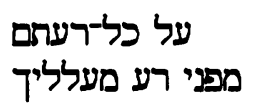

Der Ausdruck ePP + רע מעללי führt ebenfalls zu den Propheten. Er kommt in Umkehraufforderungen vor (Jes 1,16; Jer 23,22; 25,5; 26,3). Als Vergeltungsaufforderung steht es in Ps 28,4; Jer 21,12. In einem Begründungszusammenhang wie in Dtn 28,20 dagegen begegnet es nur Hos 9,15, einer Anklage gegen die Führer Israels, Jer 4,4 (poetisch) ${ }^{3}$, Jer 23,2 (dtr.), einem Wort gegen die Hirten, und Jer 44,22 (dtr.), der Begründung für die Eroberung Jerusalems. Die Wendung scheint von Hosea und Jeremia $(4,4)$ zur Begründung von Gottes Zorn eingesetzt worden zu sein. Deuteronomistische Überarbeitung an Jeremia verwendete sie weiter. Vor ihr stammt auch Jer $1,16 .{ }^{4}$ Wenn also in $28,20 \mathrm{~b} \beta$ eine Formulierung auftaucht, die im ganzen AT am meisten Jer 1,16 ähnelt und mit einer Wendung kombiniert ist, die in Jer siebenmal und sonst im AT nur noch dreimal vorkommt, liegt der Schluß nahe, daß mit diesem in Dtn 28 syntaktisch und inhaltlich auffälligen Halbvers auf Jeremia verwiesen werden sollte. ${ }^{5}$ Die Flüche von Dtn 28 stehen so im Licht des Urteils (משכט Jer 1,16), das Gott durch Jeremia ge sprochen hat.

(2.) Die Landnahmeformel in $21 \mathrm{~b} \gamma$ bedeutet eine Historisierung auf das Israel vor der Landeroberung. Es geschieht ein Perspektivenwechsel von der Beschreibung zukünftiger Möglichkeit des Fluches zur Situation der Adressaten der Moserede. Zwar ist nicht mit Sicherheit auszuschließen, daß der ursprüngliche Verfasser von 28,20-44 solch eine Nebenbemerkung

\footnotetext{
${ }^{1}$ Unberücksichtigt bleiben alle Belege, wo zwar prophetische JHWH-Rede vorkommt, aber dabei von JHWH in der 3. Person gesprochen wird (Jes 1,4;10,3; Jer 2,17; Hos 4,10). Die syntaktische Spannung in Dtn $28,20 \mathrm{~b} \beta$ entsteht gerade, weil von JHWH nicht in der 3 . Person geredet wird.

2 In Ri 10,13 antwortet Gott auf die Klagerufe der Israeliten angesichts der Ammoniterbedrohung; in 1 Sam 8,8 zieht er eine Parallele zwischen ihrem Ruf nach einem König und der Wahl anderer Götter; in 1 Kön 11,33 erklärt er, warum das Königreich Salomos geteilt wird; in 2 Kön 22,17 (= 2 Chr 34,25) begründet, warum alle Flüche der aufgefundenen Rolle Wirklichkeit werden; in Jer 1,16 kündigt Gott sein Urteil an; in Jer 2,13 vergleicht er sich mit einem Quell; in Jer 5,7 geht es um das Schwören; in Jer 16,11 um eine Strafgrunderfragung und in $2 \mathrm{Chr}$ 12,5 wird in Erweiterung gegenüber der Parallele in $1 \mathrm{Kön} \mathrm{14,25} \mathrm{der} \mathrm{An-}$ griff Pharao Schischaks auf das Jerusalem Rehabeams begründet.

${ }^{3} \mathrm{Zu}$ allen Klassifizierungen jeremianischer Passagen als poetisch oder deuteronomistisch in diesem Kapitel vgl. HeRRMANN, Jeremia, 41-52.

4 Vgl. HerRmanN, Jerenia, 41; THIEL, Jeremia 1-25, 74-76.

5 Vgl. LoHFinK, ,Jahwegesetz,“ 390 Anm. 21.
} 
im Blick auf die Adressaten der Moserede eingestreut haben könnte, doch handelt es sich um die einzige derartige Aussage in 28,20-44. So scheint es sich eher um einen späteren Zusatz zu handeln. Gehörte der Ausdruck in 21baß zum Grundbestand des Verses? Seitz möchte die Angabe des Territoriums von כלה מלה/D abtrennen. Endete also der Vers einfach mit einer Vernichtungsaussage? Dann ändert sich der Fluchinhalt. Ohne מעל האדמה handelt es sich um einen Krankheitsfluch, der zur völligen Vernichtung führt. Warum aber wird die Pest in einem eigenen Fluch genannt, wo doch in V. 22 eine Reihe von mehreren Krankheiten folgt? Außerdem stellt sich die Frage, warum in V. 21 zur Aussage der Vernichtung das einzige Mal im Kapitel 28 כלה/D verwendet wird und nicht wie sonst אבר oder. Nimmt man dagegen מעל האדמה hinzu, so wird nicht mehr völlige Vernichtung ausgesagt, sondern nur die Entleerung eines Raumes durch die Pest. Es besteht die Möglichkeit, daß die Verfluchten woanders weiterexistieren. Diese Tendenz scheint durch die Wahl des Wortes כלה/D intendiert. Denn dieses Verb drückt nicht eigentlich die Vernichtung aus, sondern daß man zu einem Ende kommt und sein Ziel erreicht. ${ }^{1}$ Gott macht durch die Pest ein Ende mit den Verfluchten. דבר ,Pest“ gehört zur Todessphäre und kann synonym zu מות ,Tod“ verstanden werden. Es geht also nicht einfach um Krankheit, sondern um Todesverfallenheit. ${ }^{2}$ אדמה bezeichnet dann nicht das Land Israel, sondern die Erdoberfläche, den Bereich der Lebenden. ${ }^{3}$ Durch die Seuche bewirkt Gott das Ende der Existenz der Lebenden auf der Erde und weist sie der Todessphäre, der Unter-Welt, zu. Derartige Todesmotive werden in den anderen Krankheitsflüchen von Dtn 28,20-44 nicht deutlich. Die Ausgrenzung von רבר aus den Krankheitsaufzählungen und die andere Formulierung rücken den Vers in die Todessphäre, zu der auch der Ausdruck des Verschwindens אדמה gehört. Der Zusatz der Landnahmeformel interpretierte מעל האדמה später zum Siedlungsgebiet Israels um. Nun ist der Bereich, in dem den Verfluchten ein Ende gemacht wird, nicht mehr der Erdboden, sondern das in Besitz zu nehmende Palästina. Das Ende auf der אדמה wird damit lokal begrenzt. Es bedeutet nicht mehr Verbannung in die Unterwelt, sondern Verbannung aus Israel. Außerhalb des von den in Moab versammelten Israeliten in Besitz zu nehmenden Landes ist eine Weiterexistenz denkbar. So drückt V. 21 den etwas merkwürdigen Gedanken aus, daß JHWH den Israeliten die Pest an den Hals schickt, um ihre Existenz in Palästina zu beenden. Die Stämme jenseits des Jordan oder die Israeliten in anderen

\footnotetext{
1 Vgl. HelfMeIER, כָלדָד, 170.

2 Vgl. WÄCHTER, Tod, $138 \mathrm{f}$.

3 Vgl. PLOGER, , 101.
} 
Ländern bleiben unbehelligt. Eine solche lokale Beschränkung der Vernichtung auf das Land westlich des Jordan kommt sonst in Dtn 28,20-44 nicht mehr vor. Ein späterer Redaktor wollte die Verse 20-44 wohl durch Landnahmeformel als Moserede in Moab historisieren.

(3.) Vom Kontext abweichende Terminologie findet man in V. 25b in dem Ausdruck כל ממלכות דארץ. Es handelt sich um die dritte ConstructusVerbindung im ganzen Deuteronomium, die einen Terminus für Volk mit in vל כליגויי הצמרץ :28 verbindet. Beide anderen stehen ebenfalls in Kapitel 28,1 und כל 28,10. Diese Variation läßt auf eine gestaltende Hand schließen, die zwischen ממלכה abwechselt. 28,1.10 עם and scheinen aber nicht derselben Schicht von Dtn 28 anzugehören wie 28,20-44*.1 Außerdem unterbricht der Perspektivenwechsel von der Niederlage auf dem Schlachtfeld (25a) zur Reputation in der internationalen Staatengemeinschaft (25b) die sonst im AT zusammengehörende Motivverbindung von Fall und Tierfraß an den nicht bestatteten Leichen (1 Sam 17,46; Jer 19,7; 34,20; Ez 39,4). Es scheint also angemessen, 25b für einen von Jeremia beeinflußten Einschub zu halten.

(4.) Inhaltliche Widersprüche zum Kontext enthält 28,36f. Das Deportationsthema allein wäre kein Grund für eine Ausscheidung. ${ }^{2}$ Doch gemäß 36a.37b wird das ganze Volk deportiert. In V. 38 lebt es aber wieder im Land und nur die Kinder werden deportiert (V. 42). 28,36f fällt durch die Nennung des Königs aus dem Rahmen und setzt das exilische ${ }^{3}$ Königsgesetz des Deuteronomiums voraus. Außerdem wird in V. 37 der Götzendienst nicht als Sünde, sondern wie in den sicher exilischen Versen Dtn 4,28; 28,64 als Strafe gedeutet. ${ }^{4}$ All diese inhaltlichen Aspekte begegnen

${ }^{1}$ Die Einleitungen enthalten im Gegensatz zu 28,20-44 deuteronomisch-deuteronomistische Formelsprache und sind, anders als der Segensabschnitt 28,7-14, lexematisch nicht mit V. 20-44 verknüpft. Sie scheinen jünger zu sein. Für den Segen gilt das Urteil von SEITZ, Studien, 275f: „Betrachtet man die Aussagen im einzelnen, so erweckt das Stück v. 7-12a sehr stark den Eindruck einer späteren kompilatorischen Arbeit. (...) Endlich deuten einige Ausdrücke auf späte Entstehungszeit hin.“

2 V. 36 gehört deshalb für IRwIN, „Criterion,“ 349, zum genuinen Bestand. Die Israeliten hatten während der Deportationen Tiglat-Pilesers 745 v. Chr. derartiges erlebt. CAZELLES, Deutéronome, 112f, sah darin Themen des Exils und verwies auf 2 Kön 17,4-6; 25,7.11; Am 5,27; 6,7; Hos 9,3; 10,6. Für CUNLIFFE-JONES, Deuteronomy, 156, bildete 28,36f eine Prophetie des Exils und kein vaticinium ex eventu. V. $36 \mathrm{f}$ stehen nach JUNKER, Deuteronomium, 532f, außerhalb des Zusammenhangs und spielen wohl auf die Deportation eines Königs aus dem Nordreich an.

3 Vgl. BraUliK, „Gedächtniskultur,“ 24. LOHFINK, „Sicherung,“ 313; GERTZ, Gerichtsorganisation, 29-31; SCHÄFER-LICHTENBERGER, Josua, 52f, 69-85.

4 Vgl. Braulik, Deuteronomium, 38: „... 41-10 eine Art Vorwort zu 5-28 aus exilischer Sicht ... ." Deuteronomium II, 208: 28,,47-68 aktualisieren die Flüche von 15-44 für die Zeit nach 586 v. Chr." 
sonst in $28,20-44^{*}$ nicht mehr und deuten auf eine exilische Entstehungszeit dieser Verse hin. ${ }^{1}$

Der Rest von Dtn 28,20-44 läßt sich als einfache Einheit verstehen. Die literarkritische Ausscheidung von Fluchreihen, wie die Serie der „Schlagen"-Flüche oder yiq!ol-x-Sätze durch Plöger, Schächter und Seitz oder der futility curses durch Jeremias griff in die Formen-, Traditions- und Überlieferungsgeschichte, denn sie arbeitete zwar gut beobachtete Formulierungskonventionen heraus, konnte aber nicht plausibel machen, daß diese Reihen einmal als eigenständiges Textstadium zusammenhängend existierten.

Die übrigen Ansatzpunkte der Literarkritik zu Dtn 28,20-44, erweisen sich weniger als tatsächliche syntaktische Störungen, inhaltliche Spannungen oder Dopplungen, sondern eher als Geschmacksache. Dies gilt zunächst für die Ausscheidung von את־־מהומה ואתדהמגערת in V. 20. Steht hinter diesem von Hölscher aufgebrachten Eingriff nicht noch das Bestreben zu ברכה in V. 8 nur ein Fluchäquivalent zu stellen? Wieso sollte man zur Erklärung mit מגערת später ein Hapaxlegomenon einfügen, das das Verständnis der Passage eher erschwert als erleichtert? Auch der Eindruck der Überfüllung scheint ein recht subjektiver Grund, um 20b $\alpha$ auszuscheiden, obgleich mit שמד אבד אמד eine inhaltliche Dopplung vorliegt. Es werden jedoch zwei verschiedene Verben verwendet und angesichts des häufigen Vorkommens beider Begriffe im Verlauf des Kapitels kann es sich auch um eine stilistische Markierung zu Beginn der Fluchsequenz handeln. Im schnellen Untergang von V. 20b (מהר) einen Widerspruch zu V. 43 zu sehen, überzeugt nicht. In 28,43 wird nicht vom Untergang der Verfluchten im Sinne des Wortes מבד gesprochen, sondern von Verarmung. V. 20 läßt auch nicht erkennen, an welche Zeitspanne man bei dem Wort מהר zu denken hat. Ebensowenig steht in V. 43, daß der soziale Abstieg langsam geschieht. Ein Widerspruch liegt also kaum vor. ${ }^{2}$

Um alle mit היה beginnenden Verse (28,23.25b.26.29b.33b.34.37) als nachträgliche Erweiterung bestimmen zu können, muß man die Prämisse übernehmen, daß zuvor selbständige Teilreihen existiert hätten. ${ }^{3}$ Nur V. 25b.37 sind tatsächlich auszusondem. Genauerer Betrachtung bedarf V. 26. Die ähnlichen Formulierungen in Jer 7,$33 ; 16,4 ; 19,7 ; 34,20$ führten

\footnotetext{
$1 \mathrm{Vgl}$. SumNER, Study, 94, 115.

2 Gegen SEITZ, Studien, 281.

3 „Es ist nicht möglich, die genannten Verse aus ihrem Kontext herauszulösen und zu einer selbständigen Teilreihe zusammenzustellen. Denn jede der einfachen Verwünschungen stellt eine Entfaltung oder Fortführung des unmittelbar vorher auftretenden Fluches dar." SEITZ, Studien, 283.
} 
vielfach dazu, den Vers als von Jeremia beeinflußten Zusatz zu betrachten. ${ }^{1}$ Thiel dagegen fand, daß die Formulierungen aus Dtn 28 ins Jeremiabuch gewandert seien. ${ }^{2}$ Meinung steht gegen Meinung. War Jeremia die Vorlage für Dtn 28,26 oder umgekehrt? Das Problem verdichtet sich noch. Ist 28,26 nämlich von Jeremia abhängig, handelt es sich frühestens um den Zusatz einer deuteronomistischen Redaktion ${ }^{3}$. Nun dürften aber auch Jer 7,33; 16,$4 ; 19,7 ; 34,20$ deuteronomistisch sein. ${ }^{4}$ In welche Richtung ging der Einfluß? Haben die deuteronomistischen Redaktoren zuerst an Dtn 28 oder an Jeremia gearbeitet? Vanoni zeigt auf, wie schwierig es ist, derartige Fragen allein mit dem exegetischen Methodenkanon zu beantworten. ${ }^{5}$

In einem solchen Fall scheint es gerechtfertigt, auf ein außerbiblisches Zeugnis zurückzugreifen: die VTE. Wächter und Jeremias hielten die Verbindung 28,25a.26 für ursprünglich, weil VTE $\S 41$, der Ninurtafluch, eine vergleichbare Motivkombination zeigt. ${ }^{6}$ Doch sind gerade die Themen des Paragraphen, die V. 25 a.26 ähneln, auch im Assurfluch VTE § 58 Z. 518 und im Palilfluch $\S 59$ in fast identischen Formulierungen zu finden. Es lagen im Assyrischen offenbar fixierte Sprachmuster für derartige Motive vor. Ähnlich formelhafte Elemente scheint es auch im Hebräischen gegeben zu haben. Sie zeigen sich, wenn man Dtn 28,26 und Jer 7,33; 16,4; $19,7,34,20$ genauer betrachtet. Vergleichbare Formulierungen stehen auch in Ps 79,2. Keiner der Verse stimmt wörtlich mit dem anderen überein. ${ }^{7}$

1 Vgl. STEUERnAGEl, Übersetzung, 101f; HOLLCHER, „Komposition,“ 221 Anm. 2; HyATT, „Jeremiah,“ 172 (von Jer 34,20 übernommen); WEIPPERT, Prosareden, 152, 186; SEITZ, Studien, 289.

2 "Die Zahl der Toten wird so enorm hoch sein, daß die Leichen unbestattet bleiben werden, den wilden Tieren zum Fraß. Diese Ankündigung ist ein Gerichtstopos, den D dem Dtn. (2826) entnommen hat und in der Parallelstelle 197 wie in 164; 3420 verwendet. Aus Dtn 2826 stammt auch ואין מחריד, das in diesem Zusammenhang nur an diesen beiden Stellen vorkommt.“ THIEL, Jeremia 1-25, 130.

${ }^{3}$ Vgl. HYATT, ,Jeremiah,“' 172; „Edition,“ 91; MAYES, Deuteronomy, 351.

${ }^{4}$ Vgl. STIPP, „Probleme,“ 235-237, 240-242; HerRmanN, Jeremia, 43, 46, 50, 59, 81;

5 „Ich nenne Argumente, die für eine bestimmte Zitier-Richtung vorgebracht werden: - bessere Verankerung im jeweiligen Kontext. Das Argument beweist nichts, denn dem Abschreiber steht es frei, das Zitat noch besser zu verankern. • die Wendung ist in einem Buch einmalig, im anderen Buch häufig gesetzt; folglich ist die einsame Verwendung Zitat. Solche Wortstatistiken beweisen gar nichts." VANONI, „Anspielungen,“ $386 \mathrm{f}$.

6 WÄCHTER, Tod, 134 Anm. 44; JerEMIAS, Kultprophetie, 168 Anm. 2, 4, 169. Auch VANONI, „Anspielungen,“ 388, löst die Frage nach der Zitationsrichtung zwischen Dtn 4,29; 30,1-10 und Jer 29,12-14 nicht durch Literarkritik, sondern durch den Rückgriff auf ein äußeres Zeugnis: „Jer 29,14aJ-dR fehlt in der LXX. (...) Den Rezipienten des Dtn wird man vielleicht Kenntnis des Jeremia-Briefes zubilligen, kaum jedoch Kenntnis von Jer 29 mit seinen spätesten Textzuwächsen.“

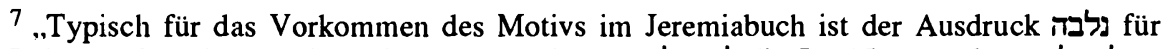
Leichen (fehlt in Jer 15 3), die Zweckbestimmung למאכל (in Jer 15 stattdessen לאכל ... 
Allerdings sind Dtn 28,26 und Jer 7,33 noch durch ואין מחריד verbunden. Diese Formel kommt auch in anderen Kontexten vor, ist nicht auf deuteronomisch-deuteronomistischen Sprache beschränkt und bezieht sich in Jes 17,2; Nah 2,12 ebenfalls auf Tiere. ${ }^{1}$ Die Möglichkeiten auszusagen, daß Vögel und Tiere Leichen fressen, sind nicht unbegrenzt. Das Motiv war aus Kriegserfahrung bekannt. Die Wortverbindung עוף השמים ,Vögel des Himmels" ${ }^{2}$ und ein Begriff für ,Leiche“ scheinen bereits der Sache nach kaum zu umgehen. ${ }^{3}$ Ähnliche Formulierungen implizieren in einem solchen Fall nicht unbedingt direkte Abhängigkeit und beweisen nicht, daß Dtn 28,26 von Wendungen aus dem Jeremiabuch beeinflußt ist.

Der Wechsel des Metrums und die veränderte Form von V. 32.33a gegenüber V. 30 fowie die inhaltliche Berührung zu V. 36 durch das עם מחר überzeugt nicht restlos als literarkritischer Grund der Ausscheidung. ${ }^{4}$ Im-

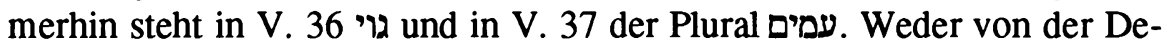
portation des ganzen Volkes noch von der Zerstreuung unter viele Völker wird in 28,32f gesprochen. Dort scheint der Feind das Land vielmehr zu besetzen und auszuplündern. Die von Seitz vorgeschlagene literarkritische Trennung zwischen den beiden Abschnitten der Frustrationsflüche (28,3032.38-41) scheint naheliegend, aber nicht zwingend. Zwar gibt es die Dopplung von Weinberg (V. 30.39) und Deportation (32.41), doch könnte es sich auch um ein stilistisches Phänomen handeln. Die Dopplungen wären dann als bewußt gesetzte Wiederholungen zu interpretieren. ${ }^{5}$ Dies tritt besonders bei dem doppelten Deportationsfluch (32.41) und den folgenden Zusammenfassungen (33.42) hervor. Die futility curses bilden ein zweistrophiges Gedicht mit parallelem Aufbau. In der ersten Strophe (V. 30-32) wird die Ausplünderung durch Feinde beschrieben, die in der Deportation der Kinder gipfelt. Die Strophe wird in V. 33 zusammengefaßt. In der 2. Strophe (V. 38-40) steht das Ungeziefer im Mittelpunkt. Trotzdem endet auch die 2. Strophe der Frustrationsflüche mit dem Verlust der Kinder. Die Zusammenfassung (V. 42) greift dann wieder auf die Schädlinge als

und להשחית) und die Zusammenstellung von בוף השמים und (immer in dieser Reihenfolge) für die fressenden Tiere." WEIPPERT, Prosareden, 184.

${ }^{1}$ Um das Ungestörtsein von Menschen auszudrücken steht die Formel in Lev 26,6; Jer 30,10; 46,27; Ez 34,28; 39,26; Mi 4,4; Zef 3,13.

2 Vgl. Houtman, Himmel, 11-13.

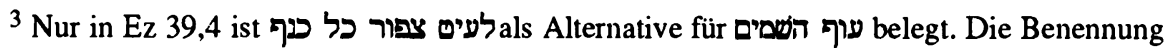
der Tiere weicht stärker ab (Ps 79,2; 1 Sam 17,46; 1 Kön 14,11; 16,4; 21,24; Ez 29,5; 39,4).

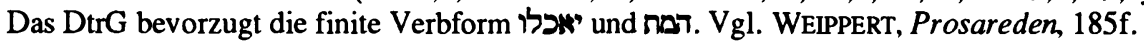

4 Gegen SEITZ, Studien, 284f, 289.

5 „Eine Wiederholung ist nicht störend, wenn sie als Stilmittel verwendet ist.“ FOHRER, Exegese. 51. 
Hauptthema zurück. Im Vergleich zur ersten Strophe wirkt die Deportation in V. 41 nicht wie eine störende Dopplung, sondern als steigernde Wiederholung.

Viele sahen in einem Deportationsfluch und so auch 28,41 grundsätzlich ein vaticinium ex eventu ${ }^{1}$. Teilt man diese Auffassung nicht, gibt es keinen Grund, V. 41 auszuscheiden. ${ }^{2}$

\section{2. 2. 4. Die Bezüge zu Jeremia}

Sumner stellte die Bezüge zwischen Dtn 28 und Jeremia zusammen und untersuchte sie. Er fand eine Abhängigkeit zwischen Dtn 28,49-52 und Jer 5,15-17 heraus. Die anderen Parallelen des Kapitels mit Jeremia führten ihn im Prophetenbuch zu Passagen, in denen die Sünde Manasses als Ursache für die Eroberung Jerusalems durch Babylon herausgestellt wurde. Der Verfasser von Dtn 28,49-52 wollte offenbar die Prophetie des Jeremia mit der Autorität des Mose verbinden. ${ }^{3} \mathrm{Ihm}$ schrieb Sumner auch die Einfügung der Jeremiabezüge in 28,20-44 zu. ${ }^{4}$

Einige Beobachtungen im Zusammenhang der oben erwähnten Bezüge von V. 20.25b.37 zu Jeremia harmonieren mit der These Sumners. 28,20b besitzt große Ähnlichkeit mit Jer 1,16aßbo. Jer 1 wird als Komposition betrachtet, die ein Porträt des Propheten zeichnen soll. Man fand darin deuteronomistische Elemente vor allem in V. 16 und der Legitimationserzählung V. 4-10. In Jer 1,7.9 dürften Formulierungen aus dem Prophetengesetz in Dtn 18,9-22 aufgenommen sein. ${ }^{5}$ Deuteronomistische Passagen in Jeremia betrachten den Propheten als die Erfüllung dieses aus dem Exil stammenden Prophetengesetzes. ${ }^{6}$ Nun gehört das Prophetengesetz zum Abschnitt der Ämtergesetze (Dtn 16,18-18,22), der seine Hauptredaktion am Anfang der Exilszeit erhalten hat. ${ }^{7}$ Einen weiteren Bestandteil der Ämtergesetze bildet das ebenfalls exilische Königsgesetz in Dtn 17,14-20, auf das sich

${ }^{1}$ Vgl. OeTtu, Deuteronomium, 94; DrIVER, Deuteronomy, 303, 313; SMTTH, Deuteronomy, 307; CUNLIFFE-JONES, Deuteronomy, 156; PLOGER, Untersuchungen, 154-158; JEREMIAS, Kultprophetie, 169 Anm. 4; SEITZ, Studien, 289.

2 Vgl. SCHÄCHTER, Fluch, 144-146. BultmanN, Fremde, 135 Anm. 56: „Auch 28,41 ist nicht ein Reflex auf die Niederlage von 587, sondern eine Anspielung auf eine übliche Praxis bei Kriegszügen ...."

3 Vgl. Study, 4-6, 38, 222.

${ }^{4} \mathrm{Vgl}$. Study, $211 \mathrm{f}$.

5 Vgl. Seybold, Jeremia, 40; THIEL, Jeremia 1-25, 65-67; BRAULIK, Deuteronomium II, 136.

6 Vgl. HerRmann, Jeremia, 33, 41, 84, 140.

7 Vgl. LOHFINK, „Sicherung,“ 313; SCHÄFER-LICHTENBERGER, Josua, 85-103; GERTZ, Gerichtsorganisation, 31. 
Dtn 28,36 mit der Einsetzung des Königs durch das Volk (Dtn 17,15), und Dtn 28,68 mit dem Hinweis auf das Versprechen, daß das Volk den Weg von Ägypten nach Palästina nie mehr sehen soll $(17,16)$, bezieht. Die Frage nach dem rechten Verhalten des Königs steht auch hinter der Königskritik im Jeremiabuch. Dorthin führen Dtn 28,25b.37a, die in Jer 24,9 eine Parallele haben. Die Datierung von Jer 24 ist umstritten. ${ }^{1}$ Hier kann den Fragen nach der deuteronomistischen Redaktion des Jeremiabuches, der Entstehung des DtrG und dem Verhältnis des Deuteronomiums zu beidem nicht nachgegangen werden. ${ }^{2}$ Wenn sich das deuteronomistische Jeremiabild am deuteronomistischen Prophetengesetz formte und die Bearbeiter von Dtn 28 authentische Jeremiaworte kannten (Jer 5,15-17), liegt es nahe, sich gegenseitig beeinflussende redaktionelle Arbeit an Jeremiaorakeln und am Deuteronomium anzunehmen.

\subsection{Sprachlich-syntaktische Analyse}

In der Forschungsgeschichte war die Serie gleichartiger Sätze mit der Struktur yiqtol- $x$ aufgefallen. Diese Struktur bestimmte Niccacci als Jussiv. ${ }^{3} \mathrm{Da}$ aber in Dtn 28 nicht nur yiqtol-x-Sätze stehen, stellt sich die Frage, welche Verben als Jussive und welche als Indikative gemeint sind. In der bisherigen Forschung entschied man sich meist für Gesamtlösungen. Entweder übersetzte man alles im Indikativ und nivellierte die beiden Hif ${ }^{\prime}$ ilKurzformen in V. 21.36, oder man schlug vor, den gesamten Abschnitt im Jussiv zu verstehen. ${ }^{4} \mathrm{Da}$ der Jussiv im Hebräischen nur im Qal der Verba

${ }^{1}$ SEYBOLD, Jeremia, 197 Anm. 1, findet in Jer 24,1-8 einen authentischen Jeremiakern; THIEL, Jeremia 1-25, 260, hält Jer 24,1-10 für deuteronomistisch und STIPP, „Probleme,“ 244-247 für nachdeuteronomistisch.

2 Die Schwierigkeit beginnt bereits mit der Definition dessen, was man als deuteronomistisch bezeichnet. Vgl. PERSON, Zechariah, 72; STIPP, „Probleme,“ 226f, 231 233, 245, 247, 257f. SEYBOLDs Ansatz scheint beachtenswert. Er unterscheidet zwischen deuteronomistischer Redaktion, „C“ genannt, und der Buchredaktion, „D“ genannt. C stellte Blöcke (z. B. Jer 1-25) zusammen und bearbeitete sie. Vgl. Jeremia, 24-29. So scheint eine gegenseitige Durchdringung der redaktionellen Arbeitsprozesse am Deuteronomium, an Jeremia und am DtrG plausibel.

${ }^{3}$ Vgl. „Point,“ 7. Es gibt eine Fülle von Ausdrücken, um Wunschformen und -sätze zu bezeichnen, z. B. Kuptitiv, Optativ, Volitiv, Injunktiv. Diese Untersuchung folgt dem Sprachgebrauch NiCCACCIs und WALTKE / O'CONNORs, die Jussiv nicht auf die morphologische Beschreibung des Verbs beschränken, sondern auch zur syntaktischen Bestimmung der volitiven Bedeutung des Prädikates verwenden. Die nicht-volitive Sachverhaltsanzeige, die in Opposition zum Jussiv steht, wird hier mit NiCCACCI Indikativ genannt. Da Dtn 28 Moserede ist, werden nur die Modusdifferenzierungen in discourse berücksichtigt. Vgl. Syntax, 73-109, 175-187.

${ }^{4}$ Vgl. SEITZ, Studien, 279; DrIVER, Deuterononiy, 305. 
tertiae infirmae und im Hif il morphologisch erkennbar ist, bleiben eindeutige Bestimmungen schwierig und werden immer wieder diskutiert. Waltke und O'Connor schlagen vor, wegen der Vieldeutigkeit der yiqtol-Formen den Modus der Verben nach semantischen Gesichtspunkten aus dem Kontext festzulegen. Verständnis und Interpretation des Textes prägen dann die Modusbestimmung, und sie bleibt letztlich subjektiv. ${ }^{1}$

Niccacci hat Kriterien vorgelegt, nach denen Jussiv und Indikativ Futur voneinander unterscheidbar sein sollen. ${ }^{2}$ Jussiv ist yiqtol- $x$ und auch $(w=) y i q t o l$. Dagegen drückt $(w=) x$-yiqtol nur dann einen Wunsch aus, wenn eine direkte volitive Form, also yiqtol-x oder Imperativ, vorausgeht oder wenn $w=y i q t o l$ folgt. Bis dahin stimmt Niccacci weitgehend mit der Differenzierung von Groß überein, der ( $w=)$ yiqtol LF- $x$ und $(w=) x$-yiqtol LF auch den Ausdruck eines Wunsches oder Gebotes zuschreibt. Der Hauptunterschied zwischen Groß und Niccacci liegt in der Bestimmung von $w=q a t a l-x$. Nach Gross kann es ebenfalls Wunsch und Gebot ausdrücken. Niccacci dagegen sieht in $w=q a t a l$ einerseits Gebote und Befehle, andererseits aber den Modus für zukünftig erwartete und im Indikativ ausgedrückte Konsequenzen oder Ergebnisse. ${ }^{3}$ Auch ( $\left.w=\right) x$-yiqtol zeigt Indikativ Futur an, wenn $w=q a t a l$ vorangeht. Sogar bei der Jussivbedeutung von yiqtol-x gibt es Ausnahmen. In einer Apodosis gibt yiqtol- $x$ Indikativ an, selbst wenn es am Versanfang steht.

Damit scheint die Entscheidung für Dtn 28 gefallen. V. 15a enthält mit seinem Konditionalsatz die Protasis, 15b-44 sind Apodosis. Damit wäre der gesamte Abschnitt als Indikativ Futur zu verstehen. ${ }^{4}$ Doch genaugenommen deckt V. 15 die Struktur des Konditional- und Hauptsatzes mit Protasis und Apodosis bereits vollständig ab. Dort findet sich die Abfolge ' $m+$ yiqtol (15a / Protasis) - $w=$ qatal (15b / Apodosis). Bedingung und Konsequenz würden nach Niccacci in diesem Vers im Indikativ Futur dargestellt. Die Konsequenz besteht im Kommen der pללות. Es wurde bereits darauf hingewiesen, daß hier abweichend von allen anderen Belegen im AT das Wort im Plural steht. Es kann als Gattungsangabe für den folgenden Text (V. 20-44) verstanden werden. Dieser Abschnitt besteht dann aus mehreren

$1 \mathrm{Vgl}$. WALTKE / O'CONNOR, Introduction, 566.

2 Vgl. „Point,“ 7-9; Syntax, 75f, 78, 80. NICCACCI verwendet die Satzposition des Verbs als Entscheidungskriterium, während Gross geschrieben hatte: „... PKKF in Funktion des Jussiv ... sind nicht stellungsgebunden, wenn sie auch die erste Position im Satz bevorzugen.“ „Rössler,“ 62. Doch lassen sich NiCCACCIs Kriterien in Dtn 28 sinnvoll anwenden und führen zu Modusvariationen, die denen in $\boldsymbol{\sigma}$ und $\mathfrak{D}$ gleichen. Die antiken Übersetzer scheinen also ähnlichen Kriterien für ihre Moduswahl gefolgt zu sein.

${ }^{3}$ Vgl. Gross, ,Rössler,“ 60-78; NiCCACCI, „Point,“ 7-10; Syntax, $182 \mathrm{f}$.

4 Vgl. NiCCACCI, „Point,“ 14f. 
Fluchsprüchen. Diese bilden daher nicht mehr einfach die Apodosis von V. 15a, sondern bestehen aus einer Folge von קללה im Sinne von Sprechakten. Im Gegensatz von V. 15b, der eigentlichen Apodosis, gibt jeder der Sätze in V. 20-44 auch ohne V. 15a einen Sinn und könnte, wie in den literarkritischen Aussonderungen von Plöger, Seitz und Schächter vorgeschlagen, auch in einem anderen Zusammenhang stehen.

Niccaccis Argumentation scheint sich nur auf einen grammatischen Satz zu beziehen und nicht auf Kausalzusammenhänge größerer Einheiten. ${ }^{1}$ Wendet man Niccaccis Kriterien auf Dtn 28,20-44 an, ergibt sich in der Verwendung des Jussivs ein ähnlich differenziertes Bild, wie es die Septuaginta in ihrem Wechsel von Optativ und Indikativ Futur widerspiegelt. B übersetzt $w=q a t a l$-Sätze nicht als Optativ, sondern als Indikativ Futur. Allerdings kann Indikativ Futur im Griechischen auch einen Wunsch ausdrücken. ${ }^{2}$

Um den Aussagewert der syntaktischen Struktur für die Modusbestimmung nach möglichst objektiven Gesichtspunkten zu erheben, qualifiziert die folgende Tabelle nur yiqtol- $x$ und $w=y i q t o l$ als Jussiv. Die Formen $(w=) x$-yiqtol und $w=q a t a l$, in deren Bewertung Niccacci und Groß nicht übereinstimmen, werden dagegen als ambivalent eingestuft. Die Tabelle beschränkt sich auf den Abschnitt 28,20-29, wo die meisten yiqtol-x-Strukturen vorkommen, und folgt der Satzaufteilung der $\mathrm{BH}^{\mathrm{t}}{ }^{3}$ Literarkritisch auszuscheidende Passagen sind eingeklammert.

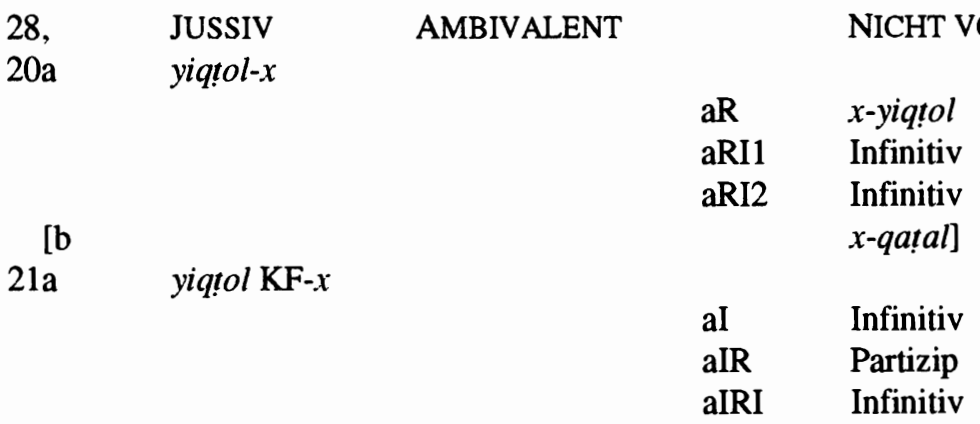

\footnotetext{
${ }^{1}$ Eine Apodosis ist nach NiCCACCI, ohne ihre Protasis unverständlich, wobei er aber innerhalb eines einzigen grammatischen Satzes bleibt. „None of the various verb forms appearing in the apodosis can exist without their protasis. In other words, the apodosis is indeed the main sentence but is not independent from the syntactic point of view.“ „Point,“ 17.

2 Vgl. KUHNER / GeRTH, Grammatik, 173.

${ }^{3} \mathrm{Vgl}$. RICHTER, $B H t, 616-621$. Relativ- oder Vergleichssätze sowie Infinitivergänzungen werden als nicht volitiv qualifiziert. Die Relativsätze gehören nicht zur eigentlichen Handlungsfolge, die Infinitive und Nominalsätze bringen sie zum Abschluß.
} 


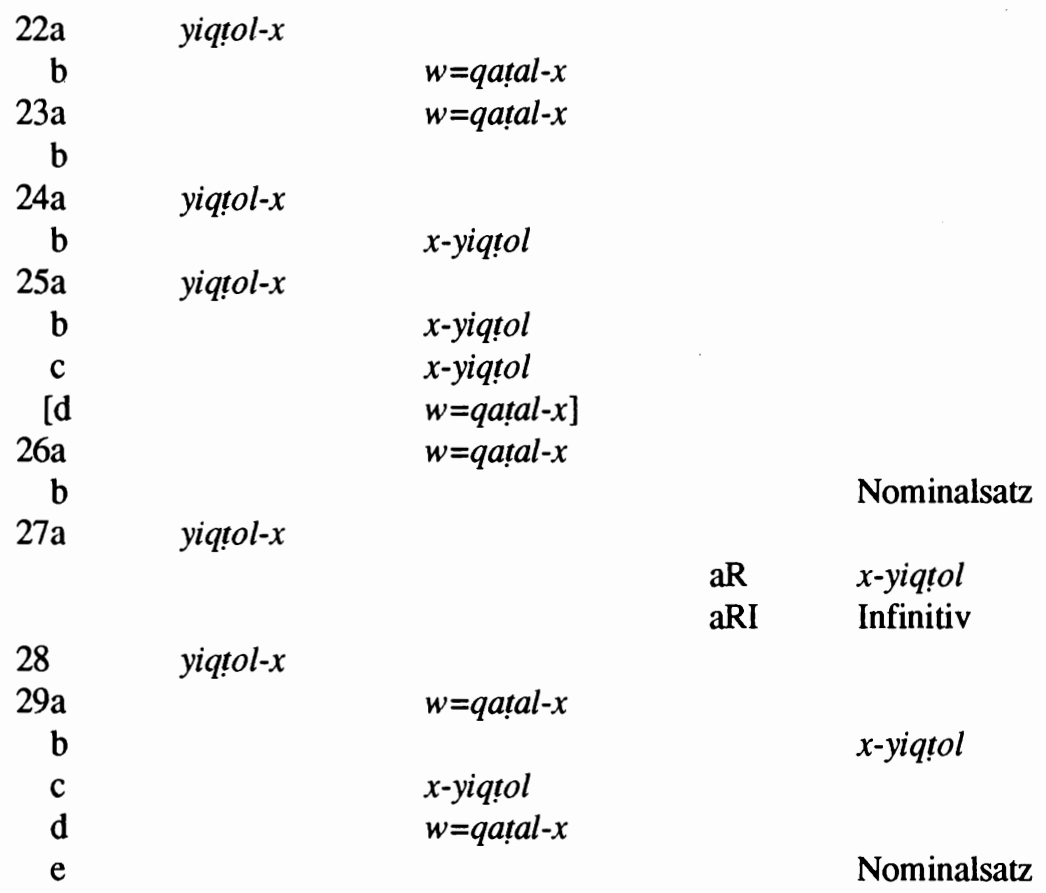

Es zeigen sich Satzreihen, die mit einer jussivischen yiqtol-x-Einleitung beginnen, zum Teil durch ambivalente $x$-yiqtol-oder $w=q a t a l$ - $x$-Strukturen weitergeführt werden und in nicht volitiven statisch-nominalen Formen wie Infinitiv oder Partizip enden. Ähnlich wie in den Flüchen von Sefire scheinen die nicht-volitiven Formen den Abschluß eines Gedankenganges oder Unterabschnitts zu markieren. ${ }^{1}$ Dies wird auch deutlich, wenn man den Wechsel von Subjekt und Objekt betrachtet. Das Objekt der jussivischen yiqtol-x-Sätze, die JHWH zum Subjekt haben, wird in den folgenden ambivalenten Sätzen zum Subjekt. Die nominalen Formen markieren den Abschluß der Handlungsfolge. Mit anderen Worten, yiqtol- $x$ drückt den Wunsch aus, JHWH möge handeln. Daraufhin erscheinen die Auswirkungen der göttlichen Aktivität auf die Verfluchten in $x$-yiqtol- und $w=q a t a l-x$ Sätzen. Dabei werden die Objekte göttlichen Handelns zu den Subjekten der Konsequenzen. Die Handlungskette endet in der nominalen Beschreibung des Zielzustandes, für den Vernichtung (20.21.22b $\beta .24 b \beta)$ oder Hilflosigkeit (26b.27b. 29b $\beta$ ) zu konstatieren ist. Danach beginnt mit dem

\footnotetext{
${ }^{1}$ Bei der Analyse der Sefire-Inschriften wurden nur morphologisch eindeutige Jussivformen als aramäischer Jussiv qualifiziert. Alle anderen galten als ambivalent, wenn sie nicht morphologisch eindeutig Indikativ waren. In Dtn 28 dagegen gelten nicht nur die morphologisch eindeutigen Jussivformen in 28,21.36 als Jussive, sondern im Hebräischen werden NICCACCI folgend auch syntaktische Gesichtspunkte berücksichtigt.
} 
nächsten yiqtol-x-Satz eine neue von JHWH initiierte Handlungskette. ${ }^{1} \mathrm{~V}$. 20 a beginnt mit der Struktur yiqtol- $x$, was nach Niccacci einen Jussiv ausmacht. In V. 21a wird der Jussiv durch die Hif'il-Kurzform von דבק auch morphologisch greifbar. V. 22a hat ebenfalls yiqtol-x, wobei das enklitische Personalpronomen der 2. Person Sg. den morphologischen Unterschied zwischen נכה /H Kurzform oder Langform verschleiert. In 22b bildet die $w=q a t a l$-Struktur den Übergang zum nicht volitiv ausgedrückten Vernichtungsziel.

Aus dem Rahmen fällt $23 \mathrm{a} \alpha_{1}$, wo nach dem Abschluß der vorausgehenden Handlungsfolge durch den Infinitiv in V. 22b ein neuer Wunschsatz zu erwarten wäre. Es steht aber die Struktur $w=q a t a l$, also nach Niccacci Indikativ. 13 übersetzt nach den Optativformen in 28,20-22a in V. 23 den Indi-

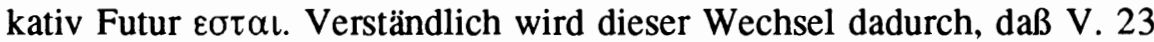
keine strafende Aktivität JHWHs konzediert, sondern eine Zustandsveränderung von Himmel und Erde beschreibt. JHWH handelt erst in V. 24, wo konsequenterweise wieder yiqtol-x steht. Vor dem eigentlichen JHWHFluch erscheint die Veränderung von Himmel und Erde als Szenenhintergrund. V. 23 stellt eine Begleiterscheinung der göttlichen Verwandlung des Regens in Staub und Asche voran. Er zielt weniger auf im Fluchwunsch formulierte Aktivität, als vielmehr auf Zustandsveränderungen im Indikativ ab.

V. 24a und 25a $\alpha$ fangen wieder mit yiqtol- $x$ an. V. 24b $\alpha, 25 \mathrm{a} \beta$ und 25a $\gamma$ haben jedoch die ambivalente Struktur $x$-yiqtol, die nach einem vorausgehenden Jussiv ebenfalls Jussiv bedeuten kann. ${ }^{2}$ So ergibt sich ab 24a eine längere Sequenz von Wunschsatz, modal ambivalenten Konsequenzen und nominalem Abschluß. Bis auf רדף in 22ba und עבד 36b werden alle w =qatal-Formen von der Wurzel היה ,werden, geschehen, sein“ gebildet, was den Eindruck verstärkt, daß dort im Indikativ die Veränderungen beschrieben werden, die aufgrund des göttlichen Schlages eintreffen werden.

V. 27 bietet wie V. 24 eine kurze Kette aus Jussiv, modal ambivalenter Folge und nicht volitivem Abschluß, V. 28f dagegen wie V. $25 \mathrm{f}$ eine längere Sequenz. In die modal ambivalente $w=q a t a l$-Dopplung von $29 \mathrm{a} \alpha_{1}$ und $29 \mathrm{~b} \alpha$ ist der Vergleichssatz 29a $\alpha_{2} \mathrm{f}$ eingeschlossen, in dem sinnvollerweise Indikativ ( $x$-yiqtol) steht. Der folgende Halbvers 29ay mit derselben Struktur $x$-yiqtol dürfte ebenfalls Indikativ sein. Das blinde Umhertasten

\footnotetext{
1 Ähnliche Ketten und Unterabschnitte entdeckte BuIS, „Siècle,“ 131, in Lev 26. Nur handelt es sich dort um $w=q a t a l$-Reihen, die mit yiqtol abgeschlossen werden. Lev 26 wäre also nach NiCCACCI Indikativ. Das ist sinnvoll, da Lev 26 JHWH-Rede ist, in der er seine Belohnungen und Strafen ankündigt. Fluch als Verwünschung ist aber immer implizite Bitte an Gott, zu agieren. Vgl. AsSMANN, „Fluchinschriften,“ 237.

2 Vgl. Niccaccl. „Point,“" 9; Syntax, 78.
} 
29a $\alpha$ führt dazu, daß die Verfluchten auf ihren Wegen nicht zum Ziel kommen $(29 \mathrm{a} \beta)$. Diese Hilflosigkeit bietet den Ausgangspunkt für die Beraubung und die Mißhandlung von 29ba. Alles jedoch ist nur die Konsequenz davon, daß JHWH schlägt (V. 28). Beginnt JHWH erst einmal zu handeln, ergeben sich die Konsequenzen für die Verfluchten mit absoluter Sicherheit und können im Indikativ aus dem an JHWH gerichteten Fluchwunsch gefolgert werden.

Als weitere strukturelle Besonderheit von Dtn 28,20-44 waren in der Forschungsgeschichte die Antithesen aufgefallen. In den aramäischen futility curses von Tell Fekheriye werden die Thesen mit der Jussivpartikel Lamed versehen. Die negierten Antithesen können keine Jussivpartikel erhalten. In Sefire dagegen sind die Verbformen der Frustrationsflüche als Jussive zu bestimmen.

Die antithetisch aufgebauten Sätze weisen immer die Struktur $x$-yiqtol auf. Das Hebräische differenziert in den futility curses den Modus nicht erkennbar zwischen These und Antithese. Nach Niccaccis Kriterien bedeuten die $x$-yiqtol-Formen in den antithetischen Sätzen Indikativ, da ihnen weder ein Jussiv oder Imperativ vorausgeht, noch ein Satz mit $w=y i q t o l$ folgt.

Von 28,30-32 wandeln sich Struktur und Inhalt allmählich. V. 30 ist streng antithetisch aufgebaut, wobei die These die Bemühung und die Antithese die Frustration enthält:

$\begin{array}{llll}30 \mathrm{a} \alpha & x \text {-yiqtol } & - & w=x \text {-yiqtol } \\ 30 \mathrm{a} \beta \gamma & x \text {-yiqtol } & - & w=l 0^{\prime} x \text {-yiqtol } \\ 30 \mathrm{~b} & x \text {-yiqtol } & - & w=l 0^{\prime} x \text {-yiqtol }\end{array}$

V. 31 gleicht dem Aufbau von V. 30ab-30b mit dem Wechsel von Position und Negation, doch stehen am Anfang der Sätze nun Partizipien. Außerdem drückt der negierte Nachsatz nicht mehr die Frustration der vorhergehenden Bemühung aus, sondern die Konsequenz des zuvor Gesagten. Logisches Subjekt der Partizipialsätze sind die Feinde, die die Verfluchten ausplündern. V. 32 enthält schließlich nur noch Partizipien und einen Nominalsatz. Durch $w=$ 'ên entsteht eine Verknüpfung zu V. 26b.29bß

$\begin{array}{llll}31 \mathrm{a} \alpha & \text { Partizip } & - & w=l 0^{\prime} x \text {-yiqtol } \\ 31 \mathrm{a} \beta & \text { Partizip } & - & w=l 0^{\prime} x \text {-yiqtol } \\ 31 \mathrm{~b} & \text { Partizip } & - & w=\text { 'ên Nominalsatz } \\ 32 \mathrm{a} \alpha_{1} & \text { Partizip } & & \\ 32 \mathrm{a} \mathrm{a}_{2} \beta & \text { Partizip } & - & w=\text { 'ên Nominalsatz }\end{array}$

V. 33 faßt die Plünderung durch die Feinde zusammen. Die reine Form der futility curses mit These-Antithese und Negation wird von V. 30 ab immer mehr aufgelöst. Die finiten Verben weichen nominalen Formen. Man ge- 
winnt den Eindruck zunehmender Erstarrung. Die in finiten Verben implizierten Handlungsmöglichkeiten weichen partizipial und nominal ausgedrückten Zustandsbeschreibungen. Das Leid und die Beraubung werden zum Dauerzustand. Die Strukturunterschiede zwischen V. 30 und V. $31 \mathrm{f}$ gehören offenbar zu dem Plan, eine Klimax der Bedrückung stilistisch auszugestalten. Die Sequenz durch Literarkritik auseinanderzureißen, erscheint nicht angemessen.

Mit V. 33 setzt die rückläufige Bewegung der palindromischen Struktur ein. Am Ende der Frustrationsflüche (30-32) stehen Aussagen, die denen von V. 29 korrespondieren. V. 33a $\alpha \beta$ beschreibt die Beraubung von Emte und Besitz mit $x$-yiqtol (vgl. 29a $\beta$ ). Darauf folgen zwei $w=q a t$ al-Sätze, die wieder mit dem Verb היה Beraubung (33b) und Verrücktheit (34a) ansprechen. Es verwundert kaum, daß die inhaltlichen Entsprechungen von V. 29 und $33 \mathrm{f}$ in der palindromischen Struktur dieses Abschnittes auch ähnliche Satzstrukturen aufweisen. In V. $35 f$ stehen wieder Jussive.

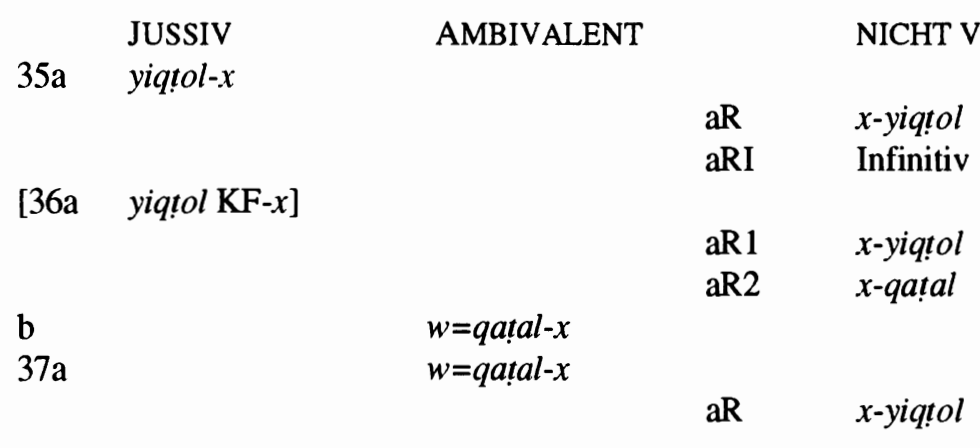

Der Jussiv in V. 36 wird mit הלך/H ,führen“ gebildet, das durch seine Kurzform morphologisch eindeutig als Wunschform erkennbar wird. Die Deportation von V. 36 führt zum Götzendienst (36b) und der Veränderung Israels zum Entsetzen der Völker (37), was in $w=q a$ tal-Sätzen ausgemalt wird. Dtn 28,36 ist der letzte Vers des Kapitels, der eindeutig eine Jussivform enthält. Es ist auch der letzte Vers innerhalb von 28,20-44, der JHWH zum Subjekt hat.

$\mathrm{Da}$ in 28,38-44 keine yiqtol-x-Strukturen mehr vorkommen, handelt es sich hier wohl um Indikative. ${ }^{1}$ Die Verse beschreiben die mit Sicherheit zu erwartende Situation der Verfluchten, wenn JHWH im Sinne der Verwünschungen agiert, und dürften, ähnlich wie das Ende der Ritualflüche in Sefire IA, durch den Modus des Indikativs den Abschluß der Fluchsequenz hervorheben.

\footnotetext{
1 Vgl. NiCCACCl, „Point,“" 19.
} 
Der zweite Abschnitt mit Frustrationsflüchen (38-41) ist strukturell mit V. 30-32 verknüpft. Am Ende jeder Einheit steht ein Satz ohne Antithese, der das Stichwort פרי מדמתך enthält und die Hauptplage der vorhergehenden Verse zusammenfaßt (V. 33.42). Dieses verknüpfende Element wird ergänzt durch die strukturelle Gleichartigkeit der Anfänge jeder Strophe. Die Satzstruktur $w=x$-yiqtol von $30 \mathrm{a}_{2}$ kommt nur noch in $38 \mathrm{~b} \alpha$ vor. In der ersten Antithese beider Strophen fehlt die eigentlich zu erwartende Negation. Dtn 28,30-32.38-41 bilden zwei Strophen eines Gedichtes. Auch die 2. Strophe lockert die Frustrationsfluchform auf. Es wird jeweils ein $k \hat{\imath}-$ Satz angefügt.

Auch V. $43 \mathrm{f}$ besteht aus Antithesen. Doch steht nicht die Bemühung der Frustration gegenüber, sondern der ג dem Israeliten. Konsequente Doppelnennung des Subjekts verleiht der Aussage besondere Eindrücklichkeit. In $43 \mathrm{a} \alpha_{1}$ wird הגר demonstrativ an den Anfang gestellt. Ab 43b bis 44b $\beta$ wären die Subjekte bereits in den Verbformen impliziert. Trotzdem steht vor jedem Verb noch das Personalpronomen. V. 43f setzt damit einen Akzent auf die Adressatenanrede, der wie ein Schlußakkord wirkt.

Die Lexemverteilung macht deutlich, daß der Abschnitt 20-44 in V. 2933 eine Mitte besitzt. Dort häufen sich die mehrmals vorkommenden Wörter. V. 29 enthält $5^{1}$, V. $31^{2}, 32^{3}$ und $33^{4}$ je 6 Wortverknüpfungen. Es handelt sich um einen Teil der palindromischen Struktur. Bis V. 35 werden, an den Leitwörtern נכה (V. 22.27.28.35), אשר לא תוכל להרפא (V. 27.35) erkennbar, Themen abgehandelt, die später zumindest in Dtn 28,20-44 keine Rolle mehr spielen. Nicht über V. 35 hinaus gehen die Lexemverknüpfun-

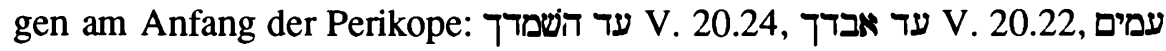
V. 23.24.

Mit V. 35 enden sowohl die palindromische Struktur als auch die „Schlagen“-Sätze. Die Verknüpfungen, die über die Abschnittgrenze von V. 35 hinausgehen, gehören größtenteils zu den beiden Strophen des Frustrationsfluchgedichts. Auch lexikalisch zeigt sich also deren Zusammengehörigkeit. Einige Lexeme bilden eine Klammer um den ganzen Abschnitt. $^{5}$

Bemerkenswert scheint auch, was lexikalisch in Dtn 28,20-44 fehlt. Man findet nicht die stereotypen Wendungen der Reihe von Ernte, Nachwuchs bei Vieh und Leibesfrucht von Dtn 28,4.11.18.51. Dies fällt um so

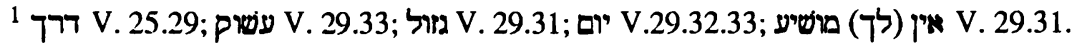

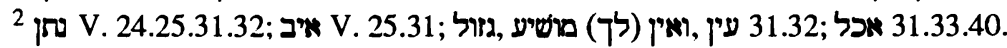

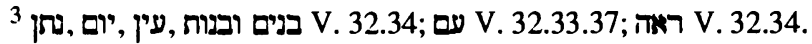

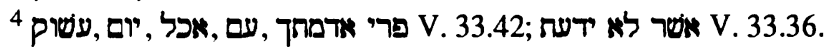

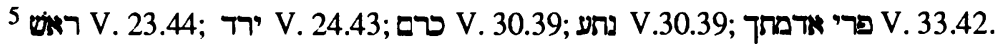


mehr auf, als die Thematik durchaus gegeben wäre. In den Frustationsflüchen geht es um den landwirtschaftlichen Ertrag, den Viehbestand und die

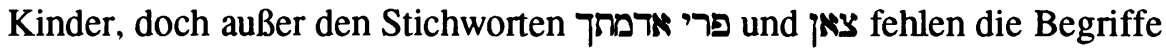
der Reihen von V. 4.11.18.51. Ebenso fehlen Bezüge zu den Konditionalund Kausalsätzen Dtn 28,15.45f.

\section{2. 4. Semantische Analyse}

Die als sekundär auszuscheidenden Passagen werden in der versweise vorgehenden Wortsemantik hervorstechender Ausdrücke ausgespart. Ihr Inhalt kam schon bei der Literarkritik zur Sprache.

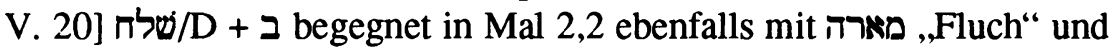
ähnlich im wohl deuteronomistischen ${ }^{1}$ Jer 24,10, wo Gott Schwert, Hunger und Pest schickt. In Am 4,10 sendet Gott die Pest. In kriegerischem Zusammenhang steht die Verbindung in Dtn 7,20, wo Gott Panik unter andere Völker schickt, sowie in 2 Kön 24,2, wo er Räuberscharen der Chaldäer, Aramäer, Moabiter und Ammoniter gegen Jojakim sendet. „Verwirrung“" ist eine Begleiterscheinung von Krieg und Krankheit. ${ }^{3}$ Die גער Bedrohung“ zugrunde liegende Wurzel beichnet einen Ausdruck des Ärgers und kann so die Bedeutung eines wirkmächtigen Fluches annehmen. ${ }^{4}$ Das Vokabular von $20 a \alpha \beta$ impliziert also bereits zwei Hauptthemen der folgenden Flüche, Krankheit und Krieg, ohne sie ausdrücklich zu nennen. אבד + מהר scheint im Deuteronomium im Zusammenhang mit Hauptgebot $(4,26 ; 7,4)$ und Landnahme $(7,22 ; 9,3)$ zu stehen.

V. 21] Die Verbindung von דבק/Heulenpest“, ,ankleben“ mit דבר ,Bent im AT einmalig. דבר bezeichnet nicht einfach eine Seuche, sondern kann synonym mit מות verwendet werden. ${ }^{5}$ Mit JHWH als Subjekt kommt דבקר nur noch dreimal im AT vor. In Jer 13,11 will Gott, daß sich das Volk wie ein Gürtel an ihn schmiegt (Jer 13,11), in Ez 3,26 klebt er die Zunge des

\footnotetext{
${ }^{1}$ Alle deuteronomistischen (dtr) Bewertungen von Jeremiastellen resultieren in diesem Kapitel aus der Tabelle über "Inhalt und Komposition des Jeremiabuches“ in HERRMANN, Jeremia, 41-52.

2 In anderen Zusammenhängen: Dtn $15,12.13 .18 ; 21,14 ; 22,7.19 .29 ; 24,1.3 .4 ; 32,14$; Ri 15,$5 ; 19.25 .29 ; 20,6.48 ; 1$ Sam 11,7; 24,20, 31,9; 1 Kön 20,34; Hos 8,14; Am 1,4.7.10.12; 2,2.5.

${ }^{3}$ Krieg: Dtn 7,23 feindliche Völker; 1 Sam 5,11 Ekron; 14,20 Philister; Krankheit: 1 Sam 5,9 Pestbeulen; Tag JHwHs: Jes 22,5; Sach 14,13; allgemein: Ez 7,7; 22,5; Spr 15,16. „Die meisten Vorkommen des Nomens מדומה beschreiben eine seitens Jahwes verursachte Bestürzung.“ HERRMANN, „Mot,“ 372.

4 Vgl. MaCINTOSH, „Consideration,“ 474f, 479. REIF, „Note,“ 242.

5 Vgl. WÄCHTER, Tod, $138 \mathrm{f}$.
} 
Ezechiel fest. In Ez 29,4, einem Spruch gegen den Pharao, der als Krokodil angesprochen wird, nimmt Gott die Rolle eines Jägers ein.

Geprägte Sprache findet sich in V. 21b. Personalpronomen + עד כלות scheint zu einer feststehenden Wendung geworden zu sein (1 Sam 15,18; 2 Sam 22,38; 1 Kön 22,11; Ez 4,8; Ps 18,38; Rut 3,3; 2 Chr 18,10). Mit dem Akkusativanzeiger $\pi$ steht es 1 Kön 3,1 und Jer 9,15 (dtr).

Auf die Besonderheiten von V. 22 wurde bereits in der Textkritik hingewiesen. Liest man Hitze, statt Schwert ${ }^{1}$, so werden sieben Krankheiten aufgezählt. ${ }^{2}$ Den Anfang machen, vielleicht in Anknüpfung an die Pest im vorhergehenden Vers, vier Menschenkrankheiten. Es folgen drei Getreidekrankheiten. Das finite Verb in $22 b \alpha$ hat die Krankheiten zum Subjekt, die hypostasiert eigenständig agieren. Der Untergang in $22 \mathrm{~b} \beta$ ist jedoch die Aktivität der Verfluchten selbst. אבד im Qal ist ebenso intransitiv wie שמד/N aus V. 20 und erweckt den Eindruck, als würden die Verfluchten in ihrem Geschick versinken. Natürlich tritt Gottes Aktivität mit dem Verb נכה deutlich hervor. Dennoch verschleiern die Infinitive der intransitiven Verben sein direktes Eingebundensein in die Vernichtung. ${ }^{3}$ Die metaphorische Verbindung von נכה/H ,schlagen“ mit Krankheiten kommt häufiger im AT vor. ${ }^{4}$

V. 24] עבר Staub, Erde“ regnet es im AT in Ps 78,27. Dort dient der Ausdruck zur metaphorischen Beschreibung des Wachtelwunders. Im Unterschied zu Dtn 28,24 scheint der Staub dort in Parallele zum Sand an Meer eine Mengenangabe zu sein und nicht eine Charakterisierung des Regens. Gemeinsam ist beiden Stellen aber der Hintergrund des Hungers. „Pulver, Asche“ löst nach Ex 9,9.10 eine der ägyptischen Plagen aus. Mose wirft in die Luft, es fällt herab und bewirkt bei den Ägyptern Geschwüre (שין vgl. V. 27). Daß Regen herabkommt (ירדין), wird im AT nur

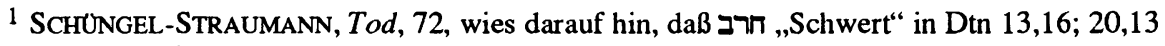
zusammen mit נכה vorkommt.

2 Ridderbos, Boek II, 80, meinte, in den 7 Plagen von V. 22, dem Lev 26,16 ähnle, sei die symbolische Zahl der Fülle enthalten.

3 Vgl. OTZEN, ,"גד," Sp. 22f.

${ }^{4}$ Vgl. Seybold, Gebet, 26. Ex 9,15 droht Mose dem Pharao mit Pestschlag. 1 Sam 4,8 erinnern sich die Philister daran, daß die Ägypter mit Pest geschlagen wurden. In Num 11,35 schlägt Gott während der Wüstenwanderung die Wachtelesser mit einer Plage, in Num 14,12 Israel mit Pest, weil sie sich weigern, daß Land zu erobern. 1 Sam 5,6.9 werden die Philister mit Pest geschlagen, in Jer 21,6 und 1 Chr 21,7.14 Israel bestraft. In Ijob 2,7 ist der Satan Subjekt.

5 ירד im Deuteronomium: Mose steigt vom Horeb wegen des goldenen Kalbs: 9,12.15; 10,5; der Bach, in den der Staub (עפר) des Kalbes geschüttet wird, fließt vom Berg herab: 9,21; die Patriarchen steigen nach Ägypten hinab: 10,22; 26,6; eine belagerte Stadt fällt: 20,20; 28,52. Dazu kommt noch Dtn 28,43. 
in Ps 72,6 gesagt. Dort handelt es sich um eine Metapher innerhalb eines Segens über den gerechten König.

V. 25a $\alpha$ ] Die Wendung נגף לפני kommt häufig im DtrG vor. Meistens ist Israel der Sieger. In Ri 20,32.36.39; 2 Sam 2,17; 18,7; 1 Kön 8,33 = 2 Chr 6,24; 1 Kön 14,12 = 2 Chr 25,22 sind die Feinde לפעינו oder לפני ישראל Sam 7,10; 2 Sam 10,15.19 = 1 Chr 19,16.19) geschlagen (ähnlich $2 \mathrm{Chr}$ 20,22). Nur in 1 Sam 4,2 wird Israel von den Philistern geschlagen, und in 4,10 flieht (נוס) es vor ihnen. Die Niederlage Israels gehörte also nicht zu den gewohnten Inhalten, die man im AT mit dem Vokabular von V. 25a $\alpha$ verbindet. Im Zusammenhang mit der Landnahme steht eine zweimal belegte Formulierung innerhalb der Warnung des Mose, das Land nach anfänglicher Weigerung nun doch zu erobem (Num 14,42 = Dtn 1,42: נגפחם לפני איביכם Lev 26,17 ähnelt mit seinem ולא תנפו לפני איבים beiden Stellen. Mit איביך liefert 25a das Stichwort für den Gesamtkomplex 25-35. Nur hier treten in Dtn 28,20-44 die Feinde auf. Das Stichwort wird

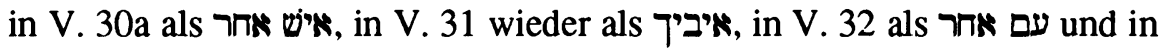
V. 33 als עם אשר לאידער in steigender Eindringlichkeit aufgenommen.

Die Gegenüberstellung יצ ,ausziehen“ und נוס ,fliehen“ gehört zur

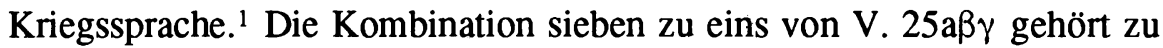
einer Formulierungstradition, für die es im AT, aber auch im AO Belege gibt. ${ }^{2}$ Nur noch Jes 4,1 wird im AT der Zahl sieben ein explizites „eins“" gegenübergestellt. Die Folgen des Krieges führen zu einem Männermangel, der zur Folge hat, daß sieben Frauen einen Mann heiraten wollen (Jes 4,1 ודחזיקו שבע נשים באיש אחד (1) In Gen 7,2 wird es bei der Auswahl der Tiere, die Noach in die Arche mitnimmt umschrieben. Sieben reine Tiere stehen je einem unreinen Tier gegenüber. In Dtn 28,25a $\beta \gamma$ impliziert die Gegenüberstellung von sieben und eins eine Antithese. Man könnte hier einen Frustrationsfluch sehen, obgleich die Negation zwischen These und Antithese fehlt. Statt dessen wird der Gegensatz durch die gegenteiligen Verben ( $($ ) $/$ ) ausgedrückt. Nicht überall, wo die Kombination sieben / eins auftaucht, gibt es auch solche Antithesen. Eine Antithese

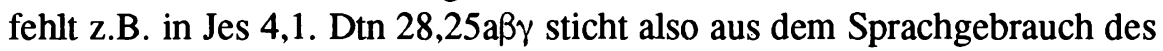
AT hervor, indem es Antithese und die explizite Nennung beider Zahlen miteinander verbindet. Häufiger findet sich im AO und im AT die Antithese, in der zwar die Zahl sieben explizit steht, das einmalige Gegenstück

\footnotetext{
${ }^{1}$ Mit gleichem Subjekt, also erfolglosem Angriff wie in Dtn 28,7.25: Gen 14,8.10; Jos 8,5.6; Ri 9,39f; 2 Sam 10,8.14; 18,3; 2 Kön 9,21.23; mit ungleichem Subjekt, d.h. Flucht der Feinde: Ri 4, 14f; 20,31f; 1 Sam 19,8; 1 Kön 20,19f; metaphorisch: Ps 114,1.3.5.

${ }^{2}$ Zur Zahl sieben im AO vgl. CATHCART, „Micah,“ 46f. Die Zahl drückt Vollständigkeit aus. Vgl. OTTO, , „ֶׁכ," Sp. 1014.
} 
aber nur durch das jeweilige Nomen ohne ein Zahlwort vertreten ist. ${ }^{1}$ Man kann also Dtn $28,25 \mathrm{a} \beta \gamma$ als außergewöhnliche Formulierung bezeichnen, die sich jedoch vorgegebener Sprachmuster bedient.

V. 26] Die Formulierungen führen in die hebräisch-biblische Fluchtradition, die sich in historischen und prophetischen Texten widerspiegelt. ${ }^{2}$ Hos 2,20 kehrt die Fluchmotive zu einer Heilsverheißung um, Ez 29,4f; Ps 79,2 schildert die Schrecken der babylonischen Eroberung. In 1 Sam 17,44.46 drohen sich Goliat und David. ${ }^{3}$ Das Motiv des Verfütterns an Tiere begegnet auch in Ez 29,5, dem Vers, welcher der zu Tב/G in V. 20 genannten Stelle folgt. Der Pharao erscheint als von Gott gejagtes Krokodil:

Dann werfe ich dich in die Wüste hinaus, dich und all die Fische des Nil. Aufs trockene Land wirst du fallen. Niemand holt dich von dort und begräbt dich. Den wilden Tieren und den Vögeln des Himmels werfe ich dich vor zum Fraß.

Hier wird deutlich, daß die Leichenverfütterung zu einem Sinnzusammenhang gehört, der hauptsächlich darauf hinausläuft, das ordentliche Begräbnis zu unterbinden. Die unbegrabene Leiche ist tabu. Sie gehört in den auBermenschlichen Bereich. Dieser Bereich außerhalb der Menschengemeinschaft kann mit der Bezeichnung „Wüste, Steppe“ umschrieben werden. Malul wies darauf hin, daß das Wort נבלה ,Leiche“ bereits auf einen Bereich ohne Eigentümer verweist, den das Hebräische mit den Begriffen שרדה ,Feld, Steppe“ und מדבר ,Wüste“ konnotiert. ${ }^{4}$ Die ähnliche Stelle Ez 32,4-

\footnotetext{
${ }^{1}$ So begegnet die Kombination 7/(1) in den futility curses in Sefire IA Z. 21-24, IIA Z. 1-3. Antithesen mit $7 /(1)$ gibt es im AT nur in zwei Vergleichen. (1) Fauler steht 7 Klugen gegenüber (Spr 26,16) und die (1) Tochter Rut ist besser als 7 Söhne (Rut 4,15). Weitere Vorkommen impliziten Zusammentreffens von $7 /(1)$ scheinen weniger aussagekräftig: (1) Mutter hat 7 Kinder Gen 46,28; Jer 15,9; (1) Unfruchtbare bekommt 7 Kinder 1 Sam 2,5; (1) Leuchter hat 7 Lampen Ex 25,37; 37,23; Num 8,2; Sach 4,2; (1) Stein hat 7 Augen Sach 3,9; (1) Haus hat 7 Säulen; (1) Land wird in 7 Teile geteilt Jos 18,5.9; (1) Fluß wird in 7 Teile geteilt Jes 11,15; (1) König hat 7 Ratgeber Esra 7,14; vgl. Est 1,10.14; nach 7 Stieren und 7 Widdern opfert man (1) Ziegenbock (Ez 45,23); nach 7 Söhnen kommt der (1) Jüngste 1 Sam 16,10f; 7 Sehnen fesseln (1) Mann Ri 16,7.8; 7 Locken fesseln (1) Mann an (1) Webstuhl Ri 16,13.
}

${ }^{2}$ Es läßt sich sogar ein Bezug innerhalb des Deuteronomiums finden. Die Stichwörter אכל מלול, נבלה,עוף aus Dtn 28,26 stehen in Dtn 14,20f zusammen: Alle reinen geflügelten Tiere dürft ihr essen. Ihr dürft keinerlei Aas essen. Hier sind Tierleichen verbotene Nahrung für Menschen, dort Menschenleichen Nahrung für Tiere.

$3 \mathrm{Vgl}$. auch 2 Sam 21,10.

4 Vgl. „Adoption,“ 103, ebd., 102: „Moreover, as the root of the word תרפה connotes the idea of something which is associated with the ownerless domain, so the root of בעלה seems to carry a similar idea: the latter has been identified with the root of the words נבלד 'villain'

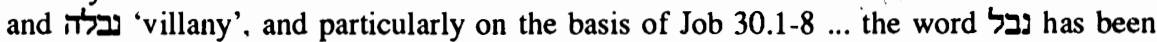
interpreted to mean a lawless person, one outcast from society and forced to live in the desert and steppe (v. 3), ... alongside beasts of prey, demons, spirits of dead and others. 
6 zeigt, daß zu diesem Komplex göttlicher Kriegführung, Tierfütterung und der Lokalisierung des Geschehens in der Wüste auch das Motiv unmäßigen Blutvergießens treten kann. Wieder ist das Pharaokrokodil angesprochen:

Dann werfe ich dich aufs Land, schleudere dich aufs freie Feld. Alle Vögel des Himmels sollen sich auf dich setzen, und ich sättige mit dir alle Tiere der Erde. Ich lege dein Fleisch auf den Bergen aus und fülle die Täler mit deinem Aas. Ich tränke das Land bis hin zu den Bergen mit der Flut deines Blutes; die Schluchten sollen sich damit füllen.

An Ezechiel wird damit außerhalb der deuteronomisch-deuteronomistischen Sprachtradition und außerhalb des Komplexes mesopotamischer Themen - es geht hier um den Pharao und Ägypten - sichtbar, daß im Hebräischen geprägte Motiv- und Wortverbindungen zur Verfügung standen. Dazu gehörten auf jeden Fall die Wendungen „Vögel des Himmels“ und „Tiere des Feldes/der Erde“. Die anderen Begriffe, wie eine explizite Nennung von Wüste oder Steppe und das Tränken des Bodens mit Blut, können hinzutreten, gehören jedoch nicht zwingend dazu, wie ihr Fehlen in Ez 29,3f zeigt. Das DtrG verbindet die „Vögel des Himmels“ gerne mit „Hunden“ (1 Kön 14,11; 16,4; 21,10), wofür es in VTE Z. 484 ein mesopotamisches Beispiel gibt. Jer 15,3 faßt alle möglichen Motivkombinationen zusammen:

Vier Plagen biete ich gegen sie auf - Spruch des Herrn: Das Schwert zum Morden, die Hunde zum Fortschleifen, die Vögel des Himmels und die Tiere des Feldes zum Fressen und Vertilgen.

Jer 16,4; 19,7; 34,15 zeigen, ähnlich wie die beiden Ezechielzitate, daß die Einzelmotive dieses Themenkomplexes variiert werden konnten, doch einige Begriffe immer wiederkehren.

V. 27] Die hier genannten Krankheiten sind außer dem bereits erwähnten גרב, dem hebräischen Gegenstück zum akkadischen garābu und dem sumerischen SAHAR.ŠUB.BA: שחין מצרים, die im AT nicht mehr belegte ägyptische Entzündung ${ }^{1}$, עפלים, die die Philister trafen ${ }^{2}$, und das Hapaxle-

Thus, תרפה denoted a thing which could not remain in society and had to be placed in the ownerless domain."

1 „For this condition one disease qualifies as does none other, namely, the so-called Oriental (or Tropical) Sore, known medically as cutaneous Leishmaniasis. The identification is altogether suitable, since the Sore is well-known in Egypt, being in fact recorded for North Africa, Egypt, Ethiopia, as well as many countries of western and central Asia." KINNIER WILSON, „Medicine,“ 362.

2 ,Thirdly, the ... 'opāilim will not have been 'haemorrhoids,' ... but those buboes which give the disease its distinctive name. The bubo, from Gk. ßovßúv 'groin,' is a swollen lymphatic gland, and ... it is found in the groin or armpit, or, rarely, in the neck, or some 75 per cent of 

klingen. Das Bild vom Umhertasten am Mittag dramatisiert den Verlust der Sehfähigkeit und der Orientierung. ${ }^{1}$

Die Verbindung von Sehfähigkeit und Sicherheit kommt auch in V. 29a zur Sprache. An den anderen Stellen im AT, wo צלח/H mit דרך verbunden wird, geht es um die Verfolgung eines Ziels, das man mit einer Reise verbindet. Reisen war im AO gefährlich. Räuber und Raubtiere konnten den Weg gefährden. Häufig befragte man die Gottheit, ob die Reise gelingen wird. Genau so machen es die fünf Männer aus Dan, die ausgesandt wurden, um einen neuen Erbbesitz zu suchen. Nach Ri 18,5 holen sie ein Orakel ein, ob Sicherheit und Erfolg der Reise gewährleistet sind. Die Antwort des Leviten in Ri 18,6 sagt ihnen zu, daß Gott über ihrem Weg wachen wird. Weil Gott hinschaut, kommen die Menschen an ihr Ziel. Das Ziel der Reise muß kein Ort sein, es kann sich auch um einen Auftrag handeln, den es zu erfüllen gilt. So sagt der Knecht, den Abraham geschickt hat, für Isaak eine Frau zu suchen, daß der Herr seine Reise gelingen ließ, nachdem er Rebekka gefunden hat und noch bevor er zu Abraham zurückgekehrt ist (Gen 24,56 vgl. Gen 24,21.40.42). Diese übertragene Bedeutung von Glück und Erfolg hat der Ausdruck in Jos 1,8, wo der Erfolg auf dem Lebensweg mit der Beachtung des Gesetzes verknüpft wird. Wenn also in $29 a \beta$ gesagt wird, daß die Verfluchten die Ziele ihrer Wege nicht erreichen, so kann konkret gemeint sein, daß sie als Blinde oder Verrückte einfach ihren Weg nicht mehr finden. Es kann aber impliziert sein, daß der wohlwollende Blick Gottes auf ihrem Leben fehlt und daß sie einer Situation ausgesetzt sind, in der Gesetze für sie keine schützende Funktion mehr besitzen.

Blindheit als Strafe im Zusammenhang mit Rechtlosigkeit und Angst findet sich in Jes 59,10 und Zef 1,17 עור). Wenn die Rechtskodizes des AT (Dtn 27,18; Lev 19,14) den Blinden vor Mutwillen schützen, zeigt dies, daß derartige Vorschriften offenbar nötig waren. Ein Blinder konnte leicht zum Opfer der Grausamkeit anderer werden. So entsteht ein Übergang zu V. 29b $\alpha$, der die Rechtlosigkeit als Beraubung und Unterdrückung qualifiziert.

V. 30] Die Kombination von Frau, Haus und Weinberg kommt im ganzen AT nur in Dtn 20,5-7 und 28,30 vor und die Reihenfolge von V.30 überhaupt nur an dieser Stelle ${ }^{2}$, doch begegnet die Zusammenstellung Haus - Weinberg auch in anderen Frustrationsflüchen. Am 5,11 und Zef 1,13 bieten fast gleichlautende Parallelen. Bei Zefanja wird der Kontext der Beraubung deutlich, der auch Dtn 28,29-33 bestimmt. Außerdem wird der

\footnotetext{
$1 \mathrm{Vgl}$. EhrLICH, Randglossen, 332.

2 Vgl. Plöger, Untersuchungen, 190.
} 
Grund für die Frustration der Bemühungen angegeben. Es geht jeweils um die Ausbeutung der schwachen Gesellschaftsschichten durch die eigenen Landsleute. Zef 1,11f nennt die Kaufleute und Geldwechsler, die ihre Geschäfte in der Haltung des praktischen Atheismus ausüben. Am 5,11 erwähnt Pachtgeld und Steuem. חלל in V. 30b $\beta$ impliziert Kultisches. Es bedeutet ,profanisieren“ und steht in der Verbindung mit Weinberg nur noch Dtn 20,6 und in der Heilsverheißung für Samaria in Jer 31,5. Nachdem Gottes Anspruch auf die Früchte des Landes durch das Opfer der Erstlingsgaben (Dtn 26,5-11) genüge getan ist, kann der Weinberg vom Menschen genutzt werden. Durch den Fluch wird also nicht nur die Inbesitznahme des Weinbergs, sondem auch das Opfer der Erstlingsgaben unmöglich. ${ }^{1}$

Die Kombination Rind - Esel - Kleinvieh führt zu Gesetzestexten. Die Lexembezüge von Dtn 28,31 zum Bundesbuch sind massiver als die zum Deuteronomium selbst. Rind und Esel stehen zusammen in Ex 21,33. Das Wort טבח ,schlachten“ aus Dtn 28,31 kommt auf das Rind bezogen im AT nur noch in Ex 21,37 vor. Wie in Dtn 28 geht es um Raub. Die Gesetze Ex 22,1-14 thematisieren Nachbarschaft, Diebstahl und Veruntreuung. Ochs und Esel sind in Ex 22,3 Diebesgut, in Ex 22,8 werden sie veruntreut und in Ex 22,9 zur Verwahrung übergeben. Auch in Ex 23,4 stehen Rind und Esel zusammen, darüber hinaus verbunden mit der zweiten Verbwurzel aus Dtn 28,31 (שוב) und mit dem Feind.

Rind und Esel $(28,31)$ findet man im Deuteronomium noch in 22,1-4 zusammen. Es sind wie im Bundesbuch sozial ausgerichtete Gesetze, die in 22,4 vorschreiben, auch für Rind und Esel eines Mitbürgers zu sorgen, sowie in 22,8, ein Hausdach abzusichem. 22,5.9.10f dagegen verbieten magische, götzendienerische Praktiken des Vermischens von Männer- und Frauenkleidung, Rind und Esel, Ackerfeld und Weinberg, Wolle und Flachs. Sumner vermutete eine Beziehung ausgleichender Gerechtigkeit zwischen den Gesetzeskodizes und ihren Fluchpassagen. Er interpretierte die Lexembezüge von Dtn 28,30f zu Dtn 20,5-7 und zu 22,1-4 als Verdeutlichung der Schuld. ${ }^{2}$ Die Flüche bestrafen gerade in dem Bereich, wo man sich durch Gesetzesübertretung Vorteile verschaffen wollte.

Doch darf man mit einem bewußten Rückbezug zu Gesetzen in den Flüchen rechnen? Es gibt Unterschiede im Detail. Warum stimmt die Reihenfolge in Dtn 20,5-7 Haus - Weinberg - Frau nicht mit der von 28,30 Frau Haus - Weinberg überein? Überhaupt kann man bei einem Aufgreifen des Kriegsbefreiungsgesetzes (Dtn 20,5-7) nicht von ausgleichender Gerech-

\footnotetext{
1 Vgl. STEInER, Taboo, 83f.

2 Vgl. Study, 148 zu V. 31/22,1-4 poetic justice, 138 zu V. 30/20,5-7, reversals, 140 zu V. 29f/6,11 reversals, doch steht dort auch Haus und Zisterne.
} 
tigkeit sprechen, die die Verfluchten gerade in ihrer Sünde trifft. Hier schützt das Gesetz den einfachen Mann aus dem Volk. Wenn ihn also Militärs oder Staatsmacht gesetzwidrig zur Kriegsteilnahme zwingen und Gott ihn dann auch noch mit diesem Fluch trifft, wäre er, obgleich eigentlich unschuldig, doppelt gestraft. Außerdem verwundert es, daß nur Gesetze aus den Dtn 20; 22 aufgegriffen sein sollen. Übertritt man die anderen Gebote straflos? In Dtn 22,1-4.5.9-11 und Ex 22,1-14 wird auch von Kleidung gesprochen (Ex 22,8; Dtn 22,5.11). Wenn auf die Gesetze angespielt wurde, ist unverständlich, warum in Dtn 28 das Fluchthema Bekleidung fehlt, zumal im AO Kleiderflüche bekannt waren (VTE Z. 492, A.745.1 Kol. IV Z. 15f). Statt bewußter Bezüge zu den Gesetzen dürften gleichartige Motivkomplexe vorliegen. Gewisse Themen handelte man offenbar in konventionellen Kombinationen ab.

Die 1. Strophe der futility curses läuft auf die Deportation der Söhne und Töchter in V. 32 hinaus. Dieser letzte Vers ist überlang, beschreibt die Aktivität der Ausgebeuteten als Ausschauhalten und Schmachten nach den Verschleppten und schließt mit dem Ausdruck ואין לאל ידך, der nur noch in Neh 5,6, unverneint in Gen 31,29, Mi 2,1; Sir 5,1; 15,11 (vgl. Spr 3,27) vorkommt. ${ }^{1}$ Der $w^{e}$ êen-Refrain verknüpft $28,30-32 \mathrm{mit}$ V. $26 \mathrm{~b}$ und V. $29 \mathrm{~b}$. Das dort vorkommende ואין מולשיע steht noch Dtn 22,37; Ri 12,3; Jes 43,11; Ps 18,42 und in JHWHs Alleinverehrungsanspruch Hos 13,4.

Für manche Krankheitsbezeichnungen in Dtn 28,34f fehlen sonst im AT gleichartige Aussagen. משגע wird häufig zur abwertenden Bezeichnung von Propheten benutzt (Jer 29,26; Hos 9,7; 2 Kön 9,11; vgl. 1 Sam 21,16 David stellt sich verrückt), jedoch wird man niemals verrückt von dem, was man sieht. ${ }^{2}$ Die ברכים, die Knie, Schenkel oder den Schoß bezeichnen können, sind im AT niemals krank. ${ }^{3}$ שים ,Schenkel“ sind in Spr 26,7 verkrüppelt, aber in Ps 147,10; Jes 47,2; Hld 5,15 gesund. Pדר "Scheitel“ ist in Dtn 33,20 zerrissen und in Ri 68,22 zerschmettert, in Dtn 33,16 und Gen 49,26 jedoch Empfänger des Segens. שחין רע kommt nur noch Ijob 2,7 vor, gefolgt von der wörtlichen Entsprechung zu Dtn 28,35b. ${ }^{4}$ Nur שין begegnet

1 Vgl. WeIl, „Gage,“ 178, 235; WATSON, „Reclustering,“ 214f schlägt vor, ואין לא לידך abzutrennen, wobei al von $l \bar{a}$ ' $\hat{a}$,,stark sein“" abgeleitet „Macht“ heißt: Es gibt keine Macht in deiner Hand.

2 (אשר) חראה (איאה 28, wird außer in 28,67 im Deuteronomium noch in 3,28; 32,52 von Mose, der das Land sehen darf, gesagt, dann aber in 22,1.4 in Sozialgesetzen, und 12,13 im Zusammenhang der Kultzentralisation.

${ }^{3}$ Das akkadische Äquivalent burku kommt jedoch laut AHw 140 in medizinischen Texten 15 vor, kann also durchaus im Zusammenhang mit Krankheit stehen.

4 Vgl. Dion, „Eclairage,“ 231. Dion setzt der von WEINFELD mit Ex 9,9f in Verbindung gebrachten Etymologie von saharšubbû folgend שח mit der von Sin gebrachten Krankheit 
im schon genannten Ex 9,9-11, in Regelungen zur Aussatzbehandlung von Lev 13,18-20.23, sowie in der Heilung von Hiskijas Krankheit durch einen Feigenbrei 2 Kön 20,7; Jes 38,21f.

Nach dem sekundären V. 36f folgt die 2. Strophe der Frustrationsflüche. Die inhaltliche Zusammengehörigkeit der beiden Strophen der futility curses von Dtn 28,30-32.38-42 erhellt aus der Kombination gleicher Stichworte in Ex 23,10-12:

Sechs Jahre kannst du in deinem Land säen und die Ernte einbringen; im siebten sollst du es brach liegen lassen und nicht bestellen. Die Armen in deinem Volk sollen davon essen, den Rest mögen die Tiere des Feldes fressen. Das gleiche sollst du mit deinem Weinberg und deinen Ölbäumen tun. Sechs Tage kannst du deine Arbeit verrichten, am siebten Tag aber sollst du ruhen, damit dein Rind und dein Esel ausruhen und der Sohn deiner Sklavin und der Fremde zu Atem kommen.

Hier findet man die Abfolge Säen (Dtn 28,38) - Weinberg (39) - Ölbäume (40) - Stier und Esel (31) - Sohn (der Sklavin, vgl. 32.41) - Fremder (43). Fast sämtliche Leitwörter von Dtn 28,31f.38-43 sind versammelt. Sie bilden also im AT zusammenhängende Themenkomplexe.

$\mathrm{Zu}$ Dtn 28,38-40 gibt es ähnliche Frustrationsflüche in Mi 6,15. Angeprangert werden von Micha gefälschte Waage und falsche Gewichte (Mi 6,11), Gewalttat, Lüge und Betrug (Mi 6,12). Es folgt ein Hinweis auf das Nordreich. Ursache für Sünde und Strafe ist die Orientierung an den Gesetzen Omris (Mi 6,16).

Die beiden Strophen des Gedichtes aus futility curses enden mit der Deportation der Kinder (V. 32.41). הלך בשבי kommt noch Jer 20,6; Am 9,4 und ähnlich in aramäischen Texten vor. ${ }^{1}$ Das Leid gipfelt im Verlust des Nachwuchses. Danach steht jeweils ein refrainartiger Schlußsatz, mit der Wortverbindung פרי אדמתך,Frucht deines Erdbodens“. Die Belegstellen des Ausdrucks פרי אדמתך deuten die Früchte als Zeichen der göttlichen Landschenkung. ${ }^{2}$

V. 43f] Bultmann bezieht den Ausdruck הגר אשר בקרבץ in 43a $\alpha \beta$ auf den Wohnsitz des גרואר בשעריך) בארך in einer Ortschaft). Es geht nicht um die

gleich, ohne auf die lexikalischen Listen zu garābu einzugehen. גרב מהין sollten aber auseinandergehalten werden.

1 Vgl. Block, Gods, 115 Anm. 52.

2 Gen 4,3 opfert Kain die Früchte des Landes; Dtn 26,2.10 opfert man die Erstlinge der Früchte des Landes; Dtn 30,9 als Zeichen neuer Gnade; Jer 7,20 ist die Vernichtung der Früchte des Landes Strafe für Götzendienst; Num 13,20 sollen Kundschafter von den Früchten des Landes mitbringen. Ps 105,35 nennt Grillen und Heuschrecken als ägyptische Plagen; Mal 3,11 spricht von der Abwehr der Schädlinge. 
nationale Größe Israel, der ein ethisch Fremder gegenübergestellt würde, sondern um typische Erfahrungen im Lebenshorizont der Ackerbau treibenden Schicht des Königreiches Juda. Ein Problem sieht Bultmann darin, daß V. 44 vor den Hintergrund der sonst üblichen Kreditgabe an den גר formuliert zu sein scheint. Solche Kreditgeschäfte der Israeliten mit Fremden werden in der Fluchaussage ins Gegenteil verkehrt. Der ר gehört aber nicht zu den Personengruppen, die nach dem deuteronomischen Gesetz Kredite von Israeliten erhielten. Er löst die Schwierigkeit dadurch, daß er in 44a eine sekundäre Umkehrung der ursprünglichen Segensverheißung des Leihenkönnens sieht, die zwischen die Aussagen der Umkehrungen der sozialen Ordnung $43.44 \mathrm{~b}$ nachträglich eingefügt wurde. In V. $43.44 \mathrm{~b}$ ist der גie persona misera des deuteronomischen Gesetzes, während er in 44a eher dem reichen, arme Israeliten ausbeutenden ג von Lev 25,47 ähnelt. ${ }^{1}$ Doch ist zu fragen, ob Bultmann das Motiv des Leihens nicht überinterpretiert. Sein Problem, daß der ג normalerweise keine Kredite empfing, besteht in V. 44a insofem nicht, als er auch nach 44a keine Kredite empfängt, sondern Kredite gibt. Der Schwerpunkt der Aussage liegt auf dem wirtschaftlichen Abstieg der Israeliten. Vielleicht wurde der גals reiche Antipode der Verfluchten gerade deshalb gewählt, weil man sich von der persona misera eine derartig kapitalkräftige Stellung am wenigsten erwartete. $\mathrm{Da} \beta 44 \mathrm{a} \beta$ einen realen Hintergrund in tatsächlichen Kreditgeschäften von reichen Israeliten mit einem ג besitzt, impliziert der Fluch nicht.

Sucht man nach Belegen der Formel הגר אשר בקרבך im Deuteronomium kommt man zur Opferparänese. In Dtn 16,11 wird nach der Regelung des Wochenfestes mit der Darbringung einer freiwilligen Gabe zur Freude gemahnt zusammen mit den Leviten, den Fremden, Waisen und Witwen. In Dtn 26,11 wird diese gängige deuteronomische Reihung marginaler Gruppen nach der Regelung der Darbringung der Erstlingsfrüchte auf die Leviten und die Fremden beschränkt. Wo steht, geht es um die Opferung der Landeserträge. Doch im Fluch wird nur noch der Fremde genannt. Der Fluch trifft alle, auch die Waisen, Witwen und Leviten, nur der Fremde ist ausdrücklich ausgenommen. ${ }^{2}$ Eine ähnliche Vorstellung steht hinter Jes 9,13-16, wo in einem Drohspruch gegen Efraim und Samaria das Bild vom Kopf und vom Schwanz auftaucht: ${ }^{3}$

\footnotetext{
${ }^{1} \mathrm{Vgl}$. Fremde, 135f. BultmanNs Überlegungen setzen eine komplizierte Entstehungsgeschichte von $28,43 \mathrm{f}$ voraus. Zuerst existierte $43 \mathrm{a} \beta \mathrm{b} .44 \mathrm{~b}$, denn $13 \mathrm{a}$ ist die Nachkonstruktion davon. Dazu kam dann V. 12b, die Verheißung des Leihenkönnens, die sich wie 15,6 aus dem Segensgedanken entwickelt. Schließlich wurde vom Segen aus der Fluch durch die Antithese von 44a ergänzt.

2 Vgl.. Friedman, „Egypt,“" $183 f$.

${ }^{3} \mathrm{Vgl}$. MAYES, Deuteronomy, 353.
} 
Da schnitt der Herr dem Volk Israel den Kopf und den Schwanz ab ... . (...) Die Führer dieses Volkes sind Verführer; wer sich von ihnen führen läßt, wird in die Irre geleitet. Deshalb verschont der Herr weder die Männer, noch hat er mit den Witwen und Waisen Erbarmen.

Da die Dopplung „Kopf / Schwanz“ noch Jes 19,15 in Parallele zu „Palme / Binse“ in einem Wort gegen Ägypten vorkommt, hat Ockinga darauf hingewiesen, daß man im Ägyptischen mit den Körperteilen Kopf und Hinterteil Ober- und Unterägypten meinte. Auch Papyrus und Binse sind Wahrzeichen der beiden Landesteile. Die Doppelausdrücke bezeichneten jeweils eine Ganzheit. In Jes 9,13; 19,15 könnte die Ganzheit Israels oder Ägyptens gemeint sein. ${ }^{1}$ Allerdings bleibt dann in Jes 9,13 unklar, wovon ganz Israel abgeschnitten wird. Von Dtn 28,44 her betrachtet, scheint die Interpretation als Hendiadyoin unmöglich, da hier ein Gegensatz zwischen Kopf und Schwanz ausgesagt wird. Der Fremde und der Verfluchte bilden gerade keine Ganzheit mehr, sondern der eine ist oben und der andere ist unten. Es scheint doch eher so, daß nach der räumlichen Ausdehnung oben / unten, hinaufsteigen / herabsteigen in Dtn 28,43aß.b mit Kopf und Schwanz in 44b die Raumdimension vorne / hinten angesprochen wird. Das ungenannte tertium comparationis muß ein Tier sein. Der Fremde wird mit dessen Kopf gleichgesetzt, befindet sich vorne, der Verfluchte mit dessen Schwanz oder Hinterteil, befindet sich also hinten. Für diese Deutung spricht die Verwendung des Vergleichs in der früharabischen Literatur. Dort wird deutlich, daß es sich bei dem Tier um ein Kamel handeln könnte. ${ }^{2}$ Zwischen die Raumdimensionen oben / unten (V. 43) und vorne / hinten (V.44) wurde in Dtn 28 die Beschreibung der wirtschaftlichen Kapazität gestellt, wodurch die Ortsangaben als Metaphern für die gesellschaftliche Stellung erkennbar werden. Das in 44a verwendete Verb לוה ,ausleihen“ kommt im Deuteronomium außer 28,12 nicht mehr vor, wohl aber im Bundesbuch (Ex 22,24, wobei in Ex 22,20 verboten wird, einen Fremden auszubeuten) sowie Neh 5,4; Jes 24,2; Ps 37,26; 112,5; Spr 19,7; 22,7. Wenn all die Schläge Gottes Wirklichkeit geworden sind, werden die

\footnotetext{
1 Vgl. ,rō’š," 31,34.

2 Im Dîwân des Ġarwal b. Aus Al-Hutej’a spielt der Dichter darauf an, daß ihn die Familie Bagị̂ die Söhne der Nase der Kamelstute, gastfreundlich aufnahm, nachdem er die unfreundliche Familie Zibiqân verlassen hatte. Er verwendet dabei offenbar arabische Redensarten: 22 qaumun humu al'anfu wal'aznbu gayru humu 23wman yusawwī b'anfu alnnaqatun alzzanabā 22Diese Leute sind die Nase, der Schwanz die anderen, 23und wer macht den Schwanz gleich der Nase der Kamelstute? Vgl. GolDZIHER, „Dîwân,“ 177. Die Lesung 'anfu „Nase“" folgt den Textzeugen CK. Das Wörterbuch Tầg al-'arûs nennt jedoch für Zeile 22 die Gegenüberstellung $z n b$ : alr'š „Kopf“. So erhält man eine genaue Entsprechung zu Dtn 28,44. Vgl. ebd. 180; DRIVER, Commentary, 307.
} 
davon Getroffenen wirtschaftlich, gesellschaftlich und räumlich das Allerletzte sein.

\subsubsection{Traditionsgeschichte \\ 6. 2. 5. 1. VTE \& 63f/Lev 26,19}

Zum Vergleich seien die Texte zunächst zitiert:

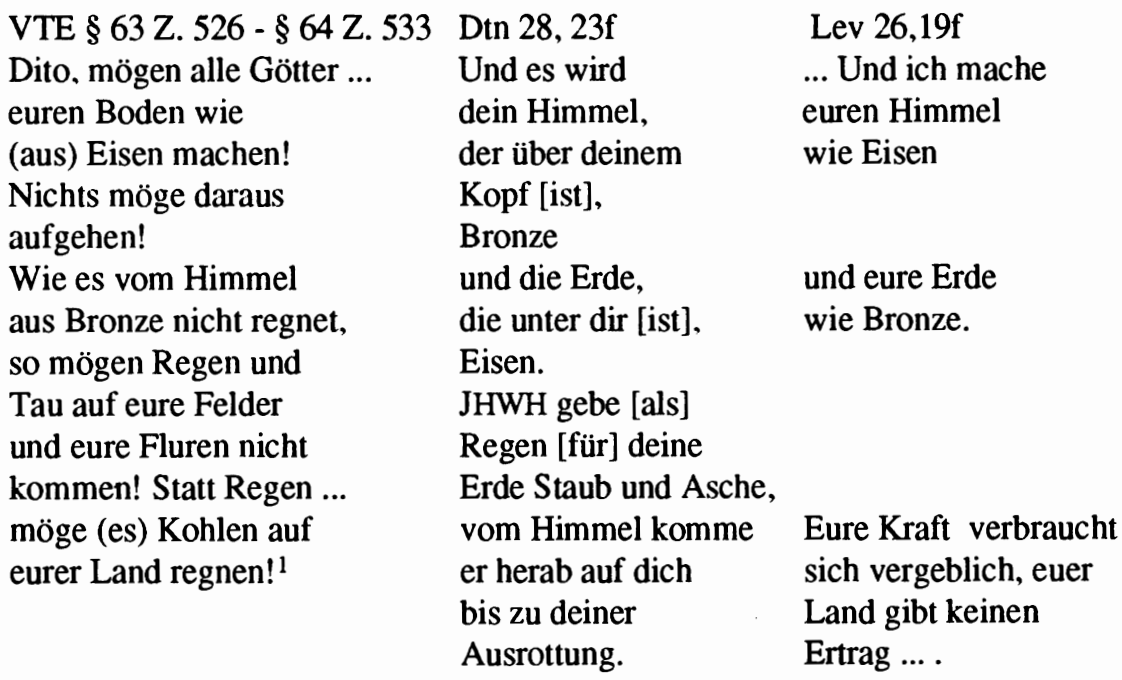

Lev 26,14-46 zeigt gegenüber Dtn 28 einige Unterschiede. Es ist JHWHRede und insofern Drohpredigt. ${ }^{2}$ Die Heimsuchungen werden durch ein Plagensteigerungsschema verstärkt und der Gesamtplan des Kapitels integriert auch die Restauration (V. 40-46). Lev 26 zeigt viel stärker palästinisches Lokalkolorit. ${ }^{3}$ Eine Kombination aus Konditional- und Konsekutivsatz (V. 18.21.23f.27) gliedert die Drohung. Dies entspricht einem Bauschema für Fluchsequenzen, das auch aus hethitischen, aramäischen und

\footnotetext{
1 Vgl. WatANABE, Thronfolgeregelung, 169.

2 Vgl. NOTH, „Fluch,“ 142-144/169-171; KORNFELD, Levitikus, 105; GERSTENBERGER, Leviticus, 371, 389.

3 ,None of these descriptions, which reflect realistic conditions of adversity and which have something of a provincial colouring, are found in Deut. 28. They are encountered, on the other hand, in the Aramaic Sefire treaty, which, as we have seen, reflects a provincial setting similar to that of Palestine. Like Lev. 26 and Amos 4 (cf. also Isa. 9:7ff.), the Sefire treaty also employs repetitive phrases and also uses the typological number seven ... . Similarly it speaks of beasts preying upon people (I, A:30-2), of pestilence (I, B:30; cf. II, $B: 11$ ), search for food, eating and not being sated (I, A:21-4), and the devastation of the land (I, A:32-3)." WEINFELD, School, 125f; vgl. PODELlA, „Nichtigkeitsfluch,“ 436.
} 
assyrischen Texten bekannt ist. ${ }^{1}$ Dtn 28 und Lev 26 folgen verschiedenen Strukturmustern für Fluchpassagen. Dtn 28 gleicht mit seinen Anrufungen Gottes den mesopotamischen Sequenzen, die von einzelnen Göttern des Pantheons Strafsanktionen erbitten. In derartigen Texten fehlt ein Refrain. Lev 26 folgt dem anderen Typ, der in regelmäßigen Abständen die Konditionen für das Eintreffen der Flüche wiederholt, dafür aber auf eine Gliederung nach dem Pantheon verzichtet und die Sanktionen summarisch an den Konditionalsatz anhängt.

Wie bei den Ähnlichkeiten zwischen Dtn 28,26 und Jer 7,33 stellt sich auch bei Dtn 28,23f und Lev 26,19 die Frage: Wer zitiert wen?

Sumner versuchte zu zeigen, daß Dtn 28,23 von Lev 26,19 abhängig sei. Dtn 28,23 habe die Umstellung der Metalle und die Relativsätze eingefügt, um einen Bezug zu Dtn 8,9 herzustellen. Mose beschreibt Palästina als

... ein Land, dessen Steine aus Eisen sind, aus dessen Bergen du Erz gewinnst.

Dtn 28,23 kehrt nach Sumner diese Landbeschreibung um. So werde der Boden mit dem harten Eisen zusammengebracht und statt der Berge sei nun der Himmel aus Kupfer. Deshalb fehlt in Dtn 28,23 die Vergleichspartikel vor den Metallen. Himmel und Erde sind nicht wie Kupfer und Eisen, sondern sie sind Kupfer und Eisen, so wie die Steine in Dtn 8,9 Eisen sind. ${ }^{2}$ Doch Sumners Erklärungsversuch überzeugt nicht. Es stimmt nur die eine Hälfte des Bildes, die Steine und das Eisen. Die Identifikation der Berge mit dem Himmel paßt nicht hinein, zumal der Parallelismus in Dtn 8,9 dadurch gebrochen ist, daß die Steine zwar aus Metall sind, die Berge aber nicht. Aus ihnen schürft man das Kupfer nur. In Dtn 28,23 werden aber sowohl Himmel als auch Erde in Metall verwandelt. Neben diese stilistischen Unstimmigkeiten tritt noch ein diachroner Aspekt. Dtn 8 gilt als spätexilisch-deuteronomistische Komposition. ${ }^{3}$ Wenn also Dtn 28 das Motiv erst als Umkehrung des spätexilischen Dtn. 8 gestaltet hat, dann müßte dies am Ende des Exils oder sogar danach gewesen sein. So spät wird man aber Dtn 28,23f kaum ansetzen können.

Watanabe rechnete mit dem Einfluß des Westens auf Assyrien. ${ }^{4}$ Doch die Untersuchung von VTE $\S 63 \mathrm{f}$ ergab, daß die in Lev 26,19 und Dtn

\footnotetext{
1 Vgl. CTH 49 und 53; Sefire IB, IIB und III. In den VTE wird ab $\$ 63$ der Konditionalsatz von Z. 513-517 durch das Dito-Zeichen wiederholt.

2 Vgl. Study, 154-157.

3 Vgl. Lohfink, „Kerygmata,“ 100; BRAULIK,Deuteronomium, 67: „8 greift dabei die Dekalogkommentierung von 6 auf, akzentuiert sie aber aus der Sicht der späten Exilszeit. So entsteht eine Art Gegenbild zu 7 ... ."Anders: PrEUSS, Deuteronomium, 49.

${ }^{4} \mathrm{Vgl}$. Thronfolgeregelung, 33f.
} 
28,23f so prägnante Parallele zwischen Himmel und Erde dort nicht besteht. Im assyrischen Text verwandeln die Götter nur den Boden in Ziegelstein und Eisen. Der Himmel dagegen ist bereits Bronze. Da das akkadische Wort für Himmel šamû auch einen Baldachin bezeichnen kann, dürfte das tertium comparationis von $\S 64$ ein damals allgemein bekannter Gegenstand gewesen sein. Die assyrischen Schreiber hätten also den Parallelismus, der die biblischen Belege auszeichnet, zerstört, statt ihn zu verwenden. Die in den VTE $\S 63$ gegenüber der Verbindung mit dem Himmel stilistisch auffälligere Verknüpfung des eisernen Bodens mit dem auch sonst in assyrischen Flüchen bekannten Ziegelsteinmotiv legt nahe, daß der Fluch in Assyrien entstand, in den Westen drang und dort ausgestaltet wurde. Eine Vermittlerrolle könnte dabei der aramäische Kulturraum gespielt haben. Immerhin schrieb man am assyrischen Hof auch aramäisch. Man verstärkte den Parallelismus zwischen Erde und Himmel vielleicht schon bei der Übersetzung der VTE in diese westsemitische Sprache.

Der in Ägypten gefundene Papyrus Amherst 63 zeigt, wie Traditionen, die ihren Ursprung in der Regierungszeit Assurbanipals haben, im aramäisch sprechenden AO fortlebten. Der Papyrus enthält unter anderem die Geschichte vom Kampf der Brüder Sarbanabal und Sarmuge, den Herren der Städte $B n n^{\prime} w(h)$ und Babylon. Es handelt sich bei diesen aramäisch entstellten Namen um Assurbanipal, Šamaš-šum-ukin und Ninive. Erzählt werden Begebenheiten, die sich vor dem historischen Hintergrund des Aufstands Šamaš-šum-ukins gegen Assurbanipal abspielten. ${ }^{1}$ Die Erzählung dürfte aus dem 6 . Jh. vor Chr. stammen und verwendet eine keilschriftliche assyrische Quelle, die den Aufstand Šamaš-šum-ukins aus assyrischer Sicht zu Propagandazwecken darstellte. ${ }^{2}$ Es handelt sich bei den feindlichen Brüdem um die beiden Söhne Asarhaddons, für die die VTE abgefaßt wurden. Die Erzählung des Papyrus Amherst 63 steht also in traditionsgeschichtlicher Verbindung mit den VTE. Im Geburtsjahr des Šamaš-šum-ukin sollen sich Himmel und Erde ähnlich verändert haben, wie es Dtn 28,23 und Lev 26,19 beschreiben. In der auf einer assyrischen Vorlage beruhenden Erzählung könnte das Motiv aus VTE § $63 \mathrm{f}$ nachwirken. Allerdings gehen die Ansichten bei der Interpretation der betreffenden

\footnotetext{
1 Vgl. STEINER / NiMS, „Ashurbanipal,“ 61.

2 Vgl. KOTTSIEPER, „Aufnahme,“ 284, 288f. „Wie kommen die assyrischen Quellen in den südsyrischen Raum? Offenbar haben wir es hier mit einem Stück assyrischer Propaganda zu tun. Da auch die westlichen Gebiete die Chance des Šamaš-šum-ukin-Aufstandes nutzten, um ihrerseits sich gegen die Assyrer aufzulehnen, ist es durchaus anzunehmen, daß die assyrische Oberherrschaft nach der Niederschlagung dieses Aufstandes ihre Sicht der Dinge propagandistisch verbreitete." Ebd., 289.
} 
Passage in Papyrus Amherst 63 auseinander, so daß unsicher bleibt, wie Motive tatsächlich miteinander kombiniert sind. ${ }^{1}$

Die verbreitete Forschermeinung zu Dtn 28,23f und Lev 26,19 lautet jedoch: Es wird überhaupt nicht zitiert. Eine sprichwörtliche Motivverbindung sei in beiden Bibeltexten verarbeitet worden. ${ }^{2}$ Wenn Lev 26,19 also ursprünglich ist, wie soll man dann die Spuren redaktioneller Manipulation beurteilen, die Reventlow und Elliger in ihren literarkritischen Analysen in dem Vers entdeckten ${ }^{3}$ Immerhin weisen Lev 26 und Dtn 28 eine ganze Reihe lexikalischer Gemeinsamkeiten auf ${ }^{4}$ und bei Lev 26,16 rechnet Elliger durchaus mit direkter Übernahme der Wendungen aus Dtn 28,22. ${ }^{5}$

\footnotetext{
${ }^{1}$ Zur Klärung dieser Frage wären intensive Studien an dem in demotischer Schrift verfaßten Text nötig, die den Rahmen dieser Arbeit überschreiten. STEINER / NIMS, „Ashurbanipal,“ 70 übersetzten so, daß die Reihenfolge und die Zuordnung der Metalle zu Dtn 28,23 passen: „The year in which was born our lord, our brother, Sarmuge, to you, bronze were the heavens, of iron, the earth; (the) ground in a bad state ..., the heavens, a fired brick." KOTTSIEPER, „Aufnahme,“ 285 Anm. 10, sieht dagegen die deutlichere Parallele in Lev 26,19. Er übersetzt: „die Erde von Bronze, die Himmel eisern, der Erdboden vernichtet durch Trockenheit und der Himmel ein glühender Ziegel ... ." Ebd. 284. Bei VLEEMING / WESSELIUS, Studies, 33, ist der Ziegelstein verschwunden, der an den Beginn von VTE § 63 - dort auf den Erdboden bezogen - erinnert: „The year (in) which was born our lord, our brother Sarmanki: ... The earth was of copper, the sky of iron, the dust ... was unclean with evil, the sky with profanity."
}

2 Vgl. Elliger, Leviticus, 369; REVENTLOW, Heiligkeitsgesetz, 150; WEINFELD, School, 117; KorNFELD, Levitikus, 105; CHOLEWINSKI, Heiligkeitsgesetz, 124; GERSTENBERGER, Leviticus, 380.

${ }^{3}$ Vgl. ReVENTLOw, Heiligkeitsgesetz, 150. Seine Reihenfolge: 19ba, 19bß, 19a, 20a, 20b. ," ... Die Periode 19a+20a dürfte erst sekundär auseinander gerissen sein." ELLIGER, Leviticus, 367. Seine Literarkritik faßt er folgendermaßen zusammen: „Eine in sich geschlossene, im

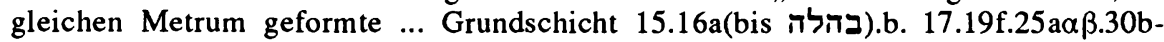
33a.37b.38 ist mit einer Sekundärschicht verschmolzen ... ." Ebd. 369. Die bedingte Verheißung in Lev 26,39-45 ist eine Fortsetzung der Sekundärschicht. Die Grundschicht war eine vordeuteronomische Agende des Herbstfestes. Vgl. ebd. 170f. Doch ElLIGERs Literarkritik, die Lev 26,19 ganz zur vordeuteronomischen Schicht rechnet, überzeugt nicht, wie CHOLEWINSKIs Bewertung zeigt. „Das Vorhandensein einer metrischen Vorlage ist ... nicht ... eindeutig ... und ihre Abgrenzung ist noch schwerer festzustellen. Darum soll der Umfang dieser Vorlage, wie sie ... nach Elliger angegeben wurde, nur als provisorisch und wahrscheinlich angesehen werden." Heiligkeitsgesetz, 124.

4 ,Hier finden sich verschiedene wörtliche Berührungen, von denen die von V.16 und Dt 28 22 am auffälligsten ist und die nur an diesen beiden Stellen vorkommenden Wörter und תחтp aufweist. Ebenso finden wir das Bild V.19b nur noch Dt 28 23. Außerdem ... noch ... : V.4 mit Dt 28 12; V.6 והרין מחריד mit Dt 28 26; V.14 mit Dt 28 15; V.16 außer mit Dt 2822 ... mit Dt 28 33.65; V.17 mit 28 25; V.29 mit Dt 28 53; V.36 mit Dt 28 65.67." REVENTLOW, Heiligkeitsgesetz, 144f.

5 Vgl. Leviticus, 367: „Andererseits lassen die Beziehungen zu Dt $2822 \ldots$ sowie zu 1 S 2 33 ... bei 16ab auf ein sekundäres schriftgelehrtes Erzeugnis schließen." Ähnlich PLOGER, Untersuchungen, 152f.: „Die beiden Dt 28,22 stehenden Ausdrücke pinden 
Außerdem wurde in Lev 26 auch sonst deuteronomisch-deuteronomistisches Gedankengut gefunden. ${ }^{1}$

Anhand der bekannten Belege ist nicht feststellbar, ob die Motive von Dtn 28,23f und Lev 26,19 sprichwortartig verbreitet waren. Immerhin steht auch Papyrus Amherst 63 in einem Traditionsverhältnis zu den VTE, da seine Erzählung auf eine Vorlage der assyrischen Hofkanzlei zurückgeht und das Schicksal der Königssöhne beschreibt, um die es in den VTE ging. Innerbiblisch scheint es nicht ausgeschlossen, den strafferen Parallelismus in Lev 26,19 als eine stilistische Vervollkommnung gegenüber Dtn 28,23 zu begreifen.

Unter Einbeziehung von VTE $\S 63 \mathrm{f}$ scheint folgende Überlieferungslinie erkennbar:

\begin{tabular}{|c|c|c|c|c|}
\hline $\begin{array}{l}\text { VTE § 63f } \\
\text { Götter: }\end{array}$ & & $\begin{array}{l}\text { Dtn } 28,23 \mathrm{f} \\
\text { unpersönlich: }\end{array}$ & & $\begin{array}{l}\text { Lev } 26,19 f \\
\text { Ich: }\end{array}$ \\
\hline & & Himmel $\Rightarrow$ Bronze & $\rightarrow$ & Himmel $\Rightarrow$ Eisen \\
\hline Erde $\Rightarrow$ Eisen & $\rightarrow$ & Erde $\Rightarrow$ Eisen & $\rightarrow$ & Erde $\Rightarrow$ Bronze \\
\hline unpersönlich: & & \multirow[t]{2}{*}{ Gott: } & & \\
\hline Himmel $=$ Bronze & $\pi$ & & & \\
\hline Regen $\Rightarrow$ Kohle & $\rightarrow$ & Regen $\Rightarrow$ Staub + & he & \\
\hline
\end{tabular}

Der VTE-Fluch spiegelt die Wertmaßstäbe der mesopotamischen Land wirtschaft wider. In weiten Teilen Assyriens war zwar Regenfeldbau möglich und die bergige Topographie des Zargosvorlandes ließ eine künstliche Wasserzufuhr nur an wenigen Stellen zu. Dennoch sind im Assyrien der neuassyrischen Zeit Bewässerungskanäle schriftlich belegt. ${ }^{2}$ Man bemühte sich, die Wasserversorgung für den Ackerbau durch Bewässerungskanäle zu sichern. Das heranfließende Wasser tränkt den Boden, macht ihn weich zur Bearbeitung und läßt Pflanzen sprießen. In einen eisenharten Boden können keine Kanäle gegraben werden, und selbst wenn es Kanäle gäbe, wäre der Eisenboden undurchdringlich für das Wasser und die keimenden

sich in einer ähnlichen Kette nur noch Lev 26,16. Wahrscheinlich sind sie aus Dt 28,22 in Lev eingefügt worden."

1 Vgl. LoHFink, „Abänderung,“ 166f/135f; B uis, „Siècle,“ 139f; GERSTENBERGER. Leviticus, 374; und zur Kommunikation zwischen priesterlich und deuteronomistisch orientierten Schreibern allgemein BETTENZOLI, „Deuteronomium,“ 398.

2 Vgl. NissEN, Grundzüge, 128f; LABAT, „Assyrien,“ 11 zu Aššur-dan; FALES, „Landscape,“ 109f: „In a text of 707 B.C., a building plot is described as tihi hir-ir-te / ša URUA-di-an, 'adjoining the canals of the city Adian'; ... . A number of canals is mentioned in two deeds transacted one year apart from each other: in the first one, a plot is located 'between the canals' (bir-ti hi-ri-a-te) also has canals as bordering elements; while in the second only fields act as borders for the plot again described as 'between the canals'." 
Pflanzen. Das führt zum Erlöschen der Vegetation. Wo es Bewässerungskanäle gibt, ist man nicht mehr allein auf den Regen angewiesen. Der Regen erhält gegenüber der Bodenbearbeitung nur noch sekundäre Bedeutung. Es wächst schon nichts mehr (VTE Z. 528) bevor der Regen ausbleibt (VTE Z. 531).

Singer hat festgestellt, daß in Vergleichen mit Metallen das schlimmere Übel in Beziehung zum härteren Metall gebracht wird. Dies scheint in den VTE der Fall zu sein. Für eine Landwirtschaft, die Felder künstlich bewässert, bedeutet es eine Katastrophe, wenn sich der Boden nicht mehr bearbeiten läßt, so daß man keine Kanäle mehr graben und keine Deiche mehr bauen kann. Deshalb steht in Mesopotamien der Boden an erster Stelle. Die Götter verwandeln ihn in das härtere Metall, das Eisen. ${ }^{1}$

In Dtn 28 tritt die Parallele zwischen Himmel-Erde / Bronze-Eisen deutlich hervor. Nun steht jedoch der Himmel an erster Stelle. Die Metalle, die Himmel und Erde zugeordnet werden, entsprechen aber noch den VTE. In V. 24 wird der Regen genannt, an der gleichen Stelle, in der er auch in VTE § 64 steht. Der Regen ist für die Landwirtschaft Palästinas wichtiger als die Beschaffenheit des Bodens. Die Erde kann noch so fruchtbar sein. wenn kein Regen fällt, wächst nichts. ${ }^{2}$ Der Himmel erhält somit in der Werteordnung Palästinas den Vorrang. Dies könnte der Grund sein, warum man bei der Verwendung des VTE-Motivs im syrisch-palästinischen Raum die Reihenfolge zu Himmel und Erde geändert und so einen Merismus geschaffen hat. Dennoch blieben einige Charakteristika des VTE-Fluchs erhalten. Die unpersönliche Formulierung von $§ 64$, die im Zusammenhang von Himmel und Regen keine Götter als Subjekt nennt, begegnet auch in Dtn 28,23. Grammatisch sind Himmel und Erde selbst Subjekt der Veränderung. Die doppelte Ausmalung des Regenmangels einmal als einfaches Ausbleiben (VTE Z. 531) und dann sein Ersatz durch das Brennmaterial Kohle (VTE Z. 533) findet ebenfalls ihre Entsprechung in Dtn 28. Erst hier tritt JHWH auf. Er verwandelt den Regen je nach Verseinteilung in Staub, oder in Staub und Asche. Beide Male wechselt dann der Satz wieder zu einer unpersönlichen Aussage (24a). Entweder der zu Staub und Asche pervertierte Regen kommt herab oder - bei der anderen Verseinteilung - es regnet nur das Verbrennungsprodukt Asche (24b).

Bei der Übertragung der assyrischen Vorlage in die westsemitische Sprache wurden Veränderungen durchgeführt, die im AO als Begleiterscheinungen des Übersetzungsvorgangs aufscheinen.

${ }^{1} \mathrm{Vgl}$. Metalle, 122: „Eine Strafe, die an sich schon schrecklich ist, wird durch die Verwendung von eisernen Strafwerkzeugen noch härter ... .“

2 Vgl. FrICK, „Ecology,“ 71, 76f. 
(1.) Die Götter (VTE Z. 526) werden zu JHWH $(28,24)$. Letzterer wird zum Subjekt der Verwandlung des Regens. Ein solcher Austausch des Gottesnamens und die Veränderung von Formulierungen geschieht auf der Bilingue von Karatepe (KAI Nr. 26).

(2.) Das Ziegelsteinmotiv (VTE Z. 527) und das Ende der Vegetation (VTE Z. 528) wurden nicht übersetzt. Derartige Auslassungen findet man auch am Beginn des Fluches in der aramäischen Version der Bisitun-Inschrift (Z. 72).

(3.) Doppelausdrücke stehen Einzelbegriffen gegenüber, die mehr oder weniger dasselbe bedeuten: Regen + Tau (VTE Z. 531) / Regen $(28,24)$; Felder + Fluren (VTE Z. 532) / Erde (28,24); Kohle (VTE Z. 533) / Staub + Asche $(28,24)$. Die Bisitun-Inschrift liefert auch für dieses Phänomen einen Beleg (persische Version Z. 75, elamitische Z. 87, babylonische Z. 107). Auf der Bilingue von Tell Fekheriye steht drei assyrischen Krankheitsbegriffen nur ein aramäischer Ausdruck gegenüber (assyrische Version Z. 37f, aramäische Z. 23)

(4.) Die Reihenfolge von Erde und Himmel wird umgedreht. Im Fluch auf der Bilingue aus Sardes (KAI Nr. 260 Z. 8) findet sich die Umstellung der Glieder einer Aufzählung. In der ägyptischen Übersetzung des Vertrags zwischen Ramses II und Hatušili III ist die Stellung von Segen und Fluch gegenüber der akkadischen Fassung (CTH 91) vertauscht.

Fales untersuchte die Bearbeitungsmethoden der assyrischen Schreiber, die veraltete Feldzugsberichte Assurbanipals auf den neuesten Stand bringen mußten. $\mathrm{Zu}$ einer ihrer Vorgehensweisen gehört die Umstellung (permutation) von Wörtern, Syntagmen oder ganzen Teilen der Erzählung. ${ }^{1}$ Die Unterschiede zwischen VTE $\$ \S 63 \mathrm{f}$ und Dtn 28,23f lassen sich also mit der Arbeitsweise altorientalischer Schreiber erklären, die Inschriften übersetzten oder Vorlagen für eine Neuedition überarbeiteten. Wer immer die hier behandelten Abschnitte der VTE ins Hebräische übersetzte, wollte nicht beweisen, wie gut er aramäisch oder assyrisch beherrschte, sondern unter Verwendung einer geeigneten Vorlage einen neuen Text für einen neuen Zweck schaffen, ähnlich wie die assyrischen Hofschreiber, die neue Königsinschriften produzierten und dabei auf bereits Vorliegendes zurückgriffen.

Lev 26,19f wirkt gegenüber Dtn 28,23f abstrakter. V. 19 enthält nur den Parallelismus Himmel - Erde. Das Regenmotiv fehlt völlig. Es ist auch nicht mehr nötig, denn der Inhalt der Aussage kann im Metallvergleich gefunden werden, der nun getreu palästinischer Gewichtung den lebensnotwendigeren Himmel zum härteren Metall verwandelt, während der un-

${ }^{1}$ Vgl. FaLES, „Code,“ 176 
wichtigere Boden zur weicheren Bronze wird. Singer erkennt richtig, daß der Himmel in Lev 26,19 noch deutlicher in den Mittelpunkt gerückt wird als in Dtn 28,23f. ${ }^{1}$ Der Parallelismus wird noch exakter, die Wertigkeit der Metalle den landwirtschaftlichen Gegebenheiten Palästinas angepaßt.

Beachtung verdient schließlich auch eine Beobachtung, auf die Sumner und Preuß hinweisen. ${ }^{2}$ Sowohl in Dtn 28 als auch in den VTE folgen auf die Vergleiche des Himmels und der Erde mit Metall Kriegsflüche, in denen es um Niederlage und Flucht vor dem Feind geht. VTE $\S 65$ ähnelt Dtn 28,25 inhaltlich so, daß man darin die Stichwortvorgabe zur Übernahme von Flüchen aus den VTE erkennen kann, die die Niederlage vor dem Feind thematisieren, wie der Assur- (§ 58) Palil- ( $(59)$ und Ninurtafluch (§ 41).

\section{VTE $\$ 65 \mathrm{Z} .534 \mathrm{f}$}

So wie Zinn in der Nähe des Feuers nicht standhält, so sollt ihr

vor eurem Feinde

[nicht] standhalten; eure

Söhne und Töchter sollt ihr mit euren Händen fassen (zur Flucht). ${ }^{3}$

\section{Dtn 28,25}

JHWH gebe dich geschlagen

vor deine Feinde,

auf einem Weg mögest du

ausziehen gegen sie, und auf

sieben Wegen fliehen vor ihnen.

Aufgrund der genannten Gemeinsamkeiten ist mit der direkten Abhängigkeit von Dtn 28,23f von den VTE zu rechnen. So erscheint eine Entwicklungslinie, die sich von den VTE zu Lev 26,19 erstreckt, vom eher zufälligen Zusammentreffen von Erde und Baldachin zu immer exakterem Parallelismus und immer konsequenterer Anpassung der Motive an die Verhältnisse Palästinas. Für die Beziehung von VTE $\S \S 63 \mathrm{f} \mathrm{zu} \mathrm{Dtn} \mathrm{28,23f}$ spricht auch die in beiden Texten anschließend folgende Thematik der Niederlage und der Flucht. Damit fallen bereits Stichworte aus VTE $\S \S$ 38A-42, denen sich das nächste Kapitel zuwendet.

\footnotetext{
1 „So bewirkt nach Lev 26,19 der eiserne Himmel, der wie eine Eisenschale keinen Regen durchläßt, erst, daß die Erde hart wie Bronze wird." SINGER, Metalle, 116. Seine Erklärung des Unterschieds zu Dtn 28,23f überzeugt nicht: „Die zunehmende Härte der Metalle ist in Dtn 28,23 bewußt gewählt - im Gegensatz zu Lev 26,19, wo der Regen versagende Himmel im Mittelpunkt steht - , um die Unfruchtbarkeit der Erde - Dtn 28,22 - deutlicher zu unterstreichen." Ebd. 116f. Der Regen wird in Lev 26,19 überhaupt nicht erwähnt. Die Unfruchtbarkeit in Dtn 28,22 resultiert weder aus dem Regenmangel noch aus der Bodenbeschaffenheit, sondern aus Getreidekrankheiten. Hinter der Abfolge der Metalle in Dtn 28,23 stehen noch die Bewertungskategorien einer Bewässerungsgesellschaft.

2 Vgl. SuMner, Study, 57; Preuss, Deuteronomium, 72f.

3 Vgl. BORGER, „Vasallenverträge,“ 173. Seine Übersetzung läßt die Ähnlichkeiten zu Dtn 28,25 deutlicher hervortreten als die von WATANABE.
} 


\section{2. 5. 2. VTE $\$ 39-42$}

Die Ähnlichkeit von Dtn 28,25a.26-30 mit VTE §§ 39-42 bildete den Ausgangspunkt dieser Untersuchung. Man verglich darüber hinaus Dtn 28,35 mit dem Gulafluch. Trotz der Gemeinsamkeiten gibt es aber auch Unterschiede zwischen dem assyrischen und dem hebräischen Text. Hier werden beide Versionen miteinander verglichen, um festzustellen, ob die Unterschiede eine direkte literarische Abhängigkeit ausschließen.

Der erste Fluch, der in beiden Texten an derselben Position innerhalb einer abgrenzbaren Reihe steht, ist der Sinfluch VTE $\S 39$ und der Fluch der Hautkrankheiten Dtn 28,27. ${ }^{1}$ Der Sinfluch ist in den VTE das zweite Glied einer Reihe von Flüchen der Astralgottheiten, die mit Anu § 38A beginnt. In Dtn 28 bildet V. 27 das zweite Glied der Krankheitsflüche mit dem Verb נכה ,schlagen“ (nach V. 22). Beide Flüche werden in Reihen fortgesetzt. Dem Mondgott folgt in $\S 40$ der mit ihm traditionell verbundene Sonnengott und in Dtn 28,28 folgt sofort ein zweiter Krankheitsfluch mit dem Verb נכה ,schlagen“. Diese unmittelbare Aufeinanderfolge zweier Krankheitsflüche ist in Dtn 28 einmalig. Immerhin trennten V. 27 von dem ersten Krankheitssatz in V. 22 vier Verse, und zwischen V. 28 und dem nächsten ,Schlagen“-Motiv in V. 35 stehen fünf Verse. Die unmittelbare Aufeinanderfolge von Dtn 28,27.28 nimmt also im Kapitel eine ähnliche Zwillingsstellung ein, wie sie aus Mesopotamien für den Sin- und Šamašfluch bekannt ist. Rein formale Gegebenheiten im jeweiligen Kontext lassen demnach bereits eine Verwandtschaft zwischen dem assyrischen und dem hebräischen Text erkennen.

\section{VTE $§ 39$ Z. 419f}

Sîn,

die Leuchte des Himmels und der Erde möge euch mit saharšubbû-Krankheit bekleiden, euer Erscheinen in der Gegenwart des Gottes ... und des Königs verbieten. Lauft wie Wildesel und Gazelle in der Steppe umher! ${ }^{2}$
Din 28,27

JHWH schlage dich

mit dem Geschwür Ägyptens und mit Beulen und mit Hautkrankheit und mit Krätze, von denen du nicht geheilt werden kannst.

Dtn 28,27 besitzt kein Epitheton wie es im assyrischen Fluch zum Gottesnamen hinzutritt. Darin folgt der hebräische Text einer westsemitischen Eigenart, die bei Gottesnamen häufig auf Epitheta verzichtet. Ähnliches ist auch in Sefire IA (Z. 25f, 38) festzustellen, wo Hadad und Inurta ohne

\footnotetext{
${ }^{1}$ Vgl. Weinfeld, ,Traces,“ 418 Anm. 3, 4; School, 117 Anm. 4; Watanabe, „Überlieferung," 110 .

2 Vgl. WatanaBE, Thronfolgeregelung, 163.
} 
Epitheton genannt werden, was in einem ähnlichen assyrischen Text kaum denkbar wäre. Außerdem verwendet das Deuteronomium den Gottesnamen ohne Epitheton, wenn JHWH als Richter handelt. ${ }^{1}$

Der Sinfluch endet im traditionell zu ihm gehörigen Motiv der Exkommunikation. Der Verfluchte wird aufgrund seiner Krankheit aus der Menschengemeinschaft ausgeschlossen. Das Anathema von Kult und Hof ist eine assyrische Ergänzung zu dem überlieferungsmäßig sehr festgelegten Fluch. Während die assyrische Version das Exkommunikationsmotiv erweitert, reduziert es die hebräische Fassung zu einer Anspielung. Hautveränderungen, und darum handelt es sich bei גרב שח שין, führen, wenn sie unheilbar sind (V. 27b), zum Ausschluß aus der Menschengemeinschaft. ${ }^{2}$ Das Thema Exkommunikation wird im Bibeltext nur angedeutet, jedoch nicht ausgeführt. ${ }^{3}$ Der biblische Verfasser setzt durch die Unheilbarkeitsaussage ein Struktursignal in seinem eigenen Text. Er verknüpft so das Krankheitsthema von V. 27 mit V. 35, dem Gegenstück der Palindromie dieses Abschnitts.

Schließlich stehen der einen sahıaršubbû-Krankheit in VTE §39 vier Krankheitsbezeichnungen im hebräischen Text gegenüber. Ein ähnliches Phänomen wurde auf der Tell Fekheriye-Bilingue festgestellt. ${ }^{4}$ Man sah im AO kein Problem darin, einen Begriff in der anderssprachigen Version desselben Textes in mehreren Äquivalenten auszudrücken. Sogar der Wechsel von „,bekleiden“ in den VTE zu ,schlagen“ im Deuteronomium läßt sich als Übersetzung begreifen, denn in der Bisitun-Inschrift wird das elamitische (Z. 76, 88) und persische (Z. 58, 78f) Verb ,schlagen“ im Babylonischen (Z. 103, 108) und Aramäischen (Z. 73) durch ,,verfluchen“ übersetzt. Warum soll also nicht aus „bekleiden“ bei der Übersetzung ins Hebräische „schlagen" werden können? Im Licht der Vorlagentreue altorientalischer Bilinguen weicht Dtn 28,27 nicht so stark von VTE $\S 39 \mathrm{ab}$, daß seine Übertragung aus der fremdsprachigen Vorlage ausgeschlossen wäre. Die fremdsprachige Quelle wird in Sprachkonventionen, Bilder und Lebenswelt der Zielsprache übergeführt.

VTE § 40 Z. 422-424

Šamaš, das Licht des Himmels und der Erde, möge für euch keine wahrhaftige,
Dtn $28,28 \mathrm{f}$

JHWH schlage dich mit

Raserei und mit Blindheit

\footnotetext{
$1 \mathrm{Vgl}$. BrauliK, Mittel, 112.

2 Vgl. Lev 21,20; 22,22.

3 Die Gründe dafür wurden in der Besprechung des Jupiterfluchs VTE $\S 43$ behandelt.

4 Vgl. FaLes, ,.Bilinguisme,“ $247 \mathrm{f}$.
} 
gerechte Rechtshandlung vollziehen, die Sicht eurer Augen verwirren!

Wandelt in Dunkelheit umher! ${ }^{1}$ und mit Verwirrung des Herzens.

Und du wirst am Mittag umhertasten, wie ein Blinder umhertastet im Dunkel, und du wirst auf deinen Wegen keinen Erfolg haben, und du wirst nur ausgebeutet und beraubt alle Tage, und es gibt keinen Retter.

Obwohl das Epitheton des Šamaš wieder keine Entsprechung im Bibeltext besitzt, verdient es doch Aufmerksamkeit. Es ist in der mesopotamischen Fluchtradition ungewöhnlich, Šamaš im Epitheton von Flüchen auf seine Lichtfunktion anzusprechen. Der VTE-Fluch trifft gerade damit die Aussagespitze von Dtn $28,28 f$. Denn auch dort geht es vor allem um Licht und Dunkelheit. Šamaš, der Gott des Rechts, verfügt über die Verfluchten eine Unrechtssituation. Auch dies steht im Bibeläquivalent, wenngleich erst in V. 29. Was anderes ist rettungslose Beraubung und Unterdrückung als massive Rechtlosigkeit? Doch der Sonnengott schenkt mit dem Licht auch das Sehvermögen. Dessen Aufhebung oder Trübung wird im assyrischen Text angekündigt. Es scheint, als gebe Dtn 28,28 mit „Blindheit“ und „Verwirrung“ beide Übersetzungsmöglichkeiten des akkadischen li-ši-ma wieder. Dies war vielleicht schon in der aramäischen Version des Šamašfluchs so.

VTE Z. 424 gibt keine göttliche Tätigkeit an, sondern richtet einen Imperativ an die Verfluchten. Dtn 28,29a gestaltet das Dunkelheitsmotiv in ähnlicher Weise aus. Nicht mehr JHWH handelt, sondern die Verfluchten selbst tasten. In beiden Texten geschieht beim Thema Dunkelheit der Subjektwechsel von der Gottheit zu den Verfluchten. Während jedoch der assyrische Imperativ das Stichwort nur kurz nennt, wird im Hebräischen das hilflos verwirrte Tasten der Erblindeten breit ausgemalt. Die Ergänzungen in den Segens- und Fluchabschnitten der Bisitun-Inschrift zeigen, daß dies nicht gegen einen Übersetzungsvorgang spricht. Die babylonische Version wurde gegenüber ihrer elamitischen Vorlage in ähnlicher Weise erweitert (Z. 102, 107). Dem assyrischen „Wandelt in Dunkelheit umher!“ entspricht das hebräische Satzgerüst „Und du wirst ... umhertasten ... im Dunkel ... .“ So könnte das Hebräische durchaus als Wiedergabe der VTE gelten. Wie Fales zeigte, gehörte jedoch die Erweiterung (amplification) vorgegebener Syntagmen zu den Arbeitstechniken assyrischer Schreiber beim Verfassen

\footnotetext{
1 Vgl. WatanaBe, Thronfolgeregelung, 163.
} 
neuer Feldzugsberichte aus alten Vorlagen. ${ }^{1}$ Wieder scheint die Arbeitsweise des biblischen Verfassers der eines altorientalischen Schreibers zu gleichen, der aus seiner Vorlage einen neuen Text erstellt.

Dtn 28,29b hat keine Parallele im Šamašfluch. Man kann darin eine Ausgestaltung der Rechtlosigkeit sehen, die eintritt, wenn der Gerichtsgott straft. Die Vorlage für diesen Halbvers steht, wie im nächsten Kapitel gezeigt werden soll, in einem anderen Paragraphen der VTE. Außerdem wird mit V. 29b ein Struktursignal für die Palindromie des hebräischen Textes gesetzt, das seine Entsprechung in Dtn 28,33b findet. Wie schon beim Sinfluch zeigt sich: Wo Dtn 28 quantitativ von der VTE-Parallele abweicht, liegt ein struktureller Grund in der Palindromie des hebräischen Textes vor.

Die Bibel reiht zwei Flüche mit der Abfolge Hautkrankheit und Sehunfähigkeit aneinander. Es läßt sich im AT nicht belegen, daß die Krankheiten von V. 27 traditionell vor den Krankheiten von V. 28 gereiht würden. Alle Krankheiten von V. 27 bezeichnen Veränderungen, die außen am Körper sichtbar sind. An keiner Stelle des AT werden עפלים oder גרח oder vor einen Augendefekt oder eine der anderen Krankheiten von Dtn 28,28 gereiht. ${ }^{2}$ Damit scheidet die Möglichkeit aus, die beiden Flüche stünden deshalb so beieinander, weil die Krankheiten in diesen Kombinationen aufgezählt wurden. Es kann auch nicht sein, daß man sich aufgrund einer mythischen Verbindung der Krankheiten mit Himmelskörpern an einer traditionellen Abfolge von Mond und Sonne orientiert hätte. Fast nie steht in den bekannten westsemitischen Texten der Mond vor der Sonne. ${ }^{3}$ Die in Dtn 28,27-29 vorzufindende Abfolge entstand also nicht, weil man im AO und in Juda diese Themen so reihte.

\footnotetext{
${ }^{1}$ Vgl. FALES, „Code," $147 \mathrm{f}$. Er unterscheidet „amplification by means of a list“, ,appositional-explanatory amplification“, „insertion of a relative clause“, „causal-final clause". Die Zusätze in V. 29a erscheinen als Apposition und Erklärung.

2 שחין steht im AT noch Ex 9,9.10.11; Lev 13,18.19.20.23; 2 Kön 20,7; Jes 38,21; Ijob 2,7; 1 Sam 5,6.9.12; 6,4f; גרב עלפים nur noch Lev 21,20; 22,22; עורון Sach 12,4; עורות 22,22; צach 12,4; 2 ; Kön 9,20; Sach 12,4. Auch der eigentliche Terminus für Aussatz צרעת (Lev 13; 14; Dtn 24,8; 2 Kön 5,3.6f.27; 2 Chr 26,19) kommt nicht in Kontexten mit Augenkrankheiten vor. Nimmt man das häufigere עור (Ex 4,11; Lev 19,4;21,18; Dtn 15,21; 27,18; 2 Sam 5,6.8; Jes 29,18; 35,5; 42,7.16.18f; 43,8; 56,10; 59,10; Jer 31,8; Zef 1,17; Mal 1,8; Ps 146,8; Ijob 29,15; Klgl 4,14) hinzu, erkennt man, daß die Haut- und Augen- oder Gemütskrankheiten von Dtn 28,27f im AT nie mehr beieinander stehen. Sie bildeten offensichtlich im Hebräischen keine traditionellen Kombinationen.

${ }^{3}$ Nur ein einziges Mal, nämlich in Ps 104,19, steht im AT ירח vשמש vor. Drei Mal steht die metaphorische Umschreibung des Mondes לבנה vor der bildhaften Umschreibung der Sonne תמה (Hld 6,10; Jes 24,23; 30,26). Es handelt sich durchwegs um späte poetische Sprache, die gegenüber den vielen Stellen, wo שמש vor vormt, keine allgemein verbreitete Tradition bezeugt.
} 
So bleibt also nur eine Erklärung: Man orientierte sich an einer außerisraelitischen Vorlage, die die Themen nach der assyrischen Reihenfolge der Götter Sin und Šamaš vorgab. ${ }^{1}$ Nun ist aber kein offizieller assyrischer Fluchtext erhalten, dessen Sin- und Šamašfluch den biblischen Formulierungen derartig gleicht wie VTE §§ 39f. Damit ist noch nicht bewiesen, daß tatsächlich die VTE die Vorlage für Dtn $28,27 \mathrm{f}$ bildeten. Es können andere noch ähnlichere Texte verschollen sein. Doch immerhin bieten die VTE nicht nur die hier beschriebenen Parallelen des Sin- und Šamašfluchs, sondern auch noch die im vorhergehenden Kapitel besprochene Parallele zwischen $\S \S 63 f$ und Dtn 28,23f. Damit gibt es also schon zwei Anknüpfungspunkte mit großer Gleichartigkeit. Es werden sich weitere finden!

Der nächste VTE-Paragraph läßt, auf den ersten Blick besehen, jedoch eine direkte Abhängigkeit der deuteronomischen Flüche von den Thronfolgevereidigungen wieder fraglich scheinen. Der Ninurtafluch $\S 41$ weicht sowohl durch seine Position als auch durch seine Formulierungen von Dtn $28,25 a .26$ ab.

VTE $\S 41$ Z. 425-427

Ninurta.

der Allererste der Götter, möge durch seinen wütenden Pfeil euch zu Fall bringen, mit eurem Blut die Steppe anfüllen, Adler und Geier euer Fleisch fressen lassen! ${ }^{2}$
Dtn 28,25a.26

JHWH gebe dich geschlagen vor deine Feinde. Auf einem Weg mögest du ausziehen gegen sie, und auf sieben Wegen mögest du fliehen vor ihnen. Und dein Leichnam wird zur Nahrung für alle Vögel des Himmels und für das Getier der Erde, und es gibt keinen, der sie verscheucht.

Abgesehen vom gemeinsamen Thema, der Niederstreckung der Vertragsbrüchigen durch den Pfeil Ninurtas und der Niederwerfung der Israeliten vor den anrückenden Feinden sowie der Verfütterung an Tiere, stimmt kaum etwas wirklich überein. Der mesopotamische Kriegsgott braucht einen Pfeil, JHWH nicht. Er füllt mit dem Blut der Getöteten die Steppe. Während im assyrischen Fluch nur Vögel fressen, sind in der Bibel auch Landtiere genannt. Die letzte Diskrepanz kann dabei noch am leichtesten ausgeräumt werden, denn das akkadische Wort für „Geier“ kann genauso „Schakal“ heißen. Bei anderer Übersetzung hätte also auch der assyrische Fluch einen Vogel und ein Landtier. Gravierender ist das Fehlen eines Äquivalents für das Motiv der blutgetränkten Erde. Dazu kommt, daß bei der Untersuchung des Ninurtafluchs von $\S 41$ identische Formulierungen in

\footnotetext{
1 Vgl. die Reihung Sin, Šamaš, Šulpae, Delebat bei EHELOLF, Wortfolgeprinzip, 12.

2 Vgl. WatANABE, Thronfolgeregelung, 163.
} 
VTE §§ 58f (Z. 518-520), dem Assur- und Palilfluch, gefunden wurden. Diese Fluchmotive sprach man verschiedenen Gottheiten zu. Die semantische Analyse von Dtn 28,25a.26 hatte ergeben, daß die in $\S 41$ auftauchenden Themen göttlicher Kriegführung, der Tränkung des Landes mit Blut und der Verfütterung von Leichen an Tiere und Vögel auch bei Ezechiel und an anderen alttestamentlichen Stellen vorkommen, wo keine Abhängigkeit von einem altorientalischen Text angenommen werden kann. AuBerdem fehlt das Motiv der blutgetränkten Erde im Assur- und Palilfluch, so daß deren Formulierungen Dtn 28,25a.26 mehr ähneln als der Ninurtafluch. Der semantische Gehalt von נבלד ,Leiche“ konnotiert auch Wüste oder Steppe als Aufenthaltsort außerhalb der Menschengemeinschaft. Möglicherweise soll die explizite Erwähnung der Leichen die Ortsangabe Wüste oder Steppe anklingen lassen. Gerade besonders verbreitete Motive hatten in unterschiedlichen altorientalischen Kanzleien Eigentraditionen ausgebildet, die in Versionen desselben Textes als gleichwertig nebeneinandergestellt werden konnten. Dazu gehörten die 1000 Götter in Hatti, denen die großen Götter in konventionellen babylonischen Texten entsprachen. Da 28,25a.26 von geprägten Elementen ${ }^{1}$ wimmelt, dürften in Juda Sprachmuster zur Verfügung gestanden sein, um die fremdsprachige Vorlage in die eigene Gedankenwelt zu übertragen.

Wenn außerdem bereits im assyrischen VTE-Text selbst dieselben Formeln einmal mit und einmal ohne das Motiv der blutgetränkten Erde verwendet wurden, ist es möglich, daß die aramäische Ausgabe nicht den gesamten Inhalt von $\S 41$ enthielt. Die Differenzen zwischen der assyrischen und der hebräischen Textgestalt können auf den doppelten Übersetzungsund Umformungsprozeß vom Assyrischen ins Aramäische und vom Aramäischen ins Hebräische zurückgehen.

Der Fluch der Göttin Delebat/Venus (VTE § 42) weist Parallelen zu dem ersten Vers der Frustrationsflüche (Dtn 28,30) auf. Dtn 28,30 wirkt wie die Kombination des Themas Frau - Haus aus dem Venusfluch der VTE mit der biblischen Reihe Haus - Weinberg, wie sie in Am 5,11 oder Zef 1,13 vorkommen:
VTE $\S 42$ Z. 428-410
Dtn $28,30.33$
Am 5,11

Venus, die unter den

Sternen (besonders)

strahlend ist, möge

vor euren Augen eure

Eine Frau heiratest du,

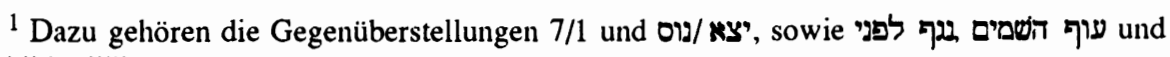
ואין מדריד. 
Gattinnen im Schoß eures

Feindes liegen lassen!

Eure Söhne

mögen

eurer Haus

nicht besitzen! aber ein anderer Mann

wird sie schänden.

Ein Haus

baust du,

aber du wirst

nicht darin wohnen.

Einen Weinberg

pflanzt du,

aber du wirst ihn

nicht einweihen.
... darum

baut ihr Häuser aus behauenen Steinen und wohnt nicht darin, legt ihr euch prächtige Weinberge an und werdet den Wein nicht trinken.
Ein fremder Feind möge all eure Habe aufteilen! ${ }^{1}$
Die Frucht deines Landes und all deinen Gewinn ißt ein Volk, das du nicht kanntest. Und du wirst nur bedrückt und mißhandelt alle Tage.

Während im assyrischen Delebatfluch einfache Fluchwünsche stehen, verwendet der hebräische Text futility curses. Dasselbe Phänomen läßt sich in der Tell Fekheriye-Bilingue feststellen. ${ }^{2}$ Übersetzung heißt damit, daß der Ausgangstext in beliebte sprachliche Gestaltungsmuster der Zielsprache gegossen wurde. Daß Frustrationsflüche zu den Themen von Dtn 28,30 verbreitet waren, zeigen die Prophetenworte. Doch außer Dtn 20,5-7; 28,30 verbindet kein AT-Text mit Weinberg und Haus die Frau. Man gewinnt den Eindruck, als habe erst die Kombination des Delebatfluchs mit den Prophetenworten zu der markanten Formulierung von Dtn 28 geführt. Im Gegensatz zu Reihung Haus - Weinberg - Frau in Dtn 20,5-7 harmoniert die Abfolge (Frau) - Haus - (Weinberg) vollkommen mit den assyrischen und prophetischen Vorbildern von Dtn 28,30.

Die Entsprechung zu VTE $§ 42$ schafft einen Übergang zu den Frustrationsflüchen, die die Mitte der palindromischen Struktur von Dtn 28,27-35 ausmachen. Die zu V. 27-29 gegenläufige Bewegung der V. 34f läßt zunächst in 28,33a das Ende des Delebatfluchs anklingen und nimmt in V. 33b wie zur Schaffung einer Naht Formulierungen von V. $29 \mathrm{~b}$ auf, um zu den folgenden Krankheitsaussagen überzuleiten, als deren Parallele der Gulafluch $^{3}$ VTE $\S 52$ gilt. Die Aussage im Gulafluch Z. 461, die Göttin

\footnotetext{
1 Vgl. WaTANABE, Thronfolgeregelung, 165.

2 Vgl. KREBERNIK. .Deuteronomiumskommentar,“ 36; FALES, „Bilinguisme,“ 249.

${ }^{3}$ Eine Anspielung auf den mesopotamischen Gulafluch steht wohl hinter Hos 5,10-13: In diesem Prophetenwort belegen gleich mehrere Motive, daß hier die Fluchtradition der Gula durchschlägt. Die ausdrückliche Nennung Assurs stellt die Aussage in einen mesopotami-
} 
möge Krankheit und Mühsal ins Herz der Verfluchten legen, greift mit murșu tānēhu innerhalb der VTE zum Anufluch (Z. 418a) zurück, begegnet sonst jedoch kaum in den Gulaflüchen. In dem akkadischen Doppelausdruck kann eine Entsprechung zu den Gemütskrankheiten gesehen werden, von dem 28,34 angesichts der Feindbedrückung spricht. Watanabe hat gezeigt, daß die in VTE Z. 461 genannten Krankheiten eine assyrische Besonderheit des Gulafluchs sind. Diese Nebentradition trifft sich mit einem Unikum in der veröffentlichten Keilschriftliteratur, dem Anufluch $\S 38 \mathrm{~A}$, wo der Himmelsgott abweichend von all seinen sonst bekannten Flüchen eben diese beiden Krankheiten herabregnen läßt.

Der Anufluch bietet also eine weitere Parallele zu Dtn 28,34f. VTE $\S$ 38A eröffnet die Reihe der Himmelsflüche. Damit ergibt sich ein geschlossener Bereich der Parallelen, der VTE $\S \S 38$ A-42 neben Dtn 28,25-35 stellt. Man kann auf die Heranziehung des Gulafluchs verzichten. Weil in den VTE bereits Anu mit den Krankheitsmotiven betraut ist, die sonst Gula zukommen. Damit verschwindet die Notwendigkeit, für das zweite Krankheitsthema Dtn 28,34f Motive aus VTE $\S 52$ heranziehen zu müssen, was die Frage aufgeworfen hätte, warum man gerade diesen Fluch noch in den Bibeltext übernahm, die dazwischenliegenden Paragraphen aber ausließ. Gleichzeitig verstärkt sich das Gewicht, das die VTE im Verhältnis zu Dtn 28 erhalten. Nicht nur $\$ \S 63 \mathrm{f}$ weist Parallelen auf, die man als Übersetzung verstehen kann, auch VTE $\S \S 38 \mathrm{~A}-42$ bietet einen geschlossenen Abschnitt, der als Vorlage für eine Übersetzungstätigkeit angesehen werden kann, an deren Ende Dtn 28,25-35 stand.

28,35 ragt über den Anufluch hinaus. Während nämlich das AT sonst niemals Krankheiten von Scheitel, Fußsohle, Knien und Schenkeln angibt, findet sich in einem Kolophon im Zusammenhang mit Gula der Hinweis auf Heilungsverfahren vom Scheitel bis zu den Nägeln. Dabei verdient es besondere Beachtung, daß diese Angabe nicht in einem offiziellen mesopotamischen Fluchtext steht, sondern im Registraturvermerk eines Schreibers. ${ }^{1}$ In solchen Schreiberkreisen wird man auch die Übersetzer der VTE ins Aramäische zu suchen haben. Die Verfasser des Deuteronomiums gehörten wahrscheinlich ebenfalls diesem Berufsstand an. Es könnte also sein, daß bei Übersetzungs- und Übertragungsvorgängen vom Assyrischen

schen Kontext. Die Sünde der Grenzverletzung ruft eine Gottheit auf den Plan, die sich für die Grenzen verantwortlich fühlt. Sie schickt unheilbare Krankheit, zu der Eiter gehört. Gula läßt die Verfluchten ,in Eiter und Blut wie in Wasser baden“. Der Bildkomplex des Gulafluchs war also in Israel bekannt.

1 Vgl. Hunger, Kolophone, 103. 
in westsemitische Sprachen derartige in Schreiberkreisen geläufige Floskeln ergänzt wurden.

\section{2. 5. 3. Dtn $28,20-44$ und VTE § 56}

Die bisherigen Beobachtungen haben viele Gemeinsamkeiten zwischen VTE $\S \S 63-65$ und Dtn 28,23f sowie zwischen VTE $\S \S 38 \mathrm{~A}-42$ und Dtn 28,27-35 zum Vorschein gebracht. Doch die Reihenfolge der übernommenen Passagen stimmt nicht überein. In Dtn 28 steht das Gegenstück zu VTE $\S \S 63 \mathrm{f}$ als V. $23 \mathrm{f}$ vor dem Gegenstück von $\S \S 38 \mathrm{~A}-42$ in V. 25-35. Außerdem wechselte der Ninurtafluch ( $\S 41)$ seinen Platz, so daß sein Pendant nun als V. 25a.26 vor den Entsprechungen zum Sin-, Šamaš- und Delebatfluch steht. Den Anufluch mit seinem Krankheitsmotiv dagegen findet man nun in V. 35 am Schluß der Reihe wieder. Wie sind diese Umstellungen zu erklären? Die Antwort findet man in VTE $\S 56$. VTE § 56 und Dtn 28,20-44 zeigen eine fast identische Themenabfolge.

$\begin{array}{lcl}\text { VTE } \$ 56 & \text { THEMA } & \text { Dtn 28, } \\ 472-475 & \text { Allgemeine Verfluchung } & 20 \mathrm{a} \\ 476-479 & \text { Todessphäre und Ortlosigkeit } & 20 \mathrm{~b} .21 \\ 479-481 & \text { (Hungersnot) + Krankheit } & 22 .(23 \mathrm{f}) \\ 481-483 & \text { Themavorgabe: Krieg } \rightarrow \text { Niederlage } & 25 \mathrm{a} \\ 483-484 & \text { Leichen als Tierfutter } & 26 \\ & & (27) \\ 485-486 & \text { Dunkelheit und Rechtlosigkeit } & 28.29 \mathrm{a} \\ 487 & \text { Elend } & 29 \mathrm{~b} \\ 488 & \text { Auswirkung des Feindeinfalls } & 30-32 \\ & \text { (Zusammenfassung 1. Strophe futility curses) } & 33 \mathrm{a} \\ 489 & \text { Elend } & 33 \mathrm{~b} \\ 490 & \text { Krankheit } & 34 \mathrm{f} \\ 490 & \text { Nahrung } & 38 \\ 491 & \text { Getränk } & 39 \\ 491 & \text { Salbe } & 40 \\ (492 & \text { Kleidung) } & \\ & \text { (Kinder } & 41) \\ 493 & \text { (Zusammenfassung 2. Strophe futility curses } & 42 \text { ) } \\ & \text { Fremde im Lebensraum } & 43 \mathrm{f}\end{array}$

In der Tabelle fehlen Gegenstücke zum Krankheitsthema von V. 27 und für V. 33a.41f. Dtn 28,23f ist eingeklammert, weil in VTE $\S 56$ die Hungersnot vor der Krankheit kommt, in Dtn 28 aber die Dürre in V. 23f nach den Krankheiten in V. 22. Die Abweichungen bei V. 23f.27.33a ergeben sich, wie noch gezeigt wird, aus dem Einbau der $\S \S 63 f, 39,42$ an den Stellen, wo die Thematik von $\S 56$ das entsprechende Fluchmotiv zuließ. Dtn 
28,41f dagegen folgt innerbiblischen Gestaltungsprinzipien, die die synchrone Analyse des Textabschnitts beschrieben hat.

Die Stichwortfolge von $\S 56$ übernehmend, schuf der biblische Verfasser seinen Text, indem er an thematisch geeigneter Stelle weitere passende Stücke aus den VTE einfügte. Dabei griff er nur Flüche heraus, die eine Beziehung zum Sonnengott bzw. zu Himmel und Erde aufweisen. ${ }^{1}$ Im folgenden werden die Themenkomplexe besprochen und die Komposition des biblischen Textes aus verschiedenen Paragraphen der VTE nachgezeichnet. In Dtn 28 werden die literarkritisch auszuscheidenden Teile weggelassen. ${ }^{2}$ Gemeinsame Stichwörter sind in der Originalsprache hinzugesetzt.

\section{Allgemeine Verfluchung}

VTE $§ 56$ Z. 472-475

Die großen Gö[tter]

des Himmels und der Erde,

welche die Weltgegenden bewohnen,

alle, deren Namen

auf dieser Tafel genannt sind

mögen euch schlagen (limhıașükunu), euch böse anblicken

mit einem bösen Fluch euch zornig verfluchen (arratu ... lìrurükunu),
Dtn 28, 20a

JHWH schicke gegen dich

den Fluch (אתדהמארה),

die Verwirrung

und die Bedrohung auf jedes Werk dei-

ner Hände,

das du unternimmst,

Dieser Abschnitt steht als Einleitung vor der palindromischen Struktur des $\S 56$. In 28,20 fehlt beim Gottesnamen wie in den meisten westsemitischen Flüchen das Epitheton. ${ }^{3}$ Ein Äquivalent für die Erwähnung der Vertragstafel wird man in V. 20 wohl kaum erwarten. Die Gottheiten werden in $\S 56$ nur einmal genannt, während der Bibeltext JHWHs Namen dauernd wiederholt. Das Verb „schlagen“ fällt auf, weil es in mesopotamischen Flüchen fast nicht vorkommt. Dennoch liefert es hier das Stichwort für die „Schlagen“-Reihe Dtn 28,22.27.28.35. Die drei assyrischen Prädikate sind nach dem ellu-ebbu-namru-Prinzip (EEN) geordnet, d.h. die Wörter und

\footnotetext{
$1 \S 38 \mathrm{~A}$, der Himmel selbst, $\S 39$ der Mondgott mit dem Epitheton „die Leuchte des Himmels und der Erde“, § 40 der Sonnengott mit dem Epitheton „das Licht des Himmels und der Erde", die zwei Astralgottheiten Ninurta $\S 41$ und Venus $\S 42, \S 56$ die großen Götter des Himmels und der Erde, § 63 Erde, § 64 Himmel mit Lexemverbindungen zu den Sonnengottflüchen in $\S \S 40,68,101$. Das Epitheton „des Himmels und der Erde“ kommt nur noch im Adadfluch vor ( $\$ 47)$. Doch der gehört nicht zur Reihe der vom Himmel angefülurten Reihe $\$ \S 38 A-42$, bei der der Sonnengott ( $\$ 40$ ) die Mitte einnimmt.

2 Die Übersetzung von VTE $\S 56$ folgt WaTANABE, Thronfolgeregelung, 167.

${ }^{3}$ Vgl. Sefire, KAI Nr. 202; KAI Nr. 214; KAI Nr. 225, KAI Nr. 226.
} 
Ausdrücke werden immer länger. ${ }^{1}$ So erhält das zweite Verb ein Adverb und dem dritten sind noch ein Nomen samt Adjektiv beigefügt. Das Hebräische weist ebenfalls eine EEN-Steigerung auf. Die Nomina, die den assyrischen Prädikaten gegenüberstehen, werden immer länger. Der Ausdruck את־המארה hat fünf Silben, אתדהמהומה ebenfalls, besitzt aber in der vorletzten Silbe einen langen Vokal, was die Nachordnung bewirkt ${ }^{2}$, und hat sechs Silben. Das letzte Glied läuft auf eine Zielangabe hinaus und endet in einem Relativsatz. Die Ausgestaltung von EEN-Konstruktionen durch Relativsätze ist in der assyrischen Literatur belegt. ${ }^{3}$ Die beiden Texten gemeinsame Wurzel ' $r r$ führt im Hebräischen die EENReihe an, während sie diese im Assyrischen in Nomen und Prädikat, also doppelt vorhanden, abschließt (arratu / lïrurükunu). Doch auch in 28,20a gehen Nomen und Prädikat auf dieselbe Wurzel, nämlich šllh, zurück (משלח / ישלח).

\section{Todessphäre und Ortlosigkeit}

VTE 56 Z. 476-479

oben euch aus den Lebendigen

herausreißen (lissahüukunu),

unten in der Unterwelt, euren

Totengeist des Wassers berauben!

Schatten und Glut mögen euch immer wieder vertreiben!

In Verborgenheit und Ecken sollt ihr euch nicht verkriechen können!

\section{$28,20 \mathrm{~b} \alpha .21$}

bis du vertilgt bist (ער השמרך)

und bis zu deinem schnellen Untergang.

JHWH klebe an dich die Pest

bis er/sie dir ein Ende gemacht hat

auf dem Erdboden.

Die Vernichtung geschieht im mesopotamischen Fluch auf zwei Ebenen, unter den Lebenden und im Totenreich. Die Vernichtungsaussage im Bibeltext ist ebenfalls zweigliedrig. Die Vorstellung, daß JHWH auch im Totenreich Unheil stiftet, fehlt. אדמה bezeichnet den Bereich der Lebenden, aus dem die Verfluchten verschwinden müssen. Hier könnte die Verbannung in die Unterwelt mitklingen. Die Pest schlägt eine Brücke zur Ortlo-

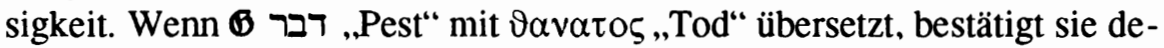
ren Zugehörigkeit zur Todessphäre. Obgleich die Formulierungen völlig

\footnotetext{
$1 \mathrm{Vgl}$. EHELOLF, Wortfolgeprinzip, $2 \mathrm{f}$.

${ }^{2} \mathrm{Vgl}$. zur Vokallänge in EEN-Strukturen EHELOLF, Wortfolgeprinzip, 5f. Das Nomen stammt von der Wurzel הום.

3 Vgl. FALES, .,Code,“' 175; EhElOLF, Wortfolgeprinzip. 20.
} 
voneinander abweichen, führt der Fluch in beiden Fällen zum Verlust des Ortes, an dem der Mensch Lebensraum und Rast finden könnte. ${ }^{1}$

\section{Hungersnot und Krankheit}

VTE $§ 56$ Z. 479-481

$28,22(-24)$

a) Brot und Wasser mögen euch abhanden kommen!

b) Not, Mangel, Hunger

c) und Seuche

mögen von euch nicht losgelöst werden.

JHWH schlage dich (יככה)

c) mit Schwindsucht und mit Fieber und mit Brand und mit Entzündung b) und mit Hitze und mit Getreidebrand und mit Getreiderost, und sie sollen dich verfolgen bis zu deinem Untergang.

a) Und es wird dein Himmel ...

Die Elemente dieses Themenkomplexes sind umgestellt. $\$ 56$ schreitet vom Verlust der Nahrung und des Wassers (a) über Hungersnot (b) zur Krankheit (c). Dtn 28 beginnt mit der Krankheit und endet mit dem Einbau der $\S \S$ 63f, die das Ausbleiben des Wassers und damit das Ende mit Nahrung versorgender Landwirtschaft zum Inhalt haben. Die Umstellung (permutation) von Textteilen gehörte zu den redaktionellen Techniken der assyrischen Schreiber, wenn sie Feldzugsberichte aktualisierten. Außerdem sind auch in altorientalischen Übersetzungen solche Vertauschungen $\mathrm{zu}$ finden. Wenn mutānu, das akkadische Wort für todbringende Krankheit, mit mehreren hebräischen Begriffen wiedergegeben wird, ähnelt dies der Bilingue von Tell Fekheriye. Dort steht im aramäischen Text nur ein Krankheitsbegriff, im assyrischen sind es jedoch drei. Die drei akkadischen Synonyme für „Hungersnot“(b) stellen eine formelhafte Wendung dar, die nach dem EEN-Prinzip gereiht wird. ${ }^{2}$ Dem stehen in V. 22 drei Hungersnot bewirkende Ursachen für Ernteschäden gegenüber. Die Umstellung der Unterpunkte schafft in der biblischen Version einen fließenden Übergang von Menschenkrankheiten über Getreidekrankheiten, der Ursache für Hungersnot, bis hin zum Wassermangel (a).

\footnotetext{
${ }^{1}$ Es ist nicht eindeutig zu entscheiden, ob VTE Z. 477-479 die Ruhelosigkeit auf lebende Menschen, die unter den Fluch fallen, beziehen oder ob schon ihr Schicksal als Totengeister ausgemalt wird. Zu letzterem gehört die Rastlosigkeit: „Oben, im Sonnenschein, soll sein Totengeist durstig durch die Außenbezirke laufen! Unten, in der Unterwelt, soll er beim Wasserspenden ... Bier ... nicht erhalten.“ FADHIL, „Grabinschrift,“ 464.

$2 \mathrm{Vgl}$. EHELOLF, Wortfolgeprinzip, 41.
} 
Themavorgabe: Krieg

VTE § 56 Z. 481-483

Die Zöpfe! eurer jungen Frauen und die Locken! eurer jungen Männer mögen im Anblick eurer Augen die Hunde und Schweine auf dem Hauptplatz der Stadt Aššur hin und her schleifen!

VTE Z. 481-483 bleiben ohne Entsprechung. Das tödliche Ende einer Kriegsgefangenschaft scheint beschrieben. Der Verfasser von Dtn 28,2044* fand hier einen Anknüpfungspunkt, um den Ninurtafluch VTE $\S 41$ einzubauen. Mit Vers 25 beginnt so ein mehrschichtiges Beziehungsgefüge zwischen Dtn 28, VTE § 56 und den übrigen Parallelen mit den VTE. Die konkreten Formulierungen in 28,25-33 entstehen aus dem Zusammenbau von $\S 56$ mit $\S \S 38 \mathrm{~A}-42$.

VTE $§ 56 Z .483 \mathrm{f}$

Die Erde möge eure

Leichen (pagrïkunu) nicht empfangen!

Im Bauch der

Hunde und Schweine (kalbī šahîi)

möge eure Grabstätte!

sein!
Leichen als Tierfutter

$\begin{array}{ll}\text { Dtn 28,25a.26 } & \text { VTE } \S 41 \\ \text { JHWH gebe dich geschlagen } & \text { Ninurta ... möge ... } \\ \text { vor deine Feinde, } & \text { euch zu Fall bringen } \\ \text { auf einem Weg mögest du } & \ldots \\ \text { ausziehen gegen sie, und auf } & \\ \text { sieben Wegen mögest du } & \\ \text { fliehen vor ihnen. } & \\ \text { Und dein Leichnam (נכלת) } & \\ \text { werde zur Nahrung } & \end{array}$

für alle Vögel des Himmels und für das Getier der Erde,

Adler und Geier euer Fleisch fressen lassen!

und es gibt keinen, der sie verscheucht.

Die Kombination „,Vögel des Himmels“ und "Getier der Erde“ folgt alttestamentlichen Sprachgewohnheiten. Doch entsteht der biblische Ausdruck geradezu aus dem Zusammenbau der Paragraphen 56 und 41.

Dazu kommt noch der an die Himmel und Erde-Motive aus $\S \S 63 \mathrm{f}$ anschließende $\S 65$. Er trägt das Thema Flucht vor den Feinden (V. 25a $\beta \gamma$ ) bei, dem in der Tabelle oben noch kein Pendant gegenübergestellt ist. $\mathrm{Zu}$ sammen mit dem Ninurtafluch $\S 41$ mit der Niederlage und der Verfütterung der Leichen an Vögel und $\S 56$ mit Vertilgung der Leichen durch Landtiere konnte der biblische Verfasser für die Komposition von V.25a.26 auf drei Vorlagen zurückgreifen. Die folgende Tabelle zeigt die Stichwortverbindungen an: 
$\S 63 \mathrm{f}$ Erde, Himmel $\S 65$ nakru

Din 28,23f Himmel, Erde

Dtn 28,25a איביך

Dtn 28,26 Vögel

Tiere
$\S 41$ nakru

Adler + Geier

$\S 56$ Hunde + Schweine

So erscheint das Kriegsthema als Nahtstelle, an welcher die zusätzlich zu $\S$ 56 verwendeten Passagen $\S \S 63 \mathrm{f}$ und $\S \S 38 \mathrm{~A}-42$ ineinander verwoben wurden. Dazu mußte der Autor von Dtn 28,20-44* aber $\S 41$ aus seinem Kontext herauslösen und an dieser Stelle einbauen. Die Vorgabe für den Einbau des nächsten Fluchs aus dieser Reihe lieferte das Leitwort ekletu „Finsternis“, welches sowohl im Šamašfluch (§ 40) als auch in § 56 auftaucht.

\section{Dunkelheit und Rechtlosigkeit}

VTE $\S 56 \mathrm{Z} .485 \mathrm{f}$

Dtn 28,27-29a

JHWH schlage dich mit dem Geschwür Ägyptens ...

JHWH schlage dich mit Raserei und mit Blindheit und mit Verwirrung des Herzens.

Eure Tage (ümïkunu) mögen finster Und du wirst am Mittag umhertasten sein, eure Jahre mögen dunkel sein! Die Finsternis (ekletu), die nicht erhellt wird, mögen sie ... als euer Schicksal bestimmen!

wie ein Blinder umhertastet im Dunkeln (באפלד), und du wirst auf deinen Wegen keinen Erfolg haben,

Dtn 28,28 besitzt ebenfalls eine doppelte Parallele in den VTE. Vor V. 28 findet sich in V. 27 die Entsprechung zum Sinfluch (§ 39). So gewinnt man den Eindruck, als seien die $\S \S 39$ und 40 zur Ausgestaltung der durch $\S 56$ vorgegebenen Themen „Dunkelheit und Rechtlosigkeit“ eingefügt worden.

\section{Elend}

VTE § 56 Z. 487

Dtn 28,29b

In M[ühsal? und Sch]laflosigkeit möge und du wirst nur ausgebeutet und euer Leben zu Ende gehen!

beraubt werden alle Tage (כל ימים), und es gibt keinen Retter.

Der Wunsch der Mühsal (tānēhu (tabtu) $\S 56$ Z. 489 geben der biblischen Textstruktur die Verknüpfungsformeln (29b.33b) zwischen den Krankheitsflüchen (V. 27f.35) und den Frustrationsflüchen vor. Die Korrespondenz der Zeilen 487 und 489 in $§ 56$ 
ergibt sich aus ihrer Verbindung mit zwei Krankheitsformulierungen, die in altorientalischen Fluchsequenzen immer wieder doppelt anzutreffen sind und chiastisch andere Themen - wie Hochflut oder Feinde - umschließen. Damit ist also die Entsprechung von V. 35 zu V. 27f ebenfalls in VTE $\S 56$ vorgegeben. Der „Mühsal und Schlaflosigkeit“ (Z. 487) stehen im Deuteronomium Mißhandlung und Beraubung gegenüber. Gemeinsam ist beiden Texten die Angabe, wie lange das Elend dauert (bis zum Lebensende / alle Tage).

Themenvorgabe: Auswirkung des Feindeinfalls

VTE $\S 56$ Z. $488 \mathrm{f}$

Din 28,30-33a

Eine Hochflut, eine unwiderstehliche Sintflut möge aus der Erde emporsteigen und eure Niederwerfung bewirken!

\author{
Eine Frau heiratest du ... \\ Dein Ochse ... \\ Deine Kinder ... \\ Die Frucht deines Landes ...
}

Z. 488-489 sprechen zwar von Hochflut, haben aber, wie gezeigt wurde, einen kriegerischen Unterton. $\S 56$ beschreibt also kriegerische Niederwerfung mit der Metapher einer Sintflut. Damit ergibt sich ein Platz für die Einfügung des Delebat/Venusfluchs, der vom Schicksal der Gattin und des Hauses in Feindeshand spricht. So erhielt Dtn 28,30 seine Position. Dtn 28,31f sind gegenüber den VTE ein Zusatz. Die babylonische Version der mehrsprachigen Bisitun-Inschrift zeigt, daß interpretierende Zusätze in Übersetzungen von Flüchen vorkommen konnten. Das refrainartige Auftauchen der Deportation (V. 33.41) geht über die VTE-Vorlage hinaus und unterstreicht die große Bedeutung, die der biblische Verfasser der Versklavung der Kinder zuschreibt.

\title{
Elend
}

VTE $\S 56$ Z. 489f

Alles Gute möge euch verboten sein!

Alles Krankhafte (mimma marṣu) möge euer Schicksal sein!
Din 28,33b-35

Und du wirst nur bedrückt und mißhandelt alle Tage.

Und du wirst verrückt bei dem Anblick, der sich deinen Augen bietet, was du [alles] mit ansehen mußt.

JHWH schlage dich mit bösem Geschwür an den Knien und an den Schenkeln, 
von dem du nicht geheilt werden kannst (אטר לאדתוכל לדרפו). von der Fußsohle bis zu deinem Scheitel.

Nach der Schilderung des feindlichen Wütens kehrt Dtn 28,34 nochmals zu allgemeinen Aussagen der Bedrückung (vgl. V. 29), des Wahnsinns (vgl. V. 28) und der Krankheit (vgl. V.27) zurück. Auch VTE $\S 56$ Z. 489f schaltet den Verwünschungen von Nahrung, Trank, Salbe, Kleidung, Lebensraum solche allgemeingültigen Flüche vor. Dabei geht es ebenfalls um den Verlust jeglicher Lebensfreude und um Krankheit. Hier liegt die Stichwortvorgabe für die Ausfaltung durch die im Anufluch VTE § 38A angesprochenen Gemütsleiden.

In V. 35 treffen sich die Krankheitsbezeichnungen des Anufluchs VTE § 38A (murșu, lā tub širi), die Krankheitsthematik von § 56 Z. 490 (mimma marșu) und auch Vokabular (murșu) der traditionell zweiten Krankheitsnennung in Fluchsammlungen, bei der die Göttin Gula angerufen wurde (§ 52). Die in Dtn 28,25-35 anzutreffende Verbindung von Krieg samt seiner Folgen und Krankheit ist in der Traditionsgeschichte des Ninurtafluchs vorgeprägt. Ninurta, der Kriegsgott, dessen Fluch 28,25f entspricht, ist nämlich der Gemahl der Gula, der großen Oberärztin, deren Fluch in V. 34f anklingt. Motive des Götterehepaars Gula und Ninurta umschließen die Thematik des Feindeinfalls.

Nahrung, Trank, Salbe, Kleidung / Kinder, Fremde im Lebensraum

VTE § 56 Z. 490-493

Asphalt und Trocken-

Asphalt mögen eure

Speise sein!

Eselsurin möge euer

Getränk (mašqitkunu) sein!

Naphta möge eure Salbung (piššatkunu) sein!
Dtn 28,38-44

Viel Samen bringst du aufs Feld

hinaus, aber wenig wirst du

ernten,

denn die Heuschrecke wird alles abfressen.

Weingärten pflanzt du, und du mühst dich, aber Wein wirst du nicht trinken (תשתח), und du wirst keinen Vorrat anlegen, denn der Wurm wird alles fressen.

Ölbäume wachsen für dich auf deinem ganzen Gebiet, aber mit Öl salbst (7or) du dich nicht, denn herunterfallen wird deine Olive.
Mi 6,15

Du wirst säen, aber nicht ernten,

du wirst Oliven pressen, aber dich mit dem Öl nicht salben; 
Die elapû(a)-Pflanze

des Flusses möge eure Decke sein!

Söhne und Töchter wirst du zeugen, aber du wirst sie nicht behalten. denn sie werden in die Gefangenschaft gehen.

Alle deine Bäume und die Frucht deines Landes nimmt die Grille in Besitz.

šédu-, utukku- und Der Fremde, der in deiner Mitte böser rābișu-Dämon [wohnt] erhebt sich über dich, mögen sich eure Häuser als Wohnhinauf, hinauf, du aber, du steigst hinab, stätte auswählen! hinunter, hinunter. Er, er leiht dir aus, aber du, du leihst ihm nicht aus. Er, er wird zum Haupt. aber du, du wirst zum Schwanz.

Die Reihenfolge von Nahrung, Trank, Salbe, und Heimat stimmt zwischen dem VTE und Dtn 28 überein. Dagegen weicht sie sowohl in A.745.1, dem anderen assyrischen Beleg dieser Motivkette, als auch in Mi 6,15', dem biblischen Beispiel für die Kombination von Korn, Wein und Öl, ab. Eine ähnliche Übereinstimmung der Motivfolge gegen die innerbiblische Parallele war schon bei Dtn 28,30 und VTE $\S 41$ im Vergleich zu Dtn 20,5-7 festzustellen. Das Prophetenwort liefert aber den Beleg, daß in der hebräischen Sprache derartige Themen als futility curses formuliert wurden. So stehen wie in Tell Fekheriye einfachen assyrischen Wunschsätzen antithetische Frustrationsflüche gegenüber. Die assyrischen Formulierungen wirken knapp, bilden aber einen Parallelismus. Gerade Parallelismen wurden von den assyrischen Schreibern mit Erweiterungen (amplification) versehen, wenn Neuausgaben der Feldzugsberichte hergestellt wurden. $\mathrm{Zu}$ solchen Erweiterungen zählt Fales ausdrücklich Kausalsätze ${ }^{2}$. Vergleicht man die assyrischen Flüche mit den hebräischen, so bestehen die

\footnotetext{
1 Vgl. SeITZ, Studien, 286; PLÖGER, Untersuchungen, 191; zu V. 30.39: Am 5.11; zu V. 3840: Mi 6,15; zu V.41: Am 9,4.

${ }^{2}$ Vgl. Fales, ,.Code," $174 f$.
} 
Unterschiede genau darin. Einfache Wunschsätze sind, westsemitischer Konvention entsprechend, zu Frustrationsflüchen geworden und die Reihe von Parallelismen wurde durch begründende $k \hat{\imath}$-Sätze erweitert. Der Verfasser von Dtn 28,20-44* wandte offensichtlich zur Übersetzung und Überarbeitung seiner Vorlage Arbeitsmethoden altorientalischer Schreiber an.

An die Stelle des Kleidungsfluches Z. 492 stellte der biblische Verfasser den Deportationsfluch. So betont er, daß die Zerstörung des Landes durch Feinde und Schädlinge ihren Höhepunkt in der Deportation der Kinder findet. Dtn 28,42 schlägt den Bogen zurück zu 28,33.

Zur Kette menschlicher Grundbedürfnisse gehört in mesopotamischen Flüchen auch der unmittelbare Lebensraum. In $\S 56$ nehmen Dämonen das Haus in Besitz. Die genannten Dämonen galten in Assyrien nicht als schlechthin böse, man schrieb ihnen vielmehr Schutzfunktionen zu. Erst im Fluch werden sie zu Bedrängem. Dtn 28,43f drückt einen ähnlichen Gedanken aus. Der Fremde erhebt sich mitten in Israel und macht die Israeliten zu Menschen zweiter Klasse. Dahinter steht beide Male die Vorstellung, daß den Menschen ihr allemächster Lebensraum ,un-heimlich“ wird. Die gemeinsame Aussage lautet: Lebensgenossen, gegen deren Nähe man sonst nichts hat, verwandeln sich in unangenehme Bedrücker. Der Bibeltext ergänzt dies durch wirtschaftliche Aspekte und die sprichwörtliche Antithese von Kopf und Schwanz (Jes 9,13; 19,15). Wieder werden geprägte hebräische Wendungen zur interpretierenden Ausgestaltung der assyrischen Vorgabe verwendet.

Die Reihenfolge der Themen gleicht sich in einer Genauigkeit, für die es weder im bisher bekannten altorientalischen Material noch in der Bibel weitere Parallelen gibt. Nach den in der Einleitung dieses Buches genannten Gesichtspunkten kann die Ähnlichkeit zwischen VTE $\S 56$ und Dtn 28,20-44* als Einzigartigkeit (uniqueness) gewertet werden, die auf literarische Abhängigkeit zurückzuführen ist. VTE $\S 56$ erwies sich als die palindromisch strukturierte literarische Schöpfung der assyrischen Hofkanzlei. Der Bauplan des Paragraphen erklärte die Umstellungen der sonst zu den VTE-Flüchen parallelen Motive in Dtn 28.

Im Vergleich mit dem assyrischen Vereidigungstext wird klar, daß Dtn 28,26-35.38-42 literarkritisch nicht aufgespalten werden kann. Das folgende Schema zeigt, wie intensiv die Strukturen unterschiedlicher Herkunft miteinander verwoben wurden. Es handelt sich wohl um das Konzept eines einzigen Autors. 


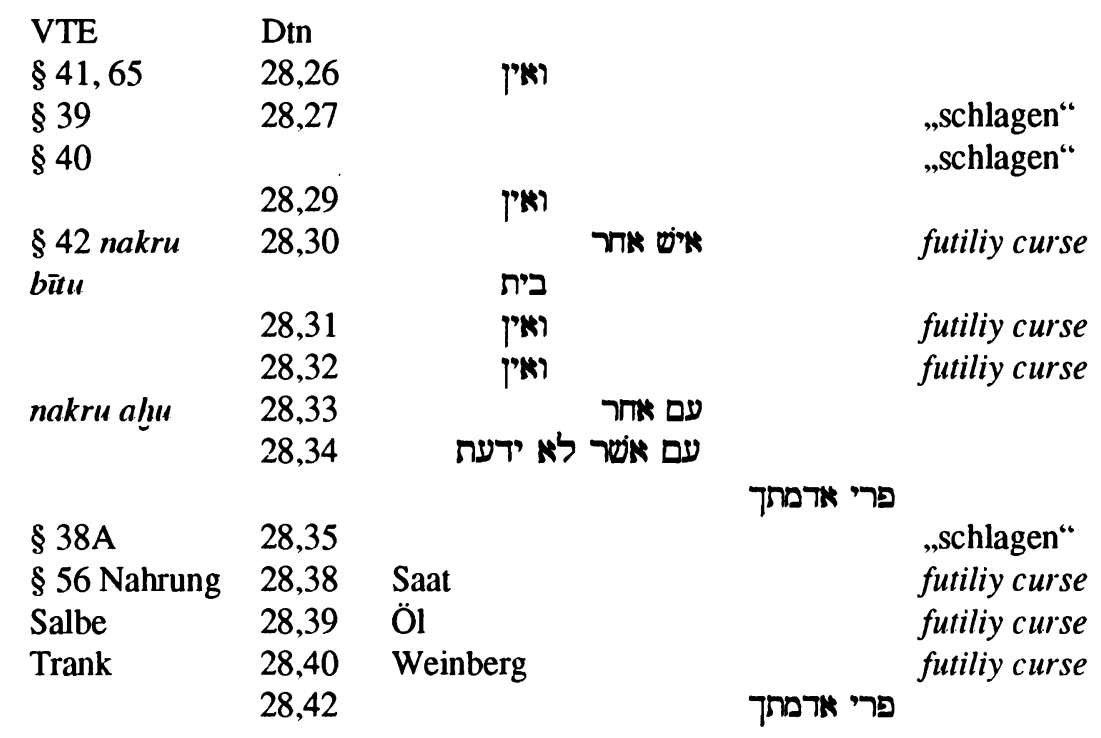

Die 1. Strophe der futility curses ist durch die $w^{e ' e ̂ n-F o r m e l n ~ m i t ~ d e n ~ v o r-~}$ angehenden anders gebauten Sätzen des Kontextes verbunden. So sind die aus VTE $\S \S 39-42$ stammenden Verse 26-30 integriert. V. 30 bildet außerdem den Anfang der futility curses. Das Gegenstück zum Delebatfluch rahmt deren 1. Strophe. Zwar findet man in V. 30-33 nicht das nakru entsprechende איב. Dennoch entspricht diesem Begriff das fremde Volk, zumal das Adjektiv ahu dem hebräischen מח bedeutungsgleich ist. Die Linie, die sich von VTE $\S \S 38 \mathrm{~A}-42$ herleitet, geht dann weiter zum Anufluch in V. 34f. In V. 34 wird das fremde Volk mit dem Ausdruck verbunden und damit vom Schluß des Delebatfluchs auch noch der Bogen zur 2. Strophe der Frustrationsflüche geschlagen (V. 42). Diese 2. Strophe verbindet prophetische Sprachmuster mit der Thematik von VTE $\S 56$.

Dtn 28,20-44* als einfache Einheit zu verstehen bedeutet, daß es die erste Form des hebräischen Textes ist, der auf einen Verfasser zurückgeht, welcher zugleich der Übersetzer seiner fremdsprachigen Vorlage war. Definiert man jedoch Literarkritik so, daß sie auch Übersetzung und Verarbeitung fremdsprachiger Texte einbezieht, so bestätigt die vorliegende Untersuchung viele Beobachtungen der Forschungsgeschichte. Die Deportation der Kinder in V. 32.41 ist tatsächlich eine Erweiterung der assyrischen Vorlage. Es handelt sich aber kaum um die Ergänzung eines vorliegenden hebräischen Textes, sondern um einen Übersetzerzusatz. Auch V. 31 ist eine Ergänzung gegenüber dem Delebatfluch. V. 23f als rhythmische Einzelsprüche auszugrenzen, wird dadurch bestätigt, daß hier in der Tat zwei 
andere Paragraphen aus den VTE in das Gerüst von $\S 56$ eingefügt wurden. Ähnliches gilt für die Ausscheidung der „Schlagen“-Reihe. Immerhin stammen die Flüche in V. 27.28.35 mit dem Verb ,schlagen“ aus dem in den VTE zusammenhängenden Stück $\S \S 38 \mathrm{~A}-42$. Nur V. 22 ist in dieser Hinsicht eine Erweiterung der ,Schlagen“-Reihe über VTE §§ 38A-42 hinaus. V. 22 hat seine Vorlage in VTE $\S 56$, der zudem das Wort „,schlagen“ vorgibt. Dieses wurde in stereotyper Gleichartigkeit im Hebräischen verwendet, sofern es sich bei den Fluchinhalten um Krankheiten handelte.

Das Konzept des hebräischen Verfassers läßt sich folgendermaßen schematisch darstellen:

\begin{tabular}{|c|c|c|}
\hline \multirow[t]{4}{*}{ VTE } & Dtn 28 & VTE $\$ 56$ \\
\hline & 20) Einleitung & Einleitung \\
\hline & 21) Pest & A) Totengeist \\
\hline & 22) Krankheiten & B) Glut/Schatten \\
\hline § 63f. Erde/Himmel & 23) Himmel/Erde & C) Hunger/Durst \\
\hline Regen & 24) Regen & D) Seuche \\
\hline$\S 65$ Feind & 25) Feind & \\
\hline$\S 41$ Adler/Geier & 26) Vögel/Tiere & E) Hunde/Schweine \\
\hline § 39 salıaršubbû & 27) A) גרב & \\
\hline$\S 40$ Verwirrung & 28) B) Verwirrung & \\
\hline Finsternis & 29) Finsternis & F) Finsternis \\
\hline Ungerechtigkeit & C) Beraubung & \\
\hline \multirow[t]{3}{*}{$\S 42$ Feind } & 30) Feind & E') Hochflut/Sintflut \\
\hline & 31f) Tiere/Kinder & \\
\hline & 33) C') Beraubung & \\
\hline § 38A Kopfkrankheit & 34) B') Verrücktheit & \\
\hline \multirow[t]{4}{*}{ Krankheit } & 35) A') שחרין & D') Krankheit \\
\hline & 38f) Saat/Weinberg & C') Speise/Getränk \\
\hline & 40f) Öl/Kinder & B') Salbe/Kleidung \\
\hline & 43f) Fremder & $\left.\mathrm{A}^{\prime}\right)$ Dämonen \\
\hline
\end{tabular}

Die Einfügung der $\S \S 38 \mathrm{~A}-42.63-65$ und der futility curses in die Themenvorgaben von $\S 56$ hat dessen palindromische Struktur zerstört. Dabei mag mitgewirkt haben, daß der biblische Verfasser aufgrund seiner religiösen Überzeugungen die Entsprechung Totengeister / Dämonen nicht übernehmen wollte. Statt dessen entstand im Bibeltext eine neue kleinere Palindromie, die die erste Strophe der Frustrationsflüche umgibt.

Diese Umstrukturierung geht mit einer inhaltlichen Akzentverschiebung einher. In dem Vereidigungstext für zwei Königssöhne standen die Šamašmotive in der Mitte (Finsternis) sowie am Anfang (Totengeist) und am Schluß (Dämonen). Denn der Sonnengott gehört mit seiner Richterfunktion fest zur altorientalischen Königsideologie. Der Bibeltext übernimmt zwar 
diese Lichtmotive und sucht zu Šamaš passende weitere VTE-Flüche, doch als Mitte seiner Fluchsequenz konzipiert er V. 29b-34a, die Beraubung durch das feindliche Volk.

Ein Exil für das ganze Volk steht nicht im Horizont von Dtn 28,20-44*. Die Wegführung der Kinder, wobei die Eltem im Lande bleiben, erinnert eher an die Kriegsereignisse, die Juda bei Sanheribs Palästinafeldzug (701 v. Chr.) heimsuchten. Ein Großteil der Bevölkerung hatte in Jerusalem Zuflucht gesucht und konnte im Lande bleiben. Viele jedoch waren in ihren Dörfern und Landstädten geblieben und wurden von Sanherib weggeführt. Dadurch wurden sicherlich Familien auseinandergerissen, was bei den Zurückgebliebenen zu Erfahrungen führte, wie sie 28,32.41 beschreibt.

Die literarische Abhängigkeit von den 672 v. Chr. fertiggestellten VTE gibt für die Entstehung von Dtn 28,20-44* die Vereidigungszeremonie in Assyrien als terminus a quo an. Man gewinnt den Eindruck, die Worte vor sich zu haben, die Joschija erschreckten, als ihm das im Tempel gefundene Buch vorgelesen wurde. Die als strukturelle Mitte der Fluchsequenz hervorgehobene Plünderung durch Feinde - möglicherweise eine Reminiszenz an unter Hiskija Erlebtes - macht die in 2 Kön 22,11-13a geschilderte Reaktion seines Urenkels verständlich.

Wie fügt sich dieses wohl älteste Stück von Dtn 28 in seinen Kontext ein? Diese Frage soll die folgende eher summarische Behandlung der Fluchergänzung (28,47-68), der parallelen Reihen (28,2-9.16-19) und des Segens $(28,7-14)$ beantworten. Dort findet man wesentlich weniger Bezüge zum AO. 

hast in Freude und in Fröhlichkeit des לאדעבדת אתדיהוה אלהיך Herzens,[als du] alles in Fülle [besaßest],

$48 \mathrm{a} \alpha \mathrm{mußt}$ du deinen Feinden dienen, $48 \mathrm{aa}_{2}$ die JHWH zu dir schicken wird $48 \mathrm{a} \beta$ in Hunger und in Durst und in Nacktheit und an allem Mangel [leiden].

$48 \mathrm{~b} \alpha \quad$ Er wird dir ein Joch aus Eisen auf deinen Nacken geben,

$48 \mathrm{~b} \beta \quad$ bis er/es dich vernichtet hat. ${ }^{1}$

49a $\alpha$ JHWH wird gegen dich eine Nation aus der Ferne aufbieten, vom Ende der Erde -

49a wie der Adler fliegt sie [herbei] -

$49 \mathrm{ba}$ eine Nation,

$49 \mathrm{~b} \beta$ deren Sprache du [noch] nicht gehört hast;

50a eine Nation mit unbeweglichem Gesicht,

$50 \mathrm{~b} \alpha$ die den Greis nicht anlächelt ${ }^{2}$

$50 \mathrm{~b} \beta$ und sich des Jünglings nicht erbarmt.

$51 \mathrm{a} \alpha_{1} \quad$ Sie wird die Frucht deines Viehs und die Frucht deines Erdbodens verzehren,

$51 \mathrm{aa} \alpha_{2}$ bis du vertilgt bist.

51aß Sie läßt dir nichts übrig vom Getreide, Most und Öl,

51ay vom Wurf deiner Lämmer und vom Zuwachs deines Kleinviehs,

בשמחה ובטגב

לבב מרב כל

ועבדת אהדיה כליך אושר ישלדתנו יהוה בירך ובעיר ברעב ובצמא ובעירם ידור ידור

ובדסר כל כל כל כל ונתן על ברזל על-צוארך

ער השמידו אתרך

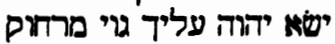
כטשטר ידאה דנישר

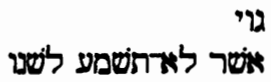
גוי עז פנים

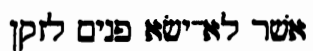

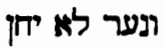
ואכל פרי בדמתך ופרי־אדמתר פרי נוכרו

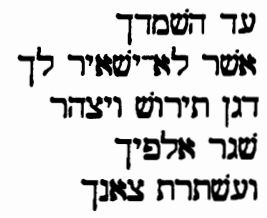

\footnotetext{
${ }^{1}$ Im Hebräischen steht die fast unübersetzbare Infinitivkonstruktion: „bis zu seinem Vernichten dich." Das enklitische Personalpronomen kann sich auf JHWH oder auf das Joch beziehen.

2 Vgl. GrubER, „Faces,“ 254 „This we see that the association of 'lifting up (one's own) face' with 'favor' derives from the fact that 'lift up the face', i. e., 'smile' is a physical expression of favor."
} 
$51 \mathrm{~b}$ bis sie dich vernichtet hat. ${ }^{1}$

52a $\alpha$ Sie wird dich belagern in allen deinen Stadtbereichen,

$52 \mathrm{a}_{2} \quad$ bis deine hohen und unzugänglichen Mauern

zusammenbrechen,

$52 \mathrm{a} \beta$ auf die du vertraust in deinem ganzen Land.

$52 \mathrm{~b} \alpha \beta \quad$ Sie wird dich belagern in allen deinen Stadtbereichen, in deinem ganzen Land,

52by das JHWH, dein Gott, dir gegeben hat.

53a $\alpha$ Du wirst die Frucht deines Leibes essen,

$53 \mathrm{aa} \alpha_{2}$ das Fleisch deiner Söhne und Töchter,

$53 \mathrm{a} \beta$ die er dir gegeben hat,

$53 \mathrm{~b} \alpha$ in der Belagerung und in der Bedrängnis,

$53 \mathrm{~b} \beta \quad$ in der dein Feind dich einschließt.

$54 \mathrm{a} \alpha$. Der verzärtelte Mann bei dir und der sehr verweichlichte -

$54 \mathrm{~b} \alpha$ böse blickt sein Auge auf seinen Bruder und auf die Frau (an) seiner Brust und auf den Rest seiner Kinder,

$54 \mathrm{~b} \beta$ die er noch hat, $55 \mathrm{a} \alpha_{1}$ um [bloß] keinem von ihnen vom Fleisch seiner Kinder abgeben zu [müssen],

55aa2 das er ißt,

$55 \mathrm{a} \beta \quad$ weil überhaupt nichts übriggeblieben ist für ihn

$55 \mathrm{~b} \alpha$ in der Belagerung und in der Bedrängnis,

$55 \mathrm{~b} \beta \quad$ mit der dein Feind dich einschließt in allen deinen Stadtbereichen.

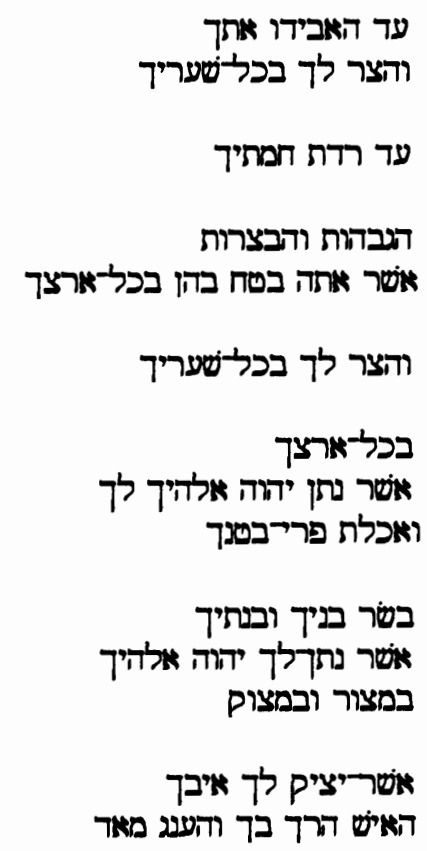

תרע עינו באחיו ובאשת חיקי
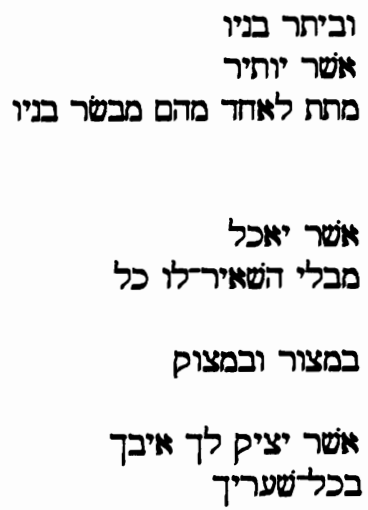

\footnotetext{
${ }^{1}$ Die Übersetzung orientiert sich an JENNI, „Faktitiv,“ 149: „Das pi. als Faktitiv zum Verbaladjektiv bedeutet nun ,verloren machen, zugrunde richten, in den Zustand der Vernichtung versetzen'. Das hi. dagegen als Kausativ zum Vorgang bedeutet ,machen, dass etwas verloren oder zugrunde geht'. Dabei setzt das hi. eine gewisse eigene Tätigkeit des Objekts voraus, was beim pi. nicht der Fall ist. Der Kausativ veranlasst, dass der Vorgang von einem neuen Zentrum ausgeht. Eben deshalb kommen als Objekte des hi. ,umkommen lassen " nur Grössen in Frage, die als selbständige Träger des Geschehens gedacht werden können, also am ehesten Personen oder Lebewesen ... ."
} 
$56 a_{1} \quad$ Die Verzärtelte bei dir und die הרכה כך והענגה

Verweichlichte,

$56 \mathrm{aO}_{2}$ die nie versucht hat, ihre Fußsohle auf die Erde zu setzen

$56 \mathrm{a} \beta$ vor Verweichlichung und Verzärtelung -

56ba böse blickt ihr Auge auf den Mann [an] ihrem Busen

$56 \mathrm{~b} \beta$ und auf ihren Sohn und auf ihre Tochter

$57 \mathrm{a} \alpha$ und auf ihre Nachgeburt, die zwischen ihren Beinen herauskommt, und auf ihre Söhne,

$57 \alpha_{2} \quad$ die sie gebären soll,

$57 \mathrm{a} \beta$ denn sie wird sie essen vor Mangel an allem - heimlich -

$57 \mathrm{~b} \alpha$ in der Belagerung und in der Bedrängnis,

57b $\beta \quad$ mit der dein Feind dich einschließt in deinen Stadtbereichen.

58a $\alpha$ Wenn du nicht alle Worte dieser Tora hältst und ausführst,

$58 \mathrm{a} \beta$ die in dieser Urkunde aufgeschrieben sind,

58b aus Furcht vor diesem verehrungswürdigen und furchterregenden Namen, [nämlich vor] JHWH, deinem Gott,

$59 \mathrm{a} \alpha$ wird JHWH die Schläge [für] dich

59aß und die Schläge [für] deinen Samen ins Wundersame steigern.

$59 \mathrm{~b} \alpha \quad$ Große und andauernde Schläge!

$59 \mathrm{~b} \beta \quad$ Und große und andauernde Krankheiten!

60a $\alpha$ Zurückbringen wird er zu dir jede Seuche Ägyptens,

60aß vor denen du Angst hast,

60b und sie werden an dir haften.

61aa Auch jede Krankheit und jeden Schlag,

61a $\beta$ der in der Urkunde dieser Tora nicht aufgeschrieben ist, -

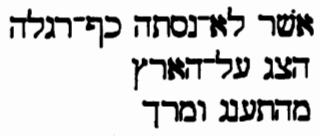

תרע עינה באיש חיקה

ובבנה ובברזה

ובשלירזה היוצת מבין רגליה

ובבניה המד אישר תלד

כי־תאכלם בחסר־כל בסתר

במצור ובמצוק

משטר יציק לך איבך

בשעריך

אםלא תשמר לעשאת

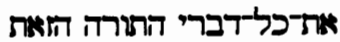

הכתובים בספר הזה דורה

ליראה אתדהשם הנכבד

ודנורא הזה את יהוה הלהיך הוריך והפלא יהוה אתדמכתך יודיך ואת מכות זרעך ידוד

מכות גדלות ונאמנות וחלים רעים ונהמנים

והשיב בך את כל־מדוה מצרים

אואשר יגרת מכניהם

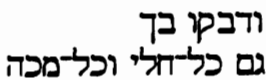

אספר לא כתוב בספר התורה הזאת לתוב 
$61 b \alpha \quad$ JHWH wird sie über dich verhängen, ${ }^{1}$

$61 \mathrm{~b} \beta \quad$ bis du vernichtet bist. ${ }^{2}$

62a $\alpha$ Ihr werdet übrigbleiben mit wenigen Männern,

62a $\beta \quad$ anstatt da $B$ ihr zahlreich werdet wie die Sterne des Himmels,

62b denn du hörtest nicht auf die Stimme JHWHs, deines Gottes.

63a $\alpha$ Es wird geschehen,

$63 \mathrm{a} \alpha_{1}$ wie JHWH Freude an euch hatte,

$63 \mathrm{a} \alpha_{2}$ indem er euch Gutes tat

$63 \mathrm{aa} \alpha_{3}$ und euch zahlreich machte,

63aß so wird JHWH Freude an euch haben,

$63 a \gamma_{1}$ indem er euch untergehen läßt

$63 a \gamma_{2}$ und euch vernichtet.

$63 \mathrm{ba}$ Ihr werdet ausgerissen aus dem Erdboden,

$63 \mathrm{~b} \beta_{1} \quad$ zu dem du kommst,

$63 \mathrm{~b} \beta_{2}$ um ihn in Besitz zu nehmen.

64a. JHWH wird dich unter alle Völker zerstreuen, vom [einen] Ende der Erde bis zum [anderen] Ende der Erde;

$64 \mathrm{~b} \alpha$ Dort mußt du anderen Göttern dienen,

$64 \mathrm{~b} \beta$ die du nicht kanntest, du [nicht] und deine Väter [nicht] [Götzen aus] Holz und Stein!

65a $\alpha$ Und bei diesen Nationen wirst du keine Ruhe finden,

$65 \mathrm{a} \beta$ und deine Fußsohle wird keinen Platz[zum Stehen] haben.

יעלם ידוה עליך

ער השמרך יפוד פלד

ונשארתם במתי מעם

תחת אשר הייתם

ככוכבי השמים לרב היחם

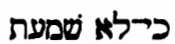

בקול יהוה אלדהיך

והיה ביה

כאטשר־שם ידוה עליכם

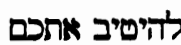

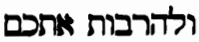

כן ישיש ידוה עליכם

לדאביד אתכם ירוד פליכה

ולדשטמיד אתכם אחם

ונסחתם מעל האדמה

אשר ראתה בארשמה

לרשתה

והפיצך יהוה בכל־המים

מקצה הארץ וער־צה הארץ

ועבדת שם אלהים אחרים

אלשר לה עידעת

אתה ואבתיך לידת

עץ וואבן

ובגוים ההם לא תרגיע

ולאציהיה מנוח לכפררגלך

${ }^{1}$ Vgl. EhrLich, Randglossen, 334:, העלה וצלי ומכה על פ', im Sinne von ,über jemanden Krankheit und Plage bringen' ist unhebräisch. יעלם עליך kann daher nur im Sinne des vorherg. כתוב בספר gefasst werden, denn man sagte auch in על עלה על ספר in Buch eintragen; vgl. 2 Chr. 20,34. Danach ist der Sinn hier: ja, selbst allerlei Krankheit und Plage, die in dieser Bundesschrift nicht verzeichnet sind, wird er an dir registrieren."

2 So grenzt $\boldsymbol{m}$ ab. Die Einteilung von $\boldsymbol{\mu}$ könnte man dagegen so übersetzen:

60 a Zurückbringen wird JHWH zu dir alle Seuchen Ägyptens, vor denen du Angst hast.

$60 \mathrm{~b}$ Haften wird an dir

61 a $\alpha$ auch jede Krankheit.

Und jeden Schlag,

a $\beta$ der nicht geschrieben ist im Buch dieser Tora,

$\mathrm{b} \alpha$ wird JHWH stark machen über dir,

$\mathrm{b} \beta$ bis du vernichtet bist. Vgl. BEN-HAYYIM, Tradition, 150. 
65b JHWH wird dir dort ein zitterndes

ונתן יהוה לך שם לב רגז

Herz geben

sowie ausgeweinte Augen und eine

trockene Kehle. ${ }^{1}$

66a Dein Leben wird vor dir in der

Schwebe sein.

66b $\alpha$ Bei Nacht und bei Tag wirst du dich

fürchten

$66 \mathrm{~b} \beta$ und auf dein Leben nicht mehr vertrauen.

67a $\alpha_{1} \quad$ Am Morgen wirst du sagen:

$67 \mathrm{aa}_{2} \quad$ Wann wird es Abend? -

$67 \mathrm{a} \beta_{1}$ und am Abend wirst du sagen:

$67 \mathrm{a} \beta_{2} \quad$ Wann wird es Morgen? -

$67 \mathrm{~b} \alpha_{1}$ wegen der Furcht [in] deinem Herzen,

$67 \mathrm{ba}{ }_{2}$ mit der du dich fürchtest,

$67 \mathrm{~b} \beta_{1}$ und wegen des Anblicks [vor] deinen Augen,

$67 \mathrm{~b} \beta_{2}$ [bei dem,] was du siehst.

$68 \mathrm{a}_{1}$ JHWH wird dich in Schiffen nach

Ägypten zurückbringen

auf dem Weg,

$68 \mathrm{a} \beta_{2}$ von dem ich dir gesagt habe,

68a $\gamma$ du wirst ihn nicht mehr sehen.

$68 \mathrm{ba} \quad$ Ihr wollt euch dort an deine

Feinde verkaufen als Knechte und

Sklavinnen,

$68 \mathrm{~b} \beta \quad$ aber es gibt keinen Käufer.

וכליון עינים ודאבון נפשד

והיו חייך תלאים לך מנד

ופחדת לילה ויומם

ולא תאמין בחייך

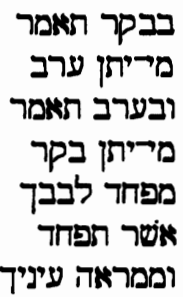

אשר תראה

והשיבך יהוה מצרים באניות

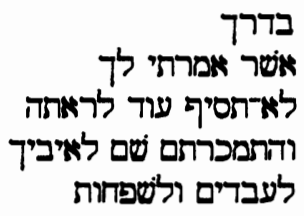

ואין קנה

\subsubsection{Textkritik}

48a $\alpha$ ועבדת] Nur (5963min fügt in Parallelisierung zu 28,36 عxعl hinzu.

48a $\alpha$ [הת-איביך] D bietet den Singular inimico tuo, was von $\alpha^{\prime}, \sigma^{-}$und $\vartheta^{-}$ gestützt wird. Es scheint also hebräische Texte mit איבץ פegeben zu haben. Damit verändert sich möglicherweise das Subjekt der folgenden singularischen Ausdrücke ונתי השמידו conterat. Mn bezieht 48b auf das Subjekt der vorhergehenden Relativsatzes $\left(48 \mathrm{a} \alpha_{2}\right)$, JHWH. Dieser Halbvers erweist sich damit als eigenständiger Satz mit einer neuen Aussage. Gott selbst wird das eiserne Joch auf den Nacken Israels legen und führt die Vernichtung herbei. $\mathfrak{D}$ dagegen läßt offen, ob Gott oder der Feind als Sub-

${ }^{1}$ Es könnte sich hier um die Beschreibung von Symptomen einer Depression handeln. Vgl. GRUBER, „Dryness,“ 366. 
jekt von ponet und conterat anzusehen ist, und so erscheint $48 \mathrm{~b}$ eher als logische Fortführung von 48a. Der Feind, dem Israel dienen muß, bringt Joch und Vernichtung. Der Bruch zwischen 48a und $b$ in $\mathbb{m}$ legt nahe, in את איביביך die lectio difficilior zu sehen, zumal in Jer 28,14 das Joch auf dem Nacken der von Nebukadnezar bedrängten Völker ebenfalls als Werk JHWHs bezeichnet wird. $\mathbb{C}$ gibt mit dem enklitischen Personalpronomen im Plural ( $b^{\prime} l j d b b j k w n$ ) wohl kaum eine hebräische Vorlage wieder.

48aß ובצמא ובעירם wird von BB ausgelassen. Das ist eine Abweichung innerhalb der 6 -Überlieferung. Wahrscheinlich wirkte das dreifach wiederholte $x \alpha l \in v$ wie ein Homoiarkton. 4Q42/4QDeut enthält wie $\mu$ die orthographische Variante ובערום, was samaritanisch ,wbārom“"1 ausgesprochen wird.

49aß יראה מ מ יראה basiert wohl auf dem fälschlichen Vertauschen von 7 und 7 .

50ba לא-ישא פנים לזין Unterschiede in den Übersetzungen werfen die Frage auf, ob das Gesicht des Feindes oder das des Greises erhoben wird. 6

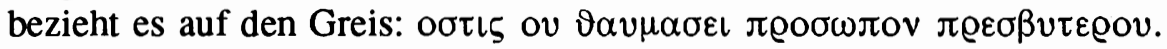
Dem entspricht Ehrlich, der im zwischen פנים und ein Zeichen für den Genitiv sieht. Auch Johnson glaubt, das Gesicht des Greises wird erhoben. $\mathfrak{D}$ quae non deferat seni bleibt unbestimmt, drückt aber eher eine Haltung im Feind aus. Dann schließt das ל das Dativobjekt an. ${ }^{2}$

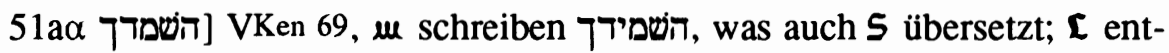
spricht השמידוך; In $\mathscr{G}$ fehlt $51 \mathrm{a} \alpha_{2}$ überhaupt, erst die Hexapla setzt unter Asteriskus $\varepsilon \omega \zeta$ $\alpha v \varepsilon x \tau \varrho \iota \psi \eta$ $\sigma \varepsilon$ hinzu, dem $O-58106 t$ sowie $\mathfrak{U}$ folgen. Allerdings zeigt $\mathbb{B}$ gegenüber $\mathfrak{m}$ Abweichungen in den ,Vernichtungsformeln“, wie schon das Plus nach $45 a \beta$ zeigte. ${ }^{3}$ Die Infinitivkonstruktion in Im gilt gegenüber den finiten Verben wohl als lectio difficilior.

51a 1 [ירוש einige Handschriften $\mu, \mathfrak{\complement}$ und 5 lesen ותירוש Die Konjunktion stammt wohl aus der Angleichung an das dritte Glied der Aufzählung.

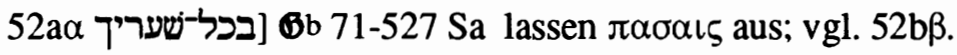

52baß והצר לך בכל־שעריך בכל־-ארצך BHK und BHS empfehlen, 52baß als Dittographie zu streichen. Tatsächlich überspringen in $\mathbb{6}$ die Handschriften 44-107' 71 dieses Versstück, doch handelt es sich dabei um eine Abweichung innerhalb der $\boldsymbol{G}$-Überlieferung, aus der keine ältere hebräische Vorlage erschlossen werden kann.

1 Ben-HayYiM, Tradition, 148; vgl. Garcla Martinez, „Manuscrits,“ 72.

2 Vgl. EhrLICH, Randglossen, 333; JohnSON, „Aspects,“ 157; GrUBER, „Faces,“ 254.

3 Vgl. DOGNIEZ / HARL, Bible, 37.39; WeVERS, Text, 98. 


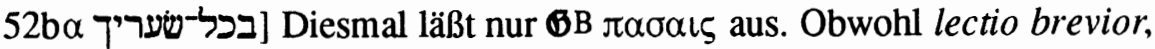
spricht die geringe Bezeugung für den sekundären Ausfall des Wortes in $\boldsymbol{G}$,

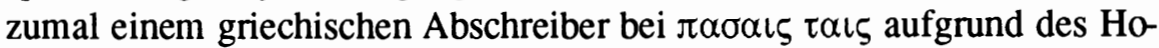
moioteleutons ein mechanischer Fehler unterlaufen sein könnte.

$52 b \beta$ בכל-ערצד] wird von 6 ausgelassen. Die Hexapla fügt mit Asteriskus $\varepsilon v \pi \alpha \sigma \eta \tau \eta \gamma \eta$ oov hinzu. Dem folgen die 6 -Handschriften $O-58106 t$ und U. Buis erklärt den Ausfall als Homoioteleuton. ${ }^{1}$

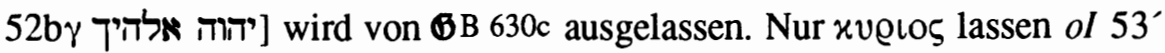
aus. $\mathcal{U}$ übersetzt o $\vartheta \varepsilon \circ \varsigma$ бov nicht.

53aß יהוה אלהיך wird von $\mu$ und $\boldsymbol{6 B}$ 630c $\mathfrak{U}$-c ausgelassen. Die alte $\boldsymbol{6}$ Handschrift 963 sowie 707 b-19 Latcod 100 U Arm und Sa haben nur xv@เos, wie auch viele hebräische Handschriften nur das Tetragramm bezeugen. Die Auslassung ist also gut bezeugt. Das Fehlen des expliziten Subjekts im Relativsatz muß wohl als lectio difficilior betrachtet werden. Außerdem ist es die lectio brevior. Die Schreiber haben später offenbar ein ausdrückliches Subjekt für den Relativsatz gesucht und zunächst nur xv@log/ יהוה hinzugefügt, später mit vielleicht den in V.53 vorherrschenden $k \bar{a}$-Endreim aufgreifen und eine Parallelität zwischen 53a $\beta$ und $\mathrm{b} \beta$ herstellen wollen. Auch die andere Stellung des Gottesnamens gegenüber dem sonst parallelen 52by läßt diesen als Zusatz erscheinen. ${ }^{2}$

53b $\beta$ יציק Hier lesen $\mu$ und $\mathbb{C} J$ Plural, passend zu in vielen hebräischen Handschriften, $\mu$ und $\mathfrak{C}$ steht ( $\mathbb{C}$ J noch mit dem enklitischen Personalpronomen im Plural). Das pluralisch verstandene Nomen führte wohl sekundär zum Pluralverb. Hempel legte dar, daß das Jod im Nomen eine mater lectionis für die Aussprache sein soll und keinen Plural anzeigt. ${ }^{3} \mathrm{Zu}-$ sammen mit der Verbform im Singular kann es als konsonantische Schreibung eines E-Lautes verstanden werden. Nach den M-Manuskripten ist die Pausa 'ojeboeka zu sprechen und dasselbe Wort lautet im samaritanischen Dialekt ,,iyyåbēk“4.

$1 \mathrm{Vgl}$. Deutéronome, 187.

2 Vgl. HEMPEL, „Septuaginta,“ 96, Anm. 20. Er gibt aber letztlich $m$ den Vorzug, indem er das Fehlen von ידוה אלהיך in und 6 B zwar auf eine hebräische Vorlage zurückführt, in der diese Worte jedoch durch Homoioteleuton ausgefallen seien. WEVERS legt dar, in 6

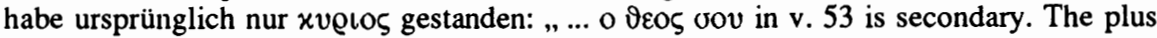
need not be dependent on later Hebrew influence at all, but rather be due to the influence of the preceding line. The textual tradition on the whole tends to add to rather than shorten a text.“ Text, 55; vgl. „Yahweh,“ 276.

3 Vgl. „Wert,“ 218 Anm. 32, 219.

4 BEN-HAYYIM, Tradition, 149. 


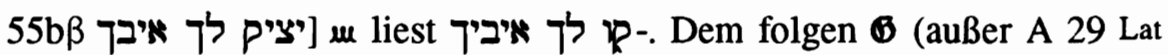

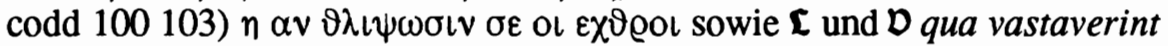
te inimici tui. Gerade der Wechsel vom Singular in $53 \mathrm{~b} \beta$ zum Plural in $55 \mathrm{~b} \beta$ in den Versionen läßt annehmen, daß ihnen tatsächlich für diesen Versteil ein Text vorlag, der $\mu$ entspricht. Es ist aber kaum wahrscheinlich, daß der Verfasser ursprünglich bei den refrainartigen Wiederholungen in $\mathrm{V}$. 53.55.57 vom Singular in den Plural wechselte, obwohl dies als lectio difficilior gelten müßte. Eher dürfte angenommen werden, daß die Setzung des Pluralverbes, die $\mu$ in allen drei Versen bezeugt, die die Versionen jedoch nur hier nachvollziehen, ein Stadium in der hebräischen Textgeschichte widerspiegelt, in der die als Pluralzeichen gedeutete mater lectionis im Nomen in V. 55b $\beta$ zur Angleichung des Verbs geführt hat, ohne daß dies in den parallelen Versen bereits übernommen worden war. Die Übersetzung folgt der lectio brevior von $\mathrm{m}$.

$56 a \alpha$ ב ] wird von $\mathcal{D}$ überhaupt nicht, von $\mathbb{G}$ und $\mathbb{C} J$ in der 2. Person Pl. übersetzt. Die Übereinstimmung von $\mathfrak{M}$ mit $\mu \mathcal{C O}$ und $\mathcal{U}$ rechtfertigt keine Textänderung.

56aa (והענגה (außer B 963 O-82 n Latcod 103 ü Sa 5) ergänzt aus 54a $\sigma \varphi \circ \delta \varrho \alpha$.

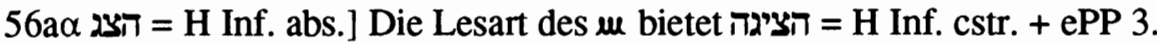
Sg. fem., welches sich auf כף כסרגליה bezieht. Die samaritanische Aussprache lautet: „aș̣īga 'al"1. Es handelt sich in we wohl um eine Verdeutlichung des Objektbezugs. ${ }^{2} \mathrm{~m}$ ist lectio difficilior und lectio brevior.

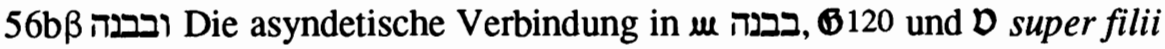
zeigt wohl eine innerhebräische Variante, der um so mehr Gewicht zukommt, als sie dem parallelen 54ba widerspricht und auch der im Vulgärtext von $\mu$ eigentlich vorherrschenden Tendenz zur syndetischen Verbindung entgegensteht. ${ }^{3}$

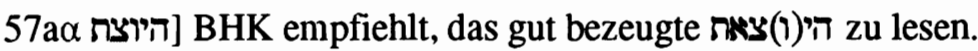

\footnotetext{
${ }^{1}$ BeN-HAYYIM, Tradition, 149; vgl. „Observations,“ 13.

2 Vgl. DrIVER, Deuteronomy, 316 Anm. 56; EHRLICH, Randglossen, 334: „Im Relativsatz kann כף רגלה, welches dem Inf. vorangeht, nicht dessen Objekt sein. In der Prosa ist eine solche Konstruktion nicht statthaft. Es bleibt daher nichts übrig, als רגלה als Objekt zum vorherg. Verbum und הצג als erklärend zu fassen. Das Objekt des letzteren ergänzt sich dann aus dem Zusammenhang. ... Der Sinn des Ganzen ist danach der: die ihren Fuss nicht abgehärtet - wörtlich nicht eingeübt - zum Setzen auf die Erde."

3 Vgl. HEMPEL, ,Wert,“ 225.
} 


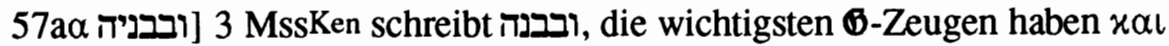

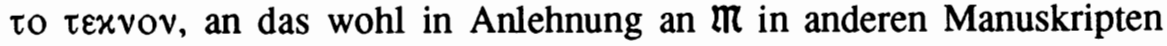

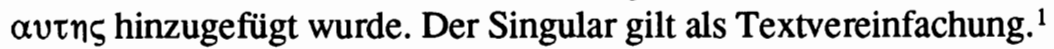

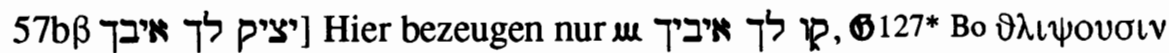
$\sigma \varepsilon$ ol $\varepsilon \chi \vartheta \varrho o l$ und $\mathcal{C} O$ den Plural. Es handelt sich wohl wieder um die Angleichung des Verbs an das Nomen, dessen Jod ursprünglich eine mater lectionis zur Angabe der Pausa war.

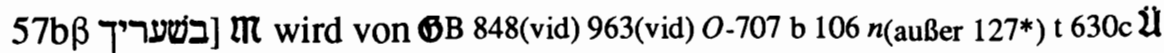
Co gut bezeugt. ${ }^{2}$ Die Einfügung von $\pi \alpha \sigma \alpha \iota \varsigma$ in den übrigen 6 -Handschriften geschah wohl unter dem Einfluß von $55 \mathrm{~b} \beta$.

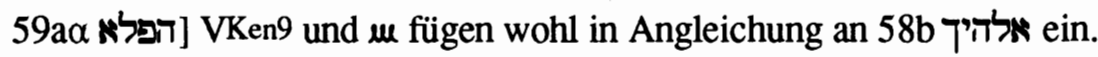

59a 1 אתדמכתך] BHK empfiehlt, mit VKen109.132 מכתיך oder mit VKen129 מכותיך zu lesen, dem auch $\mathcal{S}$ und $\mathfrak{D}$ folgen. ${ }^{3}$

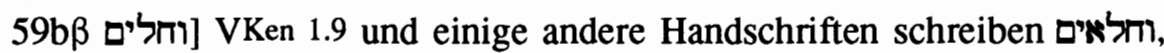
VKen 107 eine Handschrift und Cיים ודים. Dies scheinen verschiedene Versuche zu sein, die Pluralaussprache halajim in Konsonantenschrift wiederzugeben (hala(=')jim oder halajîm).

60aa כל־מדוה VG Ken84.107.167+12Mss, $\mathfrak{C}, \mu$ bieten den Plural מדוי wie in Dtn 7,15, der auch durch die Übersetzungen $\mathcal{S}, \mathfrak{C}, \mathfrak{C} J$ und $\mathfrak{D}$ gut bezeugt ist.

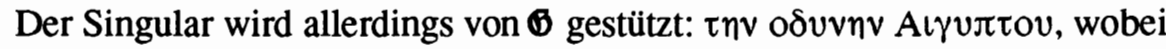

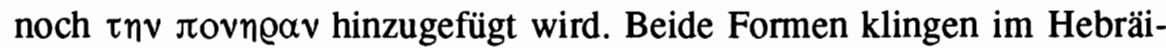
schen fast gleich und der Sinnunterschied ist minimal: jede Seuche Ägyptens / alle Seuchen Ägyptens. Wenn man מדוה liest, wird das sich auf 60a $\alpha$ beziehende מפניהם inkongruent. Für $\mathbb{M}$ spricht, daß die Numerusinkongruenz die lectio difficilior ist und daß die Schreibung מדוי eine Angleichung an Dtn 7,15 sein könnte.

60b ודבקו Der Singular ודבק in wird sonst nicht bezeugt und resultiert aus einer anderen Verseinteilung, die מלבי auf das Verb מכה un auf das Verb עלם zu beziehen scheint, so daß jedes Verb im Singular ein Objekt erhält. Dem entspricht auch der Singular im Relativsatz (כתוב), der nur auf + עלה nicht von יעלם zurückzugreifen scheint. Die m-Tradition leitet מכה (כלה

\footnotetext{
1 Vgl. BARTHÉLEMY, 296.

2 Vgl. WeVERS, „Attitude,“ 504.

${ }^{3}$ Vgl. MARTI, „Deuteronomium“, 312: „1. makkôtèkā MT K K rê liest unmögliches makkôtekā.“
} 
ePP 3. Plural m. ab, sondern von der Wurzel עלם, die mit dem aramäischen אל in Verbindung gebracht werden kann. ${ }^{1}$

61aß הזאת] VG Ken 17.69a.129+12 Mss und $\mu$ schreiben wie in Dtn 29,30; 30,$10 ; 31,26$. So übersetzen auch $\mathbb{6} \mathrm{L} 59 \mathrm{~d} 55 \boldsymbol{L}, \boldsymbol{S}$ und $\boldsymbol{C} \mathrm{J}$ Ken69, $\mu$ und die Lucianrezension lassen vermuten, daß in einem vormasoretischen Vulgärtext tatsächlich הזה stand. ${ }^{2}$ Ob man dies nun als sekundäre Angleichung an die Parallelstellen 29,30;30,10;31,26 werten, oder im Einfluß des näheren 58a $\alpha$ erkennen kann, läßt sich schwer entscheiden. Die alten Übersetzungen $\boldsymbol{B}$ und $\mathfrak{D}$ sprechen jedoch für $\mathfrak{m}$.

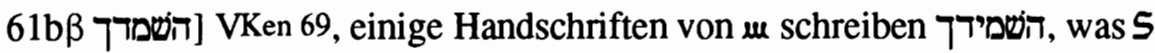
und $\mathfrak{D}$ übersetzen. Demgegenüber ist $\mathfrak{m}$ lectio brevior und difficilior.

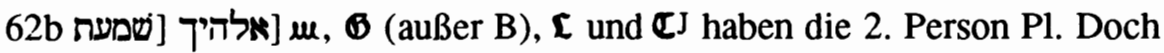
der Numeruswechsel in $\mathrm{m}$ muß als lectio difficilior gelten. $\$ 16^{*}-46-52-528$ 550' 19 44-107* Wi 45630509 haben am Versende $n \mu \omega v$ statt $v \mu \omega v$, wohl ein durch den Jotazismus bedingter Fehler. Die im Fragment 4Q42/4QDeut erhaltenen Teile von V. 58-62 stimmen mit M überein. $^{3}$

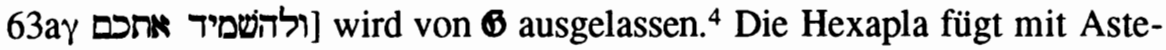

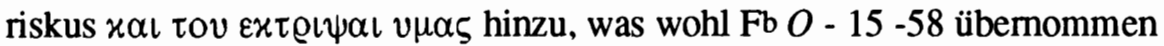
haben; $\mathrm{d}$ (außer 125) $t$ belegen nur die beiden letzten Worte dieser Angleichung an $\mathfrak{k}$.

63b $\alpha$ וונסחת G Bügt $\varepsilon v \tau \alpha \chi \varepsilon\llcorner$ hinzu, eine sonst nicht belegte Ergänzung, die wohl aus 28,24 stammt. $^{5}$

$65 b$ berien läß die Konjunktion weg. Die Versionen stützen aber die syndetische Verbindung in $\mathbb{m}$.

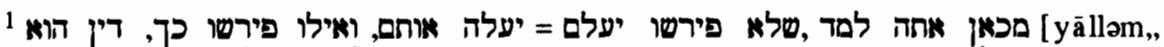

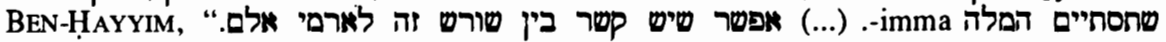
Tradition, 150 Anm. 61.

2 Vgl. HeMPEL, „Wert,“ 207.

3 Vgl. García MARTíneZ, „Manuscrits,“ 72.

${ }^{4} \mathrm{Vgl}$. DognIEZ / HaRL, Bible, 34f.: „Quelques lacunes semblent être des oublis ...; tantôt le grec n'a pas autant de verbes d'extermination que l'hébreu $(28,63)$, tantôt il en a davantage $(27,7 ; 28,24$ et 45$) \ldots .$.

5 Anders HEMPEL, „Septuaginta,“ 96 Anm. 20, der glaubt, ein ursprüngliches מהר sei als Homoiarkton ausgelassen worden. DAHOOD schlägt eine Qal Passiv Punktation vor: , ... $w^{e}$ nüsahtem ... . Though MT's niphal pointing in Deut 28,63 cannot be proved wrong, since consonantal $n$ shtm does materially permit such a pointing, the fact that the Masoretes knew of no qal passive conjugation, since qal passive does not exist in postbiblical Hebrew, and their inabiliby to vocalize Prov 2,22 correctly, weigh the balance in favor of the qal passive interpretation.“" „Lexicography VI,“ 365 ,
} 
65b ודאבון in Die Schreibung beruht wohl auf einer Variation im Gebrauch der mater lectionis. Die samaritanische Aussprache ist „wdibon nåfəš“1. ${ }^{\text {. }}$. $\mathrm{G}^{3}$ hat dies dann zu ומדיבון uminterpretiert. Vielleicht ist dies eine Angleichung an Lev 26,19 ומדיבת נפש ומדיבון.

66a תלאים לך מנגד (außer G und 376') fügt $\tau \omega v$ o o $6 \vartheta \alpha \lambda \mu \omega v$ бov an. Dieser Zusatz wird von den anderen Versionen nicht gestützt. ${ }^{2}$

66ba יומם ולילי Then die Reihenfolge geändert, was Zeitlin für ursprünglich hält. ${ }^{3}$ Doch gerade in der Abweichung von allen anderen Pentateuchstellen zeigt sich $\mathrm{m}$ als lectio difficilior.

68aa מצרימה [מצרים in Seb und $\mu$ stellt gegenüber M eine Vereinfachung dar.

68aß באניות Die Schreibung באוניות B gibt die Aussprache des Qamez Chatuf offenbar mit mater lectionis wieder. Die Schreibung des Waw muß alt sein, weil es nicht der samaritanischen Lautung „banyot" ${ }^{\star 4}$, also ohne „O" im Wortanlaut, sondern der masoretischen Aussprache entspricht. Ebenso wird das Wort auch $2 \mathrm{Chr} 8,18$ geschrieben.

68a $\gamma$ ] Die 2. Person Pl. wird von 6 unter Auslassung des Personalpronomens (nur $\mathrm{Fb}$ G-58-82-426 fügen in Angleichung an $\mathfrak{k}$ ool ein, 82 ov) sowie von $\mu$ und $\mathcal{C} \mathrm{J}$ gut bezeugt. $\mathrm{Ob}$ nun dies die Angleichung an $68 \mathrm{~b}$ ist, oder ob $\mathbb{K}$ an $68 \mathrm{a} \alpha$ angeglichen hat, kann kaum entschieden werden. Gegenüber der einheitlichen Haltung von $\mu$ und $\mathbb{C J}$, die $68 \mathrm{a} \gamma-\mathrm{b} \beta$ geschlossen in der 2. Person Pl. bieten, muß die Numerusmischung in $\mathbb{M}$ als lectio difficilior gelten.

68b והתמכרתם $\mathcal{D}$ setzt glättend in den Singular: venderis.

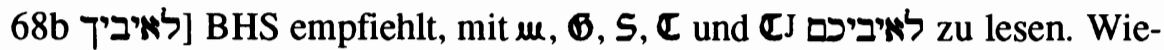
derum erscheint aber die Numerusmischung in $\mathfrak{k}$ als lectio difficilior.

\subsection{Sprachlich-syntaktische Analyse}

Die Satzsyntax unterscheidet sich von Dtn 28,20-44 in einem wesentlichen Punkt. Außer V. 49a $\alpha$ kommt die Struktur yiqtol nicht vor. Nach Niccaccis

\footnotetext{
1 BEN-HAYYIM, Tradition, 151.

2 ולדת bezeichnet in der Sprache der Mischna den Begriff des lateinischen ,suspendere " und heisst wie dies in der Schwebe, d.i., in Unsicherheit, lassen. ... מנד besagt, dass die Angeredeten nichts dazu werden tun können, um der Unsicherheit ihres Lebens abzuhelfen.“ EHRLICH, Randglossen, 334.
}

3 Vgl. ,Reflections,“ 325.

4 BEN-HAYYIM, Tradition, 151. 
Vorschlägen kann nur dieser Vers als Jussiv verstanden werden. Tatsächlich findet sich in den Versionen ein Beleg für diesen Modus. Targum Onkelos übersetzt ויתו, also der defektiven Jod-Endung eines Verbums tertiae infirmae, und Grossfeld übersetzt einen Wunschsatz ins Englische. ${ }^{1}$ Während $B$ in 28,7-44 so sorgfältig zwischen Optativ und Indikativ Futur unterschied, steht in 28,49 mit $\varepsilon \pi \alpha \xi \varepsilon \iota$ Indikativ Futur. Hier scheint also trotz der yiqtol-x-Form ein Fall für die vom Kontext abhängige Modusbestimmung gegeben zu sein, wie sie Waltke und O'Connor vorschlagen. ${ }^{2}$ Wenn der ganze Abschnitt 47-68 in Satzstrukturen gestaltet ist, die nach Niccacci Indikativ Futur verlangen, so wird auch dieser mitten darin eingebettete Vers so zu übersetzen sein. Die zweite yiqtol- $x$-Struktur dieses Abschnitts in 28,61b $\alpha$ entpuppt sich bei näherem Hinsehen als $x$ yiqtol, da $61 \mathrm{a} \alpha$ voranzustellen ist, das als casus pendens vom Relativsatz 61aß getrennt, zum Hauptsatz dazugehört. ${ }^{3}$ Wenn jedoch in Dtn 28,20-44 im Wechsel von Jussiv und Indikativ Futur eine inhaltliche Differenzierung zwischen Verwünschung und Ausmalung der Fluchfolgen herausgearbeitet wurde, so bedeutet dies für 28,47-68, daß in seinen Indikativ-Futur-Sätzen keine Flüche im Sinne von Verwünschungen mehr stehen, sondern eine Ausgestaltung der Fluchfolgen vorliegt. Die Satzsyntax legt demnach einen Gattungsunterschied zwischen Dtn 28,20-44 und 28,47-68 nahe. Die hier zu beobachtenden Phänomene decken sich mit $\boldsymbol{\sigma}$, wo ab V. 47 im Gegensatz zu vorher alle Sätze, die Gott zum Subjekt haben, im Indikativ übersetzt sind. ${ }^{4}$

Sumner ortet in V. 47-57 einen sinnvollen Gedankenfortschritt von einer Einleitung in V. 47f über die Beschreibung der fremden Nation (V. 49f) und ihrer Tätigkeit (V. 51f) bis hin zu den Tätigkeiten des Volkes in seiner Belagerungsnot (V. 53-57) ${ }^{5}$. In V. 52 wechselt der Blick von der Betrachtung der Feinde zur Beschreibung der Belagerten. Beide Absätze sind aber durch die Wurzel אכל ,essen“ (V. 51.53) miteinander verbunden. ${ }^{6}$

\footnotetext{
$1 \mathrm{Vgl}$. Targum, 80f.

2 Introduction, 566.

${ }^{3} \mathrm{Vgl}$. die Satzeinteilung von RICHTER, $B H t, 633$.

${ }^{4}$ Die Satzstrukturen sind: $x$-qatal in $47.60 \mathrm{a} \beta .62 \mathrm{a} \beta . \mathrm{b} .63 \mathrm{a} \alpha \beta .64 \mathrm{~b} \beta .68 \mathrm{a} \alpha_{2} ; w=q a$ tal in

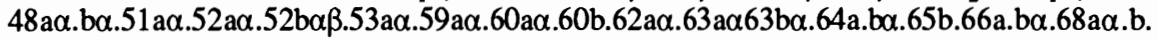
Am häufigsten ist $x$-yiqtol in $48 \mathrm{a \alpha}_{2} .49 \mathrm{a} \beta . \mathrm{b} \beta .50 \mathrm{~b} \alpha . \mathrm{b} \beta .51 \mathrm{~b} \alpha .53 \mathrm{~b} \beta .54 \mathrm{~b} \alpha . \mathrm{b} \beta .55 \mathrm{a} \alpha_{2} .55 \mathrm{~b} \beta .56 \mathrm{~b} \alpha$. $57 \mathrm{a} \alpha_{2} \cdot \mathrm{a} \beta . \mathrm{b} \beta .58 \mathrm{a} \alpha .61 \mathrm{a} .63 \mathrm{a} \gamma \delta .64 \mathrm{~b} \beta .65 \mathrm{a} \beta .66 \mathrm{~b} \beta .67 \mathrm{a} \alpha \cdot \mathrm{a} \alpha_{2} \cdot \mathrm{a} \beta . \mathrm{a} \beta_{2} \cdot \mathrm{b} \alpha_{2} \cdot \mathrm{b} \beta_{2}$.

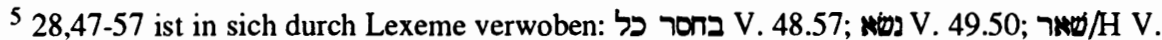

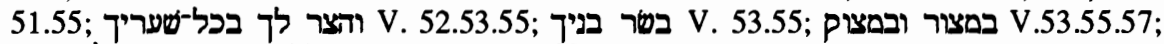
V.54.56.

6 Vgl. Study, 116a-122.
} 
Die Verknüpfung durch Wörter, die in 28,47-68 mehrmals, in 28,20-44 aber nicht vorkommen, verebbt bis V. $65 .{ }^{1}$ Es hinken dann nur noch die zwei Verbindungen von V. $68 \mathrm{zu} \mathrm{V.} 60^{2}$ und V. $67^{3}$ nach. Weiterhin zeigt sich die Verknüpfung der Verse 62-64 mit dem Abschnitt 47-574. Offenbar werden Stichwörter bewußt wiederholt. So ist es kein Wunder, daß V. 62 auch inhaltlich wie der Anschluß an V. 57 wirkt. Nach der grausamen Belagerung bleibt das Volk nur in dezimierter Zahl übrig, und JHWH verlegt sein Vernichtungswerk auf die Zerstreuung und das Unglück in der Diaspora. Man kann also eine Verbindung zwischen V. 57 und V. 62 sehen, die dadurch verstärkt ist, daß keinerlei Lexeme aus $28,47-57$ in $28,58-61$ vorkommen. Dtn 28,58-61 ist zwar in sich durch mehrere Wortwiederholungen verknüpft ${ }^{5}$, nicht jedoch mit dem Kontext, sieht man von der Verbindung zu V.68 mit שאב $/ \mathrm{H}$ ab. Seitz stellt in 28,62f ein Zwischenstück mit Brückenfunktion wie in 45f. fest. Dabei wird die Brücke zum Abschnitt 4757 geschlagen, nicht zu V. 61. 6 Dtn 28,62f greift durch sein Vokabular auf V. 47-50 zurück. Die beiden Verse sind aber auch mit V. 68 verbunden, zwar nicht durch Lexeme, aber durch das Stilmittel der Numerusmischung. Die Anrede springt zwischen der 2. Person Singular und Plural hin und her. ${ }^{7}$

Ein weiterer Unterschied zu 28,20-44 besteht darin, daß in den Abschnitt 28,47-68 Wendungen eingewoben sind, die zum deuteronomischdeuteronomistischen Sprachschatz gehören und sich nicht einfach als nachträgliche Ergänzungen ausscheiden lassen, da sie eng mit dem Kontext verbunden sind. Die folgende Tabelle zeigt, daß diese Wendungen nicht gleichmäßig über den ganzen Abschnitt verteilt sind, sondern zwischen V. 52 und V. 64 stehen. Sie häufen sich also in der Mitte. Dadurch wirkt 28,58-61 wie eingeschoben. V. 58a ist an deuteronomisch-deuteronomistisches Vokabular des Kapitels (עשה , שמר) angepaßt.

\footnotetext{
1 ג. 19.50 .65$.

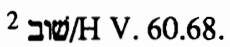

3 אמר V. 67.68

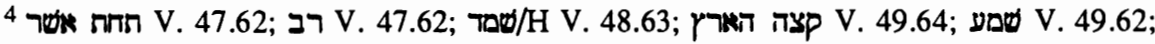

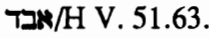

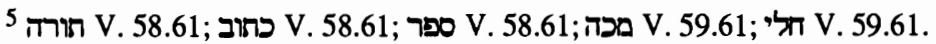

${ }^{6} \mathrm{Vgl}$. Studien, $265 \mathrm{f}$.

7 Vgl. SCHÄCHTER, Fluch, 180.
} 
Für den Charakter von 47-68 aufschlußreich ist die Betrachtung der Lexemverbindungen zum vorausgehenden Abschnitt 28,20-44. Lexeme, die mehrmals in 28,20-44 vorkommen ${ }^{8}$, sind keineswegs gleichmäßig in $28,47-$ 68 verteilt. Es werden fast ausschließlich jene Lexeme wiederholt, die in der ersten Hälfte von 28,20-44, genauer zwischen V. 24-34 zum erstenmal fallen. Außerdem erkennt man, daß die Wörter auch in V. 47-68 nicht gleichmäßig verteilt sind, sondern daß sie sich in drei Zentren häufen. Das erste Zentrum ist der Abschnitt 51-579, das zweite der Vers $64^{10}$, und das dritte V. 67.68 ${ }^{11}$. Vor allem die Verse 67.68 erscheinen damit als Schluß konzipiert, der mit den Stichworten „Feind“", das im Kapitel siebenmal vorkommt, sowie „Weg“ und ,sehen“" Schlüsselbegriffe ${ }^{12}$ aufgreift.

\footnotetext{
${ }^{1}$ Zur Landgabeformel vgl. BraUlik, Mittel, 93.

2 Der Relativsatz bezieht sich nicht auf auch die Kombination Nomen + טתן + (Perfekt mit Subjekt JHWH) + ל darf als geprägte Wendung gelten. Sie kommt nur dreimal außerhalb von Deuteronomium und DtrG vor: Gen 48,9 (בנים); Ex 16,15 (לחם) (בי־חיו), Koh 9,9). Dagegen kommt sie im Deuteronomium

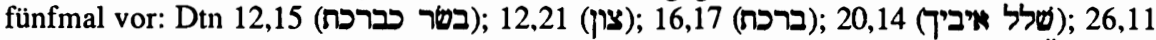

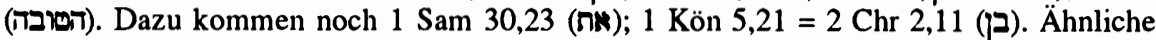
Formulierungen in Koh 3,10.11; 5,17.18; 8,15 gehören wohl nicht dazu, da sie durch die abstrakte Gottesbezeichnung םילהמה) eine eigene Sprachfärbung zeigen.

3 Vgl. HoffmanN, Reform, 361 Anm. 79.

${ }^{4} \mathrm{Vgl}$. WeINFELD, School, 337 Nr. 18.

5 Vgl. Weinfeld, School, 342 Nr. 2; BrauliK, Mittel, 95.

6 Vgl. WEINFELD, School, 358 Nr. 17.

7 Vgl. WeInFELD, School, 357 Nr. 14; HoFFMANN, Reform, 328 b. $358 \alpha+\gamma$.

8 Die Allerweltsworte היה נת und bleiben unberücksichtigt.

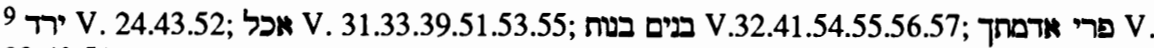
33.42.51.

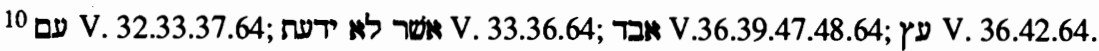

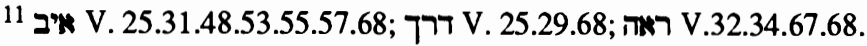

12 3x $+7 x$
} 
Einige Phänomene sprechen dafür, daß 28,47-68 bewußt als kommentierende Auslegung zu 28,24-34 gestaltet wurde. ${ }^{1}$ Es werden nämlich Bezüge ausgeblendet, die vom Vokabular her genauso vorgegeben wären wie der Feindeinfall. 28,58-61 behandelt das Thema Krankheit. 28,20.21.27.35 liefern eine Fülle von Krankheitsbezeichnungen, wobei das zweimal gesetzte שי שחין sich besonders anbieten würde. Keine dieser Bezeichnungen taucht in 28,47-68 auf. 28,58-61 orientiert sich lexikalisch nicht an 28,2044. Nur die Vertilgungsaussage mit שמד/N in V. 61 bringt lapidar die Quintessenz beider Abschnitte auf denselben Nenner. ${ }^{2}$ Die von 28,20-44 vorgegebene Thematik - Ernteschaden durch Klima oder Schädlinge - wird überhaupt nicht mehr angesprochen. Dies zeigt, daß nur das Thema Feindeinfall aus 28,20-44 aufgegriffen und ausgestaltet wird. Daß dies bewußt geschah, erkennt man an einem Detail. Der Verfasser von V. 64 verknüpfte seinen Text mit 28,20-44 höchstwahrscheinlich durch die Einfügung der Deportation und des Götzendienstes im Feindesland in V. 36f. Er verwendete in V. 37b+64a gleichartige formelhafte Wendungen, vor allem aber den Ausdruck בכל העמים, der sonst in Dtn 28 nicht mehr vorkommt. Gleichzeitig verklammert er aber auch die beiden Begriffe für ,Fremdvolk“ עם עם עa so miteinander, daß der in 28,20-44 vorherrschende Begriff in V. 64 mitten in einem Kontext, der durch das Wort (V. 49.50.65) geprägt ist, und der in 28,47-57 vorherrschende Begriff ג in V. 36 mitten in einem Kontext, der von dem Wort עם (32.33.37) bestimmt wird, steht.

Obwohl in 28,47-57 ein anderes Wort für das fremde Volk verwendet wird, scheint dennoch der Wille zu bestehen, an Vorhergehendes anzuknüpfen. Den Feinden wird wie in 28,34 die Tätigkeit אכל ,essen“ zugeschrieben. Doch sie essen gerade nicht die Nahrungsmittel, die in 28,20-44 genannt werden, sie essen nicht Ochs, Ziege, Saatgut, Oliven oder Weintrauben. Es wurden sorgfältig andere Wörter gesucht. Die Feinde essen nun die Frucht des Viehs, den Wurf des Kleinviehs, Korn, Öl und Most. Nur ein einziger Begriff bleibt gleich, פרי אמדתך, der bereits in V. 33 in Verbindung mit איב אכל איב vorkam und schon innerhalb von 28,20-44 eine Ver-

1 ,There can be no doubt that verses $45-48$ are in the Deuteronomic style and area of
thought; they were certainly written as a commentary on the punishments to come upon
disobedience of the Deuteronomic laws. But the same is to be said of the immediate sequel
tracing the invasion of Judah and the desolation of Jerusalem; their entire mood and literary
style are patently of a piece with the work of the 'Deuteronomic School.' (...) There can be
no doubt that the section was written conciously and of full purpose as a commentary on the
epilogue of the code ... ." IRWN, ,Criterion,“ 348 .

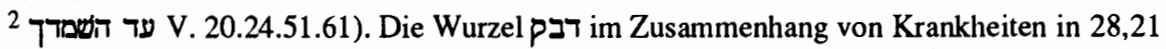
und 28,60 bietet sicherlich einen Anklang, doch werden unterschiedliche Stämme derselben Wurzel nicht als Lexemverknüpfung gewertet, da durch die Stammvariation eine semantische Veränderung herbeigeführt wird, es sich also nicht mehr um das gleiche Wort handelt. 
knüpfungsfunktion zwischen den zwei Strophen der Frustrationsflüche (V. 33.42) innehatte. Dieselbe Verknüpfungsfunktion hat dieser Begriff wohl auch in V. 51. Ähnliches geschieht in V. 68, wo das vorher nur im Zusammenhang mit Krankheiten in Constructus-Verbindung auftauchende Wort ,Feind“ verknüpft und in den Gedankenfluß von 28,47-57.62-68 eingepaßt wird.

Es gibt im Gegensatz zu 28,20-44 einen fortschreitenden Gedankengang. Am Anfang steht die Begründung des folgenden Geschehens (V. 47f). Dann kommt der Feind (V. 49-52), und das Volk erlebt die Schrecken der Belagerung (V. 53-57), am Ende der Belagerung sind nur noch wenige übrig (V. 62). Sie werden deportiert und in verschiedene Länder zerstreut (V. 63f). Auch in der Diaspora finden sie keine Ruhe (V. 65-67), und am schlimmsten geht es denen, die nach Ägypten müssen (V. 68). Im Rahmen der deuteronomischen „Fabel“ bedeutet das, Mose ergänzt die Eides-Verwünschungen (קללות) der Verse 20-44 durch die logisch voranschreitende und im Indikativ vorgetragene Ausmalung einer fluchbelasteten Zukunft, die prophetische Züge trägt.

Nur 28,58-61 paßt nicht in den logischen Gedankenfortschritt. Dieser Bruch und der Mangel lexikalischer Verknüpfungen des Abschnitts zum Kontext lassen vermuten, daß V. 58-61 nachträglich eingefügt wurden.

Dtn 28,47-68 zeichnet sich durch die Verwendung dichterischer Gestaltungsmittel aus. Immer wieder wechseln Abschnitte in Prosa mit poetischen Stücken. Metrisch gebundene Sprache fand Seitz in V. 47f mit Endreim auf $-k \bar{a}$ und $k a ̊ l l$, in V. 49f jedoch ohne Endreim, in V. 63a mit Endreim -kam und in V. $65+67$ wieder ohne Endreim. ${ }^{1}$ Hillers sah poetische Sprache in V. 53.55. ${ }^{2}$ Die Belagerung (51-57) wird in Prosa geschildert, die sprachliche Stilmittel wie Wortinversion (V. 56) und Kehrverse (V. 53.55.57) sowie deuteronomisches Vokabular verwendet. Die Wendung בחסר כל (V.48.57) umschließt den ganzen Abschnitt. ${ }^{3}$

V. 58-61 lassen sich im Versmaß lesen und weisen Endreime auf, die im Gegensatz zu den von Seitz zusammengetragenen Beispielen in 28,4768 nicht nur auf gleiche Wörter oder enklitische Personalpronomina zurückgehen, sondern ähnlich klingende Endungen unterschiedlicher Wörter miteinander kombinieren. Man hört die Endreime am deutlichsten, wenn man das Qames nach der askenasischen und jemenitischen Aussprache zu „O“ färbt. Eine derartige Färbung dieses Vokals dürfte nicht erst im maso-

1 Vgl. Studien, 265, 290f, 299.

2 Vgl. Treaty-Curses, 35-37.

3 Vgl. Buss / LeCLERCQ, Deutéronome, 179; SUMNER, Study, 116a-122; SEITZ, Studien, 290292. 
retischen Hebräisch bestanden haben, sondern kann bereits für das vorexilische Hebräisch erschlossen werden. ${ }^{1}$

'im lo' tišmor lacasôt

'at kål dibrê hattôråh hazzo't

hakketûbîm bassepar hazzoch

lejir'åh 'at haššem hannikbåd

wehannôrå' hazzah

'at Jahweh 'a lohakå

whiplà' Jahweh 'at makkotakå

we'et makkôt zar'akå

makkôt gedolôt wenae'a månôt

wå holåjim rå îm we nae'a månim

$w^{e} h e s ̌ i ̂ b ~ b^{e} k a ̊$

'et kål madweh mișrajim

'a šer jågortå mippenêham

wedåbqû båk

gam kål ḥolî wekål makkåh

'a šer lo' kåtûb besepar hattôråh

hazzo't ja'lem Jahweh 'ålakå

'ad hiššåmdåk

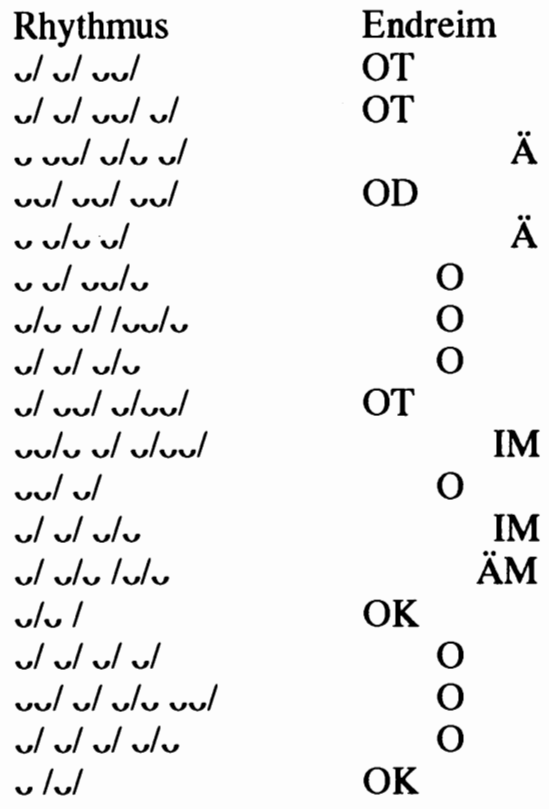

Ein parallelismus membrorum, sonst so hervorstechend in hebräischer Poesie, fehlt in diesen Versen, sieht man von 59b ab. Zwischen 61a und b ist ein Enjambement des הח nötig, um weiterhin im Rhythmus lesen zu können. Sogar die Pausaformen am Ende von V. 60 und 61 fügen sich harmonisch in die Endreimreihen ein. Ähnliche Endreimstücke findet man auch in Dtn $4 .{ }^{3}$ Reimer fand anhand der Wortwiederholungen von V. 59-61 eine chiastische Struktur, die um V. 60 kreist und den poetischen Charakter dieses Stückes bestätigt. ${ }^{4}$

1 „... Some spellings in the Dead Sea Scrolls indicate an 'o' pronunciation where MT has kamaz. Thus 1QIsa 5:17 kbwšym, ... IQIsa 27:47 šwmyr ... . The possibility of the pre-exilic antiquity of this variant pronunciation is provided by Phoenician." Young, Diversity, 199.

2 Auch die Transkription der BHt läßt sich mit ihren philologisch rekonstruierten Vokalen im Versmaß und mit Endreimen lesen. Zwar reimt sich in 58aI2 ha=nikbad nicht so gut auf $l '=$ 'śo $t$ und $h a=z \bar{o}(') t$ aus $58 \mathrm{aII}$, dafür paßt aber in $60 \mathrm{aR}$ mip=pane- $=$ im besser zu MSTRaym. Vgl. Richter, $B H t, 630,632$.

3 Vgl. Braulik, Mittel, 107, Anm. 22.

${ }^{4}$ „Return,“ 223 . Es entsprechen sich V. 59a und $61 \mathrm{~b}, 59 \mathrm{~b} \alpha$ und $61 \mathrm{a} \alpha_{2} \beta$ sowie $59 \mathrm{~b} \beta$ und $61 \mathrm{a} \alpha_{1}$. Bei diesen längeren einander entsprechenden Zeilen, werden die oben angegebenen Endreime teilweise zu Binnenreimen. REIMERs Darstellung des rückläufigen Teils der chiastischen Struktur ist inkonsequent. In V. 59 stehen die Leitwörter immer am Anfang der Zeile (ודלים מכות, ודפלא ידוה), in den ersten beiden gegenläufigen Gliedern aus V. 61 a setzt er Wörter davor (וכל - מכה, כם כל - חליחלי). Im dritten Glied schreibt REIMER den Bezug aber 
Die Stilmittel in 28,62-68 scheinen dagegen wieder konventioneller und weniger durchstrukturiert. Man findet Parallelismen in V. 63.65a.67, dazwischen aber Prosastücke. ${ }^{1}$ Dtn 28,58-61 sticht also aus seinem Kontext heraus.

\subsection{Semantische Analyse}

Seitz hat auch die Sprache dieses Abschnitts untersucht. Die semantische Untersuchungen beschränkt sich daher hier nur auf markante Wendungen und vor allem auf die Lexeme in V. 47-68, die in Dtn 28 nur einmal vorkommen.

V. 47] Die formelhafte Wendung ,JHWH, deinem Gott dienen“ ist sonst im Deuteronomium immer durch einen synonymen Begriff ergänzt. ${ }^{2}$ Dieser synonyme Begriff fehlt hier. Dadurch unterscheidet sich dieser Vers von den übrigen Belegen dieser Wendung im Deuteronomium. Floss hält deshalb Beziehungen zu Jer 5,19 für möglich. ${ }^{3}$ שמחמ Freude“ kommt im Deuteronomium nur hier vor. In Kombination mit טוב לבב,Fröhlichkeit des Herzens" bedeutet es ursprünglich Glück. ${ }^{4}$ Im Zusammenhang mit Verpflichtungen dienen beide Ausdrücke jedoch - wie das akkadische $t \bar{u} b$ libbi - zum Ausdruck der Freiwilligkeit. ${ }^{5}$ Dtn 28,47 spielt also offenbar nicht auf die Aufforderungen zur Freude in den deuteronomischen Festbestimmungen an. Dort wird nämlich immer das Verb שמש verwendet. ${ }^{6}$ Wenn in V. 47 abweichend das Nomen steht, scheint der Akzent auf der Freiwilligkeit der Dienstbereitschaft gegenüber Gott zu liegen. So entsteht der Gegensatz zwischen der Verweigerung der freiwilligen Gottesverehrung bei der Fülle an allen Gütern in V. 47 und der dafür verhängten Strafe, dem Frondienst für den Feind in einer Mangelsituation in V. 48a.

צמא .Hunger“ steht im Deuteronomium nur noch Dtn 32,24 רעב [Hich ,Durst“7 und עירם ,Blöße, Nacktheit“" kommen im Deuteronomium nicht

an den Anfang der Zeile (ילשם יהור). Größere Gleichförmigkeit ergibt sich, zieht man הזאת vor $61 \mathrm{~b}$ wie es das Enjambement beim rhythmischen Lesen fordert.

$1 \mathrm{Vgl}$. SeITZ, Studien, 265, 299.

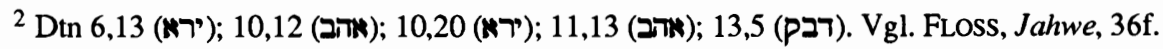

${ }^{3} \mathrm{Vgl}$. Jahwe, $315 \mathrm{f}$.

4 Vgl. MUFF,, „Joy," 9.

5 Vgl. MuFFs, „Joy." 5f, $11 \mathrm{f}$.

6 Gegen RIESENER, Stamm, 204.

${ }^{7}$ Im AT noch Ex 17,3; Ri 15,18; Jes 5,13; 41,17; 50,2; Jer 48,18; Ez 19,13; Hos 2,5; Am 8,11.13; Ps 69,22; Ps 104,11 Klgl 4,4; Neh 9,15.20; 2 Chr 32,11.

${ }^{8}$ Gen 3,7.10.11; Ez 16,7.22.39; 18,7.16; 23,29. 
mehr vor. Die drei Begriffe treten im AT nie mehr zusammen auf und gehören nicht zum deuteronomischen Sprachgut. ein eisernes Joch“ gibt es noch in Jer 28,14.

V. 49] Das Wort דאה ,fliegen, herabstoßen“ taucht außer in Ps 18,11 und dem Nifal von Lev 11,14 nur noch in Jer 48,40; 49,22 auf, dort verbunden mit נפר נים ,Adler, Geier", der im Deuteronomium noch in den Speisevorschriften 14,12 und als Metapher für Gott in 32,11 begegnet.

Im Gegensatz zu 28,20-44 herrscht in 28,47-68 für das fremde Volk der Begriff vor. Während עם eher die Zusammengehörigkeit durch Blutsverwandtschaft impliziert und auch auf Gott bezogen werden kann, hat גו eher eine geschlossene ethnische Gruppe mit eigener Regierung und eigenem Territorium im Blick. Diese Vorstellungen wohnt heute am ehesten dem Begriff „Nation“ inne. ${ }^{1}$ Bezieht man ein, daß die Schrecklichkeit des Fremdvolkes auch darin begründet ist, daß die Hebräer seine Sprache nicht verstehen, so könnte der Wechsel von עם zu auch ein anderes Bild von der feindlichen Macht implizieren. גוäre die staatlich organisierte fremde Macht, die von ihrem weit entfernten - man spricht eine ganz andere Sprache - Territorium ausrückt, um in Israel zu kämpfen. Dies würde auf Ägypten, Assyrien oder Babylonien hindeuten. עם dagegen hätte einen größeren Lokalbezug. Auch die Phönizier, Moabiter oder Aramäer im Umkreis der Israeliten gehören zu einem anderen Volk, sie sind aber Nachbarn und sprechen Sprachen, in denen sich wohl auch Hebräer verständlich machen konnten. Trotzdem kann man beide Begriffe nicht absolut auseinanderhalten, da ובגוים הדה in V. 65 sich auf בכל העמים in V. 64 bezieht. Die

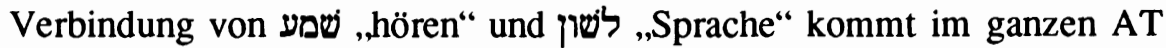
nur hier vor.

Gruber weist darauf hin, daß bei נשיא 28,50 das Erheben des eigenen Gesichts „lächeln“ bedeutet. Der Gesichtsausdruck zeigt das innere Wohlwollen im Verhalten zum Angelächelten. Bezogen auf das eigene Gesicht kommt dieser Ausdruck nur noch im aaronitischen Segen (Num $6,26)$ vor. ${ }^{2} \mathrm{Da}$ im aaronitischen Segen Gottes Antlitz lächelt, dürfte der Gegensatz Gott / Feinde aus V. 47f fortgesetzt werden. Denn auch die zweite Zuwendungsform תזן,sich erbarmen“ hat im AT fast immer Gott zum Subjekt. Von den wenigen Belegen, in denen nicht Gott Subjekt ist, kommt Klgl 4,16 der Aussage von 28,50 am nächsten. ${ }^{3}$ Die beiden Verhaltensweisen, die den Feinden in V. 50b abgesprochen werden, dürften im

\footnotetext{
1 Vgl. Clements, ,"1ג“9 967-970.

2 Vgl. „Faces,“ 253f.

${ }^{3}$ Andere Stellen, in denen $9 \pi$ nicht Gott als Subjekt hat: Ri 21,22; Jes 27,11; Ps 37,21.26; 112,5 ; Hi 19,21; 33,24; Spr 14,31; 19,17; 28,8.
} 
Kult verwendete Ausdrücke anklingen lassen. Weil man Gottes Gnade nicht wollte, wird man nun Opfer feindlicher Ungnade. Von den Stellen, in denen נקו נער ,Greis" ,Jüngling“ beieinander stehen, ähneln der Aussage von 28,50 Gen 19,4, wo es um den Untergang Sodoms geht, Jos 6,21, wo der Bann über Jericho vollzogen wird, und Jer 51,22, wo Babylon als strafendes Instrument Gottes angesprochen wird. Macdonald meint, $\mathfrak{P}^{\mathrm{P}}$ und נער bezeichnen kampffähige Männer adliger Abstammung, also Älteste und Knappen. ${ }^{1}$ Erwartete man jedoch in der Kriegführung für diese Gruppe von Kämpfem besondere Schonung, so daß man deren Ausbleiben hier als Zeichen der Grausamkeit hervorgehoben hätte? Die Zusammenstellung erscheint eher als Merismus, der die Gesamtheit der Bevölkerung einschließt.

V. 51] Die Dreiheit דגן תירוש ויצהר, Getreide, Most, Öl“ taucht im Deuteronomium noch 7,$13 ; 11,14 ; 12,17 ; 14,23 ; 18,4$ auf. Die Ausdrücke ששר אלפיך und greifen die Formulierungen von 28,4.18 in der Kombination von Dtn 7,13 auf. Nach Irwin sowie Buis und Leclercq wurden sie in 28,51 von dort übernommen. ${ }^{2}$ Kanaanäische Gottesnamen sind zu Bezeichnungen für den Nachwuchs des Viehs geworden. ${ }^{3}$ Der Kausativ אבד/H șetzt ein handlungsfähiges Objekt voraus, das zu einer Tätigkeit veranlaßt werden kann. Die Hif'il-Formen in 28,51.63 haben wie die QalFormen in 28,20-44 Menschen im Blick, die selbst Subjekt ihres Untergangs sind. Das im Kausativ zum Untergang veranlaßte Objekt ist zugleich das logische Subjekt des im Qal ausgedrückten Vorgangs. Die Feinde oder Gott vernichten also nicht unmittelbar. Die Hif ${ }^{\prime}$ il-Form von אבד ist typisch für prophetische Drohrede. ${ }^{4}$

V. 52] Den Ausdruck הומה בצורה ,befestigte Mauer" gibt es nur noch Jes 2,15; 25,12; Jer 15,20 und ähnlich Jes 22,10.5 בתח בvertrauen auf“ gehört zur Sprache der Psalmen, der Weisheit und der Propheten. ${ }^{6}$ Im

1 Vgl. „Status," 167-170; CuTler / MACDONALD, „Identification,“ 27.

2 Vgl. IRWIN, ..Criterion“"347f; BUIS / LECLERCQ, Deutéronome, 179, 381.

${ }^{3}$ Vgl. BRAULIK, ,Ablehnung," $127 \mathrm{f}$.

${ }^{4}$ Vgl. JENN, ,Faktitiv,“ 145-147, 157. „Bei der Beschränkung des hi. auf die Zukunft ist es nicht verwunderlich, dass von den 26 hi.-Stellen die Hälfte $z u$ prophetischen Drohweissagungen und vier weitere zu Drohungen ausserhalb der prophetischen Literatur (Lev. xxiii 30; Dt vii 10, xxviii 51,63) gehören." Ebd. 153.

5 Vgl. SHePPARD, ,Redaction“", 203.

בתח ב Ps 9,11; 13,6; 21,8; 25,2; 26,1; Hi 39,11; Spr 11,28; 16,20; 25,26; 29,25; 31,1; 27,$3 ; 28,7 ; 33,21 ; 22,5.6 ; 32,10 ; 37,340,4 ; 41,10 ; 44.7 ; 52,9.10 ; 55,24 ; 56,5.12 ; 62,9.11$; 78,$22 ; 84,13 ; 91,2 ; 112.7 ; 115,10.11 ; 118,8.9 ; 119,42 ; 125,1 ; 135,18143,8 ; 146,3 ; 195,9$; 196.8; Ri 9.26; 2 Kön 18,5; 19,10; Jes 12,2; 26,3.4; 30,12; 37.10; 42,17; 46,25; 47,10; 50,10; Jer 7,14; 12.5; 13,25; 17,5.7; 39,18; 48,7; 49.4; Ez 16,15; Hos 10,13; Am 6,1; Mi 7.5; Zef 3,2; 1 Chr 5,20. 
Deuteronomium kommt es nicht mehr vor. Fast immer vertraut man auf Gott, nur in Jer 5,17 vertraut man ähnlich wie in Dtn 28,52 auf die Befestigung der Stadt.

V. 54] Frau (an) der Hüfte“ kommt in Verbindung mit השת חיק dem Bruder, noch Dtn 13,7 vor. Der Bruder ist dort und in Dtn 13,9-11; 25,6.7.9 der leibliche Bruder, nicht wie sonst im Deuteronomium der Volksgenosse. ${ }^{1}$ Götzendienst (Dtn 13) und Belagerungsnot (Dtn 28,47f) zerstören die engsten Familienbande. יתר/H ,übrig lassen / haben“ gibt es im AT nur noch Dtn 28,11 und 30,9.

V. 55-57 bestehen im wesentlichen aus Wiederholungen gleichartiger Wendungen der vorhergehenden Verse. Das Motiv des Kannibalismus wird im Kapitel Traditionsgeschichte besprochen. Die Sprache von V. 47-57 weist stärkere Bezüge zu Prophetentexten als zum übrigen Deuteronomium auf.

Der Bedingungssatz in 28,58 enthält mit עשר und ששר uieder Verben der Gesetzesbeobachtung, die im Deuteronomium Reihen bilden. Doch diesmal geht es nicht um die Stimme JHWHs oder die Gebote, sondern um “alle Worte dieser Weisung“. Derselbe Ausdruck steht noch in Dtn 17,18; 27,3.8.26. ${ }^{2}$ Der Hinweis auf das ספר שU ,Urkunde, Buch“ in 28,58a $\beta$ blickt auf einen Text, der offenbar in einer einzigen Schriftrolle verzeichnet sein konnte. Haran meint, das Deuteronomium sei auf Pergament geschrieben worden, da so lange Papyrusrollen nicht hergestellt werden konnten. ${ }^{3}$ תורה ,Weisung“ erinnert an die Überschrift Dtn 4,44f, wo klargestellt wird, daß sie die חקים ומשכטים ,Gesetze und Rechtsnormen“ von Dtn 5-26,16 umfaßt. In Dtn 29,20 wird deutlich, daß zur Tora auch Segen und Fluch aus Kapitel 28 gehören. Gesetze und Rechtsnormen samt Fluch und Segen sind der Inhalt der Tora, die Mose dem Volk vorlegt (Dtn 4,8.44). ${ }^{4}$ Für Perlitt spiegelt sich in der Erwähnung der אללה und pie, die gemäß 29,19.20.26 im Torabuch aufgezeichnet sind und auf die inhaltlich auch 28,61 anspielt, das Interesse, Segen und Fluch als Auswirkung des Verhaltens gegenüber der Bundesurkunde zu erklären. Es gilt, die Gebote des deuteronomischen Torabuches einzuhalten $(28,58)$, wenn man Segen erfahren will. Im Exil galt der Fluch als erfüllt. Aus dem Buch des Bundes war ein Fluchbuch geworden. Dtn 30,1-10 zeigt den Ausweg durch den Ruf zur Umkehr. ${ }^{5}$

\footnotetext{
1 Vgl. PerlitT, „Volk,“ 30-35, 32 Anm. 4.

2 Vgl. LoHFink, Hauptgebot, $295 \mathrm{f}$.

3 Vgl. „Book-Scrolls,“ 112.

4 Vgl. Braulik, „Ausdrücke,“37/65.

5 Vgl. „Volk,“ 44f.
} 
Die Ausdrucksweise von 58b weicht von dem üblichen ,JHWH fürchten" ${ }^{\text {“1 }} \mathrm{ab}$. Es ist nämlich zunächst nicht JHWH, den man fürchten soll, sondern der Name. Dieser Name wird mit zwei Adjektiven belegt und dann durch die Apposition את ידוה אלהיך, JHWH, deinen Gott" nochmals verdeutlicht. Das Adjektiv נורץ ,furchtbar“ ist mit dem Namen noch in Ps 99,3 verbunden. Becker versteht das Adjektiv als Ausdruck numinoser Furcht, die dadurch ausgelöst wird, daß die Taten JHWHs als Gericht erlebt werden. ${ }^{2}$ Der Name und JHWH sind völlig parallelisiert. Es wurde keine Constructus-Verbindung verwendet. Es geht nicht darum, den Namen Gottes zu fürchten, sondern darum den Namen zu fürchten, was zugleich bedeutet, Gott zu fürchten. Der ehrenvolle und furchtbare Name tritt gleichsam an die Stelle Gottes. ${ }^{3}$ Junker sieht wohl zu recht in dieser Gleichsetzung einen Ausgangspunkt für die Lesung des Tetragramms durch das Wort ששמא oder. ${ }^{4}$

V. 60f] Nur einmal in Dtn 28 belegt sind פלא/H ,wunderbar machen“, das im Deuteronomium sonst nicht verwendet wird, דבק/G, das im Deuteronomium zumeist in Verbindung mit der Aufforderung auftaucht, an JHWH zu kleben und der Ausdruck כל־מדוה מצרים, der außer Dtn 7,15 im AT nicht mehr begegnet. ${ }^{6}$ Das „Anheften“ von Krankheiten wird sonst im AT nur noch 2 Kön 5,27 mit $P$ T/G ausgedrückt.

V. 62] Die Wurzel שטאר, die im Nif al vom „Rest" spricht, der bei der Strafe übrigbleibt, bezieht sich wohl nicht auf die in 28,58-61 genannten Krankheiten zurück. Wo in exilischen Texten von Israels Rest gesprochen wird, hat man zumeist die von den Babyloniern Übriggelassenen im Blick. Auch V. 62 stammt wohl aus der Exilszeit. Jedenfalls erscheint hier wie in Dtn 4,27; 2 Kön 17,18-20; 21,14 Israels Rest negativ bewertet. Die deuteronomistische Redaktion des Jeremiabuches bezeichnet mit dem

1 ירא :'to fear Yahweh' ... Deut.: 4:10, 5:26, 6:2,13,24, 8:6, 10:12,20, 13:5, 14:23, 17:19, 28:58, 31:12,13. Dtr.: Josh. 4:24; I Sam. 12:14,24; I Kgs. 8:40,43; 2 Kgs. 17:32,33,34,39,41. Jer. C: 32:39." WeINFELD, School, 332. ירא הלהים אחרים "to fear (= to worship) foreign gods'. Dtr: 2 Kgs. 17:7,35,37,38.“ Ebd. 322. Vgl. BECKER, Gottesfurcht, $106 f$.

2 Vgl. Gottesfurcht. 136f.

3 Vgl. Gottesfurcht, 38, 39 Anm. 132; 46-48.

${ }^{4} \mathrm{Vgl}$. Deuteronomium, 535. In Neh 9,5 wird der „Name“ gepriesen, in $1 \mathrm{Chr} 29,13$ gerühmt. Ohne eine Näherbestimmung durch eine Constructus-Verbindung taucht $ם$ w nur in späten Texten auf. In Jes 63,12 verschafft sich Gott einen ewigen Namen, in Mal 3,20 gilt denen, die den „Namen“ fürchten, Gottes Verheißung. Vgl. CuNLIFFE-JONES, Deuteronomy, $157 \mathrm{f}$.

5 דבק/G Dtn 10,20; 1122 + "יראי 13,5; 30,20; vgl. Jos 23,8; 2 Kön 18,6.

6 Vgl. Serrz, Studien, 300f. 
Terminus Rest diejenigen, die nach der Zerstörung Jerusalems nach Ägypten fliehen wollen. ${ }^{1}$ Hier könnte ein Zusammenhang deuteronomistischer Aussageintentionen bestehen, da die Rückkehr nach Ägypten auch in 28,68 angesprochen ist, zumal V. $62 \mathrm{f}$ und 68 durch ihre Numerusmischung stilistisch miteinander verknüpft sind. Ein weiterer Textbezug besteht zu Dtn 26,5, wo - wie in 28,62 - der sonst im AT nicht mehr auftauchende Ausdruck מתי מעם ,sehr wenige Leute“ steht. Im kleinen historischen Credo ist die Bewegung jedoch gegenläufig. ${ }^{2}$ Aus wenigen Patriarchen wird ein großes Volk. Also steht die Patriarchenverheißung im Hintergrund, die auch aus ככוכבי השמים לרב, einem Bild für die große Menge ${ }^{3}$, herausklingt $(28,62$ vgl. Dtn 11,22). Wie im kleinen historischen Credo auf die Mehrung des Volkes die Herausführung aus Ägypten folgt, so folgt in Dtn 28 auf die Verminderung des Volkes in V. 62 die Rückführung nach Ägypten in V. 68 .

V. 63] Die Verbindung von יטב/H ,wohltun“ und ,mehren“ kommt noch Dtn 30,5; Jes 23,16; Ez 36,11; Hos 10,1 vor. Dtn 30,5 und Ez 36,11 sind Heilszusagen. In Hos 10,1 wird die Verwendung der Güter des Landes zum Götzendienst angeprangert. Jes 23,15-17 enthält ein Wort gegen Tyrus, das offenbar allgemein bekannte Motive aufgreift, die auch im Hintergrund von 28,63 stehen könnten:

Dann wird Tyrus siebzig Jahre lang - solange wie ein König lebt - vergessen sein. Nach siebzig Jahren aber wird es Tyrus gehen, wie es im Lied von der Dirne heißt: Nimm die Zither, durchstreife die Stadt, vergessene Dirne! Spiele schön (יטב), und singe viel (רבה)/H), damit man an dich denkt. Nach siebzig Jahren wird sich der Herr wieder um Tyrus kümmern ... .

Daß eroberte Hauptstädte für 70 Jahre in Trümmern liegen, scheint ein im AO verbreiteter Topos gewesen zu sein. ${ }^{4}$ Könnte das Lied von der Dirne, das im Jesajawort offenbar als bei den Hörern allgemein bekannt vorausgesetzt wird, nicht auch als Allegorie für Jerusalem verstanden werden, dessen Eroberung und Zerstörung im Zusammenbrechen der belagerten Mauern $(28,52)$ wohl impliziert ist? Der Ratschlag an das zerstörte Tyrus lautete, die Hoffnung nicht aufzugeben, sondern sich bei Gott in Erinnerung zu bringen, um schließlich neues Heil empfangen zu können. Sollte 28,65 von derselben Hand stammen wie Dtn 30,1-10 könnte hier - gerade in den

\footnotetext{
1 Vgl. Hausmann, Rest, 136f.

$2 \mathrm{Vgl}$. HaUSMANN, Rest, $120 \mathrm{f}$.

${ }^{3} \mathrm{Vgl}$. Houtman, Himmel, $195 \mathrm{f}$.

${ }^{4}$ Das galt für Babylon. Vgl. Borger, Inschriften, 15. Nach Jes 23,15 gilt es auch für Tyrus und nach Jer 25,8-12; 29,10; Jes 47,6 für Jerusalem.
} 
Aussagen der tiefsten Entfremdung von Gott - in der Wortwahl schon bewußt die umkehrende Verheißung neuen Heiles in Dtn 30,5 angelegt worden sein. ${ }^{1}$ חס ,ausreißen“ - dieselbe Wurzel wie das recht häufige ${ }^{2}$ akkadische nasāhlu (VTE $\S 56$ Z. 476) - kommt im AT nur noch Ps 52,7; Spr 2,$22 ; 15,25$ vor. $^{3}$

V. 64 פוץ mit der Bedeutung ,zerstreuen“ kommt noch in Gen 11,8f. vor und beschreibt Gottes Aktion gegen die Menschen, die den Turm zu Babel gebaut haben; alle Bewohner der Erde werden in Jes 24,1 zerstreut, die Ägypter in Ez 29,12; 30,23.26. Gegen Israeliten richtet sich die Zerstreuung in Gen 49,7; Jer 13,24; 18,17; Ez 12,15; 22,15; 36,19. Doch in Verbindung mit diesem Wort keimt auch Hoffnung auf. Nach Ez 11,16 ist Gott für die Zerstreuten zum Heiligtum geworden. In Jer 30,11 kündet Gott die Vernichtung der Völker an, unter die er die Israeliten zerstreut hat und Neh 1,8 erwähnt ein Mosewort, nach welchem Gott im Anschluß an die Zerstreuung wieder die Heimführung verheißt. Damit wird wohl auf Dtn 4,27; 30,3 angespielt. ${ }^{4}$

Götterbilder aus Holz (V. 64b) können zur Not als Brennmaterial benutzt werden (Ri 6,26; 2 Kön 19,18; Mi 1,7). Der Hauptakzent liegt auf der Ohnmacht der Götzen. Sie sind menschliche Kunstprodukte. Israel kennt sie nicht (V. 64bß), weil es sie nicht in der Geschichte als wirksam erfahren hat. ${ }^{5}$ Während Götzendienst im Deuteronomium sonst Sünde ist ${ }^{6}$, ist es in 28,64 , wie schon in 4,28; 28,37 Strafe. Diese liegt darin, daß die Deportierten ohnmächtig und fern der Heimat der Ohnmacht nichtiger Götzen ausgeliefert sind, also auch religiös keinen Halt mehr finden.

V. 65] Hier steht abweichend vom überwiegenden Sprachgebrauch des Deuteronomiums לב. Diese Form des Wortes Herz gibt es im Deuteronomium nur noch in Dtn 4,11;29,3.18.? Da לב im aber auch recht häufig im DtrG verwendet wird, muß die Form in 28,65 nicht auf eine Beziehung zu Jeremia weisen, der das Wort 57mal verwendet, sondern kann auf den Einfluß deuteronomistischer Sprache zurückgehen. ${ }^{8}$ Der Vers beschreibt Symptome psychischer Leiden. דאבון נבש meint „Trockenheit der Kehle“

\footnotetext{
${ }^{1} \mathrm{Zu}$ ähnlichen Aussagen in Jer 32,41; Zef 3,17 vgl. SErTZ, Studien, 301.

2 Vgl. AHw, 749-752.

3 Vgl. WEINFELD, School, 309.

4 Vgl. SeITZ, Studien, 301.

5 Vgl. PREUSS, Verspottung, 144f., 155-157.

6 Vgl. PrEuss, Verspottung, 157.

${ }^{7}$ Dtn $29,3.18$ dürften von Jer 24,7 beeinflußt sein. Vgl. auch Jer 3,$17 ; 4,24 ; 9,13 ; 11,8$; 13,$10 ; 16,12 ; 18,12 ; 23,17$.

8 Vgl. BriggS, „Study,“ 94-97, 101; SEITZ, Studien, $301 \mathrm{f}$.
} 
als Begleiterscheinung einer Depression und כליון עינים versteht unter „Entleerung der Augen" eigentlich ausgeweinte Augen (vgl. 1 Sam 2,33; Jer 8,23; Lev 26,16). ${ }^{1}$

V. 66] תלא ,aufhängen“ steht nur noch in 2 Sam 21,12 von den Gebeinen Sauls und Hos 11,7 in einer Klage gegen den Baalskult. unpersönlich nur noch Ps 78,32; 106,12; 119,66; Ijob 15,31; 39,12 verwendet. Sonst glaubt man immer nur an Personen. ${ }^{2}$ Verbunden mit Leben kommt es nur noch in Ijob 24,22 vor, לילה ויומם noch in 1 Sam 25,16; Jes 34,10 und Jer 14,17.

V. 67] Der Vers besteht nur aus einem Frage- und Antwort-Zitat der Leidgeplagten und dem Rückbezug zu V. $34 \mathrm{~b}$ in $67 \mathrm{~b} \beta .{ }^{3}$

V. 68] Handelt es sich bei dem „Ich“, das hier spricht und seine frühere Äußerung erinnert, daß man den Weg nach Ägypten niemals wiedersehen soll, um Mose oder um Gott? Skweres entscheidet sich für Mose und nennt als Bezugstext Ex 14,13. ${ }^{4}$ Es gibt aber auch eine Beziehung zu Dtn 17,16. Dort stellt Mose ausdrücklich fest, daß Gott gesagt hat, die Israeliten würden nicht mehr nach Ägypten zurückkehren. Das Gotteswort im Hintergrund der Worte von Dtn 17,16 findet Lohfink in Hos 11,5, wobei er die Emendation zum Urteil der Rückkehr nach Ägypten ablehnt und übersetzt:

„,Zwar wird es nicht zurückkehren ins Land Ägypten - aber Assur, der ist sein König, weil sie sich weigerten, (zu mir) umzukehren '." 5

Der Gang nach Ägypten würde den Israeliten nach diesem Prophetenwort also erspart. Doch sie müssen die assyrische Fremdherrschaft erdulden. Doch auch in Hos 8,13 steht, daß die Israeliten zurück müssen nach Ägypten, und in Hos 9,3 werden Ägypten und Assur in Parallele gesetzt:

Im Land des Herrn dürfen sie nicht mehr wohnen; Efraim muß zurück nach Ägypten, und in Assur müssen sie unreine Speisen essen.

\footnotetext{
1 Vgl. GruBER, „Dryness,“ 366.

2 Vgl. WiLDBERGER, „Glauben,“ 375.

3 Vgl. SEITZ, Studien, 302.

$4 \mathrm{Vgl}$. Rückverweise, 193f.

5 LOHFINK, „Hos. XI,“ 227. REIMER, „Return,“ 224f sah den Hintergrund von Dtn 28,68 in Ex 14,13, während sich Dtn 17,16 auf 28,68 beziehe. Doch abgesehen davon, daß die Umformung der Mosedrohung aus 28,68 in ein JHWH-Wort für 17,16 problematisch erscheint, vernachlässigt er die Leserichtung.
} 
Am Ende von Dtn 28 tauchen also starke Bezüge zu Hosea auf. ${ }^{1}$ Außerdem gibt es anscheinend Anspielungen auf den Aufbruch der Judäer nach Ägypten, nachdem der babylonische Statthalter ermordet worden war. Bei der Befragung Jeremias und seiner Antwort (Jer 42f) häuft sich die auch in Dtn 28,45 anzutreffende Kombination כי + לא + שמע בקול יהוה. Die Bewertung von Israels Rest in den Schlußkapiteln des Buches Jeremia ähnelt der von Dtn 28,62. Der Unterschied besteht freilich darin, daß in Dtn 28,68 Gott die Israeliten nach Ägypten zurückbringt, während sie in Jer 43 von den selbsternannten Volksführem mitgenommen werden. Allerdings impliziert das Hitpa'al von מכר auch eine freiwillige Handlung. In 1 Kön 21,20.25; 2 Kön 17,17 bedeutet dieser Stamm, sich zu einer bösen Handlung hergeben. ${ }^{2}$ In 1 Kön 21,20.25 geht es um Ahab, der Götzendienst betreibt. 2 Kön 17,17 scheint an eine Schlüsselstelle des DtrG zu führen, die möglicherweise auch angibt, in welchem Licht Dtn 28,47-68 gelesen werden soll. Es handelt sich in 2 Kön 17,12-17 um eine geschichtstheologische Betrachtung im Anschluß an die Deportation der Israeliten durch die Assyrer.

Sie dienten den Götzen, obwohl der Herr es ihnen verboten hatte. Der Herr warnte Israel und Juda durch alle seine Propheten, durch alle Seher: ... Doch sie wollten nicht hören, sondern versteiften ihre Nacken ... ... Sie liefen nichtigen Göttern nach und wurden selbst zunichte; sie ahmten die Völker der Umgebung nach, obwohl der Herr ihnen verboten hatte, ihrem Beispiel zu folgen. ... Ihre Söhne und Töchter ließen sie durchs Feuer gehen, trieben Wahrsagerei und Zauberei und gaben sich dazu her (מכר/tD) zu tun, was dem Herrn mißfiel, um ihn zu erzürnen.

In Dtn 28,49-57 wurde wahrscheinlich Jer 5,15-17 verarbeitet. In 2 Kön 17,15 dürfte Jer 2,5 zitiert sein. Das Interesse an Propheten - besonders an Jeremia - scheint bei den Verfassem beider Texte lebendig. Lohfink hält es für möglich, daß 2 Kön 17 in Beziehung zum Prophetengesetz in Dtn 18 steht. ${ }^{3}$ Dtn 28,68 weist zurück auf das Königsgesetz Dtn 17,14-20, welches zusammen mit dem Prophetengesetz zur redaktionellen Einheit der Ämtergesetze gehört. Hier laufen offensichtlich Linien zusammen. In Dtn 28,68 geben sich die Israeliten dazu her, Sklaven und Sklavinnen der Ägypter werden zu wollen, aber keiner kauft sie. Die Wortverbindung steht auch Jes 14,2; Jer 34,11.16; Est 7,4; 2 Chr 28,10. Die

\footnotetext{
${ }^{1} \mathrm{Vgl}$. WeINFELD, School, 369. Zu einem ägyptenfreundlichen Kreisen zugeschriebenen Siegelabdruck aus dem Juda der Königszeit mit der Darstellung eines Schiffes vgl. REIMER, ,Return,“ 228.

2 Vgl. LIPINSKI, „Sale,“ 178.

$3 \mathrm{Vgl}$. ,Sicherung," $320 \mathrm{f}$.
} 
Jeremiastellen gehören zum Kontext der Sklavenfreilassung unter Zidkija. Jer 34,17 kündet das Unheil in ähnlichen Worten an wie Dtn 28,25 b. So schließt sich der Kreis zur Überarbeitung von 28,20-44 durch Redaktoren, die im Jeremiabuch und im Deuteronomium Textpassagen deuteronomistischer Sprachgestalt hinterließen.

\section{3.4. Literarkritik}

In der Forschungsgeschichte fand man in folgenden Versen Ansatzpunkte für die Literarkritik:

V. 47 galt zumeist als Anfang eines sekundären Anhangs. ${ }^{1}$ Der literarkritische Einschnitt in diesem Vers ergab sich daraus, daß man V. 45f als Abschluß des 1. Fluchabschnitts zum redaktionsgeschichtlichen Stratum der vorausgehenden Verse rechnete. ${ }^{2}$ Daher mußte in V. 47 der jüngere $\mathrm{Zu}$ satz beginnen.

In V. 51 wollte Steuernagel עד השמדך streichen, weil es in $\boldsymbol{B}$ fehlt und ihm angesichts der Vernichtungsaussage in V. 51b überflüssig erschien. $52 \mathrm{~b}$ schien ihm eine sekundäre Variante von $52 \mathrm{a}$ zu sein. ${ }^{3}$

Der Bedingungssatz in V. 58 wurde ebenfalls weitgehend als Beginn eines jüngeren Zusatzes gewertet. ${ }^{4}$ Uneinigkeit besteht allerdings darüber, wie weit der mit V. 58 beginnende Zusatz reicht.

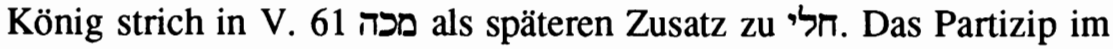
Singular כתוב bezieht sich seiner Meinung nach nur auf חלי מדי

Den nächsten literarkritischen Einschnitt setzte Steuernagel in V. 62. Der Numeruswechsel in die 2. Person Pl. in 62a, den er auf 62b ausdehnte, indem er dort zu שמעתם und veränderte, bot ihm den Anlaß für die Abgrenzung zum vorhergehenden Text. V. $63 \mathrm{~b} \beta$ strich er als formelhaften Zusatz im Singular aus dem Pluralkontext. Außerdem eliminierte er להשמיד אתכם und להרבות אתכם

\footnotetext{
$1 \mathrm{Vgl}$. STEUeRnagel, Übersetzung, 103; Deuteronomium, 150; KÓNG, Deuteronomium, 194; JUNKER, Deuteronomium, 535; RIDDERBos, Boek II, 82-84; CUNLIFFE-JONES, Deuteronomy, 157f; vRAD, Buch, 126; SCHÄCHTER, Fluch, 177-180; SUZUKI, Numeruswechsel, 265; ROSE, 5. Mose, 541.

2 Vgl. Steuernagel, Deuteronomium, 150; KonIG, Deuteronomium, 192; vRAD, Buch, 126.

3 Vgl. Übersetzung, 103.

4 Vgl. Steuernagel, Übersetzung, 99; Rahmen, 42; Deuteronomium, 154; IRWIN, „Criterion,“ 343; RIDDERBos, Boek II, 83; KRÄMER, Numeri, 518; CUNLIFFE-JONES, Deuteronomy, 157f; BUIS / LECLERCQ, Deutéronome, 179, 381; vRAD, Buch, 126; SCHÄCHTER, Fluch, 177-180; SEITZ, Studien, 298; SUZUKI, Numeruswechsel, 264; MAYES, Deuteronomy, 357, 381; BRAULIK, Deuteronomium II, 203; REIMER, „Return,“ 222.

5 Vgl. Deuteronomium, 194.
} 
als 3. Anhang der Fluchsequenz. Die Folge des literarkritischen Einschnitts in V. 62 ist, daß 28,58-61 eine kleine Einheit bilden. Die Abgrenzung dieser Einheit begründete Steuernagel mit der neuen Einleitung in V. 58, mit dem Wechsel zu allgemeinen Fluchinhalten und mit dem Verweis auf das vorliegende Buch. ${ }^{1}$ Als eigene Einheit grenzen V. 58-61 auch Krämer, vRad und Seitz aus. ${ }^{2}$ Den Numeruswechsel als Kriterium für die Ausscheidung von $62 \mathrm{f}$ verwenden auch vRad und Seitz. Seitz verweist darüber hinaus auf die inhaltliche Spannung zwischen der völligen Vernichtung in V. 61 und dem Übrigbleiben eines Restes in V. 62. Dtn 28,63 ist nicht nur durch den Numeruswechsel, sondern auch durch einen Chiasmus eng mit V. 62 verknüpft. ${ }^{3}$ Forscher, die nur in V. 58 den Beginn eines neuen Anhangs sehen und in 28,58-68 keine literarkritischen Eingriffe mehr vornehmen, begründen ihre Option für die Einheitlichkeit nicht.

Die nächste Ergänzung bildete für Steuemagel 28,64-67, wo wieder in der 2. Person Sg. gesprochen wird.

V. 68 hob Steuernagel vom Vorangehenden ab, da in diesem Vers sowohl Numeruswechsel in die 2. Person Pl., als auch ein auf JHWH bezogener Personenwechsel von der 3. Person in die 1. Person vorkommt. AuBerdem schwächt der Anfang von V. 68 seiner Meinung nach die in V. 6567 geschilderten Leiden des Exils ab. Zumindest $68 \mathrm{a} \beta \mathrm{b}$ ist für ihn eine spätere Ergänzung. ${ }^{4}$ Den Numeruswechsel als Grund zur literarkritischen Abtrennung von V. 68 nennen auch Seitz und Suzuki. ${ }^{5}$

Im äußersten Fall wurden also an einen älteren Fluchabschnitt V. 20-46 fünf Ergänzungen angehängt (28,47-57/58-61/62-63/64-67/68) und in V. 51.52.61.63 kleinere Zusätze eingefügt. Gegen diese Sicht erhoben sich jedoch Stimmen, die für größere Einheitlichkeit plädierten.

Hölscher wies V. $45 \mathrm{f}$ dem Ergänzer zu, da V. 46 nicht von V. 47-48 zu trennen sei. So nahm er vorweg, was Seitz ein Zwischenstück nannte. 28,45f schließen einerseits den ersten Fluchabschnitt ab, andererseits aber leiten sie zur Drohung von 28,47-57 über und können folglich erst vom

1 Vgl. Übersetzung, 104; Rahmen, 42; Deuteronomium, 154.

2 Vgl. KRÄMER, Numeri, 518f; vRAD, Buch, 126; SEITZ, Studien, 265: „Durch den zweimaligen Hinweis auf das schriftliche Gesetz (v. 58 und v. 61) wird eine Inklusion erzielt, die den Abschnitt v. 58-61 fest zusammenklammert.“

3 Vgl. vRAD, Buch, 126; SEITZ, Studien, 265.

${ }^{4}$ Vgl. Übersetzung, 104f; Rahmen, 42; Deuteronomium, 154.

5 Vgl. SEITZ, Studien, 300; SUZUKI, Numeruswechsel, 124. 
Verfasser dieser Verse stammen. ${ }^{1}$ So ergibt sich ein einheitliches Textstratum, das von V. 45 bis V. 57 reicht. ${ }^{2}$

In V. 62f sah Seitz ebenfalls ein Übergangsstück, das inhaltlich auf die folgende Ansage der Exilierung hinweist. In V. 62 wird nämlich das Übrigbleiben in geringer Zahl festgestellt, was zwar im Widerspruch zur Vernichtungsaussage in V. 61 steht, aber die Voraussetzung für die im folgenden dargestellte Exilierung schaff. להשמיד לה להאביד in V. 63 verknüpfen das Zwischenstück chiastisch mit ער השמידו אתך in V. 48 und in V. 51 und schlagen so eine Verbindung zum Vorhergehenden. Für eine literarkritische Ausscheidung als Glosse besteht somit kein Anlaß. Damit ergibt sich ein einheitlicher Text, der nach Seitz von V. 62 bis V. 67 reicht. $^{3}$

König widersprach Steuernagels Literarkritik in V. 51+52. Wenn man in V. עשר השמדך streicht, wird der mit beginnende Konsekutivsatz zu lang. V. 52b wäre als variierender Zusatz einer späteren Hand unbegreiflich. $^{4}$

Berücksichtigt man diese im Laufe der Forschungsgeschichte hervorgebrachten Argumente für größere Einheitlichkeit, so ergeben sich vier $\mathrm{Zu}$ sätze: V. 45-57, V. 58-61, V. 62-67, V. 68.

Doch auch die Ausgrenzung von V. 68 wirkt zweifelhaft, wenn man nicht den Numeruswechsel als Kriterium für die Literarkritik anerkennt. Die Numerusmischung kann ein rein stilistisches Merkmal sein. ${ }^{5}$ So ergibt sich, an Seitz Beobachtungen zum Zwischenstück von $62 \mathrm{f}$ anknüpfend, eine Inklusion, in der die mit Pluralelementen durchsetzten V. $62 \mathrm{f}$ und 68 den Singularabschnitt V. 64-67 umschließen. Für diese Inklusion spricht formal, daß der Brückenabschnitt von V. 62f nicht nur inhaltlich auf das Schicksal in der Fremde vorausblickt, sondern auch stilistisch eine Verbin-

\footnotetext{
1 Vgl. HÖlscher, „Komposition,“ 221 Anm. 2; SeITZ, Studien, 264.

2 Vgl. Mayes, Deuteronomy, 356; BRaUlik, Deuteronomium II, 208.

${ }^{3}$ Vgl. Studien, 265f; 299-300.

${ }^{4} \mathrm{Vgl}$. KONIG, Deuteronomium, $192 \mathrm{f}$.

5 Vgl. ReIMER, „Return,“ 224; ROMER, „Book,“ 184f. SUZUKIs Argumentation inkonsequent. Einerseits lehnt er es ab, den Numeruswechsel als literarkritisches Kriterium anzusehen, andererseits aber läßt er auch LoHFINKs Begriff der Numerusmischung nicht gelten, weil dieser nicht erkläre, warum Singular- und Pluralformen nebeneinander gestellt wurden. Wenn SUZUKI den Numeruswechsel als literarischen Kunstgriff versteht, um unterschiedliches Material miteinander zu kombinieren, scheint dahinter doch ein diachrones Erklärungsmodell zu stehen. Er unterläßt die Einordnung von 28,47-68 in seine Redaktionsgeschichte des Deuteronomiums. Der Abschnitt taucht erst im nachexilischen „latest stage of literary development" auf. Vgl. Numeruswechsel, 21-27, 123-125, 265, 364, 391f
} 
dung zur Numerusmischung in V. 68 schlägt. So tritt die Parallele zwischen V. 45f und V. $62 \mathrm{f}$ noch deutlicher hervor:

\section{V. $45 w=$ qa!al \\ V. כי לא שמטת בקול יהוה אלהיך 46

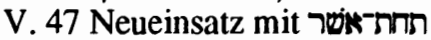

V. ער השמרך 51
V. $62 w=q a t a l$

V. 62f Numerusmischung

כי לא שמעת בקול ידהה הלדיך V. 62

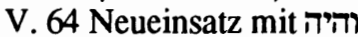

V. 68 Numerusmischung

In beiden Fällen wird zunächst das Vorausgehende durch einen $w=q a t a l$ Satz abgeschlossen. In V. 45 wird das Kommen der pלstatiert, in V. 62 die Verringerung der Volkszahl. Es folgt die in V. 46+62 gleichlautende Begründung im $k \hat{\imath}$-Satz. Schließlich wird der neue Absatz eröffnet, in V. 47 durch תחת אשר, das in Dtn 28 nur noch 28,62, also im parallelen zweiten Brückenabschnitt vorkommt, und in V. 64 durch והיה, womit die Einleitungen aus V. 1+15 wieder aufgegriffen werden. Zugleich gibt es den Vorausweis auf das Folgende. In V. 45 geschieht dies durch eine formelhafte Wendung, die mitten im eingeleiteten Abschnitt, nämlich in V. 51, wiederholt wird. In V. $62 \mathrm{f}$ durch das stilistische Element der Numerusmischung, das in V. 68 wieder auftaucht und so das Übrigbleiben in geringer Zahl und das Ausgerissenwerden aus dem Land mit dem Wunsch verbunden, sich in Ägypten als Sklaven zu verkaufen. Man könnte einwenden, daß auch der Brückenabschnitt V. $45 \mathrm{f}$ mit dem Schluß der ersten Ergänzung in V. 57 verknüpft sein sollte, um wirklich von einer Parallelität zwischen den beiden Zwischenstücken reden zu dürfen. Doch stellt 28,53-57 nochmals eine stilistisch gestaltete Untereinheit dar, die ihrerseits mit dem Anfang der Ergänzung durch Lexeme verbunden ist. So ist das Zwischenstück 28,45f lexematisch mit der folgenden Ergänzung verknüpft und 28,62f durch das Stilmittel der Numerusmischung.

Es gibt also nur drei Ergänzungsabschnitte, nämlich 28,45-57.58-61.6268. Doch ist damit noch nichts über den Entstehungsprozeß des Anhangs entschieden. V. 62 schließt nicht 28,58-61 ab. Die Krankheiten und Schläge führen nämlich zur Vernichtung (V. 61), nicht zum Übrigbleiben eines Rests. V. 62 paßt viel besser als Anschluß an V. 57. Dafür spricht auch, daß die Konstruktion eines Zwischenstückes eine gleichartige redaktionelle Ergänzungstechnik in 28,45-57 und 28,62-68 aufzeigt, während der Bedingungssatz in V. 58 den Kontext recht unvermittelt unterbricht. Nimmt man die Entstehung des Anhangs in der Reihenfolge an, wie er jetzt in Dtn $28 \mathrm{zu}$ finden ist, muß man damit rechnen, daß eine redaktionelle Hand das Stilmittel des sanften Übergangs durch eine Brückenpassage in V. $45 \mathrm{f}$ eingesetzt, später jedoch ein anderer Ergänzer den abrupten Anhang V. 58-61 hinzugestellt und schließlich ein dritter Verfasser seinen Zusatz 
wieder mit einem Zwischenstück angefügt hat. Es liegt wohl näher, 28,45ff und 28,62ff in zeitlich enger Nachbarschaft zu sehen, vielleicht sogar derselben Hand zuzuschreiben. 28,58-61 wären dann später eingefügt worden. Auch Seitz erwog diese Möglichkeit wegen der stilistischen und inhaltlichen Nähe von $28,45 \mathrm{ff}$ und $28,62 \mathrm{ff}$, verwarf sie jedoch wieder, weil er keinen Grund fand, warum 28,58-61 später gerade an dieser Stelle eingefügt werden sollte. ${ }^{1}$ Solch ein Grund läßt sich aber, wie später gezeigt wird, durchaus finden.

Akzeptiert man Numeruswechsel nicht unbesehen als literarkritisches Kriterium, so entfällt auch Steuernagels Grund zur Ausscheidung von $62 \mathrm{~b} \beta$. Es bleibt nur noch Königs Vorschlag, מכה in V. 61 wegen der Numerusinkongruenz des Relativsatzes zu streichen. König legt seinen Finger auf eine Verstehensschwierigkeit im V. 61, die sich bis zu der Frage fortsetzt, ob man יעלם mit den Masoreten von עלם oder mit den Samaritanern von einer Wurzel עלם ableiten soll. ${ }^{2}$ Entscheidet man sich für die Lesart der Masoreten, welche auch $\mathbb{\sigma}$ mit ihrem $\varepsilon \pi \alpha \xi \varepsilon l$ zu bestätigen scheint, so widerspricht das enklitische Personalpronomen der 3. Person Pl. Königs Ausschluß von מכה, da es sich auf mindestens zwei Nomina beziehen muß. Doch selbst wenn man das Mem am Ende des Verbs zur Wurzel rechnet, fordert der Singular im vorausgehenden Relativsatz nicht notwendig nur ein einziges Nomen. Es gibt nämlich im biblischen Hebräisch auch unabhängige Relativsätze. ${ }^{3}$ אש schließt dann nicht einfach an die vorausgehenden Nomina an, sondern leitet eine neue Aussage ein, die der Hauptsatz zu Ende führt. V. $61 \mathrm{a} \alpha$ bildet so einen vorausgestellten Gedanken, der im eigentlichen Sinne nicht weitergeführt wird. In jedem Fall ist ein literarkritischer Eingriff unnötig.

\subsubsection{Gattungskritik}

Die veränderte Satzstruktur ohne Jussive ab 28,47 deutet einen Gattungsunterschied gegenüber 28,20-44 an. So findet Seitz denn auch prophetische Gattungsbezeichnungen für 28,47-57. Zwar nennt er den Abschnitt noch einen begründeten Fluch, doch setzt sich dieser zusammen aus einem begründenden Drohwort (V. 47f) ${ }^{4}$ sowie der Fremdvolkbeschreibung (49f)

\footnotetext{
1 Vgl. Studien, 302.

2 Vgl. BEN-HAYYIM, Tradition, 150 Anm. 61.

${ }^{3}$ WALTKE / O'CONNOR, Introduction, 331-335.

4 ,Der aus der prophetischen Literatur stammende Gattungsbegriff deutet den ganz anderen Charakter des folgenden Abschnitts an." SEITZ, Studien, 290 Anm. 137a.
} 
und der Belagerungsschilderung (V. 51-57). ${ }^{1}$ Jedenfalls wird nicht mehr geflucht, sondern gedroht, beschrieben und geschildert. ${ }^{2}$

Westermann wies auf die Verbindungen hin, die zwischen Fluch und prophetischer Gerichtsankündigung bestehen. Vergleicht man Dtn 28,4757.62-68 mit der Struktur der prophetischen Gerichtsankündigung an Israel, so fehlen dem Deuteronomium Botenformel, Wechsel in die 1. Person der Gottesrede und die Anklage in der 3. Person. ${ }^{3}$ Doch variiert die Form der Gerichtsankündigung in ihren konkreten literarischen Ausgestaltungen. Es finden sich auch Gerichtsankündigungen ohne Botenformel (Mi 3,1-4) oder Umschlag in die Gottesrede (Mi 3,9-12; Am 4,1-3) und mit Anklagen in der 2. Person (Jes 30,12-14). ${ }^{4}$ So ergibt sich eine Struktur, die dem Gerichtswort ähnelt:

Anklage: $\quad$ Begründung $(28,47$; vgl. Jes 8,$5 ; 30,12)$

Ankündigung: $\quad$ Eingreifen Gottes (28.48-49a; vgl. Jes 8,6; Mi 3,4; Am 3.12)

Folge des Eingreifens $(28,49 \mathrm{~b}-57.62)$

Erweiterung: Eingreifen Gottes $(28,63 a)$

Folge des Eingreifens $(28,63 \mathrm{~b}-68) .^{5}$

Man kann das Schema in 28,47-57.62-68 auch zweimal durchlaufen lassen, wenn man das 2 in $62 \mathrm{~b}$ als neue Begründung versteht.

Anklage: $\quad$ Begründung 62b weil / כיהיה/ 63aa wird es geschehen

Ankündigung: $\quad 63 \mathrm{a} \beta-\delta$ Eingreifen Gottes;

$63 \mathrm{~b}-68$ Folge des Eingreifens.

Aus diesem Rahmen fällt 28,58-61 mit seinem Bedingungssatz. Deshalb beginnen in V. 58 nach Seitz wieder bedingte Flüche. ${ }^{6}$ Doch wird man 28,58-61 aufgrund seiner poetischen Form eher als Drohgedicht bezeichnen dürfen.

\section{3. 6. Redaktionsgeschichte}

28,58-61 wirkt jünger als 28,45-57 und 62-68. Dafür sprechen die poetische Sprache, die Erwähnung der Tora, die Ehrfurcht vor dem Gottesnamen, die gleichartige redaktionelle Anschlußmethode durch Zwischen-

\footnotetext{
$1 \mathrm{Vgl}$. SerTZ, Studien, 288-291.

$2 \mathrm{Vgl}$. CAZELLES, Deutéronome, 115, der 28,47-68 mit „perspectives de guerres et d'exil“ überschrieb.

$3 \mathrm{Vgl}$. Grundformen, 120-122.

4 Vgl. Grundformen, 124.

5 Vgl. WeSTERMANN, Grundformen, $133 f$.

$6 \mathrm{Vgl}$. Studien, 298.
} 
stücke in V. $45 \mathrm{f}$ und V. $62 \mathrm{f}$ sowie das fast vollständige Fehlen von Lexemen aus 28,20-44 in V. 58-61 trotz gleichartiger Krankheitsthematik.

So ergibt sich eine relative Chronologie der Redaktionsgeschichte. Der erste Zusatz zu 28,20-44 ist 45-57. Zu derselben redaktionellen Schicht gehört möglicherweise auch 28,62-68. Dafür sprechen: (1.) der sachliche Anschluß, den V. 62 gegenüber V. 57 zu bieten scheint; (2.) die durchgehende Fremdvolkbezeichnungen גו die von 28,20-44 abweicht und durch עמים in V. 64 (vgl. V. 37) mit dem ersten Fluchabschnitt harmonisiert wird; (3.) der siebte שמע-Beleg des Kapitels in V. 62, der darauf schließen läßt, daß dieselbe Hand, die V. 62 schuf, auch die שמע enthaltenden Formeln in V. 2b.45b ergänzte, wobei sie die Siebenzahl anstrebte; (4.) die Anspielungen auf Ägypten in 28,45 , die schon auf V. 68 vorauszublicken scheinen, ${ }^{1}$ zumal der Verfasser von V. 45f möglicherweise die historische Kurzgeschichte ,vom verwerflichen Ursprung der ägyptischen Gola“ (Jer 37,1143.7b) bzw. die frühexilische „Erzählung vom Untergang des palästinischen Judäertums“" (Jer 37-43,7b*) kannte, die mit der Verschleppung des Propheten Jeremia nach Ägypten endete. ${ }^{2}$ Die Ergänzung setzt die Mosaisierung des Deuteronomiums voraus (Dtn 28,45.68) und wohl auch die Eroberung Jerusalems im Jahre $586 \mathrm{v}$. Chr..

Das Verhältnis zu Dtn 30,1-10 läßt sich von Dtn 28 her nicht mit Sicherheit bestimmen. Dennoch ergeben sich durch die Einbeziehung von 30,1-10 Rückschlüsse auf die Redaktionsgeschichte von 28,45-68. Bereits Steuernagel erwog die Frage, ob 28,46.57.64-67 und 30,1-10 einem Verfasser zuzuschreiben sind. Er verwarf diese Möglichkeit aber aus literarund stilkritischen Gründen. ${ }^{3}$ In neuerer Zeit erkannte Wolff in 30,1-10 ähnliche lexematische Bezüge zu Heilsworten des Jeremia, wie sie in 28,47-57 zu Drohworten bestehen. Er führte deshalb beide Stücke auf denselben Verfasser zurück, der Jeremiatraditionen ins Deuteronomium aufnahm. Dtn 28,45ff und 30,1-10 gehören wohl nicht zur Grundschicht des DtrG, sondern zu einer Redaktion, die das Mosebild durch Anklänge an Jeremia bereicherte. ${ }^{4}$ Auch Steck sah in der Kombination von $28,45 \mathrm{ff}$ und 30,1-10 eine innerdeuteronomistische Weiterentwicklung. Ursprünglich hat das deuteronomistische Kerygma nur den Weg ins Gericht aufgezeigt, ohne eine Umkehr und Rückführung in den Blick zu nehmen. Diese Sicht kann man noch in 2 Kön 17,7ff und in der deuteronomistische Sprache verwen-

\footnotetext{
${ }^{1}$ Nach SEITZ, Studien, 300, erinnert V. 68 mit, den Worten לאיביך לעבדם a die Drohung von v. 48, daß Israel seinem Feinde dienen muß.“

2 Vgl. LoHFINK, „Gattung,“ 71-74, 80f; STIPP, Jeremia, 288f, 293.

3 Vgl. Ralimen, 42.

4 Vgl. „Kerygma,“ 81-183/318-320.
} 
denden Quelle C im Jeremiabuch erkennen. In 1 Kön 8,46-53; Dtn 4,25-31 sowie Dtn 28,45-68 und 30,1-10 liegt das erweiterte deuteronomistische Geschichtsbild vor, das die Exilierten zu neuem Gehorsam auffordern will. ${ }^{1}$ Vanoni stellte fest, daß Dtn 30,1-10 vor dem Horizont von Dtn 28,51-53.62-64 konzipiert sei. ${ }^{2}$ Auch er erwägt die Möglichkeit, daß 28,4668 von demselben Verfasser stammt wie $30,1-10 .^{3}$

Die Beziehungen zu jeremianischem Gut sind in 30,1-10 anders als in Dtn 28,47-57, wo eine Anknüpfung an wohl authentische Jeremiaworte vorliegt. Die Echtheit der jeremianischen Heilsworte, die Dtn 30,1-10 aufgreifen, ist jedoch umstritten. ${ }^{4}$ Anscheinend ergänzten Redaktoren das Deuteronomium und die Jeremiaorakel nach gleichen theologischen Perspektiven und in gleicher deuteronomistischer Formelsprache. Dtn $28,36 f .68$ setzen das Königsgesetz in Dtn 17,14-20 voraus, das erst in der Exilszeit entstand. ${ }^{5}$ Hinter der Gestaltung von 28,47-57 scheint die Hochschätzung des Jeremia als eines Propheten, der dem Prophetengesetz Dtn 18,15.18 entsprach, zu stehen. 28,45-57.62-68 setzen also exilische Texte voraus und können daher höchstens zeitgleich mit diesen oder später als diese entstanden sein.

Eine spätere Hand fügte 28,58-61 ein. Doch warum setzte sie das Drohgedicht gerade an dieser Stelle? Im Textzusammenhang bilden die Aussagen von Dtn 28,62-68; 30,1-10 eine Kreisbewegung. In 28,62-64 beginnen Vorgänge, die in 30,2-9 umgekehrt werden. Macht sich das Volk in 28,62 des Ungehorsams schuldig (לא שמעת בקול יהוה), so kehrt es in 30,2 wieder zum Gehorsam zurück (ולשמעת בקולו)). Wird es in 28,64 unter alle Völker zerstreut (והפיצך... בכל־העמים) so wird es in 30,3 wieder gesammelt (וקבצך מכל דאמים אשר הפיצך ... שמהה). Gewinnt nach 28,63 JHWH Freude daran, zu vernichten statt Gutes zu tun (כשל משר שמש יהוה עליך להטיב), so be=kehrt er sich in 30,9 selbst dazu, wieder Gutes zu tun und das Volk zu

\footnotetext{
1 Vgl. Israel, 37-141, ähnlich PERLITT, Bundestheologie, 44.

2 Vgl. „Geist,“ 88. Er nimmt auch 28,58-61 in den Horizont von Din 30,6.7 hinzu. Doch reduzieren sich die Bezüge auf das Wort זרע, das auch in 28,46 steht, und auf das Vokabular von $D$ tn 7,15 , von dem auch 28,60 abhängig ist. Dtn 30,6 fetzt also nicht $28,58.60$ voraus, sondern 7,15.

3 Vgl. „Geist,“ 89f. WidENGREN, „Gathering,“" 240f, möchte das Motiv der Zerstreuung, des Restes und der Sammlung, das in 28,62f.; 30,1-10 zu finden ist, aufgrund ähnlicher altorientalischer Aussagen in vorexilische Zeit datieren. $\mathrm{Vgl}$. dazu unten. BRAULIK, .Entstehung," 330-332, datiert 30,1-10 in die späte Exilszeit.

4 Vgl. STECK, Israel, $141 \mathrm{f}$.

5 Vgl. LOHFINK, ,Sicherung,“ 313f, 318; SCHÄFER-LiCHTENBERGER, Josua, 69-103; GERTZ, Gerichtsorganisation. $30 \mathrm{f}$.
} 
vermehren (וששב יהוה לשוש עליך לטוב כאשר שט על אבותך)! Räumlich schließt sich der Kreis von der Deportation zur Heimkehr. Damit werden Umkehr und neuer Gehorsam jedoch zu einer Angelegenheit der Heimkehrer. Was aber ist mit denen, die aus Exil und Diaspora gar nicht nach Palästina heimkehren wollen? Für sie gilt das Leben im Land, das im Verlust und in der Wiedergewinnung den Mittelpunkt von 28,62-68 und 30,1-10 darstellt, nicht als Inbegriff göttlichen Segens. Deportation und Exil, mit dem 28,6268 drohen, schrecken sie nicht, da sie sich auf einen dauernden Aufenthalt außerhalb des Verheißungslandes, vielleicht sogar in Ägypten $(28,68)$, eingestellt haben. Welchen Sinn haben Buße und Umkehr in exilischer und nachexilischer Zeit, wenn man auf Dauer in der Diaspora lebt?

Bei diesen Fragen scheint 28,58-61 anzusetzen. Weder Krieg noch Deportation spielen in diesem Abschnitt eine Rolle, sondern nur Krankheit und privates Unheil, das jeden überall treffen kann. Vor den Kreislauf von Deportation und Rückkehr in 28,62-68; 30,1-10 dürfte sehr spät im Exil, eher aber in nachexilischer Zeit ${ }^{2}$ 28,58-61 als bedingte Drohung gestellt worden sein, um jeden, der zur Beachtung der Tora verpflichtet ist, die Konsequenzen seines Ungehorsams in der ganz privaten Sphäre körperlicher Gesundheit nahezulegen. Hier spricht eine Theologie, die auch den Israeliten in der Diaspora zur Ehrfurcht vor dem ,Namen“ aufruft.

Versteht man unter „,deuteronomistisch“ jene Zusätze am Deuteronomium, die nach Joschijas Verpflichtungsakt eingefügt wurden, so sind 28,45-57.62-68 deuteronomistisch zu nennen. Doch bei dem Versuch, die Schicht präziser zu bestimmen, begibt man sich in die Diskussion um die Redaktionsgeschichte des DtrG. ${ }^{3}$ In der Terminologie von Cross wäre es Dtr II, da die Katastrophe von 586 v. Chr. vorausgesetzt ist. ${ }^{4}$

\footnotetext{
${ }^{1}$ Weder für JHWH noch für Israel sind Ausgangs- und Zielpunkt der Kreisbewegung ganz identisch. Anfangs maß sich die Freude des Wohltuns am Volk (28,63 עליך), am Ende mißt sie sich an den Vätern (30,9 מבותץ). Bei der Rückkehr werden Israel und seine Nachkommen am Herzen beschnitten sein $(30,6)$.

2 28,58-61 scheint jedenfalls jünger zu sein als 30,1-10, das „einer späten Stunde des Exils“ BRAULIK, ,Entstehung,“ 330, zugeschrieben wird.

${ }^{3}$ Vgl. ROMER, „Book,“ 186-191.

4 Vgl. Friedman, ,Egypt,“ 184, 190.
} 


\subsection{Traditionsgeschichte \\ 6. 3. 7. 1. Die Bezüge zu Jeremia ${ }^{1}$}

Seitz erwähnte Jer 5,19 als Prosaparallele zu Dtn 28,47f, während Jer 5,1517 Dtn 28,49-52 ähnelt. Durch die Verbindung von Kannibalismus und feindlicher Bedrängnis gleicht Jer 19,9 den Kehrversen Dtn 28,53.55.57. Eine direkte Abhängigkeit besteht nach Seitz jedoch nicht. Statt dessen führte er die Bezüge auf die Verwendung von Motiven aus der Gattung der Fremdvolkbeschreibung zurück, die zur Tradition altorientalischer Königshymnen und Königsinschriften gehört. ${ }^{2}$

Auch in 28,63-67 fand Seitz Bezüge zu Jeremia, darüber hinaus aber Verknüpfungen mit dem übrigen Deuteronomium. Dtn 28,63 sei älter als Jer 32,41 und Dtn 30,9. ${ }^{3}$

Sumner zeigte für den Abschnitt 28,49-57 die Abhängigkeit von Jer 5,15-17 auf, ${ }^{4}$ das zu der größeren wohl authentischen Perikope gehört, die von Jer 4,5 bis Jer 6,26 reicht. ${ }^{5}$ Er ging die Unterschiede zwischen Jer 5,1517 und Dtn 28,49-57 durch und versuchte sie zu erklären. Er erkannte:

(1.) Stilunterschiede, die sich durch die Verwendung der je eigenen Spraché beider Bücher ergeben. ${ }^{6}$

\footnotetext{
${ }^{1}$ Zur Forschungsgeschichte der literarischen Beziehungen zwischen Deuteronomium und Jeremia vgl. Floss, Jahwe, 446-451; HerrmanN, Jeremia, 66-87; Houtman, Pentateuch, 334-337, 340-342.

2 Vgl. Studien, 292-294. Er bestimmt in der Gattung Fremdvolkbeschreibung die Elemente: Kommen aus der Ferne, unverständliche Sprache, Erbarmungslosigkeit, Zerstörungswut, Raubgier, Kraft, Vergleiche mit Tieren. Aus altorientalischen Königshymnen und -inschriften bringt er aber nur Belege für die Motive Tiervergleich und Kommen aus der Ferne. Vgl. ebd. 295-297.

3 Vgl. Studien, 266.

4 Vgl. Study, 167; ähnlich äußerten sich schon Hillers, Treaty-Curses, 35-37; RUDOLF, Jerenia, 37; vgl. auch FLoss, Jahwe, 316.

5 Vgl. AlbERTZ, „Frühzeitverkündigung,“ 30, Anm. 40. HerRmanN, Jeremia, 42, der im angegebenen Abschnitt nur Jer 5,18f und 6,16-21 als „D-beeinflußt“" verzeichnet.

${ }^{6}$ So läßt Gott die Feinde in Jer 5,15 kommen (בוH), während er sie in Dtn 28,49 aufbietet (נטש). Jeremia spricht von Städten (עטר) (עיר), das Deuteronomium von Stadtbereichen.

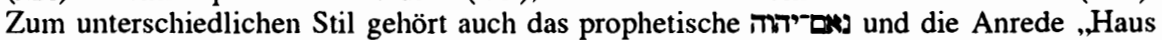
Israel" in Jer 5,15 sowie die dortige Qualifizierung der Nation (גו ) als besonders altes Volk. Die Jeremiaworte sind Poesie, Dtn 28,49-57 jedoch Prosa.
} 
(2.) Neue Aussageintentionen, die im Deuteronomium zur Veränderung der Vorlage führen, um im Sinne ausgleichender Gerechtigkeit (poetic justice) Bezüge zum Gesetz herzustellen. ${ }^{1}$

(3.) Aufnahme anderer Jeremiastellen. ${ }^{2}$

Jeremia hat kein konkretes Volk im Blick, sondern beschreibt nur vage die Gefahr aus dem Norden. Das Deuteronomium scheint in 28,49-57 jedoch auf die Babylonier anzuspielen. Ziel ist es, die Predigt des Propheten Jeremia zu bestätigen. Die Jeremiapredigt wurde bewußt verändert und nicht wörtlich übernommen, weil man ihre Aussagen nun im Munde des Mose präsentieren wollte. Jeremia sollte als der von Mose angekündigte Prophet (Dtn 18,18) dargestellt werden. ${ }^{3}$

Gegenüber der These von Seitz, die Jeremia und Dtn 28 nur durch die Gattung der Fremdvolkbeschreibung verbunden sieht, scheint Sumners Auffassung plausibler. Sumner kann erklären, warum in 28,20b.25b.37 ebenfalls Jeremiazitate eingefügt wurden. Es handelt sich um Anspielungen auf Texte, die im Prophetenbuch mit der Sünde des Manasse verbunden sind. Man wollte wohl zugleich die Sünde des Manasse als Ursache für das Eintreffen der Flüche herausstellen und die Warnungen des Jeremia als gerechtfertigt bezeugen. ${ }^{4}$ Außerdem weist Jer 5 noch weitere Bezüge zum Deuteronomium auf. In Jer 5,19 steht nämlich wie in Dtn 29,21-28 das Motiv der Strafgrunderfragung zusammen mit dem Ausdruck עזבתנ, der auch in Dtn 28,20b ergänzt wurde. ${ }^{5}$ Viele der von Sumner herausgearbeiteten Jeremiaparallelen führen zu den Prosastücken des Prophetenbuches, deren Authentizität umstritten ist. Wenn die Prosapartien im Jeremiabuch von Redaktoren stammen, die deuteronomistische Sprache verwendeten, so

\footnotetext{
${ }^{1}$ So verweise מרחק in Dtn 28,49 statt ממרחק in Jer 5,15 auf Dtn 13,7. V. 49 sei gegenüber der Jeremiavorlage umgestaltet worden, um Bezüge zu Jes 5,26 zu markieren.

2 So kommt der Adler zwar nicht in Jer 5,15-17 vor, dafür aber in Jer 48,40; 49.22. Die Wurzel des Adjektivs ,verweichlicht“ טבג steht innerhalb des Zusammenhangs von Jer 4,56,26 in 6,2. Die Grausamkeit der Nation ist in Bildern gestaltet, die nicht nur aus Jer 5,15, sondern auch aus 5,3; 6,11.22 stammen. In Jer 5,17 essen die Feinde die Kinder, im Deuteronomium die Belagerten selbst. Doch gerade dies steht in Jer 19,9. Dtn 28,48 lehnt sich an Jer 15,$14 ; 28,14$ an.

${ }^{3}$ Vgl. Study, 167-189.

${ }^{4}$ Zur ,'Manasseh allone' explanation of the Babylonian exile“" im DtrG vgl. LowERY, Kings, 171-182.

5 Vgl. anders VARGYAS, „Cylindre,“ 158, 162, der das Motiv der Strafgrunderfragung, ähnlich wie SEITZ die Fremdvolkbeschreibung, aus mesopotamischen Texten herleitet und Dtn 29,23-26 anscheinend für die ursprünglichste Form dieses Motivs im AT hält. Letztlich folgt aber auch aus dieser Sicht, daß die Redaktoren altorientalische Motive kannten und verarbeiteten, sowohl in Zusätzen zum Deuteronomium als auch zu Jeremia.
} 
waren vielleicht dieselben Kreise am Deuteronomium und am Jeremiabuch tätig und ergänzten beide Bücher nach gemeinsamen Gesichtspunkten. ${ }^{1}$

Bei der synchronen Analyse von Dtn 28,47-68 war aufgefallen, daß die Bezeichnung des Fremdvolkes von עם 28,20-44 zu in 28,49-57 wechselt und nur V. 64 und der davon abhängige V. 37 das jeweils andere Wort verwenden. Der Bezug zu Jer 5,15-17 würde den Grund für den Wortwechsel liefern. Dort wird das Fremdvolk nur genannt. Diese Terminologie wäre in Dtn 28,49-57 übernommen, und erst anschließend von V. 64 aus mit dem vorhergehenden Fluchabschnitt harmonisiert worden.

Fensham sieht in der Kriegsbeschreibung von Dtn 28,47-57 eine Anlehnung an die prophetische Ankündigung eines Kriegsordals zwischen dem Volk und JHWH, seinem Bündnisherm. Wie in Assurbanipals Beschreibung seines Feldzugs gegen die Araber, wird der Feind zum Vollzugsorgan der göttlichen Flüche.?

\section{3. 7. 2. Altorientalische Parallelen}

Seitz vergleicht die Fremdvolkbeschreibung von Dtn 28,47-57 mit den Selbstaussagen altorientalischer Könige aus dem 3. und 2. Jt. v. Chr., ohne jedoch deutlich zu machen, woher die Propheten die Motive dieser Jahrtausende älteren Königsinschriften kennen sollten. Schaut man in Königsinschriften des 1. Jts., so stellt man fest, daß die assyrischen Königsinschriften zwar auf den König als Garant der Weltordnung ausgerichtet sind, der Feind jedoch anders dargestellt wird als in der biblischen Gattung der Feindvolkbeschreibung. Die kriegerische Machtentfaltung des assyrischen Königs erhält den Charakter der göttlich legitimierten Bestrafung und der Wiederaufrichtung der rechtmäßigen Ordnung. ${ }^{3}$ Das Feindbild dagegen wird in stereotypen Bildern gezeichnet, welche die Ungerechtigkeit des Feindes herausstellen. Man wirft ihm Bundesbruch und Ehrfurchtslosigkeit, Undankbarkeit und das Vertrauen auf eigene Kraft sowie schlechte und falsche Reden vor. ${ }^{4}$ Vergleicht man die Bewertung des Feindes in assyrischen Königsinschriften mit Dtn 28,47-57, so fällt auf, daß die genannten Eigenschaften weniger auf den Feind als auf die Belagerten zutreffen, wobei derjenige, gegen den sie sich aufgelehnt haben, Gott ist. Die Belagerten sind ehrfurchtslos und undankbar $(28,47)$, sie vertrauen auf die Kraft

\footnotetext{
1 „Die Nähe zu dtr Texten im Jeremiabuch unterstreicht die Arbeit der dtr Schule hier wie dort ... ." Preuss, Deuteronomium, 157. Vgl. Friedman, „Egypt,“ 184, 186.

2 Vgl. „Ordeal,“ 132-135.

3 Vgl. FaLes, ,Enemy,“ 425-427.

4 Vgl. FaLES, ,Enemy,“ $428 \mathrm{f}$.
} 
ihrer Mauem $(28,52)$ und gehen gegeneinander in äußerster Falschheit und Grausamkeit vor (28,54b.55a.56b.57a).

Feindschaft erscheint in den assyrischen Königsinschriften als eine falsche Wahl, die der Ausländer aus Irrtum oder im Wahnsinn trifft. Dieselbe Anschauung taucht in 28,47-57 auf. Der Gottesdienst wäre vernünftig gewesen als Ausdruck der Dankbarkeit für Lebensfülle. Statt dessen verspeist man im äußersten Mangel die eigenen Kinder. Das Gottesvolk nimmt die Rolle des Feindes ein, der sich in falscher Wahl gegen die Weltordnung aufgelehnt hat, und Gott übernimmt die Rolle des Königs, der das Vergehen bestraft. Dabei bedient er sich des fremden Volkes, das er aufbietet $(28,49)$. Die semantische Untersuchung hatte herausgestellt, daß die Feinde in 28,47-57 gleichsam ein Negativbild Gottes ergeben. Sie entziehen, was der Dienst an Gott gewährt hätte. Diese Rollenumverteilung erfordert gegenüber den Königsinschriften weitreichende Abstraktion. Hinter dieser Uminterpretation königlicher Ideologie dürften, wie Seitz annahm, die Propheten stehen. ${ }^{1}$ Sie haben JHWH als strafenden Richter dargestellt und die Feinde als göttliche Strafwerkzeuge verstanden. Derartige Aussagen finden sich z.B. in Jer 4,5-6,26 (Jer 4,6.12.26; 5,15; 6,1.4.6.22). Dazu kommen Negativbewertungen Israels, die dem Bild der Feinde in assyrischen Königsinschriften entsprechen. Sie waren irregeleitet $(\mathrm{Jer} 4,10)$ und töricht (Jer 4,22; 5,21), ehrfurchtslos (Jer 4,22; 5,5.6.11.24.28), undankbar (Jer 5,7.24), hochmütig (Jer 4,17;5,17.23) und falsch im Denken und Reden (Jer 4,14; 5,2.14). Darüber hinaus wird aber immer wieder die warnende Rolle des Propheten betont (Jer 4,14; 5,5.22; 6,1.8.10). Die deuteronomistische Geschichtsdeutung in 2 Kön 17 erwähnt zweimal die Propheten, die gewarnt und das Ende vorausgesagt haben (2 Kön 17,13.23). Dies scheint ein Hinweis auf die prophetischen Wurzeln der Deutungskategorien des deuteronomistischen Geschichtsbildes zu sein. ${ }^{2}$ Für das Kannibalismusmotiv von 28,52-57 lassen sich zahlreiche ähnliche Aussagen in mesopotamischen und biblischen Texten finden. ${ }^{3}$ Hillers macht deutlich, $\mathrm{da} ß$ es sich bei diesem Motiv weniger um historische Berichterstattung als um einen symbolischen Grenzwert für die Beschreibung äußerster Hun-

\footnotetext{
1 Vgl. Studien, 297.

2 STECK, Israel, 137-141, sah in 2 Kön 17 eine ältere Form des deuteronomistischen Geschichtsbildes, die Parallelen in der C-Quelle des Jeremiabuches besitzt. Zu C vgl. HERRMANN, Jeremia, 57, 59, 86. Deuteronomistische Redaktoren hinterließen also sowohl im DtrG wie im Jeremiabuch ihr Geschichtsbild, das in Dtn 28,45ff; 30,1-10 um das Motiv der Umkehr erweitert ist. Zum Verhältnis von 2 Kön 17 und dem Prophetengesetz Dtn 18 vgl. LOHFINK, „Sicherung,“ 320f.

3 Vgl. „History,“ 155-159.
} 
gersnot handelt. ${ }^{1}$ Hungersnot resultiert aus Ernteschäden oder ist eine Folge der Belagerung. Es lassen sich zwei Traditionen unterscheiden, die Hungersnotschilderungen durch das Kannibalismusmotiv verstärken.

Kannibalismus während der Belagerung beschreibt Assurbanipal in seinem Rassam-Zylinder. Dem entsprechen in den Verträgen Flüche, die den göttlichen Richter Šamaš anrufen, und Vergleichsflüche, die keinen konkreten Umstand für die Notsituation angeben. ${ }^{2}$ Im AT gehören zu dieser Tradition neben Dtn 28,52-57 auch 2 Kön 6,28f; Bar 2,2f, Klgl. 4,10.

Die andere Tradition gehört in Mesopotamien zum Adadfluch und findet sich im Vertrag A.745.1 ebenso wie in den VTE. Hier ist der Kannibalismus einfach Folge des Nahrungsmangels, ohne daß von einer direkten Einwirkung des Feindes gesprochen würde. ${ }^{3}$ Es scheint, daß Lev 26,29 zu dieser Tradition gehört, weil vor dem eingeschobenen Plagensteigerungsrefrain (Lev 26,27) in V. 26 als unmittelbare Ursache für den Kannibalismus steht, daß Gott den Menschen ihren Vorrat an Brot entzieht. Von einer Belagerung wird hier im unmittelbaren Zusammenhang mit dem Kannibalismus nicht gesprochen. Der Adadfluch der VTE (Z. 440-452) bietet vom Kontext des AO her also keine angemessene Entsprechung zu Dtn 28,5357.

Für den bösen Blick in 28,54-57 gibt es eine Fülle von religionsgeschichtlichen Parallelen. Im Deuteronomium kommt ein ähnlicher Ausdruck noch 15,9 vor, wo er ähnlich wie in 28,54ff keine magische Handlung, sondern Hartherzigkeit bezeichnet. ${ }^{4}$

Die Deportation wird die in 28,63 mit der im Bibelhebräischen seltenen, in anderen Sprachen aber häufigen Verbwurzel Verb begegnet in Kombination mit אבד אבר /H wie in V. 63 in westsemitischen Fluchinschriften von Monumenten. ${ }^{5}$

Widengrens altorientalische Textbelege für seinen Versuch, das Motiv der Zerstreuung, des übrig bleibenden Restes und der Sammlung in Dtn 28,64; 30,3; 4,27 als verbreiteten Topos darzustellen und die vorexilische Entstehung solcher Aussagen zu erweisen, lassen auch die gegenteilige Deutung zu. Widengren präsentiert aus dem AO nur eine Selbstprädikation Hammurapis, in der dieser sich rühmt, die zerstreute Bevölkerung von Isin

\footnotetext{
1 Vgl. „History،“ 159.

2 Vgl. STRECK, Assurbanipal, 36 Kol. IV Z. 44f; 76 Kol. IX Z. 59; 134 Kol. VIII Z. 19; VTE Z. 547, 568, 570. WEIPPERT, „Kämpfe," 45f; SCHOTTROFF, Fluchspruch, 34f; WATANABE, Thronfolgeregelung, 194.

${ }^{3} \mathrm{Vgl}$. die Adadflüche in A.745.1 Kol. IV Z. 8-10; VTE Z. $448 \mathrm{f}$.

4 Vgl. Elliot, „Fear,“ 43f, 52-57.

5 Vgl. GeVIRTZ, „Curses,“145, 148.
} 
wieder gesammelt zu haben (KH Kol II Z. 49f), sowie Erwähnungen der Wiederbesiedlung Babylons durch Asarhaddon und Assurbanipal. Dazu kommen das negative Bekenntnis des Königs beim babylonischen Neujahrsfest, Babylon nicht zerstört und zerstreut zu haben, sowie ähnliche Motive in einer Inschrift des Kyrus, Gebeten und Prophetien. Alle Belege außer dem KH stammen frühestens aus neuassyrischer Zeit. ${ }^{1}$ Zwischen dem Motiv im KH und Asarhaddon klafft eine tausendjährige Lücke ohne Belege. ${ }^{2}$ Man kann also nicht sagen, daß die Sammlung der Zerstreuten ein allgemein verbreitetes altorientalisches Motiv war. Es taucht erst seit Asarhaddon regelmäßig auf und kreist dann immer um Babylon. ${ }^{3}$ Hinter den Berichten vom Wiederaufbau und der Wiederbesiedlung Babylons in den Königsinschriften Asarhaddons und Assurbanipals steckt aber kein literarisches Motiv, sondem historische Wirklichkeit. Sie bauten Babylon wieder auf, weil ihr Vater bzw. Großvater, Sanherib, es im Dezember 689 v. Chr. zerstört hatte. ${ }^{4}$ Diese Gewalttat Sanheribs hat sich so tief in das Bewußtsein der Babylonier eingeprägt, daß ihre Abwehr noch bei Kyrus nachwirkt. Wie später bei Jerusalem wurde Babylons Zerstörung durch göttlichen Zorn motiviert. Auch seine Zeit in Trümmern war auf 70 Jahre festgesetzt. Es ist anzunehmen, daß derartige Deutungsmuster für die Katastrophe ebenso wie die Hoffnung auf Sammlung der Zerstreuten auf Jerusalem erst angewendet wurden, nachdem die Katastrophe wirklich eingetreten war.

Zur Erklärung der Schiffe in 28,68 griff Schley ebenfalls auf den Rassam-Zylinder zurück. In Z. 68b-74 wird dort berichtet, daß bei Assurbanipals Ägyptenfeldzug Vasallenfürsten gekommen seien, um ihm zu huldigen. Der assyrische König habe sie gezwungen, mit ihren Truppen und Schiffen am Ägyptenfeldzug teilzunehmen. In einer Variante dieses Ägyptenberichtes in Prisma $C$ sind die Namen der Vasallen eingetragen. An zweiter Stelle steht dort Manasse von Juda. Zwar ist die Vasallenliste

1 Vgl. „Gathering,“ 234-237, 243 Anm. 23-30.

2 WIDENGREN stellt selbst fest, ,that the theme did not find expression in divine or royal epithets.“ "Gathering,“ 243 Anm. 27.

${ }^{3}$ Die Sammlung Zerstreuter durch Gottheiten in Gebeten und Prophetien bezieht sich nicht auf Völker, sondern auf Familien und kleinere Gruppen. Vgl. WIDENGREN, „Gathering,“ 237.

4 „Babylon wurde diesmal mit unglaublicher Härte behandelt. Die wenigen Bewohner, die dem Blutbad entkommen waren, wurden aus der Stadt getrieben, deportiert oder in die Sklaverei verkauft. Die Götterstatuen wurden zerbrochen oder gefangen weggeführt. Privathäuser und Tempel - alles wurde geplündert und verwüstet. (... ) Dann ließ Sanherib den Fluß über die Stadt leiten, die nur noch eine einzige offene Wunde war." LABAT, „Assyrien,“ 74. 
von Prisma $\mathrm{C}$ aus einer Inschrift Asarhaddons eingefügt worden, doch regierte Manasse auch noch während des Ägyptenfeldzuges Assurbanipals. ${ }^{1}$ Sollte also tatsächlich auch der König von Juda mit Schiffen den assyrischen Feldzug begleitet haben, dann hätte sich Manasse nicht nur der von Sumner herausgearbeiteten kultischen Vergehen schuldig gemacht, auf die die Parallelen zu jeremianischen Prosastücken in Dtn 28 anspielen, sondern sein Verhalten stand auch im Widerspruch zur späteren, im Exil formulierten, deuteronomistischen Norm königlichen Handelns, die sich in dem Gebot von Dtn 17,16 niederschlug.

\section{4. $D \operatorname{tn} 28,3-6.16-19$}

3a Gesegnet seist du in der Stadt,

$3 b \quad$ und gesegnet seist du auf dem Feld!

4 Gesegnet sei die Frucht deines Leibes und die Frucht deines Bodens und die Frucht deines Viehs, der Wurf deines Rindes und die Nachkommen deines Kleinviehs!

5 Gesegnet sei dein Korb und dein Backtrog!

6a Gesegnet seist du bei deinem Kommen,

$6 \mathrm{~b}$ und gesegnet du bei deinem Ausziehen!

16a Verflucht seist du in der Stadt,

16b und verflucht seist du auf dem Feld!

17 Verflucht sei dein Korb und dein Backtrog!

18 Verflucht sei die Frucht deines Leibes und die Frucht deines Bodens, der Wurf deines Rindes und die Nachkommen deines Kleinviehs!

19a Verflucht seist du bei deinem Kommen,

19b und verflucht seist du bei deinem Ausziehen!

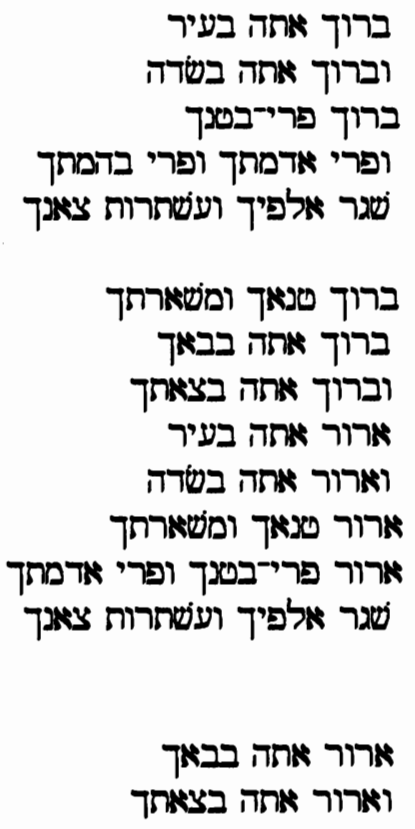

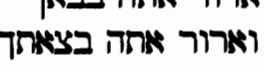

\subsubsection{Textkritik}

4 [רי בהמתך] wird von einigen 6-Handschriften ausgelassen, wohl in Angleichung an $28,18 .{ }^{2}$

1 Vgl. „Yahweh,“ 369-371.

2 Vgl. PenNa, Deuteronomio,227. 
18 eine Handschrift ergänzt wohl aus Dtn 28,4 ופרמתך. Die erhaltenen Passagen im Fragment 4Q42/4QDeut ${ }^{\circ}$ entsprechen $\pi$. $^{1}$

\subsubsection{Forschungsgeschichte}

Dtn 28,3-6.16-19 werden zumeist als älteres Gut betrachtet. ${ }^{2}$ Widersprüchliche Ansichten herrschen über den ursprünglichen „Sitz im Leben“ dieser Reihen.

Die Auffassung, daß diese Verse den gemäß der Ritualanweisung von Dtn 27,11f bei der Zeremonie auf Garizim und Ebal zu sprechenden Text enthalten, ist alt. ${ }^{3}$ Kultische Herkunft aus einer Bundesliturgie geben neben Weinfeld noch Mowinckel, Kline und Wright an. ${ }^{4}$ Auch nach vRad und Plöger wurzeln die Verse im Gottesdienst. ${ }^{5}$ Seitz sah in 28,3-6 den priesterlichen Abschiedssegen nach der Darbringung der Erstlingsfrüchte. ${ }^{6}$ Erst zur Verwendung dieses Segens als Abschluß einer Gesetzessammlung habe man die 'ārûr-Reihe (28,16-19) geschaffen.7 Andere verbanden 28,3-6.1619 von Anfang an mit dem Gesetz. ${ }^{8}$

Schottroff betonte gegenüber solchen Ortungsversuchen, daß es für die Entstehung dieser Segens- und Fluchworte im Kult oder im Zusammenhang eines Bundesrituals keine Indizien im Text gibt. Es handelt sich eher um Formulare, die im Sippenbereich entstanden und die den einzelnen, kein kollektives $\mathrm{Du}$, ansprechen, also auch nicht im Umkreis der Gesetzespromulgation angesiedelt werden können. Das Deuteronomium greift in 28,3-6.16-19 älteres Formelgut auf und rückt es damit erst in den Zusammenhang von Gesetzesverkündigung und Bundesschluß.9

Der Modus der 'ärûr- und damit wohl analog auch der bārûk-Formel schwankt nach Schottroff und Müller zwischen Indikativ und Wunschform..$^{10}$ Mitchell bestimmt die Formeln in Dtn 28 als Indikativ. Er begründet dies damit, daß sie eher Aussagen über den zukünftigen Zustand der Is-

1 Vgl. García Martínez, „Manuscrits,“ $71 \mathrm{f}$.

$2 \mathrm{Vgl}$. PREUSS, Deuterononium, 154.

3 Vgl. WEINFELD, Emergence, 80.

4 Vgl. WEINFELD „Emergence,“ 79; MOWINCKEL, Psalmenstudien, 115; KLINE, Treaty, 125; WRIGHT, „Deuteronomy,“ 493.

5 Vgl. vRAD, Buch, 124f; PLOGER, Untersuchungen, 144

6 Vgl. SEITZ, Studien, 272f.

7 Vgl. SErTZ, Studien, 258f.

8 Vgl. IRWIN, „Criterion,“ 340; JUNKer, Deuteronomium, 531; MørSTAD, Stimme, $22 \mathrm{f}$.

$9 \mathrm{Vgl}$. Fluchspruch, 225f.

$10 \mathrm{Vgl}$. SCHOTTROFF, Fluchspruch, 49; MULLER, „Segen,“ $225 \mathrm{f}$. 
raeliten sind als Wünsche oder Gebete. ${ }^{1}$ Damit sind die Formeln konstative Äußerungen, die einen Zustand beschreiben. ${ }^{2}$ Diese Interpretation mag bei Mitchell von dem Umstand bestimmt sein, daß er Dtn 28 als Gottessegen und nicht als Moserede betrachtet. Die Gegenposition nimmt Müller ein, der in Segen und Fluch Gott weitgehend eine Funktion abspricht und den Menschen in den Vordergrund rückt, der in seinen Worten numinose Kräfte freisetzt. Kaiser wiederum betont den Bittcharakter des Segens. ${ }^{3}$ In dieser Sicht und vom grammatischen Standpunkt aus können die Formeln ebensogut als Wünsche verstanden werden.

Der semantische Inhalt des Partizip Passiv bārûk enthält sowohl den Aspekt des Segnens als auch den des Preisens. Scharbert sieht diese Doppeldeutigkeit auch in 28,3-6. Segen als Gabe der verheißenen Güter führt dazu, daß man den Menschen, der die Gebote beachtet, preist. ${ }^{4}$ Die Paare Stadt / Land, Korb 5 / Backtrog, Kommen / Ausziehen drücken Totalität aus. Die Gesamtheit des Lebens und alle Aktivitäten sind umschlossen. ${ }^{6}$

\subsubsection{Literarkritik}

Noth schied V. 4.18 aus. ${ }^{7}$ Seitz grenzte V. 4.5 als deuteronomischen Zusatz zu vorgegebenem Gut aus. ${ }^{8}$ Er rekonstruierte drei Entstehungsphasen. Zunächst gab es nur die Paare 3.6 und 16.19. Dann seien die Reihen durch

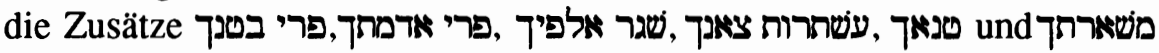
auf zehn Glieder erweitert worden, um schließlich wieder auf sechs reduziert zu werden. ${ }^{9}$ Doch für eine solche Literarkritik gibt es keine anderen Argumente als den Stilbruch der Verse 4f und 17f, die Umstellung ihrer Reihenfolge, das Metrum und die deuteronomische Sprache in V. 4.18. Zur

1 Vgl. Meaning, 40.

2 Vgl. Meaning, 40f. Zur 'ārûr-Formel ebd., 41: „It denotes someone, who has been, or who shortly will be, the object of malefaction by God ... . It connotes divine displeasure, just als bärûk connotes divine affection ... ."

3 Vgl. MUller, ,Segen,“11-14f/230-233; KaISER, „Promise,“ 160.

4 Vgl. „Geschichte,“ 27; MULller, „Segen,“ 10/229 Anm. 29; anders 11f/230f Anm. 31.

5 vommt im AT nur Dtn 26,2.4; 28,5.17 vor und ist wohl ein ägyptisches Lehnwort. Vgl. LAMBDIN, „Loan Words,“ 151.

6 Vgl. MAYes, Deuteronomy, 352; Penna, Deuteronomio, 226.

7 Vgl. Noth, „Fluch,“ 130f/158f ebd. Anm. 11: „V. 4 = V. 18 scheinen mir sekundär zu sein. Einmal stehen diese Sätze an verschiedenen Stellen innerhalb der festgeprägten Fluchformel. Sodann fehlt ihnen die rhythmische Gliederung, und auch die lange Reihe der von ,gesegnet (verflucht) sei“ abhängigen Subjekte stört den Zusammenhang der übrigen lapidaren Sätze. Die sind offenbar nach Dtn. 7,13 interpoliert."

8 Vgl. Studien, 269, 271.

9 Vgl. Studien, 271. 
literarkritischen Scheidung zwingende Widersprüche und Dopplungen nennt er nicht. ${ }^{1}$ Plöger lehnt Ausscheidungen aus den Reihen ab. Nur פרי בהמתך scheint ihm ein nachträglicher Zusatz zu sein. ${ }^{2}$ Er könnte aus 28,11 eingefügt sein. ${ }^{3}$ Allerdings ist auch diese Annahme nicht zwingend, läßt man von dem Vorurteil $\mathrm{ab}$, daß beide Reihen ursprünglich genau symmetrisch gewesen sein sollten. Leichte Durchbrechungen der Symmetrie wie die Umstellung von V. 4f.17f können aus dem ästhetischen Anliegen resultieren, allzu stereotype Gleichartigkeit zu vermeiden. Ein nachträglicher Interpolator hätte seine Zusätze wohl in der richtigen Reihenfolge plaziert. ${ }^{4}$ In dieses ästhetische Anliegen der Auflockerung stereotyper Wendungen würde auch פרי בהמתך in V. 4 gehören, da die Frucht des Viehs den Oberbegriff für die folgenden Differenzierungen in Rinder und Kleinvieh angibt und dem Segen 28,4.11 gegenüber dem Fluch einen leichten Akzent verleiht.

\subsubsection{Formenkritik}

Scharbert unterschied bei der bārâk-Formel verschiedene Formen. Die Formeln in 28,3-6 und analog auch die 'ārûr-Formeln 28,16-19 gehören zur Kategorie ohne Zusätze wie Relativsatz, Kausalsatz, Partizipialkonstruktion, oder die Einfügung ליהוה. Scharbert differenziert noch, ob bārûk sich auf einen Menschen oder auf ein Ding bezieht. Die auf Menschen bezogenen Formeln 28,3.6(16.19) umschließen zwei Sätze mit Formeln, die Lebensgüter betreffen $(28,4.5 .17 .18){ }^{6}$

Scharberts Einteilung erleichtert es, die bärâk- und 'ārûr-Formeln genauer zu beschreiben. Die Formeln von Dtn 28 sind in doppelter Weise absolut. Weder wird die Segens- oder Fluchinstanz angegeben, ein Gottesname wie bei den Formeln mit der Ergänzung ליהוא fehlt, noch wird der oder das Gesegnete und Verfluchte durch einen Relativsatz oder eine Partizipialkonstruktion näher bestimmt. Formeln mit derartigen Näherbestimmungen stimmen also nicht mit der Form von Dtn 28 überein und sollten deshalb nicht zum Vergleich mit Dtn 28 herangezogen werden. Einzig der Vergleich mit Formeln, die mit einem Kausalsatz ergänzt sind, scheint akzeptabel, da der Kausalsatz keinen Bestandteil der Formel näher bestimmt,

\footnotetext{
${ }^{1} \mathrm{Vgl}$. Studien, 269.

2 Vgl. Untersuchungen, 143f.

${ }^{3}$ Vgl. SerTZ, Studien, 269.

4 Vgl. PLÖGER, Untersuchungen, 143.

5 Vgl. „Geschichte,“ 4f.

${ }^{6}$ Vgl. „Geschichte," $14 f$.
} 
sondem nur den Grund angibt, warum die Formel gesprochen wird. Der Kausalsatz gehört also eigentlich nicht zur Formel, sondern zu ihrem Kontext. So können die Belege gleichartiger Formeln im AT in sechs Untergruppen eingeteilt werden:

(1.) bārûk + Personalpronomen (28,3.6):

1 Sam 26,25: Saul sagte zu David: Gesegnet seist du, mein Sohn David. Du wirst es sicher vollbringen, dir wird es auch bestimmt gelingen.

(2.) $b \bar{a} r \hat{k} k+$ Substantiv $(28,4.5)$ :

1 Sam 25,33 (David spricht zu Abigajil): Gepriesen sei deine Klugheit.

(3.) $b \bar{a} r u \hat{k}+$ Eigenname:

1 Kön 2,45 (Salomo spricht zu Schimi nach dem Todesurteil): Der König Salomo aber sei gesegnet, und der Thron Davids stehe fest vor dem Herrn in Ewigkeit. ${ }^{1}$

Jes 19,25: Denn der Herr der Heere wird sie segnen und sagen: Gesegnet ist Ägypten, mein Volk, und Assur, das Werk meiner Hände, und Israel, mein Erbbesitz. $^{2}$

(4.) 'ârûr + Personalpronomen $(28,16.19)$ :

Gen 3,14: Da sprach Gott ... zur Schlange: Weil du das getan hast, bist du verflucht unter allem Vieh und allen Tieren des Feldes. Auf dem Bauch sollst du kriechen und Staub fressen alle Tage deines Lebens.

Gen 4,10f (Gott spricht zu Kain): Was hast du getan? Das Blut deines Bruders schreit zu mir vom Ackerboden. So bist du verflucht, verbannt vom Ackerboden, der seinen Mund aufgesperrt hat, um ... das Blut deines Bruders aufzunehmen.

Jos 9,22f (Josua spricht zu den Gibeonitern): Warum habt ihr uns getäuscht ... . Nun seid ihr verflucht; ihr müßt für immer Sklaven, Holzfäller und Wasserträger für das Haus meines Gottes sein.

(5.) 'ārûr + Substantiv $(28,17.18)$ :

Gen 3,17: Zu Adam sprach er: Weil du auf deine Frau gehört ... hast ... : So ist verflucht der Ackerboden deinetwegen. Unter Mühsal wirst du von ihm essen alle Tage deines Lebens.

Gen 49,7 (Jakob spricht über Simeon und Levi): Verflucht ihr Zorn, da er so heftig, verflucht ihr Grimm, da er so roh. Ich teile sie unter Jakob auf, ich zerstreue sie unter Israel.

\footnotetext{
${ }^{1}$ Die bärûk-Formel in 1 Kön 2,45 scheint eine Selbstsegnung des Königs zu sein, wie sie ganz ähnlich auf westsemitischen Inschriften der Eisenzeit belegt ist. Sie taucht dort als Gegenstück zum Fluch auf, in 1 Kön 2,45 als Gegenstück zum Todesurteil über Schimi. Vgl. z. B. Karatepe-Bilingue KAI Nr. 26 Kol. I Z. 5-8, Kol. II Z. 7-13.

$2 \mathrm{Vgl}$. SCHOTTROFF, Fluchspruch, $164 \mathrm{f}$.
} 
(6.) 'àr $\hat{r} r+$ Eigenname: Gen 9,25 (Noach spricht):

Verflucht sei Kanaan. Der niedrigste Knecht sei er seinen Brüdern. ${ }^{1}$

Die Zusammenstellung der Formeln mit dem Schema bārûk / 'ārûr + Nomen zeigt, daß derartige Formeln im AT sonst weder mit dem Kult noch mit Bundesschluß noch mit Gesetzesverkündigung verbunden werden. Sie gehören vielmehr in den privaten Bereich zwischenmenschlicher Kontakte oder zu Gottesworten (Gen 3,14.17; 4,11; Jes 19,25). Während der Segen ohne weitere Erläuterungen stehen kann (1 Sam 25,33a; Jes 19,25), kommen die 'ārûr-Formeln immer als mehrgliedriger Fluchspruch vor. ${ }^{2}$ Es wird immer begründet, warum der Fluch ausgesprochen wird. Entweder handelt es sich um eine vorwurfsvolle Frage, die auf ein Vergehen hinweist (Gen 4,10; Jos 9,22), oder um Kausalsätze (Gen 3,11.17; Gen 49,7). In Gen 9,25 gibt die vorangehende Erzählung den Kontext der Formel an. Die 'ārûr-Formel ergeht also im AT immer in einem Kausalzusammenhang situiert und nicht einfach absolut. Darüber hinaus ist es im AT mit der 'ärûrFormel nie getan. Es folgt ihr immer eine Entfaltung. Die Formel allein reicht offenbar nicht aus, um das Unheil, das sie herbeiruft, explizit zu machen. Sie wird durch eine Fortführung konkretisiert. Der Fluch über die Schlange konkretisiert sich im Kriechen und Staubfressen, der Fluch über Kain konkretisiert sich im Verlust des Ackerbodens, der Fluch über die Gibeoniter konkretisiert sich im Dienst am Gotteshaus usw.

\subsubsection{Redaktionsgeschichtliche Schlußfolgerungen}

Für Dtn 28,16-19 ergibt sich, daß die Reihe allein ungenügend ist. Es fehlt der Kausalzusammenhang der die Äußerung des Fluches veranlaßte. Es fehlt die Konkretisierung der Verfluchungen. Was ist denn z.B. gemeint damit, daß man verflucht sein soll in Stadt und Land, beim Kommen und beim Gehen? Tatsächlich stellt die semantische Füllung der Formeln ein exegetisches Problem dar. ${ }^{3}$ Aus der sonstigen Verwendung derartiger Formeln im AT folgt, daß Dtn 28,16-19 keine selbständige Fluchreihe bilden konnte, die etwa als Fluch am Ende des deuteronomischen Gesetzes für sich existiert hätte. Erst die Kombination mit 28,15 und 28,20-44 liefert die Informationen, die 'ārûr-Formeln der Form 'ārûr + Nomen sonst bieten. 28,15 bringt Kontext und Begründung dafür, warum der Fluch überhaupt

${ }^{1} \mathrm{Vgl}$. SchotTrofF, Fluchspruch, 53. Die aus der Einheitsübersetzung zitierten Verse zeigen den Interpretationsspielraum beim Modus der Formeln.

2 Vgl. SCHOTTROFF, Fluchispruch, 14.

${ }^{3}$ Vgl. Plöger, Untersuchungen. 160-185; SCHOTTROFF, Fluchspruch, 60f; vdLingEN, „BW'-YS',"“60, 64, 66. 
gesprochen wird. 28,20-44 entfaltet, wie die Flüche von 28,16-19 sich im Leben der Verfluchten auswirken sollen. ${ }^{1}$ Wenn $28,16-19$ erst mit 28,15 und 28,20-44 den Informationsgehalt bieten, den man im AT sonst von diesen Formeln erwarten kann, dann folgt daraus, daß sie nicht älter sein können als 28,15.20-44. Altorientalische Beispiele zeigen, daß die Fluchgattung mit Anrufung der Gottheit den Abschluß eines Dokumentes bilden konnte. Dtn 28,20-44 lag also, vielleicht mit einem Bedingungssatz als Verbindungsglied zu den Stipulationen versehen, wohl bereits vor, als 28,16-19 entstand.

Im Gegensatz zum bösen Wort des Fluches konnte das gute Wort des Segens in der bärûk-Formel auch unmotiviert ausgesprochen werden (1 Sam 26,25; 1 Kön 2,45; Jes 19,25). So kann also für 28,3-6 nicht in gleicher Weise auf das Alter geschlossen werden wie beim Fluchpendant. Doch wo soll eine Reihe wie 28,3-6 existiert haben, bevor sie ihren Platz am Ende des Deuteronomiums erhielt? Für den Kult als Ort derartiger Formeln gibt es im AT keinen Beleg, noch nicht einmal für die Bildung von Reihen. Auch 28,3-6 dürfte also nicht der älteste Kem des Kapitels 28 sein. ${ }^{2}$

\section{4. 6. Traditionsgeschichte}

Die außerbiblischen Belege für die 'ārûr-Formel sind dürftig, und ihre Deutung ist unsicher. ${ }^{3}$ Ohne Gottesname kommt die Wurzel אר nur in der Siloam-Grabinschrift und in Khirbet Beit Lei vor. Zwei dieser Belege schließen einen Relativsatz an, so daß sie für den Vergleich mit 28,16-19 nicht in Frage kommen. ${ }^{4}$ Ein Graffito in Khirbet Beit Lei enthält die Buchstabenfolge אררח, was vielleicht ארר דו, ,er sei verflucht" bedeutet. Das wäre die mit Dtn 28,19.16 vergleichbare Form 'àrûr + Personalpronomen. Außerdem steht die Wurzel in Khirbet Beit Lei noch an der Wand, jedoch ohne Kontext. ${ }^{5}$

Aus Kuntillet 'Ajrud ist eine bārûk-Formel mit ליהוה bekannt, die nicht zum Vergleich mit Dtn 28 herangezogen werden kann. ${ }^{6}$ In einer Inschrift

\footnotetext{
1 Vgl. KLINE, Treaty, $125 \mathrm{f}$.

2 Vgl. Preuss, Deuteronomium, 154; vgl. MAYES, Deuteronomy, 352.

${ }^{3} \mathrm{Vgl}$. CRAWFORD, Blessing, 120.

${ }^{4} \mathrm{Vgl}$. CRaWford, Blessing, 123-126; Davies, Inscriptions, 88 (Nr. 15.001), 90 (Nr. 20.002).

5 Vgl. Crawford, Blessing, 127f; Davies, Inscriptions, 88f (Nr. 15.002 - 15.004).

6 Vgl. DaVIES, Inscriptions, 319 (Nr. 8.011.1, vgl. auch Nr. 25.003.2)
} 
aus Kuntillet 'Ajrud jedoch scheint die Form bārâk + Substantiv vorzuliegen. Man kann den Text folgendermaßen lesen und übersetzen:

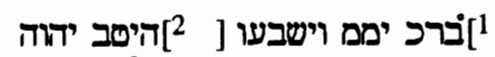

${ }^{1}$ Gesegnet seien die Tage, und sie sollen schwören ... ${ }^{2} \mathrm{JHWH}$ handelte gut ... . ${ }^{1}$

Man könnte im letzten Wort von Z. 1 auch ஜ lesen: Gesegnet seien die Tage, und sie sollen satt sein.

Der Rest des Gefäßes Samaria C 1220, das etwa aus dem Jahre 735 v. Chr. stammt, enthält die Inschrift ברכ אחזי, was möglicherweise ,gesegnet sei Ahazia" heißt. ${ }^{2}$ In En-Gedi wurde der Beginn eines Textes gefunden, bei dem auf die Buchstaben ברכ ein Personen- oder Gottesname folgt. ${ }^{3}$ Die Textfunde scheinen das Bild der alttestamentlichen Belege der Formeln zu bestätigen. Von Dtn 28,3-6.16-19 abgesehen, gehören sie nicht in Bereich ritueller Verpflichtung auf religiöse und rechtliche Ordnung. ${ }^{4}$

Das Gegenüber von Segen und Fluch und der Inhalt der Formeln, der Leib und Leben, Frauen und Kinder, aber auch die wichtigsten Lebensgüter, Nahrung und Vieh umschließt, veranlaßte Weinfeld, Dtn 28,3-6.16-19 mit griechischen Eiden zu vergleichen, die bei der Gründung einer Kolonie oder von den Mitgliedern einer Amphyktionie geschworen wurden. ${ }^{5}$ Es handelt sich jedoch nur um Entsprechungen des Inhalts, vergleichbare Formeln kommen nicht vor. So wird man auch die griechischen Eidessegnungen und -flüche in den großen altorientalischen Traditionsstrom einzuordnen haben, der für kurze Segens- und Fluchpassagen Inhalte überliefert, die in den Verträgen und Vereidigungen Hattis aus dem 2. Jt. v. Chr. ebenso anzutreffen sind, wie in Inschriften aus der persischen Zeit. ${ }^{6}$ Dtn 28,3-6.16-19 gehören ebenfalls in diese Tradition kurzer allgemein gehaltener Segens- und Fluchpassagen. Ihre konkrete Form mit dem Partizip Passiv des Verbums jedoch in vergleichbaren Texten des AO nicht zu finden. $^{7}$

1 Vgl. CRAWFORD, Blessing, 67; DAVIES, Inscriptions, 319 (Nr. 8.015.1).

2 Vgl. CRAWFORD, Blessing, 83; DAVIES, Inscriptions, 319 (Nr. 3.307.1).

3 Vgl. CRAWFORD, Blessing, 83f; DAVIES, Inscriptions, 91f (Nr. 20.002.4/6/7)

4 Vgl. SCHARBERT, „Geschichte,“ 14f, 23.

5 Vgl. „Emergence,“ 80-83; Deuteronomy 1-11, 5, 11-13.

6 Vgl. ScHOTTROFF, Fluchspruch, 67f; den hethitischen Vertrag CTH 53, wo Haupt, Frauen, Söhne, Enkelsöhne, Haus, Stadt, Land und Habe gesegnet (und verflucht) werden, und die lydisch-aramäische Bilingue aus Sardes KAI Nr. 260.

$7 \mathrm{Vgl}$. SchotTROFF, Fluchspruch, $13 \mathrm{f}$. 
6.5. $\operatorname{Dtn} 28,7-14$

7a JHWH gebe deine Feinde, die sich gegen dich erheben, geschlagen vor dich.

$7 \mathrm{~b} \alpha \quad$ Auf einem Weg ziehen sie aus gegen dich,

$7 b \beta \quad$ und auf sieben Wegen mögen sie fliehen vor dir.

8a JHWH beordere zu dir den Segen auf deine Speicher und auf alles Geschick deiner Hände,

$8 \mathrm{ba} \quad$ und er segne dich in dem Land,

$8 \mathrm{~b} \beta$ das JHWH, dein Gott, dir gibt.

$9 \mathrm{a} \alpha \quad$ JHWH wird dich erheben zum heiligen Volk für sich,

$9 \mathrm{a} \beta \quad$ wie er dir geschworen hat.

$9 \mathrm{~b} \alpha$ Denn du bewahrst die Gebote JHWHs, deines Gottes,

$9 b \beta \quad$ und du gehst auf seinen Wegen.

10a $\alpha$ Und es sehen alle Völker der Erde,

10aß daß der Name JHWHs über dir ausgerufen ist,

$10 \mathrm{~b}$ und sie fürchten sich vor dir.

$11 \mathrm{aba}$ Und JHWH wird dich beschenken zum Guten mit der Frucht deines Leibes und der Frucht deines Viehs und der Frucht deines Erdbodens in dem Land,

$11 \mathrm{~b} \beta$ von dem JHWH deinen Vätern geschworen hat,

$11 \mathrm{~b} \gamma$ [es] dir zu geben.

$12 \mathrm{a} \alpha_{1}$ JHWH öffne dir seinen guten Schatz, den Himmel,

$12 \mathrm{a}_{2}$ um deinem Land zur rechten Zeit Regen zu geben

12a $\beta$ und alle Taten deiner Hand zu segnen.

$12 \mathrm{~b} \alpha$ Und du wirst vielen Nationen leihen,

$12 \mathrm{~b} \beta$ und du. du mußt [selbst] nichts leihen.

יתן ידוה את־איביך הקמים עליך נגפים לפניך יחור יורי

כדרך אחד יצאו אליך

ובשבעה דרכים ינוסו לפניך

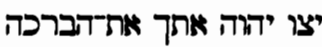
באסמיך ובכל משלח ירך מודר ידור

וברכך בארץ

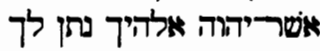
ימין יהוה לו לעם קדוש ניך

כאשטר נשבע-לך כי תשמר אתדמצות יהוה אלהיך והלכת בדרכיו

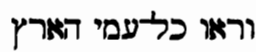
כי שם יהוה נקרא עליץ דיץ

ויראו ממך

והותרך יהוה לטובה בפרי בטנך ובפרי בהמתך ידור לורו ובפרי אדמתך על האדמה אשר נשבע יהוה לאבתיך

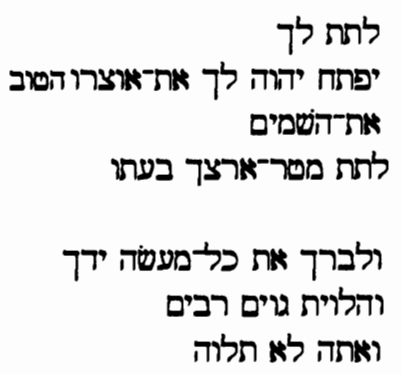


13aa Und JHWH wird dich zum Haupt und ונתנך ידוה לראש ולא לזיב nicht zum Schwanz machen,

13a $\beta$ und du wirst nur oben sein,

13ay und du wirst nicht unten sein.

והיית רק למעלה למסה

ולא תהיה למסה למעלה

$13 \mathrm{~b} \alpha_{1}$ Denn du hörst auf die Gebote JHWHs, deines Gottes,

$13 \mathrm{~b} \alpha_{2}$ die ich dir heute gebiete,

$13 \mathrm{~b} \beta_{1}$ um [sie] zu bewahren

$13 \mathrm{~b} \beta_{2}$ und auszuführen,

$14 \mathrm{a} \alpha_{1}$ und du weichst nicht ab von allen Wegen,

14a $\alpha$ die ich euch heute gebiete,

$14 \mathrm{a} \beta \quad$ rechts oder links

$14 \mathrm{~b} \alpha$ um hinter anderen Göttern herzugehen

$14 \mathrm{~b} \beta \quad$ [und] ihnen zu dienen.

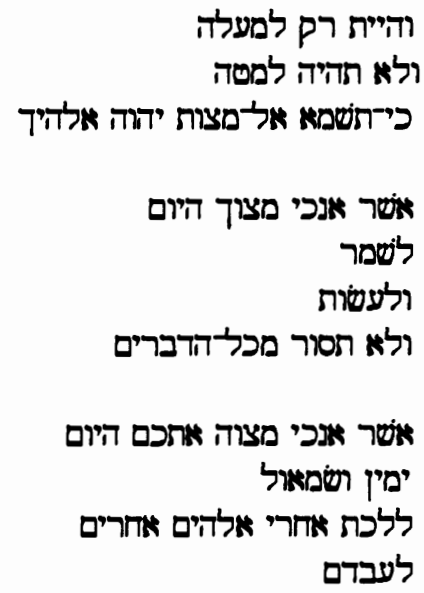

\subsection{Textkritik}

7a הקמים Einige $\mu$-Handschriften fügen für den A-Laut ein Aleph als mater lectionis ein: הקאמים.

7ba אחד [אד Eine ganze Reihe von $\mu$-Handschriften bietet das feminine Zahlwort dadurch begünstigt wurde, daß דרך im späteren Hebräisch als Femininum gilt. In den abweichenden Handschriften entsteht eine wohl unbeabsichtigte Inkongruenz zwischen femininem Zahlwort in $7 \mathrm{~b} \alpha$ und maskulinem Zahlwort in $7 \mathrm{~b} \beta$ bei demselben Nomen.

8a יצו Verbformen der benachbarten Promulgationsformeln.

$8 \mathrm{a}$ [באסמיך fügt eine mater lectionis ein, die die samaritanische Aussprache angibt: באסימיך = ,båsīmåk“"1.

8a, 12a ידך] Viele masoretische Manuskripte, $\mu$ und Fragmente aus der Geniza von Kairo bieten den Plural ידיך. Das Jod kann aber eine später verdrängte abweichende Pausaangabe ohne grammatische Bedeutung sein. ${ }^{2}$

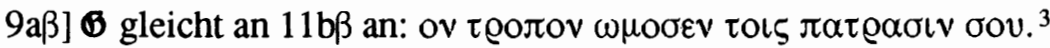

11a לפובה schreibt die maskuline Form לטגב.

\footnotetext{
1 Ben-Hayyim, Tradition, 145

2 Vgl. Penna, Deuteronomio, 227.

3 Vgl. Penna, Deuteronomio, 229.
} 
12a משר אח מת hingu, die jedoch keinen Bedeutungsunterschied bringt, da מטר durch das enklitische Personalpronomen des nomen rectum der Constructus-Verbindung sowieso determiniert ist.

14 [מצוה אתכם Einige masoretische Handschriften und $\mu$ haben das Objekt im Plural an den Singular der anderen Promulgationsformeln von Dtn 28 מצוך angeglichen. ${ }^{1}$

\section{5. 2. Sprachlich-syntaktische Analyse}

Die Kurzform צי fertigen die Übersetzung im Wunschmodus. ${ }^{2}$

Die gesamte Perikope ist durchsetzt mit geprägten Elementen deuteronomisch-deuteronomistischer Sprache. V. 14 besteht völlig aus deuteronomisch-deuteronomistischen Formeln. Er entspricht dem paränetischen Schema im Zusammenhang des Hauptgebotes (ohne Segenshinweis). ${ }^{3}$ Die Ausdrücke בכל משלח ידך in 8a und כל־מעשה ידך 12a kommen häufig im Deuteronomium vor. ${ }^{4}$ Die Landgabeformel in $8 \mathrm{~b} \beta$ und die Promulgationsformel in 13b sind geprägtes Sprachgut, ebenso wie die beiden mit geleiteten Motivationen in $9 b a$ und 13b, die mit מצות + שמר einen Ausdruck der Gesetzesbeachtung aufgreifen. ${ }^{5}$

\subsubsection{Semantische Analyse}

Unter den geprägten Elementen bezieht sich der Schwursatz ${ }^{6}$ von 28,9 auf die Erhebung $(\square / P / H)^{7}$ zum heiligen Volk ${ }^{8}$, die Israel selbst zugeschworen wurde, nicht den Vätern. Es geht also nicht um eine Väterverheißung, sondern um einen Schwur Gottes gegenüber dem Volk. Wann geschah dieser

\footnotetext{
1 Vgl. Penna, Deuteronomio, 229.

2 Vgl. NicCACCI, Syntax, 78; MULLER, ,Segen,“" 7/226, 10/229f.

3 Vgl. LOHFINK, Hauptgebot, 95f; WeINFELD, School, 304, 320.

4 כל משלדח ידך: Dtn 12,7.18; 15,10; 23,21; 28,8.20. Dieser Ausdruck kommt außerhalb des Deuteronomiums im AT nicht vor. כל מעשה ידך: Dtn 2,7; 14,29; 16,15; 24,19; (27,15);

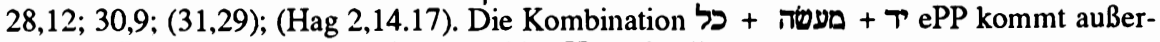
halb des Deuteronomiums nur in den beiden Haggaistellen vor.

5 Vgl. LoHFINK, Hauptgebot, 299-302.

${ }^{6}$ Dieselbe Formel steht: Gen 50,6; Ex 13,11; Dtn 2,14; 13,18; 19,9; 26,15; 29,9.12; Jos 6,22; Ri 2.15; 2 Sam 3,9; 1 Kön 1,30. Vgl. GIESEN, 27 Anm. 64.

${ }^{7}$ Die Langform $\mathrm{a} / \mathrm{H}$ ist Indikativ Futur, denn die Erhebung zum heiligen Volk ist nicht Inhalt des Segens, sondern Inhalt des Gottesschwures, ebenso wie in V. 11 der Segen sich auf die Vermehrung bezieht, die Landgabe jedoch zum Gottesschwur gehört.

8 kommt noch Ex 19,6; Dtn 7,6; 14,2.21; 26,19; 1 Sam 12,22; 2 Sam 7,23; 24,1; Jes 62,14 vor. Vgl. WEINFELD, School, 327f.
} 
Schwur? Er scheint in Dtn 26,19 vollzogen zu werden, wo ausdrücklich ein Sprechakt Gottes erwähnt wird. ${ }^{1}$ Der Gottesschwur ist jedoch bedingt. Der $k \hat{\imath}$-Satz von 9ba kann als Kausalsatz übersetzt werden oder als Konditionalsatz. ${ }^{2}$ An den Konsequenzen für die Zugehörigkeitsformel in 9a ändert sich nichts. Die Zugehörigkeit zu Gott ist in beiden Fällen abhängig vom Gebotsgehorsam, gleichgültig, ob dieser sie bedingt oder begründet. Eine Gegenleistung des Volkes ist gefordert. ${ }^{3}$ Dies entspricht der zweigliedrigen Zusage von 26,17-19. ${ }^{4}$ Die zur Motivation des Schwursatzes in 9b gehörende Wendung והלכת בדרכו erinnert an Dtn 26,17 und ist wieder formelhaft. ${ }^{5}$

Der zweite Schwursatz in $11 \mathrm{~b} \beta$ bezieht sich auf das Land (אדמה) und die Väterverheißung. ${ }^{6}$ Der Landverheißungseid wird mit den Segensgaben in der Natur verknüpft. Die Reihe aus 11a unterscheidet sich von den ähnlichen Formulierungen in Dtn 7,19; 28,4.13 und ähnelt eher 30,9 mit seinem יתר/H. Giesen lehnt es im Gefolge von Seitz ab, in 28,11 sekundäre Ergänzungen auszuscheiden und datiert die beiden Schwursätze 28,9.11 in die vorexilische Zeit. ${ }^{7}$ Auch V. 10a $\alpha$ enthält mit על נקרא + שם + ני eine geprägte Wendung. ${ }^{8}$

Zwischen diesen geprägten Elementen stehen Passagen mit Parallelen im Fluch. V. 7 ist das Pendant zu V. 25, V. 12b.13a das Pendant zu V. 43f, V. 11a enthält eine Aufzählung, die ähnlich in V. 4.18.51 steht. Die Parallelen zum Fluch kleiden ein Fachwerk aus deuteronomisch-deuteronomistischen Formeln und Wendungen aus. Für genuin wirkende Formulierungen bleibt nur wenig Raum:

\footnotetext{
1 Vgl. WeINFELD, „Emergence,“ 77; LOHFINK, „Ältesten,“ 33f.

2 Vgl. Hulst, „Opmerkingen,“ 343f.

3 Vgl. GIESEN, Wurzel, 304f.
}

${ }^{4}$ Es widerspricht jedoch den Aussagen von Dtn 7,8 und 9,5, wo die Heiligkeit Israels gerade nicht in seiner Leistung, sondern nur in Gottes Liebe gründet. Die Segensaussagen von Dtn 7,9 dürften daher jünger sein als Dtn 28,9, das den ebenso konditional/kausal gefaßten Formulierungen von Ex 19,5 ähnelt. Vgl. HuLST, „Opmerkingen,“ 344f; GIESEN, Wurzel, 305.

5 Dtn 8,6; 19,9; 26,17; 30,16; Ri 2,22; 1 Kön 2,3; 3,14; 11,33.34. Vgl. WEINFELD, School, 333.

6 Dieselbe Formel steht: Dtn 7,13; 11,9,21; 30,20; 31,20. Vgl. GIESEN, Wurzel, 24 Anm. 56.

7 Vgl. Wurzel, 290, 317.

${ }^{8}$ Am 9,12; Jer 14,9; 15,16; ähnlich: 2 Sam 6,2; 12,28; Jes 4,1; 63,19; Da 9,18; Ps 49,12; 2 Chr 7,14. Vgl. WEINFELD, School, 325, 327. 


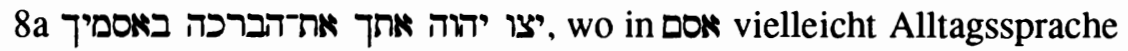
eindringt, die auch in den Sprichwörtern begegnet. ${ }^{1}$

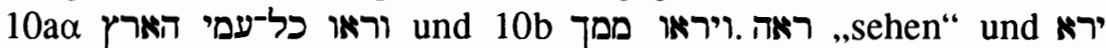
„fürchten" sind in westsemitischen Texten belegte Kombinationen ${ }^{2}$ und kommen im Deuteronomium noch zusammen in 7,19 und 20,1 vor. In Dtn 7,19 sieht Israel die Wunder des Exodus und fürchtet sich trotzdem vor den Völkern (עם), in 20,1 soll Israel sich nicht fürchten, wenn es die vielen Feinde sieht (עם רבח).

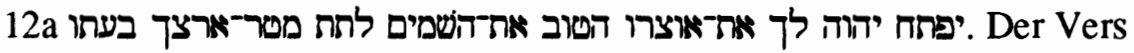
bildet das thematische Gegenstück zu 28,23f, verbunden durch die Lexeme פתח את-אוצרו הטוב Nur der Ausdruck מטר und fiur die Sprache des AT originell. Er setzt den Himmel mit einem Schatzhaus gleich, aus dem Gott sein Volk beschenkt. Der Regen ist eine Kostbarkeit. Zugleich wird die Verfügungsgewalt des Gebers deutlich. ${ }^{3}$

\subsection{Literarkritik}

Noth schied alle geprägten Wendungen als nachträgliche Zusätze aus. Übrig bleibt dann nur ein Torso aus 28,7.8a.11a.12a, da Noth auch in 12b.13a eine von 28,43.44 abhängige Ergänzung erblickt. ${ }^{4}$ Krämer rekonstruierte eine ältere Segensreihe aus 28,8.12a, in die später V. 11 eingefügt wurde, und eine jüngere, in der die Stellung Israels gegenüber den Völkern beschrieben wird, und die aus $28,7.9 \mathrm{f} .12 \mathrm{a}$ bestand. ${ }^{5}$

Während Noth und Krämer noch einen rudimentären Segen dem Fluch von V. 20-44 gegenüberstellen und Irwin und Plöger im Segen sogar die Vorlage für den Fluch sehen, ${ }^{6}$ setzt sich in der jüngeren Forschung die von Seitz vertretene Überzeugung durch, der Segen 28,7-13 sei zu Gänze eine

${ }^{1} \mathrm{Vgl}$. WeINFELD, School, 310 mit Verweis auf Spr 3,10 und den hebräischen Brief KAI Nr. 200.

2 Vgl. Avishur, Word-Pairs, 702.

${ }^{3} \mathrm{Vgl}$. Houtman, Himmel, 253,258f. Ähnliche Formulierungen sprechen von den Schatzkammern (i (13) des Sturmwindes (Ps 135,7 = Jer 10,13; 51,16), des Schnees und des Hagels (Ijob 38,22), der Urflut (Ps 33,7) oder der Waffen des Zorns (Jer 50,25)

${ }^{4} \mathrm{Vgl}$. „Fluch,“ 131f/159f. In Anm. 12 nimmt er Stellung zum Bezug zwischen 28,12f und 15,6: ,.Sollte nicht der in dem sekundären Stück Dtn. 15,4-6 stehende Satz 15,6 seinerseits erst von Dtn. 28,12b.13a abhängen? Mit Rücksicht auf V. 8 wäre nur ein anderes Verbum für ,leihen" und ,verleihen" gebraucht worden."

5 Vgl. Numeri, 507-509.

6 Vgl. IRWIN, „Criterion,“ 341f; PLOGER, Untersuchungen, 189 Anm. 237: „Dt 28,13 ist älter als Dt 28,44.“ Vgl. ebd. 150. PLOGER vergleicht $28,12 \mathrm{~b}$ mit 15,5 , obwohl er zuvor auf eine mögliche Beeinflussung von 15.5 durch 28,1 hingewiesen hatte. Gleiches müßte dann aber auch für Motiv des Ausleihens gelten. 
späte Komposition, die erst nach dem Fluch 28,20-44 entstand. ${ }^{1}$ Auf literarkritische Ausscheidungen kann verzichtet werden, da formelhafte Wendungen allein kein ausreichendes Kriterium sein können und die Herausarbeitung eines Metrums bereits ein gattungsgeschichtliches Vorurteil impliziert, wie Plöger zeigt, wenn er in 28,7-13 nach dem Rhythmus sucht, den man von einem liturgischen Text erwarten dürfe. ${ }^{2}$

28, 14 wird allgemein als sekundärer Zusatz angesehen. Dafür sprechen die Dopplung gegenüber V. 13b, der Numeruswechsel, der sonst im Segen nicht mehr vorkommt, und die rein formelhafte Sprache. ${ }^{3}$

Beläßt man die deuteronomisch-deuteronomistischen Wendungen in 28,7-13, so bilden sie ein Gerüst, das wie ein Fachwerk den Text durchzieht. Dadurch unterscheidet sich der Aufbau dieser Perikope von 28,2044 , wo solche geprägten Elemente nur eine marginale Rolle spielen und als sekundär erkannt werden konnten. 28,7-13 ist anders gestaltet als der Fluch.

\subsubsection{Redaktionsgeschichtliche Schlußfolgerungen}

Sieht man von V. 8a.10.12a ab, scheint Dtn 28,7-14 aus fertigen Versatzstücken zusammengestellt zu sein. Die Perikope erweckt den Eindruck der Fabrikation und setzt in ihren Bezügen zu Landnahmeaussagen die Historisierung des Deuteronomiums voraus. Darin könnte ein Hinweis auf ihr redaktionsgeschichtliches Verhältnis zu 28,20-44 liegen.

28,7-13 scheint zwar vorexilisch zu sein, dürfte aber kaum von demselben Verfasser wie 28,20-44* stammen. Dort fehlt ein Formelgerüst, wie es 28.7-13 durchzieht. Wendungen wie פרי בטנך und (28,11 vgl. V. 4.18) kommen in Dtn 28,20-44* nicht vor, obgleich durchaus vom Vieh und den Kindern gesprochen wird (28,31f.41). V. 12f ist, wie Seitz gezeigt hat, jünger als die parallelen Fluchverse 28,23f.43f. ${ }^{4}$ Die Nennung der גוים „Nationen“ in V. 12, die das Bild zwischenstaatlicher Geldgeschäfte entwirft, paßt nicht zum Sprachgebrauch von 28,20-44*, wo konsequent das Wort עם verwendet ${ }^{5}$ und in V. 43f vom ר, dem „Fremden“, gesprochen wird, der mitten in Israel wohnt. Außerdem wird mit der Erwähnung des Schwurs, den Gott gegenüber Israel geleistet hat (V. 9a), wohl auf Dtn

1 Vgl. SeITZ, Studien, 275; MAYES, Deuteronomy, 350, 353; PrEuSS, Deuteronomium, $155 f$.

2 Vgl. Untersuchungen, 145-150; SEITZ, Studien, $275 f$.

3 Vgl. Steuernagel, Übersetzung, 100; Plöger, Untersuchungen, 138 Anm. 31; SEITZ, Studien, 266; BERGE, Zeit, 297.

$4 \mathrm{Vgl}$. Studien, 259f.

528,36 ist sekundär. 
26,17.19 zurückverwiesen. Dtn 26,16-19 enthält vielleicht Reminiszenzen an den Verpflichtungsakt des Joschija. ${ }^{1}$ Ist dies der Fall, kann 26,16-19 nicht schon Bestandteil der Urkunde gewesen sein, auf die vereidigt wurde. Dann gehört aber auch der Segen, der auf 26,16-19 anspielt, erst zu einer Ausgabe des Deuteronomiums, die nach Joschijas Verpflichtungsakt entstand.

Da 28,7-13 hier als einfache Einheit betrachtet wird, muß es als ganzes jünger sein als $28,20-44 *{ }^{2}$ Die einzige Historisierung in $28,20-44 *$ fand sich in der Landnahmeformel von V. 21b, die sekundär sein dürfte. Dem stehen in 28,7-13 drei historisierende Formeln gegenüber (8b.11b.13b).

Ein historisiertes Deuteronomium gehörte wohl zum Erzählzusammenhang von Dtn 1 - Jos 22, den Lohfink deuteronomistische Landeroberungserzählung nennt (DtrL). ${ }^{3}$ Der Einbau des Deuteronomiums mit einem Grundbestand von Dtn 28 in DtrL könnte der geschichtliche Anlaß gewesen sein, zum Fluch 28,20-44 einen Segen zu komponieren. Dies scheint gerade dann denkbar, wenn man die Entstehung von DtrL zur Regierungszeit Joschijas ansetzt. Die Editoren schufen aus weitgehend vorgegebenen sprachlichen Elementen ${ }^{4}$ Dtn 28,7-13 und stellten es vor den älteren Fluch 28,20-44, der wohl schon in der Bundesurkunde Joschijas stand. Sie wollten damit das Leben im Land unter eine positive Verheißung rücken. ${ }^{5}$ Die Umstellungen gegenüber dem Fluch können daraus resultieren, daß man Chiasmen schaffen wollte ${ }^{6}$, sie können aber auch einfach durch Attraktion des V. 7 durch die Wurzel $\mathrm{k}$ ' in V. 6 hervorgerufen sein. ${ }^{7}$ Die korrespondierenden Aussagen von V. 12b.13a/43f behalten ihren Ort am Schluß des jeweiligen Abschnitts. Der folgende Überblick über den Segen im AO legt nahe, daß die Komposition des Segens zugleich ein Abrücken von assyrischen Mustem der Textgestaltung und eine Rückbesinnung auf westliche Traditionen bedeutet. In den westlichen Verträgen aus Huatti (2. Jt. v. Chr.) und Sefire (1. Jt. v. Chr.) findet man nämlich auch Segnungen.

Zur Vertragskonzeption in Syrien-Palästina gehörte im Gegensatz zu den einseitigen Verpflichtungen im neuassyrischen Reich, daß der Bundesherr bzw. Götter die Loyalität auch bei nicht paritätischen Verträgen be-

\footnotetext{
${ }^{1} \mathrm{Vgl}$. BrauliK, Testament, 65, 72; Deuteronomium II, $212 \mathrm{f}$.

$2 \mathrm{Vgl}$. PREUSS, Deuteronomium, 156.

3 Vgl. „Kerygmata," $92 \mathrm{f}$.

${ }^{4}$ Zur Herkunft der Formulierungen vgl. auch PLOGER, Untersuchungen, 185-189.

5 „Pour avancer, l'homme a besoin d'un stimmulant, d'une espérance.“ TROADEC, „Richesse," 50.

6 Vgl. WeINFELD, „Traces,“ 420 Anm. 1.

7 Vgl. Rose, 5. Mose, 535.
} 
lohnen. Dies zeigt sich z. B. in den Briefen des Königs 'Abdi-Hueba von Urusalim im 2. Jt. v. Chr., der vom ägyptischen König erwartet, daß dieser ihm aufgrund seiner Loyalität Truppen schickt. ${ }^{1}$ Auch private und zwischenstaatliche Verträge in Israel, von denen das AT berichtet, enthielten bilaterale Verpflichtungen. Der Untergebene war nicht einfach durch die Übermacht seines Herrn zur Loyalität gezwungen, sondern der Vertragsherr brachte Positives in das Vertragsverhältnis ein. Bei dem Vertrag mit den Gibeonitern beschwört nur der Bündnisherr Israel seine positive Leistung (2 Sam 21,1-14). ${ }^{2}$ Auch die Bündnisse der Patriarchen zeigen, daß der Vertragsherr Leistungen erbringt. So ist Verpflichtung des Abimelech beim Vertrag mit Abraham (Gen 20; 21,2234). ${ }^{3}$ Auch Bündnisgesuche, die judäische Könige an andere Herrscher senden, implizieren die Vorstellung, daß der Herrscher, der das Bündnis annimmt, zu einer Leistung zugunsten Judas verpflichtet ist (1 Kön 15,1820; 2 Kön 16,7-9). ${ }^{4}$

Betrachtet man das Bundesverhältnis zwischen JHWH und Israel unter dem Aspekt des bilateralen Charakters, der den Verträgen der Völkerschaften der Levante bereits seit den Tagen des hethitischen Reiches eigen ist, so wird verständlich, warum der Segen ein Element bildet, in dem das Deuteronomium den hethitischen Verträgen des 2. Jts. v. Chr. ähnelt, obgleich man seine Entstehung fast 1000 Jahre später ansetzt. ${ }^{5}$ Eine Abkehr von neuassyrischen Modellen und eine Aufwertung der eigenen Tradition führte anscheinend in den späten Regierungsjahren Joschijas zur Komposition von Dtn 28,7-13.

\section{6. Exkurs: Segen im Alten Orient}

Dem Segen von Dtn 28 wurde in der Forschungsgeschichte niemals ein so ähnlicher altorientalischer gegenübergestellt, der Ähnlichkeiten aufweist, die so auffällig wären wie die zwischen dem Fluch und den bisher besprochenen Paragraphen der VTE. Es gibt daher kein altorientalisches Dokument, das im Blick auf Dtn 28,3-14 besonders zu analysieren und auf seine

\footnotetext{
$1 \mathrm{Vgl}$. Moran, Lettres, 506-520.

2 Vgl. Kalluveettil, Declaration, 121f; GIESEN, Wurzel, 52-55; 53.

3 Vgl. GIESEN, Wurzel, 47-52.

4 Vgl. KalluveETTIL, Declaration, 122-139. 2 Kön 16,9 besagt nicht, daß Tiglat-Pileser die judäische Vorstellung von der Verpflichtung des Oberherrn teilt. Vielmehr verbinden sich hier die Interessen Judas mit denen Assurs, weil es bei der Unterwerfung von Damaskus um die Niederschlagung einer antiassyrischen Konspiration geht.
}

5 Vgl. McCARTHY, Treaty 1963, 125; WeINFELD, Deuteronomy 1-11, 8f. 
interne Struktur zu befragen wäre. Hier soll statt dessen ein knapper Gang durch die Geschichte des Segens im AO unternommen werden, der anhand charakteristischer Beispiele die Entwicklung und die wesentlichen Motive von Segnungen nachzeichnet. Dabei werden zunächst zwischenmenschliche Segensvorgänge behandelt und anschließend Texte, in denen Götter segnen.

Als Bestandteil eines Vertrages scheint ein Segen erstmals in einem altassyrischen Text aus Tell Leilan belegt. ${ }^{1}$ Die sumerischen Segensformeln des Kodex Lipit-Ištar belohnen den Erhalt der Inschrift:

.${ }^{45} \mathrm{Möge}{ }^{40}$ dem, der keine ${ }^{39}$ bösen Handlungen ${ }^{40} \mathrm{an}$ ihr vornimmt, ${ }^{41} \mathrm{der}$ das, was ich errichtet habe, nicht zerstört, ${ }^{42}$ die Inschrift darauf (nicht) tilgt ${ }^{43}$ (und) seinen (eigenen) Namen nicht darauf schreibt, ${ }^{44}$ langdauerndes Leben ${ }^{45}$ geschenkt werden. ${ }^{46}$ Möge er im Ekur den Nacken bis zum Himmel erheben. ${ }^{47}$ (und) die leuchtende Stim Enlils ${ }^{48}$ (ihm) vom Himmel entgegenblicken." ${ }^{\text {"2 }}$

Der Segen des Kodex Lipit-Ištar nennt zwei Segensmotive, die im ganzen AO verbreitet waren, das lange Leben und das gnädig zugewandte Antlitz der Gottheit. Die dazu passenden Fluchthemen, Verkürzung des Lebens und böser Blick, sind in Mesopotamien sehr häufig belegt. Im Kodex LipitIštar ist der Segen kürzer als die erhaltene Fluchpassage, und seine guten Wünsche sprechen andere Themen an als der Fluch.

In Verträgen der altbabylonischen Zeit blieben keine Segenspassagen erhalten. ${ }^{3}$ Dafür überliefert der KH einen Segen, der den Respekt vor dem Gesetz belohnt:

Kol. XLIX ..... ${ }^{11}$ so möge diesem Manne ${ }^{12}$ wie mir, ${ }^{13}$ dem König der Gerechtigkeit, ${ }^{14}$ der Sonnengott seinen Stab ${ }^{15}$ lang machen. ${ }^{16}$ seine Leute ${ }^{17}$ möge er in Gerechtigkeit hüten." 4

Der Segen wurde ganz auf einen Herrscher abgestimmt. Ein langes Szepter symbolisiert lange Regierungszeit, die für den Herrscher mit dem Nimbus der Gerechtigkeit umgeben wird. Während die lange Regierungszeit im Segen von Šamaš erwartet wird, wendet man sich mit dem thematischen Pendant im Fluch an Anu, der den Glanz des Königtums wegnehmen, das Szepter zerbrechen und die Geschicke verfluchen soll. ${ }^{5}$ Der Fluchabschnitt

\footnotetext{
1 Vgl. EDEM, „Treaty,“ 199, 204, 206.

2 LUTZMANN, ,Isin,“ $30 \mathrm{f}$.

${ }^{3}$ Vgl. DuRAND, ,Fragments,“ 115; ChARPIN, „Zimri-Lim,“" $143 \mathrm{fe}$

4 BORGER, ,Codex," 77.

5 Das Stichwort gišGIDRI-šu ,,sein Zepter“ verknüpft Šamašsegen und Anufluch (Kol. XLIX Z. 14f, 50). Das Wort fehlt zusammen mit derartigen Motiven im Šamašfluch des $\mathrm{KH}$.
} 
im KH ist viel länger als der Segen. Im Gegensatz zum Kodex Lipit-Ištar erfahren jedoch alle Motive des Segens ihre Umkehrung im Fluch.

Größere Parallelität zwischen Segen und Fluch findet man in den hethitischen Verträgen. Umfang und Inhalte entsprechen einander weitgehend. ${ }^{1}$ Doch auch unter den Verträgen aus Hatti gibt es einige, deren Fluch gegenüber dem Segen erweitert ist. ${ }^{2}$ Meist steht der Fluch in den hethitischen Verträgen vor dem Segen. Doch diese Stellung ist nicht unbedingt verpflichtend, wie die Abweichung in der Reihenfolge bei der ägyptischen und der babylonischen Version des Vertrags zwischen Hattušili III. und Ramses II. zeigt. Die Motive der formelhaften Fluch- und Segenspassagen weisen eine Ähnlichkeit mit Dtn 28,3-6.16-19 auf. Auch dort ist von Stadt, Land, Nachkommenschaft, (Vieh) und allem Besitz die Rede. Allerdings formulieren die hethitischen Texte den Wunsch als Aufzählung in einem Satz, während die Bibel ihn in mehrere parallele Sätze aufgliedert. An den Fluch- und Segensabschnitt des 2. Vertrages zwischen Suppiluliuma und Šattiwaza (Matiuaza/Kurtiwaza) schließt sich eine Rede des Šattiwaza an, in der er einen bedingten Fluch und Segen ausspricht, der dem vorhergehenden nicht gleicht (Z. 44-62), sondern in neuen Worten und Bildern dieselben Themen anspricht. Vielleicht liegt es an dieser Verschriftlichung der Selbstverfluchung und -segnung, wenn im Kolophon ausdrücklich die Vollständigkeit der Tafel vermerkt wird. ${ }^{3}$

Auf einigen mesopotamischen Inschriften findet sich ein kurzer Segen zum Inschriftenschutz. Die assyrischen Königsinschriften wiederholen stereotyp einen Satz, der bereits bei Puzur-Aššur III. belegt ist und noch bei Sanherib vorkommt: GN wird sein Gebet erhören. Diese Aussage ist nicht wie die meisten babylonischen Segnungen im Prekativ, sondern im Indikativ formuliert und bezieht sich auf jene königlichen Nachfahren, die die Inschrift salben und ehren, bzw. das Gebäude instand setzen. ${ }^{4}$ Wieviele und welche Gottesnamen genannt werden, hängt davon $a b$, für welchen Gott Gebäude, Weihegabe oder Inschrift bestimmt waren. In neuassyrischer Zeit werden die Segenswünsche in Bauinschriften manchmal ausführlicher. So heißt es in der „Großen Prunkinschrift" Sargons II.:

1 Vgl. z.B. den Vertrag CTH 91 zwischen Hatušili III. und Ramses II.; CTH 53 zwischen Šuppiluliuma und Tette Rs. Kol. IV Z. 48-57, WeIDNER, Dokumente, 68-71; DEL MONTE, Trattato, 154f; CTH 49 zwischen Šuppiluliuma und Aziru Rs. Z. 12-20, WEIDNER, Dokumiente, 75; DEL MONTE, Trattato, $126 \mathrm{f}$.

2 Vgl. die Verträge CTH 51, 52 zwischen Šuppiluliuma mit Šattiwaza, WEIDNER, Dokumente, 33, 35, 51, 53.

${ }^{3}$ Vgl. CTH 52 Rs. Z. 53- 63, WeIDNER, Dokumente, 57

${ }^{4} \mathrm{GN}$ ikribšu išimmê. Vgl. GraYson, Inscriptions I, 35 § 217; ,,Sennacherib,“ 96 Z. 125. 
"(186-188) Auf diese Stadt, die [ich mir] stets von ganzem Herzen gewünscht habe, [und] diesen Palast, möge Assur, der Vater der Götter, beständig mit stahlender, reiner Miene blicken, und bis in fernste Zeiten möge er (den Befehl) zu ihrer Erneuerung aussprechen. ${ }^{(189-190)}$ Möge (der Befehl dazu) aus seinem reinen Munde kommen. Ein schützender Šēdu (und) ein bewahrender Gott mögen Tag und Nacht in ihnen verharren und ihnen nicht von der Seite weichen. (191) [Auf seinen] Befehl [hin] soll der König, der sie erbaute, ein hohes Alter erreichen, höchstes Alter erlangen. (192-193) ,Bis in ewige Zeiten möge ihr Erbauer bestehen', möge über seine reinen Lippen kommen. (193194) Wer in ihnen wohnt, möge mit gesundem Leib, jubelndem Herzen und glänzender Laune darin jauchzen (und) Freude im Übermaß finden!“”

Zwar steht auch hier das hohe Lebensalter für den König im Vordergrund, aber der Segen weitet sich auf die Stadt und ihre Bewohner. Schutzgeister, Gesundheit und Lebensfreude erscheinen als Gegenstück zu Fluchmotiven, wie sie z.B. in VTE $\$ 56$ auftauchen. ${ }^{2}$

Aus Babylonien sind einige Kudurrus mit Segnungen erhalten:

\section{B.1172.3: MDP 2, 99ff:}

Kol V. ${ }^{15}$ [amēlu] Šuātu ilāni rabûti ša šamê u erșeti ${ }^{16}$ [dam] qiš lippalsūšuma ${ }^{17}$ balāt ùmī ma'dūti ${ }^{18}$ šanāt țuhdi nuhši u hengalla ${ }^{19}$ adi balțu ana isqūšu likinnū

${ }^{15}$ Besagten [Menschen] mögen die großen Götter des Himmels und der Erde ${ }^{16}$ freundlich anblicken und ${ }^{17}$ ein Leben zahlreicher Tage, ${ }^{18} \mathrm{Jahre}$ überreicher Fülle, der Fruchtbarkeit und Überfluß, ${ }^{19}$ solange er lebt, als seinen Anteil festsetzen. ${ }^{3}$

\section{B.1172.4: MDP 10, 87ff:}

Kol. III ${ }^{4}$ awilu šuātu Anu u Innin ${ }^{5}$ damqiš lippalsūšuma ${ }^{6} \bar{u} m \bar{\imath}$ rubûti lirrik 7 šanāt mašrê li'atter ${ }^{8}$ egirrû magāri lirdǐšu

${ }^{4}$ Besagten Menschen mögen Anu und Innin ${ }^{5}$ freundlich anblicken und ${ }^{6}$ die Tage der Herrschaft möge er! lang machen, ${ }^{7}$ Jahre des Reichtums möge er vermehren, ${ }^{8}$ ein Wort der Zustimmung möge ihn begleiten. ${ }^{4}$

\footnotetext{
${ }^{1}$ FuCHS, Inschriften, 355. Ähnlich lautet auch der Segen auf der Schwelleninschrift Typ IV. Vgl. ebd. 361f.

2 Vgl. aus VTE $\S 56$ zum reinen, strahlenden Blick Z. 474, zum Šèdu Z. 493, zu den wörtlich „Wohlbefinden des Fleisches, Freude des Herzens und Leuchten der Leber", FucHS, Inschriften, 355, zu übersetzenden Wünschen Z. 489f.

${ }^{3} \mathrm{Vgl}$. STEINMETZER, „T-Formen,“ 88f; UNTERLECHNER, Fluchformeln, 68.

${ }^{4}$ Vgl. UNTERLECHNER, Fluchformeln, 69. Obwohl zwei Gottheiten angerufen werden, steht nur das erste Verb im Plural, die übrigen im Singular.
} 
BE I/1 83 aus der Regierungszeit des Enlil-nadin-apli (1102-1099 v. Chr.) enhält keinen Fluch, aber einen Segen:

Rs. ${ }^{15}$ Nammu u Nanše bēelètu [ș]īrātu ${ }^{16}$ kīniš lippalsāšuma ${ }^{17}$ itti Ea bān kāla 18 šimat balāti liš̌māăšu 19 ümī labāri u šanāt mēšari 20 ana širikti lišrukāšsu

${ }^{15}$ Nammu und Nanše, die erhabenen Herrinnen, ${ }^{16}$ mögen ihn gnädig anblicken ${ }^{17}$ und mit Ea, der alles bildet, ${ }^{18}$ ihm ein Geschick des Lebens bestimmen,

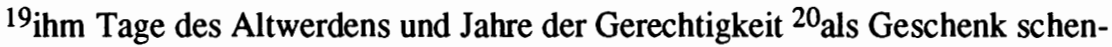
ken. ${ }^{1}$

B.1070.2: Sumer 36, 135 formuliert den ersten Teil des Segens in Nominalsätzen:

Kol. V ${ }^{8}$ Enlil lū tukultašu ${ }^{9}$ Ninurta u Nusku lū rēșušu ${ }^{10}$ šumšu zēršu per'ašu ${ }^{11}$ ina pî șalmāt qaqqadi ${ }^{12}$ likūn dūr ūmì

${ }^{8}$ Enlil sei sein Beistand, ${ }^{9}$ Ninurta und Nusku seine Hilfe, ${ }^{10}$ sein Name, sein Same und sein Nachkomme möge ${ }^{12}$ für die Dauer der Tage ${ }^{11_{i m}}$ Mund der Schwarzhäuptigen ${ }^{12}$ feststehen. ${ }^{2}$

$\mathrm{Zu}$ den bisher besprochenen Segensinhalten tritt hier der Erhalt der Nachkommenschaft, die Umkehrung eines der wohl verbreitetsten Fluchthemen Mesopotamiens.

Das akkadische Verb karābu bedeutet ,beten, weihen, segnen, grüßen“. ${ }^{3}$ Am semantischen Spektrum des Wortes erkennt man, daß eine genaue Abgrenzung des Segens von den anderen Verwendungsmöglichkeiten des Wortes nicht immer klar möglich ist. Der Segen im zwischenmenschlichen Bereich besitzt einen festen Platz in Grußformeln. In den Briefen wurde anfangs der Wunsch um Leben GN A $u$ GN B liballitüka verwendet. ${ }^{4}$ In der neuassyrischen Zeit findet man erstmals den allgemeinen Segen ,iläni likrubūka"s. Die Verwendung des Nomens šulmu als Inhalt des Grußwunsches findet seine Entsprechung im שלם, das verbunden mit JHWH in den

1 Vgl. Peiser, Texte, 66f; Ungnad, „Geschichte,“ 97; UnTERLechner, Fluchformeln, 69.

2 Vgl. UNTERLECHNER, Fluchformeln, 69.

${ }^{3} \mathrm{AHw}, 445$. Wie das hebräische ברך kann das akkadische karābu auch die Gottheit zum Objekt haben. Es bedeutet etwa ,huldigen“" und gab der Gattung der ikribu-Gebete den Namen. Vgl. LANDSBERGER, „Wort,“ 303-306.

4 Vgl. LANDSBERGER, „Wort,“ 300, ebd. 302: „Der profane Gruss ... lautete sum. silimma ,Bleibe heil“, ... (...); altbabyl. lü šalmäta, später ausschliesslich lü šulmu. (...) Danach bestand das stereotype Begrüssungsgespräch aus dem šulmu-Wunsche, der Versicherung des eigenen šlmu und der Erkundigung nach dem šulmu des Angeredeten. Dies letztere (schriftlich = ana šulmi šapäru, ...; mündlich = šlma ša'ālu) von Zeit zu Zeit zu tun ist Freundes- und Untergebenenpflicht. So wird šulma ša'àlu zum Ausdruck für ,begrüssen ' ...

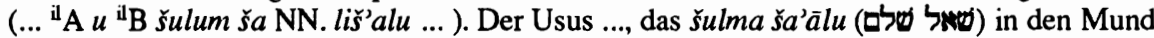
der Gottheit zu legen, begegnet in Kanaan ... schon zur Amarna-Zeit (VAB II, Nr. 96f.) und ist in den aramäischen Briefen von Elephantine das ausschliesslich Übliche."

5 LANDSBERGER, „Wort,“ 301. 
Arad- und Lachisch-Briefen belegt ist. ${ }^{1}$ Für höher gestellte Persönlichkeiten verfaßte man auch umfangreichere Segens- oder Glückwunschlisten. ${ }^{2}$ Der Sprecher kann sich unter Verwendung des Wortes karābu auch selbst segnen. ${ }^{3}$

$\mathrm{Zu}$ den Selbstsegnungen gehören viele Formeln auf mesopotamischen und westsemitischen Weiheinschriften, die Crawford als Segen klassifiziert. In diesen Formeln wird nicht das positive Verhalten anderer Menschen mit dem Segen belohnt, sondern von der Gottheit, die die Weihegabe empfing, ein Segen für den Spender erbeten. Selbstsegnungsformeln westsemitischer Inschriften wünschen zumeist langes Leben ${ }^{4}$ und dauerhafte Herrschaft. ${ }^{5}$

Eine eigene Segensgattung bilden die Segenswünsche, die für den König, z.B. bei seiner Krönung, gesprochen werden. Sie können zur größeren Gruppe der Fürbitten für den König gezählt werden. Watanabe hat einige Segnungen für assyrische Könige gesammelt. ${ }^{6}$ Reiner veröffentlichte Segnungen, die offenbar musikalisch untermalt werden sollten. ${ }^{7}$ Besonders treue Untertanen fügen ihren Inschriften einen Segen für den König hinzu. ${ }^{8}$

In den Ritualen der ikribu-Gebete für den König verschiebt sich der Segen zum Gebet. ${ }^{9}$ Als Beispiel dieser Entwicklung vom Segen zum Gebet

$1 \mathrm{Vgl}$. CRAWFORD, 87-94, 2 Sam 11,7b; Nah 2,1.

2 Vgl. WatanabE, ,Segenswünsche,“ 347.

3 Vgl. LANDSBERGER, „Wort,“ $302 \mathrm{f}$.

${ }^{4} \mathrm{Zu}$ diesem Segensthema in westsemitischen Inschriften vgl. TROPPER, Inschriften, 53; CRAWFORD, Blessing, 204 Anm. 25.

5 Vgl. CRAwFORD, Blessing, 101-115. Solche Selbstsegnungen finden sich in KAI Nr. 4, KAI Nr. 5, KAI Nr. 6, KAI Nr. 24 und anscheinend als Gedicht über Freude, Glück, viele Tage und lange Jahre auf einer amoritischen Bronzeflasche aus Tell Siran mit Anklängen an Koh 2,4-6. im AT vgl. langes Leben Dtn 5,13; 30.20; Ps 21, 5.6-7; 23,6; dauerhafte Herrschaft Dtn 17,20).

6 Vgl. WatanaBE, „Segenswünsche,“ 384-352, 361-363; „Segenswünsche II.“ 369-371.

7 Vgl. REINER, „Vœux,“" 421. Sie behandelt Texte, in denen Astralgottheiten angerufen werden. Die Segnungen sind nach den Saiten eines Musikinstruments geordnet. Ein Text lautet: „Deuxième corde: Que Enmešarra? te rende aussi brillant que ..., qu'il te ... comme une torche, qu'il te protège? Troisième corde: Que Bēlet-ilī, créatrice des dieux? et des hommes, qui fait prospérer les gens, protectrice du droit et de la justice, ... Quatrième corde: Que Šullat et Haniš ... tes ennemis, ... Cinquième corde: Que ... te calme comme (avec) une flûte, ... n'aie pas de rival, foule? ceux qui te veulent du mal comme ..., tes ennemies [comme ...]." ebd. 422. Die Themen kreisen um eine glanzvolle unangefochtene Herrschaft. ${ }^{8}$,May [the god Marduk], my lord, grant to Ashur-uballit, who loves me, king of the universe, my lord, long days together with abundant prosperity." GRAYSON, Inscriptions I, 43. BM 96947 (RT 19, 44-47) eine Inschrift des königlichen Schreibers Marduk-nadinabhe. Vgl. WATANABE, „Segenswünsche,“ $347,382 \mathrm{f}$.

9 Vgl. LANDSBERgER, „Wort,“ 310-312. Ein derartiger Segensspruch für den König findet sich am Ende des Kudurrus B.819.1 im Anschluß an Fluch, Zeugenliste und Datum: Kol. IV 
sei der Abschluß einer Königsinschrift Nebukadnezars II. (604-561 v. Chr.) anläßlich der Restauration der E-ur-imin-an-ki-zikkurat von Borsippa zitiert.

Kol. II $~{ }^{16} \mathrm{O}$ Nebo, rechtmäßiger Sohn, erlauchter Bevollmächtigter, ${ }^{17}$ Sieghafter, Liebling des Marduk! ${ }^{18}$ Auf meine Werke schaue in Gnaden freundlich ${ }^{19}$ herab! ${ }^{20}$ Ewiges Leben, Sättigung mit Nachkommenschaft, ${ }^{21}$ Festigkeit des Thrones, Dauer der Regierung, Niederwerfung der Feinde, ${ }^{22}$ Eroberung des Landes der Feinde schenke als Geschenk! ${ }^{23}$ Auf deiner zuverlässigen Tafel, die festsetzt den Bezirk ${ }^{24}$ des Himmels und der Erde, ${ }^{25}$ befiehl Länge meiner Tage, schreibe mir zu Nachkommenschaft! ${ }^{26}$ Vor Marduk, ... ${ }^{27}$ meinem väterlichen Erzeuger, laß meine Taten willkommen sein, ${ }^{28}$ sprich zu meinen Gunsten! ${ }^{29}$,Nebukadnezar ${ }^{30}$ ist wirklich ein König, der auf Erhaltung bedacht ist, ${ }^{31}$ so werde es erfunden in deinem Munde." ${ }^{\prime 1}$

Das Gebet zeigt, wie treu vorgegebene Motive durch die Jahrtausende weitergetragen wurden, es macht aber auch deutlich, daß sich die Inschriftformulare der verschiedenen Staatskanzleien durchaus voneinander unterschieden. Die Königsinschriften des neubabylonischen Reiches enthalten keine Flüche mehr, sondern nur noch ein Abschlußgebet.

Vom Segen der Götter sprechen vor allem mythische Texte. Die Götter begrüßen und verabschieden sich untereinander mit Segenswünschen. ${ }^{2}$ Niedere Götter können bei höheren für die Menschen Fürbitte einlegen. Innerhalb der Götterhierarchie unterscheidet sich also der göttliche Segen nicht vom menschlichen. Auch er ist als Wunsch an eine höhere Instanz aufzufassen. Anders verhält es sich mit dem Segen, den die Gottheit nach unten, zu niedrigeren Göttern oder den Menschen, sendet. Die göttliche Gnade wird erst in neuassyrischer Zeit durch die likrubü-Formel erbeten. Verbreiteter ist die Vorstellung vom wohlwollenden Blick und das Bewirken des šalāmu und balätu. ${ }^{3}$ In Parallele zu den konkreten Heilsgaben des Friedens und Lebens können Segen und freundlicher Blick nicht nur verbales oder visuelles Wohlwollen meinen. Vielmehr bedeutet das Angesehenwerden oder das Gesegnetsein durch die Götter für den Menschen bereits

Z. 29-32: ša Marduk-zäkir-šumi šar Bābili ūmēšu līrukū ina pan Marduk balā[ta] lutter die Tage des Marduk-zäkir-šumi, des Königs von Babylon, mögen lang sein, im Angesicht Marduks möge sich sein Leben vermehren. Vgl. UNTERLECHNER, Fluchformeln, 70; CAD 1/A II, 490 atāru 2a 1'

${ }^{1}$ LANGDON, Königsinschriften, 101, vgl. 20f. Häufig belegte Fluchmotive finden hier ihre Umkehrung in Gebetsbitten: böser Blick (Z.18), Tod (Z. 19.25), Vernichtung der Nachkommenschaft (Z.19.25), Herrschaftsverlust (Z. 21), Niederlage (Z. 21f), Diffamierung (Z. 28).

2 Vgl. LANDSBERGER, „Wort,“ $299 \mathrm{f}$.

${ }^{3}$ Vgl. LANDSBERGER, ,Wort,“ 309-314. 
eine Lebenssteigerung. Der Segen wird hier also weniger als bene-dictio, sondern vielmehr als bene-factio verstanden.

Göttlicher Segen als Wohltat ist aber kein Wunsch, sondern eine Festsetzung. Dementsprechend wird der Segen Enkis über die Welt im sumerischen Epos „Enki und die Weltordnung“ als Dekret bezeichnet. Göttlicher Segen erhält damit das Gewicht positiver Schicksalsbestimmung. ${ }^{1}$ Im ugaritischen Aqht-Gedicht spricht El, einen Becher mit Wein in der Hand, einen Trinkspruch auf den frommen Dan'el aus, welcher dessen Schicksal festlegt. Els Ausspruch wird ausdrücklich als Segen qualifiziert, ${ }^{2}$ enthält aber keine Wünsche, sondern die feierliche Proklamation, daß Dan'els Bitte gewährt wird. ${ }^{3}$ Margalit sieht in dieser Szene die Übertragung eines menschlichen Rituals in die göttliche Sphäre. Der Becher in der Hand des Gottes entspricht dem Libationsgefäß des Opfernden. Der Mensch opfert den Wein und äußert den Wunsch, die Gottheit empfängt den Wein und gewährt den Segen als Vorhersage der Wunscherfüllung. ${ }^{4}$

Von Menschen ausgesprochene Segnungen stellen in mesopotamischen und westsemitischen Inschriften zumeist Wünsche dar, die sich an eine höhere Instanz richten. Ihre Themen kommen ins Gegenteil verwandelt auch als Fluchmotive vor. Dem Fluch entspricht der Segen, dem bösen Blick das freundliche Anschauen, der Diffamierung oder Denunziation das gute Wort. Häufigste auch im AT belegte Segensthemen sind langes Leben und dauerhafte Herrschaft, aber auch Nachkommenschaft und Wohlstand. Wo göttliche Segensworte zitiert werden, erhalten diese den Charakter einer dekretierenden Schicksalsbestimmung.

1 „191. Enki decrees (its) fate: 192. 'Sumer, the great land, the land of heaven and earth, 193. Full of awesome light ... . (...) 216. The great mountain, Enlil, has pronounced your great name in heaven and earth, 217. City, whose fate Enki has decreed, 217. Shrine Ur, may you rise your neck to heaven.' 219. Then, he proceeded to the land Meluhha, 220. Enki ... decreed its fate: ..." BENITO, Enki, 123-125. BENITO charakterisiert ebd. 79 diese Passage als Enkis Segen.

${ }^{2}$ KTU 1.17:I: , 23 ltbrknn(.) ltr il(.) aby (...) ${ }^{34}$... <brkm. ybrk.> 'bdh ybrk(.) ${ }^{35}$ [dni]l. mt. $r p i$ " Margalit, Aqht, 118.

${ }^{3}$, „<Verily he would bless $>$ his servant, He would bless [Dan']el, the Rapian Pronounce benediction on the hero, [devotee of the 'Rainmaker'. 'By-my-soul (I swear): Dan'el [the Rap]ian shall live (on), By-my-vitality, the Hero, devotee of the 'Rainmaker' (shall endure). $H e$, no other [will lea]p from his (own) bed, He'll mount the [bed of lov]e. While kissing his wife [he'll impregnate], [(His) breath] will become heated as he enfolds her. [He, no other, will impregnate] the child-bearer, Passionately, [the lady of the Ra]pian. Then will a son be established in his house, A scion in his residence. " MARGALIT, Aqht, 145 (KTU 1.17:I:3445). „The scene of El's benediction ... duplicates ... Krt (1.15:II:11f.) ... .“ Ebd. 281.

${ }^{4} \mathrm{Vgl}$. Aqht, 281f. Von dieser vorhersagenden Natur des Gottessegens zieht MARGALIT eine Verbindungslinie zum Prophetensegen. Mit übernatürlicher Eingebung beschenkt, verkünden die segnenden Propheten eine bereits festgelegte günstige Zukunft. 


\section{VERSUCH EINER REDAKTIONSGESCHICHTE VON DTN 28}

Dtn 28,20-44* ist - wie in den vorhergehenden Kapiteln gezeigt wurde von den adê zur Thronfolgeregelung Asarhaddons abhängig. Dies ergibt einen Ansatzpunkt für die zeitliche Einordnung der Passage. Sie kann nicht vor 672 v. Chr. entstanden sein. Man wird sich aber auch nicht lange nach dem Fall Ninives (612 v. Chr.) oder dem adê Nebukadnezars mit Zidkija (597 v. Chr.) an einem assyrischen Vorbild orientiert haben. Für ein erst in exilische oder nachexilische Zeit zu datierendes Heranziehen der dann politisch völlig bedeutungslosen VTE könnte nur ein literarisches Interesse geltend gemacht werden, falls sie nach den Zerstörungen von 586 v. Chr. überhaupt noch greifbar waren. In Ninive jedenfalls waren die VTE-Tafeln zu jener Zeit schon ein Scherbenhaufen. So dürfte 28,20-44* aus dem 7. Jh. stammen.

Die literarische Analyse des Kapitels hatte Stilunterschiede zu Tage gefördert, die wenige Rückschlüsse auf das diachrone Verhältnis der verschiedenen Abschnitte zueinander ermöglichen.

V. 45 konstatiert den Ungehorsam bereits als in der Vergangenheit liegendes Faktum und die Gattung wechselt von pללות im Sinne einer Bezeichnung für die Textsorte von V. 20-44 zur prophetischen Drohrede, die auf Jer 5,15-17 und auf das exilische Königsgesetz Dtn 17,14-20 anspielt. 28,45-68 wird daher jünger sein als 28,20-44*.

V. 58 stört im Kontext von V. 45-68 durch die unvermittelte neue Einleitung. Der Abschnitt V. 58-61 weist poetische Sprache mit Rhythmus und Endreimen auf. Die Verse thematisieren Krankheitsschläge und passen inhaltlich nicht zu 28,45-57.62-68, wo es um Feindeinfall und Deportation geht. Sie dürften erst später an dieser Stelle eingefügt worden sein.

Der Segen in V. 7-13 ist im Gegensatz zu V. 20-44* von Sätzen mit deuteronomisch-deuteronomistischer Formelsprache durchzogen, die sich literarkritisch nur schwer ausscheiden lassen und stilistisch eher zu V. 4557.62-68 passen. Dieser Unterschied deutet darauf hin, daß V. 7-13 und V. 20-44* nicht zur gleichen Zeit entstanden sind.

Die 'ārûr-Formeln kommen im AT immer als mehrgliedriger Fluchspruch vor, der eine Begründung und eine Entfaltung verlangt. Die Funktion dieser beiden Elemente nehmen in Dtn 28 die Flucheinleitung in V. 15 und die Verwünschungen in V. 20-44 ein. Da also die 'ārûr-Reihe (V. 1619) allein unvollständig erscheint, wurde sie wohl erst für ihren Platz vor V. 20 geschaffen, wobei man traditionell vorgegebene Formelelemente und Motive verwendete. 28,16-19 dürfte also jünger sein als 28,20-44*. Die gebundene Sprache allein genügt nicht, um die bärûk-Reihe $(28,3-6)$ als älter anzusehen. Die bārûk- und 'ārûr-Reihen gehören wohl zu einer gemeinsa- 
men Redaktionsstufe, die den Anfang von Segen und Fluch parallel gestalten wollte.

Um eine über diese Feststellungen hinausgehende Redaktionsgeschichte des Kapitels entwickeln zu können, muß auf historische Prämissen zurückgegriffen werden, die weitere Kriterien zur Unterscheidung und gegenseitigen Zuordnung der Textschichten bereitstellen. Hier bleibt vieles Hypothese. Deshalb seien die Voraussetzungen, auf denen die hier versuchte redaktionsgeschichtliche Zusammenschau basiert, zunächst dargelegt.

(1.) Man kann aus 2 Kön 22f historische Informationen entnehmen, ${ }^{1}$ und es handelt sich bei dem im Tempel gefundenen Buch tatsächlich um das Deuteronomium.

(2.) Akzeptiert man 2 Kön 22 als Ausgangspunkt für die Frage nach der Gestalt des Deuteronomiums, das unter Joschija auftauchte, läßt sich schließen, daß dieses Buch noch nicht eng mit der Gestalt des Mose verbunden gewesen ist, da dessen Name nicht fällt. Das Buch wird nicht תורת משה sondern schlicht (2 Kön 22,8) genannt. ${ }^{2}$ Mag es auch als JHWH-Gesetz stilisiert gewesen sein, sprach es von ihm doch wohl in der 3. Person. ${ }^{3}$ Welche Bedeutung besaßen dann aber die Promulgationssätze in der 1. Person, die mit dem Partizip im präsentischen Sinn und ihrem im deuteronomischen Endtext die Gesetzesverkündigung zeitlich auf den Todestag des Mose und geographisch auf Moab festlegen? ${ }^{4}$ Gab es sie schon in Joschijas Urkunde? Bezogen sie sich auf einen anderen Sprecher? Diese Fragen scheint nach dem Stand der Forschung niemand mit Sicherheit beantworten zu können.

(3.) Ein weiteres Problem stellt Dtn 26,16-19 dar. Sollten diese Verse eine Reminiszenz an den Verpflichtungsakt Joschijas bewahren ${ }^{5}$, können sie nicht in der gefundenen Urkunde gestanden sein, denn sie beziehen sich auf das, was erst nach dem Fund geschehen ist. Sind aber die Redeeinleitungen in Dtn 27,1.9f erst einer deuteronomistischen, das Buch in verschiedene Mosereden strukturierenden Schicht zuzuschreiben und ist der Rest von Kapitel 27 noch jünger ${ }^{6}$, so fehlt für den Grundbestand des Kapitels 28 in der Urkunde des Joschija die Verbindung zum Gesetzesteil, den Dtn 26,16-19; 27 heute bilden.

1 Vgl. LoHFINK, ,Kultreform,“" 209, 212-214.

2 Vgl. LoHFINK, „Jahwegesetz," 389f.

${ }^{3}$ Vgl. LoHFINK, ,Jahwegesetz,“ $390 \mathrm{f}$.

4 Vgl. Braulik, ,Ausdrïcke,“ 41f/13.

5 Vgl. Braulik. Dellieronomium II. 197, 212.

6 Vgl. LohFINK, ,Ältesten," 37, 39. 
(4.) Das Buch kann zur Grundlage eines Bundesschlusses gemacht werden. Jedenfalls wird es vor bzw. bei dem Verpflichtungsakt ספר הברית genannt (2 Kön 23,2). Das muß kein Widerspruch zur vorhergehenden Qualifikation als תורד sein, denn auch altorientalische Verträge und Vereidigungen enthalten ausführliche Weisungen. ${ }^{1}$ Von Anfang an scheint das Deuteronomium Elemente von Vertrag und Gesetz vereint zu haben.

Schreibt man dem gefundenen Buch einen Vertragscharakter zu und zieht man die Existenz von Promulgationssätzen in der 1. Person, wie V. 15 einen enthält, in Zweifel, so könnten die Stipulationen ähnlich wie in den VTE als Protasis zu den Sanktionen der pללות formuliert gewesen sein.

Für die Rekonstruktion der ältesten Form von Dtn 28 ergeben sich damit zwei Alternativen:

(1.) V. 20-44* folgte unmittelbar ohne einleitenden Bedingungssatz auf den Gesetzesteil des Deuteronomiums, der durch einen einleitenden Bedingungssatz als lange Protasis gestaltet war. Dafür spricht, daß V. 15 lexikalisch mit 28,20-44 nur durch בוא in der wohl sekundären Landnahmeformel (V. 21b) und durch das Allerweltswort עשה (V. 20) verbunden ist. Die Landnahmeformel in V. 21 und wohl auch die Promulgationsformel setzen die Historisierung des Deuteronomiums voraus und dürften daher zu einer späteren deuteronomistischen Redaktionsstufe des Kapitels gehören.

(2) V. 20-44* wurde durch den Bedingungssatz V. 15 eingeleitet - wer auch immer das Subjekt der Promulgationsformel war. Dies eröffnet die Möglichkeit auch V. 1.2a $\mathrm{a}^{2}$.3-6.16-19 dem ältesten Stadium zuzurechnen. Die westsemitischen Sefire-Verträge enthielten ja auch wie manche altorientalische Gesetzeskodizes einen kurzen Segen und einen längeren Fluchteil. Also wäre Raum für die bārûk- und 'ārûr-Formeln vor $28,20-44^{*}$ gegeben. Wenn hethitischen und aramäischen Zeugnissen entsprechend von Anfang an auch ein Segen dem Fluch gegenüber gestanden hat, waren im Gegensatz zum assyrischen adê die Einleitungsformeln zur Abgrenzung der Schicksalsalternativen unverzichtbar. Für diese Sicht spricht, daß man nicht mit einer Einleitung am Anfang der Stipulationen rechnen muß, die

\footnotetext{
${ }^{1}$ Immerhin scheint auch in Dtn 4,44f תורה als Oberbegriff vor Gesetzestermini (םיה, (מספטים) und den Ausdruck עדת, das hebräische Gegenstück des akkadischen adê, gestellt worden zu sein.

2 Der $k \hat{\imath}$-Satz von V. $2 \mathrm{~b}$ gehört wohl zum deuteronomistischen Sprachgut. V. 1a ist lexematisch mit 26,19 verknüpft und wäre dann älter als 26,17-19, da diese Passage erst nach der Verpflichtungszeremonie Joschijas entstanden sein dürfte. Warum aber soll der Gedanke der Erhebung über alle Völker nicht von Anfang an in einer Segenseinleitung gestanden und 26,19 beeinflußt haben?
} 
sie als Protasis zur Apodosis der pללות ausgewiesen hätte und die womöglich jetzt im Deuteronomium nicht mehr vorhanden ist.

$\mathrm{Zu}$ entscheiden, welche der beiden Alternativen zutrifft, ist anhand der Ergebnisse dieser Studie nicht möglich. ${ }^{1}$

Jedenfalls erscheint 28,20-44* als Grundbestand, dem der Rest des Kapitels zugewachsen ist. Er dürfte beim Verpflichtungsakt des Königs Joschija vorgelegen haben. Die Entstehungszeit dieses Abschnitts läßt sich damit auf die 50 Jahre zwischen 672 und $622 \mathrm{v}$. Chr. begrenzen.

Auf der Grundlage von VTE $\S 56$, den der biblische Verfasser ins Hebräische übertrug, schuf er die Fluchsequenz Dtn 28,20-44*2, wobei er an Stellen, die durch die Themenabfolge von $\S 56$ vorgegeben waren, die Flüche aus VTE $\S 38 \mathrm{~A}-42$ und $\S 63 \mathrm{f}$ einfügte. Er wählte aus den VTE nur jene Passagen aus, die sich auf die Götter allgemein oder den Himmel und seine Gestime, besonders Šamaš, bezogen. Viele Eigenschaften des mesopotamischen Sonnengottes schrieb man in Jerusalem auch JHWH zu. Die palindromische Struktur des $\S 56$ übernahm der biblische Verfasser nicht, sondern schuf eine eigene kleinere Palindromie in V. 27-35. Außerdem ergänzte er seine Vorlage nach eigenen Aussageanliegen. Bei der Übertragung der ihm wohl aramäisch vorliegenden VTE-Version folgte er literarische Gestaltungstechniken (amplification, permutation, ellu-ebbu-namruStrukturen), wie sie assyrische Schreiber zur Überarbeitung von Feldzugsberichten anwendeten, und goß seinen Text in vorgegebene Muster (z.B. futility curses) und idiomatische Wendungen der Zielsprache, wie es mehrsprachige altorientalische Fluch- und Segenstexte auch sonst für Übersetzungen dieser Textgattungen bezeugen.

Die nächste Phase der Redaktionsgeschichte dürfte die Einfügung des joschijanischen Deuteronomiums in die vorexilische deuteronomistische

\footnotetext{
${ }^{1}$ Es ist nicht einmal sicher, daß das Buch überhaupt Flüche enthielt. Immerhin wäre es auch möglich, daß 28,20-44* zur Gestaltung der Vereidigungszeremonie geschaffen wurde, von der 2 Kön 23,1-3 berichtet, und erst zu diesem oder einem späteren Zeitpunkt mit der Urkunde verbunden wurde. Daher kann auch nicht ausgeschlossen werden, daß man Dtn 26,16-19 ebenfalls zur Gestaltung der Zeremonie verfaßte, die Verse also gleichzeitig mit 28,20-44* entstanden.

2 In 28,20-44 ergeben sich folgende literarkritische Problemstellen: (1.) V. $20 \mathrm{~b}$ - mit dem Wechsel in die 1. Person. Hier ist eine sekundäre Anspielung auf Prophetenworte anzunehmen. (2.) V. 21 b - mit der historisierenden Landnahmeformel. (3.) V. $25 \mathrm{~b}$ - mit der Unterbrechung des Zusammenhangs von Niederlage und von Tieren gefressenen Leichen (V. 25a.26) sowie dem im Deuteronomium ungewöhnlichen Ausdruck „Königreiche der Erde“. Der Halbvers dürfte von Jer 24,9 beeinflußt sein. (4.) V. 36f - wo das exilische Königsgesetz (Dtn 17,14-20) und die exilische Vorstellung vom Götzendienst als Strafe vorausgesetzt sind. Die futility curses von V. 31-33 und V. 42 sind zwar Ergänzungen gegenüber den VTE, doch läßt sich nicht mit Sicherheit erkennen, daß sie von einem späteren Verfasser stammen als dem, der die fremdsprachige Vorlage ins Hebräische übertragen hat.
} 
Landeroberungserzählung gewesen sein. Spätestens jetzt wurde aus dem Deuteronomium eine Moserede in Moab. Mosaisierung und Historisierung sind möglicherweise hier anzusetzen. Die Verpflichtung Israels auf das Deuteronomium wird wohl bereits in diesem Stadium eingeleitet durch Dtn 26,17-19, zu Segen und Fluch übergeleitet in 27,1.9f und beschrieben in 28,69; 29,1-20. ${ }^{1}$ Die Flüche gehören nun zur Selbstverpflichtung Israels, die unter der rituellen Leitung des Mose vor der Landnahme durchgeführt wurde. Der Segen (28,7-13) weist in V. 9 auf einen Schwur JHWHs hin, der wohl in 26,19 bzw. 27,9f zu finden ist. Er dürfte also frühestens zur gleichen Zeit wie diese Bestandteile einer deuteronomistischen Bearbeitung der joschijanischen Urkunde entstanden sein. Durch den Segen in V. 7-13 wird die Befolgung des Deuteronomiums stärker positiv motiviert. Dies und auch die Hinzufügung der Landnahmeformel in V. 21b scheint gerade beim Einbau in eine Erzählung verständlich, welche die Einnahme des Landes und die Lebensordnung darin in den Blick nimmt. Daß der Segen dennoch nicht denselben Umfang wie der Fluchabschnitt (V. 20-44*) erhielt, mag mit den altorientalischen Vorgaben für Texte dieser Gattungen zusammenhängen, wo im 1 . Jt. v. Chr. der Segen - falls überhaupt vorhanden - kürzer ist als der Fluch.

Sollten sie bisher noch nicht existiert haben, entstanden nun die Einleitungen (28,1f.15) und die Formeln von 28,3-6.16-19. Die gleichartigen bārûk- und 'ārûr-Reihen am Anfang des Segens- und Fluchabschnittes stellen zumindest am Anfang der jeweiligen Untereinheit ein Gleichgewicht zwischen Segen und Fluch her und ähneln sowohl damit als auch in ihren Inhalten den hethitischen Formeln des 2. Jts. v. Chr. Jedenfalls scheint die Gestalt des Kapitels 28 in einem in die deuteronomistische Landeroberungserzählung eingebauten Deuteronomium klarer hervorzutreten als die redaktionsgeschichtlichen Vorstufen. Es umfaßte wohl 28,1.2a.3-13.1520a.21-25a.26-35.38-44.69.

Im Exil fand man in den Worten Jeremias einen Schlüssel für das Verstehen der Katastrophe von 586 v. Chr. Von dessen Anklagen und Umkehrforderungen ist das deuteronomistische Prophetenbild inspiriert. Redaktoren legten im Deuteronomium dem Mose Warnungen im Stile Jeremias in den Mund. So entstand 28,45-57.62-68. Von Jeremiaworten ausgehend, wird die Belagerung Jerusalems angekündigt, die zur Zerstreuung des Volkes führt und in der Rückkehr nach Ägypten ihren Schlußpunkt findet. Der Verfasser dieses Abschnittes ergänzte die Zahl der Leitwörter des Kapitels, bis sieben Belege erreicht waren. Außerdem fügte er in 28,20-44 Elemente ein, die an Jeremia erinnern. Dazu gehören V. 20b.25b.37. In etwas unge-

\footnotetext{
1 Vgl. Braulik, Deuteronomium II, 211.
} 
schickter Weise wurden V. 25f und V. 36f in die palindromische Struktur von V. 27-35 einbezogen. Der Redaktor verknüpfte seinen Zusatz lexematisch mit der ergänzten Passage 28,45-57.62-68, indem er in V. גוי 36 schrieb, obwohl sonst in V. 20-44 עם steht, und in V. עם 64 עatt des im Kontext vorgegebenen Wortes ג verwendete. Die Einfügung von V. 36f stellt das Motiv der Deportation des Gesamtvolkes recht eindrucksvoll in die Mitte zwischen die beiden wohl älteren Erwähnungen der Wegführung der Kinder (V. 34.42). Zur Anbindung größerer Texteinheiten schuf der Redaktor Zwischenstücke mit intensiver Kontextverknüpfung (V. 4547.62f) und hinterließ in V. 2b.14 Segensmotivierungen, um die Hoffnung auf Heil nach erfahrenem Unglück aufrechtzuerhalten.

In V. 58-61 war ein anderer Verfasser am Werk. Kein Zwischenstück verbindet die Verse mit dem Kontext. Die Passage beginnt unvermittelt mit einem Bedingungssatz, statt deuteronomisch-deuteronomistischer Kunstprosa findet man nun Versmaß und Endreime. Das Verheißungsland spielt keine Rolle mehr. Die Schläge und Krankheiten, von denen gesprochen wird, bleiben abstrakt. Vermutlich soll dieser wohl nachexilische Zusatz, der vor der Deportationsdrohung in V. 62f und der Ansage von Zerstreuung, Buße und Rückkehr von 28,62-68; 30,1-10 steht, auch in der Diaspora zum Toragehorsam motivieren.

Der Kontext, den das Kapitel 28 im Deuteronomium heute hat, läßt es zu, Segen und Fluch in V. 3-13.16-44 als integrierende Bestandteile der Vereidigungszeremonie aufzufassen, deren Ritual in Dtn 29,11 angedeutet wird. Mose als liturgischer Leiter der Zeremonie spricht über Israel, das durch die „Zeichen der Selbstverwünschung“" schreitet, in einem performativen Sprechakt Segnungen und Verwünschungen aus. Durch das Ritual des Hindurchschreitens bezieht das Volk die Moseworte auf sich selbst und leistet damit den Bundeseid.

Segen und Fluch sind in dieser Sicht weder Lockung noch Drohung, weder Belohnungsversprechen noch Strafankündigung, sondern eine Bitte bzw. ein Zugeständnis an JHWH, den Eidesherm, an seinem Volk zu handeln. Im Grunde geschieht darin die Anerkennung des Bundesverhältnisses mit allen seinen Konsequenzen. Gedeih und Verderb hängen von der Beziehung zu JHWH ab. Gerade indem sich das Volk segnen und verfluchen läßt und durch die ,Zeichen der Selbstverwünschung" schreitet, willigt es in JHWHs Bundesangebot ein. Der Fluch ist nur der negative Hintergrund der eigentlich von JHWH und Israel angestrebten gegenseitigen Treue, aus der für Israel Segen und Leben fließen. Im Anschluß an die Verfluchungen der Vertragsschlußzeremonie ermahnt Mose das Volk durch ein Drohwort $(28,47-68)$. 
Im Alten Orient bezieht der Vertragseid zumeist auch die nachfolgenden Generationen der Vereidigten ein. Den Nachkommen wird der Inhalt des Vertrages, an den sie durch den Ratifikationsakt ihrer Vorfahren gebunden sind, durch das Verlesen der Vertragsurkunde - wie bei den Hethitern oder durch monumentale Stelen mit dem Vertragstext - wie im aramäischen Sefire - zur Kenntnis gebracht. So ist es auch im Deuteronomium vorgesehen $(27,3.8 ; 31,9-13)$.

In den Vertragsdokumenten und auf den Monumenten sollen Segen und Fluch die Rezeption des Textes in der Zukunft steuern und das im Dokument geforderte Verhalten motivieren. Im Gottesdienst der Synagoge erfüllt Dtn 28 diese Funktion bis heute:

„It became the custom, when the annual cycle of Torah readings would reach this chapter, to call up a volunteer for the curses ... . Such a person would often be called up, not in customary fashion, by his name, but rather as 'He who wishes' ... . The chapter itself would be read without interruption and in a low voice .... ."

\footnotetext{
${ }^{1}$ PlaUt, Deuteronomy, 311.
} 


\section{ABKÜRZUNGSVERZEICHNIS}

Abkürzungen nach SCHWERTNER, Siegfried: Internationales Abkürzungsverzeichnis für Theologie und Grenzgebiete: IATG: Zeitschriften, Serien, Lexika, Quellenwerke mit bibliographischen Angaben (Berlin, New York: de Gruyter, ${ }^{2} 1992$ ).

Publikationen altorientalischer Texte nach BORGER, Rykle, Handbuch der Keilschriftliteratur (3 Bde.; Berlin: de Gruyter, 1967-1975).

Textkritische Abkürzungen nach den Sigla der BHS und der Septuaginta aus Göttingen.

Darüber hinaus verwendete Abkürzungen:

\begin{tabular}{|c|c|c|c|}
\hline AO & Alter Orient & G & Grundstamm, Qal \\
\hline \multirow[t]{4}{*}{ ARRIM } & Annual Review of & 6 & Septuaginta \\
\hline & the Royal & GN & Gottesname \\
\hline & $\begin{array}{l}\text { Inscriptions of } \\
\text { Mesopotamia }\end{array}$ & H, H-St. & $\begin{array}{l}\text { H-Stamm, Hif'il, } \\
\text { Hof'al }\end{array}$ \\
\hline & Project & Inf. & Infinitiv \\
\hline ASJ & Acta Sumerologica & Imp. & Imperativ \\
\hline Bd. & Band & Jh. & Jahrhundert \\
\hline \multirow[t]{2}{*}{$\mathrm{BH}^{\mathrm{t}}$} & Biblia Hebraica & $\mathrm{Jt}$. & Jahrtausend \\
\hline & transcripta & $\mathrm{KF}$ & Kurzform \\
\hline \multirow[t]{6}{*}{ CTH } & LAROCHE, & $\mathrm{KH}$ & Kodex Hammurapi \\
\hline & Emmanuel, & Kol. & Kolumne \\
\hline & Catalogue des Textes & KTU & DIETRICH, Manfred, \\
\hline & Hittites (Études et & & LORETZ, Oswald, \\
\hline & $\begin{array}{l}\text { Commentaires } 75 \text {; } \\
\text { Paris Éditions }\end{array}$ & & $\begin{array}{l}\text { SANMARTÍN, Joaquín, } \\
\text { The Cuneiform }\end{array}$ \\
\hline & $\begin{array}{l}\text { Paris, Eaitions } \\
\text { Klincksieck, 1971). }\end{array}$ & & Alphabetic Texts \\
\hline & constructus & & from Ugarit, Ras Ibn \\
\hline \multirow{2}{*}{ Cstr.-Verb. } & Constructus- & & Hani and Other \\
\hline & Verbindung & & Places (Abhand- \\
\hline \multirow[t]{2}{*}{ D, D-St. } & Dopplungsstamm, & & lungen zur Literatur \\
\hline & Píel, Pu'al & & Alt-Syrien-Palästi- \\
\hline Der I & $\begin{array}{l}\text { vorexilische Form } \\
\text { des DtrG }\end{array}$ & & $\begin{array}{l}\text { nas u. Mesopota- } \\
\text { miens 8; Münster }\end{array}$ \\
\hline \multirow[t]{2}{*}{ Dtr II } & exilische Ausgabe & & Ugarit-Vlg., $\left.{ }^{2} 1995\right)$ \\
\hline & des DtrG & LF & Langform \\
\hline \multirow[t]{3}{*}{ DerG } & Deuteronomisti- & m. & maskulin \\
\hline & sches Geschichts- & & Masoretischer Text \\
\hline & werk & MARI & Mari, Annales de \\
\hline \multirow[t]{4}{*}{ DtrL } & Deuteronomistische & & Recherches \\
\hline & Landeroberungs- & & Interdisciplinaires \\
\hline & erzählung & N, N-St. & N-Stamm, Nif'al \\
\hline & (vorexilisch) & & Präfixkonjugation \\
\hline EEN & ellu-ebbu-namru & Pl. & Plural \\
\hline \multirow[t]{3}{*}{ ePP } & enklitisches Perso- & PN & Personenname \\
\hline & nalpronomen & Rs. & Rückseite \\
\hline & feminin & & \\
\hline
\end{tabular}




\begin{tabular}{|c|c|c|c|}
\hline \multirow[t]{3}{*}{ RIMA } & $\begin{array}{l}\text { The Royal } \\
\text { Inscriptions of }\end{array}$ & SAA & $\begin{array}{l}\text { State Archives of } \\
\text { Assyria }\end{array}$ \\
\hline & Mesopotamia, & SK & Suffixkonjugation \\
\hline & Assyrian Periods & Sp. & Spalte \\
\hline \multirow[t]{3}{*}{ RIMB } & The Royal & Taf. & Tafel \\
\hline & Inscriptions of & $\mathrm{tD}$ & tD-Stamm, Hitpa'el \\
\hline & $\begin{array}{l}\text { Mesopotamia, } \\
\text { Babyloian Periods }\end{array}$ & TOB & $\begin{array}{l}\text { La Bible: traduction } \\
\text { œcumenique }\end{array}$ \\
\hline \multirow[t]{4}{*}{ RIME } & The Royal & V. & Vers \\
\hline & Inscriptions of & $\mathfrak{v}$ & Vulgata \\
\hline & Mesopotamia, Early & Vs. & Vorderseite \\
\hline & Periods & VTE & Vassal-Treaties of \\
\hline 5 & Peshițta & & Esarhaddon \\
\hline$\mu$ & Samaritanus & Z. & Zeile \\
\hline
\end{tabular}

\section{VERWENDETE BIBELAUSGABEN}

Biblia Hebraica Stuttgartensia (Hg. v. K. Elliger, W. Rudolf; Stuttgart: Deutsche Bibelgesellschaft, $\left.{ }^{4} 1990\right)$.

Biblia Hebraica (Hg. R. Kittel, Stuttgart: Württembergische Bibelanstalt, ${ }^{3} 1966$ ). Biblia Hebraica transcripta (vgl. RICHTER).

The Aleppo Codex: Provided with Masoretic Notes and Pointed by Aaron Ben Asher, Bd. I: Plates (Hg. v. M. H. Goshen-Gottstein; Jerusalem: Magnes Press, 1976).

Der Hebräische Pentateuch der Samaritaner. (Hg. v. A. Freiherr v. Gall; Giessen: Töpelmann, 1918; Photomechanischer Nachdruck Berlin, 1966).

Septuaginta: vetus testamentum Graecum, Bd. II: Deuteronomium (Hg. v. Acad. Scientiarum Gottingensis; Göttingen: Vandenhoeck \& Ruprecht, 1977).

La Bible d'Alexandrie (vgl. DOGNIEZ / HARL).

Biblia Sacra iuxta Vulgatam versionem, Bd. I: Genesis - Psalmi (Hg. v. R. Weber; Stuttgart: Württembergische Bibelanstalt, 1969).

The Targum Onqelos to Deuteronomy (Hg. v. B. Grossfeld; The Aramaic Bible 9; Edinburgh: Clark, 1988).

Vetus Testamentum Syriace iuxta simplicem syrorum versionem. The Old Testament in Syriac According to the Peshitta Version, Bd. I.2, II.1b: Leviticus-Numbers (Hg. v. The Peshitta Institute Leiden; Leiden: Brill, 1991).

Einheitsübersetzung der Heiligen Schrift: Das Alte Testament (Stuttgart: Katholische Bibelanstalt; Klosterneuburg: Österreichisches Katholisches Bibelwerk, 1980). Die Heilige Schrift des Alten und des Neuen Testaments (Hg. v. Kirchenrat des Kantons Zürich; Zürich: Verlag der Zwingli Bibel, 1942, ${ }^{20} 1991$ ).

La Bible: traduction cecumenique (Paris: Cerf; Pierrefitte: Societé Biblique Française, 1988). 


\section{LITERATURVERZEICHNIS}

ABOU-ASSAF, Ali / BORDREUIL, Pierre / MILLARD, Alan R., La statue de Tell Fekherye et son inscription bilingue assyro-araméenne (Études Assyriologiques 7) Paris: Éditions Recherche sur les civilisations, 1982).

ACKROYD, Peter Runham, Israel under Babylon and Persia (NCB.OT 4; Oxford: University Press, 1970).

AEJMELAEUS, Anneli, „Function and Interpretation of כ in Biblical Hebrew,“ JBL 105 (1986) 193-209.

AL-ADMI, Khalid, „A New Kudurru of Mardouk-nadin-Ahhe: IM. 90585,“ Sumer 38 (1982) 121-133.

ALBERTZ, Rainer, „Jer 2-6 und die Frühzeitverkündigung Jeremias,“ ZAW 94 (1982) 20-47.

AMADASI GUZZO, Maria Giulia / ARCHI, Alfonso, „La bilingue fenicio-ittita geroglifica di Karatepe," Vicino Oriente 3 (1980) 85-102.

ANDERSEN, Francis I. / FREEDMAN, David Noel, ,The Orthography of the Aramaic Portion of the Tell Fekherye Bilingual," Text and Context: Old Testament and Semitic Studies for F. C. Fensham (Hg. v. W. Claassen; JSOT.S 48; Sheffield: Academic Press, 1988) 9-49.

ARISTAR, Anthony M. R., "The Semitic Jussive and the Implications for Aramaic," Maarav 4 (1987) 157-189.

ARNAUD, Daniel, „Deux Kudurru de Larsa: II: Étude épigraphique,“ $R A 66$ (1972) 163-176.

ASSMANN, Jan, „Altorientalische Fluchinschriften und das Problem performativer Schriftlichkeit: Vertrag und Monument als Allegorien des Lesens," Schrift (Hg. v. H. U. Gumbrecht u. K. L. Pfeiffer; Materialität der Zeichen, Reihe A, 12; München: Fink, 1993).

AUSTIN, John Langshaw, Zur Theorie der Sprechakte: (How to do things with Words) (Reclam Universal-Bibliothek 9396[3]; Stuttgart: Reclam, ${ }^{2}$ 1989).

AVISHUR, Yitzhaq, Stylistic Studies on Word-Pairs in Biblical and Ancient Semitic Literature (AOAT 210; Neukirchen-Vluyn: Neukirchener Vlg., 1984).

BAKER, John Austin, „Deuteronomy and World Problems,“ JSOT 29 (1984) 3-17.

BALTZER, Klaus, Das Bundesformular (WMANT 4; Neukirchen: Neukirchener Vlg., 1960).

B ARTHÉLEMY, Dominique u. a., Preliminary and Interim Report on the Hebrew Old Testament Text Project/Compte rendu préliminaire et provisoire sur le travail d'analyse textuelle de l'Ancien Testament hébreu, Bd. I: Pentateuch / Pentateuque (London: United Bible Societies; Alliance Biblique Universelle, [1974]). 
BECKER, Joachim, Gottesfurcht im Alten Testament (AnBib 25; Rom: Pontifical Biblical Institute, 1965).

BEN-HAYYIM, Zeev, The Literary and Oral Tradition of Hebrew and Aramaic: amongst the Samaritans (Bd. 3, 1; Jerusalem: Israel Academy of Sciences, 1961).

„Observations on the Hebrew and Aramaic Lexicon from the Samaritan Tradition," Hebräische Wortforschung: Festschrift zum 80. Geburtstag von W. Baumgartner (Hg. v. B. Hartmann u. a.; VTS 16; Leiden: Brill, 1967) 12-24.

BENEDICT, Warren C., „The Urartian-Assyrian Inscription of Kelishin,“JAOS 81 (1961) 359-385.

BENITO, Carlos Alfredo, "Enki and Ninmah" and "Enki and the World Order" (University of Pennsylvania, Faculty of the Graduate School of Arts and Sciences; Dissertation 1969; Ann Arbor: UMI 7016124).

BERGE, Kåre, Die Zeit des Jahwisten: ein Beitrag zur Datierung jahwistischer Vätertexte (BZAW 186; Berlin, New York: de Gruyter, 1990).

BERTHOLET, Alfred, Leviticus (HKC 3; Tübingen, Leipzig: Mohr Paul Siebeck, 1901).

BETTENZOLI, Giuseppe, „Deuteronomium und Heiligkeitsgesetz,“ VT 34 (1984) 385-398.

BLANK, Sheldon H., ,The Curse, Blasphemy, the Spell, and the Oath,“ HUCA 23 (1950/51) 73-95.

BLOCK, Daniel Isaac, The Gods of the Nations (ETS; Monograph Series 2; Winona Lake/IN: Eisenbrauns, 1988).

BOISSIER, Alfred, „Document Cassite,“ RA 29 (1932) 93-104.

BORGER, Rykle, Die Inschriften Asarhaddons, Königs von Assyrien (AfO, Beiheft 9; Graz: Selbstverlag des Herausgebers, 1956).

196. „Zu den Asarhaddon-Verträgen aus Nimrud,“ ZA 54, NF 20 (1961) 173„Marduk-zākir-šumi I. und der Kodex Hammurapi,“ OrNS 34 (1965) $168 f$. „Vier Grenzsteinurkunden Merodachbaladans I.: Der Teheran-Kudurru, SB 33, SB 169 und SB 26,“ AfO 23 (1970) 1-26.

Babylonisch-Assyrische Lesestücke (2 Hefte; AnOr 54; Rom: Biblical Institute Press, ${ }^{2}$ 1979).

Assyrisch-Babylonische Zeichenliste (AOAT 33/33A; Kevelaer: Butzon \& Bercker; Neukirchen-Vluyn, Neukirchener Vlg., ${ }^{2} 1981$ ). „Der Codex Hammurapi,“ TUAT I, 39-80. „Der Vertrag Assurniraris mit Mati'ilu von Arpad,“TUAT I, 155-158. „Der Vertrag Asarhaddons mit Baal von Tyrus,“ TUAT I, 158f. 
176.

„Die Vasallenverträge Asarhaddons mit medischen Fürsten,“ TUAT I, 160-

BORGER, Rykle / HINZ, Walter, „Die Behistun-Inschrift Darius’ des Großen,“ TUAT I, 419-450.

BRAULIK, Georg, „Die Ausdrücke für ,Gesetz' im Buch Deuteronomium,“ Bib 51 (1970) 39-66. = Ders., Studien zur Theologie des Deuteronomiums (SBAB 2; Stuttgart: Vlg. Katholisches Bibelwerk, 1988) 11-38.

Das Testament des Mose: Deuteronomium (Stuttgarter Kleiner Kommentar Altes Testament 4; Stuttgart: Vlg. Katholisches Bibelwerk, 1976).

Die Mittel deuteronomischer Rhetorik: Erhoben aus Deuteronomium 4,140 (AnBib 68; Rom: Biblical Institute Press, 1978)

„Das Deuteronomium und die Geburt des Monotheismus,“ Gott der einzige. Zur Entstehung des Monotheismus in Israel (Hg. v. E. Haag; QD 104; Freiburg/Br.: Herder, 1985) 115-159. = Ders., Studien zur Theologie des Deuteronomiums (SBAB 2; Stuttgart: Vlg. Katholisches Bibelwerk, 1988) 257300.

„Die Entstehung der Rechtfertigungslehre in den Bearbeitungsschichten des Buches Deuteronomium: Ein Beitrag zur Klärung der Voraussetzungen paulinischer Theologie," ThPh 64 (1989) 321-333.

„Die Funktion von Siebenergruppierungen im Endtext des Deuteronomiums," Ein Gott und eine Offenbarung: Beiträge zur biblischen Exegese, Theologie und Spiritualität: Festschrift für Notker Füglister OSB zum 60. Geburtstag (Hg. v. F. V. Reiterer; Würzburg: Echter, 1991) 37-50.

Deuteronomium: 1-16,17 (NEB.AT 15; Würzburg, Echter 1986).

Deuteronomium II: 16,18-34,12 (NEB.AT 28; Würzburg: Echter, 1992).

„Die Ablehnung der Göttin Aschera in Israel: War sie erst deuteronomistisch, diente sie der Unterdrückung der Frauen?," Der eine Gott und die Göttin. Gottesvorstellungen des biblischen Israel im Horizont feministischer Theologie (Hg. v. M. T. Wacker u. E. Zenger; QD 135; Freiburg/Br., Basel, Wien: Herder, 1991) 106-136.

Die deuteronomischen Gesetze und der Dekalog: Studien zum Aufbau von Deuteronomium 12-26 (SBS 145; Stuttgart: Vlg. Katholisches Bibelwerk, 1991).

„Das Deuteronomium und die Gedächtniskultur Israels: Redaktionsgeschichtliche Beobachtungen zur Verwendung von למד," Biblische Theologie und gesellschaftlicher Wandel: Für Norbert Lohfink SJ (Hg. v. G. Braulik, W. Groß u. S. McEvenue; Freiburg, Basel, Wien: Herder, 1993) 9-31.

BRICHTO, Herbert Chanan, The Problem of "Curse" in the Hebrew Bible (JBL.MS 13; Philadelphia/Pennsylvania: Society of Biblical Literature and Exegesis, 1963). 
BRIGGS, Charles A., „A Study of the Use of לבב in and in the Old Testament,“ Semitic Studies in Memory of Rev. Dr. Alex Kohut (Hg. v. G. A. Kohut; Berlin: Calvay \& Co, 1897) 94-105.

BRINKMAN, John A., „Texts and Fragments,“JCS 37 (1985) 249-251. „Kudurru,“ RLA VI, 267-274.

„Political Covenants, Treaties, and Loyalty Oaths in Babylonia and between Assyria and Babylonia," I trattati nel mondo antico: Forma ideologia funzione (Hg. v. L. Canfora, M. Liverani, C. Zaccagnini; Saggi di storia antica 2; Rom: «L'Erma» di Bretschneider, 1990) 81-111.

Brockhaus-Enzyklopädie, Bd. VII: Ex - Frt (Mannheim: Brockhaus, ${ }^{19} 1988$ ).

BUIS, Pierre, Le Deutéronome (VSal.AT 4; Paris: Beauchesne, 1969).

„Comment au septième siècle envisageait-on l'avenir de l'alliance?: Étude de Lv. 26,3-45,“ Questions disputées d'Ancien Testament: Méthode et Théologie (Hg. v. C. Brekelmans; BEThL 33; Löwen: University Press, 1974) 131-140.

BUIS, Pierre / LECLERCQ, Jacques, Le Deutéronome (SBi; Paris: Lecoffre, 1963)

BULTMANN, Christoph, Der Fremde im antiken Juda: Eine Untersuchung zum sozialen Typenbegriff "ger" und seinem Bedeutungswandel in der alttestamentlichen Gesetzgebung (FRLANT 153; Göttingen: Vandenhoeck \& Ruprecht, 1992).

BUTTERWECK, Christel, „Eine phönizische Beschwörung: Arslan-Tasch-Beschwörung," TUAT II, 435-437.

CAPLICE, Richard, „Namburbi Texts in the British Museum V,“ OrNS 40 (1971) 133-183.

„Il bilinguismo nei testi medio-assiri," Vicino Oriente 3 (1980) 131-138.

CASTELlinO, G. R., „The Šamaš Hymn: A Note on its Structure,“ Kramer Anniversary Volume: Cuneiform Studies in Honor of Samuel Noah Kramer (Hg. v. B. L. Eichler; AOAT 25; Kevelaer: Butzon \& Bercker, Neukirchen-Vluyn: Neukirchener Vlg., 1976) 71-74.

CATHCART, Kevin J., „Micah 5,4-5 and Semitic Incantations,“ Bib 59 (1978) 3848.

CAZELLES, Henri, Le Deutéronome (La Sainte Bible 5; Paris: Cerf, ${ }^{3} 1966$ ). ,.

„Les structures successives de la 'berît' dans l'Ancien Testament,“ $B C P E$ 36 (1984) 33-46. = Ders., Autour de l' exode: Études (Paris: Gabalda, 1987) 143156.

CHARPIN, Dominique, „Inscriptions votives d'époque assyrienne,“ MARI 3 (1984) 41- 81.

„Le traité entre Ibâl-pî-El II d'Ešnunna et Zimri-Lim de Mari,“ Marchands, diplomates et empereurs: Études sur la civilisation mésopotamique 
offertes a Paul Garelli (Hg. v. D. Charpin, F. Joannes; Paris: Éditions Recherche sur les civilisations, 1991) 139-166.

CHOLEWINSKI, Alfred, Heiligkeitsgesetz und Deuteronomium: Eine vergleichende Studie (AnBib 66; Rom: Biblical Institute Press, 1976).

CHRISTENSEN, Duane L., Deuteronomy 1-11 (Word Biblical Commentary 6A; Dallas/TX: Word Books, 1991).

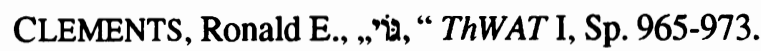

COOPER, Jerrold S., „Sumerian and Akkadian in Sumer and Akkad,“ OrNS 42 (1973) 239-246.

CRAIGIE, Peter C., „The Poetry of Ugarit and Israel,“ TB 22 (1971) 3-31. The Book of Deuteronomy (NIC; Grand Rapids/MI: Eerdmans, 1976).

CRAWFORD, Timothy Gray, Blessing and Curse in Syro-Palestinian Inscriptions of the Iron Age (The Southern Baptist Theological Seminary; Dissertation Mai 1990; Ann Arbor: UMI 9028233). = Ders., Blessing and Curse in Syro-Palestinian Inscriptions of the Iron Age (AmUSt.TR 120; New York, Bern, Frankfurt/M, Berlin, Paris, Wien: Peter Lang 1992).

CRAWLEY, Alfred Ernest, „Cursing and Blessing,“ ERE IV, 367-374.

CUNLIFFE-JONES, Hubert, Deuteronomy: Introduction and Commentary (TBC 4; London: SCM Press, ${ }^{4}$ 1974).

CUTLER, B. / MACDONALD, John, ,Identification of the NA'AR in the Ugaritic Texts,“ UF 8 (1976) 27-35.

DAHOOD, Mitchell, „Hebrew Ugaritic Lexicography VI,“ Bib 49 (1968) 355-369. „Ugaritic Studies and the Bible,“ Gr. 43 (1962) 55-79.

DAVIES, Graham I., Ancient Hebrew Inscriptions: Corpus and Concordance (Cambridge, New York, Port Chester, Melbourne, Sydney: Cambridge University Press, 1991).

DEL MONTE, Giuseppe F., „Traduzione e interferenza nei trattati siro-hittiti,“ Vicino Oriente 3 (1980) 103-119.

„Neue Bruchstücke zum Manapa-dU-Vertrag,“ OrNS 49 (1980) 58-66.

Il trattato fra Muršili II di Hattuša e Niqmepa di Ugarit (Orientis Antiqui Collectio 18; Rom: Istituto per l'oriente C. A. Nallino, 1986).

DELSMAN, Wilhelmus C., „Aramäische historische Inschriften,“ TUAT I, 625637.

DION, Paul-Eugène, ,Quelques aspects de l'interaction entre religion et politique dans le Deutéronome," ScEs 30 (1978) 39-55.

„Un nouvel eclairage sur le contexte culturel des malheurs de Job,“ $V T 34$ (1984) 213-215. 
„La bilingue de Tell Fekherye: Le roi de Gozan et son dieu; la phraseologie," Mélanges biblique orientaux en l' honneur de Matthias Delcor (Hg. v. A. Caqout, S. Légasse u. M. Tardieu; AOAT 215; Kevelaer: Butzon \& Bercker, Neukirchen: Neukirchener Vlg., 1985) 140-147.

DOGNIEZ, Cécile / HARL, Marguerite,La Bible d'Alexandrie, Bd. V: Le Deutéronome (Paris: Cerf, 1992).

DOHMEN, Christoph / OEMING, Manfred, Biblischer Kanon, warum und wozu?: Eine Kanontheologie (QD 137; Freiburg/Br., Basel, Wien: Herder, 1992).

DONBAZ, Veysel, „Two Neo-Assyrian Stelae in the Antakya and Kahramanmaras Museums," ARRIM 8 (1990) 5-24.

DONNER, Herbert, Geschichte des Volkes Israel und seiner Nachbarn in Grundzügen, Teil II: Von der Königszeit bis zu Alexander dem Großen: Mit einem Ausblick auf die Geschichte des Iudentums bis Bar Kochba (GAT 4,2; Göttingen: Vandenhoeck \& Ruprecht, 1986).

DONNER, Herbert / RÖLLIG, Wolfgang, Kanaanäische und Aramäische Inschriften: Bd. II: Kommentar (Wiesbaden: Harrassowitz, ${ }^{2} 1968$ ).

DRIVER, Samuel Rolles, Critical and Exegetical Commentary on Deuteronomy (ICC; Edinburgh: Clark, ${ }^{3} 1895$; Nachdruck 1965).

Duden: „Das große Wörterbuch der deutschen Sprache“, Bd. 2: $\mathrm{Cl}-\mathrm{F}$ (Hg. v. Wissenschafl. Rat u. d. Mitarb. d. Dudenred. unter Leitung von G. Drosdowski; Mannheim, Wien, Zürich: Bibliographisches Institut, 1976).

DURAND, Jean-Marie, „Fragments rejoints pour une histoire élamite,“ Fragmenta historiae elamiticae: Mélanges Steve (Hg. v. L. de Meyer, H. Gasche, F. Vallat; Paris: Éditions Recherche sur les civilisations, 1986) 111-128.

EBELING, Erich, „Adad,“ $R L A$ I, 22-26. „Anu,“ RLA I, 115-117.

EDEL, Elmar. „Der ägyptisch-hethitische Friedensvertrag zwischen Ramses II. und Hattusili III.," TUAT I, 135-153.

EGGER, Wilhelm, Methodenlehre zum Neuen Testament: Einführung in linguistische und historisch-kritische Methoden (Freiburg/Br., Basel, Wien: Herder, 1987).

EHELOLF, Hans, Ein Wortfolgeprinzip im Assyrisch-Babylonischen (LSSt 6 Heft 3; Leipzig: Hinrichs, 1916).

EHRLICH, Arnold B., Randglossen zur Hebräischen Bibel: Textkritisches, Sprachliches und Sachliches Bd. II: Levitikus, Numeri, Deuteronomium (Leipzig: Hinrichs, 1909).

EIDEM, Jesper, „An Old Assyrian Treaty from Tell Leilan,“ Marchands, diplomates et empereurs: Études sur la civilisation mésopotamique offertes a Paul 
Garelli (Hg. v. D. Charpin u. F. Joannes; Paris: Éditions Recherche sur les civilisations, 1991) 185-208.

ELLIGER, Karl, Leviticus (HAT 1,4; Tübingen: [Mohr] Siebeck,1966).

ELLIOT, John H., „The Fear of the Leer: The Evil Eye from the Bible to Li'l Abner,“ Foundations \& Facets Forum 4 (1988) 42-71.

EVEN-SHOSHAN, Abraham, A New Concordance of the Bible (4 Bde.; Jerusalem: Kiryat Sepher, 1980).

FADHIL, Abdulilah, „Die in Nimrud/Kalḩu aufgefundene Grabinschrift der Jabâ,“ BM 21 (1990) 461-470.

„Die Grabinschrift der Mullissu-mukannišat-Ninua aus Nimrud/Kalhu und andere in ihrem Grab gefundene Schriftträger,“ BM 21 (1990) 471-482.

FAHR, Heinz / GLESSMER, Uwe, Jordandurchzug und Beschneidung als Zurechtweisung in einem Targum zu Josua 5: (Edition des MS T.-S. B 13,12) (Orientalia Biblica et Christiana 3; Glückstadt: Augustin, 1991).

FALES, Frederick Mario, „A Literary Code in Assyrian Royal Inscriptions: The Case of Ashurbanipal's Egyptian Campaigns,“ Assyrian Royal Inscriptions: New Horizons in Literary, Ideological, and Historical Analysis: Papers of a Symposium held in Cetona (Siena) June 26-28, 1980 (Hg. v. F. M. Fales; Orientis Antiqui Collectio 17; Rom: Istituto per l'Oriente, 1981).

"The Enemy in Assyrian Royal Inscriptions: 'The Moral Judgement',“ Mesopotamien und seine Nachbarn: Politische und kulturelle Wechselbeziehungen im alten Vorderasien vom 4. - 1. Jahrtausend v. Chr. XXV. Rencontre Assyriologique Internationale, Berlin, 3.-7. Juli 1978 (Hg. v. H.-J. Nissen u. J. Renger; Berliner Beiträge zum Vorderen Orient 1. Teil 2; Berlin: Reimer, 1982) 425-435.

„Massimo sforza, minima resa: Maledizioni divine da Tell Fekheriye all'Antico Testamento," $A N N A L I$ [della facoltá di lingue e letterature staniere di Ca' Foscari] 21/3 (serie orientale 13) (1982) [1984] 1-12. 233- 250 .

„Le double bilinguisme de la statue de Tell Fekherye,“ Syria 60 (1983), „Istituzioni a confronto tra mondo semitico occidentale e Assiria nel I millennio a.C.: il trattato di Sefire," I trattati nel mondo antico forma ideologia funzione (Hg. v. L. Canfora, M. Liverani, C. Zaccagnini; Saggi di storia antica 2; Rom: «L'Erma» di Bretschneider, 1990) 149-173.

„The Rural Landscape of the Neo-Assyrian Empire: A Survey,“ State Archives of Assyria Bulletin 4 (1990) 81-142.

FALKENSTEIN, Adam, „Fluch über Akkade,“ ZA 57 NF 23 (1965) 43-124.

FENSHAM, Charles F., „Malediction and Benediction in Ancient Near Eastern Vassal-Treaties and the Old Testament," ZAW 74 (1962) 1-9. 
„Common Trends in Curses of the Near Eastern Treaties and KudurruInscriptions Compared with Maledictions of Amos and Isaiah," ZAW 75 (1963) 155-175.

"Ordeal by Battle in the Ancient Near East and the Old Testament," Studi in onore di Edoardo Volterra: Volume sesto (Hg. v. L. Aru u. a.; Pubblicazioni della facoltà di giurisprudenza dell'università di Roma 45; Mailand: Giuffrè, 1971) 127-135.

FENZ, Augustin Kurt, Auf Jahwes Stimme hören: Eine biblische Begriffsuntersuchung (WBTh 6; Wien: Herder, 1964).

FITZMYER, Joseph A., The Aramaic Inscriptions of Sefire (BibOr 19; Rom, Biblical Institute Press, 1967).

FLOSS, Johannes Peter, Jahwe dienen - Göttern dienen: Terminologische, literarische und semantische Untersuchungen einer theologischen Aussage zum Gottesverhältnis im Alten Testament (BBB 45; Köln, Bonn: Hanstein, 1975).

FOHRER, Georg u. a., Exegese des Alten Testaments: Einführung in die Methodik (UTB für Wissenschaft: Uni-Taschenbücher 267; Heidelberg, Wiesbaden: Quelle \& Meyer, ${ }^{5}$ 1989).

FRAME, G., Rulers of Babylonia from the Second Dynasty of Isin to the End of Assyrian Domination (1157-612 BC) (RIME 2; Toronto, Buffalo, London; University of Toronto Press: 1995).

FRANKENA, Rintje, „The Vassal-Treaties of Esarhaddon and the Dating of Deuteronomy," OTS 14 (1965) 122-154.

FRAYNE, Douglas R., Old Babylonian Period (2003-1595 BC) (RIME 4; Toronto, Buffalo, London; University of Toronto Press: 1990).

FRICK, Frank S., „Ecology, agriculture and patterns of settlement,“ The World of Ancient Israel. Sociological: Anthropological and Political Perspectives: Essays by Members of the Society for Old Testament Study (Hg. v. R. E. Clements; Cambridge: University Press, paperback edition 21993) 67-93.

FRIEDMAN, Richard Elliott, „From Egypt to Egypt: Dtr ${ }^{1}$ and Dtr ${ }^{2 “}$ Traditions in Transformation. Turning Points in Biblical Faith: Festschrift F. M. Cross (Hg. v. B. Halpern u. J. D. Levenson; Winona Lake/IN: Eisenbrauns, 1981) 167-192.

FUCHS, Andreas, Die Inschriften Sargons II. aus Khorsabad (Göttingen: Cuvillier, 1994).

GARCÍA MARTÍNEZ, F., „Les manuscrits du désert de Juda et le Deutéronome,“ Studies in Deuteronomy: in Honour of C.J. Labuschagne on the Occasion of his 65th Birthday (Hg. v. F. García Martínez, A. Hilhorst, J. T. A. G. M. van Ruiten, A. S. van der Woude; VTS 53; Leiden: Brill, 1994) 63-82.

GALTER, Hannes D., „On Beads and Curses,“ ARRIM 5 (1987) 11-30. 
GAMMIE, John G., ,The Theology of Retribution in the Book of Deuteronomy,“ $C B Q 32$ (1970) 1-12.

GELB, I. J. / KIENAST, B., Die altakkadischen Königsinschriften des dritten Jahrtausends v. Chr. (FAOS 7; Stuttgart: Steiner, 1990).

GERSTENBERGER, Erhard S., Das dritte Buch Mose: Leviticus (ATD 6; Göttingen: Vandenhoeck \& Ruprecht, 6. völlig neubearbeitete Auflage 1993).

GERTZ, Jan Christian, Die Gerichtsorganisation Israels im deuteronomistischen Gesetz (FRLANT 165; Göttingen: Vandenhoeck \& Ruprecht, 1994).

GESENIUS, Wilhelm, Hebräische Grammatik, völlig umgearbeitet von E. Kautzsch (Unveränderter Nachdruck der 28. Auflage; Hildesheim: Olms, 1985).

Hebräisches und aramäisches Handwörterbuch über das Alte Testament (Unveränderter Nachdruck der 17. Auflage; Berlin: Springer, 1962).

GEVIRTZ, Stanley, Curse Motifs in the Old Testament and in the Ancient Near East (University of Chicago, Oriental Languages and Civilisations, Dissertation 6. August 1959).

„Westsemitic Curses and the Problem of the Origins of Hebrew Law," $V T$ 11 (1961) 137-158. „Curse,“ IDB I, 749f.

GIESEN, Georg, Die Wurzel שכע "schwören“: Eine semasiologische Studie zum Eid im Alten Testament (BBB 56; Köln, Bonn: Hanstein, 1981).

GOLDZIHER, Ignaz, „Der Dîwân des Ġarwal b. Aus Al-Hutej’a,“ ZDMG 46 (1892) 1-53, 173-225.

GOLKA, Friedemann, „Die Figura etymologica im Alten Testament,“ „Wünschet Jerusalem Frieden": Jerusalem 1986 (Hg. v. M. Augustin u. K.-D. Schunck; BEAT 13; Collected Communications to the Congress of the International Organization for the Study of the Old Testament; Frankfurt/M., Bern, New York, Paris: Lang, 1988) 415-424.

GRAYSON, Albert Kirk, „The Walters Art Gallery Sennacherib Inscription (with 4 plates)," AfO 20 (1963) 83-96.

Assyrian Royal Inscriptions, Bd. I: From the Beginning to Ashur-reshaishi I (Records of the Ancient Near East 1, 2; Wiesbaden: Harrassowitz, 1972).

Assyrian Royal Inscriptions, Bd. II: From Tiglath-pileser I to Ashur-nasirapli II (Records of the Ancient Near East 1, 2; Wiesbaden: Harrassowitz, 1976).

160.

„Akkadian Treaties of the Seventh Century B. C.,“ JCS 39 (1987) 127 -

Assyrian Rulers of the Third and Second Millennia B. C. (to 1115 B. C.) (RIMA 1: Toronto, Buffalo, London: University of Toronto Press, 1987). 
Assyrian Rulers of the Early First Millennium BC I (1114-859 BC) (RIMA

2; Toronto, Buffalo, London; University of Toronto Press: 1991).

GREENFIELD, Jonas C., „Aramaic Studies and the Bible,“ Congress Volume: Vienna 1980 (Hg. v. J. A. Emerton; VTS 32; Leiden: Brill, 1981) 110-130.

GREENFIELD ,Jonas C. / PORTEN, Bezalel, The Bisitun Inscription of Darius the Great: Aramaic Version (Corpus Inscriptionum Iranicarum 1: Inscriptions of Ancient Iran 5: The Aramaic Versions of the Achaemenian Inscriptions, etc. Texts 1; London: Humphries, 1982).

GREENFIELD, Jonas C. / SHAFFER, Aaron, „Notes on the Curse Formulae of the Tell Fekherye Inscription,“ $R B 92$ (1985) 47-59.

GRILLOT-SUSINI, Françoise / HERRENSCHMIDT, Clarisse / MALBRAN-LABAT, Florence, „La version élamite de la trilingue de Behistun: Une nouvelle lecture,“ JA 281 (1993) 19-59.

GRIMM, Jacob / GRIMM, Wilhelm, Deutsches Wörterbuch, Bd. III: E-Forsche (Leipzig: Hirzel, 1862).

GROSS, Walter, „OTTO RÖSSLER und die Diskussion um das althebräische Verbalsystem," $B N 18$ (1982) 28-78.

„Satzfolge, Satzteilfolge und Satzart als Kriterien der Subkategorisierung hebräischer Konjunktionalsätze, am Beispiel der 'כ-Sätze untersucht,“ Text, Methode und Grammatik: Wolfgang Richter zum 65. Geburtstag (Hg. v. W. Groß, H. Irsigler u. Th. Seidl. St. Ottilien: Eos, 1991) 97-117.

GRUBER, Mayer I., „The Many Faces of Hebrew נפנים "lift up the face«,“ ZAW 95 (1983) 252-260.

„Hebrew da'bôn nepeš 'Dryness of Throat': From Symptom to Literary Convention,“ VT 37 (1987) 365-369.

HARAN, Menahem, „Book-Scrolls at the Beginning of the Second Temple Period: The Transition from Papyrus to Skins," HUCA 54 (1983) 111-122.

HAUSMANN, Jutta, Israels Rest: Studien zum Selbstverständnis der nachexilischen Gemeinde (BWANT 124; Stuttgart: Kohlhammer 1987). ,

HECKER, Karl, „Zukunftsdeutung in akkadischen Texten,“ TUAT II, 56-82.

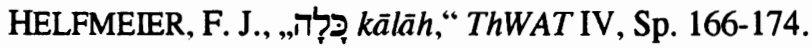

HEMPEL, Johann, „Die israelitischen Anschauungen von Segen und Fluch im Lichte altorientalischer Parallelen,“ZDMG 79 (1925) 20-110.

„Der textkritische Wert des Konsonantentextes von Kairener Genizafragmenten in Cambridge und Oxford zum Deuteronomium: Nach Kollationen von H. P. Rüger,“ NAWG I: Philologisch-Historische Klasse 10 (Göttingen: Vandenhoeck \& Ruprecht, 1959) 207-236. 
„Zur Septuaginta-Vorlage im Deuteronomium: Eine Entgegnung auf ZAW 1960, 237ff," ZAW 73 (1961) 87-96.

HERRMANN, Siegfried, Jeremia: Der Prophet und das Buch (EdF 271; Darmstadt: Wissenschaftliche Buchgesellschaft, 1990).

HERRMANN, Wolfram, „Jahwes Triumph über Mot,“ UF 11 (1979) 371-377.

HILL, Andrew E., „The Ebal Ceremony as Hebrew Land Grant?,“JETS 31 (1988) 399-406.

HILLERS, Delbert R., Treaty-Curses and the Old Testament Prophets (BibOr 16; Rom: Pontifical Biblical Institute, 1964.

„History and Poetry in Lamentations,“ CThMi 10 (1983) 155-161.

„Rite: Ceremonies of Law and Treaty in the Ancient Near East," Religion and Law: Biblical-Judaic and Islamic Perspectives (Hg. v. E. B. Firmage, B. G. Weiss u. J. W. Welch; Winona Lake/IN: Eisenbrauns, 1990) 351-364.

HINKE, William M. J., A New Boundary Stone of Nebuchadnezar I. from Nippur (BER 4; Philadelphia: University of Pennsylvania, 1907).

Selected Babylonian Kudurru Inscriptions (SSS 14; Leiden: Brill, 1911).

HIRSCH, Hans, „Die Inschriften der Könige von Agade,“ AfO 20 (1963) 1-82.

HOFFMANN, Hans-Detlef, Reform und Reformen. Untersuchungen zu einem Grundthema der deuteronomistischen Geschichtsschreibung (ATANT 66; Zürich: Theol. Vlg., 1980).

HÖLSCHER, Gustav, „Komposition und Ursprung des Deuteronomiums, “ ZAW 40 (1922) 161-255.

HORST, Friedrich, „Der Eid im Alten Testament,“ETh 17 (1957) 366-384. = Ders.: Gottes Recht: Gesammelte Studien zum Recht im Alten Testament (TB 12; München: Kaiser, 1961) 292-314.

HOUTMAN, Cornelis, Der Himmel im Alten Testament: Israels Weltbild und Weltanschauung (OTS 30; Brill: Leiden, New York, Köln, 1993).

HOUTMAN, Cees, Der Pentateuch: Die Geschichte seiner Erforschung neben einer Auswertung (Contributions to Biblical Exegesis and Theology 9; Kampen: Kok Pharos, 1994).

HUEHNERGARD, John, „The Feminine Plural Jussive in Old Aramaic,“ ZDMG 137 (1987) 266-277.

HULST, Alexander R., „Opmerkingen over de ka'aser-zinnen in Deuteronomium,“ NedThT 18 (1963) 337-361.

HUNGER, Hermann, Babylonische und assyrische Kolophone (AOAT 2; Kevelaer: Butzon \& Bercker, 1968). 
HYATT, Philip, J., „Jeremiah and Deuteronomy,“ JNES 1 (1942) 156-173. = A Prophet to the Nations: Essays in Jeremiah Studies (Hg. v. L. G. Perdue, B. W. Kovacs; Winona Lake/IN: Eisenbrauns, 1984) 113-127.

„The Deuteronomic Edition of Jeremiah,“ Vanderbilt Studies in the Humanities I (Hg. v. R. C. Beatty, J. P. Hyatt, M. K. Spears; Nashville: Vanderbilt University Press, 1951) 71-95. = A Prophet to the Nations: Essays in Jeremiah Studies (Hg. v. L. G. Perdue, B. W. Kovacs; Winona Lake/IN: Eisenbrauns, 1984) 247-267.

IMSCHOOT, P. van, „Fluch,“ $B L$, Sp. 486-488.

IRWIN, William A., „An Objective Criterion for the Dating of Deuteronomy,“ AJSL 56 (1939) 337-349.

ISER, Wolfgang, Der Akt des Lesens: Theorie ästhetischer Wirkung (UTB für Wissenschaft: Uni-Taschenbücher 636; München: Fink, 1990).

JANOWSKI, Bernd, Rettungsgewißheit und Epiphanie des Heils: Das Motiv der Hilfe Gottes "am Morgen" im Alten Orient und im Alten Testament, Bd. I: Alter Orient (WMANT 59; Neukirchen-Vluyn: Neukirchener Vlg., 1989).

JENNI, Ernst, „Faktitiv und Kausativ von אבד: zugrunde gehen'“" Hebräische Wortforschung: Festschrift zum 80. Geburtstag von Walter Baumgartner (Hg. v. B. Hartmann u. a.; VTS 16; Leiden: Brill, 1967) 143-157.

Die hebräischen Präpositionen, Bd. I: Die Präposition Beth (Stuttgart, Berlin; Köln: Kohlhammer, 1992).

JEREMIAS, Jörg, Kultprophetie und Gerichtsverkündigung in der späten Königszeit (WMANT 35; Neukirchen-Vluyn: Neukirchener Vlg., 1970).

JIRKU, Anton, Altorientalischer Kommentar zum Alten Testament (Leipzig: Deichtert, Erlangen: Scholl, 1923).

JOHNSON, Aubrey R., ,Aspects of the Use of the Term פים in the Old Testament,“ Festschrift Otto Eissfeld zum 60. Geburtstage (Hg. v. J. Fuck; Halle/Saale: Niemeyer, 1947) 155-159.

JOÜON, Paul / MURAOKA, Takamitsu, A Grammar of Biblical Hebrew (SubBib 14; Rom: Pontificio Istituto Biblico, 1991).

JUNKER, Hubert, „Das Buch Deuteronomium,“ $E B$ I, 449-557.

KAHLE, Paul / SOMMER, Ferdinand, „Die lydisch-aramäische Bilingue,“ KAF 3 (1930) 18-86.

KAISER, Walter C. Jr., „The Old Testament Promise of Material Blessings and the Contemporary Believer," TJNS 9 (1988) 151-169.

KALlUVEETTIL, Paul, Declaration and Covenant: A Comprehensive Review of Covenant Formulae from the Old Testament and the Ancient Near East (AnBib 88; Rom: Biblical Institute Press, 1982). 
KEDAR, Benjamin, Biblische Semantik: Eine Einführung (Stuttgart: Kohlhammer, 1981).

KEEL, Othmar, „Sturmgott - Sonnengott - Einziger: Ein neuer Versuch, die Entstehung des judäischen Monotheismus historisch zu verstehen, " BiKi 49 (1994) 82-92.

KEEL, Othmar / UEHLINGER, Christoph, Göttinnen, Götter und Gottessymbole: Neue Erkenntnisse zur Religionsgeschichte Kanaans und Israels aufgrund bislang unerschlossener ikonographischer Quellen (QD 134; Freiburg/Br., Basel, Wien: Herder, 1992).

„Jahwe und die Sonnengottheit von Jerusalem,“Ein Gott allein?: JHWHVerehrung und biblischer Monotheismus im Kontext der israelitischen und altorientalischen Religionsgeschichte (Hg. v. W. Dietrich u. M. A. Klopfenstein; OBO 139; Freiburg/Schweiz: Universitätsverlag, Göttingen: Vandenhoeck \& Ruprecht, 1994) 269-306.

KEIL, Carl Friedrich, Leviticus, Numeri und Deuteronomium (BKAT 1,2; Leipzig: Dörffling \& Franke ${ }^{3} 1870$; Nachdruck: Gießen, Basel: Brunnen, 1987).

KELLER, Carl-A., , pll leicht sein,“ THAT II, Sp. 641-647.

KESTEMONT, Guy, „Accords internationaux relatifs aux ligues hittites (16001200 av. J. C.). Dossier C: Le dossier Egyptien,“ OLoP 12 (1981) 15-78.

KING, Leonard W., Babylonian Boundary-Stones and Memorial Tablets in the British Museum (London: Longmans, Quaritch, Asher, Oxford: University Press, 1912).

KINNIER WILSON, James V., „Medicine in the Land and Times of the Old Testament," Studies in the Period of David and Solomon and other Essays: Papers Read at the International Symposium for Biblical Studies, Tokyo, 5-7 December. 1979 (Hg. v. T. Ishida; Tokyo: Yamakawa- Shuppansha, 1982) 337-365.

KITCHEN, Kenneth A., „Egypt, Ugarit, Qatna and Covenant,“ UF 11 (1979) 453464. 118-135.

„The Fall and Rise of Covenant, Law and Treaty,“ TyndBull 40 (1989)

KLINE, Meredith G., Treaty of the Great King: The Covenant Structure of Deuteronomy: Studies and Commentary (Grand Rapids/MI: Eerdmans, 1963).

KLOPPERS, M. H. O., „Deuteronomium 27 - die plek en bedoeling daarvan,“ NGTT 34 (1993) 242-247.

KLUGE, Friedrich, Etymologisches Wörterbuch der deutschen Sprache (Berlin, New York: de Gruyter, ${ }^{22} 1989$ ).

KÖHLER, Ludwig / BAUMGARTNER, Walter, Hebräisches und aramäisches Lexikon zum Alten Testament (4 Bde.; Leiden, New York, København, Köln: Brill, 31967-1990). 
KÖNIG, Eduard, Das Deuteronomium (KAT 3; Leipzig: Deichtert, 1917).

KORNFELD, Walter, Levitikus (NEB.AT 6; Würzburg: Echter, 1983)

KOROŠEC, Viktor, Hethitische Staatsverträge: Ein Beitrag zu ihrer juristischen Wertung (LRWS 60; Leipzig: Weicher, 1931).

KOTTSIEPER, Ingo, „Zur Etymologie von hebr. šb` I,“ UF 22 (1990) 149-168.

"Die literarische Aufnahme assyrischer Begebenheiten in frühen aramäischen Texten," La circulation des biens, des personnes et des idées dans le Proche-Orient ancien: actes de la XXXVIII Rencontre Assyriologique Internationale Paris, 8.-10. juillet 1991 (Hg. v. D. Charpin u. F. Joannès; Paris: Éditions Recherche sur les civilisations, 1992) 283-289.

KRÄMER, Karl Friedrich, Numeri und Deuteronomium (HBK 2,1; Freiburg/Br.: Herder, 1955.

KREBERNIK, Manfred, „M. Weinfelds Deuteronomiumskommentar aus assyriologischer Sicht," Bundesdokument und Gesetz: Studien zum Deuteronomium (Hg. v. G. Braulik; Herders Biblische Studien 4; Freiburg, Basel, Wien, Barcelona, Rom, New York: Herder, 1995) 27-36.

KÜHNER, Raphael / GERTH, Bernhard, Ausführliche Grammatik der griechischen Sprache, Teil II: Satzlehre, Bd. I (Darmstadt: Wissenschaftliche Buchgesellschaft, 1966; unveränderter Nachdruck der 3. Aufl., Leipzig; Hannover: Hahn, 1898).

KUPPER, Jean-Robert, „Les formules de malédiction dans les inscriptions royales de l'époque paléo-babylonienne," $R A 84$ (1990) 157-163.

LABAT, René, Manuel d'épigraphie akkadienne (Signes, Syllabaire, Idéogrammes) (Paris: Librairie Orientaliste Paul Geuthner, ${ }^{5}$ 1976).

„Assyrien und seine Nachbarländer (Babylonien, Elam, Iran) von 1000 bis 617 v. Chr. / Das neubabylonische Reich bis 539 v. Chr.," Fischer Weltgeschichte, Bd. 4: Die Altorientalischen Reiche III: Die erste Hälfte des 1. Jahrtausends (Hg. v. E. Cassin. J. Bottéro u. J. Vercoutter; Frankfurt/M.: Fischer Taschenbuch Vlg., ${ }^{2}$ 1987) 9-111.

LABAT, René / CAQUOT, André / SZNYCER, Maurice / VIEYRA, Maurice, Les religions du Proche-Orient asiatique (Le tresor sprirituel de l'humanité; Paris: Fayard, Denoel, 1970).

LAMBDIN, Thomas O., „Egyptian Loan Words in the Old Testament,“ JAOS 73 (1953) 145-155.

LAMBERT, Wilfred G., Babylonian Wisdom Literature (Oxford: Clarendon, 1960). „Gott: B. Nach akkadischen Texten," RLA III, 543-546.

LAMPARTER, Helmut, Der Aufruf zum Gehorsam: Das fünfte Buch Mose (BAT 9; Stuttgart: Calwer, 1977).

LANDSBERGER, Benno, „Das «gute Wort»,“ MAOG 4 (1928/29) 294-321. 
LANGDON, Stephen, Die Neubabylonischen Königsinschriften (VAB 4; Leipzig: Hinrichs, 1912).

LANGER, Birgit, Gott als "Licht" in Israel und Mesopotamien: Eine Studie zu Jes 60,1-3.19f (ÖBS 7; Klosterneuburg: VIg. Österreichisches Katholisches Bibelwerk, 1989).

LAYTON, Scott C., „Literary Sources for the History of Palestine and Syria: Old Aramaic Inscriptions,“ BA 51 (1988) 172-189.

LEFÈVRE, A., „Malédiction et Bénédiction,“ DBS V, Sp. 746-751.

LEHMANN, Manfred R., „Biblical Oaths,“ ZAW 84 (1969) 74-92.

LEICK, Gwendolyn, Die akkadischen Fluchformeln des 3. und 2. Jahrtausends (Dissertation: Karl Franzens Universität Graz, November 1976).

LEMAIRE, André / DURAND, Jean-Marie, Les inscriptions Araméennes de Sfiré et l'Assyrie de Shamshi-ilu (HEO 20; Genf, Paris: Librairie Droz, 1984).

LEWIS, T. / HARRISON, R. K., „Curse,“ISBE I, 837f.

LINGEN, Anton van der, „BW'-YȘ' ('To Go out and to Come in') as a Military Term," $V T 42$ (1992) 59-66.

LIPINSKI, Edward, „Sale, Transfer, and Delivery in Ancient Semitic Terminology," Gesellschaft und Kultur im alten Vorderasien (Hg. v. H. Klengel; SGKAO 15; Berlin: Akademie Vlg., 1982) 173-185.

LISOWSKI, Gerhard, Konkordanz zum hebräischen Alten Testament (Stuttgart: Deutsche Bibelgesellschaft, ${ }^{2}$ 1981).

LIVERANI, Mario, „Terminologia e ideologia del patto nelle iscrizioni reali assire," I trattati nel mondo antico forma ideologia funzione (Hg. v. L. Canfora, M. Liverani, C. Zaccagnini; Saggi di storia antica 2; Rom: «L'Erma» di Bretschneider, 1990) 113-147.

LOHFINK, Norbert, Das Hauptgebot: Eine Untersuchung literarischer Einleitungsfragen zu Din 5-11 (AnBib 20; Rom: Pontifical Biblical Institute, 1963).

Deuteronomiumsforschung) Bib 44 (1963) 261-288, 461-498. = Ders., Studien zum Deuteronomium und zur deuteronomistischen Literatur I (SBAB 8; Stuttgart: Vlg. Katholisches Bibelwerk, 1990) 99-165.

„Die Sicherung der Wirksamkeit des Gotteswortes durch das Prinzip der Schriftlichkeit der Tora und durch das Prinzip der Gewaltenteilung nach den Ämtergesetzen des Buches Deuteronomium (Dt 16,18-18,22),“ Testimonium Veritati: Festschrift Wilhelm Kempf (Hg. v. H. Wolter; FTS 7; Frankfurt: Knecht, 1971) 143-155. = Ders., Studien zum Deuteronomium und zur deuteronomistischen Literatur I (SBAB 8; Stuttgart: Vlg. Katholisches Bibelwerk, 1990) 305-323. 
„Die Abänderung der Theologie des priesterlichen Geschichtswerks im Segen des Heiligkeitsgesetzes: Zu Lev. 26,9.11-13,“Wort und Geschichte: Festschrift für Karl Elliger zum 70. Geburtstag (Hg. v. H. Gese u. H. P. Rüger; AOAT 18; Kevelaer: Butzon \& Bercker; Neukirchen-Vluyn: Neukirchener Vlg., 1973) 129-136. = Ders., Studien zum Pentateuch (SBAB 4; Stuttgart: Vlg. Katholisches Bibelwerk, 1988) 157-168.

"Gott im Buch Deuteronomium,“"La notion biblique de Dieu: Le Dieu de la Bible et le Dieu des philosophes (Hg. v. J. Coppens; BEThL 41; Gembloux: Duculot; Löwen: University Press, 1976) 101-125. = Ders., Studien zum Deuteronomium und zur deuteronomistischen Literatur II (SBAB 12; Stuttgart: Vlg. Katholisches Bibelwerk, 1991) 25-53.

„Die These vom ,deuteronomischen“ Dekaloganfang - ein fragwürdiges Ergebnis atomistischer Sprachstatistik," Studien zum Pentateuch: Walter Kornfeld zum 60. Geburtstag (Hg. v. G. Braulik; Wien: Herder, 1977) 99-109. = Ders., Studien zum Deuteronomium und zur deuteronomistischen Literatur I (SBAB 8; Stuttgart: Vlg. Katholisches Bibelwerk, 1990) 363-378.

„Die Gattung der »Historischen Kurzgeschichte« in den letzten Jahren von Juda und in der Zeit des Babylonischen Exils," ZAW 90 (1978) 319-347. = Ders., Studien zum Deuteronomium und zur deuteronomistischen Literatur II (SBAB 12; Stuttgart: Vlg. Katholisches Bibelwerk, 1991) 55-86.

„,Ich bin Jahwe, dein Arzt ${ }^{*}$ (Ex 15,26): Gott, Gesellschaft und menschliche Gesundheit in einer nachexilischen Pentateuchbearbeitung (Ex 15,25b.26),“ "Ich will euer Gott werden." Beispiele biblischen Redens von Gott (Hg. v. N. Lohfink u. a.; SBS 100; Stuttgart: Verl. Katholisches Bibelwerk, 1981) 11-73. = Ders., Studien zum Pentateuch (SBAB 4; Stuttgart: Vlg. Katholisches Bibelwerk, 1988) 91-155.

„Hos. XI 5 als Bezugstext von Dtn. XVII 16,“ VT 31 (1981) 226-228.

„Ernest W. Nicholson, God and His People. Covenant and Theology in the Old Testament, Oxford 1986 (Paperback 1988), Clarendon Press. $£$ 8,95. xii +244 S. ISBN 0-19-826727-4,“ BZ 34 (1990) 296-298.

„Kerygmata des Deuteronomistischen Geschichtswerks,“ Die Botschaft und die Boten: Festschrift für $H$. W. Wolff zum 70. Geburtstag (Hg. v. J. Jeremias u. L. Perlitt; Neukirchen-Vluyn: Neukirchener Vlg., 1981) 87-100. = Ders., Studien zum Deuteronomium und zur deuteronomistischen Literatur II (SBAB 12; Stuttgart: Vlg. Katholisches Bibelwerk, 1991) 125-142.

„Zur neueren Diskussion über 2 Kön 22-23,“ Das Deuteronomium: Entstehung, Gestalt und Botschaft (Hg. v. N. Lohfink; BEThL 68; Löwen: PeetersPress, University-Press, 1985) 2-48. = Ders., Studien zum Deuteronomium und zur deuteronomistischen Literatur II (SBAB 12; Stuttgart: Vlg. Katholisches Bibelwerk, 1991) 179-207. 
„Das Deuteronomium: Jahwegesetz oder Mosegesetz?: Die Subjektzuordnung bei Wörtern für ,Gesetz' im Dtn und in der dtr Literatur,“ ThPh 65 (1990) 387-391.

„Die Kultreform Joschijas von Juda: 2 Kön 22-23 als religionsgeschichtliche Quelle," Studien zum Deuteronomium und zur deuteronomistischen Literatur II (Hg. v. N. Lohfink; SBAB 12; Stuttgart: Verl. Katholisches Bibelwerk, 1991) 209-227.

93.

„'d(w)t im Deuteronomium und in den Königsbüchern,“ BZ 35 (1991) 86-

„Dtn 28,69 - Überschrift oder Kolophon?“” BN 64 (1992) 40-52.

„Die Ältesten Israels und der Bund: Zum Zusammenhang von Dtn 5,23; 26,17-19; 27,1.9f und 31,9," BN 67 (1993) 26-42.

„Zur Fabel in Dtn 31-32,“ Konsequente Traditionsgeschichte: Festschrift für Klaus Baltzer zum 65. Geburtstag (Hg. v. R. Bartelmus, T. Krüger u. H. Utzschneider; OBO 126; Freiburg/Schweiz: Universitätsverlag, Göttingen: Vandenhoeck \& Ruprecht, 1993) 255-279.

„Moab oder Sichem - wo wurde Dtn 28 nach der Fabel des Deuteronomiums proklamiert?"“ Studies in Deuteronomy: in Honour of C. J. Labuschagne on the Occasion of his 65th Birthday (Hg. v. F. García Martínez, A. Hilhorst, J. T. A. G. M. van Ruiten, A. S. van der Woude; VTS 53; Leiden: Brill, 1994) 139-153.

„Zur Fabel des Deuteronomiums,“ Bundesdokument und Gesetz: Studien zum Deuteronomium (Hg. v. G. Braulik; Herders Biblische Studien 4; Freiburg, Basel, Wien, Barcelona, Rom, New York: Herder, 1995) 65-78.

שמד, "ThWAT Manuskript im Druck.

LOPRIENO, Antonio, „Amenemope ed i Proverbii: un problema di comparazione lessicale,"Vicino Oriente 3 (1980) 47-76.

LOWERY, Richard, The Reforming Kings: Cults and Society in First Temple Juda (JSOT.S 120; Sheffield: Academic Press, 1991).

LUCKENBILL, David Daniel, The Annals of Sennacherib (UCIOP 2; Chicago/IL: The University of Chicago Press, 1924).

LUTZMANN, Heiner, „Aus den Gesetzen des Königs Lipit Eschtar von Isin,“ TUAT I, 23-31.

MACDONALD, John, „The Status and Role of the NA'AR in Israelite Society,“ JNES 35 (1976) 147-170.

MACINTOSH, Andrew Alexander, „A Consideration of Hebrew גער,“ VT 19 (1969) 471-479.

MACKENSEN, Lutz, Deutsches Wörterbuch in 3 Bänden, Bd. I: A-F (Reinbek bei Hamburg: Rowohlt, 1979). 
MALUL, Meir, „Adoption of Foundlings in the Bible and Mesopotamian Documents: A Study of Some Legal Metaphors in Ezekiel 16:1-7,“ JSOT 46 (1990) 97-126.

The Comparative Method in Ancient Near Eastern and Biblical Legal Studies (AOAT 227; Kevelaer: Butzon \& Bercker, Neukirchen-Vluyn: Neukirchener Vlg., 1990).

MALUSȦ, Lorenzo, „L'interpretazione Geronimiana di “ $H R B$ ' in tre passi biblici,“ BeO 19 (1977) 259-261.

MARGALIT, Baruch, The Ugaritic Poem of Aqht: Text, Translation, Commentary (BZAW 182; Berlin, New York: de Gruyter, 1989).

MARTI, Karl, „Das fünfte Buch Mose oder Deuteronomium,“ HSAT=Die Heilige Schrift des Alten Testamentes, Bd. I: Mose - Ezechiel (Hg. v. A. Bertholet; Tübingen: [Mohr] Siebeck, ${ }^{4}$ 1922) 258-327.

MAYER, Walter, „Die Finanzierung einer Kampagne (TCL 3, 346-410),“ UF 11 (1979) 571-595.

MAYES, Andrew David Hastings, Deuteronomy (NCBC softback edition; London: Marshall, Morgan \& Scott, 1981).

McCARTHY, Dennis J., Treaty and Covenant: A Study in Form in the Ancient Oriental Documents and in the Old Testament (AnBib 21; Rom: Pontifical Biblical Institute, 1963.)

Treaty and Covenant: A Study in Form in the Oriental Documents and in the Old Testament (AnBib 21; Rom: Biblical Institute Press, ${ }^{2}$ 1978).

McKAY, John W., Religion in Judah under the Assyrians 732-609 BC (SBT 2, 26; London: SCM Press, 1973).

MENDENHALL, George E., Recht und Bund in Israel und dem Alten Vordern Orient (Theologische Studien 64; Zürich: EVZ-Vlg., 1960). Übersetzung von BA 17 (1954) 2, 26-46; 3, 49-76.

„The Suzerainty Treaty Structure: Thirty Years Later,“ Religion and Law: Biblical-Judaic and Islamic Perspectives (Hg. v. E. R. Firmage, B. G. Weiss u. J. W. Welch; Winona Lake/IN: Eisenbrauns, 1990) 85-100.

MERCER, Samuel A. B., „The Malediction in Cuneiform Inscriptions,“ JAOS 34 (1915) 282-309.

MICROROBERT, Dictionnaire du français primordial (Hg. v. P. Robert u. a.; Paris: Le Robert, édition revue et mis à jour 1980).

MILLER, Christian, „The Infinitive Construct in the Lawbooks of the Old Testament: A Statistical Study,“ $C B Q 32$ (1970) 222-226.

MITCHELL, Christopher Wright, The Meaning of BRK "to bless" in the Old Testament (SBL.DS 95; Atlanta/GE: Scholars Press, 1987). 
MORAN, William L., „The Ancient Near Eastern Background of The Love of God in Deuteronomy," $C B Q 25$ (1963) 77-78.

„Deuteronomy," A New Catholic Commentary on Holy Scripture (Hg. v. R. C. Fuller, L. Johnston u. C. Kearns; rev. ed. London: Nelson, 1969) 256-276.

Les lettres d' El-Amarna: Correspondence diplomatique du pharaon (LAPO 13; Paris: Cerf, 1987).

MORROW, William, „A Generic Discrepancy in the Covenant Code,“ Theory and Method in Biblical and Cuneiform Law: Revision, Interpolation and Development (Hg. v. B. M. Levinson; JSOT.S 181; Sheffield: Academic Press, 1994) 136-151.

MØRSTAD, Erik, „Overveielser til Dtn. 28,“ NTT 60 (1959) 224-232.

Wenn du der Stimme des Herrn, deines Gottes, gehorchen wirst -: Die primären Einführungen zu Din. 28,3-6 und 16-29 (Oslo: Forlaget Land og Kirke, 1960).

MOWINCKEL, Sigmund, Psalmenstudien V: Segen und Fluch in Israels Kult und Psalmdichtung (Videnskapsselskapets Skrifter II; Hist.-Filos. Klasse 1923 Nr. 3; Kristiana: Jakob Dybwad, 1923). = Ders., Psalmenstudien: Buch III $-I V-V-V I$ (Amsterdam: P. Schnippers N. V., 1966).

MUFFS, Yochanan, „Joy and Love as Metaphorical Expressions of Willingness and Spontaneity in Cuneiform, Ancient Hebrew, and Related Literatures: Divine Investitures in the Midrash in the Light of Neo-Babylonian Royal Grants," Christianity, Judaism and Other Greco-Roman Cults: Studies for Morton Smith at Sixty, Bd. III (Hg. v. J. Neusner; Leiden: Brill, 1975).

MÜLLER, Hans Peter, „Segen im Alten Testament: Theologische Implikationen eines halb vergessenen Themas,“ ZThK 87 (1990) 1-32. = Ders., Mythos Kerygma - Wahrheit: Gesammelte Aufsätze zum Alten Testament in seiner Umwelt und zur biblischen Theologie (BZAW 200; Berlin, New York: de Gruyter, 1991) 220-252.

„Phönizische historische Inschriften,“ TUAT I, 640-645.

MÜLLER, Walter, „Bauinschrift eines Herrschers vom Tempel in Sirwah mit Bundesschließungsformel,“ TUAT I, 659f.

MUNN-RANKIN, J. Margaret, „Diplomacy in Western Asia in the Early Second Millennium B. C.," Iraq 18 (1956) 68-110.

NELSON, Richard, „Realpolitik in Judah (687-609 B.C.E.),“ Scripture in Context II: More Essays on the Comparative Method (Hg. v. W. W. Hallo u. a.; Winona Lake/IN: Eisenbrauns, 1983) 177-189.

NICCACCI, Alviero, „A Neglected Point of Hebrew Syntax: yiqtol and Position in the Sentence,"LA 37 (1987) 7-19.

The Syntax of the Verb in Classical Hebrew Prose (JSOT.S 86; Sheffield: Academic Press, 1990). 
NICHOLSON, Ernest Wilson, God and His People: Covenant and Theology in the Old Testament (Oxford: Clarendon Press 1986).

NIELSEN, Bruce Eric, תיקנוי סופרים (Union Theological Seminary; Submitted in partial fulfillment of the requirements for the degree of Master of Divinity, 1977).

NIEHR, Herbert, Der höchste Gott: Alttestamentlicher Jahweglaube im Kontext syrisch-kanaanäischer Religion des 1. Jahrtausends v. Chr. (BZAW 190; Berlin, New York: de Gruyter, 1990).

NISSEN, Hans J., Grundzüge einer Geschichte der Frühzeit des Vorderen Orients (Grundzüge 53; Darmstadt: Wissenschaftliche Buchgesellschaft, 1983).

NOTH, Martin, „Die mit des Gesetzes Werken umgehen, die sind unter dem Fluch," (AHGHIR 6,3; Riga 1938) 127-145. = Ders., Gesammelte Studien zum Alten Testament (TB 6; München: Kaiser, $\left.{ }^{3} 1966\right)$ 155-171.

Überlieferungsgeschichtliche Studien: Die sammelnden und bearbeitenden Geschichtswerke im Alten Testament (SKG.G 18; 1943; Tübingen: Niemeyer, 31967) 43-266.

O'BRIEN, Mark A., The Deuteronomistic History Hypothesis: A Reassessment (OBO 92; Freiburg/Schweiz: Universitätsverlag, Göttingen: Vandenhoeck \& Ruprecht, 1989).

OCKINGA, Boyo G., ,rō’š wezānāb kippāh we'agmôn in Jes 9,13 und 19,15,“ $B N$ 10 (1979) 31-34.

OELSNER, Joachim, „Zweisprachige Gesetze Hammurabis oder sumerische Fluchformeln?," Nouvelles Assyriologiques Brèves et Utilitaires (1993/3) 55f.

OETTLI, Samuel, Das Deuteronomium und die Bücher Josua und Richter (KKA 2; München: Beck, 1893).

OETTINGER, Norbert, Die militärischen Eide der Hethiter (StBT 22; Wiesbaden: Harrassowitz, 1976).

OTTO, Eckart, „Die Bedeutung der altorientalischen Rechtsgeschichte für das Verständnis des Alten Testaments,“ ZThK 88 (1991) 139-168.

„Vom Bundesbuch zum Deuteronomium: Die deuteronomische Redaktion in Dtn 12-26," Biblische Theologie und gesellschaftlicher Wandel: Für Norbert Lohfink SJ (Hg. G. Braulik, W. Groß u. S. McEvenue; Freiburg/Br., Basel, Wien: Herder, 1993) 260-278.

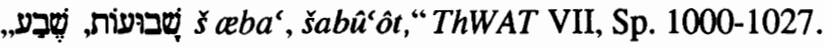

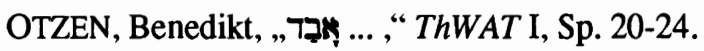

OWEN, David I. / WATANABE, Kazuko, „Eine neubabylonische Gartenkaufurkunde mit Flüchen aus dem Akzessionsjahr Asarhaddons," OA 22 (1982) 37-48.

PARPOLA, Simo, „Neo-Assyrian Treaties from the Royal Archives of Niniveh,“ JCS 39 (1987) 161-189. 
PARPOLA, Simo / WATANABE, Kazuko (Hg.), Neo-Assyrian Treaties and Loyalty Oaths (SAA 2; Helsinki University Press, 1988).

PATTE, Daniel, „Speech Act Theory and Biblical Exegesis,“ Semeia 41 (1988) 85102.

PAX, E., „Fluch: I. Biblisch,“ $L T h K$ VI, Sp. 182f.

PEDERSEN, Johannes, Der Eid bei den Semiten in seinem Verhältnis zu verwandten Erscheinungen sowie die Stellung des Eides im Islam (SGKIO; Heft 3; Straßburg: Trübner, 1914).

PEISER, Felix E., Texte juristischen und geschäftlichen Inhalts (KB 4; Berlin: Reuter \& Reichard, 1896).

PENNA, Angelo, Deuteronomio (La Sacra Bibbia, Antico Testamento; Rom, Turin: Marietti, 1976).

PERLITT, Lothar, Bundestheologie im Alten Testament (WMANT 36; Neukirchen: Neukirchener Vlg., 1969).

„Ein einzig Volk von Brüdern: Zur deuteronomischen Herkunft der biblischen Bezeichnung "Bruder «," Kirche: Festschrift für Günther Bornkamm zum 75. Geburtstag (Hg. v. D. L. Lührmann u. G. Trecker; Tübingen: Mohr, 1980) 27-52.

PERSON, Raymond Franklin, Second Zechariah and the Deuteronomic School (ISOT.S 167; Sheffield: Academic Press, 1993).

PHILLIPS, Antony, Deuteronomy (CNEB; Cambridge: University Press, 1973).

PLAUT, W. Gunther, דברים-Deuteronomy (The Torah: A Modern Commentary 5; New York: Union of American Hebrew Congegrations, 1983).

PLÖGER, Josef G., Literarkritische, formgeschichtliche und stilkritische Untersuchungen zum Deuteronomium (BBB 26; Bonn: Hanstein, 1967). ,

PODELLA, Thomas, „Notzeit-Mythologem und Nichtigkeitsfluch,“ Religionsgeschichtliche Beziehungen zwischen Kleinasien, Nordsyrien und dem Alten Testament: Internationales Symposion Hamburg 12.-21. März 1990 (Hg. v. B. Janowski, K. Koch u. G. Wilhelm; OBO 129; Freiburg/Schweiz: Universitätsverlag, Göttingen: Vandenhoeck \& Ruprecht, 1993) 427-454.

POMPONIO, Francesco, Formule di maledizione della Mesopotamia preclassica (VOA.M 1; Brescia: Paideia, 1990).

POSTGATE, J. Nicholas, Fifty Neo-Assyrian Legal Documents (Warminster/England: Aris \& Phillips, 1976).

PREUSS, Horst Dietrich, Verspottung fremder Religionen im Alten Testament (BWANT 92; Stuttgart, Berlin, Köln, Mainz: Kohlhammer 1971). “אתה - בוזא, ThWAT I, Sp. 536-568. 
Deuteronomium (EdF 164; Darmstadt: Wissenschaftliche Buchgesellschaft, 1982).

Theologie des Alten Testaments, Bd. I: JHWHs erwählendes und verpflichtendes Handeln (Stuttgart, Berlin, Köln: Kohlhammer, 1991).

PRITCHARD, James B., Ancient Near Eastern Texts Relating to the Old Testament (Princeton/NJ: Princeton University Press, ${ }^{2} 1955$ ).

PUECH, Emile, „Les inscriptions araméennes I et III de Sfiré: Nouvelles lectures,“ $R B 89$ (1982) 576-587.

„Les traités araméens de Sfiré,“ Traités et serments dans le Proche Orient Ancien (Hg. v. J. Briend, R. Lesbrun, E. Puech; Supplément aux Cahiers Evangile 81: Paris: Cerf, 1992) 88-107.

QUEEN SUTHERLAND, Kandy Maria, The Futility Curse in the Old Testament (The Southern Baptist Theological Seminary, Faculty of the Graduate School; Dissertation Mai 1982; Ann Arbor: UMI 8217985).

RAD, Gerhard von, Deuteronomium-Studien (FRLANT Neue Folge 40; der ganzen Reihe 58; Göttingen: Vandenhoeck \& Ruprecht, 1947) = Ders., Gesammelte Studien zum Alten Testament, Bd. II (TB 48; München: Kaiser, 1973) 109-153.

Das fünfte Buch Mose: Deuteronomium (ATD 8; Göttingen: Vandenhoeck \& Ruprecht, ${ }^{4} 1983$.

RASHID, Fawzi, „The Tiles of King Marduch-Shabik-Ziri. 1082-1070 B. C.“ Sumer 36 (1980) 124-149 (arab.).

Reallexikon der Assyriologie (7 Bde. erschienen; hg. v. E. Ebeling u. a.; Berlin, Leipzig, New York: De Gruyter, 1932-1990).

REGT, L. J. de, A Parametric Model for Syntactic Studies of a Textual Corpus: Demonstrated on the Hebrew of Deuteronomy 1-30 (SSN 24; Assen, Maastricht: Van Gorcum, 1988).

Supplement to A Parametric Model for Syntactic Studies of a Textual Corpus: Demonstrated on the Hebrew of Deuteronomy 1-30 (SSN 24; Assen, Maastricht: Van Gorcum, 1988).

REIF, Stefan C., „A Note on רעי,“ V VT 21 (1971) 241-244.

REIMER, David J., „Concerning Return to Egypt: Deuteronomy XVII 16 and XXVIII 68 Reconsidered," Studies in the Pentateuch (Hg. v. J. A. Emerton; VTS 41; Leiden, New York, København, Köln: Brill, 1990) 217 - 229.

REINER, Erika, „Quelques vœux,“ Marchands, diplomates et empereurs: Études sur la civilisation mésopotamique offertes a Paul Garelli (Hg. v. D. Charpin u. F. Joannès; Paris: Éditions Recherche sur les civilisations, 1991) 421-422.

RENNES, Jean, Le Deutéronome (Genf: Labor et Fides, 1967).

RESCHID, Fawzi / WILCKE, Claus, „Ein ,Grenzstein“ aus dem ersten (?) Regierungsjahr des Königs Marduk-šāpik-zēri,“ ZA 65 (1975) 34-62. 
REVENTLOW, Henning Graf, Das Heiligkeitsgesetz: Formgeschichtlich untersucht (WMANT 6; Neukirchen: Neukirchener Vlg., 1961).

RICHTER, Wolfgang: Biblia Hebraica transcripta (MUS; ATSAT 33.3; St. Ottilien: Eos, 1991).

RIDDERBOS, Jan, Het boek Deuteronomium opnieuw uit de grondtekst vertaald en verklaard Bd. I: Hoofdstuk 1-16:17 (Korte verklaring der Heilige Schrift met nieuwe vertaling; Kampen: Kok, ${ }^{2} 1963$ ).

Het boek Deuteronomium opnieuw uit de grondtekst vertaald en verklaard Bd. II: Hoofdstuk 16:18-34:12 (Korte verklaring der Heilige Schrift met nieuwe vertaling; Kampen: Kok, $\left.{ }^{2} 1964\right)$.

RIES, Gerhard, Prolog und Epilog in Gesetzen des Altertums (MBPF 76; München: Beck, 1983).

RIESENER, Ingrid, Der Stamm טבד im Alten Testament: Eine Wortuntersuchung unter Berücksichtigung neuerer Sprachwissenschaftlicher Methoden (BZAW 149; Berlin, New York: de Gruyter, 1979).

RINALDI, Giovanni, ,nebelâ,"“ BeO 22 (1980) 30.

RÖMER, Thomas, „The Book of Deuteronomy,“ The History of Israel's Traditions: The Heritage of Martin Noth (Hg. v. S. L. McKenzie u. M. P. Graham; JSOT.S 182; Sheffield: Academic Press, 1994) 178-212.

ROOY, H. F. van, „Deuteronomy 28:69 - Superscript or Subscript?““ JNSL 14 (1988) 215-222.

ROSE, Martin, 5. Mose Teilband 2: 5. Mose 1-11 und 26-34: Rahmenstücke zum Gesetzeskorpus (ZBK.AT 5; Zürich: Theologischer Vlg., 1994).

ROSENTHAL, Franz, A Grammar of Biblical Aramaic (PLO.NS 5; Wiesbaden: Harrassowitz, 1961).

RÖSSLER. Otto, „Die Verträge des Königs Bar-Ga'yah von Ktk mit König Mati'-Il von Arpad (Stelen von Sefire)," TUAT I, 178-189.

RUDOLF, Wilhelm, Jeremia (HAT I, 12; Tübingen: [Mohr] Siebeck, ${ }^{2}$ 1958).

RÜTERSWÖRDEN, Udo, Dominium terrae: Studien zur Genese einer alttestamentlichen Vorstellung (BZAW 215; Berlin; New York: de Gruyter, 1993).

SALVINI, Mirjo, „L'uso dell' assiro nel regno di Urartu,“ Vicino Oriente 3 (1980) 169-177.

SCHACHERMEYR, Fritz, „Eisen,“ RLA II, 316-319.

SCHÄCHTER, Erwin Alois, Fluch und Segen beim Bundesschließen im Alten Orient und im Alten Testament (Universität München, Katholisch-Theologische Fakultät; Dissertation 1966).

SCHÄFER-LICHTENBERGER, Christa, „Göttliche und menschliche Autorität im Deuteronomium," Pentateuchal and Deuteronomistic Studies: Papers read at the 
XIIIth ISOT Congress Leuven 1989 (Hg. v. C. Brekelmans u. J. Lust; BEThL 94; Löwen: University Press; Peeters, 1990) 125-142.

Josua und Salomo: Eine Studie zu Autorität und Legitimität des Nachfolgers im Alten Testament (VTS 58; Leiden, New York, Köln: Brill, 1995).

SCHARBERT, Josef, „«Fluchen» und «Segnen» im Alten Testament,“ Bib 39 (1958) 1-26.

„Die Geschichte der bārûk-Formel,“ BZ NF 17 (1973) 1-28.

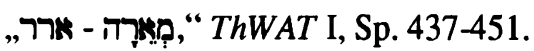

" ThWAT I, Sp. 808-841.

qll ..., "ThWAT VII, Sp. 40-49.

SCHAWE, Josef, „Bronze,“ $R L A$ II, 68f.

SCHEIL, Vincent, Textes élamites-sémitiques: quatrième série (MDP 10; Paris: Leroux, 1908).

SCHLEY, Donald G., Jr., "'Yahweh will Cause you to Return to Egypt in Ships' (Deuteronomy XXVIII 68),“ VT 35 (1985) 369-372.

SCHMITT, Rüdiger, The Bisitun Inscriptions of Darius the Great: Old Persian Text (Corpus Inscriptionum Iranicarum 1: Inscriptions of Ancient Iran 1: The Old Persian Inscriptions, Texts 1; London: School of Oriental and African Studies, 1991).

SCHOTTROFF, Willy, Der altisraelitische Fluchspruch (WMANT 30; Neukirchen: Neukirchener Vlg., 1969). „Fluch,“ $N B L$, Sp. 683-685.

SCHULTZ, Samuel Jacob, The Differences Between the Masoretic and Septuagint Texts in Deuteronomy (Cambridge/MA, Faculty of the Harvard Divinity School; Dissertation 1948).

SCHÜNGEL-STRAUMANN, Helene, Tod und Leben in der Gesetzesliteratur des Pentateuch unter besonderer Berücksichtigung der Terminologie von "töten“ (Bonn, Rheinische Friedrich-Wilhelms-Universität, Katholisch-Theologische Fakultät; Dissertation 1969).

SCHWEIZER, Harald, Metaphorische Grammatik: Wege zur Integration von Grammatik und Textinterpretation in der Exegese (MUS; ATSAT 15; St. Ottilien: EOS Vlg., 1981).

SEGAL, Juda Benzion, „Numerals in the Old Testament,“ JSS 10 (1965) 2-20.

SEIDL, Ursula / HROUDA, Barthel / KRECHER, /Joachim, „Göttersymbole und -attribute," $R L A$ III, 483-498.

SEITZ, Gottfried, Redaktionsgeschichtliche Studien zum Deuteronomium (BWANT 93; Stuttgart, Berlin, Köln, Mainz: Kohlhammer, 1971). 
SEYBOLD, Klaus, Das Gebet des Kranken im Alten Testament (BWANT 99; Stuttgart: Kohlhammer, 1973).

Der Prophet Jeremia: Leben und Werk (Urban Taschenbücher 416; Stuttgart, Berlin, Köln: Kohlhammer, 1993).

SHAFFER, Aaron, „Notes brèves 6,“ $R A 75$ (1981) 188f.

SHEPPARD, Gerald T., ,The Anti-Assyrian Redaction and the Canonical Context of Isaiah 1-39," JBL 104 (1985) 193-216.

SINGER, Karl Helmut, Die Metalle Gold, Silber, Bronze, Kupfer und Eisen im Alten Testament und ihre Symbolik (FzB 43; Würzburg: Echter, 1980).

SJÖBERG, Åke W., „Was there a Sumerian Version of the Laws of Hammurabi?,“ AuOr 9 (1991) 219-225.

SKWERES, Dieter Eduard, Die Rückverweise im Buch Deuteronomium (AnBib 79; Rom: Biblical Institute Press, 1979).

SMITH, George Adam, The Book of Deuteronomy (CBSC Series, Revised Version: Cambridge: University Press, 1918).

SODEN, Wolfram von, „Zum akkadischen Wörterbuch. 67-80,“ OrNS 24 (1955) 377-394.

„Zweisprachigkeit in der geistigen Kultur Babyloniens,“" (DÖAW.PH Sitzungsberichte 235; 1. Abhandlung; Wien: Böhlaus Nachf., 1960).

Grundriss der akkadischen Grammatik samt Ergänzungsheft zum Grundriss der akkadischen Grammatik (AnOr 33/47; Rom: Pontificium Institutum Biblicum, 1969). 1981).

Akkadisches Handwörterbuch (3 Bde., Wiesbaden: Harrassowitz, 1965-

.Mottoverse zu Beginn babylonischer und antiker Epen, Mottosätze in der Bibel,“ UF 14 (1983) 235-239. = Bibel und Alter Orient: Altorientalische Beiträge zum Alten Testament von Wolfram von Soden (Hg. v. H.-P. Müller; BZAW 162; Berlin, New York: de Gruyter, 1985) 206-212.

Einführung in die Altorientalistik (Orientalistische Einführungen in Gegenstand, Ergebnisse und Perspektiven der Einzelgebiete; Darmstadt: Wissenschaftliche Buchgesellschaft, 1985).

SOMMERFELD, Walter, „Die mittelbabylonische Grenzsteinurkunde IM 5527,“ UF 16 (1984) 299-306.

„Flüche und Fluchformeln als Quelle für die altorientalische Kulturgeschichte," Mesopotamica - Ugaritica - Biblica: Festschrift für Kurt Berghof zur Vollendung seines 70. Lebensjahres am 7. Mai 1992 (Hg. v. M. Dietrich u. O. Loretz; AOAT 232; Kevelaer: Butzon \& Bercker; NeukirchenVluyn: Neukirchener Vlg., 1993) 447-463. 
SPIECKERMANN, Hermann, Juda unter Assur in der Sargonidenzeit (FRLANT 129; Göttingen: Vandenhoeck \& Ruprecht, 1982).

STECK, Odil Hannes, Israel und das gewaltsame Geschick der Propheten: Untersuchungen zur Überlieferung des deuteronomistischen Geschichtsbildes im Alten Testament, Spätjudentum und Urchristentum (WMANT 23; Neukirchen: Neukirchener Vlg., 1967).

STEINER, Franz, Taboo (London: Cohen \& West, 1956).

STEINER, Richard C. / NIMS, Charles F., „Ashurbanipal and Shamash-shum-ukin: A Tale of two Brothers from the Aramaic Text in Demotic Script," $R B 91$ (1985) 60-81.

STEINMETZER, Franz X., „Eine Schenkungsurkunde des Königs Melišichu,“ BASS 8/2 (1910) 3-39.

„Zu den T-Formen des akkadischen Zeitwortes,“ ArOr 15 (1946) 87-92.

STEUERNAGEL, Carl, Der Rahmen des Deuteronomiums: Literarkritische Untersuchung über seine Zusammensetzung und Entstehung (Halle/Saale: Krause, 1894).

Übersetzung und Erklärung der Bücher Deuteronomium und Josua und allgemeine Einleitung in den Hexateuch (HK 1, 3; Göttingen: Vandenhoeck \& Ruprecht, 1900).

21923).

Das Deuteronomium (HAT I / 3,1; Göttingen: Vandenhoeck \& Ruprecht,

STIPP, Hermann-Josef, Jeremia im Parteienstreit: Studien zur Textentwicklung von Jer 26,36-43 und 45 als Beitrag zur Geschichte Jeremias, seines Buches und judäischer Parteien im 6. Jahrhundert (Athenäums Monografien: Theologie; BBB 82; Frankfurt/M: Hain, 1992).

Das masoretische und alexandrinische Sondergut des Jeremiabuches: Textgeschichtlicher Rang, Eigenarten, Triebkräfte (OBO 136; Freiburg/Schweiz: Universitätsverlag, Göttingen: Vandenhoeck \& Ruprecht, 1994).

„Probleme des redaktionsgeschichtlichen Modells der Entstehung des Jeremiabuches," Jeremia und die "deuteronomistische Bewegung" (Hg. v. W. Groß; BBB 98; Weinheim: Beltz Athenäum, 1995) 225-262.

STOEBE, Hans Joachim, „Anmerkungen zur Wurzel $p l$ ' im Alten Testament,“'ThZ 28 (1972) 13-23.

STRECK, Maximilian, Assurbanipal und die letzten assyrischen Könige bis zum Untergange Niniveh's, Bd. II: Texte (3 Bde.; VAB 7; Leipzig: Hinrichs, 1916).

STUART, Douglas, „Curse,“ The Anchor Bible Dictionary I (Hg. v. D. N. Freedman; New York, London, Toronto, Sydney, Auckland: Doubleday, 1992) $1218 f$. 
SUMNER, William Andrew, A Study of Deuteronomy 28 with Special Reference to the Parallels with Jeremiah (Oxford, Linacre College; Dissertation Januar 1968).

SUZUKI. Yoshihide, The 'Numeruswechsel' in Deuteronomy (Claramont Graduate School, Graduate Faculty of Religion; Dissertation 1982; UMI 8220612).

TADMOR, Hayim, „The Aramaization of Assyria: Aspects of Western Impact,“ Mesopotamien und seine Nachbarn: Politische und kulturelle Wechselbeziehungen im alten Vorderasien vom 4. - 1. Jahrtausend v. Chr.: XXV. Rencontre Assyriologique Internationale, Berlin, 3.-7. Juli 1978 (Hg. v. H.-J. Nissen u. J. Renger; Berliner Beiträge zum Vorderen Orient 1; Teil 2; Berlin: Reimer, 1982) 449-470.

„Treaty and Oath in the Ancient Near East. A Historian's Approach,“ Humanizing America's Iconic Book: Society of Biblical Literature Centennial Address 1980 (Hg. v. G. M. Tucker u. D. A. Knight; Chico/Cal., 1982) 127-152. Derselbe Artikel leicht verändert: Shnaton 5-6 (1981-1982) LXVIII, 149-173, und: ..Alleanza e dipendenza nell Antica Mesopotamia e in Israele: Terminologia e prassi," I trattati nel mondo antico: Forma, ideologia, funzione (Hg. v. L. Canfora, M. Liverani, C. Zaccagnini; Saggi di storia antica 2; Rom: «L'Erma» di Bretschneider, 1990) 17-36.

TAYLOR, James Glen, Yahweh and the Sun: Biblical and Archaeological Evidence for Sun Worship in Ancient Israel (JSOT.S 111; Sheffield: Academic Press, 1993).

Texte aus der Umwelt des Alten Testaments (3 Bde., 2 Bde. und 3 Lieferungen des 3. Bds. erschienen; hg. v. O. Kaiser, Gütersloh: Mohn, 1982-1993).

The Assyrian Dictionary of the Oriental Institute of the University of Chicago (21 Bde. geplant, 15 Bde. erschienen; hg. v. I. J. Gelb u. a.; Chicago/IL: Oriental Institute, Glückstadt: Augustin, 1956-1992).

Theologisches Handwörterbuch zum Alten Testament (2 Bde.; hg. v. E. Jenni; München: Kaiser, Zürich: Theologischer Vlg., 1971, 1976).

Theologisches Wörterbuch zum Alten Testament (7 Bde. erschienen; hg. v. G. J. Botterweck, H. Ringgren; Stuttgart, Berlin, Köln, Mainz: Kohlhammer, 19731993).

THIEL, Winfried, Die deuteronomistische Redaktion von Jeremia 1-25 (WMANT 41; Neukirchen-Vluyn: Neukirchener Vlg., 1973).

THOMPSON, John Arthur, Deuteronomy: An Introduction and Commentary (TOTC; London: Inter-Varsity Press, 1974).

THUREAU-DANGIN, François, Die Sumerischen und Akkadischen Königsinschriften (VAB 1; Leipzig: Hinrichs, 1907). _Un acte de donation de Marduk-zâkir-šumi,“"RA 16 (1919) 118-156.

TOORN, K. van der, Sin and Sanction in Israel and Mesopotamia: A Comparative Study (SSN 22; Assen, Maastricht: Van Gorcum, 1985). 
TROADEC, Henry, „Faut-il désirer la richesse? (Deut. 28,1-14),“ BVC 37 (1961) 46-52.

TROPPER, Josef, Die Inschriften von Zincirli: Neue Edition und vergleichende Grammatik des phönizischen, sam'alischen und aramäischen Textkorpus (Abhandlungen zur Literatur Alt-Syrien-Palästinas 6; Münster: Ugarit-Vlg., 1993).

UEHLINGER, Christoph, „Gab es eine joschijanische Kultreform?““ Jeremia und die deuteronomistische Bewegung (Hg. v. W. Groß; BBB 98; Weinheim: Beltz Athäneum, 1995) 57-89.

UNGNAD, A., „Zur Geschichte und Chronologie des zweiten Reiches von Isin,“ OrNS 13 (1944) 73-101.

UNTERLECHNER, Petra, Fluchformeln in Kudurru-Inschriften (Universität Wien, Geisteswissenschaftliche Fakultät, Diplomarbeit; Dezember 1991).

VANONI, Gottfried, „Der Geist und der Buchstabe: Überlegungen zum Verhältnis der Testamente und Beobachtungen zu Dtn 30,1-10," BN 14 (1981) 65-98.

"Anspielungen und Zitate innerhalb der hebräischen Bibel: Am Beispiel von Dtn 4,29; Dtn 30,3 und Jer 29,13-14,“ Jeremia und die deuteronomistische Bewegung (Hg. v. W. Groß; BBB 98; Weinheim: Beltz Athäneum, 1995) 383-395.

VARGYAS, P., „Le cylindre Rassam et la Bible,“ Oikumene 3 (1982) 157-162.

VATTIONI, Francesco, „La bilingue assiro-aramaica di Tell Fekherye,“ AION 46 (1986) 349-365.

VEENHOF, Klaas R., „An Aramaic Curse with a Sumero-Akkadian Prototype,“ BO 20 (1963) 142-144.

VLEEMING, S. P. / WeSSELIUS, J. W., Studies in Papyrus Amherst 63: Essays on the Aramaic texts in Aramaic/demotic Papyrus Amherst 63 Bd. 1 (Amsterdam: Juda Palache Instituut, 1985).

VOIGTLANDER, Elizabeth N. von, The Bisitun Inscription of Darius the Great: Babylonian Version (Corpus Inscriptionum Iranicarum. 1: Inscriptions of Ancient Iran 2: The Babylonian Versions of the Achaemenian Inscriptions, Texts 1; London: Humphries 1978).

WÄCHTER, Ludwig, Der Tod im Alten Testament (AzTh; II. Reihe 8; Stuttgart: Calwer Vlg. 1967).

WAGNER, Siegfried, ,„מin môpet “"ThWAT IV, Sp. 750-759.

WAHRIG, Gerhard, Deutsches Wörterbuch: Mit einem „Lexikon der deutschen Sprachlehre" (Gütersloh, München: Bertelsmann Lexikon Vlg., 1986).

WALTKE, Bruce K / O'CONNOR, Michael Patrick, An Introduction to Biblical Hebrew' Syntax (Winona Lake/IN.: Eisenbrauns, 1990).

WATANABE, Kazuko, „Die literarische Überlieferung eines babylonischassyrischen Fluchthemas mit Anrufung des Mondgottes Sin," ASJ 6 (1984) 99119. 
Die adê-Vereidigung anläßlich der Thronfolgeregelung Asarhaddons (BaM Bh 3; Berlin: Gebr. Mann, 1987). (1991) 347-387.

„Segenswünsche für den assyrischen König in der 2. Person Sg.," ASJ 13 „Segenswünsche für den assyrischen König II,“ ASJ 14 (1992) 369-377.

WATSON, Wilfred G. E., „Reclustering Hebrew l’ lyd-,“ Bib 58 (1977) 213-215.

WEDNER, Ernst F., Politische Dokumente aus Kleinasien: Die Staatsverträge in akkadischer Sprache aus dem Archiv von Boghazköi (Boghazköi-Studien 8; Leipzig: Hinrichs 1923; Neudruck: Hildesheim 1970).

WEIGL, Michael, „Eine ,unendliche Geschichte’; 7 (Am 7,7-8),“ Bib 76 (1995) im Druck.

WEIHER, Egbert von, Der babylonische Gott Nergal (AOAT 11; Kevelaer: Butzon \& Bercker, Neukirchen-Vluyn: Neukirchener Vlg., 1971).

WELl, Hermann M., „Gage et cautionnement dans la Bible,“ AHDO 2 (1938) 171241.

WEINFELD, Moshe, „Traces of Assyrian Treaty Formulae in Deuteronomy," Bib 46 (1965) 417-427.

1972).

Deuteronomy and the Deuteronomic School (Oxford: Clarendon Press, "The Loyalty Oath in the Ancient Near East," UF 8 (1976) 379-414.

„The Emergence of the Deuteronomic Movement: The Historical Antecedents," Das Deuteronomium: Entstehung, Gestalt, Botschaft (Hg. v. N. Lohfink; BEThL 68; Löwen: Peeters; University Press, 1985) 76-98.

"The Common Heritage of Covenantal Traditions in the Ancient World," I trattati nel mondo antico: Forma, ideologia, funzione (Hg. v. L. Canfora, M. Liverani u. C. Zaccagnini; (Saggi di storia antica 2; Rom: «L'Erma» di Bretschneider, 1990) 175-191.

Deuteronomy 1-11: A New Translation with Introduction and Commentary (AB 5; New York, London, Toronto, Sydney, Auckland: Doubleday, 1991).

WEIPPERT, Helga, Die Prosareden des Jeremiabuches (BZAW 132; Berlin, New York: de Gruyter, 1973).

WEIPPERT, Manfred, „Die Kämpfe des assyrischen Königs Assurbanipal gegen die Araber. Redaktionskritische Untersuchung des Berichts in Prisma A," WO 7 (1973/74) 39-85.

WERLITZ, Jürgen, Studien zur literarkritischen Methode: Gericht und Heil in Jes 7,1-17 und 29,1-8 (BZAW 204; Berlin, New York: de Gruyter, 1992).

WESTERMANN, Claus, Grundformen prophetischer Rede (BEvTh; Theologische Abhandlungen 31; München: Kaiser, ${ }^{2}$ 1964). 
WEVERS, John William, „The Attitude of the Greek Translator of Deuteronomy Towards His Parent Text," Beiträge zur Alttestamentlichen Theologie: Festschrift für Walter Zimmerli zum 70. Geburtstag (Hg. v. H. Donner, R. Hanhart, R. Smend; Göttingen: Vandenhoeck \& Ruprecht, 1977) 498-505.

Text History of the Greek Deuteronomy (AAWG.PH Folge 3; 106; MSU 13; Göttingen: Vandenhoeck \& Ruprecht, 1978).

„YHWH and its Appositives in LXX Deuteronomium,“ Studies in Deuteronomy: in Honour of C. J. Labuschagne on the Occasion of his 65th Birthday (Hg. v. F. García Martínez, A. Hilhorst, J. T. A. G. M. van Ruiten, A. S. van der Woude; VTS 53; Leiden: Brill, 1994) 269-280.

WHITE, Hugh C., „Introduction: Speech Act Theory and Literary Criticism,“ Semeia 41 (1988) 1-24.

WHITE, Sidnie Ann, „Three Deuteronomy Manuscripts from Cave 4, Qumran,“ JBL 112 (1993) 23-42.

WIDENGREN, Geo, „Yahwe's Gathering of the Dispersed,“ In the Shelter of Elyon: Essays on Ancient Palestinian Life and Literature in Honor of G. W. Ahlström (Hg. v. W. B. Barrick, J. R. Spencer; JSOT.S 31; Sheffield: Academic Press, 1984) 227-245.

WIJNGAARDS, Joanne, Deuteronomium (De Boeken van het Oude Testament; Roermond: J. J. Rauen \& Zonen-Uitgvers, 1971).

WILDBERGER, Hans, „,Glauben“: Erwägungen zu דאטן,“ Hebräische Wortforschung: Festschrift zum 80. Geburtstag von Walter Baumgartner (Hg. v. B. Hartmann; VTS 16; Leiden: Brill, 1967) 372-386.

WILLMES, Bernd, „Extreme Exegese‘: Überlegungen zur Reihenfolge exegetischer Methoden," BN 53 (1990) 68-99.

WINCKLER, Hugo, Die Keilschrifttexte Sargons (Leipzig: Eduard Pfeiffer, 1889).

WISEMAN, Donald J., ,The Vassal-Treaties of Esarhaddon,“ Iraq 20 (1958) 1-99, Pl. 1-53, I-XII.

"'Is it Peace?' - Covenant and Diplomacy,“VT 32 (1982) 311-326.

WISSMANN, Hermann von, Über den Inschriftenkomplex einer Felswand bei einem 'Attar-Temel im Umkreis von Marïb: Anhang: Saba's früheste bekannte Herrscher (DÖAW.PH Sitzungsberichte 299/1; Wien: Vlg. der Österreichischen Akademie der Wissenschaften, 1975).

Die Geschichte von Saba' II.: Das Großreich der Sabäer bis zu seinem Ende im frühen 7. Jh. v. Chr. (DÖAW.PH Sitzungsberichte 402; Wien: Vlg. der Österreichischen Akademie der Wissenschaften, 1982).

Wörterbuch der deutschen Gegenwartssprache, Bd. II: Deutsch - Glauben (Hg. v. R. Klappenbach u. W. Steinitz; Berlin: Akademie-Vlg., ${ }^{2} 1968$ ). 
WOLFF, Hans Walter, „Das Kerygma des Deuteronomistischen Geschichtswerks,“ ZAW 73 (1961) 171-186. = Ders., Gesammelte Studien zum Alten Testament (TB 22; München: Kaiser, 21973) 308-324.

WRIGHT, G. Ernest, „The Book of Deuteronomy,“ IB (Bd. 2; New York, Nashville: Abigdon, Cokesbury Press, 1953) 309-537.

YOUNG, Ian, Diversity in pre-exilic Hebrew (FAT 5; Tübingen: Mohr, 1993).

ZACCAGNINI, Carlo, „The Forms of Alliance and Subjugation in the Near East of the Late Bronze Age," I trattati nel mondo antico. Forma, ideologia, funzione (Hg. v. L. Canfora, M. Liverani u. C. Zaccagnini; Saggi di storia antica 2; Rom: «L'Erma» di Bretschneider, 1990) 37-79.

ZADOK, Ran, „On the Historical Background of the Sefire Treaty,“ AION 44 (1984) 529-538.

ZEITLIN, Solomon, „Some Reflections on the Text of the Pentateuch,“ $J Q R 51$ (1960/61) 321-331.

ZEVIT, Ziony, „A Phoenician Inscription and Biblical Covenant Theology,“ IEJ 27 (1977) 110-118.

ZIEGLER, Joseph, „Zur Septuaginta-Vorlage im Deuteronomium,“ ZAW 72 (1960) 237-262.

ZIMMERN, Heinrich, Zum babylonischen Neujahrsfest: Erster Beitrag (BVSGW. PH 58, 3; Leipzig: Teubner, 1906). 


\section{REGISTER}

\section{ALTORIENTALISCHE TEXTE}

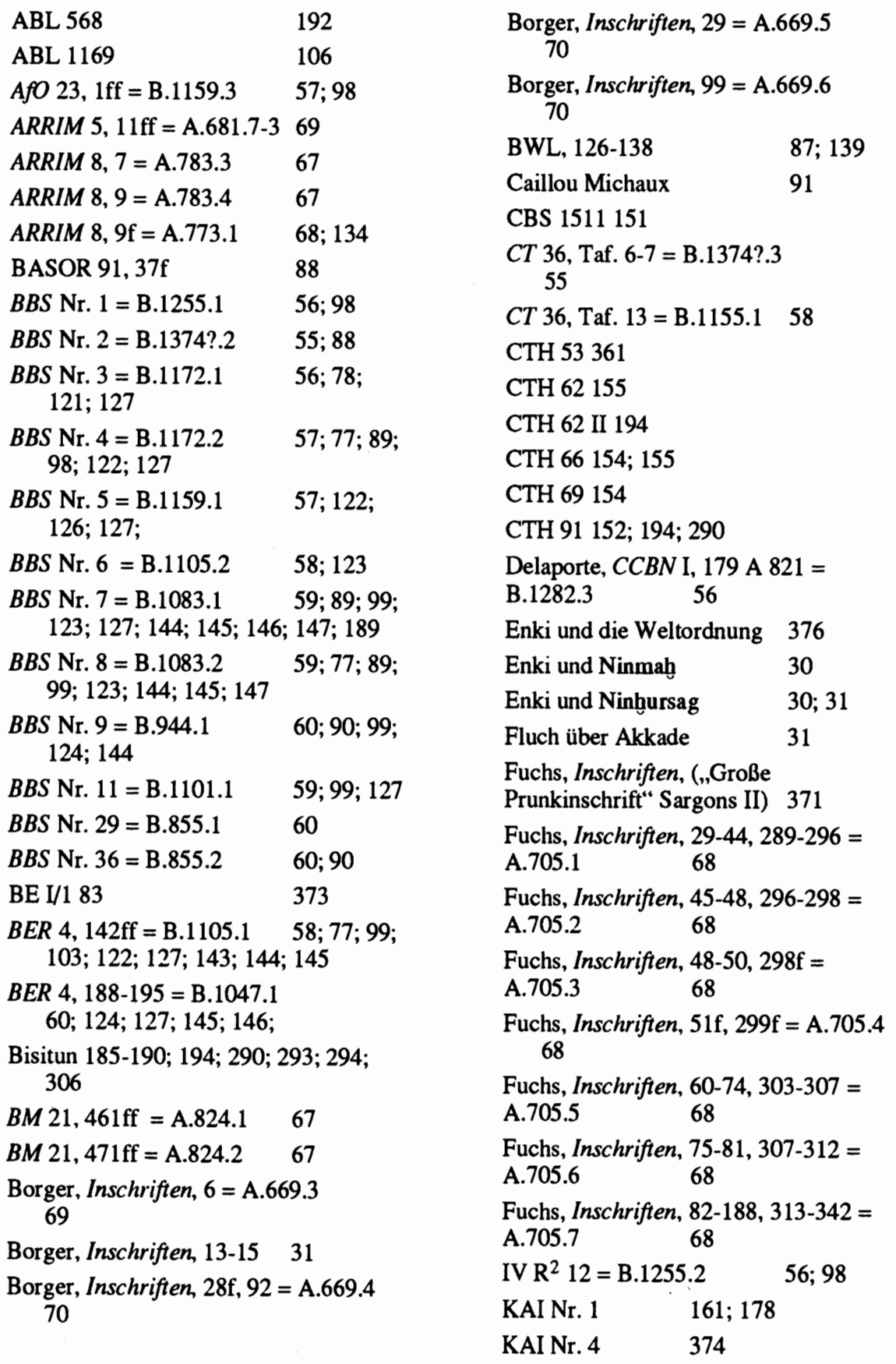


KAI Nr. $5 \quad 374$

KAI Nr. $6 \quad 374$

KAI Nr. $10 \quad 161$

KAI Nr. $13 \quad 161$

KAI Nr. $24 \quad 20 ; 179 ; 374$

KAI Nr. $26 \quad 161 ; 194 ; 290 ; 358$

KAI Nr. $27 \quad 21$

KAI Nr. $200 \quad 366$

KAI Nr. $202 \quad 179 ; 181$

KAI Nr. $214 \quad 159 ; 181$

KAI Nr. $214 \quad 179$

KAI Nr. 222-224 siehe unter Sefire.

KAI Nr. $225 \quad 180$

KAI Nr. $226 \quad 181$

KAI Nr. $260 \quad 190 ; 191 ; 194 ; 290$; 361

Karatepe siehe KAI Nr. 26.

Kelišin 163;194

Khirbet Beit Lei 360

Kodex Hammurapi $(\mathrm{KH})=$ B.1750.1 $7 ; 22 ; 24 ; 28 ; 46 ; 51 ; 55 ; 71 ; 76 ; 80$; $81 ; 88 ; 91 ; 121 ; 127 ; 140 ; 151 ; 178$; $238 ; 255 ; 353 ; 370$

KTU 1:15 $\quad 376$

KTU 1:17 376

Kuntillet 'Ajrud $180 ; 360$

Langdon, Königsinschriften, (I R $51 \mathrm{Nr}$. 1) 375

\section{Lipit-Ištar $\quad 7 ; 22 ; 370$}

Luckenbill, Sennacherib, $66=$ A.681.2 69

Luckenbill, Sennacherib, $84 \mathrm{f}=$ A.681.1 $68 ; 125$

Luckenbill, Sennacherib, $139=$ A.681.3 69; 125

Luckenbill, Sennacherib, 147 = A.681.4 69; 125

Luckenbill, Sennacherib, $148=$ A.681.5 69; 125

$M D P 2,86 \mathrm{ff}=\mathrm{B} .1282 .2 \quad 56 ; 121$

$M D P 2,95 \mathrm{f}=\mathrm{B} .1225 .1 \quad 33 ; 56$

$M D P 2,99 \mathrm{ff}=\mathrm{B} .1172 .3 \quad 57 ; 79 ; 98$; $122 ; 127 ; 372$
$M D P$ 6, 31ff $=\mathrm{B} .1159 .2 \quad 57$

$M D P 6,39 \mathrm{ff}=\mathrm{B} .1159 .5 \quad 58 ; 89 ; 91$; $122 ; 144 ; 145$

$M D P$ 6, Taf. $42-43=\mathrm{B} .1159 .6$ $58 ; 89 ; 143 ; 145$

$M D P 10,87 \mathrm{ff}=\mathrm{B} .1172 .457$; 98; 372

Papyrus Amherst 63 $286 ; 288$

Postgate, $N R G D, 115-117=\mathrm{A} .783 .1$ 67

$R A 16,117 \mathrm{ff}=\mathrm{B} .819 .1 \quad 60 ; 79$; $145 ; 374$

$R A 16,141 \mathrm{ff}=\mathrm{B} .748 .1 \quad 32 ; 61 ; 124$

$R A 29,96 \mathrm{ff}=\mathrm{B} .1374 ? .1 \quad 55 ; 121$; 127

$R A 66,163 \mathrm{ff}=\mathrm{B} .1282 .1 \quad 55 ; 97$; $183 ; 184$

$R A 66,169 \mathrm{ff}=\mathrm{B} .1246 .1 \quad 56$

RIMA $1, \mathrm{~A} \cdot 0.75 .1=\mathrm{A} \cdot 1306.1$ $62 ; 88$

RIMA $1, \mathrm{~A} .0 .75 .2=\mathrm{A} .1306 .2$ $62 ; 88$

RIMA 1, A.0.76.2 = A.1274.1-38 62

RIMA 1, A.0.76.4 = A.1274.39 62

RIMA $1, \mathrm{~A} \cdot 0.76 .9=\mathrm{A} \cdot 1274.40$ 62

RIMA 1, A.0.76.11 = A.1274.41 62

RIMA 1, A.076.14 = A.1274.42 62

RIMA 1, A.0.76.15 = A.1274.43 62

RIMA 1, A.0.76.17 = A.1274.44 62

RIMA 1, A.0.76.18 = A.1274.45 62

RIMA $1, \mathrm{~A} \cdot 0.77 .1=\mathrm{A} \cdot 1244.1$ 63

RIMA 1, A.0.77.2 = A.1244.2 63

RIMA 1, A.0.77.3 = A.1244.3 63

RIMA 1, A.0.77.4 = A.1244.4 63 
RIMA 1, A.0.77.6 = A.1244.6 63

RIMA $1, \mathrm{~A} \cdot 0.77 .8=\mathrm{A} .1244 .5$ 63

RIMA 1, A.0.77.9 = A.1244.9 63

RIMA 1, A.0.77.10 = A.1244.10 63

RIMA 1, A.0.77.13 = A.1244.7 63

RIMA 1, A.0.77.17 = A.1244.11 63

RIMA 1, A.0.77.18 = A.1244.12 64

RIMA 1, A.0.77.1008 = A.1244.8 63

RIMA $1, \mathrm{~A} \cdot 0.78 .1=\mathrm{A} \cdot 1207.1$ 64

RIMA $1, \mathrm{~A} \cdot 0.78 .5=\mathrm{A} \cdot 1207.2$ 64

RIMA 1, A.0.78.6 = A.1207.3 64

RIMA $1, \mathrm{~A} \cdot 0.78 .7=\mathrm{A} \cdot 1207.4$ 64

RIMA $1, \mathrm{~A} \cdot 0.78 .10=\mathrm{A} \cdot 1207.6$ 64

RIMA 1, A.0.78.11 = A.1207.7 64

RIMA 1, A.0.78.13 = A.1207.8 64

RIMA 1, A.0.78.14 = A.1207.9 64

RIMA 1, A.0.78.16 = A.1207.10 64

RIMA 1, A.0.78.18 = A.1207.11 65

RIMA 1, A.0.78.19 = A.1207.5 64

RIMA 1, A.0.78.22 = A.1207.12 65

RIMA 1, A.0.78.23 = A.1207.13 65

RIMA 1, A.0.78.28 = A.1207.14 65

RIMA 1, A.0.79.1 = A.1203.1 65
$R I M A 1, \mathrm{~A} .0 .86 .1=\mathrm{A} .1116 .1$ 65

RIMA 1, A.0.86.4 = A.1116.2 65

RIMA 2, A.0.87.1 = A.1077.1 65

RIMA 2, A.0.89.3 = A.1057.1 65

RIMA 2, A.0.89.10 = .A.1057.2 66

RIMA 2, A.0.98.1 =A.912.1 66

RIMA 2, A.0.99.2 = A.891.1 66

RIMA 2, A.0.100.3 = A.884.1 66

RIMA 2, A.0.100.5 = A.884.2 66

RIMA 2, A.0.101.17 = A.859.1 66

RIMA 2, A.0.101.26 = A.859.2 66

RIMA 2, A.0.101.29 = A.859.3 66

RIMA 2, A.0.101.32 = A.859.4 66

RIMA 2, A.0.101.36 = A.859.5 66

RIMA 2, A.0.101.38 = A.859.6 66

RIMA 2, A.0.101.40 = A.859.7 67

RIMA 2, A.0.101.50 = A.859.8 67

RIMA 2, A.0.101.56 = A.859.9 67

RIMA 2, A.0.101.70 = A.859.10 67

RIMB 2, B.6.26.1 = B.700.1 61

RIMB 2, B.6.31.11 = B.669.1 61

$R I M B$ 2, B.6.31.12 = B.669.2 61

$R I M B$ 2, B.6.31.15 = B.669.3 61 
RIMB 2, B.6.31.16 = B.669.4

61

$R I M B$ 2, B.6.31.17 = B.669.5

61

RIMB 2, B.6.31.18 = B.669.6

61

RIME 4, E.4.3.6.11 = B.1750.255

SAA 2 (Nr.1) = B.819.2 8; 28; 50; $60 ; 75 ; 77 ; 90 ; 91 ; 95 ; 114$

SAA 2 (Nr. 2) = A.745.1 46; 68; 71; $79 ; 84 ; 96 ; 114 ; 115 ; 118 ; 127 ; 128$; $134 ; 156 ; 170-177 ; 182 ; 194 ; 280$; $308 ; 352$

$\begin{array}{cl}\text { SAA } 2 \text { (Nr. 3) }=\text { A.681.6 } & 69 ; 72 ; 84 \\ \text { SAA } 2 \text { (Nr. 4) }=\text { A.669.1 } & 69 ; 79 ; 90 ; \\ 144 & \end{array}$

SAA 2 (Nr. 5) = A.669.2 40; 42; 69; $71 ; 82 ; 95 ; 103 ; 105 ; 125 ; 127$

SAA 2 (Nr. 8)

71

SAA 2 (Nr. 9) 96; 113

SAA 2 (Nr. 11)

113

$S A A 2$ (Nr. 12) 96

$S A A 2$ (Nr. 14) = A.669.7 70; 78; 126

Samaria C 1220 361

Sefire $21 ; 23 ; 159 ; 164-177 ; 194$; $255 ; 267 ; 292$

$182 ; 352$

Streck, Assurbanipal, $182 ; 352$

Sumer $23,45 \mathrm{ff}=$ B. 1159.458

Sumer $36,124 \mathrm{ff}=\mathrm{B} .1070 .2$ $60 ; 124 ; 127 ; 373$

Sumer 38, $121 \mathrm{ff}=\mathrm{B} .1083 .3$ $59 ; 89 ; 99 ; 123 ; 144$

Tell Fekheriye $\quad 156-161 ; 181 ; 184$; $194 ; 269 ; 290 ; 293 ; 298 ; 303 ; 308$

UF 16, 299ff 99

Unger, $P K O M$ 2, 12f, 26-33 = A.783.2 67; 90

UVB 12, 43f = B.1282.4 56

V R $33=$ B.1580?.1 55

VS I $37=$ B.711.1 $61 ; 124$

VS I $71=$ A.705.8 $68 ; 125$ :

127

VTE $\S$

$1-106$
Z. $1-670$

$38-40$

Z. $1-493$

23

Z. $25-40$

35

Z. $46-49$

35

Z. $49-82,92-413,513-634$

34

Z. 83-91

35

Z. 108

36

Z. 119

36

Z. 130

36

Z. 134f

36

Z. 147-149

36

Z. 162

36

Z. $166 \mathrm{f}$

36

Z. $194-196$

238

Z. 198-211

35

Z. 262

93

25

108

32-36

Z. $373-413$

36

Z. $377-384$

35

Z. 389

$73 ; 75$

Z. 401,407

73

$37-56$

Z. 414-463

34

Z. 414-512

41-48

Z. 414

34

$38 \mathrm{~A}+43$

73

12

$38 \mathrm{~A}-42$

72-106; $139 ; 143 ; 148 ; 300$; $304 ; 311 ; 380$

38A 82; 307

Z. $418 \mathrm{a}-\mathrm{c}$

72

Z. $418 \mathrm{a}$

127; 299

Z. $418 \mathrm{c}$

132

$39-42$

$3 ; 11 ; 100$;

141; 292-299

$39 \quad 2 ; 300$

Z. $419-430 \quad 13$

Z. 419-421 79

Z. 420

$73 ; 106$ 
40 2; 131; 140; 162; 305

$41 \begin{array}{ll}\text { Z. 422-424 } & 83 ; 127 \\ 261 ; 291 ;\end{array}$

\begin{tabular}{|c|c|}
\hline Z. $425-427$ & $92-100$ \\
\hline 42 & $2 ; 300$ \\
\hline Z. $428-430$ & $101 ; 127$ \\
\hline 43 & $105-108$ \\
\hline Z. $431-432$ & $105-108$ \\
\hline Z. 431 & 79 \\
\hline Z. 432 & $115 ; 127$ \\
\hline
\end{tabular}

44-48

Z. 434

Z. $440-452$

Z. $449 \mathrm{f}$

Z. 451

Z. 452

Z. $453 \mathrm{f}$

49

114; 127

352

$113 ; 127$

$114 ; 127$

113; 127

103

106

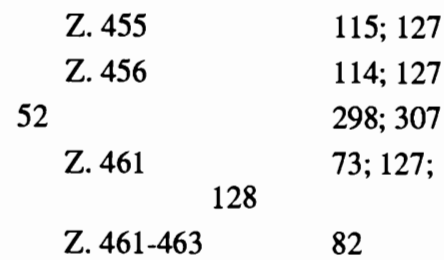

53

Z. $464 \mathrm{f}$

55

$\begin{array}{ll}\text { Z. } 470 & 115 \\ 56 & 12 ; 82 ;\end{array}$

109-128; 139; 149;

$300 ; 309 ; 380$

Z. 476

Z. 484

Z. 487

Z. 490

Z. 492

57

Z. 494

Z. 494-512

Z. 511
336

276

$73 ; 76$

73

280

203; 207

35

23; 35

113; 127

\begin{tabular}{|c|c|c|}
\hline Z. 511f & & 35 \\
\hline $58-60$ & & 94 \\
\hline $58 \mathrm{f}$ & & 297 \\
\hline 58 & & 291 \\
\hline Z. 513-517 & & $36 ; 130$ \\
\hline Z. 518 & 261 & $93 ; 130$; \\
\hline 59 & & $261 ; 291$ \\
\hline Z. 519 & & $93 ; 130$ \\
\hline 60 & & \\
\hline Z. 521 & & $74 ; 130$ \\
\hline Z. 522 & & 127 \\
\hline 61 & & 94 \\
\hline Z. 523 & & $112 ; 130$ \\
\hline 62 & & 94 \\
\hline Z. 524 & & 130 \\
\hline $63-65$ & & $129-138$ \\
\hline
\end{tabular}

$63+64$

$1 ; 2 ; 11$;

102; 141; 149; 285;

291; 296; 300; 380

63

94; 162

129-139

$112 ; 127$

Z. $526 \mathrm{f}$

Z. 528-533

64

13

162

Z. 530,531

65

$291 ; 304$

Z. $535 \quad 102$

66-68

68

$132-138$

$86 ; 88$;

$131 ; 139 ; 162$

69-100

$\begin{array}{ll}\text { Z. } 550 & 93 \\ \text { Z. } 556 & 79 \\ \text { Z. } 557+559 & 115 \\ \text { Z. } 559 & 102 \\ \text { Z. } 560,562 & 79 \\ \text { Z. } 573 & 102 ; 127 \\ \text { Z. } 573 f & 112 \\ \text { Z. } 587 & 115 \\ \text { Z. } 600 & 93\end{array}$




$\begin{array}{llcl}\text { Z. } 601 & 102 & 101 & 86 ; 87 ; 162 \\ \text { Z. } 604 & 73 & \text { Z. } 649 & 132 \\ \text { Z. } 616 \mathrm{a} & 112.127 & \text { Z. } 651 & 127 \\ \text { Z. } 618 \mathrm{a}-621 & 112 ; 127 & \text { ZA } 65,34 \mathrm{ff}=\mathrm{B} .1070 .1 & 59 ; 89 ; \\ \text { Z. } 621 & 73 & 123 ; 127 ; 143 ; 145 & \\ \text { Z. } 622,625 & 79 & & \end{array}$

\section{BIBELSTELLEN (In Auswahl)}

\begin{tabular}{|c|c|c|c|c|c|}
\hline Genesis & & 4,27 & 334 & 27,8 & $24 ; 206$ \\
\hline 3,14 & 358 & 4,44 & 198 & & 383 \\
\hline 3,17 & 358 & $4,44 f$ & 333 & $27,9 f$ & 202; 207; \\
\hline $4,10 \mathrm{f}$ & 358 & $4,45-28,68$ & 200 & & $378 ; 381$ \\
\hline 9,25 & 359 & 4,45 & 200 & 27,11 & $200 ; 203$ \\
\hline 14,18 & 141 & $5-28$ & 5 & & 204 \\
\hline 20 & 369 & 5,1 & $195 ; 200$ & 27,12 & 202 \\
\hline 49,7 & 358 & $\begin{array}{l}5,27-31 \\
7,19\end{array}$ & $\begin{array}{l}24 \\
365\end{array}$ & $27,14-26$ & $\begin{array}{l}202 ; 204 ; \\
220\end{array}$ \\
\hline Exodus & & 8,9 & 285 & 27,14 & 202 \\
\hline $10,18-22$ & 107 & 11,21 & 25 & $27,15-26$ & 214 \\
\hline 14,13 & 337 & $12-26$ & 33 & $28,38-40$ & 30 \\
\hline $17,13 \mathrm{f}$. & 17 & 12,11 & 141 & 28,1 & $202 ; 203$ \\
\hline 21,33 & 279 & 13,1 & 174 & & $204 ; 208$ \\
\hline 21,37 & 279 & 13,7 & 333 & & 217 \\
\hline $22,1-14$ & 279 & 13,19 & $226 ; 233$ & $28,1 f$ & $34 ; 221$ \\
\hline 22,8 & 280 & $16,18-18,2$ & $2 \quad 263$ & & $222-238$ \\
\hline 22,20 & 283 & 17,3 & 141 & $28,1-13$ & 213 \\
\hline 22,24 & 283 & $17,14-20$ & $263 ; 338$; & $28,3-14$ & $6 ; 201 ;$ \\
\hline $23,10-12$ & 281 & & $346 ; 377$ & $28,3-13$ & $220 ; 231 ;$ \\
\hline & & 17,16 & 337 & & $236 ; 369$ \\
\hline Levitikus & & $18,9-22$ & 263 & $28,3-6$ & $221 ; 225$ \\
\hline 26 & $210 ; 284$ & 18,15 & 346 & & $354-361$ \\
\hline & 291 & 18,18 & $346 ; 349$ & $28,7-14$ & $218 ; 221$ \\
\hline $26,14-46$ & 284 & 20 & 280 & & $362-368$ \\
\hline $26,14-38$ & 212 & $20,5-7$ & $278 ; 279$ & $28,7-12$ & 43 \\
\hline 26,16 & 287 & & $298 ; 308$ & 28,7 & $177 ; 184$ \\
\hline 26,19 & 49; 138; & 22 & 280 & 28,8 & 189 \\
\hline & $149 ; 284$ & $22,1-4$ & 279 & 28,9 & $230 ; 231$ \\
\hline & $291 ; 285$ & $22,5-11$ & $279 ; 280$ & $28,12-13$ & $249 ; 252$ \\
\hline & $\begin{array}{l}286 ; 288 ; \\
291\end{array}$ & $26,16-19$ & $\begin{array}{l}27 ; 197 ; \\
368 ; 378\end{array}$ & 28,13 & $\begin{array}{l}204 ; 230 ; \\
234\end{array}$ \\
\hline 26,26 & $30 ; 160$ & 26,16 & $205 ; 207$ & $28,13 \mathrm{f}$ & 231 \\
\hline 26,29 & 352 & $26,17-19$ & 381 & 28,14 & $204 ; 230$ \\
\hline & & 26,19 & $225 ; 365$ & $28,15-68$ & 216 \\
\hline Numeri & & $27-30$ & 196 & $28,15-45$ & $220 ; 213$ \\
\hline $5,21 \mathrm{f}$ & 219 & 27 & 195 & $28,15-19$ & 214 \\
\hline & & 27,1 & 27; 202; & 28,15 & $33 ; 34 ; 204$ \\
\hline Deuterono & mium & & 207; 378; & & $208 ; 211$ \\
\hline 1 - Jos 22 & 368 & & 381 & & $212 ; 216$ \\
\hline 4,19 & 141 & 27,3 & 383 & & $217 ; 221 ;$ \\
\hline $4,25-31$ & 346 & & & & $222-238$ \\
\hline
\end{tabular}




\begin{tabular}{|c|c|c|c|c|c|}
\hline \multirow[t]{3}{*}{$28,16-44$} & $201 ; 217$ & $28,63 \mathrm{f}$ & 234 & 2 Könige & \\
\hline & $218 ; 220$ & 28,64 & 107 & $6,28 f$ & 352 \\
\hline & $232 ; 236$ & 28,68 & 234 & $16,7-9$ & $15 ; 369$ \\
\hline \multirow[t]{3}{*}{$28,16-19$} & $212 ; 221$ & 28,69 & $49 ; 197-200$ & 17 & 351 \\
\hline & $232 ; 354-$ & $28,69-30,20$ & $0 \quad 200$ & $17,7 \mathrm{ff}$ & 345 \\
\hline & 361 & $29,1-20$ & 381 & $17,12-17$ & 338 \\
\hline 28,19 & 234 & 29,1 & $198 ; 200$ & $17,18-20$ & 334 \\
\hline $28,20-57$ & $41-48$ & 29,11 & $27 ; 23 ;$ & $20,12 f$ & 15 \\
\hline \multirow[t]{5}{*}{$28,20-44$} & $221 ; 239$ & & 201;203; & 21,14 & 334 \\
\hline & $312 ; 309$ & & $207 ; 382$ & $22 f$ & 378 \\
\hline & $323 ; 325$ & 29,13 & 23 & $22,11-13$ & 312 \\
\hline & $343 ; 345 ;$ & $29,19-23$ & 183 & $23,1-3$ & 228 \\
\hline & $350 ; 367$ & $29,21-28$ & 349 & 23,2 & 379 \\
\hline $28,20-36$ & $214 ; 218$ & $29,9-14$ & $197 ; 201$ & $23.11 \mathrm{f}$ & 142 \\
\hline 28,20 & 189 & $29-30$ & 198 & & \\
\hline 28,21 & 169 & 30,1 & 236 & Jesaja & \\
\hline $28,21 \mathrm{f}$ & 160 & $30,1-10$ & $335 ; 345 ;$ & 5,10 & 160 \\
\hline \multirow[t]{4}{*}{$28,23 \mathrm{f}$} & $1 ; 2 ; 1349$ & & 346 & $7,1-9$ & 15 \\
\hline & $73 ; 94 ; 138$ & 30,9 & 365 & $9,13-16$ & 282 \\
\hline & $149 ; 284-$ & 30,10 & $226 ; 233$ & 9,13 & 309 \\
\hline & 292 & $30,15-20$ & 203 & $10,1.3$ & 141 \\
\hline $28,24-34$ & 327 & 30,15 & 25 & 18,4 & 142 \\
\hline $28,25-33$ & $143 ; 149$ & 30,23 & 207 & 19,15 & 309 \\
\hline \multirow[t]{2}{*}{28,25} & $102 ; 177$ & $31,9-13$ & 383 & 19,25 & $358 ; 360$ \\
\hline & 184 & 33,1 & 198 & $23,15-17$ & 335 \\
\hline $28,26-35$ & $2 ; 3$ & 33,2 & 142 & $30,12-14$ & 344 \\
\hline $28,26-30$ & 13 & & & 28,15 & 21 \\
\hline $28,27-30$ & 128 & Josua & & 47,6 & 32 \\
\hline $28,27-29$ & 91 & $9.22 \mathrm{f}$ & 358 & & \\
\hline $28,30-31$ & 30 & & & Jeremia & \\
\hline 28,30 & $10 ; 184234$ & Richter & & $1,7.9$ & 263 \\
\hline 28,31 & 104 & $9,19 f$ & 217 & 1,16 & $257 ; 263$ \\
\hline 28,32 & 107 & $9,56 \mathrm{f}$ & 217 & 2,5 & 338 \\
\hline 28,33 & 104 & & & 3,25 & $233 ; 234$ \\
\hline 28,36 & $107 ; 169$ & 1 Samuel & & $4,5-6,26$ & 351 \\
\hline $28,38-44$ & 169 & 17,46 & 259 & $5,15-17$ & $234 ; 263$ \\
\hline $28,38-42$ & 184 & 25,33 & 358 & 5,19 & $348 ; 349$ \\
\hline 28,41 & 107 & 26,25 & $358 ; 360$ & 7,33 & 261 \\
\hline \multirow[t]{3}{*}{$28,47-68$} & $221 ; 226$ & & & & $338 ; 348$ \\
\hline & $231 ; 313$ & 2 Samuel & & & $350 ; 377$ \\
\hline & 353 & $21,1-14$ & 369 & 15,3 & 276 \\
\hline $28,47-57$ & $227 ; 234$ & & & 16,4 & $261 ; 276$ \\
\hline $28,45-48$ & 227 & l Könige & & 19,7 & $259 ; 261 ;$ \\
\hline \multirow[t]{4}{*}{28,45} & $32 ; 33 ; 208$; & 2,45 & $358 ; 360$ & & 276 \\
\hline & $211 ; 212$ & $8,46-53$ & 346 & 19,9 & 348 \\
\hline & $216 ; 221$ & 14,11 & 276 & 20,6 & 281 \\
\hline & $222-238$ & $15,18-20$ & 369 & 24,9 & $250 ; 264$ \\
\hline $28,49-52$ & 263 & 16,4 & 276 & $25,8-12$ & 32 \\
\hline 28,49 & 32 & 21,10 & 276 & 29,10 & 32 \\
\hline $28,53-57$ & 183 & 21,20 & 338 & 29,18 & 250 \\
\hline 28,58 & $33 ; 231$ & 21,25 & 338 & 29,22 & 218 \\
\hline \multirow[t]{2}{*}{28,62} & $33 ; 226$ & & & 34,15 & 276 \\
\hline & $231 ; \quad 233$ & & & 34,20 & $259 ; 261$ \\
\hline
\end{tabular}




\begin{tabular}{|c|c|c|c|c|c|}
\hline $37-43,7$ & 345 & 5,11 & $278 ; 297$ & 12,4 & 277 \\
\hline $40,1-6$ & 234 & 9,4 & 281 & & \\
\hline 40,3 & 233 & & & Psalm & \\
\hline $42,1-9$ & 234 & Micha & & 79,2 & 261 \\
\hline 42,6 & 233 & $3,1-4$ & 344 & 110,4 & 141 \\
\hline 43 & 338 & $3,9-12$ & 344 & & \\
\hline $43,4-7$ & 234 & 6,11 & 281 & \multicolumn{2}{|c|}{ Klagelieder } \\
\hline \multirow[t]{2}{*}{43,7} & 233 & 6,12 & 281 & $2,5-7$ & 107 \\
\hline & & 6,15 & $281 ; 308$ & 4,10 & 352 \\
\hline Ezechiel & & 6,16 & 281 & & \\
\hline 29,4 & 273 & & & Daniel & \\
\hline 29,5 & 275 & Nahum & & 9,11 & $219 ; 220$ \\
\hline $32,4-6$ & 275 & 2,14 & 16 & & \\
\hline \multirow[t]{2}{*}{39,4} & 259 & & & 2 Chronik & \\
\hline & & Zefanja & & $28,5-7$ & 15 \\
\hline Hosea & & 1,13 & $278 ; 297$ & 33,11 & 17 \\
\hline 8,13 & 337 & & & & \\
\hline 9,3 & 337 & Haggai & & Baruch & \\
\hline 11,5 & 337 & 1,6 & 160 & $2,2 \mathrm{f}$ & 352 \\
\hline Amos & & Sacharja & & & \\
\hline $4,1-3$ & 344 & 1,6 & 237 & & \\
\hline
\end{tabular}

WORTREGISTER (in Auswahl)

\begin{tabular}{|c|c|c|c|c|c|}
\hline \multicolumn{2}{|c|}{ AKKADISCH } & \multirow{2}{*}{$\begin{array}{l}\text { būšānu } \\
\text { dajjānu }\end{array}$} & \multirow{2}{*}{$\begin{array}{l}80 \\
90\end{array}$} & garābu & 43; \\
\hline$a b \bar{u} b u$ & 117 & & & \multicolumn{2}{|c|}{$80 ; 276$} \\
\hline \multirow[t]{3}{*}{ adê } & \multirow{3}{*}{$\begin{array}{l}1 ; 15 \\
17 ; 22 \\
75\end{array}$} & dāmu & 95 & & 87 \\
\hline & & \multirow[t]{2}{*}{$d i^{\prime} u$} & 72 & haläpu & \multirow{2}{*}{$\begin{array}{l}79 \\
189\end{array}$} \\
\hline & & & 160 & \multirow{2}{*}{$\begin{array}{l}\text { halāqu } \\
\text { hušahhu }\end{array}$} & \\
\hline aganutill & 39 & diliptu & 73 & & 113; \\
\hline \multicolumn{2}{|c|}{$57-61 ; 130$} & \multicolumn{2}{|c|}{$74 ; 115$} & \multicolumn{2}{|c|}{116} \\
\hline annuku & 133 & \multicolumn{2}{|c|}{160} & \multicolumn{2}{|c|}{ hīrtu 102; 103} \\
\hline \multirow{2}{*}{ arāru } & 31 ; & $\operatorname{din} u$ & 85 & ikribu & 374 \\
\hline & $38 ; 113$ & ekletu & 84; & imittu & 95 \\
\hline \multicolumn{2}{|c|}{189} & \multicolumn{2}{|c|}{$85 ; 111$} & kakkāäu & 103 \\
\hline \multirow{2}{*}{ ardūtu } & $15 ; 48$ & \multicolumn{2}{|c|}{$115 ; 305$} & \multirow{2}{*}{$\begin{array}{l}\text { kakku } \\
\text { kaqqaru }\end{array}$} & 95 \\
\hline & 38 & epqu & 80 & & 84 \\
\hline \multicolumn{2}{|c|}{ 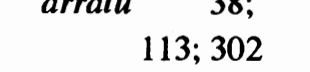 } & eqlu & 132 & \multicolumn{2}{|c|}{$130 ; 132$} \\
\hline ašarēdu & $93 ; 95$ & erēbu & 79 & & ; 137; \\
\hline balātu & 375 & $\bar{e} r u$ & 95 & 13 & \\
\hline$b \bar{u} u$ & 102 & erșetu & 84 & karābu & 373 \\
\hline bubbulu & 117 & & ; 114; & kasāādu & 113 \\
\hline bubuttu & 116 & & & kittu & 85 \\
\hline bubūtu & 113 & $e \check{s ̌ u}$ & $83 ; 85$ & lazzu & 38 \\
\hline & 116 & $\bar{e} t \underline{u}$ & 116 & & \\
\hline & & gamlu & 95 & mahāru & 114 \\
\hline
\end{tabular}




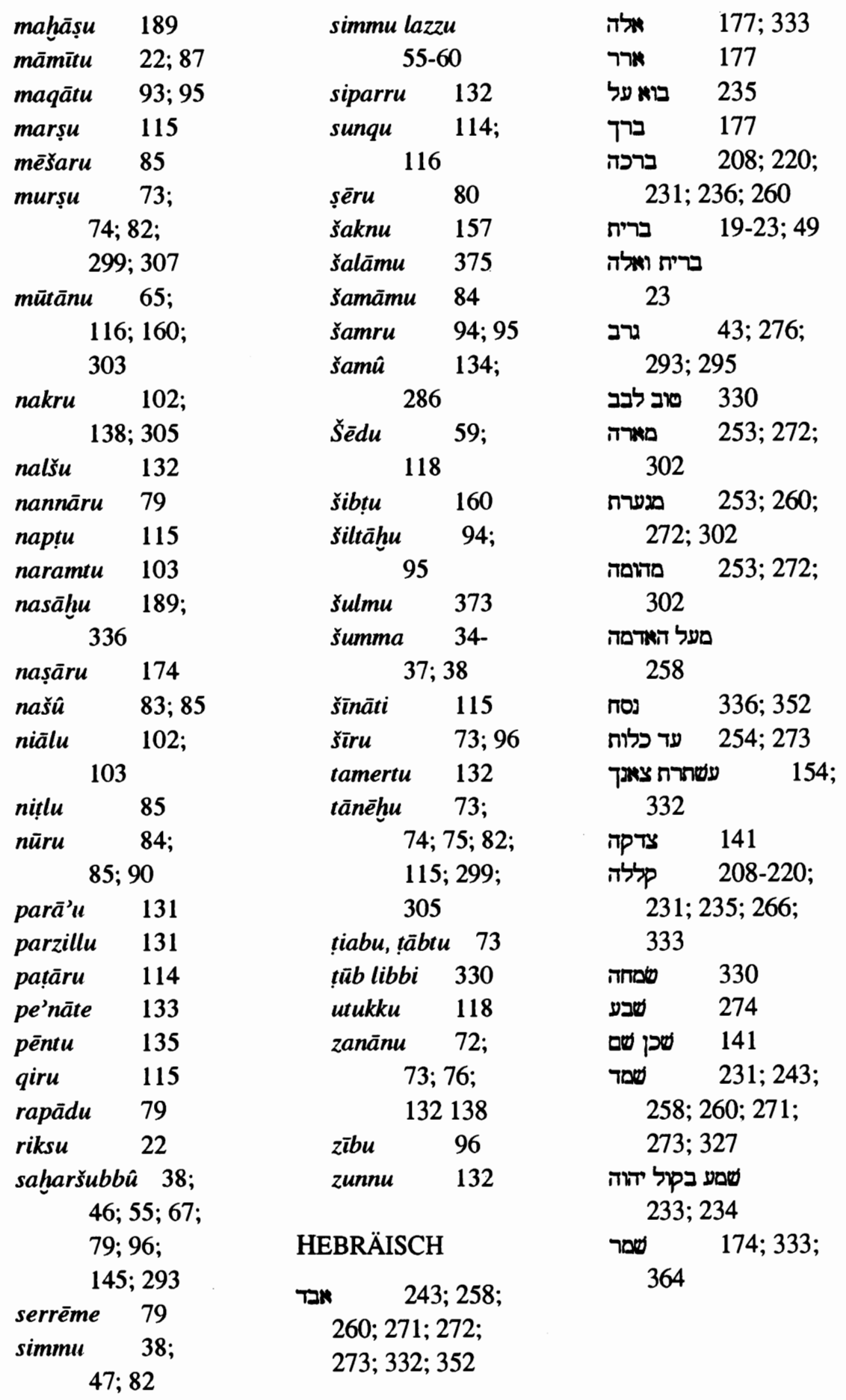





\section{Zum vorliegenden Buch}

Die Ähnlichkeiten zwischen einigen Flüchen der adê-Vereidung anläßlich der Thronfolgeregelung Asarhaddons (VTE) und in Deuteronomium 28 bezeugen nicht den Einfluß einer im ganzen Alten Orient verbreiten Tradition, sondern resultieren aus literarischer Abhängigkeit des Bibeltextes von den VTE.

Die vorliegende Studie kommt zu diesem Ergebnis, nachdem die Flüche der VTE mit den publizierten mesopotamischen Fluchpassagen, angefangen beim Kodex Hammurapi, verglichen wurden und anhand mehrsprachiger Inschriften die Übersetzungstreue des Alten Orients überprüft wurde. Die Differenzen zwischen den VTE und Dtn 28 bewegen sich in dem Rahmen, den man im Alten Orient bei Übersetzungen tolerierte.

Die Gemeinsamkeiten umfassen eine fast identische Reihenfolge der Inhalte von VTE $\S \S 39,40,42$ und Dtn 28,27-30 (Hautkrankheit, Finsternis und Schändung der Ehefrau), gleichartige Motive in $\S 63 f$ und Dtn 28,23f (bronzener Himmel und eiserne Erde, Regen verwandelt in Kohle oder Asche; Lev 26,19 dürfte von Dtn 28,23f abhängen) und eine Themenabfolge in VTE $\S 56$, die der von Dtn 28,20-44 weitgehend entspricht. Der palindromisch gestaltete $\S 56$ ruft die großen Götter des Himmels und er Erde an und stellt Motive des Sonnengottes in die Mitte. Der Sonnengott trug in Mesopotamien Züge, die in Jerusalem JHWH zugeschrieben wurden. Der hebräische Verfasser übernahm VTE $\S 56$ und fügte an thematisch geeigneter Stelle weitere mit dem Sonnengott oder dem Himmel verbundene Abschnitte aus den VTE ein. Innerhalb von $\S \S 39-42$ steht der Fluch des Sonnengotts in $\S 40$. Auch die $\S \S 63 f$, wo es um Himmel ind Erde geht, zeigen deutliche Lexembezüge zu Sonnengottflüchen (\$§ 40,68, 101).

Der mesopotamische Hintergrund von Dtn 28,20-44 ermöglicht es, die Funktion des Kapitels 28 in der "Fabel» des Deuteronomiums neu zu beleuchten. Die Abhängigkeit von den VTE läßt Schlußfolgerungen für die Redaktionsgeschichte zu: Dtn 28,20-44 (ohne V. 20b,25b,26f) dürfte zum ältesten Kern des Kapitels gehören. Bei der Einfügung des Urdeuteronomiums in die deuteronomistische Landeroberungserzählung kamen der Segen (28,7-13) und wohl auch 28,21b.69 hinzu. Spätestens in dieser Redaktionsphase wurden 28,1.2a.3-6.15.16-19 geschaffen.

Deuteronomistischer Redaktion der Exilszeit sind 28,2b.14.20b. 25b.36f.45-57.62-68 zuzuordnen. Den letzen Zusatz bildet wohl die poetische Passage in 28,58-61. 



\section{Summary}

The similarities between some of the curses found in the Vassal-Treaties of Esarhaddons (VTE) and in Deuteronomy 28 cannot be explained by a common Ancient Near Eastern curse tradition but attest a definite literary influence. This main conclusion of the present study is based first upon a detailed comparison of the VTE curses with other curses attested in Mesopotamian inscriptions, second on the analysis of ANE translation methods.

The similarities consist of (a) the same curse motifs in the same sequence in VTE $\S 39,40,42$ and Deut. 28:27-30 (skin-disease, darkness, and violated wife), (b) the same kind of motifs in VTE $\S \S 63 f$ and Deut. 28:23f (sky and earth being of metal, rain changed into coal or ashes), and (c) a common thematic structure in VTE $\$ 56$ and Deut. 28:20-44. When compared to other ANE and biblical lists of curses, these motifcombinations and sequences are unique and were not part of a common ANE tradition.

In composing VTE $\$ 56$ - the curse of the Great Gods - Assyrian scribes chiasically arranged traditional curse formulas around the sun-god's motifs of darkness which forms the center of $\S 56$. The VTE $\S \S 39-42$ sequence also contains the sun-god's curse, and a further sun-god's curse in found in the context of VTE $\$ \S 63 f$. Considering sun-related metaphors of the $\mathrm{YHWH}$ cult in Jerusalem and the remarkable differences appearing between the respective versions of ANE bilingual curse inscriptions, it seems likely that Deut. 28:20-44 was created by translating sun-god-related parts of the VTE and combining them according to the thematic structure of VTE $\S 56$.

The Mesopotamian background of Deut. 28 sheds new light on the chapter's role in the plot of Deuteronomy. Its relationship to the VTE offers insights for the redactional history of Deut. 28:

V. 20-44 (without 20b.21b.25b.36f) seem to form the oldest part.

V. 7-13 and probably V.1.2a.3-6.15-19.69 appear to belong to a preexilic (early) deuteronomistic expansion.

V. 2b.14.25b.36f.45-57.62-68 may present a deuteronomistic addition from the time of the exile.

The latest insertion is a poetic passage in V. 58-61. 